Philipp Bergel

\title{
Rechnungshöfe als vierte Staatsgewalt?
}

Verfassungsvergleich der Rechnungshöfe Deutschlands, Frankreichs, Österreichs, Spaniens, des Vereinigten Königreichs und des Europäischen Rechnungshofs im Gefüge der Gewaltenteilung

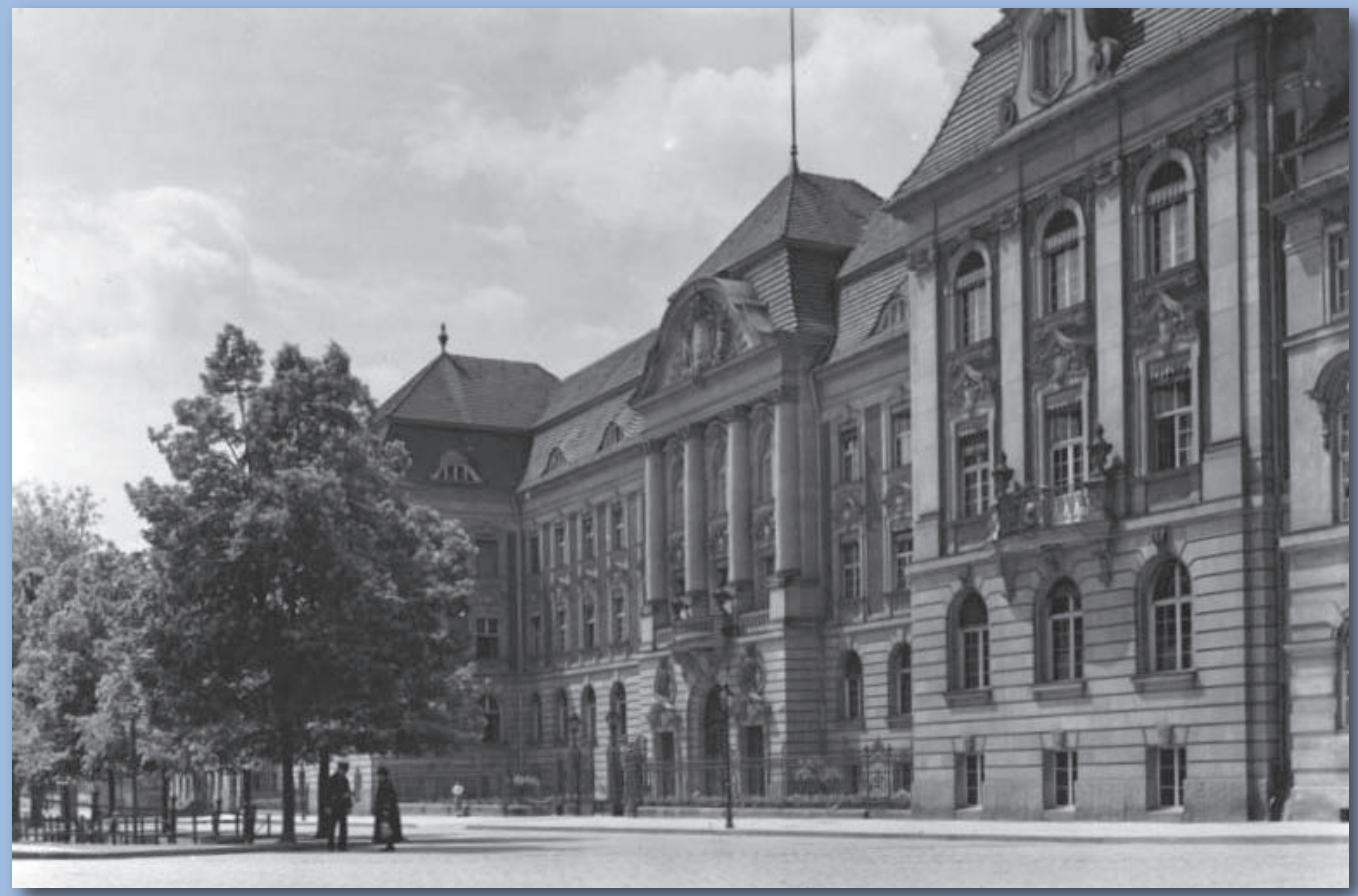





\section{Philipp Bergel}

Rechnungshöfe als vierte Staatsgewalt?

This work is licensed under the

Creative Commons License 3.0 "by-nd", allowing you to download, distribute and print the document in a few copies for private or educational use, given that the document stays unchanged and the creator is mentioned.

You are not allowed to sell copies of the free version.

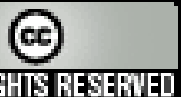


erschienen in der Reihe der Universitätsdrucke

im Universitätsverlag Göttingen 2010 
Philipp Bergel

Rechnungshöfe als vierte Staatsgewalt?

Verfassungsvergleich der Rechnungshöfe Deutschlands, Frankreichs, Österreichs, Spaniens, des Vereinigten Königreichs und des Europäischen Rechnungshofs im Gefüge der Gewaltenteilung

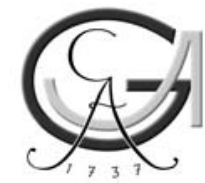

Universitätsverlag Göttingen 2010 


\section{Bibliographische Information der Deutschen Nationalbibliothek}

Die Deutsche Nationalbibliothek verzeichnet diese Publikation in der Deutschen Nationalbibliographie; detaillierte bibliographische Daten sind im Internet über $<$ http://dnb.ddb.de> abrufbar.

Address of the Author / Anschrift des Autors

Philipp Bergel

e-mail: philippbergel@googlemail.com

Dieses Buch ist auch als freie Onlineversion über die Homepage des Verlags sowie über den OPAC der Niedersächsischen Staats- und Universitätsbibliothek (http://www.sub.uni-goettingen.de) erreichbar und darf gelesen, heruntergeladen sowie als Privatkopie ausgedruckt werden. Es gelten die Lizenzbestimmungen der Onlineversion. Es ist nicht gestattet, Kopien oder gedruckte Fassungen der freien Onlineversion zu veräußern.

Satz und Layout: Philipp Bergel

Umschlaggestaltung: Franziska Lorenz

Titelabbildung: Potsdam, Rechnungshof des deutschen Reiches;

Bundesarchiv Bild 146-2006-0219

Quelle: wikipedia.de

(C) 2010 Universitätsverlag Göttingen

http://univerlag.uni-goettingen.de

ISBN: 978-3-941875-57-9 
Man wird sagen: „Die Rechnungen langweilen mich.“ Ich erwidere: „Das Wohl des Staates erfordert, dass ich sie nachsehe, und in diesem Falle darf keine Mühe mich verdrießen."

Friedrich der Große, 1784

„Der Europäische Rechnungshof ist das finanzielle Gewissen Europas.“

Hans Kutscher als Präsident des Europäischen Gerichtshofes 



\section{Vorwort}

Die vorliegende Arbeit hat der juristischen Fakultät der Georg-August-Universität Göttingen im Jahr 2008 als Dissertation vorgelegen. Sie wurde nach Abschluss des Promotionsverfahrens im Sommersemester 2010 auf den entsprechenden Stand gebracht.

Mein Dank gilt meinem Doktorvater Prof. Dr. Christian Calliess, der diese Arbeit angeregt und betreut hat. Als besonders angenehm habe ich die gute Arbeitsatmosphäre am Lehrstuhl empfunden. Hierfür sei Prof. Calliess und meinen ehemaligen Kollegen besonders gedankt. Herrn Prof. Dr. Thomas Mann danke ich für die Übernahme des Zweitgutachtens im Promotionsverfahren.

Ganz besonders danke ich meinen Eltern für ihre Unterstützung bei meinem Promotionsvorhaben und für den Rückhalt, den ich während dieser Zeit und während des gesamten Studiums durch sie hatte.

Besonders gedankt sei auch den Mitarbeitern des Niedersächsischen Landesrechnungshofes, die mich während meines dortigen Forschungsaufenthaltes freundlich und kompetent unterstützt haben.

Göttingen, im Juni 2010 



\section{Inhaltsverzeichnis}

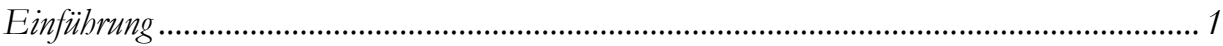

Erster Teil: Der Bundesrechnungshof..........................................................................

I. Historische Entwicklung ..........................................................................................

1. Die General-Rechenkammer in der absoluten Monarchie Preußen seit 1714 ................................................................................................... 6

2. Die Ober-Rechnungskammer in der preußischen konstitutionellen Monarchie nach der oktroyierten Verfassung vom 5. Dezember 1848........... 9

3. Rechnungswesen in Preußen und im Deutschen Reich seit 1871 ...............10

4. Rechnungswesen in der Weimarer Republik seit 1919 .................................12

5. Stellung des Rechnungshofes zur Zeit des Nationalsozialismus 1933-1945

6. Die Entwicklung des Bundesrechnungshofes in der Bundesrepublik

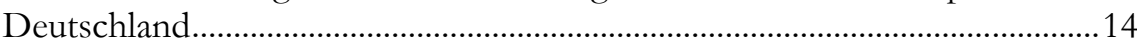

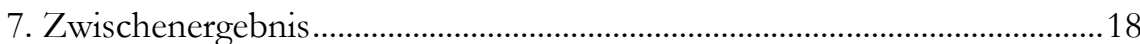

II. Institutionelle Garantie des Bundesrechnungshofes .........................................19

III. Weitere verfassungsrechtliche Hilfsgarantien ...................................................2 20

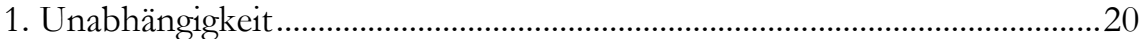

a) Persönliche Unabhängigkeit .......................................................................20

b) Sachliche Unabhängigkeit..........................................................................24

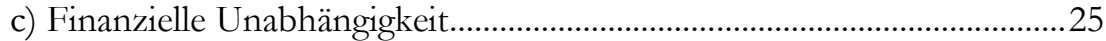

2. Informations- und Zugangsrechte....................................................................25

IV. Die Aufgaben des Bundesrechnungshofes....................................................26

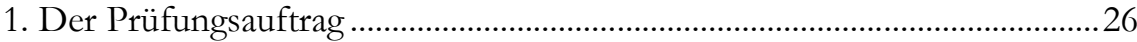

a) Gegenstand und Umfang der Prüfung ...................................................26

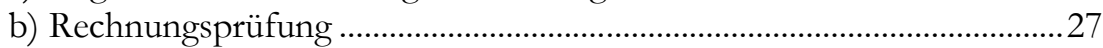

c) Ordnungsmäßigkeits- und Wirtschaftlichkeitsprüfung der Haushalts- und Wirtschaftsführung................................................................2

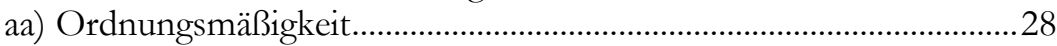

bb) Wirtschaftlichkeit.................................................................................29

2. Funktionale Bedeutung der externen Finanzkontrolle...................................29

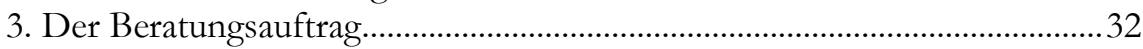

a) Formen der Beratung ....................................................................................... 33

b) Probleme hinsichtlich der Beratung...........................................................36

c) Beratung durch den Bundesbeauftragten für

Wirtschaftlichkeit in der Verwaltung................................................................36

4. Behandlung politischer Entscheidungen ..........................................................37

5. Bekanntmachung und Veröffentlichung der Ergebnisse in den

Berichten des Bundesrechnungshofes.................................................................38

6. Unterrichtungs- und Anhörungserfordernisse - Pflicht, den

Bundesrechnungshof von bestimmten Maßnahmen zu unterrichten 
V. Der Bundesrechnungshof als Forderung des Demokratieprinzips .42

VI. Die Stellung des Bundesrechnungshofes im System der

Gewaltenteilung .43

1. Staatsgewalt und öffentliche Finanzen............................................................... 44

2. Gewaltenteilung im deutschen Verfassungsrecht ............................................46

a) Die Grundlagen der Gewaltenteilung im Grundgesetz ..........................46

b) Zweck der Gewaltenteilung ......................................................................4

c) Die Verwirklichung der horizontalen (organisatorischen)

Gewaltenteilung im Grundgesetz.....................................................................48

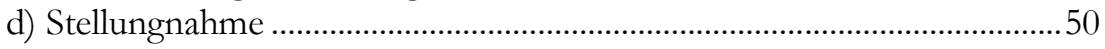

3. Einordnung des Bundesrechnungshofes........................................................50

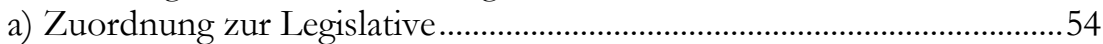

aa) Der Bundesrechnungshof als Hilfsorgan der Legislative...................54

bb) Der Bundesrechnungshof als funktionaler Bestandteil

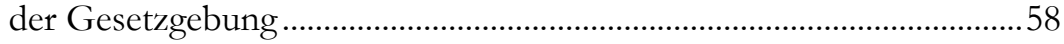

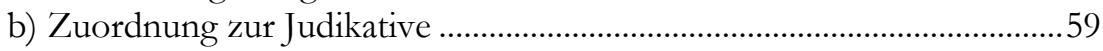

c) Zuordnung zur Exekutive.............................................................................63

aa) Probleme der Zuordnung mit Hilfe der Subtraktionsmethode

bb) Andere Ansatzpunkte für eine Zuordnung zur

Exekutive

๙) Rechtsnatur und Funktion der Aufgaben des

Bundesrechnungshofes als möglicher Anknüpfungspunkt einer

Zuordnung zur Exekutive.

ß) Der Bundesrechnungshof als Behörde...........................................66

ץ) Rechtsnatur von Prüfungsankündigungen.....................................67

$\alpha \alpha)$ Meinungsstand in Literatur und Rechtsprechung ...................67

$\beta \beta)$ Zwischenergebnis .....................................................................73

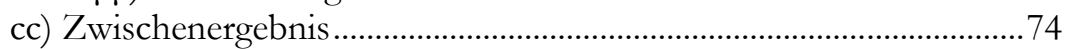

d) Doppelfunktion, die die gleichzeitige Zuordnung zu

Legislative und Exekutive begründet .............................................................75

e) „Vierte Gewalt“ oder Einrichtung sui generis..............................................76

aa) Vierte Staatsgewalt.................................................................................

bb) Institution sui generis beziehungsweise Sonderstellung

zwischen oder außerhalb der Gewalten .....................................................79

VII. Rechtsschutzmöglichkeiten des Bundesrechnungshofes...............................83

1. Verwaltungsgerichtliche Durchsetzung von Prüfungsrechten.....................84

a) Vorgehen gegenüber Stellen innerhalb der

Bundesverwaltung

b) Vorgehen gegenüber Stellen außerhalb der unmittelbaren

Bundesverwaltung....

2. Organstreitverfahren zur Wahrung verfassungsrechtlich garantierter

Rechte 
3. Abstraktes Normenkontrollverfahren

VIII. Selbsteinschätzung des Bundesrechnungshofes von seiner

Stellung und von der Wahrnehmung seiner Funktion 88

1. Auszüge aus Veröffentlichungen von Rechnungshofsmitgliedern .............88 88

2. Analyse ausgewählter Rechnungshofberichte.................................................90

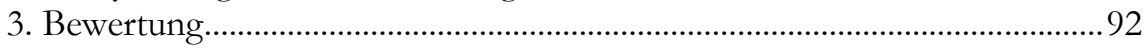

IX. Zusammenfassung der Ergebnisse des 1. Teils ...............................................93

Zweiter Teil: Ausgewäblte mitgliedstaatliche Rechnungshöfe ………….................................95

A. Frankreich: Die Cour des comptes ..........................................................................100

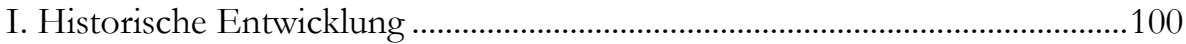

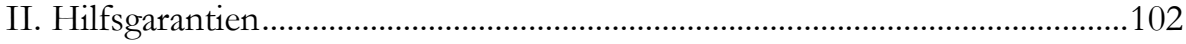

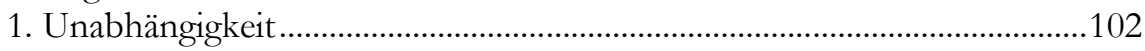

2. Informations- und Zugangsrechte.................................................................103

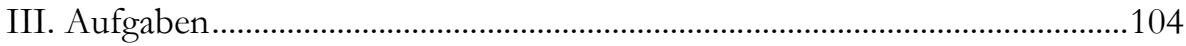

1. Rechnungsprüfung und Kontrolle der Haushaltsführung..........................104

2. Gerichtliche Funktion .......................................................................................104

3. Beratung und Unterstützung von Parlament und Regierung.....................106

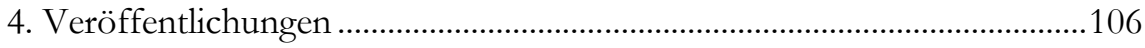

IV. Stellung im System der Gewaltenteilung...........................................................106

1. Gewaltenteilung im französischen Verfassungsrecht.................................106

2. Einordnung der Cour des comptes .............................................................107

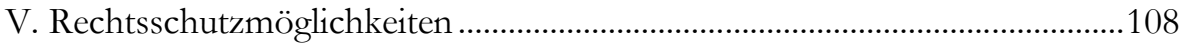

B. Österreich: Der Rechnungshof..............................................................................109

I. Historische Entwicklung ..................................................................................109

II. Verfassungsrechtliche Hilfsgarantien............................................................113

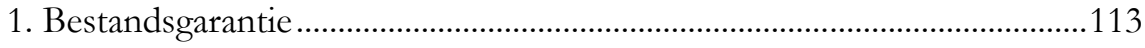

2. Unabhängigkeit ............................................................................................113

a) Persönliche Unabhängigkeit .......................................................................113

b) Sachliche Unabhängigkeit.........................................................................115

3. Informations- und Zugangsrechte................................................................117

III. Aufgaben....................................................................................................117

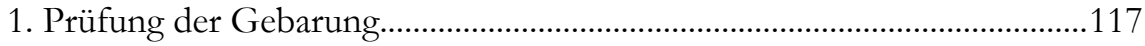

2. Berichterstattung ..........................................................................................119

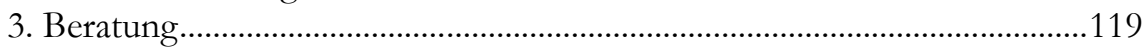

IV. Stellung im System der Gewaltenteilung......................................................120

1. Gewaltenteilung im österreichischen Verfassungsrecht...............................120

2. Einordnung des österreichischen Rechnungshofes....................................121

V. Rechtsschutzmöglichkeiten .......................................................................123

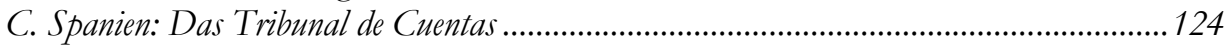

I. Historische Entwicklung ………………………………………………….....124

II. Verfassungsrechtliche Hilfsgarantien...........................................................126

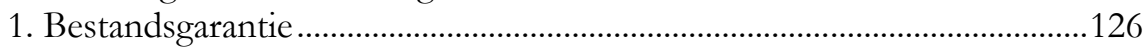


2. Unabhängigkeit ..........................................................................................127

3. Informations- und Zugangsrechte..............................................................128

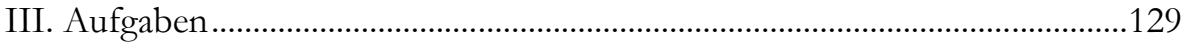

1. Finanzkontrollfunktion .............................................................................129

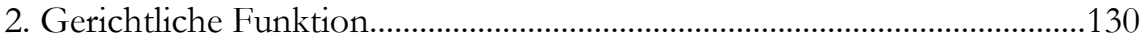

3. Berichterstattung ...........................................................................................131

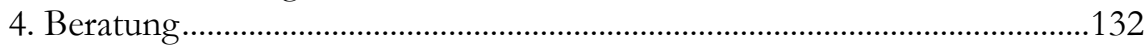

IV. Stellung im System der Gewaltenteilung......................................................132

1. Gewaltenteilung im spanischen Verfassungsrecht......................................132

2. Einordnung des Tribunal de Cuentas ...........................................................133

V. Rechtsschutzmöglichkeiten............................................................................135

D. Vereinigtes Königreich: Comptroller and Auditor General und National Audit

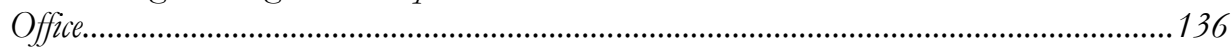

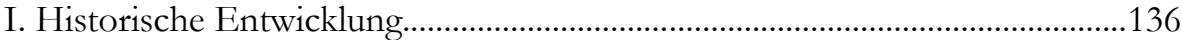

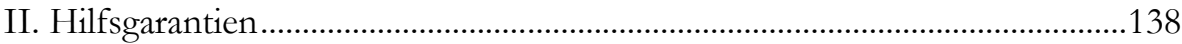

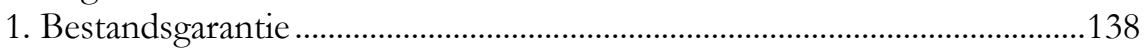

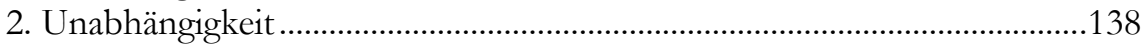

3. Informations- und Zugangsrechte...........................................................139

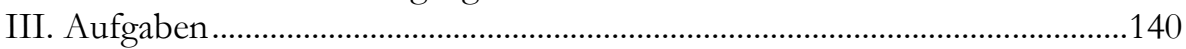

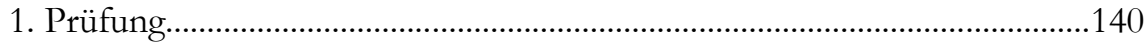

2. Berichterstattung ........................................................................................ 141

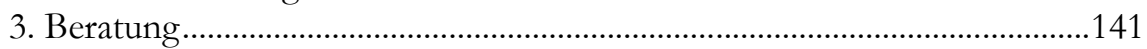

IV. Stellung im System der Gewaltenteilung des Vereinigten

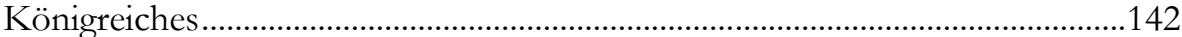

1. Die Ausprägung der Gewaltenteilung............................................................142

2. Die Verortung des Comptroller and Auditor General und des

National Audit Office .......................................................................................142

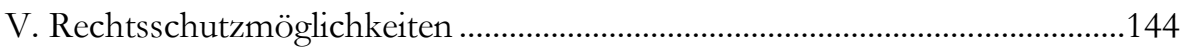

Dritter Teil: Der Europäische Rechnungshof (Curia Rationum) ........................................145

I. Entwicklung der externen Finanzkontrolle von den Anfängen der

Europäischen Gemeinschaften bis heute ………………………………………...147

II. Vertragliche Hilfsgarantien ............................................................................153

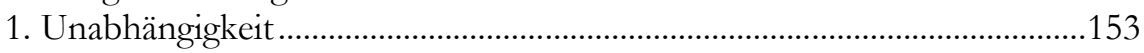

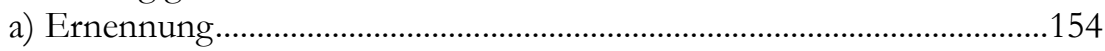

b) Amtszeit und Wiederwahlmöglichkeit....................................................156

c) Amtsenthebung und Aberkennung von

Ruhegehaltsansprüchen oder vergleichbarer Vorteile ................................157

2. Geschäftsordnungsautonomie und interne Organisation............................157

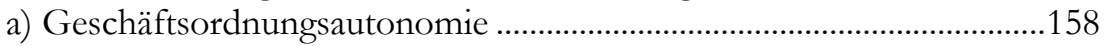

b) Interne Organisation ..............................................................................158

3. Informations- und Zugangsrechte..............................................................159

a) Gegenüber anderen Gemeinschaftsorganen...........................................159 
b) Gegenüber Mitgliedstaaten.........................................................................160

III. Aufgaben und Kompetenzen des Europäischen Rechnungshofes .............164

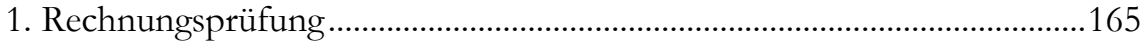

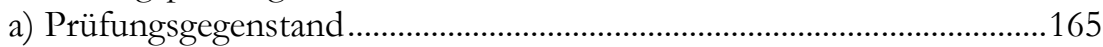

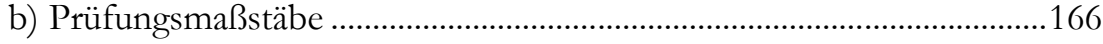

aa) Rechtmäßigkeit ………………………………………………….....166

bb) Ordnungsmäßigkeit..............................................................................168

cc) Wirtschaftlichkeit (im weiteren Sinne) ...............................................169

c) Prüfungsumfang und Prüfungsansatz....................................................169

d) Prüfungszeitpunkt...................................................................................171

2. Beratung und Anhörungserfordernisse vor Erlass finanzrechtlicher Vorschriften.

a) Obligatorische Anhörung bei Entlastung und gemeinschaftlicher Normsetzung ................................................................172

b) Beratung auf Ersuchen anderer Gemeinschaftsorgane ........................173

3. Veröffentlichungen ...................................................................................... 174

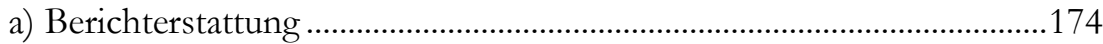

b) Weiterverfolgung früherer Bemerkungen................................................175

c) Rechtsschutz gegen Berichte des Europäischen

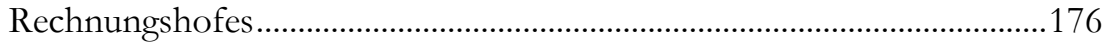

4. Rechtsnatur der Handlungsformen ...............................................................177

IV. Stellung des Europäischen Rechnungshofes im Organgefüge der

Europäischen Gemeinschaft................................................................................180

1. Gewaltenteilung in der Europäischen Gemeinschaft...................................180

a) Ausgestaltung der horizontalen Kompetenzverteilung nach dem EG-Vertrag und dem Vertrag über die Arbeitsweise der Union

aa) Funktionsverteilung im Normsetzungsverfahren ..........................181

bb) Parlamentarische Kontrollfunktion ..................................................182

cc) Exekutive Funktion durch Kommission und Rat............................183

dd) Gerichtliche Kontrollfunktion ...........................................................183

ee) Finanzkontrollfunktion .......................................................................183

ff) Geteilte Kompetenzen bei der Organbesetzung...............................184

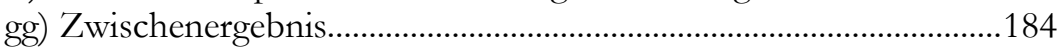

b) Das Prinzip des institutionellen Gleichgewichts.......................................185

aa) Die Rechtsprechung des Europäischen Gerichtshofs.....................185

bb) Der Meinungsstand im Schrifttum ..................................................186

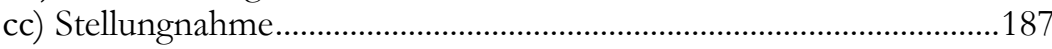

c) Einordnung des Europäischen Rechnungshofes..................................193

2. Betrachtung der Wahrnehmung seiner Stellung anhand ausgewählter Rechnungshofberichte .................................................................198

V. Rechtsschutzmöglichkeiten vor dem EuGH ...................................................201

1. Rechtsschutz gegenüber anderen Gemeinschaftsorganen..........................202 
a) Nichtigkeitsklage Art. 230 EGV (Art. 263 AEUV) ...................................202

b) Untätigkeitsklage Art. 232 EGV (Art. 263 AEUV)..................................203

VI. Die Zusammenarbeit des Europäischen Rechnungshofes und der obersten Rechnungskontrollbehörden der Mitgliedstaaten

1. Die Rechnungshöfe im europäischen Staaten- und

Verfassungsverbund. 205

a) Der europäische Staaten- und Verfassungsverbund.............................205

b) Bedeutung für das europäische Rechnungshofsystem.........................208

2. Zusammenarbeit einzelstaatlicher Rechnungshöfe im Rahmen von

EUROSAI und INTOSAI .............................................................................213

VII. Zusammenfassung der Ergebnisse des 3. Teils .........................................213

Vierter Teil: Rechtsvergleichende Stellungnahme und Resümee.............................................217

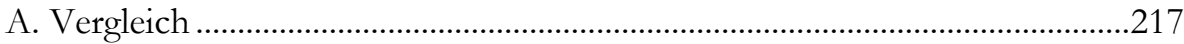

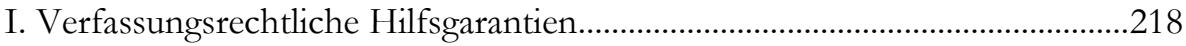

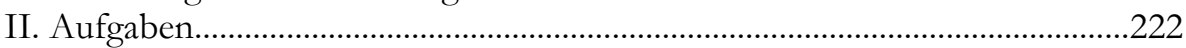

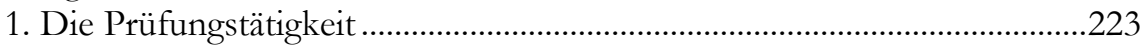

2. Die Beratungstätigkeit ...........................................................................223

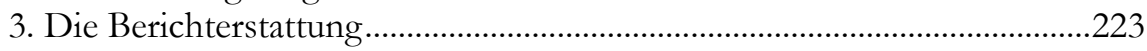

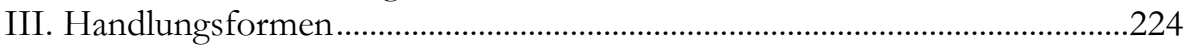

IV. Einordnung in das staatliche Gewaltenteilungsschema

beziehungsweise das institutionelle Gleichgewicht auf europäischer

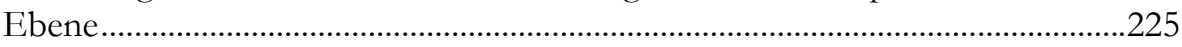

V. Klagemöglichkeiten der obersten Rechnungskontrollorgane ......................230

1. Gegenüber Prüfungsunterworfenen.........................................................230

2. Gegenüber anderen Staatsorganen zur Wahrung des

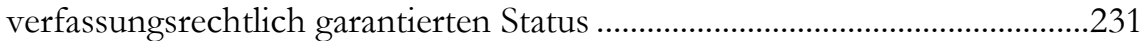

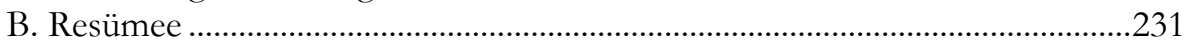

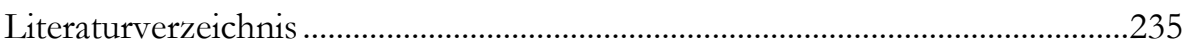




\section{Einführung}

Ein Staat muss wie jede andere Wirtschaftseinheit dafür Sorge tragen, dass die vorhandenen Mittel bestimmungsgemäß eingesetzt werden und Transparenz über den Umgang mit ihnen sichergestellt ist. Dafür ist es entscheidend, einen genauen Überblick darüber zu behalten, was mit den zur Verfügung stehenden Geldern geschieht. Je größer die Wirtschaftseinheit ist, desto komplexer und unübersichtlicher ist auch die Kontrolle der Einnahmen und Ausgaben. Bei der Europäischen Union mit einem Haushalt von rund 100 Milliarden Euro und einer staatsähnlichen Einnahmen- und Ausgabenstruktur stellen sich die gleichen Probleme wie bei den Mitgliedstaaten. Um Misswirtschaft mit staatlichen Geldern verhindern zu können und überhaupt um mit den kaum überschaubaren staatlichen Geldern sinnvoll wirtschaften zu können, sind daher Kontrollinstanzen unabdingbar. Dabei hat sich die Einrichtung externer, unabhängiger Kontrollorgane, die außerhalb der wirtschaftenden Staatsorgane stehen, als besonders wirksam erwiesen. Von den kontrollierten Institutionen unabhängige Rechnungshöfe sind damit unverzichtbarer Teil des Systems der Finanzkontrolle. Im Gegensatz zu Selbstkontrollmechanismen innerhalb der Exekutive üben sie echte Fremdkontrolle aus. Die gegenseitige Kontrolle der Staatsgewalten im Bereich des öffentlichen Finanzwesens wird größtenteils überhaupt erst durch ihre Arbeit ermöglicht. Die starken faktischen Einwirkungsmöglichkeiten der Rechnungshöfe, insbesondere über die Öffentlichkeit, auf die Staatsgewalten durch die Veröffentlichung der Prüfungsbe- 
richte, Aussprechen von Warnungen und Beratung während der Entscheidungsphase über Gesetzesvorhaben macht ihre Einordnung in das Schema der Gewaltenteilung beziehungsweise das institutionelle Gleichgewicht notwendig. Unsicherheit über die Einordnung der Rechnungshöfe besteht, weil sie die klassischerweise dreigeteilte Staatsgewalt hinsichtlich ihres Wirtschaftens kontrollieren, also genau dem Hauptzweck der Gewaltenteilung, die Kontrolle von Staatsmacht zu verwirklichen, dienen und dies auch in weitgehender Unabhängigkeit tun.

Vor diesem Hintergrund ist auch die Ausstattung des Europäischen Rechnungshofs mit Organqualität zu sehen, die ihn auf eine Ebene mit den die Aufgaben der Legislative, Exekutive und Judikative ausübenden Organe gehoben hat. Es stellt sich damit im Hinblick auf die Zusammenarbeit oberster Rechnungskontrollbehörden im europäischen Staaten- und Verfassungsverbund und auch auf die in der europarechtlichen Literatur bisher weitgehend vernachlässigte Einordnung des Europäischen Rechnungshofes die Frage nach ihrem verfassungsrechtlichen Standort und ihrer Beziehungen zueinander im europäischen Rechnungshofsystem. Die Erörterung der Stellung mehrerer mitgliedstaatlicher Rechnungshöfe sowie des Europäischen Rechnungshofes und der anschließende Rechtsvergleich sollen hier für mehr Klarheit sorgen.

Die verfassungsrechtliche Einordnung der Rechnungshöfe in Europa, sowohl der nationalen als auch des Europäischen Rechnungshofes, ist von daher bedeutsam, als es nach dem EG-Vertrag zwischen den mitgliedstaatlichen europäischen obersten Rechnungskontrollbehörden und dem Europäischen Rechnungshof zu einer vertrauensvollen Zusammenarbeit unter Wahrung ihrer Unabhängigkeit kommen soll. Hierbei spielt zur Beurteilung ihrer Objektivität, der Aussagekraft ihrer Berichte sowie der Auswahl der Prüfungsgegenstände nicht nur die Frage nach den von den jeweiligen Kontrollorganen angewandten Prüfungsmaßstäben und -methoden eine Rolle, sondern auch ihre verfassungsrechtliche Stellung. Dabei steht die Unabhängigkeit von den geprüften Organen im Vordergrund, eng verbunden mit der Einordnung in das jeweilige System der Gewaltenteilung.

In dieser Arbeit sollen exemplarisch der Bundesrechnungshof, die französische Cours des comptes, der österreichische Rechnungshof, das spanische Tribunal de Cuentas und der britische Comptroller and Auditor General hinsichtlich ihrer Stellung im jeweiligen Verfassungsrecht sowie der Europäische Rechnungshof und seine Stellung im institutionellen Gefüge der Europäischen Union behandelt werden. Geschichte und Aufgaben der Rechnungshöfe werden dabei insoweit behandelt, als sie zur Einordnung in das Gewaltenteilungsschema von Bedeutung sind, wobei insbesondere auch auf verfassungsrechtliche Hilfsgarantien der Rechnungshöfe einzugehen sein wird und auf die Möglichkeiten, diese Rechte selbst gerichtlich zu verteidigen. Schließlich soll ein Vergleich zwischen den verschiedenen nationalen Rechnungshöfen und dem Europäischen Rechnungshof erfolgen und die daraus folgenden Konsequenzen erörtert werden. Anhand dieser Einordnung werden auch Unterschiede und Gemeinsamkeiten zwischen den Gewalten- 
teilungskonzepten verschiedener Mitgliedstaaten und dem System des institutionellen Gleichgewichts der Europäischen Union deutlich werden. Weiter werden Vorschläge zur Sicherung beziehungsweise Verbesserung der Wirksamkeit der Rechnungshöfe erarbeitet.

Auch wird die Frage zu behandeln sein, inwieweit Rechnungshöfe im modernen Parteienstaat, der von der Durchdringung der drei klassischen Staatsgewalten durch Parteien und Interessenverbände geprägt ist, hierzu zumindest teilweise ein wirksames Gegengewicht bilden können und von Verfassung wegen sollen. Die Rationalisierung staatlichen Handelns, die Förderung des Treffens richtiger Entscheidungen, die als Grundzweck durch die Gewaltenteilung verfolgt wird, ist ein weiterer Aspekt. 



\section{Erster Teil: Der Bundesrechnungshof}

\section{Historische Entwicklung ${ }^{1}$}

Der Bundesrechnungshof blickt auf eine fast 300-jährige Geschichte zurück, beginnend mit der im Jahre 1714 gegründeten Preußischen General-Rechenkammer, in deren Tradition er sich sieht. In allen seitdem in Deutschland dagewesenen Staatsformen, dem Absolutismus, der konstitutionellen Monarchie, der Weimarer Republik, dem totalitären Staat während des Nationalsozialismus und der repräsentativ-parlamentarischen Demokratie der Bundesrepublik wurde die Notwendigkeit einer externen, meistens unabhängigen Finanzkontrolle gesehen.

Im Kontext der verfassungsrechtlichen Einordnung des Bundesrechnungshofes ist eine kurze Darstellung dieser Geschichte hilfreich, um die Entwicklung der Rechnungsprüfung in Deutschland mit ihren wechselnden Abhängigkeiten von anderen Staatsorganen sowie ihren Aufgaben, Privilegien und Einflussmöglichkeiten zu verdeutlichen.

\footnotetext{
${ }^{1}$ Ein kurzer Überblick zur Entstehung der Rechnungsprüfung und ihrer Vorläufer seit der Antike findet sich bei v.Ditfurth, Zur Geschichte der Königlich Preußischen Ober-Rechnungskammer, 1909, S. 1-7.
} 


\section{Die General-Rechenkammer in der absoluten Monarchie Preußen seit 1714}

Die wohl 1714 (eine Gründungsurkunde ist nicht auffindbar) ${ }^{2}$ durch Friedrich Wilhelm I. (1713-1740) gegründete preußische General-Rechenkammer ${ }^{3}$ ist zwar nicht die älteste deutsche Rechnungskontrollbehörde ${ }^{4}$, gilt aber als Vorläufer des heutigen Bundesrechnungshofes, wurde ihr doch im Jahre $1868^{5}$ zusätzlich die Rechnungsprüfung des Norddeutschen Bundes und 1871 die des Deutschen Reiches übertragen, so dass sie von da an zugleich als „Rechnungshof des deutschen Reiches" fungierte, also von Preußen ,geliehen" wurde . ${ }^{6}$

Wie sich aus der königlichen Order vom 16. Juni 1717 ergibt, legte Friedrich Wilhelm I. fest, dass die General-Rechenkammer „ein besonderes Kollegium seyn“ müsse, das von „Niemandem anders“ als dem König ,allein dependieren“ sollte. ${ }^{7}$ Die General-Rechenkammer war dem Monarchen allein untergeordnet als Instrument, das ihm einen Überblick über das gesamte Finanz- und Rechnungswesen Preußens gab. Auch wird aus der Instruktion deutlich, dass sie von Anfang an auf eine Kollegialverfassung angelegt war.

Ihre Aufgabe war es, alle Rechnungen zu prüfen und dem Monarchen Bericht zu erstatten, ob und inwieweit seine Verordnungen, Instruktionen und Anweisungen eingehalten und die jeweiligen Etatgrenzen beachtet wurden. ${ }^{8}$ Dabei oblag der Rechenkammer jedoch nur die Superrevision in Form der Kontrolle der Hauptrechnungen, die Kontrolle der Einzelrechnungen der Verwaltung erfolgte als Vorprüfung jeweils durch die übergeordnete Behörde. ${ }^{9}$

2 Siehe dazu: Haase, Die Errichtung und die erste Instruktion der preußischen OberRechnungskammer, FinArch 1922, 1, mit dem Versuch einer Rekonstruktion der Gründungsurkunde; v.Ditfurth, Zur Geschichte der Königlich Preußischen Ober-Rechnungskammer, 1909, S. 8.

${ }^{3}$ Ab 1723 Bezeichnung als preußische Ober-Kriegs- und Domainen-Rechen-Kammer (kurz OberRechenkammer), ab 1802 Ober-Rechnungskammer, vgl. Hertel, Die preußische OberRechnungskammer, 1884, S. 11, 15.

${ }^{4}$ Sächsischer Ober-Rechen-Rat gegründet 1707, vgl. hierzu: Grupp, Die Stellung der Rechnungshöfe in der BRD, 1972, S. 15, 17 ff. m.w.N.; v.Pfublstein, Der Weg von der preußischen Generalrechenkammer zum Bundesrechnungshof, in: Bundesrechnungshof, 250 Jahre Rechnungsprüfung, 1964, S. 14.

${ }^{5}$ Die Tätigkeit wurde am 01.01.1869 aufgenommen, Wagner, 50 Jahre Bundesrechnungshof, AöR 2001, 93 (102).

${ }^{6}$ Hierauf wird unter I.3. noch näher eingegangen..

7 Siehe hierzu Haase, Die Errichtung und die erste Instruktion der Preußischen OberRechnungskammer, FinArch 1922, 1 ff. ( 61 f., Anlage 23); Grupp, Die Stellung der Rechnungshöfe in der BRD, 1972, S. 22; v.Pfublstein, Der Weg von der Generalrechenkammer zum Bundesrechnungshof, in: Bundesrechnungshof, 250 Jahre Rechnungsprüfung,1964, S. 17.

${ }^{8}$ Grupp, Die Stellung der Rechnungshöfe in der BRD, 1972, S. 23; zum allgemeinen Prüfungsauftrag: Haase, Die Errichtung und die erste Instruktion der Preußischen Ober-Rechnungskammer, FinArch 1922, 1 ff. (33 unten).

9 Haase, Die Errichtung und die erste Instruktion der Preußischen Ober-Rechnungskammer, FinArch 1922, 1 ff. (35 f.). 
Das durch die Prüfungen der Rechenkammer erlangte Wissen ermöglichte dem König die Kontrolle der Verwaltung. Auf dieser Grundlage konnte Friedrich Wilhelm I. durch Instruktion vom 20. Dezember 1722 eine Neuordnung der öffentlichen Belange in Preußen vornehmen, wobei der preußischen GeneralRechenkammer, wenn auch nur kurz, eine positiv-konstruktive Rolle zugedacht wurde: ${ }^{10}$ Die Instruktion verpflichtete die Minister des Generaldirektoriums, sich vor der Verabschiedung des Budgets zur General-Rechenkammer zu begeben, um den Etat „,noch einmal durchzugehen und zu examinieren“. ${ }^{11}$ Es wurde also eine (Zwangs-) Beratung der Exekutive durch die Rechenkammer vorgeschrieben.

Dieser Beratungsauftrag wurde schon ein Jahr später, mit Instruktion vom 2. März 1723, als zu weit gehend wieder eingeschränkt, in der Form, dass die Generaldirektion von nun an ermächtigt war, ein Mitglied der Ober-Rechenkammer an der Beratung des Budgets zu beteiligen, wenn sie dies für nötig hielt. ${ }^{12}$

Unter Friedrich II., dem Großen, (1740-1786) gab es keine Instruktion des Inhalts, dass die Ober-Rechenkammer zur Beratung herangezogen werden konnte; erst sein Nachfolger Friedrich Wilhelm II. (1786-1797) knüpfte wieder an die Regelung an. ${ }^{13}$ So ergibt sich aus einer Instruktion des Monarchen an die OberRechenkammer vom 2. November 1786, dass ihr Präsident jeweils zum Jahresende dem König über Lage und Zustand des Rechnungswesens „einen getreuen und ausführlichen Bericht zu erstatten“ hatte. ${ }^{14}$

Die Frage, die im Mittelpunkt der staatsrechtlichen Einordnung der Rechenkammer in der absoluten Monarchie stehen muss, ist ihr Verhältnis zum König und insbesondere zu „seiner“ Exekutive. Die Entwicklung ist dabei geprägt von der wechselnden Abhängigkeit von der Verwaltung. Einen ersten Wendepunkt hinsichtlich der Stellung der General-Rechenkammer stellt das Jahr 1723 dar: Die bis dahin selbständige General-Rechenkammer wurde mit der Instruktion vom 2. März $1723^{15}$ als „Ober-Krieges- und Domainen-Rechen-Kammer“ dem von fünf Ministern geleiteten Generaldirektorium als „subalternes Collegium“ zugeordnet und büßte damit ihre Unabhängigkeit ein. ${ }^{16}$ Der Grund hierfür waren wohl die starken Spannungen, die zwischen den obersten preußischen Finanzbehörden im Verhältnis untereinander und zur Rechenkammer bestanden, so dass sich Fried-

${ }^{10}$ Wittrock, Der Rechnungshof als Berater, DÖV 1989, 346 (347).

11 Wittrock, Der Rechnungshof als Berater, DÖV 1989, 346 (347) m.w.N.

12 Vgl. Punkt 7. der Instruktion abgedruckt bei Hertel, Die Preußische Ober-Rechnungskammer, 1884, (Anlage II.), S. 23; Wittrock, Der Rechnungshof als Berater, DÖV 1989, 346 (347).

13 Wittrock, Der Rechnungshof als Berater, DÖV 1989, 346 (347).

${ }^{14}$ Sectio II, $\int 18$ der Instruktion, abgedruckt bei Hertel, Die Preußische Ober-Rechnungskammer, 1884, S. 84 (Anlage XV.).

15 Abgedruckt bei Hertel, Die preußische Ober-Rechnungskammer, 1884, S. 21 ff. (Anlage II.).

16 Vgl. Punkt 1. der Instruktion bei Hertel, Die preußische Ober-Rechnungskammer, 1884, S. 22 (Anlage II.); v.Pfublstein, Der Weg von der preußischen Generalrechenkammer zum Bundesrechnungshof, 1964, S. 18; H. Schäfer, Wer kontrolliert unsere Steuergelder? Finanzprüfung durch den BRH, 1977, S. 27; Haase, Die Errichtung der preußischen Ober-Rechnungskammer, FinArch 1922, 1 (42) m.w.N. 
Der Bundesrechnungshof

rich Wilhelm I. schließlich entschloss, diese zu einer einzigen Behörde, dem Generaldirektorium, zu verschmelzen. ${ }^{17}$

Durch Instruktion König Friedrich Wilhelms II. vom 2. November $1786^{18}$ kam es wieder zu einer Stärkung der Stellung der Rechenkammer und zu einer gewissen Unabhängigkeit von den bestehenden Verwaltungsbehörden einschließlich des Generaldirektoriums. Unter anderem sollten die Rechnungen nicht mehr im Beisein eines Geheimen Finanz-Rates aus dem Generaldirektorium abgenommen werden (vgl. Sectio II $\int 2$ Abs. 2 der Instruktion) ${ }^{19}$; außerdem erhielt der Präsident der Rechenkammer das unmittelbare Vorschlagsrecht allein dem König gegenüber bei der Bestellung neuer Mitglieder (vgl. Sectio I \4 Abs. 2). ${ }^{20}$

Am 19. Februar 1798 erließ Friedrich Wilhelm III. (1797-1840) eine Instruktion $^{21}$, die die Selbständigkeit der Ober-Rechenkammer, insbesondere die Unabhängigkeit vom Generaldirektorium, erneut bestimmte (vgl. \ 2 der Instruktion) ${ }^{22}$. Jedoch war ihr Chef zugleich Mitglied des Generaldirektoriums (vgl. \323 und mithin Teil der Exekutive auf Ministerialebene. Erst rund hundert Jahre nach der Eingliederung in das Generaldirektorium wurde die Stellung der Institution durch königliche Instruktion vom 18. Dezember 1824 wieder dergestalt neu geregelt, dass sie ein selbständiges, nur dem König verantwortliches Kollegium sei, ${ }^{24}$ sie gewann somit wieder „echte“ Unabhängigkeit von der Verwaltung. Die Instruktion sah in \49 weiter vor, dass dem König jährlich Bericht über festgestellte Verwaltungsmängel und Bedenken der Rechnungskammer zu erstatten war, worin sich ihr bereits erwähnter Beratungsauftrag wiederfindet. ${ }^{25}$

Die Ober-Rechnungskammer stellte ebenso wie ihre Vorläufer letztlich ein Hilfsorgan des absoluten Monarchen dar, um die ihm untergeordnete Verwaltung

${ }_{17}$ Grupp, Die Stellung der Rechnungshöfe in der BRD, 1972, S. 25 f. m.w.N.

18 Abgedruckt bei Hertel, Die preußische Ober-Rechnungskammer, 1884, S. 75 ff. (Anlage XV.).

19 Damit „die Ober-Rechen-Kammer ihre Erinnerungen bey Revision der Rechnungen ganz frey und ohne gêne machen kann", wobei zu beachten ist, dass der Präsident gleichzeitig dem Generaldirektorium angehörte.

20 Vgl. auch Grupp, Die Stellung der Rechnungshöfe in der BRD, 1972, S. 29 f. m.w.N.

${ }^{21}$ Abgedruckt bei Hertel, Die preußische Ober-Rechnungskammer, 1884, S. 98 ff. (Anlage XIX.).

22 „So sollen hiermit alle Verhältnisse, worin selbige (Anm. die ORK) bisher mit dem GeneralDirectorio gestanden, gänzlich aufgehoben, und dieselbe als ein für sich bestehendes, ganz unabhängiges Landes-Collegium, welches seine Verfügungen an alle Kammern und übrige Unterbehörden im Namen und auf speciellen Befehl Seiner Majestät des Königs zu erlaßen hat, angesehen, und in seinem Range dem General-Directorio gleichgesetzt werden.“.

23 Ausführlich zum Ganzen Grupp, Die Stellung der Rechnungshöfe in der BRD, 1972, S. 31 f.; vgl. auch: v.Pfublstein, Der Weg von der preußischen Generalrechenkammer zum Bundesrechnungshof, 1964, S. 28; Hertel, Die preußische Ober-Rechnungskammer, 1884, S. 98 f.

24 Vgl. $\ 50$ S. 1 der Instruktion, abgedruckt bei: v.Pfublstein, Der Weg von der preußischen Generalrechenkammer zum Bundesrechnungshof, 1964, S. 38.

25 Wittrock, Der Rechnungshof als Berater, DÖV 1989, 346 (347); Abgedruckt bei: Hertel, Die preuBische Ober-Rechnungskammer, 1884, S. 127 ff. (161). 
überwachen zu können. ${ }^{26}$ Daneben sollte sie ihm durch die Prüfungsergebnisse selbst und durch die damit verbundene fortschrittliche Aufgabe der Beratung das nötige Wissen verschaffen, um legislative und exekutive Entscheidungen zu treffen. Die Unabhängigkeit von der zu kontrollierenden Verwaltung wurde schon von Anfang an als Voraussetzung für eine effektive externe Kontrolle durch die Ober-Rechnungskammer erkannt, jedoch zumindest zeitweise (1723-1824) abgeschafft beziehungsweise eingeschränkt, weil der König die Querelen zwischen den Ministern und der Rechnungskammer schnell leid war.

2. Die Ober-Rechnungskammer in der preußischen konstitutionellen Monarchie nach der oktroyierten Verfassung vom 5. Dezember 1848

Das hohe Ansehen, das die preußische Ober-Rechnungskammer genoss, und der unbestreitbare Nutzen ihrer Finanzkontrolle für den Staat führten dazu, dass in Preußen das in der absoluten Monarchie entwickelte Organ der externen Finanzkontrolle in die konstitutionelle Monarchie übernommen werden konnte. ${ }^{27}$ War das Verhältnis der Ober-Rechnungskammer zur Exekutive seit der Instruktion von 1824 weitgehend geklärt, stellte sich nun auch die Frage nach ihrem Verhältnis zum Parlament.

Die Parlamente erlangten im Zuge der Übertragung von Staatsgewalt auf die Volksvertretungen zunächst die Budgethoheit. Diese war aber, ohne die Möglichkeit zu überprüfen, ob und inwieweit den eigenen Beschlüssen, insbesondere dem Haushaltsplan, Folge geleistet wurde, wenig wert.

Die preußische oktroyierte Verfassung vom 5.12.1848 bestimmte in Art. 103: „Zu Etatüberschreitungen ist die nachträgliche Genehmigung der Kammern erforderlich. Die Rechnungen über den Staatshaushalt werden von der OberRechnungskammer geprüft und festgestellt. Die allgemeine Rechnung über den Staatshaushalt jeden Jahres, einschließlich ihrer Uebersicht der Staatsschulden, wird von der Ober-Rechnungskammer zur Entlastung der Staats-Regierung den Kammern vorgelegt.

Ein besonderes Gesetz wird die Einrichtung und Befugnisse der OberRechnungskammer bestimmen."

Hiernach verkehrte die Ober-Rechnungskammer unmittelbar mit dem Parlament, indem sie die Rechnung vorlegte. Das war so wohl nicht gewollt und wurde bereits kurze Zeit später durch die preußische revidierte Verfassung vom

\footnotetext{
${ }^{26}$ Vogel/Kirchbof, in: Bonner Kommentar, Art. 114, Rn. 6 (Stand: 32. Lieferung, Januar 1974): Rechnungsprüfung ursprünglich als „Hilfsinstrument der Verwaltungsspitze, um untergeordnete Verwaltungsstellen überwachen“, und „dem Inhaber der Regierungsgewalt einen Überblick über die Verwaltung zu verschaffen“; Beckensträter, Die Stellung der Rechnungshöfe im System der Dreiteilung der Staatsgewalt, 1961, S. 26: „Instrument der monarchischen Gewalt“.

27 Stern, Staatsrecht, Bd. II, 1980, S. 411.
} 
31.1.1850 wieder abgeschafft. ${ }^{28} \mathrm{Im}$ Wesentlichen wurde die Vorschrift zwar in Art. 104 übernommen, aber Satz 3 änderte sich:

„Die allgemeine Rechnung... einschließlich der Staatsschulden, wird mit den Bemerkungen der Ober-Rechnungskammer zur Entlastung der Staatsregierung den Kammern vorgelegt.“

Sehr umstritten war von nun an, was diese „Bemerkungen“ beinhalten sollten. Einerseits setzen die sinnvolle Wahrnehmung des Budgetrechts und die Kontrolle und Entlastung der Regierung durch das Parlament die entsprechenden notwendigen Informationen voraus, andererseits wurden die Berichte der OberRechnungskammer noch als Privileg der Krone gesehen und daher dem Parlament vorenthalten.

Die Ober-Rechnungskammer enthielt sich jedenfalls mit der Begründung, zunächst müsse als Grundlage jeder Bemerkung das in der Verfassung vorgesehene klarstellende Gesetz erlassen werden, was über Jahre zu heftigen Auseinandersetzungen zwischen Parlament, Regierung und Krone führte. ${ }^{29}$

1862 führten die Konflikte, im Zuge derer das Parlament schließlich auch der Regierung die Entlastung verweigerte, zu Zugeständnissen, dergestalt dass Bemerkungen auf Erlass vom 21.07.1862 dem Landtag zugeleitet wurden. ${ }^{30}$ Jedoch enthielten diese nur Informationen über Etatüberschreitungen, extraordinäre Ausgaben und Erinnerungen, wenn Behörden im Verwaltungsverfahren gegen das Haushaltsgesetz verstoßen hatten; die erheblich wichtigeren Informationen über sonstige Verstöße gegen Gesetze, Verordnungen, Finanzvorschriften etc. sowie über unwirtschaftliches Haushalten blieben dem Landtag dagegen weiterhin vorenthalten. ${ }^{31}$

Insbesondere blieb Adressat des seit der Instruktion vom 18. Dezember 1824 ergehenden Berichts ${ }^{32}$ über Mängel und Bedenken zunächst allein der König, ab 1862 wurde er auch der Regierung, aber nicht dem Parlament zugeleitet ${ }^{33}$.

\section{Rechnungswesen in Preußen und im Deutschen Reich seit 1871}

Das preußische Ober-Rechnungskammer-Gesetz, das am 27. März 1872 in Kraft trat, bestätigte in $\int 1$ erneut, dass die Ober-Rechnungskammer eine „dem König unmittelbar untergeordnete, den Ministern gegenüber selbständige Behörde“ sei, der die Kontrolle des gesamten Staatshaushaltes obliegt. \5 bestimmte die per-

\footnotetext{
28 Ausführlich: Grupp, Die Stellung der Rechnungshöfe in der BRD, 1972, S.45 f.

29 Ausführlich: v.Pfuhlstein, Der Weg von der Generalrechenkammer zum Bundesrechnungshof, in: Bundesrechnungshof, 250 Jahre Rechnungsprüfung,1964, S. 53.

30 v.Pfublstein, Der Weg von der Generalrechenkammer zum Bundesrechnungshof, in: Bundesrechnungshof, 250 Jahre Rechnungsprüfung,1964, S. 53.

31 v.Pfublstein, Der Weg von der Generalrechenkammer zum Bundesrechnungshof, in: Bundesrechnungshof, 250 Jahre Rechnungsprüfung,1964, S. 53.

32 Oben: A.I.1.

33 v.Pfublstein, Der Weg von der Generalrechenkammer zum Bundesrechnungshof, in: Bundesrechnungshof, 250 Jahre Rechnungsprüfung,1964, S. 52.
} 
sönliche Unabhängigkeit seiner Mitglieder, die dadurch unterstrichen wurde, dass sie hinsichtlich disziplinarrechtlicher Maßnahmen den Richtern gleichgestellt wurden.

Außerdem ist bemerkenswert, dass der Ober-Rechnungskammer auferlegt wurde, in ihrem jährlichen Geschäftsbericht für den König Vorschläge über Änderungen von Gesetzen und Verordnungen zu unterbreiten. ${ }^{34}$ Damit erfolgte eine klare Festlegung des Beratungsauftrages neben dem Prüfungsauftrag als selbständige Aufgabe.

Auch die umstrittenen Bemerkungen wurden durch das OberRechnungskammer-Gesetz von 1872 endlich geregelt. Nach \ 18 wurden diese über die Staatsregierung dem Landtag zugeleitet und bildeten die Grundlage für die Entlastung der Regierung. Sie beinhalteten danach im Wesentlichen die rechnungsmäßige Richtigkeit von Einnahmen und Ausgaben, die Einhaltung des „Staatshaushalts-Etats“ sowie Aussagen über Etatüberschreitungen beziehungsweise außeretatmäßige Ausgaben, die der nachträglichen Genehmigung des Parlaments bedürfen. ${ }^{35}$

Zu einem unmittelbaren Kontakt zwischen Landtag und Rechnungskammer kam es immer noch nicht, ebensowenig zu der teilweise bereits geforderten Mitwirkung des Parlaments ${ }^{36}$ an der Besetzung der Rechnungskammer.

Eine dem preußischen Gesetz entsprechende Regelung für das Deutsche Reich kam nicht zustande. Die Finanzkontrolle des Norddeutschen Bundes und ab 1871 des Deutschen Reichs nahm die preußische Ober-Rechnungskammer wahr. Diese wurde immer wieder für ein oder mehrere Jahre vom Reich geliehen (vgl. nur Reichsgesetz vom 28.10.1871 (RGBl. S. 344); eine dauerhafte oder zumindest längerfristige Regelung scheiterte hingegen 1868 und erneut 1902 im Reichstag 37

In der Zeit der konstitutionellen Monarchie war das Privileg des Monarchen, alleiniger Adressat des jährlichen Berichtes zu sein, zentraler Gegenstand parlamentarischer Auseinandersetzungen. Zur Durchsetzung eines vollen parlamentarischen Budgetrechts aber war der Zugang zu Informationen nötig. Versuche, dieses Privileg zu beseitigen, scheiterten zunächst, was die Macht des Königs nach der fehlgeschlagenen Revolution von 1848 widerspiegelt. ${ }^{38}$

Mit der Zeit konnte jedoch erstritten werden, dass Prüfungen und Berichte der Ober-Rechnungskammer zumindest teilweise nicht mehr nur dem König oder in

\footnotetext{
34 v.Pfuhlstein, Der Weg von der Generalrechenkammer zum Bundesrechnungshof, in: Bundesrechnungshof, 250 Jahre Rechnungsprüfung,1964, S. 58.

35 \ 18 Ober-Rechnungskammer-Gesetz abgedruckt bei: Grupp, Die Stellung der Rechnungshöfe in der BRD, 1972, S. 47.

36 Vgl. hierzu Nachweise bei: v.Pfublstein, Der Weg von der Generalrechenkammer zum Bundesrechnungshof, in: Bundesrechnungshof, 250 Jahre Rechnungsprüfung,1964, S. 55.

37 Ausführlich: Wagner, 50 Jahre Bundesrechnungshof, AöR 2001, 93 (102), Stern, Staatsrecht, Bd. II, 1980, S. 413.

38 Vgl. Wittrock, Der Rechnungshof als Berater, DÖV 1989, 346 (348).
} 
eingeschränkter Form der Regierung, sondern auch dem Parlament dienten. Zwar wurden die Bemerkungen über den Umweg der Staatsregierung dem Parlament zugeleitet, um direkten Kontakt mit der Rechnungskammer zu vermeiden, aber sie konnten so eine entscheidende Grundlage für die Wahrnehmung des Budgetrechts und die Entlastung der Regierung bilden.

Die Versorgung des Parlaments mit den Informationen der Rechnungskammer folgte letztlich mit starker zeitlicher Verzögerung auf die Erringung erst des Budgetrechts und dann des Rechts, die Regierung zu entlasten, obwohl oder gerade weil eine wirksame Wahrnehmung dieser beiden Funktionen die Kenntnisse über die Staatsfinanzen und den Umgang mit ihnen voraussetzt.

Die Entwicklung führte letztlich dazu, dass neben die klassische Funktion der Rechnungskammer, die Verwaltungskontrolle durch den König beziehungsweise durch die Regierung zu ermöglichen, die Unterstützung des Parlaments bei der Kontrolle der Regierung (Regierungs- oder Verfassungskontrolle) ${ }^{39}$ trat, also der Kontrolle der Übereinstimmung der Rechnung mit dem Haushaltsgesetz, insbesondere der Einhaltung des Haushaltsplanes durch die Regierung, die vom Parlament entlastet werde musste.

\section{Rechnungswesen in der Weimarer Republik seit 1919}

Die Weimarer Reichsverfassung sah zwar bereits 1919 die Regelung der Rechnungsprüfung durch ein Reichsgesetz vor ${ }^{40}$, erst durch $\ 118$ der Reichshaushaltsordnung ${ }^{41}$ von 1923 wurde mit dem Reichsrechnungshof „eine der Reichsregierung gegenüber selbständige, nur dem Gesetz unterworfene oberste Reichsbehörde" geschaffen.

Gerade wegen der grundsätzlichen Nähe zur Reichsregierung war es nötig, die Unabhängigkeit des Reichsrechnungshofes explizit festzuschreiben. Diese Regierungsnähe zeigt sich etwa darin, dass die Bestellung des Präsidenten und des Vizepräsidenten gem. \119 Abs.1 und 3 S. 1 RHO allein Sache der Regierung war. Auffällig ist auch, dass die Bemerkungen des Reichsrechnungshofes gem. \108 Abs. 1 RHO dem Reichsminister der Finanzen zu übermitteln waren, der sie dann Reichstag und Reichsrat zuleitete. Eine besondere Privilegierung der Reichsregierung enthielt auch $\int 98 \mathrm{RHO}$, wonach die umfassende Auskunftspflicht aller Verwaltungsbehörden gegenüber dem Rechnungshof nicht für die Reichsministerien galt.

Mit der Weimarer Republik kam es jedoch auch zu einer Stärkung parlamentarischer Rechte: So nahm der Reichstag selbst (und nicht die Reichsregierung!) bei Beratung über den Entwurf der Reichshaushaltsordnung mit $\int 101$ RHO eine Vorschrift auf, die neben den Reichsministern auch dem Reichstag das Recht

\footnotetext{
39 Zum Begriff siehe unten IV.2.

40 Art. 86 S. 2 Verfassung des Deutschen Reiches vom 11.08.1919 (RGBl. 1919, S. 1383).

${ }^{41}$ Reichshaushaltsordnung vom 31. Dezember 1922 (RGBl. 1923 II, S. 17).
} 
zugestand, sich vom Reichsrechnungshof gutachtlich beraten zu lassen. ${ }^{42}$ Hinzu kam die Einführung des Wirtschaftlichkeitsmaßstabes durch die Reichshaushaltsordnung von 1922, die das Aufgabenfeld beträchtlich erweiterte, von der Prüfung der formalen Korrektheit und Vollständigkeit der Rechnungen hin zu der Bewertung des wirtschaftlich sinnvollen und angemessenen Wirtschaftens des Staates. ${ }^{43}$

\section{Stellung des Rechnungshofes zur Zeit des Nationalsozialismus 1933-1945}

Zwar blieb es nach der Machtergreifung durch die Nationalsozialisten 1933 bei einer grundsätzlichen Fortgeltung der Weimarer Reichsverfassung, jedoch mit starken Einschränkungen. ${ }^{44}$ So sollten die Novellen der Reichshaushaltsordnung aus den Jahren 1933 und 1936 den Reichsrechnungshof „zu einem wirksamen Kontrollinstrument der Reichsregierung“ machen ${ }^{45} .{ }^{46}$ Die erste stärkte die Stellung des Präsidenten des Rechnungshofes dadurch, dass er die Geschäftsordnung erlassen konnte, die Geschäfte leitete und die gesamte Tätigkeit beaufsichtigte. Die traditionelle Kollegialverfassung des Rechnungshofes wurde so de facto zugunsten des in den meisten Bereichen des staatlichen und sozialen Lebens eingeführten „Führerprinzips“ aufgegeben. ${ }^{47}$ Die Auswirkungen auf die persönliche richterliche Unabhängigkeit der einzelnen Mitglieder des Rechnungshofes, die gerade durch die Kollegialverfassung und damit die rechnungshofinterne Weisungsfreiheit gewährleistet werden sollte, sind offensichtlich.

Die zweite Novelle zentralisierte die Rechnungsprüfung, indem die Landesrechnungshöfe aufgelöst und im Grunde durch Außenabteilungen des Reichsrechnungshofes ersetzt wurden. ${ }^{48}$

Der damalige Präsident des Reichsrechnungshofes Müller schrieb 1940, ${ }^{49}$ dass das „Kontrollrecht des Rechnungshofes ein ius sui generis sei und als solches Teil

42 Wittrock, Der Rechnungshof als Berater, DÖV 1989, 346 (348).

${ }^{43}$ Hufeld, in: Isensee/Kirchhof, HStR, Bd. III, 2005, \56, Rn. 8 m.w.N.

${ }^{44}$ Grupp, Die Stellung der Rechnungshöfe in der BRD, 1972, S. 79.

45 Grupp, Die Stellung der Rechnungshöfe in der BRD, 1972, S. 79 f.; Klein, Die Finanzkontrolle im nationalsozialistischen Staat, in: FS Schäfer, 1975, S. 209 (212 ff., 216 f.) m.w.N.

46 Zur Entwicklung im Dritten Reich, insbesondere den Gesetzesänderungen im Einzelnen: Heinig, Das Budget, Bd. I, 1949, S. 122 ff.; Vgl. zur Novelle von 1933: Saemisch, Der Rechnungshof des Deutschen Reichs nach der Novelle zur Reichshaushaltsordnung, DJZ 1934, Sp. 172 ff.; Die politischen Hintergründe beleuchtet Dommach, Der Reichsrechnungshof während der Amtszeit seines Präsidenten Saemisch (1922 bis 1938), in: FS zur 275. Wiederkehr der Errichtung der Preußischen General-Rechen-Kammer, 1989, S. 65 (101 ff.).

${ }^{47}$ vgl. hierzu: Stern, Die staatsrechtliche Stellung des Bundesrechnungshofes, in: FS zur 275. Wiederkehr der Errichtung der Preußischen General-Rechen-Kammer, 1989, S. 11 (39) m.w.N.; Dommach, Der Reichsrechnungshof während der Amtszeit seines Präsidenten Saemisch (1922 bis 1938), in: FS zur 275. Wiederkehr der Errichtung der Preußischen General-Rechen-Kammer, 1989, S. 65 (102 f.).

48 Heinig, Das Budget, Bd. I, 1949, S. 126.

49 Müller, Die staatsrechtliche und staatspolitische Stellung des Rechnungshofs im Dritten Reich, FinArch N.F. 7 (1940), 193 ff. (199). 
der in der Hand des Führers vereinigten Regierungsgewalt. ... Vom Führer leitet der Rechnungshof seine Aufgabe her. ... Er ist Werkzeug des Führers und übt dieses Hoheitsrecht im Auftrage des Führers aus." Aus diesen Äußerungen wird das Selbstverständnis des Reichsrechnungshofes im Nationalsozialismus klar, von einem unabhängigen Kontrollorgan konnte nicht mehr die Rede sein.

In diesem Zusammenhang ist auch zu erwähnen, dass das Budget- und Entlastungsrecht des Parlaments gegenüber der Regierung auf diese selbst übergegangen war, so dass die Reichsregierung sich nun selbst entlastete. ${ }^{50}$ Auch die Zahlung von Mitteln an die NSDAP wurde nach Vereinbarung zwischen dem Präsidenten des Reichsrechnungshofes und dem Schatzmeister der Partei nur noch von der die Mittel empfangenden Institution kontrolliert und war der Kontrolle durch den Rechnungshof entzogen. ${ }^{51}$

Rein rechtlich wurde (zumindest theoretisch) die richterliche Unabhängigkeit der Mitglieder zwar beibehalten, ${ }^{52}$ de facto war der Reichsrechnungshof aber wie gesehen im Rahmen der Gleichschaltung zu einem bloßen Werkzeug Hitlers degradiert worden, so dass eine unabhängige Finanzkontrolle nicht mehr erfolgen konnte.

Das Beispiel der im Nationalsozialismus ergriffenen Maßnahmen machen die Bedeutung und die Einflussmöglichkeiten, die die Institution einer unabhängigen, externen Finanzkontrolle haben kann, am besten deutlich. Sie zeigen aber zugleich, wie fragil und abhängig von den jeweiligen Machthabern eine solche Stellung ist. Öffentliche Finanzen bilden eine entscheidende Grundlage für die Ausübung jeder Art staatlicher Macht, die Kontrolle ihrer Verwendung stellt einen nicht zu vernachlässigenden Machtfaktor dar, den das Hitlerregime sich von Anfang an zu Nutze machen wollte. Wäre der Rechnungshof als bloßes Hilfsorgan ohne nennenswerte Einflussmöglichkeiten zu klassifizieren und hätten ihn die Machthaber als ziemlich bedeutungslos angesehen, wäre es wohl kaum für nötig erachtet worden, ihn fast von Anfang an gleichzuschalten.

6. Die Entwicklung des Bundesrechnungshofes in der Bundesrepublik Deutschland

Nach Kriegsende und Zusammenbruch von 1945 nahm die Außenstelle des Reichsrechnungshofes in Hamburg ihre Tätigkeit wieder auf und wurde so zur „Keimzelle“ des Wiederaufbaus der Finanzkontrollbehörden. ${ }^{33}$ Später setzte sie

50 Müller, Die staatsrechtliche und staatspolitische Stellung des Rechnungshofs im Dritten Reich, FinArch N.F. 7 (1940), 193 ff. (200).

${ }^{51}$ Grupp, Die Stellung der Rechnungshöfe in der BRD, 1972, S. 80.

52 Dommach, Der Reichsrechnungshof während der Amtszeit seines Präsidenten Saemisch (1922 bis 1938), in: FS zur 275. Wiederkehr der Errichtung der Preußischen General-Rechen-Kammer, 1989, S. 65 (104); Grupp Die Stellung der Rechnungshöfe in der BRD, 1972, S. 80 f.

53 v.Pfublstein, Der Weg von der Generalrechenkammer zum Bundesrechnungshof, in: Bundesrechnungshof, 250 Jahre Rechnungsprüfung,1964, S. 91. 
ihre Tätigkeit als „Rechnungshof für Sonderaufgaben“ fort. Mit Gesetz des Wirtschaftsrates über die Errichtung eines Rechnungshofes für das Vereinigte Wirtschaftsgebiet vom 3.11.1948 wurde in Frankfurt am Main der „Rechnungshof im Vereinigten Wirtschaftsgebiet" errichtet, ${ }^{54}$ der unmittelbarer Vorläufer des Bundesrechnungshofes war. Der Bundestag bestimmte zunächst die Fortgeltung dieses Gesetzes durch das Haushaltsgesetz 1949, das am 7.6.1950 verkündet wurde und rückwirkend zum 21.9.1949 in Kraft trat..$^{55}$ Nach $\$ 1$ Abs. 2 des Haushaltsgesetzes übernahm der Rechnungshof für das Vereinigte Wirtschaftsgebiet bis auf weiteres die Aufgaben des Bundesrechnungshofes. Der Bundesrechnungshof wurde schließlich mit Rückwirkung zum 1.4.1950, also fast ein Jahr nach Inkrafttreten des Grundgesetzes, durch das Gesetz über Errichtung und Aufgaben des Bundesrechnungshofes errichtet. ${ }^{56} \$ 1$ Abs. 2 dieses Gesetzes bezeichnete den Bundesrechnungshof als eine „der Bundesregierung gegenüber selbständige, nur dem Gesetz unterworfene oberste Bundesbehörde“.

Aufgaben und Stellung des Bundesrechnungshofes waren zunächst noch vom klassischen Verständnis der Weimarer Zeit, an die die ersten Regelungen zur Rechnungsprüfung in der Bundesrepublik anknüpften, geprägt. So galt etwa die Reichshaushaltsordnung im Wesentlichen fort. Die Berichte des Bundesrechnungshofes wurden nach wie vor gem. $\ 108$ Abs. 1 RHO über den Umweg der Regierung, das heißt vom Finanzminister, dem Parlament vorgelegt. Auch blieb es bei der Bestellung des Präsidenten und Vizepräsidenten durch die Bundesregierung gem. \119 Abs. 3 RHO. Der Bundesrechnungshof stand so zunächst der Bundesregierung nahe.

Diese Regelungen konnten den Anforderungen an eine moderne Finanzkontrolle im repräsentativ-parlamentarischen System der Bundesrepublik nicht mehr gerecht werden. Problematisch erschien besonders die große Distanz zwischen Bundesrechnungshof und Parlament, das für seine Tätigkeit mehr als die Ministerien mit ihren eigenen großen Verwaltungsapparaten auf die Informationsverschaffung durch den Rechnungshof angewiesen war. Dem sollte die Haushaltsrechtsreform von 1969 Abhilfe schaffen. Sie führte vor allem zu einer näheren Heranführung des Bundesrechnungshofes an das Parlament, ${ }^{57}$ so leitet der Bun-

\footnotetext{
54 WiGBl. S. 115.

55 Gesetz über die Aufstellung und Ausführung des Bundeshaushalsplans für das Rechnungsjahr 1949 sowie über die Hauhaltführung und über die vorläufige Rechnungsprüfung im Bereich der Bundesverwaltung (Haushaltsgesetz 1949 und Vorläufige Haushaltsordnung) vom 7. Juni 1950, BGBl. 1950, S. 199.

56 Vgl. zur Errichtung: $\iint 1$ Abs. 1, 14 S. 1 Gesetz über Errichtung und Aufgaben des Bundesrechnungshofes vom 27.11.1950 (BGBl. S. 765).

${ }^{57}$ So die Intention des Rechtsausschusses des Bundestages, zu BT-Drucksache V/3605, S. 13; Stern, Der verfassungsrechtliche Status der Rechnungshöfe, in: Böning/v.Mutius, Finanzkontrolle im repräsentativ-demokratischen System, 1990, S. 11 (35); Blasius, Finanzkontrolle und Gesetzgebung, DÖV 1989, 298 (302); in diese Richtung auch: Schulze, Aufgabenwandel der Finanzkontrolle: Bestandsaufnahmen aus der Prüfungspraxis, in: Engelhardt/Schulze/Thieme, Stellung und
} 
desrechnungshof nach Art. 114 Abs. 2 S. 2 GG 58 in seiner neuen Fassung seinen Jahresbericht unmittelbar den für die Entlastung der Regierung zuständigen Organen, Bundestag und Bundesrat, zu.

Die Annäherung des Bundesrechnungshofes an das Parlament, das vor der Haushaltsrechtsreform nur über den (systemwidrigen) Umweg des Bundesfinanzministers die Prüfungsberichte erhielt, zeigt seine Bedeutung sowohl für die Legislative als auch für die Exekutive und macht zugleich auch einen Grund für die Einordnungsschwierigkeiten im System des gewaltengeteilten Staat deutlich.

Weiter wurde im Zuge der Haushaltsrechtsreform in Art. 114 Abs. 2 S. 1 GG und S. 3 i.V.m. $\int 88$ Abs. 1 BHO die Aufgabe des Bundesrechnungshofes, Wirtschaftlichkeit und Ordnungsmäßigkeit der Haushalts- und Wirtschaftsführung zu prüfen, verfassungsrechtlich festgelegt, um Zweifel über deren Zulässigkeit auszuräumen. 59

Es kam auch zu einer Erweiterung des Beratungsauftrages: Mit der Bundeshaushaltsordnung ${ }^{60}$, die die Reichshaushaltsordnung ersetzte, erfolgte neben der Normierung der ohnehin schon bestehenden Praxis ${ }^{61}$, dass der Bundesrechnungshof in seinem Bericht über die Prüfungsergebnisse auch Maßnahmen für die $\mathrm{Zu}$ kunft vorschlagen kann (vgl. \97 Abs. 2 Nr. 4 BHO) (unselbständige Beratung) ${ }^{62}$, auch die Entscheidung, den ständig wachsenden Vorrat an Prüfungserfahrungen als Entscheidungshilfe für Legislative und Exekutive zu nutzen. $\int 88$ Abs. 2 BHO eröffnet seitdem Bundestag, Bundesrat und Bundesregierung gleichrangig die Möglichkeit, den Bundesrechnungshof, unabhängig von einer konkreten Prüfung, um seinen auf die Prüfungserfahrung gestützten Rat zu ersuchen (selbständige Beratung).

Die Bundeshaushaltsordnung berechtigte den Rechnungshof weiter, Stellen außerhalb der Bundesverwaltung zu prüfen, die Zuwendungen vom Bund erhalten haben ( 991 Abs. 1 Nr. 3 BHO). Nach der Reichshaushaltsordnung (vgl. \64 a RHO) war er bis dahin auf eine entsprechende Vereinbarung zwischen zuwendender Behörde und Zuwendungsempfänger angewiesen, ${ }^{63}$ was eine systemwidrige Abhängigkeit von der Exekutive bedeutete.

1985 wurde die Haushaltsrechtsreform durch Erlass des neuen Bundesrechnungshofgesetzes ${ }^{64}$ sinnvoll weitergeführt, indem die seit langem (eigentlich schon

Funktion der Rechnungshöfe im Wandel?, 1993, S. 33; B. Tiemann, Die staatsrechtliche Stellung und Funktion des Bundesrechnungshofes nach der Haushaltsreform, DVBl. 1970, 954 (955).

58 Zwanzigstes Gesetz zur Änderung des Grundgesetzes vom 12.5.1969 (BGBl. I S. 357).

${ }^{59} \mathrm{Vgl}$. Schriftlicher Bericht des Rechtsausschusses zu BT-Drucksache V/3605, S. 13.

${ }^{60}$ Bundeshaushaltsordnung (BHO) vom 19. August 1969 (BGBl. I S. 1284).

${ }^{61}$ Vgl. hierzu: Wittrock, Der Rechnungshof als Berater, DÖV 1989, 346 (347).

62 Zum Begriff der unselbständigen und selbständigen Beratung im Einzelnen unter IV.3.a).

63 Vialon, Haushaltsrecht, 1959, Erläuterungen zu \$ 64 a RHO, S. 812.

${ }^{64}$ Bundesrechnungshofgesetz (BRHG) vom 20. Juli 1985 (BGBl. I S. 1445). 
im Rahmen der Haushaltsrechtsreform von 1969) ${ }^{65}$ geplante Veränderung des Ernennungsverfahrens von Präsident und Vizepräsident verabschiedet wurde. Diese erfolgt zwar weiter auf Vorschlag der Bundesregierung, gesteht aber letztlich dem Parlament das letzte Wort durch die geheime Abstimmung mit der Mehrheit seiner Mitglieder über den Vorgeschlagenen zu. ${ }^{66}$

Auch oblag es, wie aus $\int 2$ Abs. 1 BRHG n.F. deutlich wird, von nun an nicht mehr der Bundesregierung, den Sitz des Bundesrechnungshofes zu bestimmen (vgl. \1 Abs. 3 BRHG a.F. ${ }^{67}$ ), sondern dem Gesetzgeber.

$1997 / 1998$ kam es zur Ersetzung der organisatorisch und personell in die geprüfte Verwaltung eingegliederten Vorprüfungsstellen (vgl. zur alten Regelung \100 BHO a.F.) durch die dem Bundesrechnungshof unterstellten Prüfungsämter des Bundes, die seinen Weisungen folgen und seiner Dienst- und Fachaufsicht unterstellt sind (vgl. \ 20 a $^{68}$ BRHG, \ $100^{69}$ BHO). Diese Änderung war bereits bei Erlass des Bundesrechnungshofgesetzes im Jahre 1985 erwogen, aber letztlich zugunsten einer bloßen Stärkung der Einflussmöglichkeiten des Bundesrechnungshofes auf die Vorprüfungsstellen verworfen worden. ${ }^{70}$ Sie stellt eine weitere systemgerechte Stärkung der Selbständigkeit von der Exekutive dar, indem sie die praktisch bedeutsame Stufe der Vorprüfung in den Aufgabenbereich des Rechnungshofes selbst eingliedert.

Schließlich kam es infolge der Verlegung der Bundeshauptsstadt nach Berlin und den damit einhergehenden Maßnahmen des Bundes für die Stadt und Region Bonn ${ }^{71}$ zum Umzug des Bundesrechnungshofes von Frankfurt am Main nach Bonn, wo er seit dem 1. Juli 2000 seinen Sitz hat ${ }^{72}$ (vgl. $\int 2$ Abs. 1 S. $1^{73}$ BRHG).

${ }^{65}$ Das im Rahmen der Haushaltsreform von 1969 zunächst vorgesehene Gesetz über die Organisation des Bundesrechnungshofes kam aus Zeitgründen nicht zustande; auch Gesetzesentwürfe des Finanzministers und des Bundesrechnungshofes aus den Jahren 1973 und 1974 wurden ad acta gelegt. Vgl. Gesetzesbegründung zum BRHG vom 10.05.1985, BT-Drucksache 10/3323, S. 9; zu den Änderungsvorschlägen im Einzelnen: H. Schäfer, Verfassungsrechtliche Stellung Bundesrechnungshof - Parlament, Bulletin d. Bundesregierung Nr. 118 vom 22.10.1977, 1083 (1084).

${ }^{66}$ Zur Ernennung siehe ausführlich unter III.1.a).

${ }^{67}$ Gesetz über Errichtung und Aufgaben des Bundesrechnungshofes vom 27.11.1950 (BGBl. S. 765).

${ }^{68}$ Eingeführt durch Art. 3 Haushaltsrechts-Fortentwicklungsgesetz vom 22.12.1997 (BGBl. I S. 3251).

${ }^{69}$ Geändert durch Art. 2 Haushaltsrechts-Fortentwicklungsgesetz vom 22.12.1997 (BGBl. I S. 3251).

70 Eickenboom/Heuer, Das neue Bundesrechnungshofgesetz, DÖV 1985, 997 (1000).

71 \ 1 Abs. 1, SS 6, 7 Berlin/Bonn-Gesetz vom 26.04.1994 (BGBl. I, S. 918).

72 Siehe die Bekanntmachung des Organisationserlasses zur Sitzverlagerung des Bundesrechnungshofes vom. 26.08.1999 (BGBl. I S. 1915), wonach mit Wirkung vom 01.07.2000 der Sitz des Bundesrechnungshofes von Frankfurt/M. nach Bonn verlagert wird.

${ }^{73}$ Neugefasst durch $\int 7$ Abs. 1 Nr. 7, Buchst. g) Berlin/Bonn-Gesetz vom 26.04.1994 (BGBl. I S. 918). 


\section{Zwischenergebnis}

Die Rechnungshöfe dienten klassischerweise der Kontrolle der Verwaltung und der Informationsverschaffung als Grundlage, um legislative und exekutive Entscheidungen treffen zu können, wobei sich auch die Beratungsfunktion immer mehr als eigenständige Aufgabe etablierte. So waren sie in der absoluten Monarchie ein Werkzeug des Königs, der alle Staatsgewalt in sich vereinigte, um ihm einen Überblick über die Staatsfinanzen zu verschaffen, Misswirtschaft entgegenzuwirken und Entscheidungen auf Grundlage ihrer Informationen treffen zu können. Die Unabhängigkeit des Rechnungshofes von der zu kontrollierenden Verwaltung und insbesondere den Ministerien als Verwaltungsspitze kristallisierte sich mehr und mehr als Garant für eine effektive Wahrnehmung der externen Finanzkontrolle heraus.

Mit dem Wechsel zur konstitutionellen Monarchie und den zunehmenden Rechten des Parlaments, insbesondere des Budgetrechts und des Rechts, die Regierung zu entlasten, wurde schließlich auch das Parlament Empfänger zunächst der inhaltlich sehr beschränkten Bemerkungen, später auch der Berichte, die ihm eine sinnvolle Ausübung genannter Rechte überhaupt erst ermöglichten. Nachdem das Budgetrecht für die Volksvertretungen erkämpft worden war, bedurfte es aber noch langwieriger Auseinandersetzungen, um auch die notwendigen Informationen von der Ober-Rechnungskammer zu erhalten. Dieses Privileg, das einen nicht zu unterschätzenden Machtfaktor darstellt, behielt sich die Krone noch lange allein vor. Die Tatsache, dass der Übertragung des Budgetkontrollrechts und des Rechts zur Entlastung der Regierung auf das Parlament erst nach zähem Ringen und mit starker zeitlicher Verzögerung das Recht auf den Zugang der dazu nötigen Informationen folgte, lässt erahnen, dass es sich um eines der umkämpftesten innenpolitischen Probleme dieser Zeit handelte.

Als Ergebnis dieser Entwicklung tritt letztlich neben die ältere Funktion des Rechnungshofes, dem König zur Verwaltungskontrolle zu dienen, die, die Regierungskontrolle (oder Verfassungskontrolle) durch das Parlament zu ermöglichen. Die Entwicklung der Rechnungsprüfung in Deutschland zeigt klar die Tendenz einer sukzessiven Annäherung des Rechnungshofes an das Parlament, verbunden mit einer gleichzeitigen Stärkung der Selbständigkeit von der Exekutive. Bereits in der konstitutionellen Monarchie war die Forderung nach Zugang des Parlaments zu Informationen des Rechnungshofes ein wichtiger Teil der innerstaatlichen Auseinandersetzung. Wie gesehen kam es diesbezüglich zu einer schrittweisen Verbesserung der Informationsmöglichkeiten. Jedoch blieb der Rechnungshof noch in der Weimarer Republik trotz der Bedeutung des Parlaments ein eher der Reichsregierung nahestehendes, wenn auch von dieser und der Verwaltung unabhängiges, Organ. Das zeigen die Formulierung des \ 118 RHO, die Ernennungsregeln des $\int 119$ Abs.1 und 3 S. 1 RHO und insbesondere die bis zur Haushaltsrechtsreform von 1969 fortgeltende Regelung des \ 108 Abs. 1 RHO über die 
Zuleitung der Bemerkungen an das Parlament über den Umweg des Finanzministers.

Im nationalsozialistischen Staat gab es nach der Gleichschaltung des Reichsrechnungshofes de facto keine unabhängige Finanzkontrolle.

In der Bundesrepublik rückte der Bundesrechnungshof sichtbar näher an den Bundestag. Die Haushaltsrechtsreform von 1969 beseitigte so zunächst den in Hinblick auf die Unabhängigkeit und die Funktion der Informationsverschaffung sowohl für Exekutive als auch für Parlament systemwidrigen Umweg über den Finanzminister und führte eine direkte Zuleitung der Berichte des Bundesrechnungshofes an den Bundestag ein. Auch wurde der Beratungsauftrag des Bundesrechnungshofes normiert, wobei die Möglichkeit von Bundestag und Bundesrat, gleichrangig wie Bundesregierung und -ministerien den Rechnungshof um Rat zu ersuchen, entscheidend ist.

Was die Besetzung des Präsidenten und Vizepräsidentenposten angeht, erhielt der Bundestag mit dem neuen Bundesrechnungshofgesetz von 1985 schließlich das letzte Wort, wenn auch kein eigenes Vorschlagsrecht. Dies war ein weiterer Schritt, um die Unabhängigkeit des Bundesrechnungshofes zu stärken. Eine weitere positive Entwicklung für die Unabhängigkeit sowie die Objektivität und Aussagekraft der Prüfungen des Bundesrechnungshofes war 1997/98 die Ersetzung der Vorprüfungsstellen durch die ihm untergeordneten Prüfungsämter.

\section{Institutionelle Garantie des Bundesrechnungshofes}

Art. 114 Abs. 2 GG enthält eine institutionelle Garantie für das Bestehen des Bundesrechnungshofes in seiner konkreten Form. ${ }^{74}$ Das heißt, garantiert sind seine typenbestimmenden Merkmale. ${ }^{75}$

Durch die Haushaltsrechtsreform von 1969 wurde Art. 114 GG dahingehend formuliert, dass „der“ Rechnungshof (nämlich in seiner konkreten Ausgestaltung) garantiert wird im Gegensatz zu „einem“ Rechnungshof (der lediglich die entsprechenden Aufgaben wahrnimmt), von dem noch in Art. 114 GG a.F. die Rede war. Auch schon nach der alten Fassung ging die wohl überwiegende Meinung von der Garantie eben „des“ (damals noch) in Frankfurt am Main ansässigen Rechnungshofes in seiner Ausgestaltung nach $\int 1$ BRHG aus. ${ }^{76}$ Diese konstitutionelle Verankerung des Bundesrechnungshofes als Institution in Art. 114 Abs. 2 GG (einhergehend mit der richterlichen Unabhängigkeit seiner Mitglieder, den Prüfungsrechten und der Berichterstattung an Bundestag, Bundesrat und Bundesregierung) bedeutet im Vergleich zu den Vorgängerinstitutionen eine erhebliche materielle

\footnotetext{
74 Stern, Staatsrecht, Bd. II, 1980, S. 418 ff.; Siekmann, in: Sachs, GG, Art. 114, Rn. 26 m.w.N.

75 Siekmann, in: Sachs, GG, Art. 114, Rn. 26.

76 Vgl. Klein, in: Bundesrechnungshof, 250 Jahre Rechnungsprüfung, 1964, S. 133 (135) m.w.N.; Stern, Staatsrecht, Bd. II, 1980, S. 421.
} 
Der Bundesrechnungshof

Aufwertung. Insbesondere ist jede Veränderung seines grundgesetzlichen Rechtsstatus nur mit einer verfassungsändernden Zwei-Drittel-Mehrheit gem. Art. 79 Abs. 2 GG möglich.

Noch in der Weimarer Republik war man von derartigen verfassungsrechtlichen Garantien weit entfernt, in der Reichsverfassung findet sich in Art. 86 S. 2 lediglich die lapidare Feststellung, dass „die Rechnungsprüfung durch Reichsgesetz geregelt wird“.

\section{Weitere verfassungsrechtliche Hilfsgarantien}

Art. 114 Abs. 2 GG garantiert nicht nur den Bestand des Bundesrechnungshofes, sondern auch die Wahrnehmung seiner Aufgaben. Der Verfassungstext selbst enthält dabei nur die Prüfung der Wirtschaftlichkeit und Ordnungsmäßigkeit der Haushalts- und Wirtschaftsführung als Aufgabenzuweisung und die Garantie der Unabhängigkeit seiner Mitglieder als notwendige Voraussetzung für deren sinnvolle Wahrnehmung. Weitere zur Durchführung der Prüfung notwendige Garantien, insbesondere die finanzielle Unabhängigkeit und die Informations- und Zugangsrechte, müssen als von der „funktionalen Verfassungsgarantie“"77 des Art. 114 Abs. 2 GG umfasst angesehen werden, auch wenn sie nur durch einfaches Gesetz verbürgt sind. Ein entsprechender Willen des Verfassungsgesetzgebers wird durch die Einführung des Gesetzesvorbehaltes des Art. 114 Abs. 2 S. 3 GG und dessen Begründung deutlich. ${ }^{78}$

\section{Unabhängigkeit}

\section{a) Persönliche Unabhängigkeit}

Die Bestandsgarantie des Bundesrechnungshofes geht einher mit verfassungsrechtlichen Hilfsgarantien. Am entscheidendsten wird das Wesen des Bundesrechnungshofes wohl von der Garantie der richterlichen Unabhängigkeit seiner Mitglieder geprägt (Art. 114 Abs. 2 GG i.V.m. Art. 97 GG; 3 Abs. 4 BRHG). Wer Mitglied in diesem Sinne ist, konkretisiert \3 Abs. 1 BRHG: Danach zählen dazu der Präsident, der Vizepräsident, die Leiter der Prüfungsabteilungen und die Prüfungsgebietsleiter. Art. 114 GG sichert über die persönliche Unabhängigkeit auch die Unabhängigkeit des Bundesrechnungshofes als Einrichtung insgesamt. ${ }^{79}$

77 Stern, Staatsrecht, Bd. II, 1980, S. 425.

78 Schriftlicher Bericht des Rechtssausschusses des Bundestages zu BT-Drucksache V/3605, S. 13: Durch den Gesetzesvorbehalt ,soll ermöglicht werden, dass ohne verfassungsrechtliche Zweifel durch einfaches Bundesgesetz dem Rechnungshof Zuständigkeiten und Aufgaben übertragen werden, die er entweder aus Tradition, kraft Übertragung durch einfache Gesetze oder auf Grund von Vereinbarungen... ausgeübt hat".

79 Ausführlich: Stern, Der verfassungsrechtliche Status der Rechnungshöfe, in: Böning/v.Mutius, Finanzkontrolle im repräsentativ-demokratischen System, 1990, S. 11 (29 ff.); Vogel/Kirchbof, 
Der ehemalige Bundespräsident Theodor Heuss ${ }^{80}$ bezeichnete die Unabhängigkeit als „ein wesentliches Element des Richtertums, das in die Leitung des Rechnungshofes eingebaut ist“. Er führte weiter aus, diese sei „,im Staate, der seiner Natur nach aus dem Machtstreben von Parteien und Gruppen seine Bewegungskräfte gewinnt, ein neutrales Element, in dem sich die Dauer des Objektiven konstituiert oder doch konstituieren soll“".

Die unbedingte Unabhängigkeit wird einhellig als die „conditio sine qua non der Wirkungskraft jeder Finanzkontrolle“"81 gesehen; von Arnim spricht von der Unabhängigkeit als „Lebenselement der Kontrolle“.82

Die Gewährleistung der Unabhängigkeit stellt letztlich auch Anforderungen an die innere Organisation des Bundesrechnungshofes. Das bedeutet in erster Linie, dass sich ein hierarchischer Aufbau und ein damit verbundenes Weisungsrecht verbietet, ${ }^{83}$ es würde der verfassungsrechtlich verbürgten persönlichen Unabhängigkeit der Mitglieder nicht gerecht. Die Ausgestaltung der internen Weisungsfreiheit wird nicht durch eine monokratisch organisierte Behörde verwirklicht werden können, vielmehr ist die traditionelle, gerichtsähnliche Kollegialverfassung wohl am besten geeignet, die Unabhängigkeit zu gewährleisten, ${ }^{84}$ ohne dass diese verfassungsrechtlich vorgeschrieben wäre. Hierbei wird jedoch das starke Gewicht des Präsidenten des Bundesrechnungshofes zu Recht kritisch betrachtet, ${ }^{85}$ ist seine Rolle doch eine stärkere als die eines primus inter pares. Zu nennen sind hier die Möglichkeiten, gem. \9 Abs. 1 S. 2 BRHG zu einem Zweierkollegium sowie gem. $\int 11$ Abs. 2 BRHG als Vorsitzender zu einem Senat hinzuzutreten und damit gem. $\int 15$ Abs. 2 BRHG bei Stimmengleichheit mit seiner Stimme den Ausschlag zu geben.

Wie es um die Gewährleistung echter persönlicher Unabhängigkeit in der Praxis bestellt ist, hängt auch entscheidend von der Ausgestaltung des Ernennungs-

Bonner Kommentar, Art. 114, Rn. 184 f. (Zweitbearbeitung 1973); v.Arnim, Grundprobleme der Finanzkontrolle, DVBl. 1983, 664 (670); Maunz, in: Maunz/Dürig, GG, Art. 114, Rn. 19 (Stand: Lfg. 23 Oktober 1984).

80 Aus der Rede von Theodor Heuss anlässlich der Einweihung des Dienstgebäudes des Bundesrechnungshofes am 19. November 1953, DÖH 1954, 6.

81 v.Pfublstein, Der Weg von der Preußischen Generalrechenkammer zum Bundesrechnungshof, in: Bundesrechnungshof, 250 Jahre Rechnungsprüfung, 1964, S. 8.

82 v. Arnim, Staatslehre, 1984, S. 407.

83 Stern, Staatsrecht, Bd. II, 1980, S. 424.

84 Siekmann, in: Sachs, GG, Art. 114, Rn. 34 f.; Wittrock, Warum muss Finanzkontrolle unabhängig sein?, DVBl. 1984, 823 (825); Stern, Staatsrecht, Bd. II, 1980, S. 424; Maunz, in: Maunz/Dürig, GG, Art. 114, Rn. 20 (Stand: Lfg. 23 Oktober 1984); ausführlich: Stern, Die staatsrechtliche Stellung des Bundesrechnungshofes und seine Bedeutung im System der Finanzkontrolle, in: FS zur 275. Wiederkehr der Errichtung der Preußischen General-Rechen-Kammer, 1989, S. 11 (38 f.); vgl. zu Entscheidungen durch Kollegien $\iint$ 8, 9 sowie zur Einstimmigkeit der Entscheidung durch ein Kollegium \ 15 Abs. 1 BRHG.

85 Siekmann, in: Sachs, GG, Art. 114, Rn. 35. 
verfahrens der Mitglieder und von den Möglichkeiten ab, diese wieder aus dem Amt zu entfernen.

Nach \119 Abs. 3 RHO $^{86}$, der Vorgängerregelung von \ 5 des Bundesrechnungshofgesetzes vom 11.07.1985, wurden Präsident und Vizepräsident des Bundesrechnungshofes allein auf Vorschlag der Bundesregierung, und zwar auf Initiative des Bundesministers der Finanzen, vom Bundespräsidenten ernannt. ${ }^{87}$

Diese Regelung wurde trotz Kritik seitens des Schrifttums und des Rechnungshofes selbst ${ }^{88}$ durch die Haushaltsrechtsreform von 1969 und auch in unmittelbarem Anschluss daran nicht geändert. Das im Rahmen der Haushaltsrechtsreform zunächst vorgesehene Gesetz über die Organisation des Bundesrechnungshofes kam aus Zeitgründen nicht zustande; auch Gesetzesentwürfe des Bundesrechnungshofes und des Finanzministers aus den Jahren 1973 und 1974 wurden ad acta gelegt. ${ }^{89}$ Als problematisch wurde besonders das alleinige Vorschlagsrecht der Bundesregierung empfunden. ${ }^{90}$ Der Kontrollierte wirkte bei der Ernennung seines eigenen Kontrolleurs mit. Dies ist erstaunlich, sollte die Haushaltsrechtsreform den Bundesrechnungshof doch bewusst näher an das Parlament rücken. ${ }^{91}$ Sie änderte jedoch nichts an der vorkonstitutionellen Regelung des $\int 119$ Abs. 3 RHO, die allenfalls den Vorstellungen von einem zwar unabhängigen, aber der Reichsregierung nahestehenden Reichsrechnungshof in der Weimarer Republik gerecht wurde ${ }^{92}$ und die weder den Grundsätzen einer modernen Finanzkontrolle noch der verfassungsrechtlichen Stellung des Bundesrechnungshofes entsprach.

Das Problem hinsichtlich der Ernennung erkannte auch der Gesetzgeber und führte mit dem Erlass des Bundesrechnungshofgesetzes vom 11. Juli 1985 die Haushaltsrechtsreform von 1969 letztlich konsequent fort und dies eben mit der

86 Reichshaushaltsordnung vom 31.12.1922 (RGBl. 1923 II, S. 17) i.d. Fassung vom 01.01.1964 („Der Reichspräsident ernennt unter Gegenzeichnung des Reichsministers der Finanzen den Präsidenten und den Vizepräsidenten sowie die Direktoren und Ministerialräte“).

87 v.Arnim, Grundprobleme der Finanzkontrolle, DVBl. 1983, 664 (670); Gesetzesbegründung zum BRHG vom 10.05.1985, BT-Drucksache 10/3323, S. 1 f., 12.

${ }^{88}$ H. Schäfer, Verfassungsrechtliche Stellung Bundesrechnungshof - Parlament, Bulletin der Bundesregierung Nr. 118 vom 22.10.1977, 1083 (1084); v.Arnim, Grundprobleme der Finanzkontrolle, DVBl. 1983, 664 (670 f.); Mann, Unabhängige Kontrolleure? Probleme der Besetzung von Kontrollämter, dargestellt am Leitungspersonal von Rechnungshöfen, ZParl. 1981, 353 (357ff.) mit zahlreichen Nachweisen: Stellt fest, dass Präsidenten der Rechnungshöfe in Bund und Ländern fast ausnahmslos Mitglieder der Regierungsparteien waren, die vorher hohe Stellungen (insbesondere problematisch als es sich oft um vormals politische Beamte handelte) in Ministerien innehatten; Sigg, Die Stellung der Rechnungshöfe, 1983, S. 58 f.

89 Siehe Gesetzesbegründung zum BRHG vom 10.05.1985, BT-Drucksache 10/3323, S. 9; zu den Änderungsvorschlägen im Gesetzesentwurf im Einzelnen: H. Schäfer, Verfassungsrechtliche Stellung BRH - Parlament, Bulletin d. Bundesregierung Nr. 118 vom 22.10.1977, 1083 (1084).

90 v.Arnim, Grundprobleme der Finanzkontrolle, DVBl. 1983, 664 (670 f.); a.A.: (der damalige Bundesrechnungshofspräsident!) H. Schäfer, Wer kontrolliert unsere Steuergelder?, 1977, S. 33.

91 Siehe oben Fn. 57.

92 Oben: I.4. 
Intention, die als veraltet erachteten Regelungen den Erfordernissen einer modernen Finanzkontrolle anzupassen. ${ }^{93}$

Die Ernennung gestaltet sich gem. $\int 5$ Abs. 1 BRHG $^{94}$ so, dass Bundestag und Bundesrat auf Vorschlag der Bundesregierung den Präsidenten und den Vizepräsidenten jeweils mit einfacher Mehrheit wählen, die dann vom Bundespräsidenten ernannt werden. Die Amtszeit beträgt zwölf Jahre ( $\int 3$ Abs. 2 S. 2 BRHG), eine Wiederwahl ist (wie gem. \4 Abs. 2 BVerfGG auch bei Verfassungsrichtern) ausgeschlossen (vgl. \5 Abs. 1 S. 4 BRHG). Die Ernennung der übrigen Mitglieder und Beamten erfolgt nach $\int 5$ Abs. 2 BRHG auf Vorschlag des Präsidenten des Bundesrechnungshofes, wobei er bei Ersteren vorher den Ständigen Ausschuss des Großen Senats des Bundesrechnungshofes zu hören hat.

Der Gesetzesbegründung ${ }^{95}$ zum Bundesrechnungshofgesetz ist zu entnehmen, dass, um der besonderen Stellung und Bedeutung des Bundesrechnungshofes, der „der Legislative und der Exekutive dient“, Rechnung zu tragen, nunmehr eine Regelung gewählt werden sollte, die „ein auf Konsens angelegtes Zusammenwirken der gesetzgebenden Körperschaften und der Bundesregierung“ bei der Ernennung etabliert. ${ }^{96}$

Die seit 1985 geltenden Regelungen sind im Wesentlichen geeignet, die Unabhängigkeit des Bundesrechnungshofes in hohem Maße zu gewährleisten. So hohe Hürden wie für die Ernennung von Verfassungsrichtern sind in Hinblick auf die ungleich größeren Einflussnahmemöglichkeiten derselben wohl nicht erforderlich. Jedoch finden sich insbesondere zwei Anknüpfungspunkte, in denen Verbesserungsmöglichkeiten bestehen:

Als Erstes sei hier das alleinige Vorschlagsrecht für den Posten des Präsidenten und des Vizepräsidenten durch die Bundesregierung genannt. Getragen von der Regierungsmehrheit im Parlament kann diese so faktisch allein die Spitze des Bundesrechnungshofes bestellen. ${ }^{97}$ Dem könnte etwa durch die Einführung eines Vorschlagsrechts des scheidenden Präsidenten und Vizepräsidenten und eines Gremiums der Präsidenten der Landesrechnungshöfe abgeholfen werden. Zumindest könnte diesen die Erstellung einer Liste geeigneter Kandidaten auferlegt werden, aus der die Bundesregierung auswählen kann. Weiter könnte neben dem Vorschlagsrecht der Bundesregierung auch ein Vorschlagsrecht der Fraktionen etabliert werden ${ }^{98}$ und dem Parlament auf diese Weise ein positives Auswahlrecht gegeben werden.

93 Siehe zu dieser Zielsetzung: Entwurf eines Gesetzes über den Bundesrechnungshof vom 10.05.1985, BT-Drucksache 10/3323, S. 1, 12.

94 Gesetz über den Bundesrechnungshof (BRHG) vom 11. Juli 1985 (BGBl. I S. 1445).

95 BT-Drucksache 10/3323.

96 BT-Drucksache 10/3323, S. 9 (s.a. S. 2 und 12).

97 Auch wenn auf ein einvernehmliches Treffen dieser Entscheidung auf Basis einer breiten parlamentarischen Mehrheit hingewirkt werden soll, vgl.: Begründung zum BRHG, BT-Drs. 10, 3323, S. 12.

98 S 8 Abs. 2 BVerfGG sieht dies für die Wahl von Richtern am Bundesverfassungsgericht vor. 
Zweitens ist problematisch, dass im Parlament nur eine einfache Mehrheit für die Wahl erforderlich ist (vgl. \5 Abs. 1 S. 2 BRHG). Für die Ernennung von Präsident und Vizepräsident könnte die Erfordernis einer Zweidrittelmehrheit im Parlament eingeführt werden. ${ }^{99}$ Sonst ernennt der zu Kontrollierende, die Bundesregierung, getragen durch ihre Parlamentsmehrheit, den Kontrolleur. Allenfalls die dem Art. 114 Abs. 2 geschuldeten ${ }^{100}$ gleichrangigen Mitwirkungsrechte des Bundesrates können hierzu ein gewisses Korrektiv bilden, das eine Verständigung und Einigung auf breiter Basis, insbesondere in Zeiten unterschiedlicher Mehrheitsverhältnisse, gewährleisten kann. Vergleichend sei hier auf die Regelungen zur Ernennung des Comptroller and Auditor General im Vereinigten Königreich hingewiesen, die auf Antrag des Unterhauses hin erfolgt, wobei die Initiative hierfür vorher vom Premierminister im Einverständnis mit dem Vorsitzenden des Committee of Public Accounts, der traditionell der Opposition angehört, ausgeht. ${ }^{101}$ Auf diese Weise findet eine Einbindung der Opposition statt, und die Ernennung des obersten Finanzkontrolleurs wird auf eine breite parlamentarische Basis gestellt.

Auch hinsichtlich der Absetzbarkeit und der Verhängung von Disziplinarmaßnahmen gelten für die Mitglieder des Bundesrechnungshofes, ihrer Unabhängigkeit geschuldet, besondere Regelungen. Sie sind zwar ihrem Status nach Beamte, genießen aber gem. Art. 114 Abs. 2 S. 1 GG richterliche Unabhängigkeit und unterfallen wie Richter dem Schutz des Art. 97 GG.102 \ 3 Abs. 4 S. 2 BRHG verweist auf die Vorschriften über Unabhängigkeit und Disziplinarmaßnahmen, die für Richter an obersten Gerichtshöfen gelten (Vgl. auch \18 BRHG). Für die Amtsenthebung gelten somit die Vorschriften des \30 DRiG. ${ }^{103}$

\section{b) Sachliche Unabhängigkeit}

Unabhängigkeit besteht auch bei der Bestimmung des Prüfungsgegenstandes, hierin sind die Mitglieder weisungsfrei und nur dem Gesetz unterworfen. Die sachliche Unabhängigkeit spiegelt sich weiter in der Geschäftsordnungsautonomie nach \20 BRHG wider, die es dem Große Senat erlaubt, Einzelheiten der Organisation und Verfahren festzulegen.

\footnotetext{
${ }^{99}$ So schon zur Rechtslage vor Erlass des BRHG im Jahre 1985: Der damalige Präsident des Bundesrechnungshofes Wittrock, Möglichkeiten und Grenzen der Finanzkontrolle, Bulletin der Bundesregierung 1982, 524 (527); ebenso v.Arnim, Grundprobleme der Finanzkontrolle, DVBl. 1983, 664 (672) m.w.N.; Sigg, Stellung der Rechnungshöfe, 1983, S. 58 f. Die Wahl von Präsident und Vizepräsident mit Zwei-Drittel-Mehrheit gibt es beispielsweise in Niedersachsen (vgl. Art. 70 Abs. 2 NV).

100 Piduch, in: ders., Bundeshaushaltsrecht, Art. 114, Rn. 33 (Stand: 21. EL Januar 1986).

101 Unten: 2. Teil D. II. 2.

102 Siehe hierzu: Dressler, in: Bundesrechnungshof, 250 Jahre Rechnungsprüfung, 1964, S. 157 (160).

103 Zum Ganzen: v.Mutius/Nawrath, in: Heuer, Kommentar zum Haushaltsrecht, Art. 114 GG, Rn. 15 ff. (Stand: 28. EL Juni 1999).
} 
Die Unabhängigkeit des Bundesrechnungshofes drückt sich ferner durch die räumliche Trennung seines Sitzes von dem der Hauptorgane der Legislative, Exekutive und Judikative aus. Mit dem Bonn-Berlin Gesetz vom 26. April 1994 ist der Sitz des Bundesrechnungshofes von Frankfurt a. M. nach Bonn verlegt worden. (Der Umzug wurde am 1. Juli 2000 abgeschlossen.) Die räumliche Trennung ist eine Fortführung der traditionellen deutschen Praxis, die sich schon seit dem „Berlin-Potsdam-Prinzip“104 (analog zum Berlin-Leipzig-Prinzip der Gerichte) zeigte. ${ }^{105}$ In der Bundesrepublik wurde daraus die Trennung Bonn-Frankfurt/M. und im Zuge der deutschen Wiedervereinigung mit dem Umzug des Regierungssitzes nach Berlin schließlich Berlin-Bonn (vgl. \ 1 Abs. 3 BRHG).

\section{c) Finanzielle Unabhängigkeit}

Nach allgemeiner Meinung muss auch eine zur Ausübung seiner verfassungsrechtlichen Tätigkeit notwendige Mindestausstattung mit Personal- und Sachmitteln als verfassungsmäßig abgesichert gelten, ${ }^{106}$ sie bildet eine unabdingbare Voraussetzung für die unabhängige Ausübung der externen Finanzkontrolle.

\section{Informations- und Zugangsrechte}

Unverzichtbar für eine sinnvolle Ausübung der externen Finanzkontrolle sind Informations- und Zugangsrechte des Bundesrechnungshofes, die sich aus $\iint 94$, 95 BHO ergeben. Sie sind als von der „funktionellen Verfassungsgarantie“ des Art. 114 Abs. 2 GG umfasst anzusehen. ${ }^{107}$ Zeit und Art der Prüfung sind in das Ermessen des Bundesrechnungshofes gestellt, er kann Vor-Ort-Prüfungen vornehmen und Sachverständige hinzuziehen. Art. 95 BHO statuiert eine Auskunftspflicht, wonach dem Bundesrechnungshof von den geprüften Stellen Unterlagen, die er für die Prüfung für erforderlich hält, zuzuleiten und seinen Beauftragten die verlangten Auskünfte zu erteilen sind. Eigene Mittel, seine Ersuchen selbst durchzusetzen, etwa in Form von Bußgeldern oder sonstigen Zwangsmitteln, gibt ihm die Bundeshaushaltsordnung hingegen nicht.

104 Die Ober-Rechnungskammer war mit Kabinettsorder vom 28. Oktober 1817 von Berlin nach Potsdam verlegt worden, wofür aber ursprünglich der Mangel an Wohnraum in Berlin die maßgebliche Rolle gespielt haben dürfte; vgl. v.Pfublstein, Der Weg von der Generalrechenkammer zum Bundesrechnungshof, in: Bundesrechnungshof, 250 Jahre Rechnungsprüfung,1964, S. 36.

105 Zum räumlichen Abstand: Stern, Die staatsrechtliche Stellung des Bundesrechnungshofes und seine Bedeutung im System der Finanzkontrolle, in: FS zur 275. Wiederkehr der Errichtung der Preußischen General-Rechen-Kammer, 1989, S. 16 f. m.w.N.; v.Arnim, Grundprobleme der Finanzkontrolle, DVBl. 1983, 664 (669 f.).

106 Siekmann, in: Sachs, GG, Art. 114, Rn. 36; Stern, Die staatsrechtliche Stellung des Bundesrechnungshofes und seine Bedeutung im System der Finanzkontrolle, in: FS zur 275. Wiederkehr der Errichtung der Preußischen General-Rechen-Kammer, 1989, S. 40 m.w.N.; Vogel/Kirchhof, in: Bonner Kommentar, Art. 114, Rn. 185 (Stand: 31. EL, März 1973).

107 Oben: Fn. 77. 
Die Rechtsnatur von Prüfungsankündigungen und der anschließenden Prüfungen, insbesondere das Problem, ob es sich bei ihnen um Verwaltungsakte handelt, ist eng mit der Frage verbunden, ob der Bundesrechnungshof hierdurch Staatsgewalt ausübt, was für eine Zuordnung zur Exekutive sprechen könnte. Aus diesem Grund wird sie unter VI. 3. c) $\gamma$ ) bei der Frage nach der möglichen Zuordnung des Bundesrechnungshofes zur Exekutive erörtert.

\section{Die Aufgaben des Bundesrechnungshofes}

Für die verfassungssystematische Einordnung des Bundesrechnungshofes ist hinsichtlich der Wahrnehmung seiner Aufgaben deren Qualität im Vergleich zu Handlungen von Legislative, Judikative und Exekutive zu untersuchen und außerdem die Frage „cui bono?“ - zu wessen Nutzen wird der Bundesrechnungshof tätig- zu beantworten.

\section{Der Prüfungsauftrag}

Aus Art. 114 Abs. 2 S.1 GG ergibt sich, dass es zunächst Aufgabe des Bundesrechnungshofes ist zu prüfen, und zwar die Rechnungen im engeren Sinne (Rechnungsprüfung) sowie die Wirtschaftlichkeit und Ordnungsmäßigkeit der Haushalts- und Wirtschaftsführung (rechnungsunabhängige Finanzkontrolle) ${ }^{108}$.

\section{a) Gegenstand und Umfang der Prüfung}

Bezüglich des Gegenstandes und Umfangs der Prüfung enthält Art. 114 Abs. 2 GG einen uneingeschränkten Generalauftrag an den Bundesrechnungshof. Hieraus ergibt sich das haushaltsrechtliche Prinzip der Lückenlosigkeit der Finanzkontrolle, ${ }^{109}$ es darf also keine „prüfungsfreien Räume“ geben. ${ }^{110}$ Entsprechend sieht die Bundeshaushaltsordnung in $\$ \int 88-92$ die gesamte Haushalts- und Wirtschaftsführung des Bundes als Gegenstand der Prüfung durch den Bundesrechnungshof vor, das heißt den Bundeshaushaltsplan einschließlich der Sondervermögen des Bundes, die bundesunmittelbaren und sonstigen Personen des öffentlichen Rechts sowie die Prüfung staatlicher Betätigung bei privatrechtlichen Unternehmen. Der Prüfungsauftrag des Bundesrechnungshofes erstreckt sich somit

\footnotetext{
108 Vogel/Kirchhof, in: Bonner Kommentar, Art. 114, Rn. 194 (Zweitbearbeitung 1973).

109 v.Mutius/Nawrath, in: Heuer, Kommentar zum Bundeshaushaltsrecht, Art. 114, Rn. 10 (Stand: 28. EL Juni 1999); Huber, Die institutionelle Verfassungsgarantie der Rechnungsprüfung, in: FS Nikisch, 1958, S. 347 f.; Schwarz, in: v.Mangoldt/Klein/Starck, GG, Art. 114, Rn. 52, mit zahlreichen Nachweisen.

110 St. Rspr. BVerwGE 116, 92 (94); 98, 163 (170); 82, 56 (60 f.); vgl. \ 88 Abs. 1 BHO: „Die gesamte Haushalts- und Wirtschaftsführung des Bundes... wird vom Bundesrechnungshof... geprüft; vgl. auch $\ 42$ Abs. 1 HGrG.
} 
„potentiell auf die gesamte Staatstätigkeit"111 oder ist besser gesagt im Wesentlichen deckungsgleich mit der Aufgabenverantwortung des Bundes ${ }^{112}$. Was die Kontrollobjekte angeht, so unterliegen alle staatlichen Stellen aller drei Gewalten, soweit sie staatliche Mittel verwenden, seiner Kontrolle. ${ }^{113}$

Natürlich muss und kann der Bundesrechnungshof im Gegensatz zu einem Teil seiner Vorgänger ${ }^{114}$ nicht alle relevanten Vorgänge prüfen, er muss sich auf Stichproben beschränken; ${ }^{115}$ ob und in welchen Bereichen er diese vornimmt, kann er jedoch nach eigenem pflichtgemäßem Ermessen auswählen (vgl. \42 Abs. 3 HGrG; vgl. auch \5 PO-BRH), hierin findet sich das Prinzip der universellen Prüfungszuständigkeit wieder. Eine Vollprüfung aller haushaltsrelevanten Vorgänge findet hingegen schon seit der Zeit vor dem ersten Weltkrieg nicht mehr statt. ${ }^{116}$

Ausdruck findet das Prinzip auch in $\int 42$ Abs. 4 HGrG, \ 97 Abs. 4 BHO, wonach Bemerkungen zu geheimzuhaltenden Angelegenheiten hinsichtlich des Adressaten, der die Berichte des Bundesrechnungshofes hierüber erhält, besonders zu behandeln sind. Hieraus wird deutlich, dass auch diese grundsätzlich der Prüfung durch den Bundesrechnungshof unterliegen (vgl. \19 BRHG). ${ }^{117}$

\section{b) Rechnungsprüfung}

Die Prüfung der Rechnung nach Art. 114 Abs. 2 S. 1 GG bezieht sich auf die nach Abs. 1 der Vorschrift vom Bundesfinanzminister jährlich abzulegende Rechnung. Durch die Rechnungsprüfung wird die äußere, buchhalterische Korrektheit der Rechnungsführung kontrolliert. ${ }^{118}$

\section{c) Ordnungsmäßigkeits- und Wirtschaftlichkeitsprüfung der Haushalts- und Wirtschaftsführung}

Neben der Rechnungsprüfung im engeren Sinne weist Art. 114 Abs. 2 S. 1 GG dem Bundesrechnungshof die Kontrolle der Ordnungsmäßigkeit und Wirtschaftlichkeit der Haushalts- und Wirtschaftsführung zu. Diese rechnungsunabhängige Finanzkontrolle umfasst auch die Vorgänge, die nicht in der vom Finanzminister vorzulegenden Rechnung auszuweisen sind. Es muss sich hierbei zwar um abgeschlossene Verwaltungsvorgänge handeln, sie müssen aber nicht unbedingt aus

\footnotetext{
111 v. Arnim, Grundprobleme der Finanzkontrolle, DVBl. 1983, 664.

112 Schwarz, in: v.Mangoldt/Klein/Starck, GG, Art. 114, Rn. 53 m.w.N.

113 S. Tiemann, Die staatsrechtliche Stellung der Finanzkontrolle des Bundes, 1974, S. 41.

114 Oben: I. Geschichtliche Entwicklung.

115 Bundesrechnungshof, Erfolgsbericht 2006, Vorbemerkungen, S. 8.

116 Hoffmann, Die Kontrolle der Regierung durch parlamentarische Rechnungsprüfung im Deutschen Bundestag, 1970, S. 137.

117 Vgl. Wittrock, Über die Kontrolle geheimer Ausgaben, Verw 1988, 277 (284 ff.).

118 Siekmann, in: Sachs, GG, Art. 114, Rn. 11.
} 
Der Bundesrechnungshof

dem Zeitraum des Rechnungsjahres stammen. ${ }^{119}$ Diese sogenannte ,gegenwartsnahe Prüfung“ kann daher auch vor der Rechnungslegung erfolgen, ${ }^{120}$ was die Effizienz der Finanzkontrolle durch größere zeitliche Nähe zu den finanzwirksamen Vorgängen erhöht, können die Behörden doch eher und effektiver auf offengelegte Probleme reagieren.

Zu bemerken ist, dass besonders seit der Haushaltsrechtsreform von 1969 die Prüfung der Wirtschaftlichkeit stark in den Vordergrund gerückt ist, wie auch der große Anteil von Wirtschaftlichkeitsprüfungen in den Berichten des Rechnungshofes zeigt. Die Prüfung von Belegen auf ihre Ordnungsmäßigkeit, auf die die klassische Rechnungsprüfung ausgerichtet war, hat dem entgegen an Bedeutung verloren. ${ }^{121}$

\section{aa) Ordnungsmäßigkeit}

Die Prüfung der Ordnungsmäßigkeit umfasst neben der Prüfung rechnungstechnischer Richtigkeit (die schon in der Rechnungsprüfung an sich enthalten ist) ${ }^{122}$ auch und vor allem die Kontrolle der Rechtmäßigkeit in Form der Einhaltung der den Einnahmen und Ausgaben zugrundeliegenden Rechtsgrundlagen (insbesondere Haushaltsgesetz und Haushaltsplan mit den dazugehörigen Unterlagen) ${ }^{123}$ sowie allgemein der für die Haushalts- und Wirtschaftsführung geltenden Vorschriften und Grundsätze. ${ }^{124}$ Die Prüfung der Rechtsgrundlagen umfasst dabei nach der Rechtsprechung des Bundesverfassungsgerichtes ${ }^{125}$ und der herrschenden Meinung ${ }^{126}$ auch die Prüfung ihrer Verfassungsmäßigkeit. ${ }^{127}$

119 Stern, Die staatsrechtliche Stellung des Bundesrechnungshofes und seine Bedeutung im System der Finanzkontrolle, in: FS zur 275. Wiederkehr der Errichtung der Preußischen GeneralRechen-Kammer, 1989, S. 21.

120 Maunz, in: Maunz/Dürig, GG, Art. 114, Rn. 28 (Stand: Lfg. 23 Oktober 1984); Schwarz, in: v.Mangoldt/Klein/Starck, GG, Art. 114, Rn. 83.

121 Göke, Der Niedersächsische Landesrechnungshof: Wandel und Struktur der Finanzkontrolle in Niedersachsen, NdsVBl. 2001, 62 (66).

122 Vogel/Kirchhof, in: Bonner Kommentar, Art. 114, Rn. 93 (Zweitbearbeitung 1973).

123 BVerfGE 20, 56 (96); v.Mutius/Nawrath, in: Heuer, Kommentar zum Haushaltsrecht, Art. 114, Rn. 26 (Stand: 28. EL Juni 1999).

124 Vgl. \ 4 Abs. 2 Prüfungsordnung des Bundesrechnungshofes vom 19. November 1997 (Abrufbar unter: http://bundesrechnungshof.de/wir-ueber-uns/rechtsgrundlagen/ pruefungsordnung/pobrh.pdf): „Die Prüfung der Ordnungsmäßigkeit umfasst die Beachtung von Vorschriften, die der Leistung von Ausgaben, der Erhebung von Einnahmen sowie dem Eingehen von Verpflichtungen zugrunde liegen; sie umfasst auch die fehlerfreie Errechnung, Belegung und Buchung der Einnahmen und Ausgaben sowie die Einhaltung der für die Haushalts- und Wirtschaftsführung geltenden Vorschriften und Grundsätze.“; Vogel/Kirchhof, in: Bonner Kommentar, Art. 114, Rn. 93 (Zweitbearbeitung 1973); Kisker, in: Isensee/Kirchhof, HStR, Bd. IV, 1990, J 89, Rn. 110.

125 BVerfGE 20, 56 (96).

126 Statt vieler: Kisker, in: Isensee/Kirchhof, HStR, Bd. IV, 1990, J 89, Rn. 110 m.w.N.

127 Vgl. IV. 2. Funktionale Bedeutung der externen Finanzkontrolle. 
bb) Wirtschaftlichkeit

Bei den rechnungsunabhängigen Prüfungszuständigkeiten fällt besonders die Aufgabe der Prüfung der Wirtschaftlichkeit auf. Das Grundgesetz enthält hierfür keine Legaldefinition. \90 Nr. 3 und 4 BHO konkretisiert den Grundsatz dahingehend, dass „die Prüfung sich darauf erstreckt, ob wirtschaftlich und sparsam verfahren wird und ob die Aufgabe mit geringerem Personal- oder Sachaufwand oder auf andere Weise wirksamer erfüllt werden kann“".

Als Maßstab bei der Bewertung, ob wirtschaftlich verfahren wurde, ist darauf abzustellen, ob „ein bestimmtes Ergebnis mit möglichst geringem Mitteleinsatz (Sparsamkeits- oder Minimalprinzip) oder ob mit einem bestimmten Mitteleinsatz das bestmögliche Ergebnis erzielt wurde (Ergiebigkeits- oder Maximalprinzip), letztlich also auf eine möglichst optimale Relation zwischen dem verfolgten Zweck und den eingesetzten Mitteln“".128

Weiter umfasst die Wirtschaftlichkeitsprüfung die Erfolgskontrolle, bei der Wirksamkeit und Zweckmäßigkeit des Verwaltungshandelns sowie die Zielerreichung untersucht werden, ${ }^{129}$ und den Grundsatz der Sparsamkeit, also die Prüfung, ob die Mittel auf den zur Zielerreichung notwendigen Umfang beschränkt wurden. ${ }^{130}$ Der Blick in die Berichte des Bundesrechnungshofes offenbart, dass die Prüfung der Wirtschaftlichkeit heute einen ganz erheblichen Teil seiner Prüfungstätigkeit ausmacht.

\section{Funktionale Bedeutung der externen Finanzkontrolle}

Neben der formellen Rechnungskontrolle der rechnerischen Richtigkeit der Belege und der Übereinstimmung mit den dafür maßgeblichen Vorschriften ${ }^{131}$ als der klassischen Ausprägung der Rechnungsprüfung ist die funktionale Bedeutung der Finanzkontrolle durch den Bundesrechnungshof nach ihrer Zielrichtung als Verwaltungskontrolle und als Verfassungs- beziehungsweise Regierungskontrolle hervorzuheben: ${ }^{132}$

Verwaltungskontrolle ist die Prüfung der finanzwirksamen Vorgänge mittelverwaltender Stellen auf ihre sachliche Richtigkeit, das heißt die Einhaltung der geltenden Gesetze, Verordnungen und Verwaltungsvorschriften; weiter wird ge-

128 Vgl.: Allgemeine Verwaltungsvorschriften zur BHO (VV-BHO) v. 14.03.2001 (GMBl 2001, S. 310, zu \ 7 BHO, Ziffer 1); \ 4 Abs. 3 S. 1 PO-BRH; Blasius, Der Rechnungshof: Kontrolleur und Informant, DÖV 1993, 642 (643); v.Arnim, Grundprobleme der Finanzkontrolle, DVBl. 1983, 664; Hufeld, in: Isensee/Kirchhof, HStR, Bd. III, 2005, \56, Rn. 8.

${ }^{129} \mathrm{Vgl} . \$ 4$ Abs. 3 S. 2 PO-BRH.

130 Vgl. \ 4 Abs. 3 S. 3 PO-BRH; s. zum Ganzen: Bundesrechnungshof, Der Bundesrechnungshof und die Prüfungsämter des Bundes, 2005, S. 16.

131 Grupp, Die Stellung der Rechnungshöfe in der BRD, 1972, S. 84; Siekmann, in: Sachs, GG, Art. 114, Rn. 11.

132 Vgl. BVerfGE 20, 56 (96); v.Amim, Grundprobleme der Finanzkontrolle, DVBl. 1983, 664 (665); Brunner, Kontrolle in Deutschland, 1972, S. 189; S. Tiemann, Die staatsrechtliche Stellung der Finanzkontrolle des Bundes, 1974, S. 41 m.w.N. 
prüft, ob zweckmäßig und wirtschaftlich verfahren wurde. ${ }^{133}$ Verwaltungskontrolle dient damit der Kontrolle der Verwaltung durch Regierung und Parlament, ${ }^{134}$ aber vor allem auch der Selbstkontrolle ${ }^{135}$ der kontrollunterworfenen Stellen, die über die Prüfungsergebnisse in einer Prüfungsmitteilung informiert werden.

Daneben erfolgt gegenüber der Regierung die Verfassungskontrolle, zum Teil auch als Regierungskontrolle ${ }^{136}$ bezeichnet, die die Überprüfung der Einhaltung von Haushaltsgesetz und Haushaltsplan einschließlich der dazugehörigen Unterlagen, in denen sich der Wille des Gesetzgebers manifestiert hat, beinhaltet (vgl. \ 90 Nr. 1 BHO). ${ }^{137}$ Geprüft wird also, ob die Mittel bestimmungsgemäß eingesetzt wurden und die im Haushaltsplan zur Verfügung gestellten Beträge eingehalten und nicht überschritten wurden. ${ }^{138}$ Zielrichtung der Verfassungskontrolle ist damit die Unterstützung des Parlaments bei seiner Kontrolle der Regierung, die nach Art. 110 GG verfassungsrechtlich an den Haushaltsansatz gebunden ist ${ }^{139}$. Haushaltsgesetz und Haushaltsplan selbst sind zwar grundsätzlich nicht Gegenstand, sondern Maßstab der Rechnungsprüfung, jedoch ist auch die (wenn auch unverbindliche) Überprüfung der Verfassungsmäßigkeit von haushaltsrechtlich relevanten Gesetzen als Bestandteil der Verfassungskontrolle vom Bundesverfassungsgericht gebilligt worden. ${ }^{140}$

Sowohl bei der Rechnungsprüfung im engeren Sinne als auch bei der gegenwartsnahen Prüfung der Wirtschaftlichkeit und Ordnungsmäßigkeit der Haushalts- und Wirtschaftsführung handelt es sich um eine reine Kontrollfunktion, dem Bundesrechnungshof kommen keinerlei Mitentscheidungsbefugnisse zu. ${ }^{141}$ Ziel der Prüfung ist es, Missstände aufzuzeigen und ihre Beseitigung durch Mitteilung an die zuständigen Organe und gegebenenfalls durch Veröffentlichung zu bewirken. Außerdem soll die Rechtmäßigkeit der Verwaltung gesichert, ihre Leistungsfähigkeit verbessert und Fehlentwicklungen vermieden werden (vgl. \3 Abs. 1 S. 2 PO-BRH). Abgesehen von der faktischen Druckausübung, die der Rechnungshof durch Mitteilung und gegebenenfalls Veröffentlichung von Prüfungsergebnissen erzielen kann, ist es also grundsätzlich den Kontrollierten selbst überlassen, auf Kritik zu reagieren und Missstände abzustellen.

\footnotetext{
133 Grupp, Die Stellung der Rechnungshöfe in der BRD, 1972, S. 84; S. Tiemann, Die staatsrechtliche Stellung der Finanzkontrolle des Bundes, 1974, S. 41.

134 v.Arnim, Grundprobleme der Finanzkontrolle, DVBl. 1983, 664 (665).

135 Brunner, Kontrolle in Deutschland, 1972, S. 189.

136 v. Arnim, Staatslehre, 1984, S. 398.

137 BVerfGE 20, 56 (96); S. Tiemann, Die staatsrechtliche Stellung der Finanzkontrolle des Bundes, 1974, S. 42.

138 Grupp, Die Stellung der Rechnungshöfe in der BRD, 1972, S. 84.

139 Mahrenboly, in: AK zum GG, Art. 114, Rn. 17.

140 BVerfGE 20, 56 (96).

141 Siekmann, in: Sachs, GG, Art. 114, Rn. 27.
} 
Weiter dient die Prüfung dazu, ,wesentliche Erkenntnisse über die Haushalts- und Wirtschaftsführung der Verwaltung und der sonstigen geprüften Stellen zu gewinnen“ (vgl. \3 Abs. 1 S. 1 PO-BRH). Diese Erkenntnisse können dem Rechnungshof zur Verbesserung seiner zukünftigen Prüfungstätigkeit und insbesondere bei der Beratung dienen. Durch die Rolle, die er für das Parlament wahrnimmt, obliegt es ihm, dieses bei der Wahrnehmung seiner Aufgaben zu unterstützen, das heißt, ihm in erster Linie bei der Ausübung des Budgetrechts und der Entlastung der Bundesregierung einen „möglichst umfassenden Überblick über die Haushaltswirtschaft des Bundes" zu geben und es zu beraten (vgl. \ 3 Abs. 2 PO$\mathrm{BRH})$.

Diese Kontrolle erbringt der Bundesrechnungshof in völliger Unabhängigkeit zu Legislative, Exekutive und Judikative, insbesondere ist sein Kontrollauftrag unbeschränkt, und er kann nach eigenem pflichtgemäßem Ermessen eigeninitiativ tätig werden.

Von ihrer Funktion her ist die Finanzkontrolle nicht als typischerweise einer Staatsgewalt zugehörig einzuordnen. ${ }^{142}$ Sie wird in jeweils sehr unterschiedlicher funktionaler Ausprägung von Legislative, Exekutive und Bundesrechnungshof ausgeübt: 143

So wird Finanzkontrolle von der Verwaltung als interne Revision der Behörden ${ }^{144}$ wahrgenommen und ist hier klar der Exekutive zuzuordnen. In den Bereich der Exekutive fiel früher auch die Vorprüfung durch die in die zu prüfende Verwaltung eingegliederten Vorprüfungsstellen (vgl. \ 100 BHO a.F.), ${ }^{145}$ die allerdings 1997/1998 durch die dem Bundesrechnungshof unterstellten Prüfungsämter des Bundes ersetzt wurden, ${ }^{146}$ was im Rahmen einer unabhängigen und effektiven externen Finanzkontrolle auch notwendig war. Systemgerecht wurde so die Einflussmöglichkeit der Exekutive auf die praktisch bedeutsame Vorprüfung ausgeschaltet.

Auch das Parlament übt in engem Zusammenhang mit dem Budgetrecht und der Entlastung der Bundesregierung Finanzkontrolle aus (vgl. Art. 114 Abs. 1 GG), die klar der Legislative als typische Funktion zugeordnet werden kann. ${ }^{147}$ Der Haushaltsausschuss empfiehlt aufgrund des Berichtes des Bundesrechnungs-

142 Vgl. hierzu Stern, Staatsrecht, Bd. II, 1980, S. 447; Brunner, Kontrolle in Deutschland, 1972, S. 191; Degenhart, Kontrolle der Verwaltung durch Rechnungshöfe, VVDStRL 55 (1996), 190 (204) spricht davon, dass sich in der grundgesetzlichen Finanzkontrolle das ,allgemeine Verfassungsgebot der Kontrolle" realisiert; S. Tiemann, Die staatsrechtliche Stellung der Finanzkontrolle des Bundes, 1974, S. 298.

143 Heun, Staatshaushalt und Staatsleitung, 1989, S. 503.

144 Bundesrechnungshof, Der Bundesrechnungshof und die Prüfungsämter des Bundes, 2005, S. 6; S. Tiemann, Die staatsrechtliche Stellung der Finanzkontrolle, 1974, S. 297; vgl. auch Stern, Der verfassungsrechtliche Status der Rechnungshöfe, in: Böning/v.Mutius, Finanzkontrolle im repräsentativ-demokratischen System, 1990, S. 11 (14 f.).

145 Vgl. Grupp, Die Stellung der Rechnungshöfe in der BRD, 1972, S. 136.

146 Vgl. oben I.6. Die Entwicklung des BRH in der Bundesrepublik.

147 S. Tiemann, Die staatsrechtliche Stellung der Finanzkontrolle, 1974, S. 182 ff., 297. 
hofes, der Regierung die Entlastung zu erteilen, außerdem prüft er gem. \96 Abs. 4 S. 1 GO-BT bei Finanzvorlagen, also in der Regel Gesetzentwürfen, deren Vereinbarkeit mit dem laufenden und dem künftigen Haushaltsplan. Der Rechnungsprüfungsausschuss, als sein Unterausschuss, prüft die Haushalts- und Wirtschaftsführung des Bundes. Die Berichte des Bundesrechnungshofes stellen für die parlamentarische Prüfungstätigkeit die Grundlage dar, wodurch man auf die Idee kommen könnte, ihn als Teil dieses Kontrollvorganges zu sehen und daher der Legislative zuzuordnen, wie unten noch zu erörtern sein wird. In Einzelfällen kann Finanzkontrolle ferner durch parlamentarische Untersuchungsausschüsse erfolgen.

Ähnlichkeit besteht auch zur Tätigkeit der Judikative. Diese ist zur Kontrolle und rechtsverbindlichen Entscheidung über die Rechtmäßigkeit staatlicher Akte berufen. In diese Richtung geht auch die Kontrolle der Ordnungsmäßigkeit durch den Rechnungshof, ist sie doch in erster Linie nichts anderes als eine Rechtmäßigkeitsprüfung, ${ }^{148}$ wobei die Einhaltung der haushaltsrechtlichen Normen im Vordergrund steht, aber auch die Gesetz- bzw. Verfassungsmäßigkeit der Normen geprüft werden kann, auf denen die fraglichen Ausgaben beruhen. ${ }^{149}$ Wie ein Gericht vergleicht der Rechnungshof dabei „Sachverhalt und Norm, Prüfungsgegenstand und Prüfungsmaßstab, Ist und Soll “ ${ }^{150}$. Hinzu kommt, dass er diese Kontrolltätigkeit in richterlicher Unabhängigkeit verrichtet. Wesentlicher Unterschied ist jedoch, dass der Rechnungshof im Gegensatz zu Gerichten nicht entscheidet, sondern lediglich kontrolliert, feststellt und berichtet, ohne dass dies mit den unmittelbaren Rechtsfolgen einer rechtsverbindlichen Entscheidung verbunden ist.

\section{Der Beratungsauftrag}

Art. 114 Abs. 2 S. 3 GG sieht vor, dass weitere Befugnisse des Bundesrechnungshofes durch Bundesgesetz festgelegt werden können. So ergibt sich aus Art. 114 Abs. 2 S. 3 i.V.m. $\ 42$ Abs. 5 HGrG und $\ 88$ Abs. 2 BHO, dass der Bundesrechnungshof als Berater von Bundestag, Bundesrat, Bundesregierung und Bundesministern fungiert und damit die Möglichkeit hat, sich schon im Stadium der Planung eines Projekts beratend einzuschalten.

Diese im Rahmen der Haushaltsrechtsreform von 1969 ergangene Entscheidung des Gesetzgebers, die im Rahmen der Prüfungstätigkeit gewonnenen Erkenntnisse für Organe der Legislative und Exekutive zu nutzen, führte zu einer neuen qualitativen Dimension ${ }^{151}$ der Tätigkeit des Bundesrechnungshofes durch

\footnotetext{
148 Siehe oben Fn. 124.

149 BVerfGE 20, 56 (96); Vogel/Kirchhof, in: Bonner Kommentar, Art. 114, Rn. 96, 97 (Zweitbearbeitung 1973); Kisker, in: Isensee/Kirchhof, HStR, Bd. IV, 1990, \$ 89, Rn. 110 m.w.N.; insbesondere auch: v.Arnim, Grundprobleme der Finanzkontrolle, DVBl. 1983, 664 (668).

${ }^{150}$ Hufeld, in: Isensee/Kirchhof, HStR, Bd. III, 2005, \56, Rn. 15; siehe hierzu auch: Krebs, Kontrolle in staatlichen Entscheidungsprozessen, 1984, S. 170.

151 Wittrock, Parlament, Regierung und Rechnungshof, ZParl 1986, 414 (422).
} 
die gesetzliche Festschreibung des Beratungsauftrages neben dem Prüfungsauftrag.

Der Beratungsauftrag ergibt sich zwar nicht unmittelbar aus dem Wortlaut des Grundgesetzes, jedoch zielt der Gesetzesvorbehalt in Art. 114 Abs. 2 S. 3 GG nach dem Willen des verfassungsändernden Gesetzgebers ${ }^{152}$ auf die verfassungsrechtliche Klarstellung seiner Zulässigkeit und gesetzlichen Verankerung ab, wie

die ebenfalls im Rahmen der Haushaltsrechtsreform ergangenen Regelungen der Beratung zeigen.

\section{a) Formen der Beratung}

$\mathrm{Zu}$ differenzieren ist zwischen unselbständiger und selbständiger Beratung. Nach der schon vor der gesetzlichen Regelung bestehenden Praxis konnte der Bundesrechnungshof unselbständig beraten, ${ }^{153}$ also in unmittelbarem Zusammenhang mit einer Prüfung in Form von „Vorschlägen, Empfehlungen, Anregungen und dergleichen “ beratend tätig werden. ${ }^{154}$

Die unselbständige Beratung steht letztlich in unmittelbarem Zusammenhang mit der Kontrolle und den damit verbundenen Berichten. Eine sinnvolle Kontrolle ist nur möglich, wenn in Form der unselbständigen Beratung auch die entsprechenden Schlüsse aus ihr gezogen werden. Auch setzt Beratung vorherige Prüfung voraus, da sie nur aufgrund von Prüfungserfahrungen erfolgen darf (vgl. \42 Abs. 5 HGrG, \ 88 Abs. 2 S. 1 BHO). ${ }^{155}$ So dient die Prüfung auch der „Gewinnung wesentlicher Erkenntnisse über die Haushalts- und Wirtschaftsführung“ (vgl. nur \ 3 Abs. 1 S. 1 PO-BRH), die eine sinnvolle Beratung überhaupt erst ermöglichen. Prüfung und Beratung können somit zurecht als „zwei Seiten derselben Medaille“ bezeichnet werden. ${ }^{156}$ Zumindest die Aufgabe der unselbständigen Beratung folgt aus Art. 114 Abs. 2 GG, sie wird durch die BHO konkretisiert, dies zeigt auch die Intention des Gesetzgebers ${ }^{157}$.

Mit $\int 88$ Abs. 2 BHO wurde weiter die Ermächtigung des Bundesrechnungshofes zur selbständigen Beratung geschaffen. Wie aus der Norm deutlich wird,

152 Schriftlicher Bericht des Rechtssausschusses des Bundestages zu BT-Drucksache V/3605, S. 13: Durch den Gesetzesvorbehalt „soll ermöglicht werden, dass ohne verfassungsrechtliche Zweifel durch einfaches Bundesgesetz dem Rechnungshof Zuständigkeiten und Aufgaben übertragen werden, die er entweder aus Tradition, kraft Übertragung durch einfache Gesetze oder auf Grund von Vereinbarungen... ausgeübt hat"“.

153 Vgl. Kisker, in: Isensee/Kirchhof, HStR, Bd. IV, 1990, \89 Rn. 103; Wittrock, Der Rechnungshof als Berater, DÖV 1989, 346 (347).

154 Blasius, Finanzkontrolle und Gesetzgebung, DÖV 1989, 298 (302); Wittrock, Der Rechnungshof als Berater, DÖV 1989, 346 (347); Piduch, in: ders., Bundeshaushaltsrecht, $\int 88$ BHO, Rn. 5, (Stand: 21. EL, Januar 1986).

$155 \mathrm{Krebs}$, Kontrolle in staatlichen Entscheidungsprozessen, 1984, S. 171, betont die Unmöglichkeit einer klaren Abgrenzung zwischen Prüfung und Beratung.

156 Blasius, Der Rechnungshof: Kontrolleur und Informant, DÖV 1993, 642 (644, Fn. 8).

157 Vgl. Fn. 152. 
kann der Rechnungshof hierbei auch hinsichtlich Fragen beratend tätig werden, die nicht in einem unmittelbaren Zusammenhang mit einer bestimmten gerade laufenden Rechnungsprüfung stehen.

Aus dem Wortlaut der $\int 42$ Abs. 5 HGrG, $\ 88$ Abs. 2 S. 1 BHO ergibt sich ausdrücklich, dass der Bundesrechnungshof beratend tätig werden „kann“. Es handelt sich folglich um ein Beratungsrecht, nicht um eine Beratungspflicht; ${ }^{158}$ es steht somit im Ermessen des Bundesrechnungshofes, selbst zu entscheiden, ob und wann er tätig werden will. Dies kann sowohl auf Ersuchen von Bundestag, Bundesrat, Bundesregierung oder eines Bundesministeriums hin erfolgen oder auf eigenen Entschluss hin. Dabei wird der Bundesrechnungshof von Amts wegen tätig unter Umständen auch gegen den Willen des zu Beratenden ${ }^{159}$ (beispielsweise in jüngerer Zeit bei Beschaffungsvorhaben der Bundeswehr die Kritik am Raketenabwehrsystem MEADS160 oder die Feststellung eklatanter Mängel beim Arbeitslosengeld II $\left.{ }^{161}\right)$. Beratung für die Legislative und auch für die Entscheidungsträger der Exekutive liefert Entscheidungshilfen, manchmal auch Hilfe, von zunächst geplanten Entscheidungen abzusehen. ${ }^{162}$

Eine Beschränkung erfährt der Beratungsauftrag durch die Bundeshaushaltsordnung dahingehend, dass der Bundesrechnungshof nur „aufgrund von Prüfungserfahrungen" beratend tätig werden darf (vgl. $\ 42$ Abs. 5 HGrG, $\ 88$ Abs. 2 S. 1 BHO). Diese Bindung an den Prüfungsgegenstand der Finanzkontrolle ist sinnvoll, der Bundesrechnungshof soll kein allgemeiner Ratgeber oder Kritiker von Legislative und Exekutive sein, sondern seine Spezialkenntnisse in Hinblick auf die Wirtschafts- und Ordnungsmäßigkeit der staatlichen Finanzen nutzbar machen. Die Beratung, ob selbständig oder unselbständig, basiert jedenfalls auf der Prüfungserfahrung. Insbesondere bei der unselbständigen Beratung wird der enge Zusammenhang deutlich und damit auch, dass eine klare Trennung zwischen den beiden Tätigkeiten kaum möglich ist. ${ }^{163}$ Maßstab der Tätigkeit des Bundesrechnungshofes ist bei allen Formen der Beratung die Sicherung von „Wirtschaftlichkeit und Ordnungsmäßigkeit" der Wirtschafts- und Haushaltsführung.

Dabei kann die Beratung durchaus schon vor dem Treffen einer Entscheidung über die fragliche Materie einsetzen, ${ }^{164}$ sie darf also mit dem Ziel erfolgen, auf eine künftige Entscheidung des Beratenen, namentlich des Bundestages, Bundesrates,

\footnotetext{
${ }^{158}$ Hufeld, in: Isensee/Kirchhof, HStR, Bd. III, 2005, \56, Rn. 40.

159 v. Arnim, Grundprobleme der Finanzkontrolle, DVBl. 1983, 664 (665) m.w.N.

160 Bundesrechnungshof, Bemerkungen 2005 zur Haushalts- und Wirtschaftsführung des Bundes, S. 211 (Punkt 78).

161 Vgl. „Arbeitslosengeld II hat eklatante Mängel - Rechnungshof rügt schwere Mängel / Mehr Kontrolle durch Arbeitsagentur gefordert", Frankfurter Allgemeine Zeitung vom 22. Mai 2006, S. 13.

162 Wittrock, Der Rechnungshof als Berater, DÖV 1989, 346.

163 Schwary, in: v.Mangoldt/Klein/Starck, GG, Art. 114, Rn. 97.

164 Bundesrechnungshof, Der Bundesrechnungshof und die Prüfungsämter des Bundes, 2005, S. 13.
} 
der Bundesregierung oder einzelner Bundesminister, Einfluss zu nehmen; ${ }^{165}$ diese Möglichkeit liegt in der Natur jeder Beratung.

Die besondere Stellung des Bundesrechnungshofes im Staatsaufbau und die Schwierigkeiten seiner Einordnung rühren auch von ebendieser Beratungsfunktion her. Beratung gilt als besonders effektiv, wenn sie durch externe Berater stattfindet, um größtmögliche Objektivität zu gewährleisten und Betriebsblindheit zu verhindern.

Dies gilt für staatliche Stellen ebenso wie für private Unternehmen, die sich beraten lassen. Dabei kann die Beratung in vielen Fällen auch durch außerhalb der Verwaltung stehende private Beratungsunternehmen erfolgen mit dem Ziel, die Wirtschaftlichkeit etwa durch das Aufzeigen von Einsparungspotential oder die effektivere Gestaltung bestimmter Abläufe zu verbessern. Beratung in verschiedenster Form findet demnach gleichermaßen für private Unternehmen und öffentliche Stellen statt, und zwar durch staatliche Stellen oder externe private Berater $^{166}$. Hierin zeigt sich, dass der zwar an die Prüfungserfahrungen gebundene, aber ansonsten freie Beratungsauftrag des Bundesrechnungshofes nicht als eine typischerweise administrative oder im Bereich der Legislative zu verortende Tätigkeit eingeordnet werden kann; im Gegenteil erschwert er die Einordnung des Bundesrechnungshofes in das System der Staatsgewalten.

Beratung bewegt sich typischerweise im Vorfeld sowohl legislativer als auch exekutiver Entscheidungen, beziehungsweise begleitet sie die Entscheidungsträger und gibt ihnen eine Stellungnahme, die zur Optimierung ihrer Entscheidungen beitragen kann und soll.

Für die Einordnung erschwerend hinzu kommt, dass Adressaten der Beratung, und zwar als Nutznießer, wenn die Beratung infolge eines entsprechenden Ersuchens erfolgte, wie auch als möglicherweise Kritisierte, sowohl Stellen der Exekutive als auch Organe der Legislative sein können sowie in beschränktem Maße grundsätzlich auch solche der Judikative, soweit es um Mittelverwendung bei ihrer Selbstverwaltung geht.

Die große praktische Bedeutung und die starken faktischen Einflussmöglichkeiten auf die Entscheidungsfindung zeigen sich in dem breiten Feld und der Bedeutung der vom Bundesrechnungshof aufgenommenen Bereiche, in denen er beratend tätig wird. ${ }^{167}$

Die Beratung hängt demnach aufs engste mit der Prüfung zusammen, handelt es sich doch im Wesentlichen um die Fruchtbarmachung von auf Prüfungserfahrungen beruhenden Erkenntnissen für zukünftige Entscheidungen, um Fehlentscheidungen staatlicher Entscheidungsträger, die auf dem Gebiet der Finanzen oft

\footnotetext{
165 Nebel, in: Piduch, Bundeshaushaltsrecht, Art. 114 GG, Rn. 28 (Stand: 35. EL Juli 1998).

$166 \mathrm{Vgl}$. hierzu die zehn Eckpunkte, die der Bundesrechnungshof für die Inanspruchnahme privater

Berater durch staatliche Stellen formulierte: Bundesrechnungshof, Pressemitteilung vom 19.12.2005.

167 Vgl. zahlreiche Beispiele unter VII. 2.
} 
ein Kenntnisdefizit im Vergleich mit dem Bundesrechnungshof haben, zu vermeiden.

Im Ergebnis lässt sich die Beratungstätigkeit genauso wenig wie die Prüfungsaufgaben des Bundesrechnungshofes als „typisch“ einer Staatsgewalt zuordnen.

\section{b) Probleme binsichtlich der Beratung}

Beratung ist hinsichtlich der späteren Prüfung ergangener Entscheidungen nicht unproblematisch. So stellt sich grundsätzlich die Frage, ob in Fällen begleitender Beratung die daraufhin ergangenen Beschlüsse später noch unvoreingenommen vom Bundesrechnungshof geprüft werden können. Teilweise wird von einer „Spannungslage von Beratung und Kontrolle“168 gesprochen. Jedoch darf nicht vergessen werden, dass es schließlich doch die beratenen Stellen sind, die die Entscheidung im Rahmen des ihnen zustehenden Ermessens treffen. Der Rechnungshof berät nur unverbindlich und entscheidet nicht mit. $\mathrm{Zu}$ einem anderen Ergebnis käme man, wenn etwa Zustimmungs- oder Einverständnisvorbehalte für den Rechnungshof bestünden, dann wären Kontrollierter und Kontrolleur identisch, was unzulässig wäre. ${ }^{169}$

Eine entscheidende Einschränkung der Beratung ist, dass sie nur ,aufgrund von Prüfungserfahrungen" erfolgen darf. Der Bundesrechnungshof soll nur seine Erfahrung in den von Verfassungs wegen auch seiner Prüfung unterliegenden Bereichen einbringen. Alles andere wäre nicht systemgerecht, schließlich ist der Bundesrechnungshof ein Spezialist und kein allgemeiner Berater der Politik. Mit diesen Einschränkungen ist sichergestellt, dass einerseits ein einheitlicher Rahmen für die Inhalte der Beratungs- und der Kontrolltätigkeit gilt und dass andererseits hinsichtlich einer eventuellen späteren Kontrolle „die Unparteilichkeit und Unbefangenheit der Prüfer nicht in unvertretbarem Maße berührt wird“"170.171

\section{c) Beratung durch den Bundesbeauftragten für Wirtschaftlichkeit in der Verwaltung}

Eine weitere Form der Beratung erfolgt durch den Präsidenten des Bundesrechnungshofes in seiner Funktion als Bundesbeauftragter für Wirtschaftlichkeit in der Verwaltung. Traditionell wird der Präsident des Bundesrechnungshofes zu diesem Amt von der Bundesregierung bestellt. Seine Aufgabe ist es, durch Vorschläge, Gutachten oder Stellungnahmen auf eine wirtschaftliche Erfüllung der Bundesaufgaben und auf eine dementsprechende Organisation der Bundesverwaltung

\footnotetext{
168 Sigg, Die Stellung der Rechnungshöfe, 1983, S. 33 f.; in diese Richtung auch: Schwarz, in: v.Mangoldt/Klein/Starck, GG, Art. 114, Rn. 98 m.w.N.

169 P. Kirchhof, Die Steuerung des Verwaltungshandelns durch Haushaltsrecht und Haushaltskontrolle, NVwZ 1983, 505 (515).

170 P. Kirchhof, Die Steuerung des Verwaltungshandelns durch Haushaltsrecht und Haushaltskontrolle, NVwZ 1983, 505 (515).

${ }^{171}$ Siehe auch: Blasius, Finanzkontrolle und Gesetzgebung, DÖV 1989, 298 (303).
} 
einschließlich ihrer Sondervermögen und Betriebe hinzuwirken. ${ }^{172}$ Er kann auf Anregung von Bundesregierung, Bundesministerien, Bundestag oder Bundesrat, aber auch aus eigener Initiative beratend tätig werden sowie örtliche Erhebungen nach Unterrichtung des zuständigen Bundesministers vornehmen oder durch Beauftragte vornehmen lassen. ${ }^{173}$ Die Öffentlichkeit wird durch eine seit 1987 herausgegebene Schriftenreihe über besonders bedeutsame Gutachten informiert.

\section{Behandlung politischer Entscheidungen}

Grundsätzlich hat der Bundesrechnungshof politische Entscheidungen zu respektieren und tut dies auch. ${ }^{174}$ Das bedeutet, dass es nicht Aufgabe des Bundesrechnungshofes ist, die für den staatlichen Entscheidungsträger politisch maßgebenden Gründe einer Entscheidung mit finanziellen Auswirkungen zu beurteilen. Teilweise wird diese Zurückhaltung kritisiert, ${ }^{175}$ jedoch zeigt ein Blick auf die Handhabung durch den Bundesrechnungshof, dass er so zurückhaltend gar nicht mehr agiert. Auch sind die Grenzen zur Beurteilung politischer Entscheidungen bei der Wirtschaftlichkeitsprüfung und insbesondere der Beratung fließend, so dass eine klare Trennung zwischen politischen und wirtschaftlichen Erwägungen oft kaum möglich ist.

So überprüft der Bundesrechnungshof das Vorliegen der Voraussetzungen und die Folgen politischer Entscheidungen, mithin ob die mit der Entscheidung beabsichtigte Wirkung erreicht wird. ${ }^{176}$ So ist zum Beispiel bei der Zahlung von Subventionen nicht seine Aufgabe die politische Entscheidung zu überprüfen, also politisch zu bewerten, ob und aus welchen Beweggründen bestimmte Subventionen gezahlt werden sollen; er kann aber prüfen, ob bei ihrer Gewährung die Voraussetzungen beachtet wurden und die gewünschte Wirkung erzielt wurde. ${ }^{177}$ Vor allem aber unterliegen nur politische Entscheidungen „im Rahmen des geltenden Rechts" nicht der Beurteilung durch den Bundesrechnungshof, ${ }^{178}$ das kann aber nichts anderes heißen, als dass er bei Zweifeln die Rechtmäßigkeit haushaltsrelevanter politischer Entscheidungen im Rahmen der Ordnungsmäßigkeitsprüfung nach Art. 114 Abs. 2 S. 1 GG prüfen kann, was auch der Rechtsprechung des Bundesverfassungsgerichtes entspricht. ${ }^{179}$

\footnotetext{
172 Vgl. Richtlinien über die Tätigkeit des Bundesbeauftragten für Wirtschaftlichkeit in der Verwaltung (BWV) vom 26. August 1986 (BAnz Nr. 163, S. 12485).

173 Siehe Fn. 172.

174 Wittrock, Möglichkeiten und Grenzen der Finanzkontrolle, Bulletin der Bundesregierung, 1982, 524 (527).; Bundesrechnungshof, Bemerkungen 2002, S. 7 (Zf. 2.1); vgl. auch: \ 6 Abs. 1 PO-BRH.

175 v.Arnim, Staatslehre, 1984, S. 402; Hesse/Ellwein, Das Regierungssystem der Bundesrepublik Deutschland, 2004, Bd. 1, S. 245 f.

176 Bundesrechnungshof, Bemerkungen 2002, S. 7 (Zf. 2.1); vgl. auch: \6 Abs. 1 S. 2 PO-BRH.

177 Bundesrechnungshof, Der Bundesrechnungshof und die Prüfungsämter des Bundes, 2009, S. 16

178 Bundesrechnungshof, Der Bundesrechnungshof und die Prüfungsämter des Bundes, 2005, S. 16; Bundesrechnungshof, Bemerkungen 2002, S. 7 (Zf. 2.1).

179 Oben: IV. 1. c) aa).
} 
Weiter kann der Bundesrechnungshof im Rahmen der Beratung Gesetzesänderungen empfehlen, wenn er feststellt, dass die vom Gesetzgeber verfolgten Ziele nicht erreicht wurden beziehungsweise nicht erreichbar sind, oder wenn sie wirtschaftlicher verwirklicht werden könnten (vgl. \97 Abs. 2 Nr. 4 BHO Empfehlung von Maßnahmen für die Zukunft). ${ }^{180}$

Dass es nicht Aufgabe des Bundesrechnungshofes ist, politische Grundentscheidungen zu überprüfen und zu beurteilen, zeigt der Katalog der ihm zugewiesenen Aufgaben: Er ist in erster Linie ein Kontrollorgan, das auch beratend tätig wird und über seine Tätigkeiten (auch die Öffentlichkeit) informiert; das Treffen der grundsätzlichen politischen Entscheidungen ist anderen staatlichen Funktionsträgern überlassen. Der Bundesrechnungshof wird nicht staatsleitend tätig. Er stellt jedoch ein idealiter eine gewisse Konstanz garantierendes, rationalisierend wirkendes Element im Umgang mit den Staatsfinanzen dar, indem er bei der Erstellung des Haushaltsplans seine Erfahrung einbringt (vgl. \27 Abs. 2 BHO), Legislative und Exekutive begleitend berät und finanzwirksame Maßnahmen prüft. Dabei liegt es in der Natur der Sache, dass der Rechnungshof um so eher Gehör findet, je schlechter die finanzielle Situation ist, in der der Staat sich befindet.

5. Bekanntmachung und Veröffentlichung der Ergebnisse in den Berichten des Bundesrechnungshofes

Kernstück der Veröffentlichungen des Bundesrechnungshofes bilden seine Jahresberichte, die „Bemerkungen“, in denen er die Prüfungs- und Beratungsergebnisse für die Bundesregierung, den Bundestag und den Bundesrat jedes Jahr zusammenfasst (vgl. Art. 114 Abs. 2 S. 2 GG, \ 97 BHO, \ 50 Abs. 1 PO-BRH). Diese werden als Bundestagsdrucksachen veröffentlicht. Der Bundesrechnungshof macht sie außerdem durch die Vorstellung auf einer Pressekonferenz der Öffentlichkeit zugänglich, die Berichte können angefordert werden und sind auf der Internetseite des Bundesrechnungshofes ${ }^{181}$ abrufbar.

Auch die Berichterstattung in Angelegenheiten von besonderer Bedeutung nach $₫ 99 \mathrm{BHO}$ ist mit der Veröffentlichung verbunden.

Die Berichterstattung an Bundestag, Bundesrat und Bundesregierung umfasst ebenfalls die Beratung aufgrund von Prüfungserfahrungen nach $\ 88$ Abs. 2 BHO (vgl. \42 Abs. 1 Nr. 3 PO-BRH), die aber allenfalls der Parlamentsöffentlichkeit unterliegt, sofern sie nicht in die Bemerkungen aufgenommen oder als Angelegenheit von besonderer Bedeutung veröffentlicht wird.

Bereits im Verlauf der Prüfung beziehungsweise unmittelbar nach ihrem Abschluss teilt der Bundesrechnungshof gem. \96 BHO die Prüfungsergebnisse

\footnotetext{
${ }_{180}$ Vgl. \ 6 Abs. 2 PO-BRH; Bundesrechnungshof, Bemerkungen 2005, S. 7 (Zf. 2.2).

181 http://www.bundesrechnungshof.de/veroeffentlichungen.
} 
seiner jährlich etwa 600 Prüfungen ${ }^{182}$ den zuständigen Dienststellen zur Äußerung innerhalb einer von ihm zu bestimmenden Frist mit.

Gleichrangige Adressaten der Bemerkungen des Bundesrechnungshofes sind nach Art. 114 Abs. 2 S. 2 GG Bundesregierung, Bundestag und Bundesrat, die er durch seine Prüfungs- und vor allem durch seine Beratungstätigkeit unterstützt. Der Bundestag hat in der Praxis den größten Informationsbedarf, verfügt er doch nicht über die Apparate der Ministerien, die der Bundesregierung und mittelbar über die Landesregierungen auch dem Bundesrat zuarbeiten. Insofern ist die Unterstützung durch den Bundesrechnungshof entscheidend für die Behauptung des Budgetrechts des Parlaments gegenüber der „Wissensmacht der Exekutive“183. Hieraus jedoch eine Sonderstellung des Rechnungshofes für das Parlament herzuleiten, ${ }^{184}$ verbietet sich angesichts des eindeutigen Wortlautes des Grundgesetzes. In Art. 114 Abs. 2 S. 2 GG wird nämlich die Bundesregierung an erster Stelle vor dem Bundestag als Adressat genannt, was jedoch wohl eines der letzten Überbleibsel einstiger Regierungsnähe des Rechnungshofes sein dürfte.

Der Stellenwert, den der Bundesrechnungshof den Berichten und der meist damit verbundenen Information der Öffentlichkeit zumisst, wird in der von ihm erlassenen Prüfungsordnung deutlich:

Aus $\int 44$ PO-BRH ergibt sich, dass bei der Beurteilung, ob Prüfungsergebnisse von Bedeutung i.S.d. \97 Abs. 1 BHO sind, was eine Veröffentlichung in den Bemerkungen bedeuten würde, der Informationsbedarf der Legislative zu beachten ist, aber ,,auch dem Informationsinteresse der Öffentlichkeit Rechnung getragen werden" soll.

$\int 54$ PO-BRH regelt Berichte über Angelegenheiten von besonderer Bedeutung (vgl. \99 BHO), nach Abs. 1 S. 3 soll „diese Form der Berichterstattung gewählt werden, wenn eine Unterrichtung der Öffentlichkeit angezeigt erscheint“".

Öffentlichkeit und Transparenz sind ein Gebot der Demokratie. Deshalb hat der Bundesrechnungshof auch „nicht die Veröffentlichung seiner Berichte zu rechtfertigen, sondern nur die Nichtveröffentlichung“"185. Auch haben die Steuerzahler ein berechtigtes Interesse daran zu erfahren, wie die Finanzmittel vom Staat, der diese gleichsam treuhänderisch verwaltet, verwendet werden. ${ }^{186}$

Der Bundesrechnungshof nimmt sehr bewusst seine Rolle als Informant der Öffentlichkeit durch die Veröffentlichung von Berichten und durch meist damit verbundene Pressekonferenzen und Pressemitteilungen sowie durch seinen Inter-

\footnotetext{
182 Bundesrechnungshof, Der Bundesrechnungshof und die Prüfungsämter des Bundes, 2005, S. 12.

183 Wernstedt, Rede anlässlich des Festakts zum 50-jährigen Bestehen des Niedersächsischen Landesrechnungshofes am 5. November 1998, S. 1.

184 Zum Verhältnis des Bundesrechnungshofes zum Parlament im Einzelnen: VI. 3. a).

185 v.Arnim, Finanzkontrolle in der Demokratie, in: ders., Finanzkontrolle im Wandel, 1989, S. 57; ausführlich dazu: Blasius, Der Rechnungshof: Kontrolleur und Informant, DÖV 1993, 642 (645 f.).

186 Schwary in: v.Mangoldt/Klein/Starck, GG, Art. 114, Rn. 51 m.w.N.; Brunner, Kontrolle in Deutschland, 1972, S. 185.
} 
netauftritt wahr. Dies kann dazu führen, den Druck auf die Staatsorgane zu erhöhen, sich mit seiner Kritik oder Änderungsvorschlägen zu beschäftigen und tätig zu werden. Die Bezeichnung der „Öffentlichkeit als Schwert des Bundesrechnungshofes“"187 ist damit durchaus zutreffend. Die Öffentlichkeitsarbeit der Rechnungshöfe wird in der Literatur ganz überwiegend begrüßt. ${ }^{188}$ Mahrenholz spricht sogar von einer „Verfassungspflicht“, die Öffentlichkeit zu informieren. ${ }^{189}$ Der Gegenansicht, die die Öffentlichkeitsarbeit von Rechnungshöfen in Ermangelung einer ausdrücklichen Rechtsgrundlage für unzulässig hält, ${ }^{190}$ ist entgegenzuhalten, dass die Information der Öffentlichkeit und damit die Transparenz im demokratischen Staat eine Notwendigkeit ist. Für den Rechnungshof kann hier nichts anderes gelten als etwa für das Bundesverfassungsgericht, das ebenfalls Pressekonferenzen abhält, ohne dass es eine geschriebene Rechtsgrundlage hierfür gibt, das gleiche gilt auch für Bundestag und Ministerien. ${ }^{191}$ Jedoch ist eine differenzierte Sichtweise angebracht, denn das Recht, an die Öffentlichkeit zu gehen, kann nicht uneingeschränkt gelten. Die Grenze der Zulässigkeit stellt die notwendige Zurückhaltung des Rechnungshofes hinsichtlich politischer Entscheidungen dar, es ist nicht seine Aufgabe, in Hinblick auf anstehende Entscheidungen von Legislative oder Exekutive die Öffentlichkeit zu mobilisieren. ${ }^{192}$

Schließlich findet jeweils rund zwei Jahre nach der Veröffentlichung der Bemerkungen eine Kontrolle ihres Erfolges statt: ${ }^{193}$ Der Bundesrechnungshof unterrichtet in seinem Ergebnisbericht dann darüber, welche Maßnahmen geprüfte Stellen unternommen haben, um offengelegte Mängel abzustellen, und ob und wie die Berichte des Bundesrechnungshofes vom Parlament aufgegriffen und umgesetzt wurden. ${ }^{194}$ Durch diese Art der Erfolgskontrolle wird einerseits dem auf die Zukunft gerichteten Element der Prüfung und Beratung Rechnung getragen, andererseits die Wirkungskraft des Rechnungshofes in Hinblick auf die Umsetzung seiner Erkenntnisse durch geprüfte Stellen und Gesetzgeber gestärkt. ${ }^{195}$ In der

187 v. Arnim, Finanzkontrolle in der Demokratie, in: ders., Finanzkontrolle im Wandel, 1989, S. 39 (57) m.w.N.

188 Vgl. neben den eben aufgeführten: v.Arnim, Grundprobleme der Finanzkontrolle, DVBl. 1983, 664 (673 ff.) m.w.N.; Sigg, Die Stellung der Rechnungshöfe im politischen System der BRD, 1983, S. 76 ff.; so schon Vialon, Haushaltsrecht, 1959, S. 1072; mit Einschränkungen auch: Krebs, Kontrolle in staatlichen Entscheidungsprozessen, 1984, S. 214 f. m.w.N.

189 Mabrenhol: Festrede anlässlich des Festakts zum 50-jährigen Bestehen des Niedersächsischen Landesrechnungshofes am 5. November 1998, S. 17 f.

190 Wieland, Rechnungshofkontrolle im demokratischen Rechtsstaat, DVBl. 1995, 894 (902 f.).

191 Mabrenholz. Festrede anlässlich des Festakts zum 50-jährigen Bestehen des Niedersächsischen Landesrechnungshofes am 5. November 1998, S. 18.

192 v.Mutius, Finanzkontrolle und Öffentlichkeit, in: FS zur 275. Wiederkehr der Errichtung der Preußischen General-Rechen-Kammer, 1989, S. 305 ff. (322); so wohl auch Krebs, Kontrolle in staatlichen Entscheidungsprozessen, 1984, S. 215 m.w.N.

193 Vgl. Allg. Verwaltungsvorschriften zur BHO v. 14.03.2001 (GMBl 2001, Zu \ 7, Ziffer 2.2, S.310 f.).

194 Bundesrechnungshof, Der Bundesrechnungshof und die Prüfungsämter des Bundes, 2005, S. 12.

195 Bundesrechnungshof, Bemerkungen 2002, S. 9 (Zf. 5). 
Regel finden nahezu alle auf die Beanstandungen hin ergangenen Empfehlungen die Zustimmung des Parlaments, was die Grundvoraussetzung für ihre Umsetzung ist und die Bedeutung der parlamentarischen Unterstützung für Zielerreichung und Effektivität der Finanzkontrolle durch den Bundesrechnungshof zeigt. ${ }^{196}$

Bundesrechnungshofpräsident Engels betonte im Hinblick auf die Ergebnisberichte die Rolle des Rechnungshofes als Informant der Öffentlichkeit: „Vollständig wird das Bild über die Arbeit des Bundesrechnungshofes jedoch erst dann, wenn man erfährt, ob und wie das Parlament die Bemerkungen aufgreift und wie die Bundesverwaltung sie in die Praxis umsetzt" ${ }^{\text {"197. }}$.

Erstaunlich ist, dass der Bundesrechnungshof im Bundestagswahljahr 2005 auf eine Veröffentlichung des Ergebnisberichts verzichtet hat, um sich im Bundestagswahlkampf nicht dem Vorwurf politischer Einmischung auszusetzen. ${ }^{198}$ Dementsprechend bezog sich der Ergebnisbericht 2006 auf die Bemerkungen der Jahre 2003 und 2004. Zwar ist es geboten, dass der Bundesrechnungshof, insbesondere im Vorfeld von Wahlen, Zurückhaltung übt, jedoch scheint die entgegen der Regel erfolgte Nichtveröffentlichung eines regelmäßigen, jährlich erscheinenden Berichtes, der auch Missstände und Versäumnisse offenlegt, hier ein fragwürdiges Mittel zu sein.

Im Ergebnis dienen die Berichte des Bundesrechnungshofes einerseits der Exekutive, insbesondere den Ministerien, dazu, Missstände zu erkennen und abzustellen, andererseits dem Parlament, damit es die notwendigen Kenntnisse bekommt, um die Regierung zu entlasten und um die finanziellen Folgen bereits erlassener und zukünftiger Gesetze absehen zu können. Natürlich dienen sie auch der Öffentlichkeit, die so insbesondere über den ordnungsgemäßen und wirtschaftlichen Umgang ihrer Vertreter mit Steuergeldern informiert wird.

6. Unterrichtungs- und Anhörungserfordernisse - Pflicht, den Bundesrechnungshof von bestimmten Maßnahmen zu unterrichten

Neben das Recht des Bundesrechnungshofes, nach eigenem pflichtgemäßem Ermessen zu prüfen, stellt das Gesetz ( $(102 \mathrm{BHO})$ die Pflicht bestimmter staatlicher Stellen, ihn über allgemeine Verwaltungsvorschriften zu informieren. Hintergrund ist, dass der Bundesrechnungshof in diesem Bereich immer auf dem aktuellen Kenntnisstand bleibt und sich gegebenenfalls dazu äußern kann. ${ }^{199}$ Einer Anhörung des Bundesrechnungshofes bedarf es in den Fällen des $\$ 103$ BHO bei Erlass oder Änderungen von Vorschriften über das Haushaltswesen und die Rechnungsprüfung. Nach \27 Abs. 2 BHO sind auch die Voranschläge für den Entwurf des

196 Bundesrechnungshof, Ergebnisbericht 2006 (Folgerungen aus den Bemerkungen 2003 und 2004), S. 3.

197 Bundesrechnungshof, Ergebnisbericht 2006, Vorwort (S. 3).

198 Rechnungshof vermisst Disziplin, Frankfurter Allgemeine Zeitung vom 27.07.06, S. 11.

199 Bundesrechnungshof, Der Bundesrechnungshof und die Prüfungsämter des Bundes, 2005, S. 15. 
Haushaltsplans dem Bundesrechnungshof zuzuleiten, der dazu Stellung nehmen kann und somit bereits in der Erstellungsphase beratend tätig wird.

\section{Der Bundesrechnungshof als Forderung des Demokratie- prinzips}

Die Staatsform der Demokratie macht eine unabhängige Finanzkontrolle durch den Bundesrechnungshof aus mehrerlei Hinsicht notwendig. Neben Rechnungskontrolle und Verwaltungskontrolle ist wie gesehen auch die Verfassungskontrolle erheblich. ${ }^{200}$ Darin wird festgestellt, ob die Regierung sich bei der Ausführung des Haushaltsgesetzes am Willen des Gesetzgebers orientiert hat. Teilweise wird die Verfassungskontrolle, die dem Parlament mit seinen dementsprechenden Ausschüssen obliegt, vom Rechnungshof wahrgenommen, dessen sich der Bundestag in diesem Zusammenhang bedient. Er schafft überhaupt erst die Grundlage, die die Kontrolle der Bundesregierung durch den Bundestag ermöglicht. So könnte das Parlament sein Entlastungsrecht ohne die Arbeit des Rechnungshofes nicht sinnvoll wahrnehmen.

Ein anderer Aspekt seiner Bedeutung für die Demokratie ist die Information des Souveräns, des Volkes selbst, über den Zustand der öffentlichen Finanzen. Transparenz ist ein erheblicher Bestandteil moderner Demokratien; gerade im finanziellen Bereich, in dem das Geld des Volkes durch dessen Repräsentanten, denen es zu treuen Händen überlassen ist, ${ }^{201}$ verwaltet wird, ist sie von Bedeutung. Externe Finanzkontrolle ist hiervor ein „republikanisches Muss“202, weil sie in besonderem Maße Kontrolle durch den Souverän selbst, beziehungsweise seine Vertretung darüber gewährleistet, wie die von ihm abgeleitete Staatsgewalt im Umgang mit den öffentlichen Finanzmitteln von seinen Repräsentanten ausgeübt wird. ${ }^{203}$ So kann beispielsweise auch die Einrichtung unabhängiger Rechnungshöfe in den ehemaligen Ostblockstaaten als ein „Beweis“ dafür gewertet werden, dass diese wieder funktionierende Demokratien geworden sind. ${ }^{204}$ Die Notwendigkeit des Bestehens eines unabhängigen Rechnungshofes ergibt sich aus dem Demokratieprinzip selbst, nach dem das Volk ein Recht auf Information über das Verhalten der Volksvertreter zur Ermöglichung der Meinungsbildung haben muss.

\footnotetext{
200 Oben: IV. 2.

201 Brunner, Kontrolle in Deutschland, 1972, S. 185; Stern, Die staatsrechtliche Stellung des Bundesrechnungshofes und seine Bedeutung im System der Finanzkontrolle, in: FS zur 275. Wiederkehr Errichtung der Preußischen General-Rechen-Kammer, 1989, S. 15.

202 Heintzen, in: v.Münch/Kunig, GG, Art. 114, Rn. 1.

203 In diese Richtung bereits der erste Präsident des Bundesrechnungshofes, Mayer, Rechnungshöfe und Publizität, DÖH 1954, 4 f.; Schwarz, in: v.Mangoldt/Klein/Starck, GG, Art. 114, Rn. 51 f.

204 Friedmann, Finanzkontrolle von Mitteln der Europäischen Gemeinschaft, in: Rechnungshof Rheinland-Pfalz, Kooperation der Finanzkontrolle in Ostdeutschland, 1999, S. 239.
} 
Diesen Aspekt, unter dem die Funktion des Bundesrechnungshofes gesehen werden muss, verdeutlicht auch eine gewisse Ähnlichkeit zur Funktion, die der freien Presse hinsichtlich der Information der Öffentlichkeit zukommt. Das Bundesverfassungsgericht hat die herausragende Stellung von Presse und Pressefreiheit für den demokratischen Staat wie folgt beschrieben: „Eine freie, nicht von der öffentlichen Gewalt gelenkte, keiner Zensur unterworfenen Presse ist ein Wesenselement des freiheitlichen Staates; ...Soll der Bürger politische Entscheidungen treffen, muss er umfassend informiert sein... In der repräsentativen Demokratie steht die Presse zugleich als ständiges Verbindungs- und Kontrollorgan zwischen dem Volk und seinen gewählten Vertretern in Parlament und Regierung“. ${ }^{205}$

Eine Wirkungsweise, die in diese Richtung zielt, kann man auch in der Bedeutung der Arbeit unabhängiger Rechnungshöfe erkennen, selbst wenn sich diese nur auf den sehr beschränkten Bereich der öffentlichen Finanzen bezieht, dafür aber stärker in die Tiefe geht. Durch ihre Veröffentlichungen geben sie dem interessierten Bürger selbst die Möglichkeit, sich anhand der Berichte zu informieren. Zugleich liefern sie die Grundlage für die Presse, ihrerseits über die Ergebnisse zu berichten und sie so einer noch größeren Öffentlichkeit zugänglich zu machen, was sich darin zeigt, dass Kritikpunkte der Rechnungshöfe sehr häufig von der Presse aufgegriffen werden.

Die diesbezügliche Funktion und Bedeutung des Rechnungshofes als „Hilfsorgan“ des Souveräns selbst zeigt auch der Blick in seine Geschichte, so diente er als lediglich vom Monarchen dependierendes Organ dazu, diesem einen Überblick über die öffentlichen Finanzen zu verschaffen.

\section{Die Stellung des Bundesrechnungshofes im System der Gewaltenteilung}

Dadurch, dass Rechnungshöfe die Staatsgewalten (besser gesagt die (drei-)geteilte Staatsgewalt) als unabhängiges Organ hinsichtlich ihres Wirtschaftens mit den Staatsfinanzen kontrollieren, stellt sich die Frage, wie sie im Rahmen des Gewaltenteilungsschemas einzuordnen sind. Grundsätzlich scheint es möglich, sie einer der herkömmlichen drei Gewalten zuzuordnen, sie als eigene vierte Staatsgewalt oder als Institution sui generis, die außerhalb des Systems der Staatsgewalten beziehungsweise zwischen den Gewalten steht, einzuordnen.

Stern spricht davon, dass „mit den Rechnungshöfen spätestens Ende des neunzehnten Jahrhunderts ein feingesponnenes Gebilde... im Schnittpunkt zwi-

205 BVerfGE 20, 162 (174 f.). 
schen den politischen Gewalten entstanden ist, dessen staatstheoretische und dogmatische Deutung ausgesprochen schwierig ist". 206

Hinsichtlich dieser Einordnungsproblematik existiert eine Vielzahl an Literatur. Dabei werden oder wurden alle denkbaren Einordnungen, nämlich als Teil der Legislative, der Exekutive, der Judikative sowie als vierte Gewalt oder Institution sui generis vertreten.

\section{Staatsgewalt und öffentliche Finanzen}

Dem Bundesrechnungshof kommt die Rolle zu, den Umgang der Staatsgewalten mit öffentlichen Finanzen zu kontrollieren beziehungsweise ihre wechselseitige Selbstkontrolle zu ermöglichen. Zunächst soll das Verhältnis von Staatsgewalt und staatlichen Finanzmitteln betrachtet werden.

Unter Staatsgewalt im Sinne des Art. 20 Abs. 2 GG ist die ,gesamte staatliche Herrschaftsmacht" zu verstehen. ${ }^{207}$ Öffentliche Finanzmittel sind eine faktische Voraussetzung für die Ausübung von Staatsgewalt. Staatsgewalt und öffentliche Finanzen bedingen sich gegenseitig, sie sind aufeinander angewiesen und ohne einander nicht denkbar ${ }^{208}$. So bedarf es einerseits der Ausübung von Staatsgewalt, insbesondere durch die Erhebung von Abgaben, um den Staat mit Finanzmitteln auszustatten, andererseits ist er in weiten Bereichen auf ebendiese angewiesen, um Staatsgewalt überhaupt ausüben zu können. Die Finanzen stellen somit einen erheblichen Machtfaktor dar, ohne den Staatsgewalt fast in keinem Bereich ausgeübt werden könnte. ${ }^{209}$ Dem Staatshaushalt und seiner Kontrolle kommt im innerstaatlichen Machtgefüge eine Schlüsselstellung zu, ${ }^{210}$ was sich schon in der geschichtlichen Entwicklung im Ringen zwischen Parlament und Monarch um das Budget- und Entlastungsrecht gezeigt hat.

Insbesondere die Entwicklung zum Leistungsstaat, besonders in der zweiten Hälfte des 20. Jahrhunderts, führte dazu, dass bei der Ausübung von Staatsgewalt zur staatlichen Aufgabenerfüllung nicht mehr nur mit Gewalt und Zwang durchsetzbare Anordnungen im Vordergrund stehen, sondern die Bereitstellung von Geld und geldwerten Leistungen. Dieser Aspekt der Ausübung von Staatsgewalt in Form der Leistungsverwaltung im 20. Jahrhundert führte zwangsläufig auch zu einer Vermehrung der Aufgaben und einem Bedeutungszuwachs der externen

206 Stern, Die staatsrechtliche Stellung des Bundesrechnungshofes und seine Bedeutung im System der Finanzkontrolle, in: FS zur 275. Wiederkehr der Errichtung der Preußischen GeneralRechen-Kammer, S. 19; ders., Staatsrecht, Bd. II, 1980, S. 414 f.

207 Sachs, in Sachs, GG, Art. 20, Rn. 29; Stern, Staatsrecht II, 1980, S. 533; Böckenförde, HStR, Bd. II, 2004, \ 24, Rn. 12 f..

208 Vogel, in: Isensee/Kirchhof, HStR, Bd. IV, 1990, \ 87 Rn. 1; so auch Brunner, Kontrolle in Deutschland, 1972, S. 185.

${ }^{209} \mathrm{Vgl}$. Hufeld, in: Isensee/Kirchhof, HStR, Bd. III, 2005, \ 56 Rn. 5; Brunner, Kontrolle in Deutschland, 1972, S. 185; Vogel/Waldhoff, in: Bonner Kommentar, Vorbem. z. Art. 104a-115, Rn. 309 ff. (Stand: 81. Lfg. November 1997).

${ }^{210}$ F. Schäfer, Zur Stellung des Präsidenten des Bundesrechnungshofes, in: FS Schäfer, 1975, S. 147. 
Finanzkontrolle, man denke nur an die notwendige Kontrolle im öffentlichen Sozial- und Gesundheitswesen.

Dieser Machtfaktor Geld (beziehungsweise der Umgang der Staatsgewalt mit den öffentlichen Finanzmitteln), der in so engem Zusammenhang mit der Ausübung der zur Verhinderung von Machtmissbrauch im modernen Rechtstaat geteilten Staatsgewalt steht, bedarf ebenso wie jene selbst der Beschränkung und Kontrolle ${ }^{211}$.

Das Machtgefüge im Staate ist erheblich von der Verteilung der Finanzmittel abhängig, was eine gegenseitige Kontrolle der Staatsgewalten hinsichtlich Verwendung und Umgang mit öffentlichen Finanzen notwendig macht. Kontrolle setzt jedoch fundierte Kenntnisse voraus, etwa bei der Entlastung der Bundesregierung durch das Parlament (vgl. Art. 114 Abs. 1 GG), dabei ist der Kontrollierende auf die Berichte des Bundesrechnungshofes als unabhängiger, sachverständiger Kontrollinstanz angewiesen.

In der Systematik des Grundgesetzes kommt der „Finanzverfassung“212 eine Sonderrolle zu, ${ }^{213}$ die ihre Bedeutung unterstreicht: Das Grundgesetz regelt sie als erste deutsche Verfassung ${ }^{214}$ in einem eigenen Abschnitt („X. Finanzwesen“). Ebendort findet sich auch die externe Finanzkontrolle durch den Bundesrechnungshof und nicht in einem der Abschnitte über die drei Staatsgewalten (Abschnitte VII (Bundesgesetzgebung), VIII (Ausführung von Bundesgesetzen), IX (Rechtsprechung)). Dieser X. Abschnitt des Grundgesetzes enthält gewaltenübergreifend $^{215}$ Regelungen aus allen drei Funktionsbereichen (vgl. nur Art. 104a GG Verwaltungszuständigkeiten; Art. 105 GG Gesetzgebungskompetenzen; Art. 108 GG Finanzverwaltung und Finanzgerichtsbarkeit). Der Bundesrechnungshof muss vor diesem Hintergrund betrachtet werden, der seinen besonderen Status im Gewaltengefüge des Grundgesetzes verdeutlicht, zugleich aber eine Einordnung nach verfassungssystematischen Kriterien erschwert.

Im Ergebnis ist die Abhängigkeit der Staatsgewalt von öffentlichen Finanzmitteln offensichtlich. Die Bedeutung des Bundesrechnungshofes ergibt sich daraus, dass er diesen Machtfaktor kontrolliert und die diesbezügliche gegenseitige Kontrolle der Gewalten untereinander überhaupt erst ermöglicht. Vor diesem Hinter-

${ }^{211}$ Vogel, in: Isensee/Kirchhof, HStR, Bd. IV, 1990, \87 Rn. 2.

${ }^{212}$ Zum Begriff siehe weitere Nachweise bei Vogel, in: Isensee/Kirchhof, HStR, Bd. IV, 1990, \ 87 Rn. 4.

213 Vogel/Waldhoff, in: Bonner Kommentar, Vorbem. z. Art. 104a-115, Rn. 12 ff. (Stand: 81. Lfg. 1997); Degenhart, Kontrolle der Verwaltung durch Rechnungshöfe, VVDStRL 55 (1996), 190 (201 f., 205) m.w.N.: „In der Finanzverfassung des Grundgesetzes werden die staatlichen Finanzfunktionen...zusammengefasst und gebündelt zu einer die Gewaltengliederung übergreifenden Finanzgewalt. Sie werden von der allgemeinen Systematik der Gewaltengliederung abgeschichtet.“ siehe auch: F. Kirchbof, Grundsätze der Finanzverfassung des vereinten Deutschland, VVDStRL 52 (1993), 71 (78 f., 85 f.); Grupp, Die Stellung der Rechnungshöfe in der BRD, 1972, S. 139.

${ }^{214}$ Vogel, in: Isensee/Kirchhof, HStR, Bd. IV, 1990, \$ 87 Rn. 5.

215 Degenhart, Kontrolle der Verwaltung durch Rechnungshöfe, VVDStRL 55 (1996), 190 (201 f., 205) m.w.N. 
grund ist, in Hinblick auf die Systematik der rechtsstaatlichen Kontrollmechanismen zur Begrenzung der Staatsgewalt, eine Einordnung des Bundesrechnungshofes in das Gewaltenteilungssystem und damit in das Gefüge gegenseitiger Abhängigkeiten und Kompetenzen keineswegs von rein theoretischem Interesse oder gar unbedeutend.

\section{Gewaltenteilung im deutschen Verfassungsrecht}

An dieser Stelle sollen für die dann folgende Einordnung des Bundesrechnungshofes in das Gewaltenteilungsschema zunächst die Grundlagen der Gewaltenteilung im Grundgesetz, ihr Sinn und Zweck und ihre konkrete Ausgestaltung dargestellt werden. Für die Einordnung eines Staatsorgans wie hier des Bundesrechnungshofes ist das Prinzip der horizontalen (organisatorischen) Gewaltenteilung maßgeblich.

Zwar trägt die Finanzkontrolle in Deutschland durch das Bestehen von Landesrechnungshöfen auch der vertikalen Gewaltenteilung Rechnung, diese ist aber für die organisatorische Einordnung des Bundesrechnungshofes unerheblich. Auch ist die vertikale Gewaltenteilung nicht als unverzichtbarer Bestandteil des Rechtsstaatsprinzips zu verstehen, ${ }^{216}$ wie der Blick auf zentralistisch angelegte Staaten zeigt. 217 Dabei kann die Ausgestaltung der Organisation der Rechnungskontrollorgane als duales Modell wie in Deutschland, bei dem Bund und Länder jeweils über eigene Rechnungshöfe verfügen, oder als einheitliches Modell, bei dem ein Rechnungshof für alle staatlichen Körperschaften zuständig ist, sowie als Kombinationen aus beiden erfolgen. ${ }^{218}$

\section{a) Die Grundlagen der Gewaltenteilung im Grundgesetz.}

Im Grundgesetz ist die Gewaltenteilung in Art. 20 Abs. 2 S. 2 sowie in Art. 1 Abs. 3 angelegt, beide unterstrichen durch die Ewigkeitsklausel des Art. 79 Abs. 3. In Art. 20 Abs. 1 und Abs. 2 S. 1 GG findet sich die verfassungsrechtliche Festlegung auf die Staatsform Demokratie, das Volk als Souverän ist alleiniger Träger der (unteilbaren) Staatsgewalt. ${ }^{219}$ Der in Art. 20 Abs. 2 Satz 2 GG positivierte Grundsatz der Gewaltenteilung trifft auf das demokratische Prinzip mit dem Volk als alleinigem und einheitlichem Träger der Staatsgewalt. Die Gewaltenteilung muss vor diesem Hintergrund als Verteilung von Zuständigkeiten verstanden

216 Hofmann, Die Bindung staatlicher Macht, in: H/M/M/W, Rechtsstaatlichkeit in Europa, 1996, S. 11.

217 Die Landesregelungen entsprechen im Wesentlichen denen auf Bundesebene und werden hier nicht näher behandelt.

218 Ausführlich hierzu am Beispiel Deutschlands und Österreichs: Isensee, Finanzkontrolle im Bundesstaat, ZÖR 63 (2008), S. 29.

${ }^{219}$ Herzog, in: Maunz/Dürig, GG, Art. 20, II. Abschnitt, V., Rn. 25 (Stand: 18. Lfg. September 1980); BVerfGE 83, 60 (71); Wrege, Das System der Gewaltenteilung im Grundgesetz, Jura 1996, 436 m.w.N. 
werden, die Staatsgewalt als solche wird nicht geteilt, sondern von verschiedenen Organen, die die Funktionen der Gesetzgebung, der Vollziehung und der Rechtsprechung wahrnehmen, ausgeübt. ${ }^{220}$ Begrifflich wird anstelle von Gewaltenteilung auch von „Gewaltentrennung“ oder „Funktionentrennung“ gesprochen, da die verschiedenen Begriffe aber zumindest im Kern inhaltlich übereinstimmen ${ }^{221}$ und da auch das Grundgesetz selbst, etwa in Art. 20 Abs. 2 und Art. 92 GG, von „Gewalten“ spricht, soll hier an der herkömmlichen Terminologie festgehalten werden. Zur Verdeutlichung könnte man auch von Gewaltverteilung sprechen, die gerade keine Gewaltzerteilung ist.

Art. 20 Abs. 2 S. 2 GG selbst legt nur fest, dass es verschiedene Funktionsträger („besondere Organe“) geben muss, die Staatsgewalt ausüben; eine Aussage über die Aufgaben und Befugnisse dieser Organe sowie ihr Verhältnis zueinander, also der Gewaltentrennung und Balance, enthält er nicht, ihm kommt somit selbst keine Zuweisungsfunktion zu. ${ }^{222}$ Die Aufgaben der verschiedenen Staatsfunktionen und damit auch ihr Verhältnis zueinander sind vielmehr an anderen Stellen des Grundgesetzes ausführlich geregelt.

\section{b) Zweck der Gewaltenteilung}

Die Ausübung der Staatsgewalt wird in verschiedene Zuständigkeitsbereiche aufgeteilt, deren Funktionen von unterschiedlichen Organen wahrgenommen werden. Durch gegenseitige Kontrollbefugnisse soll eine Beschränkung und Mäßigung der Staatsgewalt erreicht werden. Dieses System der checks and balances soll durch gegenseitige Hemmung und Kontrolle ${ }^{223}$ zur Erreichung eines Machtgleichgewichts führen. Vor diesem Hintergrund der Begrenzung staatlicher Macht ist das Prinzip der Gewaltenteilung vor allem als grundlegender Bestandteil des formellen ${ }^{224}$ Rechtsstaatsprinzips zu verstehen, ${ }^{225}$ dient es doch durch die Machtbegrenzung der Sicherung der Freiheit des Einzelnen. Hervorzuheben ist, dass der überzeitliche Sinn der Gewaltenteilung nicht nur defensiv die Verhinderung von Machtmissbrauch ist, sondern dass sie auch konstruktiv der Rationalisierung, der

220 BVerfGE 68,1 (87 ff.); Böckenförde, in: Isensee/Kirchhof, HStR, Bd. II, 2004, 『 24, Rn. 87; Schnapp, in: v.Münch/Kunig, GG, Art. 20, Rn. 41; Stern, Staatsrecht, Bd. II, 1980, S. 533.

221 Wank, Gewaltenteilung - Theorie und Praxis in der BRD, Jura 1991, 622 (623) m.w.N.; auch das Bundesverfassungsgericht spricht ebenso von Gewalten wie auch von Funktionen, vgl. statt vieler: BVerfGE 9, 268 (279).

222 Schnapp, in: v.Münch/Kunig, GG, Art. 20, Rn. 41.

223 BVerfGE 3, 225 (247); 7, 183 (188); 9, 268 (279); 22, 106 (111); 30, 1 (27 f.); 34, 52 (59); dieser Gedanke findet sich schon bei Montesquieu: „Que le pouvoir arrête le pouvoir“".

224 Schmidt-Aßmann, in: Isensee/Kirchhof, HStR, Bd. II, 2004, \26, Rn. 18; Sommermann, in: v.Mangoldt/Klein/Starck, GG, Art. 20, Rn. 197; BVerfGE 83, 60 (71); 68, 1 (87).

225 Badura, Staatsrecht, 2003, S. 312, Rn. 46; Sachs, in: Sachs, GG, Art. 20, Rn. 77; Sommermann, in: v.Mangoldt/Klein/Starck, GG, Art. 20, Rn. 197; Hofmann, in: H/M/M/W, Rechtstaatlichkeit in Europa, S. 11. 
Förderung richtiger Entscheidungen und damit auch der Optimierung staatlichen Handelns dient (Rationalisierungs- ${ }^{226}$ oder Optimierungsfunktion ${ }^{227}$ ). ${ }^{228}$

Erst aus dieser Perspektive lässt sich die Rolle der Rechnungshöfe in richtigem Licht sehen; sie dienen genau den mit der Gewaltenteilung verfolgten Zielen: der Förderung richtiger Entscheidungen, besonders durch die Wirtschaftlichkeitsbewertung staatlicher Maßnahmen, ebenso wie der Stärkung rechtsstaatlicher Kontrollmechanismen. Sie sollen so der Optimierung des die Legislative, Exekutive und Judikative betreffenden, im Grundgesetz vielfach gewaltenüberschneidend ${ }^{229}$ geregelten Finanzwesens dienen.

\section{c) Die Verwirklichung der horizontalen (organisatorischen) Gewaltenteilung im Grundgesetz.}

Ausgangspunkt der Gewaltenteilung ist Art. 20 Abs. 2 S. 2 GG, wonach alle Staatsgewalt ,vom Volke in Wahlen und Abstimmungen und durch besondere Organe der Gesetzgebung, der vollziehenden Gewalt und der Rechtsprechung ausgeübt" wird. Wie gesehen kommt der Norm dabei keine eigenständige Zuweisungsfunktion zu, vielmehr legt sie als eine Art Programmsatz fest, dass die Staatsgewalt auf verschiedene Organe aufgeteilt sein muss. Die Aufgaben im Einzelnen und das Verhältnis der Gewalten zueinander sind an anderen Stellen im Grundgesetz geregelt.

Die Gewaltenteilung im Grundgesetz ist stark geprägt von Gewaltenüberschneidungen und -verschränkungen. Das Hauptorgan der Exekutive bildet die Bundesregierung mit den ihr nachgeordneten Ministerien und Verwaltungen (vgl. Art. 62 GG). ${ }^{230}$ Aus der Wahl des Bundeskanzlers auf Vorschlag des Bundespräsidenten durch den Bundestag (Art. 63 Abs. 1 GG) wird die Funktionenverschränkung zwischen Legislative und Exekutive deutlich. Sie zeigt sich weiter im Recht des Bundestages, dem Bundeskanzler und damit der gesamten Bundesregierung gem. Art. 67 GG das Misstrauen auszusprechen und einen Nachfolger zu wählen. Insofern kommt dem Bundestag eine Kontrollbefugnis hinsichtlich der Regierung zu. ${ }^{231}$ Auf der anderen Seite wirkt die Bundesregierung durch ihr Initiativrecht gem. Art. 76 GG am Gesetzgebungsverfahren mit. Sie hat auch das Recht, Rechtsverordnungen, also materielle Gesetze, die nicht dem formellen

226 BVerfGE 68, 1 (86), v.Arnim, Staatslehre, 1984, S. 500 m.w.N.; ders., Finanzkontrolle im Wandel, S. 41 unten; ausführlich zur Rationalisierungsfunktion der Rechnungshofkontrolle: Krebs, Kontrolle in staatlichen Entscheidungsprozessen, 1984, S. 175 ff.; Schmidt-Aßmann, in: Isensee/Kirchhof, HStR, Bd. II, 2004, \$ 26, Rn. 50, m.w.N.

227 Degenhart, Kontrolle der Verwaltung durch Rechnungshöfe, VVDStRL 55 (1996), 190 (198).

228 BVerfGE 68, 1 (86) , v.Arnim, Staatslehre, 1984, S. 500 m.w.N.; ders., Finanzkontrolle im Wandel, S. 41 unten; Schmidt-Aßmann, in: Isensee/Kirchhof, HStR, Bd. II, 2004, \$26, Rn. 50, m.w.N.

${ }^{229}$ Oben: VI. 1. Staatsgewalt und öffentliche Finanzen.

230 Zur Funktionenteilung zwischen der für die politische Gestaltung zuständigen, der parlamentarischen Kontrolle unterliegenden Regierung und der zum Gesetzesvollzug verpflichteten Verwaltung: BVerfGE 83, 60 (72).

231 BVerfGE 49, 89 (125). 
Gesetzesbegriff des Grundgesetzes unterfallen und damit nicht der Gesetzgebung $^{232}$, innerhalb der engen Bestimmtheitserfordernisse des Art. 80 Abs. 1 S. 2 GG zu erlassen. Ferner ist der Bundesrat, der aus Vertretern der Regierungen der Länder besteht, maßgeblich an der Gesetzgebung beteiligt.

Bei der Festsetzung und Auszahlung staatlicher Mittel an die politischen Par-

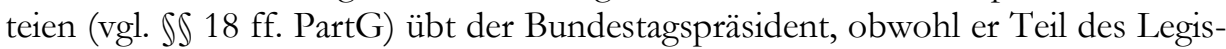
lativorgans Bundestag ist, Verwaltungstätigkeit als mittelverwaltende Stelle und damit als Verwaltungsbehörde aus. ${ }^{233}$

Was die Gewaltenverschränkung angeht, nimmt die Rechtsprechung eine besondere Rolle ein. Sie ist klar von den anderen Teilgewalten getrennt, Art. 97 Abs.1 GG verbietet sogar jeden Eingriff von Legislative und Exekutive in die Rechtsprechung, die gem. Art. 92 GG durch das Bundesverfassungsgericht und die Bundes- und Landesgerichte ausgeübt wird, in konkreten Fällen. ${ }^{234}$ Insofern wird der Rechtsprechung ein weiter, unantastbarer Kernbereich zugestanden, so dass eine ziemlich konsequente Trennung gegenüber den anderen Gewalten besteht. ${ }^{235}$ Aber auch hier gibt es gewisse Überscheidungen, so stellen Maßnahmen der Justizverwaltung materiellrechtlich nicht Rechtsprechung, sondern Verwaltung und damit Exekutivtätigkeit dar. ${ }^{236}$

Eine personelle Gewaltenteilung ist im Grundgesetz mangels Inkompatibilitätsregelungen nur lückenhaft $\mathrm{zu}$ finden. Zwischen Legislative und Exekutive besteht sie gar nicht, ${ }^{237}$ so sind Regierungsmitglieder oft gleichzeitig Bundestagsabgeordnete. Regelungen finden sich in Art. 55, 66, 94 Abs. 1 S. 3, 137 GG. Hervorzuheben ist insbesondere die Unvereinbarkeit des Amtes als Bundesverfassungsrichter mit der Mitgliedschaft in Bundestag, Bundesrat, Bundesregierung oder entsprechenden Landesorganen gem. Art. 94 Abs. 1 S. 3 GG. Für Richter und über $\int 3$ Abs. 4 S. 2 BRHG auch für Mitglieder des Bundesrechnungshofes gelten die Inkompatibilitätsregelungen des $\int 36$ DRiG. Strikte personelle Unvereinbarungsregeln sind somit nur bei den Angehörigen der Judikative und eben des Bundesrechnungshofes zu finden.

Problematisch ist, dass politische Parteien und Interessenverbände vom Gewaltenteilungsschema nicht erfasst werden und wegen ihrer dominierenden Stellung und der in alle staatlichen Einrichtungen reichenden Einflüsse die Intentionen der Gewaltenteilung zu einem guten Teil unterlaufen können. ${ }^{238}$ Insofern

\footnotetext{
232 Degenhart, Staatsrecht I, 2006, Rn. 130, 126, 266.

233 BVerfGE 28, 97 (102 f.); 27, 152 (157); Detterbeck, Allgemeines Verwaltungsrecht, 2005, Rn. 9).

234 BVerfGE 7, 183 (188); 36, 174 (185); Detterbeck, in: Sachs, GG, Art. 97, Rn. 2; Stern, Staatsrecht, Bd. II, 1980, S. 892 f; siehe auch Herzog, in: Maunz/Dürig, GG, Art. 97, Rn. 22 (Stand: 18. Lfg. September 1980),

235 BVerfGE 7, 183 (188); 36, 174 (185); wenngleich die Trennung auch hier nicht absolut ist, vgl. BVerfGE 30, 1 (27 f.).

236 Stern, Staatsrecht, Bd. II, 1980, S. 901 f.; Detterbeck, Allgemeines Verwaltungsrecht, 2005, Rn. 8.

237 Stern, Staatsrecht, Bd. II, 1980, S. 538.

238 Sachs, in: Sachs, GG, Art. 20, Rn. 92; v.Arnim, Staatslehre, 1984, S. 501 ff.
} 
Der Bundesrechnungshof

stellt sich die Frage, inwieweit unabhängige Institutionen wie der Bundesrechnungshof hierzu wirksame Gegengewichte bilden sollen und können.

\section{d) Stellungnabme}

Wie die Ausgestaltung im Grundgesetz mit ihren Verschränkungen und Überschneidungen deutlich macht, ist Sinn und Zweck der Gewaltenteilung nicht die scharfe Trennung der Funktionen der Staatsgewalt, sondern gegenseitige Kontrolle und Begrenzung zu ihrer Mäßigung, zum Schutz der Freiheit des Einzelnen und zur Rationalisierung staatlichen Handelns. Entscheidend ist dabei, dass die Balance aufrechterhalten wird und keine Gewalt die Überhand gewinnt. ${ }^{239}$ So handelt es sich zwar um ein System, das geprägt ist von Überscheidungen und Verschränkungen, jede der drei Gewalten enthält aber gegen Dispositionen durch die anderen geschützte Kernbereiche, die die wesensbestimmenden Merkmale des Funktionsbereichs umfassen. ${ }^{240}$ Hinsichtlich des positiv bestimmbaren Inhalts der einzelnen Gewalten besteht teilweise Unklarheit; hierauf wird im Rahmen derEinordnung des Bundesrechnungshofes unter VI. 3. noch im Einzelnen einzugehen sein.

Im Ergebnis ist zwar mit dem Wortlaut des Grundgesetzes von einer grundsätzlichen Dreiteilung auszugehen, jedoch stellt sich die Frage, ob alle Staatsorgane ausnahmslos einer der drei Gewalten zugeordnet werden müssen oder ob das Grundgesetz selbst Ausnahmen zulassen kann und auch zulässt. ${ }^{241}$ Diese Frage soll für den Bundesrechnungshof im Folgenden beantwortet werden.

\section{Einordnung des Bundesrechnungshofes}

Die Frage nach der Einordnung des Bundesrechnungshofes stellt sich nicht nur aus allgemeinem verfassungsrechtlichem Interesse. Einerseits macht die Bedeutung öffentlicher Finanzen für die Ausübung von Staatsgewalt und die damit verbundene Notwendigkeit, Missbrauch auf diesem Gebiet durch eine effektive unabhängige Finanzkontrolle zu verhindern, ihre Beantwortung erforderlich. Ande-

239 Ausführlich hierzu: BVerfGE 3, 225 (247); 7, 183 (188); 9, 268 (279).

240 BVerfGE 9, 268 (280), 30, 1 (27 f.), 34, 52 (59) Herrog, in: Maunz/Dürig, GG, Art. 20, II. Abschnitt, V., Rn. 115 (Stand: 18. Lfg. September 1980); Stern, Staatsrecht, Bd. II, 1980, S. 541 f. m.w.N.; Schmidt-Aßmann, in: Isensee/Kirchhof, HStR, Bd. II, 2004, \26, Rn. 56 m.w.N.

241 Dies deutete das Bundesverfassungsgericht bereits in BVerfGE 3, 225 (247 f.) Rz. 54 an: Betont wird in dieser Entscheidung der Sinn der Gewaltenteilung in der Mäßigung der Staatsgewalt. Angesichts dessen, dass das Prinzip nirgends rein verwirklicht sei und Überschneidungen und Einflussnahmen der Gewalten untereinander gebräuchlich, sei es zumindest zweifelhaft, „ob Durchbrechungen des Prinzips durch den originären Verfassungsgeber hiernach überhaupt geeignet sein können, jene letzten Grenzen zu überschreiten, deren Nichtbeachtung zur Rechtungültigkeit auch einer ursprünglichen Verfassungsnorm führen könnte“; siehe auch: BVerfGE 30, 1 (27 f.): „Das Gewaltenteilungsprinzip verlangt keine strikte Trennung der Gewalten, vielmehr sind Verschränkungen und Durchbrechungen typisch. Die Grenze dafür bildet der jeder einzelnen Gewalt vorbehaltene Kernbereich“. 
rerseits kommt dieser Frage auch erhebliche praktische Bedeutung zu, besonders angesichts von Regelungen der Europäischen Union, die die Transparenz für den Bürger verbessern sollen und ihm Zugang zu Informationen bestimmter staatlicher Stellen gewähren. Wollte man etwa eine Zuordnung des Bundesrechnungshofes zur Exekutive annehmen, so hätte dies wohl zur Folge, dass Bürger zum Beispiel im Rahmen des Umweltinformationsgesetzes und des Informationsfreiheitsgesetzes auch gegenüber dem Bundesrechnungshof Zugang zu Informationen verlangen könnten. ${ }^{242}$

Die Einordnung des Bundesrechnungshofes in das Gewaltenteilungsschema wird seit jeher als problematisch betrachtet. Die Verortung bereitet aus unterschiedlichsten Gründen Schwierigkeiten.

Zunächst regelt das Grundgesetz Rechtsstatus und Aufgaben des Rechnungshofes im gesonderten gewaltenübergreifenden X. Abschnitt „Finanzwesen“.243

Weiter ist aus dem Grundgesetz nicht klar erkennbar, welchem Funktionsbereich die Finanzkontrolle zugeordnet ist, zumal sie in unterschiedlichen Ausprägungen auch von Legislative und Exekutive ausgeübt wird und Ähnlichkeiten auch zur Kontrollfunktion der Gerichte bestehen. ${ }^{244}$ Die Haupttätigkeitsfelder, Kontrolle und Beratung, lassen sich nicht ohne weiteres als für diese typisch einer Staatsgewalt zuordnen. ${ }^{245}$ Bei Organisation und Tätigkeit des Rechnungshofes sind Elemente aller drei Staatsfunktionen zu finden.

Die außerordentliche Rolle des Bundesrechnungshofes wird durch die verfassungsrechtliche Garantie seines Bestehens und durch die seinen Mitgliedern verliehene richterliche Unabhängigkeit noch deutlicher.

Ein weiteres Problem ist die grundsätzlich bestehende Ungewissheit über den Inhalt der Staatsfunktionen, wie schon der Versuch der Bestimmung dessen, was Exekutive ist, mit Hilfe der Subtraktionsmethode zeigt, also durch eine negative Definition, ohne inhaltlich positiv festlegen zu können, was exekutivisches Handeln ist.

Es stellt sich auch die Frage, wie die rechnungshofspezifische Aufgabe der Prüfung der Wirtschaftlichkeit und Wirksamkeit des Einsatzes von Finanzmitteln zu bewerten ist.

Des Weiteren ist die Funktion der externen Rechnungsprüfung durch die Institution eines Rechnungshofes nicht an eine bestimmte Staatsform geknüpft. Wie

${ }^{242}$ Hauser, Stellung des Bundesrechnungshofs im System der Gewaltenteilung und in der öffentlichen Verwaltung, DVBl. 2006, 539.

243 Degenhart, Kontrolle der Verwaltung durch Rechnungshöfe, VVDStRL 55 (1996), 190 (201 f., 205) m.w.N. : „In der Finanzverfassung des Grundgesetzes werden die staatlichen Finanzfunktionen...zusammengefasst und gebündelt zu einer die Gewaltengliederung übergreifenden Finanzgewalt. Sie werden von der allgemeinen Systematik der Gewaltengliederung abgeschichtet.“; Grupp, Die Stellung der Rechnungshöfe in der BRD, 1972, S. 139; Zur Sonderrolle der Finanzverfassung siehe oben VI. 1. Staatsgewalt und öffentliche Finanzen, Fn. 213, 215.

244 Oben: IV. 2..

245 Oben: IV. 2., Fn. 142. 
Der Bundesrechnungshof

sich aus der deutschen Geschichte zeigt, gab es (mehr oder weniger unabhängige) Rechnungshöfe zur Zeit der Monarchie in ihren unterschiedlichen Ausgestaltungen ebenso wie in der Weimarer Republik und auch dem totalitären nationalsozialistischen Staat. Das erschwert die Einordnung, zumal die Institution des Rechnungshofes über 250 Jahre alt ist und somit viel älter als die meisten anderen Staatsorgane selbst mit ihren Vorgängern. Zudem war seine Stellung im Verfassungssystem, insbesondere das Verhältnis zu den anderen Einrichtungen des Staates, bis heute großen Veränderungen unterworfen. So ist die Entwicklung seit Inkrafttreten des Grundgesetzes von einer sukzessiven Stärkung seiner Unabhängigkeit von der Exekutive bei einer gleichzeitigen „Annäherung“ an das Parlament sowie der Erweiterung seiner Aufgaben geprägt. Dies hat immer wieder die Debatte über die staatsrechtliche Verortung angeregt.

Vom materiellen Funktionsgehalt lässt sich die Finanzkontrolle nicht als typischerweise einer Staatsgewalt zugehörig einordnen. ${ }^{246}$ So wird Finanzkontrolle, allerdings keine externe, auch von Legislative und Exekutive ausgeübt. Im Bundestag sind hier vor allem die Kontrollbefugnisse des Haushaltsausschusses gem. S 94 GOBT einschließlich seines ständigen Unterausschusses, des Rechnungsprüfungsausschusses, zu nennen, im Bundesrat die des Finanzausschusses. In Einzelfällen kann, sachlich begrenzt auf den konkreten Fall, Finanzkontrolle auch durch einen vom Bundestag nach Art. 44 GG eingesetzten Parlamentarischen Untersuchungsausschuss stattfinden. Diese Formen der Finanzkontrolle lassen sich unproblematisch der Legislative zuordnen. ${ }^{247}$

Von der Exekutive wird im Wege der internen Revision Selbstkontrolle im finanziellen Bereich ausgeübt. 248

Auch ein Blick auf ausländische Rechtsordnungen zeigt, dass externe oberste Rechnungsprüfungsstellen, auch wenn Aufgaben und Privilegien vergleichbar ausgestaltet sind wie beim Bundesrechnungshof, jeder der drei Gewalten zugeordnet werden können oder eine Sonderstellung außerhalb von diesen einnehmen können. ${ }^{249}$

Die Finanzkontrolle in ihren vielfältigen Ausprägungen stellt ein komplexes, gewaltenübergreifendes System von Prüfungszuständigkeiten und -verfahren

\footnotetext{
246 Oben: IV. 2.

247 Vgl. S. Tiemann, Die staatsrechtliche Stellung der Finanzkontrolle, 1974, S. 297; Stern, Staatsrecht, Bd. II, 1980, S. $420 \mathrm{f}$.

248 Oben: IV. 2.; Bundesrechnungshof, Der Bundesrechnungshof und die Prüfungsämter des Bundes, 2005, S. 6; S. Tiemann, Die staatsrechtliche Stellung der Finanzkontrolle, 1974, S. 297; siehe auch Stern, Der verfassungsrechtliche Status der Rechnungshöfe, in: Böning/v.Mutius, Finanzkontrolle im repräsentativ-demokratischen System, 1990, S. 11 (14 f.).

${ }^{249}$ Vgl. die Darstellung im 2., 3. und 4. Teil dieser Arbeit; eine Übersicht nach einer Umfrage, auf die die Rechnungshöfe von 68 Staten antworteten, bieten Beran/Konvicka, Finanzkontrolle international gesehen, 1967, unter Frage 17, S. 72-75; vgl. auch B. Tiemann / S. Tiemann, Zum staatsrechtlichen Standort der Finanzkontrolle in rechtsvergleichender Sicht, Der Staat, Bd. 13 (1974), 497.
} 
dar. 250 Vom materiellen Funktionsgehalt der Aufgabe der Finanzkontrolle kann, dadurch dass diese selbst sich nicht klassischerweise einer bestimmten Gewalt zuordnen lässt, folglich nicht ohne weiteres auf die Einordnung der externen Finanzkontrolle in das Gewaltenteilungsschema geschlossen werden. Vielmehr ist für einen Einordnungsversuch die Untersuchung und der Vergleich mit den einzelnen Gewalten nötig.

In engem Zusammenhang mit der Problematik der Einordnung des Bundesrechnungshofes steht die Frage: „cui bono?“, die in den folgenden Erörterungen geklärt werden soll.

Selbst wenn man richtigerweise von einer grundsätzlichen Dreiteilung der Staatsgewalt im Grundgesetz ausgeht, könnte eine partielle Ausnahme von diesem Prinzip durch die Einordnung des Bundesrechnungshofes als vierte Gewalt oder Institution sui generis durch das Grundgesetz selbst gewollt sein. ${ }^{251}$ Dafür könnte auch sprechen, dass die Zuordnung der externen Finanzkontrolle durch den Bundesrechnungshof zu einer der drei Gewalten dazu verleiten könnte, ,ihre Unterordnung unter ein Verfassungsorgan der jeweiligen Gewalt zu fordern, zu fördern und zu erleichtern" 252 .

Entgegen den Versuchen, die Einteilung der Staatsfunktionen neu zu bestimmen, ${ }^{253}$ hält das Bundesverfassungsgericht am Gewaltenteilungsprinzip in Form seiner grundsätzlichen Dreiteilung als einem der „tragenden Organisationsprinzipien" der Verfassung fest.254 Allerdings räumt es ein, dass dieses Prinzip vom Verfassungsgeber nirgends „rein verwirklicht" wurde und dass das Grundgesetz weitgehende Verschränkungen und Überschneidungen der Funktionen mit gegenseitigen Einflussnahmen der Gewalten enthält.255 Diese Verschränkung erschwert einerseits eine klare Trennung, was unter Legislative, Exekutive und Judikative zu verstehen ist, und damit auch eine Einordnung des Bundesrechnungshofes, andererseits legt sie nahe, dass eine Durchbrechung oder Ausnahme vom Grundsatz der Dreiteilung durch die Verfassung selbst nicht unbedingt unzulässig ist. ${ }^{256}$

Der Schluss auf eine gewollte Ausnahme kann aber nur dann gezogen werden, wenn eine Einordnung unter eine der bestehenden drei Gewalten nicht möglich

250 Stern, Staatsrecht, Bd. II, 1980, S. 420 f.; Degenhart, Kontrolle der Verwaltung durch Rechnungshöfe, VVDStRL 55 (1996), 190 (201 f., 205).

251 Dieselbe grundsätzliche Erwägung trifft auch Grupp, Die Stellung der Rechnungshöfe in der BRD, 1972, S. 140, lehnt sie aber im Ergebnis zumindest für die Einordnung des Bundesrechnungshof ab.

${ }^{252}$ H. Schäfer, Wer kontrolliert unsere Steuergelder? Finanzprüfung durch den Bundesrechnungshof, S. 30.

${ }^{253}$ Nachweise bei Stern, Staatsrecht, Bd. II, 1980, S. 543 ff.

254 BVerfGE 3, 225 (247).

255 BVerfGE 3, 225 (247); 7, 183 (188); 12, 268 (279).

256 BVerfGE 3, 225 (247): „Ob Durchbrechungen des Prinzips (der Dreiteilung) durch den originären Verfassungsgeber hiernach überhaupt geeignet sein können, jene letzten Grenzen zu überschreiten, deren Nichtbeachtung zur Rechtsungültigkeit auch einer ursprünglichen Verfassungsnorm führen könnte, ist zumindest zweifelhaft.“ 
ist. Zuerst ist also die Möglichkeit der Zuordnung des Bundesrechnungshofes zu Legislative, Judikative oder Exekutive zu untersuchen.

\section{a) Zuordnung zur Legislative}

Vor allem in der älteren Literatur wurde zum Teil eine Zuordnung des Bundesrechnungshofes zur Legislative angenommen, ${ }^{257}$ die von Bundestag und Bundesrat ausgeübt wird. Schon die Novellierung des Art. 114 Abs. 2 GG aus dem Jahr 1969 spricht scheinbar für diese Sichtweise, sollte der Bundesrechnungshof hierdurch doch weiter an das Parlament ,angenähert“" werden ${ }^{258}$. Das wirft die Frage auf, was unter Annäherung zu verstehen ist, insbesondere ob diese an der staatsrechtlichen Einordnung des Bundesrechnungshofes in das Gewaltenteilungsgefüge in Form einer denkbaren Zuordnung zur Legislative etwas ändert oder auch nur klarstellt. Ein „Heranrücken“ beziehungsweise eine „Annäherung“ kann für sich genommen jedoch noch kein Grund sein, den Bundesrechnungshof der Legislative zuzurechnen. Vielmehr ist das Verhältnis zur Gesetzgebung insgesamt zu betrachten. Dabei erscheinen zwei Möglichkeiten einer Zuordnung zur Legislative denkbar: Der Bundesrechnungshof könnte der Legislative als bloßes „Hilfsorgan“ oder als „funktioneller Bestandteil“" derselben zuzuordnen sein.

aa) Der Bundesrechnungshof als Hilfsorgan der Legislative

Zuweilen wird der Bundesrechnungshof als „Hilfsorgan der Legislative“ bezeichnet. ${ }^{259}$ In seiner ursprünglichen Funktion war er dies jedenfalls nicht, denn die Institution der Finanzkontrolle durch Rechnungshöfe ist älter als das Budget- und Entlastungsrecht der Parlamente, ja sogar als diese selbst, zumindest nach unserem heutigen Verständnis. Wie die geschichtliche Darstellung zeigt, kam es jedoch in Deutschland zu einer zunehmenden Annäherung der Rechnungshöfe an das

${ }^{257}$ Menzel, Der staatsrechtliche Standort der Finanzkontrolle in der Bundesrepublik und im Ausland, DÖV 1968, 593 (598 f.) m.w.N.; zahlreiche Nachweise bei: Stern, Staatsrecht, Bd. II, 1980, S. 444 (Fn. 193).

${ }^{258}$ Siehe oben Fn. 57, mit Hinweis auf die entsprechenden Gesetzesmaterialien.

259 Brockmeyer, in: Schmidt-Bleibtreu/Klein, GG, Art. 114 Rn. 9; Sigg, Die Stellung der Rechnungshöfe, 1983, S. 26; mit Einschränkungen auch: Hufeld, in: Isensee/Kirchhof, HStR, Bd. III, 2005, S 56, Rn. 1 ff., der dies jedoch als rein funktionsbeschreibenden Terminus verstanden haben will; dagegen: Siekmann, in: Sachs, GG, Art. 114, Rn. 24; Stern, Bundesrechnungshof und Finanzkontrolle aus verfassungsrechtlicher Sicht, DÖV 1990, 261 (264); ders. Staatsrecht, Bd. II, 1980, S. 447; Kisker, in: Isensee/Kirchhof, HStR, Bd. IV, 1990, \89, Rn. 127; Groß, Exekutive Befugnisse der Rechnungshöfe, Verwaltungsarchiv 2004, 194 (202) m.w.N.; Maunz, in: Maunz/Dürig, GG, Art. 114, Rn. 23 (Stand: Lfg. 23 Oktober 1984); S. Tiemann, Die staatsrechtliche Stellung der Finanzkontrolle des Bundes, 1974, S. 319 ff. m.w.N.; Wittrock, Möglichkeiten und Grenzen der Finanzkontrolle. Das Verhältnis des Bundesrechnungshofes zum Bundestag, ZParl. 1982, 209 (216); ders., Auf dem Weg zu einem neuen Bundesrechnungshof-Gesetz, DÖV 1984, S. 649 (650); Brunner, Möglichkeiten und Grenzen der öffentlichen Finanzkontrolle, in: FS Schäfer, 1975, S. 169 (184); Schwarz, in: v.Mangoldt/Klein/Starck, GG, Art. 114, Rn. 76 m.w.N.; Krebs, Kontrolle in staatlichen Entscheidungsprozessen, 1984, S. 180. 
Parlament. Im Folgenden soll erörtert werden, ob diese letztlich in einer Stellung des Bundesrechnungshofes als Hilfsorgan gemündet hat.

Die beiden für den Bundesrechnungshof maßgeblichen Gesetzesänderungen durch die Haushaltsrechtsreform von 1969 und das neue Bundesrechnungshofgesetz von 1985 haben die Rolle des Parlaments gegenüber der Exekutive gestärkt, insbesondere sei hier die direkte Berichterstattung des Bundesrechnungshofes an den Bundestag ohne Umweg über den Finanzminister genannt. Dazu kommt das „letzte Wort“ bei der Besetzung des Amtes des Bundesrechnungshofspräsidenten sowie die Normierung des Beratungsauftrages und die damit einhergehende Erweiterung um die selbständige Beratung, die letztlich, wie die zahlreichen oben genannten Beispielen zeigen, besonders dem Bundestag nützlich ist. ${ }^{260}$

In den Gesetzesmaterialien zur Änderung des Art. 114 GG im Rahmen der Haushaltsrechtsreform von 1969 wird der Bundesrechnungshof an einer Stelle als „Hilfsorgan sowohl der Exekutive als auch der Legislative“ bezeichnet. ${ }^{261}$ In der späteren Debatte zum neuen Bundesrechnungshofgesetz von 1985 taucht dagegen dieser Terminus nicht mehr auf, ${ }^{262}$ ebensowenig wie im Gesetzesentwurf selbst, in dem es lediglich heißt, dass der Bundesrechnungshof „,mit seiner externen Finanzkontrolle sowohl der Exekutive wie der Legislative dient". 263

Im Rahmen der dem Bundesrechnungshofgesetz von 1985 vorangegangenen Diskussion war die weitere Annäherung des Bundesrechnungshofes an das Parlament ein wichtiger Gesichtspunkt, wobei man sich schließlich darauf verständigte, das neue Gesetz solle sicherstellen, dass der Bundesrechnungshof mit Vorrang den Bundestag bei der Wahrnehmung seiner Aufgaben unterstützt. ${ }^{264}$ Dieser Tendenz liegt die Überlegung zugrunde, dass der Bundestag im Verhältnis zur Bundesregierung mit den ihr zuarbeitenden Ministerialapparaten und im Verhältnis zum von den entsprechenden Länderführungen getragenen Bundesrat ein ganz erhebliches und nicht zu schließendes Informationsdefizit hat. ${ }^{265}$ Fraglich ist, ob dadurch die Eigenschaft des Bundesrechnungshofes als Hilfsorgan begründet werden kann. Gegen die Reduzierung auf den Status als Hilfsorgan verwehrt sich der Rechnungshof selbst, ${ }^{266}$ auch würde er seiner Rolle nicht gerecht. Schon vom

260 Oben: IV. 3. a); V.

261 Vgl. schriftlicher Bericht des Rechtsausschusses, zu Drucksache V/3605, S. 13.

262 Vgl. Plenarprotokolle 10.WP, 136. Sitzung, 10/136, S. 10138: „BRH soll ein unabhängiger, starker Partner des Parlaments sein“; 148. Sitzung, 10/148, S. 11012.

${ }^{263}$ Gesetzesentwurf zum BRHG, BT-Drs. 10/3323, S. 2, 9.

264 Eickenboom/Heuer, Das neue Bundesrechnungshofgesetz, DÖV 1985, 997 (998).

265 Wittrock, Auf dem Weg zu einem neuen Bundesrechnungshofgesetz, DÖV 1984, 649 (653); ders., Der Rechnungshof als Berater, DÖV 1989, 346 ff.; Kopp, Der Rechnungshof als gemeinsames „, föderatives“ Bund-Länder-Organ, 1978, S. 8: „Kein Parlament ist neben seinen sonstigen Aufgaben in der Lage, die Detailarbeit zu leisten, die eine wirksame Finanzkontrolle voraussetzt".

266 So zumindest die ehemaligen Präsidenten des Bundesrechnungshofes Wittrock, Möglichkeiten und Grenzen der Finanzkontrolle. Das Verhältnis des Bundesrechnungshofes zum Bundestag, ZParl 1982, 209 (216) und H. Schäfer, Wer kontrolliert unsere Steuergelder?, 1977, S. 33; ders., Der Bundesrechnungshof im Verfassungsgefüge der Bundesrepublik, DÖV 1971, 542 (543); Stern, 
Wortsinn her setzt eine Hilfsorganeigenschaft eine gewisse Abhängigkeit von einem Hauptorgan voraus ${ }^{267}$ und bedeutet ein Tätigwerden nicht in eigener, sondern in fremder Zuständigkeit. ${ }^{268}$ Aber gerade die Unabhängigkeit steht bei der grundgesetzlichen Regelung des Art. 114 Abs. 2 S. 1 GG im Vordergrund. Der Bundesrechnungshof leitet die Legitimation seiner Aufgaben und damit insbesondere seinen Prüfungsauftrag direkt aus dem Grundgesetz, nicht etwa von einem Auftrag durch das Parlament ab. ${ }^{269}$

Das gewichtigste Argument gegen eine solche Einstufung liefert das Grundgesetz selbst jedoch dadurch, dass der Begriff des Hilfsorgans in Art. 45 b GG für den Wehrbeauftragten benutzt wird; anders als dieser wird der Bundesrechnungshof im Grundgesetz gerade nicht als Hilfsorgan bezeichnet. ${ }^{270}$ Hilfsorgan ist somit ein verfassungsrechtlich festgelegter Begriff, der, wie die Ausgestaltung im Falle des Wehrbeauftragten zeigt, Abhängigkeit impliziert. So wird dieser etwa allein vom Bundestag ernannt und abberufen und muss auf dessen Verlangen auch im Bundestag erscheinen. ${ }^{271}$ Auf den Bundesrechnungshof als eigenständiges, unabhängiges Staatsorgan, dessen Aufgaben nur durch das Grundgesetz und durch Gesetze bestimmt werden, passt diese Bezeichnung keinesfalls. ${ }^{272}$

Auch die Verwendung der Bezeichnung als „Hilfsorgan“ in einer weniger status- als vielmehr funktionsbeschreibenden Sichtweise ${ }^{273}$ ist abzulehnen. Danach wäre der Bundesrechnungshof funktionell auch als Hilfsorgan der Exekutive zu sehen, ${ }^{274}$ die auf seine Tätigkeit ebenso angewiesen ist, so dass diese Überlegung unter dem Gesichtspunkt der Einordnung nicht weiterzuhelfen vermag. Außerdem erschöpfen sich die Aufgaben des Bundesrechnungshofes keineswegs in der bloßen Zuarbeit für den Bundestag oder für Organe der Exekutive. Kontrolle und Beratung münden nur allzu oft in Kritik an Vorhaben oder bereits umgesetzten Akten des Gesetzgebers. Ein Aspekt der Tätigkeit ist sicherlich die Unterstützung des Parlaments bei der Wahrnehmung seiner Aufgaben, andererseits wird der Rechnungshof aber nach eigenem Ermessen tätig und „berät“ auch gegen den

Die staatsrechtliche Stellung des Bundesrechnungshofes und seine Bedeutung im System der Finanzkontrolle, in: FS zur 275. Wiederkehr der Errichtung der Preußischen General-RechenKammer, 1989, S. 11 (41).

267 H. Schäfer, Wer kontrolliert unsere Steuergelder?, S. 33; siehe auch: Maunz, in: Maunz/Dürig, Kommentar zum GG, Art. 114, Rn. 23 (Stand: Lfg. 23 Oktober 1984).

268 Klein, in: Maunz/Dürig, GG, Art. 45b, Rn. 15 f. (Stand: Lfg. 35, Februar 1999).

269 So schon Peucker, Grundfragen neuzeitlicher Finanzkontrolle, 1952, S. 30.

270 Maunz, in: Maunz/Dürig, Kommentar zum GG, Art. 114, Rn. 23 (Stand: Lfg. 23 Oktober 1984).

271 Vgl. Gesetz über den Wehrbeauftragten; S. Tiemann, Die staatsrechtliche Stellung der Finanzkontrolle des Bundes, 1974, S. 320.

272 Ausführlich: B. Tiemann, Zur Staatsrechtlichen Stellung und Funktion des Bundesrechnungshofes nach der Haushaltsreform, DVBl. 1970, 954 (957); siehe auch Grupp, Die Stellung der Rechnungshöfe in der BRD, 1972, S. 145 f.; Wittrock, Auf dem Weg zu einem neuen Bundesrechnungshofgesetz, DÖV 1984, 649 (650).

273 So Hufeld, in: Isensee/Kirchhof, HStR, Bd. III, 2005, 』56, Rn. 1-3.

274 Vgl. zu den Gesetzesmaterialien: Fn. 261. 
Willen des Beratenen. Der Bundesrechnungshof kann Prüfungs- und Beratungswünschen des Parlaments und seiner Ausschüsse nachkommen (und tut dies in aller Regel auch) ${ }^{275}$, aber er muss es nicht. ${ }^{276}$ Kontrolle, Beratung und (öffentliche) kritische Berichterstattung sind Mittel, um die Entscheidungen staatlicher Organe zu rationalisieren; dem Bundesrechnungshof als unabhängigem Expertengremium kommt dadurch eine Rolle zu, die über die bloße Hilfeleistung an das Parlament weit hinausgeht.

Insofern ist, was die Hilfs- und Unterstützungsaufgaben angeht, die der Bundesrechnungshof für den Bundestag wahrnimmt, die Bezeichnung als „Partner des Parlaments“277 treffender, weil diese im Gegensatz zum Terminus „Hilfsorgan“ keine Abhängigkeit impliziert, die nach dem Grundgesetz nicht vorgesehen ist, ja sogar ausgeschlossen werden soll ${ }^{278}$. Vielmehr arbeitet der Bundesrechnungshof dem Parlament und der Regierung aus „kritischer Distanz“ zu. ${ }^{279}$

Hinzu kommt, dass der Rechnungshof nicht nur für die Legislative prüft, sondern auch Teile dieser selbst, wie sich etwa aus $\ 53$ AbgG ergibt, wonach er Rechnung sowie wirtschaftliche und ordnungsgemäße Verwendung der den Fraktionen zugewiesenen Mittel prüft. ${ }^{280}$

Eine andere Beurteilung ergibt sich auch nicht aus den Regelungen zur Ernennung der Mitglieder des Bundesrechnungshofes. So erfolgt die Ernennung von Präsident und Vizepräsident durch den Bundespräsidenten nach der Wahl durch Bundestag und Bundesrat auf Vorschlag der Bundesregierung (vgl. \5 BRHG). Die Legislative hat kein eigenes Vorschlagsrecht. Schon bei der Besetzung wird somit der besondere gewaltenüberschneidende Charakter deutlich. Dieser Mechanismus ist zumindest der Versuch der Sicherung der Unabhängigkeit gegenüber Legislative und Exekutive dadurch, dass nur beide zusammen die Ämter des Präsidenten und des Vizepräsidenten besetzen können und dass es so bereits im Ernennungsverfahren zu einer gegenseitigen Kontrolle der beiden Staatsgewalten kommen soll.

Im Ergebnis ist die Rolle des Bundesrechnungshofes nicht auf die eines Hilfsorgans der Legislative beschränkt. Zwar arbeitet er seinem Auftrag gemäß dem Parlament zu, dies aber aus einer völlig unabhängigen Position; auch handelt es

275 Bundesrechnungshof, Der Bundesrechnungshof und die Prüfungsämter des Bundes, 2005, S. 15.

276 Blasius, Der Rechnungshof - Kontrolleur und Informant, DÖV 1993, 642 (643, 645)

277 So Korthals, Beiträge der Rechnungshöfe zur Verwaltungsreform, DÖV 2000, 855; so zum Rechnungshof der Freien und Hansestadt Hamburg dessen ehem. Präsident Schulze, Aufgabenwandel der Finanzkontrolle: Bestandsaufnahmen aus der Prüfungspraxis, in: Engelhardt/Schulze/Thieme, Stellung und Funktion der Rechnungshöfe im Wandel?, 1993, S. 33 (39).

278 Stern, Staatsrecht, Bd. II, 1980, S. 447.

279 Kisker, Sicherung von „Wirtschaftlichkeit und Sparsamkeit“ durch den Rechnungshof, NJW 1983, 2167 (2170).

280 Vgl. auch Beschluss der Konferenz der Präsidenten der Rechnungshöfe des Bundes und der Länder vom 30. September bis 2. Oktober 2002 in Bonn zu den Prüfungsrechten bei Fraktionen (abgedruckt bei Engels, in: Heuer, Kommentar zum Haushaltsrecht, VIII/2.10 (Stand 38. EL Dezember 2004)). 
sich bei diesen Unterstützungstätigkeiten nur um einen Teil seiner zahlreichen Aufgaben. Die gewaltenüberschneidend ausgestalteten Regelungen über die Ernennung der Führung des Bundesrechnungshofes unterstreichen dies; um die Unabhängigkeit des Bundesrechnungshofes zu sichern, hat die Legislative kein Vorschlagsrecht, sondern beschließt über die von der Bundesregierung gemachten Vorschläge.

Selbst von einer ,faktisch sehr deutlichen Zuordnung zum Deutschen Bundestag“'281 zu sprechen, geht im Ergebnis zu weit. ${ }^{282}$ Es ließe die Stellung des Bundesrechnungshofes in seiner Bedeutung als eigenständiges Staatsorgan und seine gewaltenübergreifende Organisation und Funktion außer Acht.

bb) Der Bundesrechnungshof als funktionaler Bestandteil der Gesetzgebung

Eine Zuordnung des Bundesrechnungshofes zur Legislative könnte zu bejahen sein, wenn ihm Mitentscheidungsmacht bei der Gesetzgebung zukäme. In einer solchen Mitentscheidung wäre zugleich die Ausübung von Staatsgewalt zu sehen. 283

Die Grenzen zwischen nachvollziehender und bewertender Kontrolle sind fließend. Durch die Bewertung finanzieller Vorgänge auf der einen und insbesondere durch die zukunftsgerichtete Beratung auf der anderen Seite kommt dem Bundesrechnungshof in der Weise Mitgestaltungsmacht zu, 284 als er Entscheidungsgrundlagen liefert. Diese sind jedoch, zumindest rechtlich, völlig unverbindlich. Der Bundesrechnungshof hat nicht die Funktion mitzuentscheiden, vielmehr liefert er durch seine Beratung einen Beitrag zur Entscheidungshilfe. ${ }^{285}$ Dies wird dadurch deutlich, dass keine Entscheidung des Parlaments an einen Zustimmungsvorbehalt des Bundesrechnungshofes geknüpft ist. Es besteht, unbeschadet der Anhörungs- und Unterrichtungserfordernisse nach \S 102, 103 sowie $\int 27$ Abs. 2 BHO, ${ }^{286}$ nicht einmal die Pflicht, seine Berichte zu Kenntnis zu nehmen oder Stellung zu beziehen, wie dies etwa beim Europäischen Rechnungshof, auf dessen Bemerkungen die kontrollierten Organe zu antworten haben (vgl. Art. 248 Abs. 4 S. 2; 276 Abs. 1 S. 2 EGV) ${ }^{287}$, der Fall ist. Der Bundesrechnungshof entscheidet nicht, seine Aufgabe ist es vielmehr, den Gesetzgeber und die Regierung zu informieren.

Auch die Möglichkeit, Gesetze oder Gesetzesänderungen im Bereich der Finanzgesetzgebung vorzuschlagen, ist hinsichtlich ihrer Folgen rechtlich unver-

\footnotetext{
281 Eickenboom/Heuer, Das neue Bundesrechnungshofgesetz, DÖV 1985, 997 (998).

282 Ebenso Stern, Der verfassungsrechtliche Status der Rechnungshöfe, in: Böning/v.Mutius, Finanzkontrolle im repräsentativ-demokratischen System, 1990, S. 11 (36).

283 BVerfGE 83, 60 (73).

${ }^{284}$ Hufeld, in: Isensee/Kirchhof, HStR, Bd. III, 2005, \56, Rn. 4.

285 Wittrock, Der Rechnungshof als Berater, DÖV 1989, 346 (347).

286 Oben: IV. 6.

${ }^{287}$ Entspricht nach dem Lissabon-Vertrag Art. 287 Abs. 4 S. 2; Art. 319 Abs. 1 S. 2 AEUV).
} 
bindlich. ${ }^{288}$ Die Ausübung von Staatsgewalt kann somit hinsichtlich von Mitentscheidungsbefugnissen ebenso verneint werden wie für den Bereich von Gesetzesvorschlägen mangels ihrer Rechtsverbindlichkeit. ${ }^{289}$

Eine Zuordnung zur Legislative ergibt sich auch nicht allein aus der Tatsache, dass der Bundesrechnungshof der Vorbereitung der Entlastung der Bundesregierung durch den Bundestag dient. Wie schon erwähnt ist dies nur eine, wenn auch sehr wichtige, Funktion seines breiten Tätigkeitsspektrums. Auch stellt sich die Frage, ob es sich bei der Entlastung der Bundesregierung durch Bundestag und Bundesrat materiellrechtlich überhaupt um legislative Tätigkeit handelt, erfolgt diese doch durch einfachen Parlamentsbeschluss. ${ }^{290}$

Im Ergebnis erschöpfen sich die Aufgaben des Bundesrechnungshofes gerade nicht in der Zuarbeit für die Legislative, vielmehr kontrolliert er auch diese selbst und übt gegebenenfalls in seinen Berichten Kritik an Gesetzen und auch Gesetzesvorhaben hinsichtlich ihrer finanziellen Auswirkungen. Die historische Entwicklung zeigt die Veränderung weg von einem Hilfsorgan der Verwaltungsspitze zur Kontrolle der ihr unterstellten Verwaltung in Richtung Parlament, geht aber nicht soweit, dass der Bundesrechnungshof, sei es als Hilfsorgan oder als funktionaler Bestandteil, als Teil der Legislative verstanden werden könnte. Die Reduzierung auf die Stellung als Hilfsorgan würde dem verfassungsrechtlichen Auftrag des Bundesrechnungshofes und seiner Bedeutung im Staat nicht gerecht, auf der anderen Seite kommen ihm auch keine Mitentscheidungsbefugnisse zu, die die Zuordnung zur Legislative rechtfertigen könnten. Der Bundesrechnungshof ist somit nicht der Legislative zuzuordnen.

\section{b) Zuordnung zur Judikative}

Eine Zuordnung zur Rechtsprechung wurde in der älteren Literatur vereinzelt vertreten. ${ }^{291}$

Anhaltspunkte für die Zuordnung zur Judikative können schon in der Bezeichnung als Rechnungshof 292 und in seinem gerichtsähnlichen Aufbau mit der

\footnotetext{
288 Oben: IV. 3. b).

${ }^{289}$ In diese Richtung jedoch für den Bereich der Exekutive: BVerfGE 83, 60 (73).

${ }^{290}$ H. Schäfer, Der Bundesrechnungshof im Verfassungsgefüge der Bundesrepublik, DÖV 1971, 542 (543).

291 Vgl. vor allem Beckensträter, Die Stellung der Rechnungshöfe im System der Dreiteilung der Staatsgewalt, 1961, S. 134 ff., 183 ff., 191, kommt zu dem Ergebnis, dass „Rechnungshöfe - ohne Gerichte zu sein - zur Rechtsprechung gehören“ (S. 193); Vogel, Verfassungsrechtliche Grenzen der öffentlichen Finanzkontrolle, DVBl. 1970, S. 193 (195), sieht den Bundesrechnungshof durch seine Kontrollfunktion „am ehesten der Judikative vergleichbar“, wobei sie „materiell zweifellos von der rechtsprechenden Tätigkeit zu unterscheiden" sei und sie im Ergebnis zwischen Legislative und Exekutive einordnet; zahlreiche Nachweise zur älteren Literatur bei Fittschen, Durchsetzung der Prüfungsrechte der Rechnungshöfe, Verwaltungsarchiv 1992, S. 165 f. und Stern, Staatsrecht, Bd. II, 1980, S. 445.
} 
Aufteilung in Senate gesehen werden. Besonders die richtergleich garantierte Unabhängigkeit seiner Mitglieder scheint auf den ersten Blick dafür zu sprechen.

Rechtsprechung kann definiert werden als „verbindliche Entscheidung von Rechtsstreitigkeiten durch eine unabhängige, allein an Gesetz und Recht gebundene staatliche Instanz in einem mit besonderen Garantien ausgestalteten Verfahren“"293. Das Bundesverfassungsgericht beschreibt die „letztverbindliche Klärung der Rechtslage in einem Streitfall im Rahmen besonders geregelter Verfahren" als typisches Merkmal rechtsprechender Tätigkeit. ${ }^{294}$

Formell ist die Tätigkeit des Bundesrechnungshofes eindeutig keine Rechtsprechung, weist das Grundgesetz diese doch in Art. 92 ausdrücklich den Gerichten zu, ein solches ist er jedoch zweifellos nicht. Nun ist zu klären, welche inhaltlichen Gemeinsamkeiten und Unterschiede bestehen, und ob sie, so sie denn zu dem Ergebnis führten, dass der Bundesrechnungshof materiell Rechtsprechung ausübt, eine Zuordnung zur Judikative begründen können.

Jedoch unterscheidet sich die Finanzkontrolle durch den Bundesrechnungshof schon in ihrer Zielrichtung und Wirkung von gerichtlicher Kontrolle: Er trifft keine rechtsverbindliche Entscheidung in einer Rechtssache; Feststellungen des Rechnungshofes in seinen Bemerkungen beziehungsweise Mitteilungen über die rechtswidrige Verwendung staatlicher Mittel entbehren rechtlicher Verbindlichkeit und Durchsetzbarkeit.

Weiter kann der Bundesrechnungshof grundsätzlich im Rahmen der Verfassungskontrolle die Verfassungswidrigkeit von Haushaltsgesetz und Haushaltsplan feststellen, was eine Ähnlichkeit zur verfassungsgerichtlichen Kontrolle nahelegen könnte; jedoch sind auch derartige Feststellungen nicht verbindlich. Außerdem unterscheiden sich Gegenstand, Zweck und Maßstab seiner Prüfung von der verfassungsgerichtlichen. ${ }^{295}$

Entscheidender Unterschied ist also, dass Gerichtsurteile im Gegensatz zu Feststellungen des Rechnungshofes rechtlich bindend sind. Auf dem Wege der richterlichen Rechtsfortbildung stellen sie sogar eine Rechtsquelle dar. ${ }^{296}$ Die Stellungnahmen und Berichte des Bundesrechnungshofes dagegen haben eher den Charakter von beratenden, zwar ernstzunehmenden, aber nicht verbindlichen Gutachten. Ihre Beachtung und Umsetzung durch die Adressaten in Legislative und Exekutive (besonders in der Ausgestaltung als Gubernative) wird allein durch politischen Druck und den Druck der Öffentlichkeit („Öffentlichkeit als Schwert

\footnotetext{
292 So auch das französische Verständnis des Wortes „Cour“, vgl. Mart, Die Finanzkontrolle der Europäischen Gemeinschaften, in: FS zur 275. Wiederkehr der Errichtung des Preußischen General-Rechen-Kammer, 1989, S. 469 (476).

293 Maurer, Staatsrecht I, 2007, S. 613 m.w.N.

294 BVerfGE 103, 111 (137 f.).

295 BVerfGE, 20, 56 (96).

296 Wrege, Das System der Gewaltenteilung im Grundgesetz, Jura 1996, 436 (438) m.w.N.
} 
der Rechnungshöfe“" ${ }^{297}$ aufgrund des hohen Ansehens des Bundesrechnungshofes vorangetrieben.

Auch der Ablauf des Prüfungsverfahrens ist nicht gerichtsförmig ausgestaltet. Anders als im Rechtsstreit gibt es keine zwei Parteien, sondern nur den unabhängigen Prüfer und die geprüfte staatliche Stelle. Sowohl die Grundstruktur des Verfahrens als auch die Vorgehensweise ist damit eine völlig andere.

Die Kontrolle durch den Rechnungshof geht vom Prüfungsansatz teilweise sogar über den gerichtlichen hinaus. Das zeigt sich insbesondere darin, dass der Rechnungshof im Gegensatz zu einem Gericht auf eigene Initiative tätig wird. ${ }^{298}$ Er ist nicht auf eine ex-post-Kontrolle beschränkt und auch hinsichtlich der Maßstäbe, die der Kontrolle durch Gerichte einerseits und durch den Bundesrechnungshof andererseits zugrunde liegen, bestehen erhebliche Unterschiede. ${ }^{299}$ So werden die Prüfungsgegenstände nicht nur anhand des Maßstabes der RechtmäBigkeit, sondern auch der Wirtschaftlichkeit, also eines Wertungskriteriums, das im Gegensatz zu denen der Rechtsprechung nicht rein rechtlicher Natur ist, gemessen. 300 Dieser Wirtschaftlichkeitsmaßstab gibt ihm über den Maßstab der Rechtmäßigkeit hinausgehend eigenständige staatsorganisatorische Bedeutung. Hinzu kommt die Aufgabe der Beratung, die in engem Zusammenhang mit der Kontrolle (insbesondere der der Wirtschaftlichkeit) steht und nicht in die Kategorien der Judikative zu fassen ist.

Der Blick auf die grundsätzliche Zielrichtung des Auftrages von Rechtsprechung zum einen und Finanzkontrolle durch den Bundesrechnungshof zum anderen zeigt weitere Unterschiede auf: Dient das Handeln der Rechtsprechung auch der Wahrnehmung der Interessen der Parteien im Rechtsstreit, so nimmt der Bundesrechnungshof allein das öffentliche, das Allgemeininteresse wahr. ${ }^{301}$ Der Rechnungshof prüft zudem ausschließlich im innerstaatlichen Bereich, er prüft keine privaten natürlichen oder juristischen Personen, sondern er prüft lediglich bei diesen, sofern sie Empfänger staatlicher Mittel sind (vgl. \91 BHO).

Der Gewährleistung einer effektiven Verwirklichung der Kontrolle dient die garantierte richterliche Unabhängigkeit der Mitglieder der Kontrollinstitutionen von den zu kontrollierenden Staatsorganen. Diese ist somit lediglich eine folgerichtige und unbedingt notwendige Ergänzung der Aufgabe der Kontrolle und lässt sich nur über diese erklären. Ein eigenständiger Aussagewert kommt der Unabhängigkeit, etwa um als Argument für die Zuordnung des Bundesrechnungshofes zur Judikative zu dienen, damit nicht zu. Genauso verhält es sich mit

\footnotetext{
297 Oben Fn. 187.

298 Krebs, Kontrolle in staatlichen Entscheidungsprozessen, 1984, S. 206.

299 Degenhart, Kontrolle der Verwaltung durch Rechnungshöfe, VVDStRL 55 (1996), 190 (203), der betont, dass der Finanzverfassung des GG eigene Maßstäbe (im Vergleich mit der Judikative) zugrunde liegen.

300 Krebs, Die rechtliche Stellung der Rechnungshöfe, VerwArch 1980, 77 (81) m.w.N.

301 Blasius/Stadtmann, Justiz und Finanzkontrolle, DÖV 2002, 12 (19).
} 
dem gerichtsähnlichen Aufbau des Bundesrechnungshofes: Mit der der Sicherstellung des Kollegialprinzips dienenden Einteilung in Senate ist diese Organisationsform der bestmöglichen Gewährleistung der Unabhängigkeit und damit auch der Optimierung seiner Funktion geschuldet. Hinsichtlich einer möglichen Zuordnung zur Judikative sind diese „Gemeinsamkeiten“ zu den Gerichten ohne viel Aussagekraft; vielmehr muss es auf die Funktion und die Art ihrer Wahrnehmung im Prüfungsverfahren und die daraus erwachsenden Folgen ankommen, die sich wie gesehen aber stark unterscheiden.

Gemeinsam ist die Kontrollfunktion, wobei jedoch der Bundesrechnungshof in Ermangelung der Fähigkeit, rechtsverbindlich zu handeln, auf die Mithilfe anderer Staatsorgane angewiesen ist, wenn es darum geht, aus der Kontrolle Konsequenzen zu ziehen. Er liefert damit die Grundlage für staatliche Selbstkontrolle. In der Gemeinsamkeit der Kontrollfunktion erklärt sich auch die Unabhängigkeit der Richter und der Mitglieder des Bundesrechnungshofes, um ihre Wirksamkeit und Objektivität zu garantieren.

Im Ergebnis ist der Bundesrechnungshof nicht der Judikative zuzuordnen. Er entscheidet keinen Rechtsstreit und seine Beanstandungen sind auch nicht rechtlich verbindlich, sondern haben lediglich den Charakter von Vorschlägen. Es kann ihnen aber durchaus faktische Verbindlichkeit zukommen, ${ }^{302}$ indem sie dazu führen, dass auf den für die beanstandeten Maßnahmen Verantwortlichen Druck ausgeübt wird. Rechtsverbindliche Entscheidungen trifft der Bundesrechnungshof nur innerhalb des Kontrollprozesses, etwa über das Ob und Wie sowie über Art, Zeit und Ausmaß des Tätigwerdens.

Dennoch bestehen funktionale und dadurch bedingt auch organisatorische Ähnlichkeiten mit der rechtsprechenden Gewalt. So dient die Rechtsprechung der Kontrolle der Rechtmäßigkeit staatlichen Handelns. Auch die Finanzkontrolle durch den Bundesrechnungshof dient der Kontrolle der Legislative und Exekutive auf dem Gebiet der Staatsfinanzen auf ihre Recht- und im Rahmen der Gesetze auch Zweckmäßigkeit. Die Ähnlichkeiten gehen so weit, dass es vereinzelt Ansätze in der Literatur gibt, die Funktion der Kontrolle an sich in ihren unterschiedlichen Ausprägungen als eigenständige Staatsfunktion einzuordnen. ${ }^{303}$

Die funktionale Ähnlichkeit zu den Gerichten erklärt auch die grundgesetzlichen Hilfsgarantien, insbesondere die richterliche Unabhängigkeit, die die Effektivität der Kontrolle sicherstellen.

Die Prüfung durch den Bundesrechnungshof erstreckt sich im Übrigen auch auf die Haushalts- und Wirtschaftsführung der Gerichte des Bundes. ${ }^{304}$ Aber natürlich kommt dieser geringere Bedeutung zu als der Kontrolle und Beratung der beiden anderen Gewalten; schließlich treffen Gerichte in aller Regel keine finanz-

\footnotetext{
302 Hierzu: Krebs, Kontrolle in staatlichen Entscheidungsprozessen, 1984, S. 173, 175.

${ }^{303}$ Nachweise bei Krebs, Kontrolle in staatlichen Entscheidungsprozessen, 1984, S. 38 ff., im Ergebnis ablehnend; ebenso: Brunner, Kontrolle in Deutschland, 1972, S. 49.

${ }^{304}$ Groß, Exekutive Befugnisse der Rechnungshöfe, VerwArchiv 2004, S. 194 (204) m.w.N.
} 
wirksamen Maßnahmen in größerem Maßstab. Gemeinsam haben Bundesrechnungshof und Rechtsprechung also die Kontrolle von Legislative und Exekutive.

\section{c) Zuordnung zur Exekutive}

Häufiger vertreten wird die Zuordnung des Bundesrechnungshofes zur Exekutive. ${ }^{305}$ Traditionell stellten die Rechnungshöfe Organe dar, die die Regierung bei der Kontrolle der ihr unterstellten Verwaltung unterstützen.

\section{aa) Probleme der Zuordnung mit Hilfe der Subtraktionsmethode}

Für die Festlegung dessen, was Exekutive ist, könnte man auf die negativ abgrenzende Subtraktionsmethode zurückgreifen, danach umfasst sie alle staatlichen Funktionen, die weder der Gesetzgebung noch der Rechtsprechung zuzuordnen sind $^{306}$. Nach der Subtraktionsmethode wäre der Bundesrechnungshof eindeutig der Exekutive zuzuordnen, wenn auch mit einer gewissen Sonderstellung wegen seiner Unabhängigkeit („Verwaltungsbehörde im ministerialfreien Raum“307). Diese Zuordnung mit Hilfe der Subtraktionsmethode ist aber vorliegend problematisch, weil sie gerade von einer ausnahmslosen Dreiteilung der Gewalten ausgeht. Auch müsste so jede staatliche Funktion selbst dann, wenn sie durch ihr Handeln keine Staatsgewalt ausübt (was insbesondere beim Bundesrechnungshof fraglich ist und im Folgenden noch zu klären ist), einer der drei zugeordnet werden. Es erscheint aber schon sehr problematisch, ob ein Staatsorgan, das keine Staatsgewalt ausübt, auch in den dafür üblichen Kategorien verortet werden kann und muss. Wenn aber alles, was nicht unter die ersten beiden Gewalten fällt, der dritten zuzuordnen sein soll, ist eine Einordnung nach funktionalen und inhaltlichen Kriterien nicht möglich. Und die Frage, ob das Grundgesetz tatsächlich von

305 Wagner, 50 Jahre Bundesrechnungshof, AöR 2001, 93 (130) m.w.N.; Huber, Die institutionelle Verfassungsgarantie der Rechnungsprüfung, in: FS Nikisch, 1958, S. 331: hält die Tätigkeit des BRH für Verwaltungstätigkeit (S. 335 f.), an späterer Stelle jedoch spricht er im Hinblick auf seine Unabhängigkeit von einem „der Justiz analogen Verfassungsstatus“ und will hieraus eine „besondere Art der Gewaltenteilung“ herleiten, geprägt „von der Trennung der prüfenden von den übrigen Staatsgewalten, d.h. nicht nur von der vollziehenden, sondern auch von der rechtssetzenden“ (S. 341); B. Tiemann, Die staatsrechtliche Stellung und Funktion des Bundesrechnungshofes nach der Haushaltsrechtsreform, DVBl. 1970, 954 (958 f.): „Sonderstellung innerhalb des Bereichs der Exekutive“; Groß, Exekutive Befugnisse der Rechnungshöfe, VerwArchiv 2004, 194 (221); Grupp, Die Stellung der Rechnungshöfe in der BRD, 1972, S. 159 m.w.N.; Maun₹, in: Maunz/Dürig, GG, Art. 114, Rn. 13 (Stand: Lfg. 23 Oktober 1984); VGH Kassel NVwZ-RR 1994, 511; NVwZ-RR 1994, 515; OVG Münster, Urt. V. 9.5.1978 - XII A 687/76, DÖV 1979, 682 (683 f.): „Erstattung des jährlichen Prüfungsberichts stellt ein schlichtes Verwaltungshandeln, einen Realakt, dar".

306 Maurer, Staatsrecht I, 2007, J 18 Rn. 2.

307 Grupp, Die Stellung der Rechnungshöfe in der BRD, S. 151 ff. (163) m.w.N.; Maunz, in: Maunz/Dürig, GG, Art. 114, Rn. 24 (Stand: Lfg. 23 Oktober 1984); Hufeld, in: Isensee/Kirchhof, HStR, Bd. III, 2005, \56, Rn. 12: „ministerialfreie oberste Bundesbehörde“. 
besagter Ausnahmslosigkeit ausgeht, soll ja gerade für den vorliegenden Fall geklärt werden.

Wie gesehen ist die grundgesetzliche Gewaltenteilung geprägt von einem System der Funktionenverschränkungen der unterschiedlichen Staatsorgane. Die einzelnen Gewalten sind nur insofern strikt getrennt, als es sich um ihre unverzichtbaren Kernbereiche handelt. Die Subtraktionsmethode ihrerseits setzt eine strikte Trennung voraus, die so nicht existiert.

Ihren Sinn hatte diese negative Abgrenzungsmethode, als im 19. Jahrhundert die Funktionsbereiche der Legislative und Judikative vom bis dahin die alleinige Staatsgewalt ausübenden Monarchen ausgegliedert wurden: Alles, was nicht diesen beiden Bereichen zuzuordnen war, fiel folgerichtig in den Zuständigkeitsbereich des Monarchen als der Exekutive. ${ }^{308}$ Diese klare, negative Abgrenzung kann heute nicht mehr so einfach getroffen werden, die drei Gewalten stehen gleichberechtigt nebeneinander und es gibt keinen ersichtlichen Grund, warum gerade alles, was nicht der Legislative oder Judikative (sofern überhaupt so trennscharf differenziert werden kann) zuzurechnen ist, zur Exekutive gehört. Ebenso gut könnte man auf die Idee kommen, alles, was nicht Judikative oder Exekutive ist, der Legislative oder entsprechend der Judikative zuordnen, denn eine positive Definition, was unter den Bereichen der Rechtsetzung und Rechtsprechung zu verstehen ist, ist dem Grundgesetz ebensowenig zu entnehmen wie eine für die Exekutive. ${ }^{309}$ Insofern muss sich die Subtraktionsmethode Beliebigkeit vorwerfen lassen, weil die Einordnung willkürlich davon abhängt, mit welchen beiden Gewalten man bei der Anwendung dieser Ausschlussmethode beginnt. ${ }^{310}$ Die Subtraktionsmethode kann hinsichtlich der Einordnung in diesem Fall zu keinem befriedigenden Ergebnis führen, so dass zu untersuchen ist, inwieweit andere, nämlich positive Kriterien seine Zuordnung zur Exekutive zu begründen oder auszuschließen vermögen.

bb) Andere Ansatzpunkte für eine Zuordnung zur Exekutive

Versucht man nach inhaltlichen Kriterien zu einer positiven Definition dessen zu gelangen, was Exekutive ist, so umfasst sie zunächst einmal den Vollzug von Gesetzen, was durch die Regierung und Verwaltung geschieht. ${ }^{311}$ Darüber hinausgehend muss „die unmittelbare Gestaltung des staatlichen und gesellschaftlichen Lebens" der vollziehenden Gewalt im weiteren Sinne zuzurechnen sein, womit die

\footnotetext{
308 Maurer, Staatsrecht I, 2007, \18, Rn. 2.

309 S. Tiemann, Die staatsrechtliche Stellung der Finanzkontrolle des Bundes, 1974, S. 309; Grupp, Die Stellung der Rechnungshöfe in der BRD, 1972, S. 138; Hauser, Stellung des Bundesrechnungshofs im System der Gewaltenteilung und in der öffentlichen Verwaltung, DVBl. 2006, 539 (540); Stern, Staatsrecht, Bd. II, 1980, S. 449, S. 734 ff.; Maurer, Allgemeines Verwaltungsrecht, 2004, S. 3.

310 Hauser, Stellung des Bundesrechnungshofs im System der Gewaltenteilung und in der öffentlichen Verwaltung, DVBl. 2006, 539 (540).

311 Maurer, Staatsrecht I, 2007, S. 592 f.
} 
„Verwirklichung und Durchsetzung gesetzlicher wie auch eigener Konzeptionen“ umfasst sind. ${ }^{312}$

๙) Rechtsnatur und Funktion der Aufgaben des Bundesrechnungshofes als möglicher Anknüpfungspunkt einer Zuordnung zur Exekutive

Die Kontrollaufgabe des Bundesrechnungshofes und die Zusammenstellung und Zuleitung seiner Berichte stellen für das Parlament eine verfassungsrechtlich notwendige Voraussetzung für die diesem obliegende Finanzkontrolle dar, was gegen eine Zuordnung zur Exekutive spricht. ${ }^{313}$ Kontroll- und Beratungsfunktion werden ihm vom Grundgesetz zugewiesen und sind Verfassungsaufgaben und keine Verwaltungs- oder Regierungsaufgaben. ${ }^{314}$

Der zweite Hauptaspekt seiner Tätigkeit liegt in der Beratung. Durch die wie gesehen oftmals kritische Wahrnehmung derselben ähnelt er häufig eher einem externen Beratungsunternehmen als einer Verwaltungsstelle. Die Vielzahl seiner Aufgaben, die etwa die Analyse und Bewertung von Rechtsgrundlagen und ihrer wirtschaftlichen Folgen, Wirtschaftlichkeitsuntersuchungen für die unterschiedlichsten Arten von Projekten und die damit verbundene Beratung der Entscheidungsträger umfassen, unterscheiden sich deutlich von dem, was man unter Verwaltungstätigkeit versteht. ${ }^{315}$ Der Bundesrechnungshof „,vollzieht“ nicht; er führt keine Gesetze aus, sondern kontrolliert einerseits ihre Einhaltung, wobei diese Aufgabe, die Ordnungsmäßigkeitsprüfung, die ihn augenscheinlich in eine der Rechtsprechung ähnelnde Funktion rückt, auch nur ein Aspekt seines facettenreichen Aufgabenbereichs ist, andererseits beurteilt er die Folgen von Gesetzen hinsichtlich ihrer finanziellen Auswirkungen. ${ }^{316}$ Weder durch die Ausübung der Finanzkontrolle noch durch Beratung und Berichterstattung wird der Rechnungshof gestaltend tätig; das heißt, seine Tätigkeit hat keine unmittelbaren rechtlichen oder faktischen Auswirkungen. Vielmehr bewegt er sich damit im rein innerstaatlichen Bereich und kann allein durch Überzeugungskraft, nicht mit Hilfe gesetzlich zugeteilter Entscheidungsgewalt, andere Staatsorgane dazu bringen, Veränderungen vorzunehmen. Die fehlende Möglichkeit, rechtsverbindliche Entscheidungen gegenüber dem Bürger oder staatlichen Einrichtungen zu treffen oder als rechtswidrig festgestelltes Verhalten auf dem Gebiet der öffentlichen Finanzen zu sanktionieren, lassen eine Einordnung unter die vollziehende Gewalt nicht zu. Gegen eine solche Einordnung spricht im Übrigen auch, dass Art. 114 Abs. 2 S. 1 GG ausdrücklich die richterliche Unabhängigkeit seiner Mitglieder und damit des

\footnotetext{
312 Maurer, Staatsrecht I, 2007, S. 593.

313 Krebs, Kontrolle in staatlichen Entscheidungsprozessen, 1984, S. 179.

314 In diese Richtung auch Fittschen, Durchsetzung der Prüfungsrechte der Rechnungshöfe, Verwaltungsarchiv 1992, 165 (173 f.) m.w.N.

315 Hauser, Rechtsqualität von Prüfungsankündigungen des Bundesrechnungshofs, DÖV 2004, 786 (787).

316 Degenhart, Kontrolle der Verwaltung durch Rechnungshöfe, VVDStRL 55 (1996), 190 (205f.).
} 
Bundesrechnungshofes als Ganzem von Funktionsträgern der Exekutive bestimmt.

\section{ß) Der Bundesrechnungshof als Behörde}

In $\int 1$ S. 1 des Bundesrechnungshofsgesetzes ${ }^{317}$, wie auch schon in der Vorgängerregelung, 318 wird der Bundesrechnungshof als „Oberste Bundesbehörde“ bezeichnet. Bereits diese Bezeichnung könnte ein Indiz für die Zugehörigkeit zur Exekutive sein, schließlich sind Behörden üblicherweise Teil der Verwaltung und als solche der Exekutive. Dagegen spricht aber schon die Gesetzesbegründung, ${ }^{319}$ wonach der Bundesrechnungshof nur, „soweit es um seine eigene Verwaltung geht, Oberste Bundesbehörde ist; bei seiner Aufgabenerfüllung wird er nicht als Verwaltungsbehörde, sondern als unabhängige Institution tätig, die beiden Gewalten dient und somit zwischen Legislative und Exekutive steht". Nach dem Willen des Gesetzgebers wird der Bundesrechnungshof damit im Rahmen des Prüfungsverfahrens nicht als Behörde tätig, ${ }^{320}$ so dass die Bezeichnung als Behörde folglich nicht geeignet ist, als Anknüpfungspunkt für eine Zuordnung zur Exekutive zu dienen. Der Bundesrechnungshof ist aus Verwaltungsstrukturen und -hierarchien völlig ausgegliedert; die Behördenform stellt insofern ein reines „Organisationsund Arbeitsmittel“ dar, das für sich genommen nicht die Zuordnung zur Exekutive mit sich bringt. 321

Auch ließe die Behördenform, soweit man sie denn annehmen möchte, für sich allein genommen noch nicht unbedingt einen Schluss auf die Verortung im Verfassungsgefüge zu, gibt es doch auch im Bereich der Legislative Verwaltungsbehörden, wie die Bundestagsverwaltung oder den Wehrbeauftragten des Bundestages $^{322}$ oder den Bundestagspräsidenten, soweit er als Verwaltungsbehörde bei

317 Gesetz über den Bundesrechnungshof (BRHG) vom 11.7.1985 (BGBl. I S. 1445).

318 Vgl. $\int 1$ Abs. 2 Gesetz über Errichtung und Aufgaben des Bundesrechnungshofes vom 27.11.1950 (BGBl. S. 765).

319 Entwurf eines Gesetzes über den Bundesrechnungshof, BT-Drucksache 10/3323 v. 10.05.1985, S. 10. (vgl. auch Schriftlicher Bericht des Rechtsausschusses zu BT-Drucksache V/3605, S. 13); Siehe auch mit zahlreichen Nachweisen zu den entsprechenden Plenarprotokollen, die diese Einschätzung stützen: Hauser, Stellung des Bundesrechnungshofs im System der Gewaltenteilung und in der öffentlichen Verwaltung, DVBl. 2006539 (542).

320 Eickenboom/Heuer, Das neue Bundesrechnungshofgesetz, DÖV 1985, 997 (1000); Plöger, in: Heuer, Kommentar zum Haushaltsrecht, \1 BRHG, Rn. 1 (Stand: 41. EL Februar 2006); Klostermann, in: Heuer, Kommentar zum Haushaltsrecht, \94 BHO, Rn. 19 (Stand: 37. EL Mai 2004); Hauser, Stellung des Bundesrechnungshofs im System der Gewaltenteilung und in der öffentlichen Verwaltung, DVBl. 2006, 539 (542).

321 S. Tiemann, Die staatsrechtliche Stellung der Finanzkontrolle des Bundes, 1974, S. 313; ebenso: $H$. Schäfer, Wer kontrolliert unsere Steuergelder? Finanzprüfung durch den Bundesrechnungshof, 1977, S. 31: „Selbst wenn man den BRH als „Verwaltungsbehörde im ministerialfreien Raum“ ansieht, ist damit noch nichts für eine Entscheidung über das Wesen der Rechnungsprüfung gewonnen."

322 H. Schäfer, Der Bundesrechnungshof im Verfassungsgefüge der Bundesrepublik, DÖV 1971, 542 (543). 
der Festsetzung und Auszahlung staatlicher Gelder an politische Parteien nach dem Parteiengesetz tätig wird. ${ }^{323}$ Schließlich werden auch im Bereich der Judikative im Rahmen der Rechtsprechungsverwaltung materiell Verwaltungsaufgaben wahrgenommen. ${ }^{324}$

\section{భ) Rechtsnatur von Prüfungsankündigungen}

Für die Zuordnung zur Exekutive könnte es sprechen, wenn der Bundesrechnungshof Staatsgewalt in exekutivtypischer Form ausübte. Was die Wahrnehmung von Prüfung, Beratung und Berichterstattung angeht, ist das wie gesehen nicht der Fall, jedoch stellt sich die Frage nach der Rechtsnatur von Prüfungsankündigungen, nämlich ob in ihnen Verwaltungsakte zu sehen sind.

Prüfungsankündigungen können grundsätzlich gegenüber Stellen des Bundes und gegenüber Stellen außerhalb der Bundesverwaltung ergehen. Gegenüber Stellen des Bundes kann mangels Außenwirkung, handelt es sich doch um eine Maßnahme innerhalb desselben Rechtsträgers, schon kein Verwaltungsakt vorliegen. ${ }^{325}$ Fraglich ist aber, wie Prüfungsankündigungen gegenüber Stellen außerhalb der Bundesverwaltung zu bewerten sind, wobei es sich um juristische Personen des öffentlichen Rechts sowie des Privatrechts handeln kann. Entscheidender Unterschied ist, dass Stellen außerhalb der Bundesverwaltung nicht Prüfungsadressat, sondern lediglich Erhebungsobjekt sind, wie \91 BHO („Prüfung bei den Stellen außerhalb der Bundesverwaltung ${ }^{6}$ ) eindeutig zu entnehmen ist. ${ }^{326}$ Im Mittelpunkt stehen Prüfungsankündigungen für die praktisch bedeutsamste ${ }^{327}$ Zuwendungsprüfung nach \ $91 \mathrm{BHO}$ neben der Betätigungsprüfung nach \ $92 \mathrm{BHO}$, der Prüfung juristischer Personen des Privatrechts gem. $\int 104$ BHO sowie bundesunmittelbarer juristischer Personen des öffentlichen Rechts gem. \$S 111, 112 BHO.

\section{$\alpha \alpha)$ Meinungsstand in Literatur und Rechtsprechung}

In Literatur und obergerichtlicher Rechtsprechung besteht Uneinigkeit über die Verwaltungsakteigenschaft der Prüfungsankündigungen. Die Unklarheiten ergeben sich aus dem Fehlen einer eindeutigen Ermächtigungsgrundlage für den Erlass solcher Verwaltungsakte, der Ungewissheit über die Behördeneigenschaft des Bundesrechnungshofes sowie über Außenwirkung, die wie gesehen ohnehin nur

323 BVerfGE 28, 97 (102 f.); 27, 152 (157).

324 Stern, Staatsrecht, Bd. II, 1980, S. 901 f.; Detterbeck, Allgemeines Verwaltungsrecht, 2005, Rn. 8.

325 Hauser, Rechtsqualität von Prüfungsankündigungen des Bundesrechnungshofs, DÖV 2004, 786 (788); so auch Groß, Exekutive Befugnisse der Rechnungshöfe, Verwaltungsarchiv 2004, 194 (206) m.w.N.

326 BVerwGE, 116, 92 (95); Kammer, in: Heuer, Kommentar zum Haushaltsrecht, \ 91, Rn. 1 (Stand: 28. EL Juni 1999); a.A. Behrendt, Die Prüfungstätigkeit des Bundesrechnungshofs außerhalb der unmittelbaren Bundesverwaltung, 2004, S. 31 ff., 42.

327 Hauser, Rechtsqualität von Prüfungsankündigungen des Bundesrechnungshofs, DÖV 2004, 786 (789). 
gegenüber Stellen außerhalb der Bundesverwaltung vorliegen kann, und Regelungscharakter der Prüfungsankündigungen.

Nach einer Ansicht ist in derartigen Prüfungsankündigungen gegenüber Stellen außerhalb der Bundesverwaltung rechtsverbindliches Handeln und Ausübung von Staatsgewalt in verwaltungstypischer Form durch den Erlass von Verwaltungsakten durch die „Behörde“ Bundesrechnungshof zu sehen. ${ }^{328}$

Da die entsprechenden Landeshaushaltsordnungen an den maßgeblichen Stellen wortgleich der Bundeshaushaltsordnung entsprechen, können auch die im Folgenden aufgeführten Fälle herangezogen werden, in denen es um Prüfungsankündigungen von Landesrechnungshöfen geht. So ging der Bayerische Verwaltungsgerichtshof davon aus, dass es sich bei der Prüfungsankündigung des Bayerischen Obersten Landesrechnungshofes gegenüber einer Handwerkskammer, die auf Art. 111 Abs. 1 BayHO $^{329}$ gestützt wurde, um einen Verwaltungsakt handele. ${ }^{330}$ Er entschied, dass der Anordnung Regelungscharakter zukomme, weil „für den Einzelfall verbindlich festgestellt wird, dass die Haushalts- und Wirtschaftsführung der Handwerkskammer der Prüfung durch den Rechnungshof unterworfen ist". 331 Auch wenn die BayHO keine Befugnisnorm zur Durchsetzung dieser Prüfungsrechte im Einzelfall enthalte, könne der Rechnungshof seine Prüfungsrechte gegenüber juristischen Personen des öffentlichen Rechts mittels Verwaltungsakt durchsetzen; „die Einräumung von Prüfungsrechten biete zugleich die Grundlage für den Erlass eines entsprechenden Verwaltungsaktes“, zumal der Gesetzgeber den Rechnungshof ausdrücklich zu einer obersten Staatsbehörde bestimmt habe. 332

Das Bundesverwaltungsgericht als anschließende Revisionsinstanz ließ die Frage, ob es sich um einen Verwaltungsakt handele, ausdrücklich offen, da es sich um die Auslegung und Anwendung von Landesrecht durch das Berufungsgericht handelte, die für das Revisionsgericht bindend seien. ${ }^{333}$ Es stellte jedoch fest, dass die Tätigkeit der Rechnungshöfe im Vergleich zum Verwaltungshandeln in jeder Hinsicht eine unabhängige, eigenen Regeln folgende sei, die insbesondere keine Aufsichtsmaßnahme darstelle. ${ }^{334}$

\footnotetext{
328 Groß, Exekutive Befugnisse der Rechnungshöfe, Verwaltungsarchiv 2004, 194; Fittschen, Durchsetzung der Prüfungsrechte der Rechnungshöfe, Verwaltungsarchiv 1992, 165; Behrendt, Die Prüfungstätigkeit des Bundesrechnungshofs außerhalb der unmittelbaren Bundesverwaltung, 2004, S. 66 ff..

${ }^{329}$ Bayerische Haushaltsordnung vom 08.12.1971 (BayRS 630-1-F); Art. 111 Abs. 1 BayHO stimmt nahezu wörtlich mit $₫ 111 \mathrm{BHO}$ überein.

330 Bayerischer VGH München, Urteil v. 23.07.1992 - 22 B 91.1708, DVBl. 1992, 1606.

331 Bayerischer VGH München, Urteil v. 23.07.1992 - 22 B 91.1708, DVBl. 1992, 1606.

332 Bayerischer VGH München, Urteil v. 23.07.1992 - 22 B 91.1708, DVBl. 1992, 1606 (1608).

333 BVerwGE 98, 163 (164 f.), lässt offen, ob der Rechnungshof durch seine „Sonderstellung im Staatsaufbau rechtlich daran gehindert ist, seine Befugnisse durch Verwaltungsakt geltend zu machen"; ebenfalls offenlassend OVG Lüneburg, NJW 1984, 2652 = DVBl. 1984, 837; BVerwGE $82,56(60)$.

334 BVerwGE 98, 163 (173 f.).
} 
Der Auffassung des BayVGH schloss sich der Hessische VGH der Sache nach auch für Prüfungsanordnungen nach $\int 94 \mathrm{BHO}$ aus dem Grunde an, dass der Bundesrechnungshof „schon aus Gründen der nötigen Effizienz“ die Befugnis haben müsse, Verwaltungsakte zu erlassen. Zwar ergebe sich diese Befugnis nicht direkt aus der Bundeshaushaltsordnung beziehungsweise den jeweiligen Landeshaushaltsordnungen, jedoch sei die Behörde Bundesrechnungshof im hoheitlichen Über- Unterordnungsverhältnis im Zweifel berechtigt, auch ohne ausdrückliche Befugnis einen Verwaltungsakt zu erlassen. ${ }^{335}$

Diese Einschätzung mit der Begründung, dass sich die Befugnis zum Erlass von Verwaltungsakten bereits aus dem bloßen Bestehen eines Subordinationsverhältnisses ergeben könne, und damit der Schluss von der Zuweisung der Prüfungskompetenz auf das Bestehen einer Kompetenz zum Erlass von Verwaltungsakten entspricht hingegen nicht mehr dem gängigen Verständnis der Wesentlichkeitstheorie, die nicht nur auf „Eingriffe in Freiheit und Eigentum“ beschränkt ist ${ }^{336},{ }^{337}$ so dass eine gesetzliche Ermächtigungsgrundlage auch in diesem Falle notwendig wäre.

Andere Stimmen in Literatur und Rechtsprechung verneinen daher die Einstufung von Prüfungsankündigungen als Verwaltungsakte. ${ }^{338}$

Der Bundesrechnungshof selbst betonte als Antragsteller vor dem Hessischen VGH, ihm fehle bereits die Eigenschaft einer Behörde i.S.d. VwVfG, er werde darüber hinaus durch eine Prüfungsankündigung gegenüber dem Adressaten einer solchen nicht hoheitlich tätig und treffe diesem gegenüber auch keine Regelungen, die Rechtswirkung nach außen entfalten. ${ }^{339}$

Das Schleswig-Holsteinische Verwaltungsgericht verneinte die Befugnis des Schleswig-Holsteinischen Landesrechnungshofes, Verwaltungsakte gegenüber

335 Hessischer VGH 10. Senat, Entscheidung vom 21.11.2000 - 10 TG 2627/99, Rz. 25, DÖV 2001, 873.

336 BVerfGE 40, 237 (248 ff.); 8, 155 (167).

337 BVerwGE 72, 265 (266 f.); Schleswig-Holsteinisches VG - 14. Kammer, Entscheidung vom 17.06.2003 - 14 A 148/01, Rz. 42 m.w.N.

338 Hauser, Rechtsqualität von Prüfungsankündigungen des Bundesrechnungshofs, DÖV 2004, 786 m.w.N.; Klostermann, in: Heuer, Kommentar zum Haushaltsrecht, \94 BHO, Rn. 19 (Stand: 27. EL Mai 2004); Belemann, Rechtsschutzprobleme im Bereich der Finanzkontrolle, DÖV 1990, 58 (62); Hockenbrink, Zur Befugnis der Rechnungshöfe, im Prüfungsverfahren Verwaltungsakte zu erlassen, DÖV 1991, 241; Havekate, Schutz subjektiv-öff. Rechte i.d. Rechnungsprüfung, AöR 107, 539 (549); in diese Richtung auch Grupp, Die Stellung der Rechnungshöfe in der BRD, 1972, S 119; so wohl auch Nebel, in: Piduch; Bundeshaushaltsrecht, \ 95 BHO, Rn. 2 a.E. (Stand: 35. EL 1998); sowie im Ergebnis wohl auch BSGE 52, 294 (296) jedoch ohne nähere Begründung.

339 Hessischer VGH, Entscheidung vom 21.11.2000 - 10 TG 2627/99 Rz. 15, DÖV 2001, 873; So auch der Vizepräsident des Bundesrechnungshofs, Hauser, Rechtsqualität von Prüfungsankündigungen des Bundesrechnungshofs, DÖV 2004, 786; ders., Stellung des Bundesrechnungshofs im System der Gewaltenteilung und in der öffentlichen Verwaltung, DVBl. 2006, 539; siehe auch: Bundesrechnungshof, Der Bundesrechnungshof und die Prüfungsämter des Bundes, 2005, S. 16: „Der Bundesrechnungshof hat keine Exekutivgewalt.“. 
Stellen außerhalb der Verwaltung zu erlassen. ${ }^{340}$ Grund dafür war in erster Linie, dass die einschlägigen haushaltsrechtlichen Bestimmungen der Landeshaushaltsordnung und des Landesrechnungshofgesetzes ${ }^{341}$ keine ausdrückliche oder auch nur im Wege der Auslegung ermittelbare Ermächtigungsgrundlage hierfür enthalten. ${ }^{342}$ Gegen die Auslegung als Ermächtigungsgrundlage spreche, dass sich den jeweiligen Normen weder für den Adressaten noch für das Entscheidungsorgan entnehmen lässt, unter welchen tatbestandlichen Voraussetzungen der Rechnungshof solche (unter Umständen grundrechtsrelevanten) Eingriffe vornehmen darf. Und auch auf der Ermessensseite hätten die Rechnungshöfe nach bundesrechtlichen (wie auch nach den landesrechtlichen) Regelungen weitgehend freie Hand. Hinzu komme die unbestimmte Formulierung des $₫ 95 \mathrm{BHO}$, aus der sich die Auskunftspflicht und die Pflicht zur Vorlage von Unterlagen ergibt, was gegen die Einstufung als taugliche Ermächtigungsgrundlage spreche.

Probleme würde auch die gerichtliche Überprüfbarkeit der Ermessensausübung mit sich bringen. So müsste der Bundesrechnungshof etwa begründen, warum er gerade den ausgewählten Zuwendungsempfänger und gerade den Prüfungsgegenstand zu dem von ihm bestimmten Zeitpunkt geprüft hat, was dem staatsinternen Charakter der Rechnungsprüfung und der Unabhängigkeit widerspräche. ${ }^{343}$

Fraglich ist, ob die Prüfungsankündigungen überhaupt über einen eigenständigen Regelungscharakter verfügen, was Voraussetzung für die Einstufung als Verwaltungsakt wäre. Gegen die Annahme des Regelungscharakters in den Fällen der Zuwendungsprüfung nach $\int 91 \mathrm{BHO}$ spricht vor allem, dass die Individualisierung des Prüfungs- und Erhebungsrechts des Bundesrechnungshofes bereits Bestandteil des Zuwendungsbescheides ist. ${ }^{344}$ Für eine erneute rechtsverbindliche Feststellung dieses Prüfungsrechtes durch den Bundesrechnungshof in seiner Prüfungsankündigung besteht somit kein Raum, ${ }^{345}$ denn dieses wurde von der Behörde, die den Zuwendungsbescheid erlassen hat, bereits individualisiert. Entsprechendes gilt im Falle der Betätigungsprüfung nach $\ 92 \mathrm{BHO}$, in dem die Individualisierung durch Satzung bzw. Gesellschaftsvertrag erfolgt, für Prüfungen bei juristischen Personen des Privatrechts nach $\$ 104$, bei denen die Prüfung vereinbart oder in Satzung oder Gesellschaftsvertrag festgelegt ist, sowie in den Fällen der Prüfung bundesunmittelbarer Personen des öffentlichen Rechts gem. \$S

\footnotetext{
340 Schleswig-Holsteinisches VG - 14. Kammer, Entscheidung vom 17.06.2003 - 14 A 148/01.

${ }^{341}$ Ebensowenig wie Bundeshaushaltsordnung und Bundesrechnungshofgesetz.

342 Schleswig-Holsteinisches VG - 14. Kammer, Entscheidung vom 17.06.2003 - 14 A 148/01, Rz. 38.

343 Belemann, Rechtsschutzprobleme im Bereich der Finanzkontrolle, DÖV 1990, 58 (62); SchleswigHolsteinisches VG - 14. Kammer, Entscheidung vom 17.06.2003 - 14 A 148/01, Rz. 36.

${ }^{344}$ Hauser, Rechtsqualität von Prüfungsankündigungen des Bundesrechnungshofs, DÖV 2004, 786 (788 f.).

345 Hauser, Rechtsqualität von Prüfungsankündigungen des Bundesrechnungshofs, DÖV 2004, 786 (789).
} 
111, 112 BHO, bei denen die Individualisierung in aller Regel im Errichtungsgesetz erfolgt. 346

Wie gesehen ist auch die Einstufung des Bundesrechnungshofes als Oberste Bundesbehörde, soweit es nicht um die Wahrnehmung seiner eigenen Verwaltung geht, abzulehnen. Selbst die Gegenansicht, die die Behördeneigenschaft des Bundesrechnungshofes bejaht, differenziert zum Teil dahingehend, dass der Bundesrechnungshof aufgrund seiner besonderen verfassungsrechtlichen Kontroll- und Berichtsaufgaben nur im Prüfungsverfahren gegenüber den Prüfungsunterworfenen als Behörde anzusehen sein soll. 347

Die Außenwirkung von Prüfungsankündigen ist, selbst wenn sie gegenüber Stellen außerhalb der Bundesverwaltung erfolgen, nur schwerlich anzunehmen, sie sind vielmehr Teil des Prüfungsverfahrens, das staatsinternen Charakter hat, wie besonders die Formulierung des $\int 91$ BHO („Prüfung bei Stellen außerhalb der Bundesverwaltung ${ }^{6}$ ) deutlich macht, wonach diese Stellen nicht Prüfungsadressat, sondern lediglich Erhebungsobjekt sind. 348

Weiter ist in $\int 95 \mathrm{BHO}$ vom „Erbitten“ der benötigten Auskünfte die Rede. Das „Erbitten“ gegenüber einem zur Auskunft Verpflichteten wäre eine sehr ungewöhnliche Formulierung, wenn daraus auf eine hoheitliche, mit Befehl und Zwang durchsetzbare Maßnahme mit Regelungscharakter einer Behörde geschlossen werden sollte. Dass der Bundesrechnungshof offensichtlich auch gar keine Verwaltungsakte erlassen will, spiegelt sich in $\int 25$ Abs. 2, Spgstr. 4, 5 der von ihm erlassenen Prüfungsordnung (PO-BRH) wider; danach enthalten „Prüfungsankündigungen“ „die Bitte, die vom Bundesrechnungshof Beauftragten zu unterstützen und Arbeits- sowie Sachmittel zur Verfügung zu stellen“ sowie „gegebenenfalls die Bitte, [die bereitzuhaltenden Prüfungsunterlagen] nach besonderen Vorgaben aufzubereiten“.

Hinzukommt, dass die Bundeshaushaltsordnung dem Bundesrechnungshof keinerlei eigene rechtliche Möglichkeiten zur Verfügung stellt, um einen eventuellen Verwaltungsakt auch selbst durchzusetzen.

Unstreitig ist wohl, dass das Prüfungsverfahren des Bundesrechnungshofes kein Verwaltungsverfahren i.S.d. $\int 9 \mathrm{VwVfG}$ ist: ${ }^{349}$ Es ist weder auf Erlass eines Verwaltungsaktes noch eines öffentlich-rechtlichen Vertrages gerichtet, sondern

346 Im Einzelnen und mit zahlreichen Beispielen: Hauser, Rechtsqualität von Prüfungsankündigungen des Bundesrechnungshofs, DÖV 2004, 786 (789).

347 Fittschen, Durchsetzung der Prüfungsrechte der Rechnungshöfe, Verwaltungsarchiv 1992, 165 (179).

348 BVerwGE 116, 92 (95); Hockenbrink, Zur Befugnis der Rechnungshöfe, im Prüfungsverfahren Verwaltungsakte zu erlassen, DÖV 1991, 241 (242); Haverkate, Der Schutz subjektiv-öffentlicher Rechte in der Rechnungsprüfung, AöR 107 (1982), 539 (549); a.A. Bebrendt, Die Prüfungstätigkeit des Bundesrechnungshofs außerhalb der unmittelbaren Bundesverwaltung, 2004, S. 31 ff., 42.

349 Hauser, Rechtsqualität von Prüfungsankündigungen des Bundesrechnungshofs, DÖV 2004, 786 (787); Hockenbrink, Zur Befugnis der Rechnungshöfe, im Prüfungsverfahren Verwaltungsakte zu erlassen, DÖV 1991, 241 (242) m.w.N. 
Der Bundesrechnungshof

auf die Darstellung konkreter Prüfungsergebnisse und jährlicher Bemerkungen, ohne dass den Rechnungshöfen dabei Exekutivbefugnisse zukämen. ${ }^{350}$

Unterstrichen wird dies durch die grundsätzliche Nichtanwendbarkeit des VwVfG ${ }^{351}$, die sich aus $\int 17$ Abs. 2 BRHG ergibt, der hinsichtlich der Aufgabenerfüllung des Bundesrechnungshofes ausnahmsweise nur auf $\int 20$ Abs. 5 VwVfG verweist, aber nicht auf das Gesetz als Ganzes. ${ }^{352}$

Gegen die Einstufung von Prüfungsankündigungen als Realakt statt als Verwaltungsakt spricht auch nicht, wie von manchen befürchtet, ${ }^{353}$ dass diese zu einer Verkürzung des Rechtsschutzes des Prüfungsunterworfenen führen würde. Der Bundesrechnungshof hätte im Falle der Weigerung des Adressaten, seinem Auskunftsverlangen zu entsprechen, als ultima ratio den Verwaltungsrechtsweg zu beschreiten, um seine Rechte mit einem Antrag nach \123 VWGO oder einer Leistungsklage durchzusetzen, so dass die Rechte des Betroffenen keinesfalls verkürzt würden. ${ }^{354}$

Unabhängig davon kann auch eine Anfechtungsklage zulässig sein, soweit der Bundesrechnungshof eine Prüfungsankündigung erlässt, die die Form eines Verwaltungsaktes hat und vom Adressaten als solcher zu verstehen ist, was aber nichts an der materiellen Rechtsqualität des Bescheids ändert. ${ }^{355}$

Ferner können im anschließenden Prüfungsverfahren unter Umständen Rechte Prüfungsbetroffener, insbesondere Anhörungserfordernisse, zu beachten sein. Das ist insbesondere dann der Fall, wenn eine Prüfung bei einer juristischen Person des Privatrechts vorgenommen wird und es nachfolgend zu einer Erwähnung in einem Rechnungshofbericht kommt, die sich auf ihre Geschäftsinteressen auswirken kann. ${ }^{356}$ Der genannte Fall ist aber von äußerst geringer praktischer Bedeu-

350 So zum Schleswig-Holsteinischen Landesrechnungshof: Schleswig-Holsteinisches VG - 14. Kammer, Entscheidung vom 17.06.2003 - 14 A 148/01, Rz. 31.

351 Haverkate, Der Schutz subjektiv-öffentlicher Rechte in der Rechnungsprüfung, AöR 107 (1982), 539 (549) m.w.N.; Belemann, Rechtsschutzprobleme im Bereich der Finanzkontrolle, DÖV 1990, 58 (61).

352 Eickenboom/Heuer, Das neue Bundesrechnungshofgesetz, DÖV 1985, 997 (1000); vgl. auch Regierungsentwurf zum BRHG, BT-Drs. 10/3323, S. 15 (zu \ 17) Die Regelungen des VwVfG gelten danach nur bei Angelegenheiten außerhalb der Aufgabenerfüllung des BRH unmittelbar; so wohl auch Fittschen, Verwaltungsarchiv 1992, 165 (172).

353 Fittschen, Durchsetzung der Prüfungsrechte der Rechnungshöfe, Verwaltungsarchiv 1992, 165 (172).

354 Hauser, Rechtsqualität von Prüfungsankündigungen des Bundesrechnungshofs, DÖV 2004, 786 (788).

355 Klostermann, in: Heuer, Kommentar zum Haushaltsrecht, \94, Rn. 19 (Stand: 37. EL Mai 2004); zum Bayerischen Obersten Rechnungshof: BVerwGE 98, 163 (164 f.), das offen lässt, ob der Rechnungshof durch seine „Sonderstellung im Staatsaufbau rechtlich daran gehindert ist, seine Befugnisse durch Verwaltungsakt geltend zu machen“.

356 Ferdinand Kopp, Rechtsschutz des Bürgers gegen den Inhalt und die Verbreitung von Prüfungsberichten eines Rechnungshofs, JuS 1981, 419 (426); Eickenboom/Heuer, Das neue Bundesrechnungshofgesetz, DÖV 1985, 997 (1000); Haverkate, Der Schutz subjektiv-öffentlicher Rechte in der Rechnungsprüfung, AöR 107 (1982), 539 (545 ff.); einschränkend: Belemann, Anm. zum Urteil 
tung, da der Bundesrechnungshof bei der Prüfung bei juristischen Personen des Privatrechts diese in seinen Berichten grundsätzlich anonymisiert (vgl. \9 Abs. 2 PO-BRH), was in Hinblick auf die Grundrechtsrelevanz auch notwendig ist.

$\beta \beta)$ Zwischenergebnis

Im Ergebnis sprechen die besseren Argumente für die Ablehnung der Verwaltungsaktqualität. Jedoch bedarf die Frage der Rechtsnatur von Prüfungsankündigungen wohl einer endgültigen verfassungsgerichtlichen Klärung; bisher hat das Bundesverfassungsgericht sie allerdings ausdrücklich offen gelassen. ${ }^{357}$

Nur am Rande bemerkt sei die geringe praktische Relevanz der Frage nach der Rechtsnatur von Prüfungsankündigungen: Zum einen kommt eine Verweigerung der Zusammenarbeit durch den Prüfungsadressaten fast nie vor, zum anderen ist der Rechnungshof, um erfolgsversprechend prüfen zu können, auf die Zusammenarbeit angewiesen, so dass ein Prozess beziehungsweise die Anwendung von Zwangsmitteln kontraproduktiv wären, wenn auch als ultima ratio nicht ausgeschlossen 358.359

Festzuhalten bleibt, dass selbst dann, wenn man Prüfungsankündigungen Verwaltungsaktqualität zumäße, dies noch keineswegs zwangsläufig zu einer Zuordnung des Bundesrechnungshofes zur Exekutive führte. ${ }^{360}$ Diesen Schluss zieht im Übrigen auch der Hessische VGH in seiner Entscheidung ausdrücklich nicht. ${ }^{361}$ Das Bundesverwaltungsgericht erwähnt in dieser Richtung die Frage, ob der Bundesrechnungshof durch seine Sonderstellung im Staatsaufbau grundsätzlich am Erlass von Verwaltungsakten gehindert sein könnte, lässt sie im Ergebnis aber offen. ${ }^{362}$

Die Prüfungsankündigung ist nur ein vorbereitender Teilaspekt der eigentlichen Tätigkeit des Bundesrechnungshofes. Die Kernaufgaben des Bundesrech-

des OVG Münster vom. 9.5.1978 - XII A 687/76, DÖV 1979, S. 684 (685), der dies nur für den Fall einer „willkürlichen Prüfung ohne sachlichen Anlass“ oder, „wenn Prüfungsfeststellungen ehrverletzende Behauptungen in bezug auf einen Dritten enthalten, die unrichtig sind.“.

${ }^{357}$ BVerfGE 74, 69 (75 f.): „Sollte in einer solchen Aufforderung kein Verwaltungsakt zu sehen sein, so wäre jedenfalls eine verwaltungsgerichtliche Unterlassungsklage zulässig. In Betracht käme auch eine [...] Feststellungsklage, dass ein Prüfungsrecht des Rechnungshofes nicht besteht.“"

$358 \mathrm{Zu}$ den Rechtschutzmöglichkeiten VI.4.; Entsprechend äußerte sich Bundesrechnungshofpräsident Engels im Gespräch mit der Frankfurter Allgemeinen Zeitung, hinsichtlich der Prüfung der gesetzlichen Krankenkassen: „Wenn unser Prüfungsrecht bestritten wird, werden wir es einklagen.“, Frankfurter Allgemeine Zeitung vom 16. März 2007, S. 11.

359 So gab zwischen den Jahren 1980 und 1998 nur dreizehn Fälle, in denen der Bundesrechnungshof zur Durchsetzung von Prüfungsrechten gerichtlich tätig werden musste; Antwort des Parlamentarischen Staatssekretärs Diller auf eine Parlamentarische Anfrage vom 5. Januar 1999, BTDrs. 14/257, S. 12.

360 Vgl. hierzu VI.2.c), wo in diesem Kontext bereits auf exekutive Tätigkeiten hingewiesen wurde, die vom Bundestagspräsidenten trotz seiner Zuordnung zur Legislative sowie der Gerichtsverwaltungen trotz ihrer Zuordnung zur Legislative ausgeübt werden.

361 Die Einordnung offenlassend: Hessischer VGH, Entscheidung vom 21.11.2000 - 10 TG 2627/99 Rz. 16, DÖV 2001, 873.

362 BVerwGE 98, 163 (164 f.). 
Der Bundesrechnungshof

nungshofes, nämlich Kontrolle und Beratung von Staatsorganen der Exekutive und Legislative, sind wie gesehen Verfassungs- und keine Regierungs- oder Verwaltungsaufgaben, ${ }^{363}$ die unmittelbar aus dem Grundgesetz folgen. Auch widerspräche die Zuordnung zur Exekutive dem Willen des Gesetzgebers.

Die Rechnungsprüfung verfolgt staatsinterne ${ }^{364}$ Zwecke, mit der Prüfung staatlicher Einnahmen und Ausgaben hat sie das Ziel, den Umgang staatlicher Stellen mit öffentlichen Finanzmitteln zu kontrollieren und zur Optimierung beizutragen. Auch die Veröffentlichung der Berichte ist letztlich nur ein dem aus dem Demokratieprinzip entspringenden Transparenzgebot geschuldetes erwünschtes Nebenprodukt dieser innerstaatlichen Tätigkeit. Prüfungsgegenstand ist allein die Haushalts- und Wirtschaftsführung des Bundes (vgl. \88 BHO). Stellen außerhalb der Bundesverwaltung sind somit niemals Prüfungsadressat oder -gegenstand, sondern vielmehr bloßes Erhebungsobjekt. Dieser staatsinterne Charakter der Rechnungsprüfung spricht gegen die Befugnis, Prüfungsankündigungen in Form von Verwaltungsakten zu erlassen (das gleiche muss für Vorlage- und Auskunftsverlangen nach $\int 95 \mathrm{BHO}$ gelten) ${ }^{365}$ sowie gegen die Zuordnung zur Exekutive und für eine Sonderstellung im System der Gewaltenteilung.

Der Bundesrechnungshof ist als unabhängiges Organ gerade zur Kontrolle der Exekutive berufen. Darin besteht traditionell seine Hauptaufgabe, wie der geschichtliche Vergleich zeigt. Gegen die Zuordnung des Bundesrechnungshofes zur Exekutive spricht auch die Entwicklung seit 1950 hin zu einer sukzessiven Stärkung seiner Selbständigkeit, ${ }^{366}$ ganz besonders gegenüber der Exekutive. Seine Stellung ist vielmehr geprägt von einer Position zwischen Legislative und Exekutive. Sie ergibt sich aus seinen Aufgaben und auch aus den durch seine Unabhängigkeit stark begrenzten Einflussmöglichkeiten durch diese Staatsgewalten.

Eine Zuordnung zur Exekutive wird seiner Sonderstellung aus diesen Gründen nicht gerecht und ist daher abzulehnen.

cc) Zwischenergebnis

Im Ergebnis lässt sich der Bundesrechnungshof weder nach der Subtraktionsmethode noch anhand positiver Abgrenzungskriterien der Exekutive zuordnen. Im Übrigen brächte eine solche Zuordnung auch Gefahren für seine Unabhängigkeit mit sich. Aus der fast dreihundertjährigen Geschichte des Bundesrechnungshofes und seiner Vorgänger zeigt sich, dass zu Zeiten der Monarchie ebenso wie zur

\footnotetext{
363 Nebel, in Piduch, Bundeshaushaltsrecht, Art. 114, Rn. 29 (Stand: 21.EL Januar 1986).

364 Schleswig-Holsteinisches VG - 14. Kammer, Entscheidung vom 17.06.2003 - 14 A 148/01, Rz. 36; Haverkate, Der Schutz subjektiv-öffentlicher Rechte in der Rechnungsprüfung, AöR 107 (1982), 539 (549); Hockenbrink, Zur Befugnis der Rechnungshöfe, im Prüfungsverfahren Verwaltungsakte zu erlassen, DÖV 1991, 241 (242, 243).

365 Klostermann, in: Heuer, Kommentar zum Haushaltsrecht, \ 95 BHO, Rn. 22 m.w.N. (Stand: 27. EL Mai 2004).

366 Oben: I. Historische Entwicklung.
} 
Zeit des nationalsozialistischen Unrechtsstaates der Rechnungshof der Exekutive zugeordnet war. So kam es zu einer abhängigen Kontrolle, die einseitig im Interesse des jeweiligen Machthabers stattfand. Insofern spricht auch das Demokratieprinzip ${ }^{367}$ für eine unabhängige, keiner Gewalt zugeordnete Stellung.

\section{d) Doppelfunktion, die die gleichzeitige Zuordnung zu Legislative und Exekutive begründet}

Die bereits erwähnte Aussage des Rechtsauschusses des Bundestages, ${ }^{368}$ der Bundesrechnungshof sei „Hilfsorgan sowohl der Legislative als auch der Exekutive“, dürfte wohl Piduch dazu veranlasst haben, dem Bundesrechnungshof eine Doppelrolle zuzusprechen, in der er sowohl der Legislative als auch der Exekutive zuzurechnen sei. ${ }^{369}$ Dagegen sprechen die Gründe, aus denen schon die Zuordnung zu jeder einzelnen der beiden Gewalten abgelehnt wurde. Der Bundesrechnungshof ist weder ein Hilfsorgan der Legislative noch der Exekutive. Seine Tätigkeit kann auch funktional keiner der beiden Gewalten zugeordnet werden, sie enthält vielmehr Elemente aller drei Gewalten sowie allein rechnungshoftypische. Die Stellung des Bundesrechnungshofes ist eine sowohl parlaments- als auch ministerialfreie. ${ }^{370}$

Gegen die Annahme einer Doppelzugehörigkeit sprechen auch die für das Grundgesetz typischen Funktionenverschränkungen und -überschneidungen. Im Rahmen dieser erfolgt ausnahmsweise etwa Rechtsetzung durch Organe der Regierung und Verwaltung oder Regierung und Verwaltung durch Organe der Gesetzgebung, ${ }^{371}$ ohne dass hier doppelte Zugehörigkeiten von Organen zu mehreren Gewalten konstruiert würden. ${ }^{372}$

Richtig ist sicherlich, dass sich die externe Rechnungskontrolle im Spannungsfeld $^{373}$ zwischen Legislative und Exekutive bewegt. Jedoch ist vor allem zu beachten, dass im modernen Parteienstaat Parlament und Regierung in aller Regel keine Gegensätze mehr darstellen wie noch in der konstitutionellen Monarchie. Die Bundesregierung und die sie tragende Regierungsmehrheit im Parlament sind eng miteinander verbunden, wie das Fehlen diesbezüglicher Inkompatibilitätsregeln zeigt. Der Wille der regierenden Parteien zur Macht unterbindet in diesem Verhältnis häufig eine echte Kontrolle durch das Parlament. Der Bundesrechnungs-

\footnotetext{
367 Oben V. Der Bundesrechnungshof als Forderung des Demokratieprinzips.

368 Vgl. Fn. 261, schriftlicher Bericht des Rechtsausschusses, zu Drucksache V/3605, S. 13.

369 Piduch, in: ders., Bundeshaushaltsrecht, (Stand: 1969), Art. 114, Rn. 32 - 36; so wohl auch Nebel, in: Piduch, Bundeshaushaltsrecht, (Stand: Januar 1986), Art. 114, Rn. 29 in der aktuellen Fassung des Kommentars.

370 Krebs, Die rechtliche Stellung der Rechnungshöfe, Verwaltungsarchiv 1980, 77 (82).

371 BVerfGE 30, 1 (28).

372 B. Tiemann, Zur staatsrechtlichen Stellung und Funktion des Bundesrechnungshofes nach der Haushaltsreform, DVBl. 1970, 954 (957) m.w.N.; S. Tiemann, Die staatsrechtliche Stellung der Finanzkontrolle des Bundes, 1974, S. 319.

373 H. Schäfer, Wer kontrolliert unsere Steuergelder?, 1977, S. 32 f.
} 
hof soll daher gerade ein kritisches, notwendigerweise unabhängiges und eigenständiges Organ sein.

\section{e) „Vierte Gewalt“oder Einrichtung sui generis}

Finanzfunktionen sind im Grundgesetz gewaltübergreifend geregelt, dementsprechend kann auch die Finanzkontrolle nicht einer einzelnen Teilgewalt zugeordnet werden. Art. 20 Abs. 2 S. 2 GG zwingt insofern nicht dazu, jedes Staatsorgan unbedingt in das Dreiteilungsschema einzuordnen, die Verfassung selbst kann Ausnahmen begründen. ${ }^{374}$ Angesichts der Tatsache, dass der Bundesrechnungshof keine Staatsgewalt ausübt, insbesondere nicht hoheitlich gegen Grundrechtsträger vorgehen kann, führte eine solche Einordnung auch nicht zu den typischen Problemen der Gesetzesbindung. Die Einordnung außerhalb der drei Gewalten ist nicht als Verstoß gegen den Gewaltenteilungsgrundsatz zu sehen, sondern vielmehr als eine Verstärkung des grundgesetzlichen Systems von Machtkontrollen und -balancierungen durch Vermeidung von Kontrollschwächen.

Ähnlich wie bei Gerichten bestehen nur minimale Verschränkungen mit Legislative und Exekutive, nämlich hinsichtlich der Besetzung der Ämter des Präsidenten und Vizepräsidenten, die in Hinblick auf die demokratische Legitimation des Bundesrechnungshofes notwendig sind. Die Besetzung der höchsten Ämter des Hofes durch Bundestag und Bundesregierung verleiht der Institution mittelbare personelle demokratische Legitimation, zusätzlich zu der „,verfassungsunmittelbaren institutionellen und funktionellen demokratischen Legitimation“, die ihm dadurch zukommt, dass er eine unmittelbar durch das Grundgesetz, das seinerseits auf dem Volkswillen beruht, geschaffene Institution ist. 375

Diese Trennung verdeutlicht die Stellung außerhalb von Legislative und Exekutive, eine Trennung, die ähnlich strikt wie bei den Gerichten ist. Unterstrichen wird sie durch die Systematik des Grundgesetzes, das die Finanzkontrolle durch den Bundesrechnungshof wie das gesamte Finanzwesen in einem separaten Abschnitt zentral und gewaltenübergreifend regelt. Auch in der historischen Entwicklung ist klar die Tendenz einer Verstärkung der Unabhängigkeit (besonders von der Exekutive) zu erkennen.

Als Ergebnis stellt sich im Folgenden die Frage, wie genau die Stellung des Bundesrechnungshofes außerhalb der drei Gewalten zu bestimmen ist.

\footnotetext{
374 BVerfGE 30, 1 (27 f.); Stern, Staatsrecht, Bd. II, 1980, S. 448; Krebs, Die rechtliche Stellung der Rechnungshöfe, VerwArch 1980, 77 (83): gegen „zwanghafte Einordnung in das „ProkrustesBett" des Dreierschemas".

375 v.Arnim, Finanzkontrolle in der Demokratie, in: ders., Finanzkontrolle im Wandel, 1989, S. 39 (42 f.).
} 
a) Vierte Staatsgewalt

Die Einordnung des Bundesrechnungshofes als vierte Staatsgewalt ${ }^{376}$ wurde früher vereinzelt, aber wohl eher im übertragenen Sinne, vertreten, um die Bedeutung einer unabhängigen externen Finanzkontrolle zu betonen. Der Idee, die Rechnungskontrolle als vierte Staatsgewalt zu klassifizieren, könnte sowohl die sprichwörtliche Bezeichnung der Presse als solche wie auch die Existenz einer eigenen Kontrollgewalt im chinesischen Staatsrecht ${ }^{377}$ Pate gestanden haben. Dabei stellt sich von vornherein die Frage nach der grundsätzlichen Vergleichbarkeit mit einer derart unterschiedlichen Rechtsordnung sowie danach, wie treffend die Übersetzung ist, liegen doch die Einordnung als Staatsgewalt und als Staatsfunktion sehr nah beieinander. Die Tatsache, dass der Bundesrechnungshof auf eigene Initiative tätig wird und bei der Wirtschaftlichkeitsbewertung einen großen Beurteilungsspielraum hat, könnte in diese Richtung weisen. Hervorzuheben ist auch eine gewisse mittelbare Mitwirkung an der Willensbildung von Legislative und Exekutive.

Staatsgewalt im Sinne des Art. 20 Abs. 2 GG kann definiert werden als die ,gesamte staatliche Herrschaftsmacht", 378 die insbesondere alle rechtsverbindlichen Entscheidungen staatlicher Organe gegenüber dem Bürger, auch bloße Mitentscheidungsbefugnisse, umfasst; nicht dazu zählen hingegen „,vorbereitende und rein konsultative Tätigkeiten". ${ }^{379}$ Der Bundesrechnungshof bereitet Informationen auf. Dabei bewegt er sich auch im kaum abzugrenzenden Bereich zwischen nachvollziehender und bewertender Kontrolle. ${ }^{380}$ Besonders kommt ihm in der begleitenden Beratung, die er eigeninitiativ und unabhängig vornimmt, in mittelbarer Form Mitgestaltungsmacht zu. Die Entscheidung selbst trifft aber allein das betreffende Organ, es besteht nicht einmal Pflicht der Beratenen, sich mit den Vorschlägen auseinanderzusetzen. Der Entscheidungsgrundlage, die der Bundesrechnungshof liefert, kann allenfalls faktische, nie aber rechtliche Verbindlichkeit zukommen. Der Bundesrechnungshof übt somit keine Hoheitsgewalt aus. Sein Handeln wirkt lediglich mittelbar auf die Entscheidungsprozesse der zur Entscheidung berufenen Verfassungsorgane ein. So ist der Finanzkontrolle nicht die

376 Heuss, DÖH 1954, 6; F. Schäffer, DÖH 1954, 9; Vialon, Haushaltsrecht, 1959, S. 1072: heißt die Bezeichnung als vierte Gewalt gut, ,wenn man mit ihr die Selbständigkeit und Unabhängigkeit der Prüfung und der Prüfungseinrichtung umschreiben will“, sie gehe aber zu weit, wenn man damit die Tätigkeit des BRH in ein gleichberechtigtes Verhältnis zu Legislative, Judikative und Exekutive bringen wolle; Peucker, Grundfragen neuzeitlicher Finanzkontrolle, 1952, forderte weitere verfassungsrechtliche Stützen in Form verfassungsrechtlicher Hilfsgarantien und spricht für eine Ausgestaltung ,zu einer Art vierter Gewalt im Sinne der Montesquieu'schen Gewaltenteilungslehre" aus; weitere Nachweise bei Stern, Staatsrecht, Bd. II, 1980, S. 446 (Fn. 200).

377 B. Tiemann / S. Tiemann, Zum staatsrechtlichen Standort der Finanzkontrolle in rechtsvergleichender Sicht, Der Staat 1974, 519 f.; Detailliert zum chinesischen Kontroll-Yuan: Heinig, Das Budget, Bd. 1, 1949, S. 42, 139 ff.

378 Sachs, in Sachs, GG, Art. 20, Rn. 29; Stern, Staatsrecht II, 1980, S. 533.

379 Sachs, in Sachs, GG, Art. 20, Rn. 29; BVerfGE 47, 253 (273); 83, 60 (73 f.); 93, 37 (68); 77, 1 (40).

${ }^{380}$ Hufeld, in: Isensee/Kirchhof, HStR, Bd. III, 2005, \56, Rn. 4. 
Rolle zugedacht, unmittelbar gestaltende staatliche Tätigkeit auszuüben, ${ }^{381}$ so dass die Einordnung als „vierte Staatsgewalt“ schon in Ermangelung der Ausübung hoheitlicher Gewalt nicht in Betracht kommt. Aus diesem Grund ist er auch selbst nicht als Verfassungsorgan einzustufen. ${ }^{382}$ Die Qualifizierung als Verfassungsorgan setzt zunächst die Grundlage des jeweiligen Organs im Grundgesetz voraus. Das ist beim Bundesrechnungshof in Art. 114 GG der Fall. Neben dieser formellen Erwähnung in der Verfassung ist aber weiter notwendig, dass das jeweilige Organ an der Gesamtwillensbildung des Staates mitwirkt, ${ }^{383}$ was der Bundesrechnungshof wie gesehen nicht tut. ${ }^{384}$

Abgesehen davon wäre diese Annahme in Hinblick auf die Bindung der drei herkömmlichen Teilgewalten an die Verfassung beziehungsweise an Recht und Gesetz über Art. 20 Abs. 3 GG sehr problematisch. Die besondere Bedeutung dieser Begrenzung der Staatsgewalt an sich, die durch die Ewigkeitsgarantie des Art. 79 Abs. 3 GG noch hervorgehoben wird, kann man nicht einfach als überkommen abtun. Auch das Argument, das Grundgesetz selbst könne Ausnahmen von der grundsätzlichen Dreiteilung vorsehen, ist zumindest, was eine Interpretation als eigene „,vierte Gewalt“ angeht, mit größter Vorsicht zu behandeln. Wurde der Bindung der Teilgewalten über Art. 20 Abs. 3 GG vom Verfassungsgeber eine so große Bedeutung beigemessen, dass er die Notwendigkeit sah, diese noch durch Art. 79 Abs. 3 GG zu untermauern, so sind an eine Interpretation der Verfassung dahingehend, dass diese selbst weitere nicht ausdrücklich genannte Teilgewalten vorsehe, allerhöchste Anforderungen zu stellen, wenn man dies überhaupt für zulässig halten will. Das Grundgesetz sieht in Art. 20 Abs. 2 S. 2 GG drei Gewalten vor, für die Einstufung einer weiteren Staatsfunktion als eigene „Gewalt“ müsste das Grundgesetz selbst dies ausdrücklich bestimmen. Eine Einordnung außerhalb der Gewaltentrias als weitere „Gewalt“, etwa hinsichtlich einer auswärtigen Gewalt, der Rechnungsprüfung oder der Planung wird daher zurecht abgelehnt. ${ }^{385}$ Die Bezeichnung des Bundesrechnungshofes, der Presse oder anderer Institutionen als vierte Staatsgewalt erfolgt in aller Regel auch nur im übertragenen Sinn, um ihre besondere Rolle hervorzuheben, die in der politischen Realität an Bedeutung den Teilgewalten nahekommen soll.

Eine ganz andere Frage ist hingegen, ob jedes staatliche Handeln unbedingt unter eine der drei Teilgewalten subsumiert werden muss oder ob das Grundgesetz diesbezüglich hinsichtlich Tätigkeiten, die als nicht zu den Staatsgewalten

\footnotetext{
381 H. Schäfer, Wer kontrolliert unsere Steuergelder, 1977, S. 32.

382 So auch die überwiegende Ansicht im Schrifttum, vgl. Häußer, Zur Antragsbefugnis der Rechnungshöfe im verfassungsrechtlichen Organstreit, DÖV 1998, 544 (545 f.) m.w.N.

383 Maurer, Staatsrecht I, S. 370.

384 Grupp, Die Stellung der Rechnungshöfe in der BRD, 1972, S. 94.

385 Schmidt-Aßmann, in: Isensee/Kirchhof, HStR, Bd. II, 2004, \ 26, Rn. 52; Stern, Staatsrecht, Bd. II, 1980, S. 537 m.w.N.
} 
gehörend charakterisiert werden können, Ausnahmen vorsehen kann und vorsieht.

bb) Institution sui generis beziehungsweise Sonderstellung zwischen oder außerhalb der Gewalten

Als Folge der Einordnungsschwierigkeiten wird der Bundesrechnungshof daher als Einrichtung sui generis bezeichnet beziehungsweise ihm eine Sonderstellung 386 eingeräumt, die ihren Standort zwischen oder neben den Gewalten haben soll.

386 Eickenboom/Heuer, Das neue Bundesrechnungshofgesetz, DÖV 1985, 997 (1000): „Staatsorgan zwischen Exekutive und Legislative"; Stern, Staatsrecht, Bd. II, 1980, S. 448; ders., Der verfassungsrechtliche Status der Rechnungshöfe, in: Böning/v.Mutius, Finanzkontrolle im repräsentativ-demokratischen System, 1990, S. 11 (35); Korthals, Perspektiven für eine wirksamere öffentliche Finanzkontrolle, DÖV 2002, 600 (601): „keiner der drei klassischen Gewalten angehörige „Institution sui generis“; Krebs, Die rechtliche Stellung der Rechnungshöfe, VerwArch 1980, 77 (83) wendet sich gegen die Einordnung der Finanzkontrolle in das „Prokrustes-Bett des Dreierschemas", statt dessen von Legislative und Exekutive gleichermaßen distanzierte Sonderstellung; Degenhart, Kontrolle der Verwaltung durch Rechnungshöfe, VVDStRL 55 (1996), 190 (192ff., 205 f.): „Kontrollfunktionen dürfen nicht auf eine Teilgewalt bezogen werden“; Arndt, Staatshaushalt und Verfassungsrecht, JuS 1990, 343 (346): „,keiner staatlichen Gewalt zuzuordnen, vielmehr im Dienst der ordnungsgemäßen Ausübung aller drei Staatsgewalten“; Müller, Die institutionelle Unabhängigkeit der Rechnungshöfe, DVBl. 1994, 1276; Peucker, Grundfragen neuzeitlicher Finanzkontrolle, 1952, S. 32: Einrichtung sui generis, die in sich Elemente aller drei Gewalten vereinigt, aber in völliger Unabhängigkeit von diesen ihren gesetzlichen Kontrollauftrag ausübt; Siekmann, in: Sachs, GG, Art. 114, Rn. 24: ,...keiner einzelnen Gewalt zuzuordnen, sondern als Einrichtung im Dienst der ordnungsmäßigen Ausübung aller Staatsgewalt anzusehen. “; Di Fabio, in: Isensee/Kirchhof, HStR II, 2004, \27, Rn. 33; Sigg, Die Stellung der Rechnungshöfe, 1983, S. 21 ff., 27; Schwar\%, in: v.Mangoldt/Klein/Starck, GG, Art. 114, Rn. 47, 76: „Keiner der drei Gewalten zuordenbar ... Sonderstellung im Dienste der Gewaltenteilung und -kontrolle“; $S$. Tiemann, Die staatsrechtliche Stellung der Finanzkontrolle des Bundes, 1974, S. 338, betont die aus der „Mehrdimensionalität des Wirkungsbereichs“ des Bundesrechnungshofes erwachsende Sonderstellung im Gewaltenteilungssystem, nicht einer Gewalt, sondern dem Gewaltenteilungsprinzip an sich, zuzuordnen; S. 206 ff.: Bundesrechnungshofkontrolle weder Exekutive, Legislative noch Judikative zuzuordnen; Häußer, Zur Antragsbefugnis der Rechnungshöfe im verfassungsrechtlichen Organstreit, DÖV 1998, 544 (546); Vogel, Verfassungsrechtliche Grenzen der öffentlichen Finanzkontrolle, DVBl. 1970, S. 193 (195): „Standort zwischen Exekutive und Legislative...am ehesten der rechtsprechenden Gewalt vergleichbar"; B. Tiemann / S. Tiemann, Zum staatsrechtlichen Standort der Finanzkontrolle in rechtsvergleichender Sicht, Der Staat, Bd. 13 (1974), 497 (525): ,...institutionell aus der Sphäre der Staatsgewalten ausgegliedert"“; so wohl auch Hufeld, in: Isensee/Kirchhof, HStR, Bd. III, 2005, \56, Rn. 55, 56; Vogel/Kirchhof, Bonner Kommentar, Art. 114, Rn. 174 (Zweitbearbeitung 1973): „BRH ist ein Organ, das, ohne mit eigener Vollzugsgewalt ausgestattet zu sein, selbständig die gegenseitige Kontrolle zwischen den „Gewalten“ insbesondere zwischen Legislative und Exekutive - vermittelt und insoweit zwischen den drei Gewalten steht“; so wohl auch Brunner, Kontrolle in Deutschland, 1972, S. 190 f.: „Rechnungshöfe sind keiner anderen Gewalt zuzurechnen, sie stehen neben Parlament, Regierung und Gerichten.“; Patrig, Haushaltsrecht, Bd. II, Art. 114, Rn. 10 (Stand: 7. EL, 1989): „Rechnungshöfe nehmen eine Sonderstellung ein...zwischen Exekutive und Legislative“. F. Schäfer, Zur Stellung des Präsidenten des Bundesrechnungshofes, in: FS Schäfer, 1975, S. 147 (152): „Rechnungsprüfung lässt sich nicht restlos in eine der drei Gewalten...eingliedern; BRH ist eine „Einrichtung besonderer Art" selbständig gegenüber den politischen Gewalten, andererseits Regierung und Parla- 
Für sich allein genommen hat die Bezeichnung als Institution sui generis beziehungsweise eigener Art ebensowenig wie die Feststellung, dem Bundesrechnungshof komme eine Sonderstellung zu, inhaltlich einen eigenständigen Aussagewert. Man könnte den Bundesrechnungshof auch als Institution sui generis innerhalb einer der drei Gewalten einordnen ${ }^{387}$ oder ihm eine durch seine Unabhängigkeit und Aufgaben begründete Sonderstellung innerhalb einer von ihnen, etwa der Exekutive, zuordnen ${ }^{388}$. Für die Verortung im Gewaltenteilungsschema ist die Bezeichnung für sich allein also nicht sehr hilfreich, Aussagekraft kann ihr nur durch eine genaue Konkretisierung ihrer Ausgestaltung verliehen werden.

Die externe Finanzkontrolle durch den Bundesrechnungshof lässt sich wie gesehen weder aus der geschichtlichen Entwicklung noch von der Systematik des Grundgesetzes oder von Inhalt und Funktionen einer der drei Gewalten zuordnen. Die Finanzverfassung des Grundgesetzes ist gewaltenübergreifend geregelt, dem entspricht auch die Rolle des Bundesrechnungshofes als Finanzkontrollorgan. Jedes staatliche Tätigwerden, das mit finanzwirksamen Folgen verbunden ist, unterliegt seiner Kontrolle, dabei kann es sich um Handlungen sowohl der Legislative als auch der Exekutive und (wenn auch in selteneren Fällen) der Judikative handeln.

Dafür, dass der Bundesrechnungshof eine selbständige Rolle zwischen Legislative und Exekutive einnimmt, spricht die Änderung des Art. 114 GG im Jahre 1969: So sind seitdem Bundestag, Bundesrat und Bundesregierung ausdrücklich als Empfänger der Prüfungsberichte bestimmt. Nach Art. 114 Abs. 2 GG a.F. wurden die Bemerkungen des Bundesrechnungshofes zusammen mit der Bundeshaushaltsrechnung vom Bundesfinanzminister dem Parlament vorgelegt. Art. 114 Abs. 2 S. 2 GG n.F. bestimmt, dass der Bundesrechnungshof sowohl der Bundesregierung als auch dem Bundestag und dem Bundesrat jährlich zu berichten hat. Der unmittelbare Zugang zum Parlament verstärkt die Unabhängigkeit von der Exekutive. Die Änderungen von 1969, ergänzt durch die Bestimmung neuer Ernennungsregeln durch den Erlass des Bundesrechnungshofgesetzes im Jahre 1985, machen die Stellung des Bundesrechnungshofes zwischen Legislative und Exekutive klar. Dies wird auch durch die Intention des Gesetzgebers deutlich, wie sie aus Plenarprotokollen ${ }^{389}$ und den Gesetzesbegründungen zu den maßgeblichen

ment als Hilfseinrichtung (nicht Organ!) dient"; so wohl auch: Dreßler, in: 250 Jahre Rechnungsprüfung, S. 157 ff., der die unabhängige, selbständige Stellung des BRH im Spannungsfeld zwischen Regierung und Legislative betont.

387 Vialon, Streitfragen der öffentlichen Finanzkontrolle, FinArch, Bd. 22 (1962/63), S. 11: „Die Tätigkeit der Rechnungshöfe ist unmittelbar keine vollziehende Gewalt, sondern kontrolliert diese“, „Rechnungshöfe sind...eine verwaltungsmäßig garantierte, ergänzende Institution eigener Art der vollziehenden Gewalt".

388 So etwa: B. Tiemann, Zur staatsrechtlichen Stellung und Funktion des Bundesrechnungshofes nach der Haushaltsreform, DVBl. 1970, 954 (959).

389 Nachweise bei: Hauser, Stellung des Bundesrechnungshofs im System der Gewaltenteilung und in der öffentlichen Verwaltung, DVBl. 2006, 539 (541 f.). 
Reformen ersichtlich ist. Aus der Gesetzesbegründung zum Bundesrechnungshofgesetz ergibt sich, wie schon an anderer Stelle gesehen, dass der Bundesrechnungshof „,bei seiner Aufgabenerfüllung nicht als Verwaltungsbehörde, sondern als unabhängige Institution tätig wird, die beiden Gewalten dient und somit zwischen Legislative und Exekutive steht (vgl. auch schriftlicher Bericht des Rechtsausschusses zu BT-Drucksache V/3605, S 13). Hierbei ist der Bundesrechnungshof weisungsfrei und nur dem Gesetz unterworfen.“390

Diese Stellung des Bundesrechnungshofes zwischen Exekutive und Legislative klingt auch schon im schriftlichen Bericht des Rechtsausschusses des Bundestages zur Haushaltsrechtsreform von 1969 zu den Änderungen des Art. 114 GG an. ${ }^{391}$ Der Bundesrechnungshof ist damit im ministerial- und parlamentsfreien Raum anzusiedeln. ${ }^{392}$

Ziel der Gewaltenteilung ist es, einerseits staatliche Macht zu begrenzen und andererseits positiv die Entscheidungen der verschiedenen Organe durch gegenseitige Kontrolle zu rationalisieren. Der Bundesrechnungshof dient genau diesen Zielen: Durch die Rechtmäßigkeitskontrolle überwacht er im finanziellen Bereich die Einhaltung der gesetzlich vorgegebenen Regeln durch die handelnden Organe; durch die Wirtschaftlichkeitskontrolle soll die Erreichung der politisch gesetzten Ziele (die nicht unter die Überwachung fallen) mit den dazu wirksamsten und wirtschaftlichsten Instrumentarien gewährleistet werden, also eine Optimierung staatlichen Handelns herbeigeführt werden. Diese Stellung im Dienste der gegenseitigen Kontrolle im Rahmen der Gewaltenteilung wird auch dadurch deutlich, dass das Grundgesetz in Art. 114 die Vorschriften über den Bundesrechnungshof in unmittelbarem Zusammenhang mit der Entlastung der Bundesregierung durch das Parlament regelt.

Für eine Rolle zwischen den Gewalten spricht auch die Funktion des Rechnungshofes als Sachwalter der Allgemeinheit ${ }^{393}$ und Gegengewicht zu Pluralismusdefiziten im Parteienstaat. ${ }^{394}$ Die Staatsgewalt geht vom Volke aus und das Volk hat ein großes Interesse daran zu wissen, was mit den Steuergeldern geschieht. Es wird unter Umständen auch von diesem Faktor die Wahl seiner Vertreter abhängig machen. Der Bundesrechnungshof dient so dem Volk selbst durch die Kontrolle aller Träger öffentlicher Ämter, die diese Gelder treuhänderisch verwalten. Sein Bestand und die unabhängige Ausübung seiner Aufgaben sind damit Ausfluss des Demokratieprinzips in seiner Ausformung als Transparenzgebot.

\footnotetext{
390 Regierungsentwurf des BRHG, BT-Drucksache 10/3323, S. 10 (zu \1), S. 12 (zu \5).

391 zu BT-Drucksache V/3605, S. 13.

392 S. Tiemann, Die staatsrechtliche Stellung der Finanzkontrolle, 1974, S. 320.

393 v.Arnim, Finanzkontrolle in der Demokratie, in: ders., Finanzkontrolle im Wandel, 1989, S. 42; Vogel/Kirchhof, in: Bonner Kommentar, Art. 114, Rn. 19 (Stand: 31. Lfg., Zweitbearbeitung, März 1973): „Interessenvertreter der Allgemeinheit; Sigg, Die Stellung der Rechnungshöfe im politischen System der BRD, 1983 , S. 27.

394 v. Arnim, Staatslehre, 1984, S. 502 f.
} 
Art. 20 Abs. 2 S. 2 GG bestimmt die Bindung der Legislative an die Verfassung und die Bindung von Exekutive und Judikative an Recht und Gesetz. Auf dem Gebiet des Finanzwesens obliegt die Kontrolle des Handelns der in die drei Funktionen geteilten Staatsgewalt im Rahmen eben dieser Grenzen dem Bundesrechnungshof. Er ist das Organ, das eine wirksame gegenseitige Kontrolle der Staatsgewalten untereinander auf das Handeln im Rahmen der verfassungsmäßigen (und einfachgesetzlichen) Vorgaben hin auf diesem komplizierten und schwer zu überblickenden Gebiet erst ermöglicht.

Aus der Zusammenschau des Art. 20 Abs. 2 S. 2 und Art. 114 Abs. 2 GG wird die besondere Stellung des Bundesrechnungshofes im Dienste der Gewaltenteilung deutlich. Zwar ist ein eigenes Einschreiten des Bundesrechnungshofes im Wege rechtsverbindlicher Maßnahmen nicht vorgesehen, jedoch gibt er einerseits den „drei Staatsgewalten“ das notwendige Werkzeug in die Hand, effektiv gegenseitige Kontrolle über das Handeln im Rahmen der rechtlichen Vorgaben ausüben zu können. Andererseits ermöglicht er in beschränktem Maße dem Volk als Souverän für den Fall, dass die Selbstkontrollmechanismen des gewaltengeteilten Staates, etwa durch parteipolitisch bedingte Unterwanderung, im Finanzbereich versagen, durch öffentlichen Druck oder entsprechendes Wahlverhalten zu reagieren. Das Grundgesetz hat mit dem unabhängigen Bundesrechnungshof ein Instrument geschaffen, das mit dem Gewaltenteilungsprinzip einhergehend die Ziele der gegenseitigen Kontrolle der Staatsgewalten und der Rationalisierung ihres Handelns sicherstellen soll. 395 Dies geschieht auch durch die Veröffentlichung der Berichte, so dass die praktische Wirksamkeit bei der Verfolgung dieser Ziele teilweise sogar über das zunehmend am Pluralismusdefizit des Parteienstaates krankende Gewaltenteilungsprinzip hinausgeht. ${ }^{396}$ Insbesondere kann sich dies in faktischem politischem Zwang auf das Parlament, gegenüber der Regierung oder auf die Regierung gegenüber der untergeordneten Verwaltung tätig zu werden, auswirken, um aufgedeckte Missstände zu beseitigen.

Die staatsinterne Kontrolle durch Rechnungshöfe dient damit der Hemmung staatlicher Macht, der Rationalisierung staatlicher Entscheidungen ${ }^{397}$ sowie ihrer Transparenz.

Somit kann aus der Zusammenschau des Art. 20 Abs. 2 S. 2 mit Art. 114 Abs. 2 GG gefolgert werden, dass der Bundesrechnungshof durch das Grundgesetz

395 In diese Richtung auch: Krebs, Die rechtliche Stellung der Rechnungshöfe, VerwArch 1980, 77 (83), für eine der Eigenart der Finanzkontrolle entsprechende Sonderstellung außerhalb des Dreierschemas, „von Legislative und Exekutive gleichermaßen distanzierte und unabhängige Finanzkontrolle stellt keine verfassungswidrige „Systemwidrigkeit“ dar, sondern kann vielmehr als bestätigende Konkretisierung des Art. 20 Abs. 2 S. 2 GG aufgefasst werden“.

396 Schwary, in: v.Mangoldt/Klein/Starck, GG, Art. 114, Rn. 75 f.: „Rechnungshof als „neutrales Gegengewicht“ zum parteienstaatlich dominierten parlamentarischen Regierungssystem,...im Dienste der Gewaltenteilung und -kontrolle“.

397 Ausführlich zur Rationalisierungsfunktion der Rechnungshofkontrolle: Krebs, Kontrolle in staatlichen Entscheidungsprozessen, 1984, S. 41, 175 ff.; siehe oben Fn. 226. 
selbst eine von Legislative, Exekutive und Judikative getrennte Sonderstellung als Kontrollorgan zwischen beziehungsweise neben den Gewalten besetzt. Dabei rückt ihn der Zweck seiner Aufgaben mit ihrer Bedeutung als Arbeitsgrundlage für das Parlament in eine funktionale Nähe zum Bundestag. Die Einrichtung des Bundesrechnungshofes als einer von Legislative und Exekutive unabhängigen externen Finanzkontrollinstitution stellt keine verfassungswidrige „Systemwidrigkeit“" dar, sondern muss vielmehr als Bestätigung des Art. 20 Abs. 2 GG und des Systems der Gewaltenkontrolle der Verfassung angesehen werden. ${ }^{398}$

Auch ein Konflikt mit dem Prinzip der Gesetzesbindung des Art. 20 Abs. 3 GG ist nicht zu befürchten: Erstens ergibt sich eine solche Bindung schon über Art. 114 Abs. 2 S. 3 i.V.m. Art. 20 Abs. 3 GG, wonach der seinerseits an die verfassungsmäßige Ordnung gebundene Gesetzgeber die „,weiteren Befugnisse“ des Bundesrechnungshofes regelt, ${ }^{399}$ zweitens übt der Bundesrechnungshof selbst keine Staatsgewalt in Form rechtsverbindlicher Handlungen aus, sondern wird im innerstaatlichen Bereich tätig.

Im Ergebnis kann hinsichtlich der Einordnung des Bundesrechnungshofes festgehalten werden, dass er weder unmittelbar noch mittelbar Staatsgewalt ausübt und dass ihm eine von der dreigeteilten Staatsgewalt verselbständigte Sonderstellung als Institution sui generis im Staatsgefüge zukommt, wobei ihn der Zweck seiner Tätigkeit in eine funktionale Nähe zum Bundestag rückt. Im Dienste der Gewaltenteilung ermöglicht er die Selbstkontrolle anderer Funktionsträger und dient so der Rationalisierung ${ }^{400}$ staatlichen Handelns. Es besteht in Teilaspekten eine funktionale Ähnlichkeit zur Kontrollfunktion der Rechtsprechung, jedoch mit den genannten entscheidenden Unterschieden.

\section{Rechtsschutzmöglichkeiten des Bundesrechnungshofes}

Im Rahmen des Rechtsschutzes sollen hier allein die Möglichkeiten des Bundesrechnungshofes, zur Wahrung seiner Rechte gerichtlich vorzugehen, untersucht werden, die der Absicherung seines verfassungsrechtlichen Status und der Durchsetzung seiner Aufgaben dienen. Nicht untersucht werden hingegen Rechtsschutzmöglichkeiten von Prüfungsunterworfenen, sich gegen Prüfungsankündigungen oder die Erwähnung in Berichten zur Wehr zu setzen, was den Rahmen dieser Arbeit überstiege.

Der Rechnungshof hat nicht die Möglichkeit, rechtsverbindlich zu handeln. Aus diesem Grund stellt sich die Frage, inwieweit er zum einen seine Informations- und Zugangsrechte gegenüber staatlichen und nichtstaatlichen Stellen ge-

\footnotetext{
398 Krebs, Die rechtliche Stellung der Rechnungshöfe, Verwaltungsarchiv 1980, 77 (83) m.w.N.

399 Hauser, Stellung des Bundesrechnungshofs im System der Gewaltenteilung und in der öffentlichen Verwaltung, DVBl. 2006, 539 (540 f.) m.w.N.

400 Siehe oben Fn. 226.
} 
richtlich durchsetzen kann und zum anderen die seinen Rechtsstatus garantierenden Rechte gegenüber anderen Staatsorganen zu verteidigen vermag.

\section{Verwaltungsgerichtliche Durchsetzung von Prüfungsrechten}

Der gerichtlichen Durchsetzung von Prüfungsrechten kommt in der Praxis eher geringe Bedeutung zu, so waren es zwischen 1980 und 1998 nur 13 Verfahren, in denen der Bundesrechnungshof als Kläger oder Prozessbeteiligter gerichtlich tätig werden musste ${ }^{401}$.

$\mathrm{Zu}$ differenzieren ist die gerichtliche Einklagung von Prüfungsrechten gegenüber Stellen der Bundesverwaltung und solchen außerhalb derselben.

\section{a) Vorgehen gegenüber Stellen innerhalb der Bundesverwaltung}

Hinsichtlich der Durchsetzung von örtlichen Erhebungen gem. \94 BHO und Informations- und Auskunftsverlangen gem. $\ 95$ BHO gegen Stellen der Bundesverwaltung ergibt sich der Klageanspruch aus einfachgesetzlichen Normen, so dass der Weg zu den Verwaltungsgerichten nach $\int 40$ Abs. 1 S. 1 VwGO eröffnet ist. Zu erwägen wäre, ob es sich für den Fall, dass die Bundesregierung selbst Prüfungsrechten des Bundesrechnungshofes nicht nachgekommen ist, um einen verfassungsrechtlichen Organstreit handelt, schließlich ist dieser antragsberechtigt nach $\ 63$ BVerfGG ${ }^{402}$. Jedoch muss hinsichtlich des Vorliegens der notwendigen doppelten Verfassungsunmittelbarkeit differenziert werden, ob die grundsätzliche Prüfungskompetenz des Bundesrechnungshofes gem. Art. 114 Abs. 2 GG bestritten wird (beispielweise ihre Erstreckung auf bestimmte Bereiche oder Vorgänge der Bundesverwaltung) oder ob lediglich verfahrensrechtliche Fragen im Einzelfall bestritten werden wie die Verweigerung, Rechten nach $\$ \int$ 94, 95, 96 BHO nachzukommen. ${ }^{403}$ Für den an dieser Stelle erheblichen letzteren Fall wird inhaltlich nicht über spezifisches Verfassungsrecht gestritten, so dass mangels doppelter Verfassungsunmittelbarkeit ebenfalls der Verwaltungsrechtsweg eröffnet ist.

In der obergerichtlichen Rechtsprechung findet sich die Problematik der Klage gegen Stellen der unmittelbaren Bundesverwaltung nur in einer Entscheidung, in der die Zulässigkeit des Rechtstreites als „In-Sich-Prozess“ bejaht wird. 404

Statthafte Klageart wäre aufgrund der unzweifelhaften Ermangelung der Verwaltungsaktqualität die allgemeine Leistungsklage beziehungsweise aufgrund der

\footnotetext{
401 Antwort des Parlamentarischen Staatssekretärs Diller auf eine Parlamentarische Anfrage vom 5. Januar 1999, BT-Drs. 14/257, S. 12.

402 Zur Antragsbefugnis des Bundesrechnungshofes unten: 4. b).

403 v.Mutius/Nawrath, in: Heuer, Kommentar zum Haushaltsrecht, Art. 114, Rn. 13 (Stand 28. EL Juni 1999); Groß, Exekutive Befugnisse der Rechnungshöfe, Verwaltungsarchiv 2004, 194 (207 f.) m.w.N.

404 BSGE 52, 294 (296); Klostermann, in: Heuer, Kommentar zum Bundeshaushaltsrecht, \94 BHO, Rn. 20 (Stand: 37. EL Mai 2004), \ 95 Rn. 23(Stand: EL 32 Juli 2001); befürwortend auch: Groß, Exekutive Befugnisse der Rechnungshöfe, Verwaltungsarchiv 2004, 194 (207).
} 
regelmäßig bestehenden Eilbedürftigkeit der Antrag nach \123 Abs. 1 S. 2 VwGO.

Das Fehlen weiterer Entscheidungen zeigt jedoch die offensichtlich geringe praktische Bedeutung auch angesichts der Möglichkeit, vorrangig die Bundesregierung zwecks Ausübung ihrer Aufsichtsrechte oder als letzte Option den Bundestag anzurufen ${ }^{405}$.

\section{b) Vorgehen gegenüber Stellen außerhalb der unmittelbaren Bundesverwaltung}

Als ultima ratio nach der Anrufung der Zuwendungs- oder auch Aufsichtbehörde steht dem Bundesrechnungshof auch gegenüber Stellen außerhalb der unmittelbaren Bundesverwaltung der Verwaltungsrechtsweg offen, weil sich der Klageanspruch aus einfachgesetzlichen öffentlich-rechtlichen Normen der Bundeshaushaltsordnung ergibt und das streitige Rechtsverhältnis nicht entscheidend vom Verfassungsrecht geprägt ist. Damit handelt es sich um eine öffentlich-rechtliche Streitigkeit nichtverfassungsrechtlicher Art im Sinne des $\int 40$ Abs. 1 S. 1 VwGO. 406

Aus der hier vertretenen Ansicht, dass es sich bei Prüfungsankündigungen ebenso wie bei Vorlage und Auskunftsverlangen nicht um Verwaltungsakte handelt, folgt, dass die Leistungsklage die statthafte Klageart zu ihrer Durchsetzung ist ${ }^{407}$ oder bei Eilbedürftigkeit ein Antrag nach \ 123 Abs. 1 S. 2 VwGO zu stellen wäre.

So gab in einer Entscheidung aus dem Jahr 2002 auch das BVerwG einer Leistungsklage des Bundesrechnungshofes gegen den Freistaat Bayern (Länderfinanzverwaltung) statt und bejahte seine Prüfungskompetenz und die Zulässigkeit einer Prüfungsankündigung. ${ }^{408}$

\section{Organstreitverfahren zur Wahrung verfassungsrechtlich garantierter Rechte}

Aus verfassungsrechtlicher Sicht interessanter ist die Frage, welche Möglichkeiten dem Bundesrechnungshof zur Verfügung stehen, um seinen verfassungsrechtlichen Status zu behaupten. In erster Linie also, welche gerichtlichen Möglichkeiten

405 Belemann, Rechtsschutzprobleme im Bereich der Finanzkontrolle, DÖV 1990, 58 (63); Groß, Exekutive Befugnisse der Rechnungshöfe, Verwaltungsarchiv 2004, 194 (206 f.).

406 Klostermann, in: Heuer, Kommentar zum Bundeshaushaltsrecht, \94 BHO, Rn. 19 (Stand: 37. EL Mai 2004); BVerwGE 116, 92 (93).; BVerfGE 74, 69 (75); OVG Münster v. 9.5.1978, NJW 1980, 137 (138); so auch VGH München, Urteil vom 16.2.1995 - 9 B 94. 778, NVwZ 1996, 1130 (1131); OVG Lüneburg, Urteil vom 14.5.1984 - 8 OVG A 23/83 -, DVBl. 1984, S. 837 (838); Bebrendt, Die Prüfungstätigkeit des Bundesrechnungshofs außerhalb der unmittelbaren Bundesverwaltung, 2004, S. 179 f. m.w.N.

407 Klostermann, in: Heuer, Kommentar zum Bundeshaushaltsrecht, \94 BHO, Rn. 19 (Stand: 37. EL Mai 2004), § 95 Rn. 22 f. (Stand: 32. EL Juli 2001); so auch VGH München, Urteil vom 16.2.1995 - 9 B 94. 778, NVwZ 1996, 1130 (1131); OVG Lüneburg, Urteil vom 14.5.1984 - 8 OVG A 23/83 -, DVBl. 1984, S. 837 (838).

408 BVerwGE 116, 92. 
der Bundesrechnungshof hat, um die rechtliche Wahrung seiner Unabhängigkeit sicherzustellen.

In Betracht kommt insoweit nur der Antrag im Rahmen eines Organstreitverfahrens nach Art. 93 Abs. 1 Nr. 1 GG i.V.m. IS 13 Nr. 5, 63-67 BVerfGG.

Art. 93 Abs. 1 Nr. 1 GG nennt „oberste Bundesorgane oder andere Beteiligte, die durch dieses Grundgesetz oder in der Geschäftsordnung eines obersten Bundesorgans mit eigenen Rechten ausgestattet sind,“ hinsichtlich Streitigkeiten über ihre verfassungsrechtlichen Rechte und Pflichten als mögliche Antragssteller in einem Organstreitverfahren. Der Streit, ob es sich beim Bundesrechnungshof um ein oberstes Bundesorgan handelt, kann dahinstehen, weil er dadurch, dass ihn Art. 114 GG mit eigenen Rechten ausstattet, jedenfalls als anderer Beteiligter Antragssteller sein kann. ${ }^{409}$ Der enger gefasste $\int 63$ BVerfGG, der den Bundesrechnungshof nicht ausdrücklich erwähnt, ist daher verfassungskonform auszulegen. ${ }^{410}$ Der Bundesrechnungshof muss die Möglichkeit haben, sich gegen Maßnahmen anderer Staatsorgane zur Wehr zu setzen, die etwa seine verfassungsrechtlich gewährte Stellung gefährden oder ihn bei der Wahrnehmung seiner Aufgaben behindern. Dafür muss ihm der Weg vor das Bundesverfassungsgericht offen stehen. ${ }^{411}$ Das Grundgesetz stattet den Bundesrechnungshof mit dem besonderen Privileg der richterlichen Unabhängigkeit aus und weist ihm besondere Aufgaben zu. Hieraus folgt, dass er seine verfassungsrechtlichen Privilegien auch selbständig verteidigen können muss, sonst ist die Unabhängigkeit im Konfliktfall nicht viel wert.

Die Frage, ob der Bundesrechnungshof ein Verfassungsorgan ist, was in Ermangelung staatsleitenden Tätigwerdens ganz überwiegend verneint wird, ${ }^{412}$ ist für die Möglichkeit, seine grundgesetzlich garantierten Rechte vor dem Bundesverfassungsgericht im Wege eines Organstreitverfahrens geltend zu machen, hingegen ohne Belang.

409 Schwarz, in: v.Mangoldt/Klein/Starck, GG, Art. 114, Rn. 119 m.w.N.; Korthals, Perspektiven für eine wirksamere öffentliche Finanzkontrolle, DÖV 2002, 600 (607) m.w.N.; Häußer, Zur Antragsbefugnis der Rechnungshöfe im verfassungsrechtlichen Organstreit, DÖV 1998, 544 (549); v.Mutius/Nawrath, in: Heuer, Kommentar zum Haushaltsrecht, Art. 114, Rn. 13 m.w.N. (Stand 28. EL Juni 1999); a. A.: Maun₹, in: Maunz/Dürig, GG, Art. 114, Rn. 26 m.w.N. (Stand: Oktober 1984 Lfg. 23).

410 Sturm, in: Sachs, GG, Art. 93, Rn. 46 ff. m.w.N.; So schon bejahend zur Fähigkeit politischer Parteien Verletzungen ihres verfassungsrechtlichen Status im Wege eines Organstreitverfahrens geltend zu machen der Beschluss des BVerfG vom 20. Juli 1954, BVerfGE 4, 27.

411 v.Mutius/Nawrath, in: Heuer, Kommentar zum Haushaltsrecht, Art. 114 GG, Rn. 13 m.w.N. (Stand 28. EL Juni 1999); Mahrenbolz, in: AK zum GG, Art. 114, Rn. 52; Müller, Die institutionelle Unabhängigkeit der Rechnungshöfe, DVBl. 1994, 1276 (1277); Belemann, Rechtsschutzprobleme im Bereich der Finanzkontrolle, DÖV 1990, 58 (63) m.w.N.

412 Häußer, Zur Antragsbefugnis der Rechnungshöfe im verfassungsrechtlichen Organstreit, DÖV 1998, 544 (545 f.) m.w.N. 


\section{Abstraktes Normenkontrollverfahren}

Teilweise wird die Einführung der Antragsbefugnis des Bundesrechnungshofes im abstrakten Normenkontrollverfahren nach Art. 93 Abs. 1 Nr. 2 GG, IS 13 Nr. 6, 76 ff. BVerfGG vorgeschlagen. ${ }^{413}$ Dies könnte in der Praxis sinnvoll erscheinen, insbesondere bei einem wegen Überschreitung der Kreditgrenzen gem. Art. 115 Abs. 1 S. 2 GG verfassungswidrigen Haushaltsgesetz, welches aus politischen Gründen von Parlament und Regierung nicht verhindert wird. Die Einführung der Antragsbefugnis im abstrakten Normenkontrollverfahren würde die Aufgabe des Bundesrechnungshofes, die Ordnungsmäßigkeit der Haushalts- und Wirtschaftsführung zu prüfen, dadurch sinnvoll ergänzen, dass er die Verfassungswidrigkeit eines finanzwirksamen Gesetzes nicht nur rechtlich unverbindlich feststellen, sondern vom Bundesverfassungsgericht prüfen lassen könnte. ${ }^{414}$

Nach derzeitiger Verfassungslage ist eine Antragsbefugnis im abstrakten Normenkontrollverfahren nicht vorgesehen. Auf den ersten Blick könnte sie auch hinsichtlich der bei politischen Entscheidungen gebotenen Zurückhaltung der Rechnungshöfe problematisch erscheinen. Jedoch würde es sich bei solchen Verstößen gegen Grundregelungen der grundgesetzlichen Finanzverfassung um Fragen handeln, die den Kernbereich der Ordnungs- und Rechtmäßigkeitsprüfung des Bundesrechnungshofes im Rahmen seiner Verfassungs- beziehungsweise Regierungskontrolle betreffen. Ihm über die rechtlich unverbindliche Möglichkeit, eine solche Rechtslage in seinen Berichten zu beanstanden, hinausgehend, das Recht einzuräumen, Verstöße durch das Bundesverfassungsgericht klären zu lassen, wäre eine sinnvolle Ergänzung seiner Rechte und eine Verstärkung der grundgesetzlichen Kontrollmechanismen. So würden diese gerade in einem Bereich gestärkt werden, in dem sie besonders schwach sind. Erließe die von der Regierungsmehrheit getragene Bundesregierung Gesetze aus Gründen politischer Opportunität, die aufgrund ihrer finanziellen Folgen verfassungswidrig wären, sähe sie sich einem unabhängigen Kontrolleur gegenüber, der die Möglichkeit hätte, die beanstandeten Gesetze vom Bundesverfassungsgericht verbindlich prüfen zu lassen.

${ }^{413}$ Korthals, Perspektiven für eine wirksamere öffentliche Finanzkontrolle, DÖV 2002, 600 (606 f.); Kisker, in: Isensee/Kirchhof, HStR, Bd. IV, 1990, \89, Rn. 110; v.Arnim, Grundprobleme der Finanzkontrolle, DVBl. 1983, 664 (668); ders., Staatslehre, 1984, S. 404; Böning, Finanzkontrolle im repräsentativ-demokratischen System, in: Böning/v.Mutius, Finanzkontrolle im repräsentativdemokratischen System, S. 39 (53).

${ }^{414}$ Korthals, Perspektiven für eine wirksamere öffentliche Finanzkontrolle, DÖV 2002, 600 (607) mit zahlreichen Beispielen und Nachweisen. 


\section{Selbsteinschätzung des Bundesrechnungshofes von seiner Stellung und von der Wahrnehmung seiner Funktion}

Die Befugnisse des Bundesrechnungshofes und die Ermessensspielräume, die er insbesondere bei der Wirtschaftlichkeitsprüfung und vor allem auch hinsichtlich der Auswahl der Prüfungsobjekte sowie der Art und Weise der Berichterstattung und Beratung hat, geben ihm Einfluss darauf, „seinen Status und seine Wirkungsmöglichkeiten bis zu einem gewissen Grad selbst zu bestimmen“"415. Innerhalb des von der Verfassung gesetzten Rahmens hat der Bundesrechnungshof hierbei einen großen Spielraum. Die Wirksamkeit seiner Kontrolle und die Einflussmöglichkeiten, die er auf den Staat hat, hängen nicht zuletzt auch davon ab, wie selbstbewusst der Rechnungshof seine Aufgaben wahrnimmt und wie er seinen Kontroll- und Beratungsauftrag im Einzelnen ausübt.

Um die eigene Sicht des Rechnungshofes von seiner Rolle zu ergründen, sollen an dieser Stelle Berichte und sonstige Veröffentlichungen des Bundesrechnungshofes sowie Beiträge von (ehemaligen) Rechnungshofpräsidenten zur wissenschaftlichen Diskussion untersucht werden. Teilweise ist hierauf bereits oben unter IV. 4. „Behandlung politischer Entscheidungen“ eingegangen worden. Im Vordergrund steht im Folgenden die verfassungsrechtliche Einordnung.

Schon in einer Studie des Internationalen Sekretariats der Obersten Rechnungskontrollbehörden, die auf einem an alle Mitglieder versandten Fragebogen aus dem Jahre 1963 beruht, äußerte der Bundesrechnungshof auf die Frage, welche Stellung er im System der Staatsgewalten einnehme, etwas nebulös, dass er „weder der gesetzgebenden noch der rechtsprechenden Gewalt zuzuordnen sei $^{\prime \prime} .416$

\section{Auszüge aus Veröffentlichungen von Rechnungshofsmitgliedern}

Bundesrechnungshof und Rechnungshöfe der Länder teilen die Auffassung, dass sie weder Staatsgewalt ausüben noch einer der drei Gewalten in ihrer Form als Legislative, Judikative und Exekutive zuzuordnen sind. Dieses Bild wird auch aus Veröffentlichungen, die von Präsidenten oder Vizepräsidenten deutscher Rechnungshöfe geschrieben wurden, deutlich oder klingt zumindest in ihnen an:

Hans Schäfer, Präsident des Bundesrechnungshofes von 1971-1978, setzte sich immer wieder in Veröffentlichungen ausführlich mit der Stellung des Rechnungshofes im Verfassungsgefüge auseinander. Er kommt letztlich zu dem Ergebnis, dass sich eine Zuordnung zu einer der drei Gewalten nicht rechtfertigen lasse und der Rechnungshof vielmehr eine Behörde sui generis „,im Spannungsfeld zwischen der gesetzgebenden und vollziehenden Gewalt" sei. ${ }^{417}$

\footnotetext{
415 v. Arnim, Finanzkontrolle in der Demokratie, in: ders., Finanzkontrolle im Wandel, 1989, S. 40.

416 Beran/Konvicka, Finanzkontrolle international gesehen, 1967, S. 72.

${ }^{417}$ H. Schäfer, Wer kontrolliert unsere Steuergelder? Finanzprüfung durch den Bundesrechnungshof, 1977, S. 29 ff., 34; ders., Verfassungsrechtliche Stellung Bundesrechnungshof - Parlament, Bulle-
} 
Sein Nachfolger, Karl Wittrock, Präsident des Bundesrechnungshofes von 1978 1985, wendet sich deutlich gegen die Einstufung des Bundesrechnungshofes als Hilfsorgan des Parlaments. ${ }^{418}$ Er betont, dass neben der Nähe zum Bundestag auch das „konstruktiv sachbezogene Verhältnis des Bundesrechnungshofes zur Bundesregierung als der obersten Repräsentanz der Exekutive“ zu sehen sei. ${ }^{419}$

Heinz. Günter Zavelberg, Präsident des Bundesrechnungshofes von 1985 - 1993, beschreibt den Bundesrechnungshof als unabhängiges Organ der Finanzkontrolle, das als solches außerhalb der drei Gewalten stehe und weder Hilfsorgan der Regierung noch des Parlaments sei. ${ }^{420}$

Ernst Heuer, Vizepräsident 1985-1996, beschreibt den Bundesrechnungshof als Staatsorgan zwischen Exekutive und Legislative. ${ }^{421}$ Mit dem neuen Bundesrechnungshofgesetz sieht er diese Konstruktion unterstrichen und der entgegenstehenden Ansicht, er sei der Exekutive zuzuordnen, den Boden entzogen. ${ }^{422}$

Auch der Vizepräsident des Bundesrechnungshofes, Norbert Hauser, sieht den Bundesrechnungshof als „Interessenvertreter der Allgemeinheit im Spannungsverhältnis zwischen den Gewalten und somit keiner von ihr zugehörig“. ${ }^{423}$ Explizit lehnt er die Klassifizierung des Bundesrechnungshofes als Behörde, außer wenn es um das verwaltende Tätigwerden im Rahmen der eigenen Selbstorganisation durch seine Präsidialabteilung (vgl. \2 Abs. 2 S. 3 BRHG) geht, ab. ${ }^{424}$

Auch ein Blick auf das Selbstverständnis der Landesrechnungshöfe ist hier sinnvoll, entsprechen die maßgeblichen Regelungen zu Stellung und Aufgaben doch zum Teil wörtlich der bundesrechtlichen.

Der ehemalige Präsident (1989-2001) des Hessischen Rechnungshofes, Udo Müller, hält eine Zuordnung zu einer der drei Gewalten für unmöglich, vielmehr seien die Rechnungshöfe von Bund und Ländern im pluralistischen Verfassungsverständnis „eine neue Form des Kompetenzausgleichs von eigener staatsrechtlicher Qualität“.425

Der ehemalige Präsident des Bayerischen Obersten Rechnungshofes, Gotthard Brunner, hält die Rechnungshöfe ,,weder der Exekutive noch dem Parlament zuor-

tin der Bundesregierung Nr. 118 vom 22.11.1977, S. 1083; in diese Richtung auch schon ders., Der Bundesrechnungshof im Verfassungsgefüge der Bundesrepublik, DÖV 1971, 542 (543).

418 Wittrock, Möglichkeiten und Grenzen der Finanzkontrolle. Das Verhältnis des Bundesrechnungshofes zum Bundestag, ZParl 1982, 209 (216).

419 Wittrock, Auf dem Weg zu einem neuen Bundesrechnungshofgesetz, DÖV 1984, 649 (651).

420 Zavelberg, Staatliche Finanzkontrolle in Deutschland, Verw. 1995, 513 (514).

421 Eickenboom/Heuer, Das neue Bundesrechnungshofgesetz, DÖV 1985, 997.

422 Eickenboom/Heuer, Das neue Bundesrechnungshofgesetz, DÖV 1985, 997 (1000) m.w.N.

423 Hauser, Stellung des Bundesrechnungshofs im System der Gewaltenteilung und in der öffentlichen Verwaltung, DVBl. 2006, 539 (542).

424 Hauser, Stellung des Bundesrechnungshofs im System der Gewaltenteilung und in der öffentlichen Verwaltung, DVBl. 2006, 539 (543).

425 Müller, Die institutionelle Unabhängigkeit der Rechnungshöfe, DVBl. 1994, 1276. 
denbar“, „Sie stehen im Spannungsfeld zwischen Legislative und Exekutive“.426 Er warnt auch vor einer Änderung dieses Standorts wegen der unabsehbaren Folgen für die Unabhängigkeit.

Der Präsident des Rechnungshofes von Schleswig-Holstein, Gernot Korthals, betont die Unabhängigkeit der Rechnungshöfe und ordnet sie als keiner der drei klassischen Gewalten zugehörig, sondern vielmehr als Institutionen sui generis ein. 427 Insbesondere lehnt er die Einstufung als Hilfsorgane der Parlamente ausdrücklich ab. Seiner Ansicht nach verstehen sich Rechnungshöfe heute als „moderne zukunftsorientierte Beratungsdienstleister", die zugleich Partner des Parlaments wie auch der Exekutive sind. ${ }^{228}$

Dem ehemaligen Präsidenten des Niedersächsischen Landesrechnungshofes, Heiner Herbst, zufolge versteht sich dieser nicht mehr nur als kritischer Kontrolleur staatlichen Finanzgebarens, sondern als ,beratender Partner sowohl der Legislative als auch der Exekutive". ${ }^{429}$

So auch Paul Georg Schneider: Als ehemaliger Präsident des Rechnungshofes Rheinland-Pfalz betont er, dass Rechnungshöfe sich nicht in das traditionell dreigliedrige Gewaltenteilungsschema einordnen lassen, sondern vielmehr ,als Einrichtungen eigener Art“ zwischen den Gewalten stehen, wobei sie auch nicht „als Hilfsorgane" der einen oder anderen Gewalt dienen. ${ }^{430}$

\section{Analyse ausgewählter Rechnungshofberichte}

In einer aktuellen Veröffentlichung des Bundesrechnungshofes wird die eigene Sichtweise klar und eindeutig dargelegt: Der Bundesrechnungshof sieht sich hiernach als „Institution eigener Art, die weder der Legislative oder der Judikative noch der Exekutive zuzurechnen" ist und insbesondere auch keine Exekutivgewalt hat. 431

Bei der Wahrnehmung seines Prüfungs- und Beratungsauftrages beurteilt der Bundesrechnungshof nicht politische Entscheidungen, sehr wohl aber ihre Voraussetzungen oder Auswirkungen. ${ }^{432}$ Das ergibt sich auch aus dem gesetzlichen Auftrag gem. \97 Abs. 2 Nr. 4 BHO, wonach der Bundesrechnungshof Maßnahmen für die Zukunft in seinen Bemerkungen zu empfehlen hat. Dass auch der

426 Brunner, Möglichkeiten und Grenzen der öffentlichen Finanzkontrolle, in: FS Schäfer, 1975, S. 169 (184).

${ }^{427}$ Korthals, Perspektiven für eine wirksamere öffentliche Finanzkontrolle, DÖV 2002, 600 (601).

428 Korthals, Beiträge der Rechnungshöfe zur Verwaltungsreform, DÖV 2000, 855.

${ }^{429}$ Heiner Herbst in seiner Rede anlässlich des 50-jährigen Bestehens des Niedersächsischen LRH am 5. November 1998, S. 7.

430 Schneider, Externe Finanzkontrolle in Deutschland, Vortrag anlässlich des III. EURORAIKongresses in Straßburg 1998.

431 Bundesrechnungshof, Der Bundesrechnungshof und die Prüfungsämter des Bundes, 2005, S. 6, 16 f.

432 Wittrock, Möglichkeiten und Grenzen der Finanzkontrolle, Bulletin der Bundesregierung, 1982, 524 (527).; Bundesrechnungshof, Bemerkungen 2002, S. 7 (Zf. 2.1); Bundesrechnungshof, Der Bundesrechnungshof und die Prüfungsämter des Bundes, 2005, S. 16; vgl. auch: \6 Abs. 1 PO-BRH. 
Bundestag auf derartige Expertisen großen Wert legt, zeigt seine Bitte an den Bundesrechnungshof, dem Haushaltsausschuss Prüfungsergebnisse mitzuteilen, die ,zu gesetzgeberischen Maßnahmen geführt haben oder für anstehende Gesetzesvorhaben von Bedeutung sind“.433

Der Bundesrechnungshof beurteilt entsprechend auch die Wirksamkeit von Gesetzen, was dem Gesetzgeberwillen entspricht, wie sich aus den Materialien zum Bundesrechnungshofgesetz von 1985 ergibt. ${ }^{434}$ So empfiehlt er auch Gesetzesänderungen, wenn er über Erkenntnisse verfügt, dass bestehende Gesetze zu Ergebnissen führen oder zu führen drohen, die vom Gesetzgeber nicht gewollt sind.

Eine besondere Rolle kommt in diesem Zusammenhang der Aufgabe der Beratung zu. Die große praktische Bedeutung und die starken faktischen Einflussmöglichkeiten auf die Entscheidungsfindung in der Bundesrepublik zeigt sich schon in den folgenden Beispielen, in denen in jüngerer Zeit eine Beratung des Bundestages durch den Bundesrechnungshof stattgefunden hat:

Beschaffung eines Großraumtransportflugzeuges Airbus A400M,435 Machbarkeitsstudien für Magnetschwebebahnstrecken in Bayern und NordrheinWestfalen, ${ }^{436}$ Einsatz externer Berater in der Bundesverwaltung, wobei der Bundesrechnungshof zehn für den Beratereinsatz unverzichtbare Eckpunkte festlegte, ${ }^{437}$ Auswirkungen der Aufteilung der Regierungsfunktionen auf Berlin und Bonn sowie diesbezügliche Optimierungsmöglichkeiten, ${ }^{438}$ Ermittlung von Einsparpotential bei Auslandseinsätzen der Bundeswehr durch bessere Nutzung gewonnener Erkenntnisse, ${ }^{439}$ Ausbau und Finanzierung der Schienenwege durch den Bund, ${ }^{440}$ Reform des Schuldenmanagements des Bundes, ${ }^{441}$ Beschaffungsvorhaben der Bundeswehr (Raketenabwehrsystem MEADS), ${ }^{442}$ Kritik an der Verwaltung und Kontrolle des Arbeitslosengeldes II, ${ }^{443}$ Prüfung bei der Deutschen Bahn: Versäumnisse bei der Instandhaltung und Erneuerung des Schienennetzes führen

\footnotetext{
433 Beschlussempfehlung und Bericht des Haushaltsausschusses, BT-Drs. 14/9460, S. 2.

434 BT-Drs. 10/3510, S. 4.

435 Bundesrechnungshof, Bemerkungen 2004, S. 34.

436 Bundesrechnungshof, Bericht vom 4. Juni 2002.

437 Bundesrechnungshof, Pressemitteilung vom 19.12.2005.

438 Bundesrechnungshof, Bericht vom 17. Juni 1999; Bericht vom 9. Oktober 2002; Ergebnisbericht 2003, S. 85.

439 Bundesrechnungshof, Bemerkungen 2005, S. 140.

440 Bundesrechnungshof, Bericht vom 08.03.2006.

441 Bundesrechnungshof, Bemerkungen 2005, S. 35.

442 Bundesrechnungshof, Bemerkungen 2005 zur Haushalts- und Wirtschaftsführung des Bundes, S. 211.

443 Vgl. „Arbeitslosengeld II hat eklatante Mängel - Rechnungshof rügt schwere Mängel / Mehr Kontrolle durch Arbeitsagentur gefordert“, Frankfurter Allgemeine Zeitung vom 22. Mai 2006, S. 13.
} 
zu Sicherheitsmängeln, ${ }^{444}$ Studie des Bundesrechnungshofes zu Möglichkeiten der Reform der Entwicklungshilfe. ${ }^{445}$

Diese Auswahl an Beispielen macht die Bedeutung des Beratungsauftrages des Bundesrechnungshofes deutlich. Es handelt sich hier um bedeutende wirtschaftliche Großprojekte, teilweise um organisatorische Grundsatzentscheidungen, die fast alle eines gemeinsam haben: die wirtschaftliche Bedeutung und ihre Umstrittenheit in Politik und Öffentlichkeit. Der Bundesrechnungshof schafft durch seine Beratung damit oft erst die sachliche Entscheidungsgrundlage durch die Aufbereitung, wirtschaftliche Bewertung (wozu auch das Aufzeigen möglicher Alternativen gehört) und damit Nutzbarmachung der zugrundeliegenden Sachverhalte für die Entscheidungsträger.

Die selbstbewusste Herangehensweise und die Betonung der eigenen Unabhängigkeit von staatlichen Entscheidungsträgern zeigt sich auch in der gegen alle Widerstände aus Verbänden und zum Teil auch aus der Politik angekündigten umfassenden Kontrolle der Krankenkassen. Die Überwachung der gesetzlichen Krankenkassen, die immer wieder wegen unangemessen hoher Ausgaben für die Verwaltung und wegen üppiger Vorstandsgehälter in der Kritik standen, soll zu „einer neuen Schwerpunktaufgabe“ gemacht werden, wobei ein voller Zugriff auf die Bücher gefordert wird und notfalls auch eingeklagt werden soll. 446

\section{Bewertung}

Bereits das Vorwort einer Veröffentlichung des Bundesrechnungshofes aus dem Jahre 2005 von seinem Präsidenten Dieter Engels spiegelt die selbstbewusste Wahrnehmung der Aufgaben und das Bewusstsein über die Einflussmöglichkeiten des Bundesrechnungshofes wider. So wird deutlich gemacht, dass sich das Parlament in regelmäßig über 90\% der Fälle den Vorschlägen des Bundesrechnungshofes anschließt. ${ }^{447}$ Außerdem betont Engels die Dimensionen der Tätigkeit durch den Hinweis, dass jährlich öffentliche Ausgaben und Einnahmen in Höhe von über 500 Milliarden Euro durch den Bundesrechnungshof und seine nachgeordneten Prüfungsämter geprüft würden und dass der Rechnungshof durch seine Hinweise und Empfehlungen jährlich für Einsparungen und Mehreinnahmen in Höhe von 3 bis 5 Milliarden Euro sorge; dem stünden Kosten von „,nur“ etwa 80 Millionen Euro jährlich für die Finanzierung der Arbeit des Hofes entgegen. ${ }^{448}$

Aussagekräftig ist auch der Blick auf die Auswahl der Prüfungsobjekte. Es handelt sich dabei um Themen von größter Bedeutung, wie schon die hier aufgeführten Beispiele verdeutlichen. Die Beratungsfunktion des Hofes, der mit der

\footnotetext{
${ }^{444}$ Frankfurter Allgemeine Zeitung vom 03.03.2007, S. 11.

445 Frankfurter Allgemeine Zeitung vom 02.03.2007, S. 13.

446 Vgl. Bundesrechnungshofspräsident Engels, in: Frankfurter Allgemeine Zeitung vom. 16.03.2007, S. 11.

447 Bundesrechnungshof, Der Bundesrechnungshof und die Prüfungsämter des Bundes, 2005, S. 2 f.

448 Bundesrechnungshof, Der Bundesrechnungshof und die Prüfungsämter des Bundes, 2005, S. 2 f.
} 
Untersuchung häufig im Vorfeld politischer Entscheidungen tätig wird und eine unabhängige Expertise abliefert, ist damit geeignet, als Entscheidungsgrundlage zu dienen. Es ist Aufgabe und Wille des Bundesrechnungshofes, so seine Erfahrung in staatliche Entscheidungsprozesse einzubringen, und wie gesehen legt das Parlament auch großen Wert auf sie. Entscheidend für die Wirksamkeit ist aber, dass das Parlament den Empfehlungen folgt.

\section{Zusammenfassung der Ergebnisse des 1. Teils}

Aus der langen Geschichte von Bundesrechnungshof und seinen Vorgängerinstitutionen wird deutlich, dass ihre Verortung im Staatsaufbau stets Ausdruck der herrschenden Machtverhältnisse im Staat war. Zunächst war sie Hilfsorgan des absoluten Monarchen und nur diesem zur Verwaltungskontrolle unterstellt. Mit der Notwendigkeit, wachsende Zugeständnisse an das Parlament zu machen, erkämpfte sich dieses im 19. Jahrhundert schließlich das Budgetrecht. Bis es jedoch auch Empfänger der Berichte des Rechnungshofes wurde, was für die sinnvolle Ausübung dieses Rechtes unabdingbar war, bedurfte es jedoch weiterer Auseinandersetzungen mit der Krone. In der Weimarer Republik war der Rechnungshof per Gesetz unabhängig von der Reichsregierung, stand dieser faktisch aber recht nahe. Auch der Reichsstag profitierte unmittelbar von den Berichten und hatte sogar das Recht, sich beraten zu lassen. Im nationalsozialistischen Staat kam es zur Gleichschaltung des Rechnungshofes. Das traditionelle die Unabhängigkeit der Institution wahrende Kollegialprinzip wurde zugunsten des „Führerprinzips“ aufgegeben; der Rechnungshof war faktisch nur noch ein Werkzeug der nationalsozialistischen Machthaber.

Nach der Errichtung des Bundesrechnungshofes im Jahre 1950 wurde zunächst im Wesentlichen an die Stellung aus der Weimarer Zeit angeknüpft. Der Rechnungshof war völlig unabhängig, eine gewisse strukturelle Nähe zur Regierung war aber nicht zu verleugnen. Dem schaffte die Haushaltsreform von 1969 Abhilfe, indem sie den Bundesrechnungshof näher an das Parlament rückte; sinnvoll weitergeführt wurde die Reform schließlich 1985 durch das neue Bundesrechnungshofgesetz.

Was die Entwicklung der Aufgaben deutscher Rechnungshöfe angeht, so nahmen sie ursprünglich eine Vollprüfung der Rechnungen des Staates vor, wovon aber bereits vor dem ersten Weltkrieg zugunsten einer stichprobeweisen Prüfung Abstand genommen wurde. Bei der heutigen externen Finanzkontrolle durch den Bundesrechnungshof kommt neben der Rechnungsprüfung im engeren Sinne und der Ordnungsmäßigkeitsprüfung vor allem der Prüfung der Wirtschaftlichkeit eine bedeutende Rolle zu. Letztere nimmt einen großen Teil seiner Berichterstattung ein. Hinsichtlich der Maßstäbe anhand derer der Bundesrechnungshof prüft, ist es somit zu einer Verschiebung von der einstigen Rechnungsprüfung im engeren Sinne, wie sie noch einige seiner Vorläufer ausschließlich vornahmen, hin zur 
Prüfung der Ordnungsmäßigkeit und Wirtschaftlichkeit gekommen. Zu den Prüfungen kommt der Beratungsauftrag, dem der Bundesrechnungshof auf Bitte anderer Staatsorgane hin nachkommen kann, den er aber auch aus eigener Initiative, unter Umständen sogar gegen den Willen des zu Beratenden, ausübt. Zuletzt kommt ihm die Aufgabe zu, Bundestag, Bundesrat, Bundesregierung, Bundesministerien und auch die Öffentlichkeit durch seine Berichte von den Ergebnissen seiner Prüfungen zu unterrichten. Alle diese Aufgaben sind als eigenständige „rechnungshoftypische“ Tätigkeiten zu bewerten; von ihrer Eigenart und ihrem materiellen Funktionsgehalt lassen sie sich keiner der drei Gewalten zuordnen, auch wenn es wie gesehen gewisse Ähnlichkeiten insbesondere zum Tätigkeitsbereich der Judikative gibt.

Die bis heute umstrittene Einordnung im System der Gewaltenteilung ist daher dahingehend zu beantworten, dass der Bundesrechnungshof weder Organ der Legislative noch der Exekutive und Judikative ist. In Ermangelung der Ausübung von Staatsgewalt kann er auch nicht als „,vierte Staatsgewalt“ eingeordnet werden, seine Tätigkeit ist vielmehr eine staatsinterne ohne rechtsverbindliche Folgen; zumal an eine derartige Verortung wegen Art. 20 Abs. 3 GG höchste Anforderungen zu stellen wären. Seine Stellung ist als unabhängige Sonderstellung zwischen den Gewalten zu umschreiben, wobei eine strukturelle Nähe zum Bundestag besteht, der am meisten auf die Arbeit des Bundesrechnungshofes angewiesen ist. Er stärkt so das Prinzip der Gewaltenteilung durch die Verbesserung der gegenseitigen Kontrolle der Staatsgewalten auf dem Gebiet der Staatsfinanzen und durch seinen Beitrag zur Rationalisierung auf diesem Gebiet. Als Forderung des Demokratieprinzips und Garant für Transparenz in allen finanzrelevanten Bereichen staatlichen Tätigwerdens kommt dem Bundesrechnungshof überragende Bedeutung zu.

Als Rechtsschutzmöglichkeit steht ihm zur Durchsetzung seiner Prüfungsund Informationsrechte nach $\ 91-96$ BHO der Weg vor die Verwaltungsgerichte offen. Er kann diese im Wege der Leistungsklage einklagen. Hinsichtlich seiner verfassungsrechtlichen Hilfsgarantien, insbesondere der Unabhängigkeitsgarantien und auch des Bestehens seines lückenlosen Prüfungsauftrages, ist der Bundesrechnungshof im Rahmen eines Organstreitverfahrens vor dem Bundesverfassungsgericht antragsbefugt. Zu erwägen wäre, ihm in Zukunft auch die Möglichkeit zu geben, ein abstraktes Normenkontrollverfahren anzustrengen, was seine Aufgabe der (im Ergebnis unverbindlichen) Verfassungs- beziehungsweise Regierungskontrolle sinnvoll ergänzen würde. 


\section{Zweiter Teil:}

\section{Ausgewählte mitgliedstaatliche Rechnungshöfe}

Im folgenden zweiten Teil sollen die ausgewählten mitgliedsstaatlichen Rechnungshöfe Frankreichs, Österreichs, Spaniens und des Vereinigten Königreichs jeweils einzeln dargestellt werden. Im dritten Teil wird der Europäische Rechnungshof untersucht und sodann werden alle untersuchten Rechnungshöfe im Wege der Rechtsvergleichung einander gegenübergestellt.

Die untersuchten obersten Rechnungskontrollinstitutionen wurden aufgrund ihrer, trotz zumeist starker struktureller Ähnlichkeiten hinsichtlich ihrer Aufgaben, unterschiedlich ausgeprägten Stellung im Aufbau des betreffenden Staatssystems ausgewählt. Sie weisen teilweise so unterschiedliche Ausgestaltungsformen auf, dass ein Vergleich besonders interessant ist, als er zum einen die verschiedenen Möglichkeiten der Ausgestaltung und zum anderen die trotz allem bestehenden Gemeinsamkeiten verdeutlicht. Gemeinsam ist ihnen allen, dass sie Bestandteil des Rechnungshofsystems des europäischen Staaten- und Verfassungsverbundes sind.

Ziel ist, den Wert der Rechtsvergleichung als Erkenntnismethode ${ }^{449}$ nutzend die Bestimmung von Unterschieden und Gemeinsamkeiten der unterschiedlichen

449 Krüger, Eigenart, Methode und Funktion der Rechtsvergleichung im öffentlichen Recht, in: FS Kriele, 1997, S. 1393 (1403); Wieser, Vergleichendes Verfassungsrecht, 2005, S. 19. 
Ausgewählte mitgliedstaatliche Rechnungshöfe

Ausgestaltungsformen der Rechnungshöfe sowie ihrer Vor- und Nachteile herauszuarbeiten. Rechtsvergleichung erfolgt durch die Wissenschaft, um den eigenen Blickwinkel zu erweitern und eine möglichst optimale Lösung für ein Problem zu finden und ist damit eine Methode zur Rationalitätssteigerung bei der Lösung einzelstaatlicher Rechtsfragen. ${ }^{450}$ Die Rechtsvergleichung vermag es, durch die Schaffung von Distanz zur eigenen Rechtsordnung Vor- und Nachteile verschiedener Modelle sichtbar zu machen. ${ }^{451}$ So wird auf die Frage einzugehen sein, inwieweit der Vergleich mit ausländischen Institutionen die hier vertretene Einordnung des Bundesrechnungshofes im System der Gewaltenteilung zu untermauern vermag.

Als Grundvoraussetzung der Rechtsvergleichung ist zunächst die grundsätzliche Vergleichbarkeit der untersuchten Rechnungshöfe festzustellen. Die Rechtsvergleichung innerhalb verwandter Rechtsordnungen wird dabei im Allgemeinen als die am meisten Erkenntnisse einbringende erachtet. ${ }^{452}$ Dies geschieht vorliegend im Wege eines Mikrovergleiches ${ }^{453}$, der auf die externen Finanzkontrollinstitutionen in ihrem unmittelbaren verfassungsrechtlichen Kontext beschränkt bleibt. Deutliche Parallelen bestehen dabei hinsichtlich Zielsetzung, Aufgaben und Prüfungsmaßstäben.

Hinsichtlich der Frage nach der Vergleichbarkeit des Europäischen Rechnungshofes mit denen der Mitgliedstaaten muss im Auge behalten werden, dass ein Zweck der Rechtsvergleichung die Schaffung supranationalen Rechts ist, ${ }^{454}$ so dass ihm für die Schaffung und Weiterentwicklung des europäischen Staaten- und Verfassungsverbundes zentrale Bedeutung zukommt. ${ }^{455}$ So sind in Errichtung und Ausgestaltung des Europäischen Rechnungshofes deutlich erkennbar Elemente zu finden, die den sich in vielen Aspekten ähnelnden Rechnungshofmodellen der Mitgliedstaaten entstammen.

Für die Vergleichbarkeit des Europäischen Rechnungshofs spricht weiter, dass die Finanzverfassung der Europäischen Union große Ähnlichkeiten mit der eines Staates aufweist. Sie verfügt über eigene Einnahmen und auch ihr Haushalts- und Budgetkreislauf weist in seinen Grundzügen Parallelen zum nationalstaatlichen

450 Sommermann, Die Bedeutung der Rechtsvergleichung für die Fortentwicklung des Staats- und Verwaltungsrechts in Europa, DÖV 1999, 1017 (1025).

451 Sommermann, Die Bedeutung der Rechtsvergleichung für die Fortentwicklung des Staats- und Verwaltungsrechts in Europa, DÖV 1999, 1017 (1020).

452 Krüger, Eigenart, Methode und Funktion der Rechtsvergleichung im öffentlichen Recht, in: FS Kriele, 1997, S. 1393 (1404 f.); Wieser, Vergleichendes Verfassungsrecht, 2005, S. 21.

453 Zum Begriff: Starck, Rechtsvergleichung im öffentlichen Recht, JZ 1997, 1021 (1025 f.).

454 Starck, Rechtsvergleichung im öffentlichen Recht, JZ 1997, 1021 (1025 f.).

455 Sommermann, Die Bedeutung der Rechtsvergleichung für die Fortentwicklung des Staats- und Verwaltungsrechts in Europa, DÖV 1999, 1017 (1026 ff.); Martinez. Soria, Die Bedeutung der (Verfassungs-) Rechtsvergleichung für den europäischen Staaten- und Verfassungsverbund: Die Methode der Rechtsvergleichung im Öffentlichen Recht, in: Göttinger Online-Beiträge zum Europarecht, Nr. 48. 
auf.456 Hinzu kommen Überschneidungen der Zuständigkeiten mit mitgliedstaatlichen Rechnungshöfen bei der Kontrolle mitgliedstaatlich verwalteter Gemeinschaftsmittel.

Die Vergleichbarkeit zeigt sich auch im Bestehen internationaler Zusammenschlüsse wie INTOSAI und EUROSAI, die dem Erfahrungsaustausch und der Verbesserung der Arbeitsweise etwa durch die Festlegung gemeinsamer Richtlinien und Grundsätze dienen. Im europäischen Rechnungshofsystem erfolgt eine solche Zusammenarbeit im Rahmen des Kontaktausschusses, die wie gesehen bereits zur Schaffung gemeinsamer Finanzkontrollrichtlinien, der Erarbeitung eines gemeinsamen Prüfungshandbuchs und anderen Projekten geführt hat, die geeignet sind, die Zusammenarbeit zu verbessern. ${ }^{457}$ Im Ergebnis ist die grundsätzliche Vergleichbarkeit der untersuchten Rechnungshöfe klar zu bejahen. Es handelt sich bei allen von ihnen um Institutionen, die als Kernaufgabe die Kontrolle der Ordnungsmäßigkeit und Wirtschaftlichkeit staatlichen Umgangs mit den Staatsfinanzen sowie die Berichterstattung hierüber und die Beratung anderer staatlicher Funktionsträger gemeinsam haben. Allein in der Ausgestaltung der Institutionen zur Verwirklichung dieser Aufgaben bestehen mehr oder weniger starke Unterschiede, aber auch viele grundsätzliche Gemeinsamkeiten.

Eine einheitliche Methodik für die Rechtsvergleichung im öffentlichen Recht gibt es nicht. ${ }^{458}$ Vielmehr ist für den jeweiligen Einzelfall in einer rechtsvergleichenden Studie individuell festzustellen, welche Form der Vergleichung am aussagekräftigsten und erfolgversprechendsten erscheint.

Als Grundlage bietet sich ein Dreistufenmodell an, das auf der Feststellung der maßgeblichen Normen, dem Verstehen derselben und dem Vergleich im eigentlichen Sinn besteht: 459

Auf der ersten Stufe geht es mithin darum, die für die Untersuchung maßgeblichen Rechtsnormen festzustellen und unter Berücksichtigung ihres Standortes in der Gesamtrechtsordnung zu beschreiben. Die zweite Stufe dient dem Verstehen der Normen, wobei insbesondere außerrechtliche Faktoren zu berücksichtigen sind, wie im Fall der Ausgestaltung der externen Finanzkontrolle insbesondere die historische und politische Entwicklung sowie Vorläufervorschriften. Die Ziele dieser beiden Stufen, die Feststellung der maßgeblichen Normen und ihr Verste-

456 Magiera, Finanzkontrolle in der EG, in: v. Arnim (Hrsg.), Finanzkontrolle im Wandel, 1989, S. $221 \mathrm{f}$.

457 Weber, Vertrauensvolle Zusammenarbeit zwischen Europäischem Rechnungshof und den Rechnungshöfen der Mitgliedstaaten, in: Österreichischer Rechnungshof (Hrsg.), Positionen - Öffentliche Finanzkontrolle in Österreich, 2007, S. 37, 40 f., mit zahlreichen Beispielen erfolgreicher Verbesserung der Zusammenarbeit.

458 Constantinesco, Rechtsvergleichung II, 1972, S. 32; Starck, Rechtsvergleichung im öffentlichen Recht, JZ 1997, 1021 (1026) ; Wieser, Vergleichendes Verfassungsrecht, 2005, S. 21.

459 Im Einzelnen: Wieser, Vergleichendes Verfassungsrecht, 2005, S. 42 ff., der auf das von Constantinesco entwickelte Dreiphasenmodell verweist, vgl. Constantinesco, Rechtsvergleichung II, 1972, S. $137 \mathrm{ff}$. 
hen innerhalb der Gesamtrechtsordnung und im Kontext rechtlicher und außerrechtlicher sie beeinflussender Faktoren, wurden für die hier untersuchten Rechnungshöfe in einem jeweils eigenen Abschnitt in den ersten drei Teilen dieser Arbeit verfolgt. Eine klare Trennung zwischen Feststellung und Verstehen ist dabei weder möglich noch sinnvoll ${ }^{460}$. Besonders bei einem Vergleichsgegenstand, der so viele zu berücksichtigende Aspekte bietet wie die Vergleichung verschiedener Rechnungshofmodelle im jeweiligen Staatsaufbau, lassen sie sich nicht immer trennen, sondern gehen oft fließend ineinander über. Auch wurden in den ersten drei Teilen bereits, wenn es sinnvoll erschien, vereinzelt Aspekte untersuchter Rechnungshöfe zueinander in Beziehung gesetzt und verglichen, um das Verständnis an der entsprechenden Stelle zu verbessern.

Die dritte Stufe kann als die eigentliche Vergleichung bezeichnet werden: Die zu vergleichenden Vorschriften werden zueinander in Beziehung gesetzt. So können Unterschiede und Gemeinsamkeiten herausgearbeitet werden, und es werden Vor- und Nachteile der verschiedenartigen Ausgestaltungen deutlich.

Vorliegend werden die Rechnungshöfe hinsichtlich ihrer Einordnung im Verfassungssystem, insbesondere in Hinblick auf die Gewaltenteilung, die durchaus sehr unterschiedlich ausgestaltet ist, und hinsichtlich ihres Verhältnisses zu den jeweiligen Einzelgewalten betrachtet. Dazu werden in den ersten drei Teilen dieser Arbeit geschichtliche Entwicklung, (verfassungsrechtliche) Hilfsgarantien, Aufgaben, die Einordnung in das jeweilige System der Gewaltenteilung sowie die Rechtschutzmöglichkeiten der Rechnungshöfe einzeln untersucht. Im vierten Teil sollen diese miteinander verglichen werden. Es erscheint dabei am zweckmäßigsten, diese Aspekte der Ausgestaltung nacheinander in der Abfolge, in der sie bereits zu jedem einzelnen Rechnungshof erörtert wurden, abzuhandeln. So können die gewonnenen Erkenntnisse sachlich geordnet nebeneinander gestellt und verglichen werden.

Innerhalb jedes der zu untersuchenden Punkte werden dabei die einzelnen Rechnungshofmodelle grundsätzlich in der Reihenfolge, in der sie in den ersten drei Teilen untersucht wurden, nebeneinandergestellt. Wenn es zweckmäßig erscheint, richtet sich die Reihenfolge hingegen nach inhaltlichen Gesichtspunkten, da durch das direkte Nebeneinanderstellen bestimmter Merkmale, wie etwa der Einordnung ins Schema der Gewaltenteilung, Unterschiede und Gemeinsamkeiten am besten erkennbar werden.

Der Vergleich erlaubt es im Ergebnis, losgelöst von der einzelnen nationalen Ausprägung Vor- und Nachteile der unterschiedlichen Ausgestaltungen zu erkennen und Verbesserungsvorschläge zu erarbeiten. Ziel ist es, die hier vorgenommene Einordnung des Bundesrechnungshofes durch die Gegenüberstellung verständlich zu machen und weiter zu zeigen, inwieweit trotz der teils sehr unterschiedlichen Ausgestaltungen durch die untersuchten Mitgliedsstaaten grundsätzli-

460 Constantinesco, Rechtsvergleichung II, 1972, S. 278. 
che Gemeinsamkeiten bestehen, die sich letztlich auch in der Gestaltung des Europäischen Rechnungshofes wiederfinden. 


\section{A. Frankreich: Die Cour des comptes}

\section{Historische Entwicklung}

Die französische Cour des comptes feierte 2007 ihr 200-jähriges Bestehen. In ihrer gegenwärtigen Form als unabhängige oberste Rechnungskontrollbehörde wurde sie von Napoleon I. durch Dekret vom 16. September 1807 errichtet. 461 Die Finanzkontrolle an sich blickt in Frankreich jedoch auf eine noch längere Tradition zurück. ${ }^{462}$

Bereits im 13. Jahrhundert ging aus der „curia regis“ eine Kommission hervor, die sich mit den staatlichen Rechnungen zu beschäftigen hatte. ${ }^{463}$ Im Jahre 1303 wurde in Paris eine Rechnungskammer, die sogenannte „camera compotorum“, eingerichtet, die ihren Sitz im Stadtpalast hatte. ${ }^{464}$ Die Verordnung von Pontoise vom 18. Juli 1318 durch Philipp V., „den Langen“, sah vor, den gesamten Staat jährlich durch die Rechnungskammer prüfen zu lassen. ${ }^{465}$

\footnotetext{
461 Service communication Cour des comptes, Cour des comptes, 2007, S. 8.

462 Ausführlich zur geschichtlichen Entwicklung: Descheemaeker, La Cour des comptes, 2005, S. 10.

463 Descheemaeker, La Cour des comptes, 2005, S. 10; Service communication Cour des comptes, Cour des comptes, 2007, S. 7.

464 Service communication Cour des comptes, Cour des comptes, 2007, S. 7.

465 Service communication Cour des comptes, Cour des comptes, 2007, S. 7.
} 
Die weitere Entwicklung stärkte die Rechnungskammer, bis sie im 15. Jahrhundert zum zweitwichtigsten Organ der Monarchie nach dem Rat wurde. ${ }^{466}$ Die Kammer hatte einerseits über den Staatsbesitz zu wachen, zum anderen hatte sie rechtsprechende Funktion. 467

Bereits 1467 gestand eine Verordnung Ludwigs XI. den Mitgliedern weitgehende Unabsetzbarkeit zu, dergestalt dass sie nur durch Tod, freiwilligen Amtsverzicht oder Verurteilung wegen Unredlichkeit ihres Amtes enthoben werden konnten. ${ }^{468}$

Die zuletzt 13 Rechnungskammern (Chambres des comptes) aus der absolutistischen Zeit des Ancien Régime wurden nach der Revolution von der Nationalversammlung im Jahre 1791 per Dekret zunächst durch die Commission des comptes, später Bureau de compatibilité, ersetzt. Diese waren noch dem Corps législatif zugeordnet, wurden aber ab 1795 durch die Commission de la compatibilité nationale ersetzt, die bei der Exekutive angesiedelt war. ${ }^{469}$

Mit Gesetz vom 16. September $1807^{470}$ wurde die Commission schließlich durch die Cour des comptes ersetzt, die bis heute besteht. Von ihrer Funktion her knüpfte die neu geschaffene Cour an die der Chambres des comptes aus der vorrevolutionären Zeit an. Bereits im Ancien Régime hatten die Rechnungskammern auch rechtsprechende Funktion ausgeübt, eine solche erhielt der Hof erneut unter Napoleon, wobei es in der Hierarchie direkt unter der Cour des Cassation stand. 471 Weitgehende Unabhängigkeit wurde durch die Eigenschaft der Mitglieder als Richter und ihre Ernennung auf Lebenszeit erreicht ${ }^{472}$.

Ursprünglich war der Jahresbericht nur dem Kaiser vorzulegen, der Rechnungshof war somit Instrument der Exekutive. ${ }^{473}$ Das änderte sich erst mit dem Gesetz vom 21. April 1832, nach dem der Bericht auch den beiden Kammern der Legislative zuzuleiten war (vgl. Art. 15) (74. $^{475}$

Nach dem zweiten Weltkrieg wurden der Cour angegliederte Institutionen geschaffen; zu nennen ist insbesondere die mit Gesetz vom 25. September 1948 gegründete Cour de discipline budgétaire et financière, die als spezielles Verwal-

466 Service communication Cour des comptes, Cour des comptes, 2007, S. 7.

467 Descheemaeker, La Cour des comptes, 2005, S. 10 ff.; Service communication Cour des comptes, Cour des comptes, 2007, S. 7.

468 Service communication Cour des comptes, Cour des comptes, 2007, S. 7.

469 Heinig, Das Budget, Band I, 1949, S. 64; Service communication Cour des comptes, Cour des comptes, 2007, S. 8.

470 Auszugsweise abgedruckt bei Descheemaeker, La Cour des comptes, 2005, S. 16.

471 Art. 7 Gesetz vom 16 September 1807.

472 Art. 6 Gesetz vom 16 September 1807.

473 Heinig, Das Budget, Band I, 1949, S. 65; Arnaud, La Cour des comptes Française, in: FS Schäfer, 1975, S. 310 (321).

474 Abgedruckt bei Heinig, Das Budget, Band I, 1949, S. 67.

475 Arnaud, La Cour des comptes Française, in: FS Schäfer, 1975, S. 310 (320 f.). 
tungsgericht bestimmte Verfehlungen im Bereich der Staatsfinanzen zu ahnden hat. ${ }^{476}$

Die weitere Entwicklung bis heute ist vor allem durch eine starke Ausweitung der Kompetenzen des Rechnungshofes geprägt: Neben die eigentliche Kontrolle der öffentlichen Finanzen des Staates trat die Kontrolle staatlicher Einrichtungen, insbesondere der Einrichtungen der sozialen Sicherheit (seit 1950) sowie der staatlichen Unternehmen (seit 1976) ${ }^{477} .4781996$ kam die Prüfung von Stellen, die finanzielle Hilfen der europäischen Union in Anspruch nehmen, hinzu. ${ }^{479}$

Die Verfassung der fünften Republik vom 4. Oktober $1958^{480}$ (im Folgenden CF) weist dem Rechnungshof die Unterstützung von Parlament und Regierung bei der Kontrolle der Ausführung der Haushaltsgesetze zu. Die einfachgesetzlichen Regelungen über die Cour des comptes sind im Gesetzbuch über die Finanzrechtsprechung (Code des Juridictions Financières, im Folgenden CJF) zusammengefasst. ${ }^{481}$

Die Tendenz zur Dezentralisierung im klassischen Zentralstaat Frankreich in jüngerer Zeit spiegelt sich auch in der Organisation des Rechnungswesen wider, indem regionale Rechnungskontrollkammern (Chambres régionales et territoriales des comptes) errichtet wurden. Diese regionalen Rechnungskammern, es sind 22 in Frankreich selbst und 4 in den französischen Überseegebieten, bestehen größtenteils seit 1982 und sind zuständig für die Finanzkontrolle des lokalen öffentlichen Haushaltswesens. ${ }^{482}$ Die Regelungen über die Regionalkammern finden sich im zweiten Buch des CJF.

\section{Hilfsgarantien}

Die Hilfsgarantien für die Cour des comptes ergeben sich nicht direkt aus der Verfassung, sondern sind einfachgesetzlich festgelegt.

\section{Unabhängigkeit}

Die Ausgestaltung als Gericht garantiert die Unabhängigkeit des französischen Rechnungshofes. Seine Mitglieder haben gem. Art. L 120-1 CJF die Qualität von Richtern und sind unabsetzbar. Als Mitglieder in diesem Sinne gelten alle Angehörigen des Rechnungshofes vom Premier Président bis zum Auditeur zweiter Klas-

\footnotetext{
476 Service communication Cour des comptes, Cour des comptes, 2007, S. 31 mit einem Überblick über weitere Institutionen.

477 National Audit Office, State Audit in the European Union, 2005, S. 91.

478 Descheemaeker, La Cour des comptes, 2005, S. 19 ff.

479 Art. 45 des Gesetzes Nr. 06-314 vom 12. April 1996.

${ }^{480}$ In jeweils aktueller Fassung abrufbar unter http://www.legifrance.gouv.fr/html/constitution/constitution.htm.

481 In jeweils aktueller Fassung abrufbar unter http://www.ccomptes.fr/CC/References.html.

482 Ausführlich Descheemaeker, La Cour des comptes, 2005, S. 167.
} 
se. ${ }^{483}$ Damit verdeutlicht die Unabsetzbarkeit, die bereits die Regelungen von 1807 vorsahen und die 1967 durch Gesetz wiederbestätigt wurde, die besondere Rolle der Rechnungsprüfer. ${ }^{484}$ Die Ausgestaltung als Gericht ist geeignet, die Unabhängigkeit des französischen Rechnungshofes bestmöglich zu gewährleisten. ${ }^{485}$

Die Unabhängigkeit spiegelt sich auch im Aufbau des Rechnungshofes wider: Er ist kollegial organisiert ${ }^{486}$ und typisch für ein Gericht in Kammern ${ }^{487}$ aufgeteilt.

Die Ernennung des Präsidenten und der obersten Ränge im Rechnungshof erfolgt per Dekret durch den Ministerrat nach Art. L121-1 CJF. Die Amtszeit des Präsidenten ist grundsätzlich unbegrenzt, es gilt jedoch ein Höchstalter von 68 Jahren. ${ }^{488}$ Die Regierung ernennt die Kammerpräsidenten der sieben Kammern des Hofes aus einer Liste, die der Präsident vorlegt; für sie gilt eine Altersgrenze von 65 Jahren. ${ }^{489}$

Auch die sachliche Unabhängigkeit wird durch die freie Wahl des Prüfungsgegenstandes $^{490}$ und die unabhängige Aufstellung des Prüfungsprogramms für das folgende Jahr durch den Premier Président des Hofes auf Vorschlag der Kammerpräsidenten gem. Art. R 112-3 CJF gewährleistet. Die Eigenschaft des Rechnungshofes als von Legislative und Exekutive unabhängige Verwaltungsgerichtsbarkeit wurde auch vom französischen Verfassungsgericht, dem Conseil Constitutionnel, als verfassungsrechtlich garantiert anerkannt. ${ }^{491}$

Besondere finanzielle Unabhängigkeit genießt der französische Rechnungshof, nachdem ihm seit 2005 ein eigenständiges Budget zuerkannt wird. ${ }^{492}$

\section{Informations- und Zugangsrechte}

Der französische Rechnungshof verfügt über sehr weitgehende Informations- und Zugangsrechte. ${ }^{493}$ Er hat gem. Art. L 140-1 CJF, Art. R 141-3 CJF Zugang zu allen Dokumenten von Stellen, die seiner Prüfung und Rechtsprechung unterliegen. Zudem verfügt er nach Art. L 140-1 CJF über das Recht, bei Verweigerung oder Behinderung des Zuganges zu Informationen eine Geldstrafe von bis zu

483 Ausführlich zur Einteilung und Bedeutung der verschiedenen Dienstgrade: Descheemaeker, La Cour des comptes, 2005, S. $25 \mathrm{ff}$.

484 Descheemaeker, La Cour des comptes, 2005, S. 30.

485 Léonard, La Cour des comptes de France et la Cour des comptes fédérale d'Allemagne, in : Bundesrechnungshof, 250 Jahre Rechnungsprüfung, 1964, S. 190 (192 f.).

486 Descheemaeker, La Cour des comptes, 2005, S. 75.

${ }^{487} \mathrm{Zu}$ den einzelnen Kammern und ihren Zuständigkeiten Service communication Cour des comptes, Cour des comptes, 2007, S. 9.

488 National Audit Office, State Audit in the European Union, 2005, S. 92.

489 National Audit Office, State Audit in the European Union, 2005, S. 92.

490 Service communication Cour des comptes, Cour des comptes, 2007, S. 18.

${ }^{491}$ Décision du Conseil constitutionnel 2001-448 DC du 25 juillet 2001.

492 National Audit Office, State Audit in the European Union, 2005, S. 91.

493 Ausführlich: Descheemaeker, La Cour des comptes, 2005, S. 70 ff. ; National Audit Office, State Audit in the European Union, 2005, S. 93. 
$15.000 € z u$ verhängen. Auch die verspätete Anfertigung von Rechnungen und verspätete Antworten auf verbindliche Anfragen des Rechnungshofes durch öffentliche Rechnungsführer (Comptables publics) können gem. Art. L 131-6 CJF bestraft werden.

\section{Aufgaben}

1. Rechnungsprüfung und Kontrolle der Haushaltsführung

Die Cour des comptes kontrolliert die öffentliche Haushaltsführung auf ihre Ordnungsmäßigkeit, Wirtschaftlichkeit (insbesondere die Überprüfung der günstigsten Zweck-Mittel-Relation) sowie auf die Wirksamkeit der Zielerreichung. ${ }^{494}$

Dabei handelt es sich ausschließlich um eine ex-post-Kontrolle. ${ }^{495}$ Die Präventivkontrolle wird deswegen abgelehnt, weil befürchtet wird, sie könne den Charakter der Unabhängigkeit eventuell später geübter Kritik beeinträchtigen. ${ }^{496}$

\section{Gerichtliche Funktion}

Prägend für das französische System der Finanzkontrolle durch die Cour des comptes ist ihre gerichtliche Tätigkeit. Sie dient gem. Art. L. 111-1 S.2 CJF als Berufungsgericht gegen Entscheidungen der Chambres régionales. Der Rechnungshof ist damit ein Verwaltungsgericht, das sich am Ende mehrerer Instanzen von Finanzgerichten befindet und über dem als weitere Instanz nur die Cour de Cassation steht. ${ }^{497}$ Als Gericht ist der Cour des comptes auch eine eigene Staatsanwaltschaft zugeordnet, ${ }^{498}$ die die Interessen der Republik gegenüber den mittelverwaltenden Stellen wahrnimmt, die der Jurisdiktion des Rechnungshofes unterliegen.

Die Cour des comptes kann die öffentlichen Rechnungsführer zur Verantwortung ziehen, soweit Einnahmen oder Ausgaben, für die sie verantwortlich sind, nicht ordnungsgemäß sind. Dieser Möglichkeit liegt die besondere Ausgestaltung des Systems der Finanzkontrolle in Frankreich zugrunde. Sie basiert darauf, dass der öffentliche Rechnungsführer vor jeder Zahlung selbst die Ordnungsmäßigkeit

\footnotetext{
494 Service communication Cour des comptes, Cour des comptes, 2007, S. 16.

495 Descheemaeker, La Cour des comptes, 2005, S. 45.

496 Léonard, La Cour des comptes de France et la Cour des comptes fédérale d'Allemagne, in : Bundesrechnungshof, 250 Jahre Rechnungsprüfung, 1964, S. 190 (196 f.).

${ }^{497}$ Léonard, La Cour des comptes de France et la Cour des comptes fédérale d'Allemagne, in : Bundesrechnungshof, 250 Jahre Rechnungsprüfung, 1964, S. 190 (196 f.).

498 Service communication Cour des comptes, Cour des comptes, 2007, S. 10 f.
} 
des ihr zugrundeliegenden Verwaltungshandeln zu überprüfen hat und die öffentlichen Mittel erst dann freigeben darf. ${ }^{499}$

Geregelt ist die gerichtliche Überprüfung in Art. L. 111-1 S. 1 CJF, wonach „der Rechnungshof über die Konten der öffentlichen Rechnungsführer urteilt“ und gem. L. 111-3 CJF die „Ordnungsmäßigkeit von Einnahmen und Ausgaben kontrolliert, wie sie in den öffentlichen Buchhaltungen ausgewiesen sind“, und sich der ordnungsgemäßen Verwendung von Krediten, Fonds und sonstigen Werten durch die staatliche Verwaltung vergewissert. Es erfolgt mithin eine Rechnungskontrolle (Kontrolle der rechnerischen Richtigkeit) sowie eine der Ordnungsmäßigkeit. Im Anschluss daran wird dem öffentlichen Rechnungsführer die Entlastung erteilt, wenn die Vorgänge korrekt waren, oder es wird ein Verfahren gegen ihn eingeleitet, soweit Rechnungen fehlen oder Ausgaben nicht ordnungsgemäß waren. ${ }^{500}$ Der Rechnungsführer hat für die Richtigkeit beanstandeter Rechnungen zu sorgen, anderenfalls haftet er im Falle seiner Verurteilung und muss eine Geldstrafe zahlen. ${ }^{501}$ Es können nicht jedes Jahr alle Rechnungen überprüft werden, so dass oft im Abstand von bis zu fünf Jahren eine Prüfung des gesamten seit der letzten Überprüfung vergangenen Zeitraums erfolgt. ${ }^{502}$

Im Gegensatz zu den öffentlichen Rechnungsführern unterliegen die Anweisungsbefugten (Ordonnateurs) nicht der Rechtsprechung durch den Hof, ${ }^{503}$ ihr Umgang mit öffentlichen Geldern unterliegt aber dennoch seiner Kontrolle und kann Gegenstand seiner Bemerkungen sein. ${ }^{504}$ Jedoch können Fehler anderer Bediensteter als der Rechnungsführer genauso Schaden anrichten, ${ }^{505}$ daher kann bei schweren Verfehlungen die Cour de discipline budgétaire et financière angerufen werden, die der Cour des comptes angegliedert ist und deren Kompetenzen sich aus dem dritten Buch des CJF ergeben.

In manchen Fällen kann die Zuständigkeit der Cour des comptes dennoch für Personen eröffnet sein, die keine öffentlichen Rechnungsführer sind, aber, ohne dazu berechtigt zu sein, wie solche mit öffentlichen Geldern umgegangen sind. Sie werden in diesem Fall gem. Art. L 131-2 CJF als „De-facto-Rechnungsführer“ (Comptable de Fait) zur Rechenschaft gezogen. ${ }^{506}$

499 Léonard, La Cour des comptes de France et la Cour des comptes fédérale d'Allemagne, in : Bundesrechnungshof, 250 Jahre Rechnungsprüfung, 1964, S. 190 (196 f.) ; ausführlich zum französischen System: Descheemaeker, La Cour des comptes, 2005, S. 46 ff.

500 Service communication Cour des comptes, Cour des comptes, 2007, S. 16.

501 Léonard, La Cour des comptes de France et la Cour des comptes fédérale d'Allemagne, in : Bundesrechnungshof, 250 Jahre Rechnungsprüfung, 1964, S. 190 (196 f.); im einzelnen Descheemaeker, La Cour des comptes, 2005, S. 47 ff.

502 National Audit Office, State Audit in the European Union, 2005, S. 93 f.

$503 \mathrm{Zu}$ den geschichtlichen Gründen, die in der Ausbildung der mächtigen Zentralexekutive unter Napoleon I. liegen, vgl. Heinig, Das Budget, Band I, 1949, S. 64 f.

504 Service communication Cour des comptes, Cour des comptes, 2007, S. 24 f.

505 Arnaud, La Cour des comptes Française, in: FS Schäfer, 1975, S. 310 (327).

506 Beran/Konvicka, Finanzkontrolle international gesehen, 1967, S. 43 f. 
Das Verfahren vor der Cour des comptes ist ihrer gerichtlichen Funktion entsprechend kontradiktorisch mit entsprechenden Rechten des Angeklagten ausgestaltet. ${ }^{507}$

\section{Beratung und Unterstützung von Parlament und Regierung}

Art. 47 Abs. 6 der französischen Verfassung ebenso wie Art. L 111-2 CJF sieht die Unterstützung von Parlament und Regierung durch die Cour des comptes bei der Kontrolle der Ausführung der Haushaltsgesetze vor. Der durch die Verfassungsreform von 1966 eingeführte Art. 47-1 CF betont in Abs. 5 ausdrücklich die Unterstützung von Parlament und Regierung bei der Kontrolle der Anwendung der Gesetze über die Finanzierung der Sozialversicherung.

Auch kann der Erste Präsident des Rechnungshofes dem Parlament und seinen Ausschüssen jederzeit Feststellungen und Bemerkungen seiner Institution vorlegen. Natürlich können staatliche Stellen wie parlamentarische Ausschüsse oder Ministerien den Rechnungshof darum ersuchen, Prüfungen in ihrem Zuständigkeitsbereich vorzunehmen.

\section{Veröffentlichungen}

Gem. Art. L 136-1 CJF werden jedes Jahr ein Jahresbericht sowie Sonderberichte dem Parlament vorgelegt und dem Staatspräsidenten zugeleitet. Die Stellungnahmen der Minister werden seit 1967 gemeinsam mit den sie betreffenden Bemerkungen des Rechnungshofes im Amtsblatt veröffentlicht. ${ }^{508}$ Die öffentlichen Berichte machen vor allem Themen von grundsätzlicher Bedeutung der breiten Öffentlichkeit zugänglich.

Die Cour des comptes überprüft auch den Erfolg früherer Bemerkungen, um zu sehen, ob diese umgesetzt wurden, und veröffentlicht ihre Erkenntnisse hierüber im Jahresbericht. ${ }^{509}$

\section{Stellung im System der Gewaltenteilung}

\section{Gewaltenteilung im französischen Verfassungsrecht}

Die Gewaltenteilung in Frankreich wird bereits aus der Struktur der Verfassung deutlich: In jeweils einem eigenen Abschnitt befinden sich die Regelungen über Präsident (Titel II), Regierung (Titel III) und Parlament (Titel IV) daneben die

\footnotetext{
507 Zur Ausgestaltung des Verfahrens vgl. ausführlich: Descheemaeker, La Cour des comptes, 2005, S. $51 \mathrm{ff}$. .

508 Arnaud, La Cour des comptes Française, in: FS Schäfer, 1975, S. 310 (322 f.) ; außerdem können sie auf der Internetseite des Cour des comptes eingesehen werden, http://www.ccomptes.fr/CC/Publications.html.

509 Service communication Cour des comptes, Cour des comptes, 2007, S. 26.
} 
über die ordentliche Gerichtsbarkeit (Titel VIII), den Hohen Gerichtshof (Titel IX) und den Verfassungsrat (Titel VII), der neben beratenden auch richterliche Aufgaben in Form eines Verfassungsgerichtshofes ${ }^{510}$ wahrnimmt, indem er gem. Art. 61 CF über die Verfassungsmäßigkeit bestimmter Gesetze zu entscheiden hat. Die Regelungen über die Cour des comptes finden sich in Titel V der Verfassung, der die Beziehungen zwischen Parlament und Regierung zum Gegenstand hat. Gem. Art. 47 Abs. 6 und Art. 47-1 Abs. 5 CF hat der Hof die Aufgabe, Parlament und Regierung zu unterstützen.

Der Staatsaufbau Frankreichs ist als parlamentarische Präsidialrepublik geprägt von der starken Stellung des direkt gewählten (vgl. Art. 6, 7 CF) Präsidenten, der (neben der Regierung) Hauptorgan der Exekutive ${ }^{511}$ ist. Dieser bildet ein echtes Gegengewicht zum aus Nationalversammlung und Senat (vgl. Art. 24 CF) bestehenden Parlament, was besonders in Situationen der „cohabitation“ deutlich wird, wenn der Präsident einer anderen politischen Richtung angehört als die gegenwärtige Parlamentsmehrheit. Die Gewaltenteilung zwischen Legislative und Exekutive als sich gegenseitig kontrollierenden und mäßigenden Gewalten ist damit stärker ausgeprägt als in parlamentarischen Demokratien (etwa Deutschland und Österreich), in denen maßgebliches Organ der Exekutive lediglich die von der Parlamentsmehrheit getragene Regierung ist.

Die Unabhängigkeit der Gerichtsbarkeit ist nach Art. 64 ff. CF gewährleistet, die Richter verfügen über einen entsprechenden Status.

\section{Einordnung der Cour des comptes}

Die Cour des comptes ist durch ihren Status als Gericht eindeutig der Judikative zuzuordnen. Damit einher gehen die typischen richterlichen Unabhängigkeitsgarantien gegenüber Legislative und Exekutive. Jedoch kommt dem Hof durch die Besonderheiten, die die Aufgabe der externen Finanzkontrolle mit sich bringt, auch eine gewisse Sonderstellung zu, die ihn von einem gewöhnlichen Gericht unterscheidet. Ausgangspunkt dafür ist Art. 47 Abs. 6 CF, wonach „der Rechnungshof Parlament und Regierung bei der Kontrolle der Ausführung der Haushaltsgesetze unterstützt“". Die Unterstützungstätigkeit geht einher mit Beratung und Berichterstattung und ist keine gerichtliche, sondern eine rechnungshofspezifische Tätigkeit. Der Rechnungshof nimmt dabei eine Stellung zwischen Exekutive und Legislative ein. ${ }^{512}$ Die Hilfstätigkeit hat sich in den letzten Jahren weiter in Richtung der Unterstützung des Parlaments entwickelt, was teilweise als Problem für die unabhängige Stellung des Hofes in der Mitte zwischen Legislative und Exekutive gesehen wird. ${ }^{513}$ Jedoch darf bei dieser Entwicklung nicht außer Acht

510 Kortmann, The French Republic, in: Prakke/Kortmann, Constitutional Law of 15 EU Member States, 2004, S. 237 (282).

511 Guimezanes, Introduction au droit française, 1995, S. 72.

512 Descheemaeker, La Cour des comptes, 2005, S. 150.

513 Descheemaeker, La Cour des comptes, 2005, S. 150. 
gelassen werden, dass das Parlament viel stärker auf die Unterstützung durch den Rechnungshof angewiesen ist als die Regierung, weil es nicht über einen Verwaltungsunterbau wie die Ministerien verfügt, auf den es in Fachfragen zurückgreifen kann. Die Berichte und Beratung durch den Rechnungshof sind conditiones sine quae non für die Ausübung des Budgetrechts des Parlaments und seine Kontrollbefugnisse gegenüber der Exekutive. Aus diesen Gründen ist es nicht zwingend, dass der Rechnungshof tatsächlich und in jeder Hinsicht „in der Mitte“ zwischen Parlament und Regierung steht.

Im Ergebnis ist die französische Cour des comptes ein Gericht, das aber zugleich durch seine (verfassungsrechtlich vorgeschriebene) Beratungspflicht von Parlament und Regierung eine durchaus rechnungshoftypische Sonderstellung zwischen Legislative und Exekutive einnimmt, ohne dabei einer der beiden Gewalten zugeordnet zu sein. Die gerichtliche Ausgestaltung und Ausstattung der Cour des comptes mit entsprechenden Imperiumsbefugnissen bietet den Vorteil, dass die öffentlichen Rechnungsführer bei Verfehlungen unmittelbar vom Rechnungshof zur Rechenschaft gezogen werden können. Jedoch ist die Eigenschaft als Gericht nicht ohne weiteres auf andere Systeme übertragbar, setzt sie doch eine den französischen Besonderheiten entsprechende Ausgestaltung der Verwaltungsstrukturen mit der Möglichkeit der persönlichen Haftung von öffentlichen Rechnungsführern voraus. Diese Ausgestaltung dürfte sich in der französischen Verfassungstradition wohl aus dem bereits unmittelbar nach der Revolution eingeführten Grundsatz aus Art. 15 der Erklärung der Menschen- und Bürgerrechte vom 26. August 1789 ergeben, dass „die Gesellschaft das Recht hat, jeden Mitarbeiter der öffentlichen Verwaltung zur Rechenschaft zu ziehen“; sie ist somit nicht ohne weiteres auf Staaten mit anderer Rechtstradition übertragbar.

\section{Rechtsschutzmöglichkeiten}

In seiner Eigenschaft als Gericht ist der französische Rechnungshof zumindest hinsichtlich der Durchsetzung von Prüfungsrechten gegenüber prüfungsunterworfenen Stellen nicht auf Rechtsschutz angewiesen, da er diese selbst durch vollstreckbare Urteile und die Verhängung von Zwangsgeldern durchzusetzen vermag.

Eigene Klagemöglichkeiten gegen andere Staatsorgane sind weder in der französischen Verfassung noch im Gesetzbuch über die Finanzrechtsprechung vorgesehen. 


\section{B. Österreich: Der Rechnungshof}

\section{Historische Entwicklung}

Als ältester Vorläufer des heutigen österreichischen Rechnungshofes wird die am 23. Dezember 1761 mit Handschreiben ${ }^{514}$ von Kaiserin Maria Theresia errichtete Hofrechenkammer angesehen. ${ }^{515}$ Ihre Errichtung zu diesem Zeitpunkt erfolgte keineswegs zufällig, sondern erklärt sich in der durch den Siebenjährigen Krieg begründeten Notlage, in der sich der Staatshaushalt Österreichs befand. Die Aufgaben der Hofrechenkammer waren die Leitung und Überwachung sämtlicher Buchhaltungen, die bis dahin den Hofstellen unterstellt gewesen waren sowie die Verbesserung des Rechnungswesens und seiner Methodik. ${ }^{516}$ Dabei war ihr von Anfang an eine sehr privilegierte Stellung gegeben. Ihr Status war von der unmittelbaren Unterstellung unter die Krone geprägt, was ein direktes Zugangsrecht zu der Monarchin in wichtigen Angelegenheiten mit sich brachte und zugleich, hier zeigen sich Parallelen zur preußischen Ober-Rechenkammer zu dieser Zeit, die

514 Abgedruckt in: FS Österreichischer Rechnungshof, 1961, Anhang.

${ }^{515} \mathrm{Zu}$ den Vorläufern der Rechen-Cammer siehe Tesar, Die oberste Rechnungskontrollbehörde Österreichs - ein Streifzug durch die Geschichte des Rechnungshofes, in: FS Österreichischer Rechnungshof, 1961, S. 1.

516 Hager, Die Entwickelung der Rechnungskontrolle von der ersten Hofrechenkammer bis zum Rechnungshof, Österreichisches Verwaltungsblatt, 1936, 55 (56). 
Unabhängigkeit gegenüber allen anderen Staatsorganen bedeutete. 517 Außerdem hatte sie das Recht der Präventivkontrolle, das heißt in allen wichtigen Finanzangelegenheiten konnte sie Gutachten abgeben, die bis zur Entscheidung durch die Kaiserin aufschiebende Wirkung hatten. ${ }^{518}$

Diese Privilegien gegenüber der kontrollierten Verwaltung bargen natürlich Konfliktpotential, deshalb war die weitere Entwicklung von ständigen Veränderungen der verfassungsrechtlichen Stellung der Hofrechenkammer geprägt, indem ihr immer wieder Privilegien aberkannt oder wieder zuerkannt wurden, je nachdem welche Kräfte stärkeren Einfluss auf den Monarchen auszuüben vermochten. So kam es 1768 zur Einschränkung und 1773 zum völligen Entfall der Präventivkontrolle. ${ }^{519} 1773$ wurde zudem die Unabhängigkeit aufgehoben, aber es dauerte nur ein Jahr, bis die Hofrechenkammer nahezu ihre alte Stellung als gleichrangige und unabhängige Hofstelle zurückgewann. ${ }^{520}$ Bis zur Errichtung des „GeneralRechnungs-Direktoriums“ am 19. September 1805 wurde die Kontrollstelle zweimal aufgelöst und in jeweils unterschiedlicher Ausgestaltung wieder errichtet. ${ }^{521}$ Die Kontrolle durch das General-Rechnungs-Direktorium erstreckte sich auf eine Vielzahl der Buchhaltereien, denen wiederum die Verwaltungsstellen unterstanden; sie war wieder unmittelbar der Krone unterstellt. 522

Mit kaiserlicher Verordnung vom 27. März 1854523 wurde das GeneralRechnungs-Direktorium in die K. K. Oberste Rechnungs-Controlsbehörde umgewandelt, die weiterhin unmittelbar dem Kaiser untergeordnet war und in ihrem Rang neben den Ministerien stand. 524

Mit kaiserlicher Verordnung vom 21. November $1866^{525}$ ging die Kontrollbehörde schließlich im neuen Obersten Rechnungshof auf. Seine Stellung unterschied sich nicht wesentlich von der seines Vorgängers, als die Unabhängigkeit durch Unterstellung unter die Krone und die Gleichstellung mit den Ministerien gewährleistet war. Die fortschrittliche Aufgabe, die Sparsamkeit und GesetzmäBigkeit der Gebarung zu prüfen, trat zudem gegenüber der altmodischen reinen

517 Tesar, Die oberste Rechnungskontrollbehörde Österreichs - ein Streifzug durch die Geschichte des Rechnungshofes, in: FS Österreichischer Rechnungshof, 1961, S. 1 (5).

518 Tesar, Die oberste Rechnungskontrollbehörde Österreichs - ein Streifzug durch die Geschichte des Rechnungshofes, in: FS Österreichischer Rechnungshof, 1961, S. 1 (5).

519 Hager, Die Entwickelung der Rechnungskontrolle von der ersten Hofrechenkammer bis zum Rechnungshof, Österreichisches Verwaltungsblatt, 1936, 55 (56).

520 Tesar, Die oberste Rechnungskontrollbehörde Österreichs - ein Streifzug durch die Geschichte des Rechnungshofes, in: FS Österreichischer Rechnungshof, 1961, S. 1 (8)

521 im Einzelnen: Tesar, Die oberste Rechnungskontrollbehörde Österreichs - ein Streifzug durch die Geschichte des Rechnungshofes, in: FS Österreichischer Rechnungshof, 1961, S. 1 (8 ff.)

522 Tesar, Die oberste Rechnungskontrollbehörde Österreichs - ein Streifzug durch die Geschichte des Rechnungshofes, in: FS Österreichischer Rechnungshof, 1961, S. 1 (12).

523 RGBl. Nr. $71 / 1854$.

${ }^{524}$ Hager, Die Entwickelung der Rechnungskontrolle von der ersten Hofrechenkammer bis zum Rechnungshof, Österreichisches Verwaltungsblatt, 1936, 55 (57).

525 RGBl. Nr. 140/1866. 
Rechnungsprüfung auf zahlenmäßige Richtigkeit in den Vordergrund, ${ }^{526}$ mithin das, was heute als Ordnungsmäßigkeits- und Wirtschaftlichkeitsprüfung bezeichnet wird.

Das Bestehen von Rechnungshöfen ist grundsätzlich unabhängig von der Staatsform, zudem verfügte der österreichische Oberste Rechnungshof über ein hohes Renommée, so dass nach dem ersten Weltkrieg und dem Ende der Donaumonarchie im Jahre 1918 die provisorische Nationalversammlung den Fortbestand des Obersten Rechnungshofes als Staatsrechnungshof für die Republik Österreich beschloss. ${ }^{527}$ Anfangs unterstand der Rechnungshof dabei noch dem gewissermaßen die Funktion der Krone als Spitze der Exekutive wahrnehmenden Staatsrat. ${ }^{528}$ Diese für die neu geschaffene demokratische Ordnung eigentlich systemwidrige Zuordnung beseitigte das Gesetz vom 9. Februar 1919529. Der Staatsrechnungshof wurde der Nationalversammlung als dem ersten Hauptlegislativorgan der demokratischen Republik, der es aufgegeben war, die Verfassung zu schaffen, ${ }^{530}$ unterstellt. ${ }^{531}$ Das Bundesverfassungsgesetz (B-VG) vom 1. Oktober 1920532 regelte die Rechnungs- und Gebarungskontrolle in einem eigenen Hauptstück, die Unterstellung des von nun an als Rechnungshof bezeichneten Organs unter den Nationalrat, dem Bundesparlament, wurde in Art. 122 B-VG beibehalten. Wahl und Abberufung seines Präsidenten oblagen fortan dem Hauptausschuss des Nationalrates. Durch die Verfassungsnovelle von $1925^{533}$ wurde die Zuständigkeit des Rechnungshofes auf die Gebarungskontrolle der Länder mit Ausnahme von Wien ausgedehnt, wobei er (bis heute, vgl. Art. 122 Abs. 1 B-VG) als Organ des jeweiligen Landtages tätig wird. ${ }^{534}$

Die neue „ständisch-autoritäre“ Verfassung vom 24. April 1934 änderte die Regelung der Ernennung des Rechnungshofpräsidenten und wies dem Hof neue Kontrollbefugnisse zu. ${ }^{535}$

526 Tesar, Die oberste Rechnungskontrollbehörde Österreichs - ein Streifzug durch die Geschichte des Rechnungshofes, in: FS Österreichischer Rechnungshof, 1961, S. 1 (18).

527 \ 16 des Beschlusses vom 30. Oktober 1918, StGBl. Nr. 1/1918.

528 Ermacora, Der österreichische Rechnungshof im System der Staatsgewalten, in: FS Österreichischer Rechnungshof, 1961, S. 72 (73).

529 StGBl. Nr. 85/1919.

${ }_{530} \mathrm{Zu}$ Nationalversammlung und Entstehungsphase des B-VG vgl. Öblinger, Verfassungsrecht, 1999, S. $40 \mathrm{ff}$.

531 Ermacora, Der österreichische Rechnungshof im System der Staatsgewalten, in: FS Österreichischer Rechnungshof, 1961, S. 72 (73): ,...die Rechnungskontrolle wurde der im neuen demokratisch-republikanischen Staatswesen herrschenden Gewalt unterstellt: der Nationalversammlung““.

532 BGBl. Nr. 1/1920.

533 B-VG-Novelle vom 30. Juni 1925, BGBl. Nr. 268/1925

534 Hager, Die Entwickelung der Rechnungskontrolle von der ersten Hofrechenkammer bis zum Rechnungshof, Österreichisches Verwaltungsblatt, 1936, 55 (59).

535 Tesar, Die oberste Rechnungskontrollbehörde Österreichs - ein Streifzug durch die Geschichte des Rechnungshofes, in: FS Österreichischer Rechnungshof, 1961, S. 1 (21). 
Nach dem „Anschluss“ Österreichs an das Deutsche Reich übernahm mit Durchführungsverordnung vom 19. August 1939 der Rechnungshof des Deutschen Reiches die Aufgaben, der ehemalige Rechnungshof in Wien wurde Außenabteilung. 536

Mit dem Ende des Zweiten Weltkrieges wurden am 1. Mai $1945^{537}$ die Bundesverfassung sowie alle anderen Bundesverfassungsgesetze und -bestimmungen nach dem Stand vom 5. März 1933 wieder in Kraft gesetzt, ${ }^{538}$ damit wurden auch die vor 1934 geltenden Regelungen über den Rechnungshof wieder eingeführt. ${ }^{539}$ Am 16. Juni 1948 wurde das die Rechnungskontrolle regelnde fünfte Hauptstück des Bundesverfassungsgesetzes novelliert ${ }^{540}$ und ein neues Rechnungshofgesetz erlassen.

Die Stellung des Rechnungshofes im Staatsaufbau ist seitdem gleich geblieben, er untersteht gem. Art. 122 Abs. 1 S. 1 B-VG unmittelbar dem Nationalrat. Eine österreichische Besonderheit ist, dass der Rechnungshof in Angelegenheiten, die die Bundesgebarung betreffen beziehungsweise in die Vollzugsverantwortung des Bundes fallen, als Organ des Nationalrates tätig wird und entsprechend beim Tätigwerden in Länderangelegenheiten als Organ des jeweiligen Landtages (Art. 122 Abs. 1 S. 2 B-VG). Art. 122 Abs. 2 B-VG betont die Unabhängigkeit des Rechnungshofes von Bundes- und Landesregierungen.

Seit 1975 ist der Präsident des Rechnungshofes berechtigt, an Verhandlungen des Nationalrates und seiner Ausschüsse über die Rechnungshofberichte und bestimmte den Hof betreffende Anträge teilzunehmen (Art. 123a Abs. 1 B-VG) und auch dazu gehört zu werden (Art. 123a Abs. 2 B-VG).

Im Ergebnis ist die Ausgestaltung der externen Finanzkontrollinstitutionen in der Monarchie Österreich bis zum Ende des ersten Weltkrieges typisch für diese Staatsform, wie der Vergleich mit der Entwicklung in Preußen und dem Deutschen Reich bis 1918 zeigt. Die entsprechenden Institutionen hatten überwiegend gemeinsam, dass sie Organe der Krone ${ }^{541}$ waren und unabhängig neben den Ministerien oder entsprechenden obersten Verwaltungsstellen standen. Das bedeutet, sie waren organisatorisch wie funktionell Organe der Exekutive. ${ }^{542}$ Die unmittelbare Unterstellung unter den Monarchen, dem allein auch der Rechenschaftsbe-

\footnotetext{
536 Heinig, Das Budget, Bd. 1, 1949, S. 83 m.w.N.; RGBl. I, S. 1441.

537 Verfassungsgesetz über das neuerliche Wirksamwerden des B-VG i.d.F. von 1929, StGBl. Nr. 4/1945.

538 Öblinger, Verfassungsrecht, 1999, S. 44.

539 Tesar, Die oberste Rechnungskontrollbehörde Österreichs - ein Streifzug durch die Geschichte des Rechnungshofes, in: FS Österreichischer Rechnungshof, 1961, S. 1 (22).

${ }^{540}$ B-VG vom 16. Juni 1948, BGBl. Nr. 143/1948.

${ }^{541}$ Ermacora, Der österreichische Rechnungshof im System der Staatsgewalten, in: FS Österreichischer Rechnungshof, 1961, S. 72 f.; Kopp, Der Rechnungshof als gemeinsames „föderatives“ Bund-Länder-Organ, 1978, S. 14.

542 Ermacora, Der österreichische Rechnungshof im System der Staatsgewalten, in: FS Österreichischer Rechnungshof, 1961, S. 72 (75).
} 
richt vorzulegen war, ohne dass Beziehungen zum Parlament bestanden, ${ }^{543}$ verdeutlicht die Bedeutung des Überblicks über die Finanzen als Machtfaktor im Staat. Nach einjähriger Zwischenzeit 1918/1919, in der der Rechnungshof dem Staatsrat unterstellt war, wurde er schließlich 1919 dem Parlament zugeordnet. Die Regelung nach dem Zweiten Weltkrieg knüpfte an die Rechtslage vor 1934 an, so dass die Ausgestaltung durch das Bundesverfassungsgesetz von 1920, die den Rechnungshof dem Nationalrat unterordnete, mit Ausnahme der Zeit von 1934 bis 1945 in ihren wesentlichen Regelungen bis heute gilt.

\section{Verfassungsrechtliche Hilfsgarantien}

\section{Bestandsgarantie}

Die besondere Bedeutung, die der österreichische Verfassungsgeber der Rechnungs- und Gebarungskontrolle durch den Rechnungshof einräumt, wird dadurch deutlich, dass sie durchgehend seit 1920 in einem eigenen, dem fünften, Hauptstück des Bundesverfassungsgesetzes geregelt ist. Die Art. 121 - 128 B-VG enthalten bereits sehr detailliert die Ausgestaltung der Rechnungshofkontrolle, insbesondere die Funktions- und Organstruktur des Hofes, seine Aufgaben und die Möglichkeit, im Streitfalle den Verfassungsgerichtshof anzurufen. Die Verfassung enthält damit eine sehr weitgehende institutionelle Garantie, die Ausgestaltung der Finanzkontrolle und des Rechnungshofes an sich sind in ihren wesentlichen Merkmalen der Regelung durch den einfachen Gesetzgeber entzogen. ${ }^{544}$ Sein Bestand ist in der „weitgehend durch die österreichische Verfassungstradition geprägten Form“ garantiert. ${ }^{545} \mathrm{Im}$ Umkehrschluss aus der verfassungsrechtlichen Aufgabenzuweisung muss auch die zu ihrer Wahrnehmung notwendige Mindestausstattung an Personal und Finanzmitteln als garantiert angesehen werden. ${ }^{546}$

\section{Unabhängigkeit}

\section{a) Persönliche Unabhängigkeit}

Nach Art. 122 Abs. 2 B-VG ist der Rechnungshof unabhängig von der Bundesregierung und den Landesregierungen und nur den Bestimmungen des Gesetzes unterworfen. Jedoch wird den Mitgliedern keine richterliche Unabhängigkeit zugestanden.

\footnotetext{
543 Kopp, Der Rechnungshof als gemeinsames „föderatives“ Bund-Länder-Organ, 1978, S. 14 m.w.N.

544 Hengstschläger, Der Rechnungshof, 1982, S. 66 ff.

545 Hengstschläger, Der Rechnungshof, 1982, S. 70.

546 Hengstschläger, Der Rechnungshof, 1982, S. 70 f.; Kopp, Der Rechnungshof als gemeinsames „föderatives" Bund-Länder-Organ, 1978, S. 73.
} 
Art. 122 Abs. 1 B-VG bestimmt, dass der Rechnungshof unmittelbar dem Nationalrat untersteht, dieser wählt auf Vorschlag seines Hauptausschusses auch den Rechnungshofpräsidenten (Art. 122 Abs. 4 B-VG). Für die Amtszeit des Präsidenten wurde 1988 die relativ lange Dauer von zwölf Jahren ohne Wiederwahlmöglichkeit eingeführt (Art. 122 Abs. 4 S. 1 B-VG), um die Unabhängigkeit besser zu gewährleisten. ${ }^{547}$

Darüber hinaus dienen auch die persönlichen Inkompatibilitätsvorschriften der Absicherung der persönlichen Unabhängigkeit. So darf nach Art. 122 Abs. 5 B-VG der Präsident des Rechnungshofes keinem allgemeinen Vertretungskörper, das heißt dem Nationalrat, Bundesrat, einem Landtag oder Gemeinderat, ${ }^{548}$ angehören und in den letzten vier Jahren keine Regierungsfunktion wahrgenommen haben. Art. 126 B-VG erklärt die Eigenschaft als Mitglied des Rechnungshofes für unvereinbar mit der Tätigkeit in Leitung oder Verwaltung eines der Kontrolle durch den Rechnungshof unterliegenden Unternehmens oder eines sonstigen auf Gewinn gerichteten Unternehmens.

Zweifel an der Gewährleistung der Unabhängigkeit in der Praxis können jedoch aufkommen angesichts der Wahl des Rechnungshofpräsidenten mit einfacher (gewöhnlich die Regierung tragender) Mehrheit und entsprechend der Möglichkeit, diesen jederzeit durch Beschluss des Nationalrates abzuberufen (Art. 123 Abs. 2 B-VG). Letztlich ernennt so der Kontrollierte durch seine Regierungsmehrheit im Parlament seinen Kontrolleur. ${ }^{549}$

Nach einem Entwurf des Rechnungshofes selbst aus den 70er Jahren, der unter anderem eine Reform der Regelungen der Bundesverfassung vorsah, sollten Präsident und Vizepräsident (das Amt des Vizepräsidenten wurde 1994 abgeschafft) von der aus Nationalrat und Bundesrat bestehenden Bundesversammlung bei Anwesenheit mindestens der Hälfte der Mitglieder und mit einer Zwei-DrittelMehrheit gewählt werden; entsprechendes sollte für die Abberufung gelten. ${ }^{550}$ Stimmen aus Literatur und Praxis haben darüber hinaus schon des Öfteren die Einräumung eines gerichtsähnlichen Status für den Rechnungshof mit entsprechender richterlicher Unabhängigkeit seiner Mitglieder gefordert. 551

547 H. Schäffer, Kontrolle der Verwaltung durch Rechnungshöfe (Länderbericht Österreich), VVDStRL 55 (1996), S. 278 (283).

548 Kandutsch, Öffentliche Finanzkontrolle in Österreich unter besonderer Berücksichtigung von Organisations- und Wirtschaftlichkeitsprüfungen, in: FS Schäfer, 1975, S. 189 (190).

${ }^{549}$ So auch Hengstschläger, Der Rechnungshof, 1982, S. 60.

550 Ausführlich zu den Änderungsvorschlägen durch den Entwurf: Kandutsch, Öffentliche Finanzkontrolle in Österreich unter besonderer Berücksichtigung von Organisations- und Wirtschaftlichkeitsprüfungen, in: FS Schäfer, 1975, S. 189 (201 ff., 205 f.).

${ }^{551}$ Ermacora, Der österreichische Rechnungshof im System der Staatsgewalten, in: FS Österreichischer Rechnungshof, 1961, S. 72 (77); Kobl, Die heutige Stellung des Rechnungshofes, seine Organisation und seine Aufgaben, in: FS Österreichischer Rechnungshof, 1961, S. 35 (49); weitere Nachweise bei H. Schäffer, Kontrolle der Verwaltung durch Rechnungshöfe (Länderbericht Österreich), VVDStRL 55 (1996), S. 278 (281). 
Im Verhältnis zum Parlament ist auf das in Art. 123a B-VG garantierte Recht des Rechnungshofpräsidenten hinzuweisen, an allen den Rechnungshof und seine Arbeit betreffenden Sitzungen des Nationalrates teilzunehmen und dort auch gehört zu werden (vgl. \20 Abs. 1-3 GOGNR). Seine Anwesenheit kann auch von Nationalrat, Ausschüssen und Unterausschüssen verlangt werden ( $\int 20$ Abs. 4 GOGNR).

Diese Stellung zeigt sich auch in der inneren Organisation des Rechnungshofes, der nicht als Kollegialorgan, sondern monokratisch organisiert ist. ${ }^{552}$ Der Präsident verfügt über ein Weisungsrecht gegenüber allen Mitgliedern. ${ }^{553}$ Dieser Aufbau ergibt sich zwangsläufig aus der Tatsache, dass der Rechnungshof als Organ dem Parlament untergeordnet und der Rechnungshofpräsident diesem verantwortlich ist. Die Organisationsform als Kollegialorgan hingegen brächte die Frage mit sich, wer diese Verantwortung tragen sollte, vor allem da dann Entscheidungen des Rechnungshofes gar nicht unbedingt gemäß dem Willen des Präsidenten mangels Weisungsrecht zustande gekommen sein müssten. ${ }^{554}$

Was die Ernennung der Beamten des Rechnungshofes angeht, bestimmt Art. 125 Abs. 1 S. 1 B-VG, dass diese nach dem Vorschlag durch den Rechnungshofpräsidenten dem Bundespräsidenten obliegt, wobei dieser die Ernennungsbefugnis, wie in Österreich für die Bundesbeamtenernennung üblich und in Art. 125 Abs. 1 S. 2 B-VG auch für den Rechnungshof ausdrücklich vorgesehen, hinsichtlich der niederen Ränge dem Rechnungshofpräsidenten übertragen hat. ${ }^{555}$

\section{b) Sachliche Unabhängigkeit}

Der Rechnungshof bestimmt grundsätzlich selbst, in welchen Zeitabschnitten er die Prüfung der Gebarung einzelner Organe oder Rechtsträger vornimmt. 556 Sachliche Unabhängigkeit bedeutet immer auch Weisungsfreiheit, die Ausgestaltung im Bundesverfassungsgesetz zeigt jedoch, dass es in Österreich hiervon durchaus bedeutsame Ausnahmen gibt.

Zumindest Weisungen i.S.d. Art. 20 Abs. 1 B-VG seitens des Nationalrates oder eines Landtages sind ausgeschlossen, handelt es sich hierbei doch um ein verwaltungsrechtliches Instrument, das vorbehaltlich verfassungsrechtlicher Aus-

\footnotetext{
552 Vgl. schon ; Kobl, Die heutige Stellung des Rechnungshofes, seine Organisation und seine Aufgaben, in: FS Österreichischer Rechnungshof, 1961, S. 35 (40); Hengstschläger, Der Rechnungshof, 1982, S. 166 ff.;

${ }_{553}$ Hengstschläger, Der Rechnungshof, 1982, S. 135 ff., 166; Kandutsch, Öffentliche Finanzkontrolle in Österreich unter besonderer Berücksichtigung von Organisations- und Wirtschaftlichkeitsprüfungen, in: FS Schäfer, 1975, S. 189 (202).

554 Kandutsch, Öffentliche Finanzkontrolle in Österreich unter besonderer Berücksichtigung von Organisations- und Wirtschaftlichkeitsprüfungen, in: FS Schäfer, 1975, S. 189 (202).

555 Kandutsch, Öffentliche Finanzkontrolle in Österreich unter besonderer Berücksichtigung von Organisations- und Wirtschaftlichkeitsprüfungen, in: FS Schäfer, 1975, S. 189 (190 f.).

556 Öblinger, Verfassungsrecht, S. 150, Rn. 335.
} 
nahmen nur gegenüber Verwaltungsstellen gilt, ${ }^{557}$ so dass es der Unabhängigkeit widerspräche. ${ }^{558}$ Dies gilt aber erstaunlicherweise nicht für verbindliche Prüfungsaufträge. Für den deutschen Bundesrechnungshof wurde festgestellt, dass Bundestag ebenso wie Bundesministerien diesem Prüfungswünsche mitteilen können, die er aufnehmen kann, aber nicht muss. In Österreich hingegen sieht Art. 126b Abs. 4 S. 1 B-VG hinsichtlich der Gebarungsprüfung im Bereich des Bundes vor, dass der Nationalrat als Legislativorgan den Rechnungshof mit der Gebarungsüberprüfung bestimmter in seinen Zuständigkeitsbereich fallender Akte verbindlich beauftragen kann (vgl. auch $₫ 99$ Geschäftsordnung des Nationalrates) ${ }^{559}$. Unter „Gebarung“ wird ,jedes Verhalten, das finanzielle Auswirkungen (auf Ausgaben, Einnahmen und Vermögensbestände) hat", verstanden. ${ }^{560}$ Nach Art. 126b Abs. 4 S. 2 B-VG ,hat der Rechnungshof [auch] auf begründetes Ersuchen der Bundesregierung oder eines Bundesministers solche Akte durchzuführen“. Entsprechendes gilt gem. Art. 127 Abs. 7 B-VG für Prüfungsverlangen von Landtagen und begründete Ersuchen von Landesregierungen.

Angesichts der österreichischen Ausgestaltung der Stellung des Rechnungshofes als eines unmittelbar dem Nationalrat unterstellten Organs und damit seiner strukturellen Nähe zur Legislative verwundert das Gebundensein an Prüfungsaufträge des Nationalrats nicht sehr. Ungewöhnlich ist hiervor aber die Befugnis der Exekutivorgane Bundesregierung, Bundesminister und Landesregierungen, den Rechnungshof rechtsverbindlich mit Prüfungen zu beauftragen. Gerade diese unterliegen schließlich auch seiner Kontrolle, so dass es möglich erscheint, den Rechnungshof durch eine Vielzahl von Prüfungsaufträgen in seiner Fähigkeit einzuschränken, aus eigener Initiative Prüfungen im Zuständigkeitsbereich von Ministerien vorzunehmen, die den verantwortlichen Regierungen nicht so angenehm erscheinen. ${ }^{561}$

In diesem Zusammenhang ist auf Art. 123 Abs. 1 B-VG hinzuweisen, wonach der Präsident des Rechnungshofes hinsichtlich seiner Verantwortlichkeit den Mitgliedern der Bundesregierung beziehungsweise einer Landesregierung gleichgestellt ist, je nachdem ob er als Organ des Nationalrates oder eines Landtages tätig wird. Diese Verantwortlichkeit bezieht sich auf „Gesetzesverletzungen, die durch die Amtstätigkeit schuldhaft, also vorsätzlich oder fahrlässig begangen" wurden, worunter auch die Weigerung, einem Ersuchen auf Prüfung nachzukommen, fal-

\footnotetext{
557 Hengstschläger, Der Rechnungshof, 1982, S. 53 m.w.N.

558 Atžnanger, Zur Verantwortlichkeit des Präsidenten des Rechnungshofes, ÖJZ 1989, 161 (165); H. Schäffer, Kontrolle der Verwaltung durch Rechnungshöfe (Länderbericht Österreich), VVDStRL 55 (1996), S. 278 (284); Öblinger, Verfassungsrecht, S. 149, Rn. 331.

${ }^{559}$ Geschäftsordnungsgesetz des Nationalrates 1975, BGBl Nr. 410/1975 in der Fassung BGBl I Nr. 194/1999.

${ }^{560}$ Kopp, Der Rechnungshof als gemeinsames "föderatives" Bund-Länder-Organ, 1978, S. 24 m.w.N.

561 Wobei die Prüfungskapazität vielfach als Grenze für Prüfungsverlangen, so dass der Rechnungshof bei ihrer Erreichung Aufträge auch ablehnen könnte, Kopp, Der Rechnungshof als gemeinsames „föderatives“ Bund-Länder-Organ, 1978, S. 73.
} 
len kann, da diese Pflicht in Art. 126b Abs. 4 bzw. Art. 127 Abs. 7 B-VG normiert ist. ${ }^{562}$

Nach dem Gesagten muss die sachliche Unabhängigkeit als lediglich eingeschränkt gewährleistet charakterisiert werden.

Im Ergebnis ist festzustellen, dass die Regelungen zur Unabhängigkeit bis heute immer wieder der Kritik ausgesetzt gewesen sind. Die mit der Unterordnung unter das Parlament verbundenen Ernennungs- und Abberufungsregelungen, das Recht von Parlamenten und Stellen der Exekutive, Prüfungsaufträge zu geben, und die damit verbundene monokratische Organisation des Rechnungshofes werden vielfach als unzureichende Lösung, eine unabhängige, neutrale externe Finanzkontrolle zu gewährleisten, gesehen. ${ }^{563}$

\section{Informations- und Zugangsrechte}

Das Bundesverfassungsgesetz selbst führt in Art. 126b bis 127b lediglich die der Prüfung durch den Rechnungshof unterworfenen Stellen auf. Für die Regelung der „näheren Bestimmungen über Einrichtung und Tätigkeit des Rechnungshofes" sieht Art. 128 B-VG den Erlass eines Bundesgesetzes vor. Die Informationsund Zugangsrechte ergeben sich daher aus $\int 3,4$ des Rechnungshofgesetzes ${ }^{564}$ (im Folgenden: RHG). \3 Abs. 2 RHG weist dem Rechnungshof weitgehende Informationsrechte zu und verpflichtet die zu prüfenden Stellen, ihm alle notwendigen Auskünfte zur Verfügung zu stellen, daneben berechtigt er ihn zu Vor-OrtPrüfungen.

\section{Aufgaben}

\section{Prüfung der Gebarung}

Gemäß Art. 121 Abs. 1 B-VG obliegt dem Rechnungshof die Überprüfung der Gebarung von Bund, Ländern, Gemeindeverbänden, Gemeinden und anderen gesetzlich bestimmten Rechtsträgern.

562 Hengstschläger, Der Rechnungshof, 1982, S. 151 f.; Kopp, Der Rechnungshof als gemeinsames „föderatives“ Bund-Länder-Organ, 1978, S. 67; vgl. auch At_wwanger, Zur Verantwortlichkeit des Präsidenten des Rechnungshofes, ÖJZ 1989, 161 (163ff.).

563 Vgl. Fn. 551; Ermacora, Der österreichische Rechnungshof im System der Staatsgewalten, in: FS Österreichischer Rechnungshof, 1961, S. 72 (78 f.) m.w.N., der als Ausdruck der Unabhängigkeit auch eine räumliche Trennung des Sitzes des Rechnungshofes von den Organen der Legislative und Exekutive nach deutschem Vorbild vorschlägt; Hengstschläger, Der Rechnungshof, 1982, S. 151 f.; zurückhaltend: Kandutsch, Öffentliche Finanzkontrolle in Österreich unter besonderer Berücksichtigung von Organisations- und Wirtschaftlichkeitsprüfungen, in: FS Schäfer, 1975, S. 189 (198 ff.); .

564 Bundesgesetz vom 16. Juni 1948 über den Rechnungshof, BGBl. Nr. 144/1948. 
Konkretisiert wird die Gebarungsprüfung durch Art. 126b B-VG für den Bereich des Bundes, durch Art. 127 B-VG für den Bereich der Länder sowie durch Art. 127a B-VG für den Bereich der Gemeinden.

Die Prüfungsmaßstäbe der Gebarungsprüfung ergeben sich aus Art. 126b Abs. 5 B-VG, danach erstreckt sich die Prüfung auf ziffernmäßige Richtigkeit (also die richtige Verbuchung von Einnahmen und Ausgaben), die Rechtmäßigkeit sowie die Wirtschaftlichkeit im weiteren Sinne, umfassend die Sparsamkeit, Wirtschaftlichkeit und Zweckmäßigkeit. Etwas widersprüchlich ist, dass das fünfte Hauptstück mit „Rechnungs- und Gebarungskontrolle“ überschrieben ist, diese Differenzierung aber im Gesetzestext nicht mehr vorgenommen wird.

Der Begriff der Gebarungsprüfung umschreibt damit nichts anderes als die für Rechnungshöfe typische Prüfung von Recht- und Ordnungsmäßigkeit sowie Wirtschaftlichkeit staatlichen Handelns und entspricht damit dem in Deutschland eher üblichen Begriff der Finanzkontrolle.

Von ihrem Umfang her umfasst die Prüfung, wie aus Art. 126b Abs. 1 B-VG deutlich wird, die „gesamte Staatswirtschaft des Bundes“ sowie „Stiftungen, Fonds und Anstalten“, die vom Bund verwaltet werden. Art. 126b Abs. 2 B-VG erstreckt die Prüfung weiter auf Unternehmen, an denen der Bund mehrheitlich beteiligt ist. Seine Entsprechung hinsichtlich des Prüfungsumfangs auf Länderebene findet die Vorschrift in Art. 127 Abs. 1 B-VG und für den Bereich der Gemeinden in Art. 127a Abs. 1 B-VG. Grundsätzlich ist die Finanzkontrolle durch den Rechnungshof in Österreich auf Lückenlosigkeit angelegt, es soll, wie auch in Deutschland, keine kontrollfreien Räume geben. ${ }^{565}$ Es tun sich jedoch dadurch Lücken im Kontrollumfang auf, als Gemeinden unter 20.000 Einwohnern nach Art. 127a Abs. 1 B-VG nicht seiner Kontrolle unterliegen, sondern gem. Abs. VII nur fallweise auf begründetes Ersuchen der zuständigen Landesregierung geprüft werden. In der Praxis sind damit $99 \%$ der Gemeinden der Kontrolle durch den Rechnungshof entzogen, eine Kontrolle findet sonst nur durch hauseigene Prüfer und die Aufsichtsbehörden des Landes statt. ${ }^{566}$ Eine weitere Lücke entsteht dadurch, dass gem. Art. 126b Abs. II B-VG nur Unternehmen überprüft werden, an denen der Staat mit mindestens $50 \%$ beteiligt ist oder die er in entsprechender Weise beherrscht. ${ }^{567}$ Die Kontrolle erfolgt grundsätzlich ex post, eine begleitende

\footnotetext{
565 H. Schäffer, Kontrolle der Verwaltung durch Rechnungshöfe (Länderbericht Österreich), VVDStRL 55 (1996), S. 278, 290.

566 Isensee, Finanzkontrolle im Bundesstaat, ZÖR 63 (2008), S. 29 (34) m.w.N.

${ }^{567}$ Isensee, Finanzkontrolle im Bundesstaat, ZÖR 63 (2008), S. 29 (35), schlägt vor, die Beteiligungsgrenze von $50 \%$ auf $25 \%$ zu senken, wie dies im Burgenland und der Steiermark bereits geschehen ist.
} 
Kontrolle ist hingegen nicht vorgesehen, ${ }^{568}$ weil befürchtet wird, sie könnte in die Eigenverantwortlichkeit der Exekutive eingreifen. ${ }^{569}$

\section{Berichterstattung}

Gem. Art. 126d Abs. 1 S. 1 B-VG erstattet der Rechnungshof dem Nationalrat einen Jahresbericht, er kann jederzeit Sonderberichte verfassen und dem Nationalrat berichten. Die Berichte sind gem. S. 3 der Vorschrift zu veröffentlichen. Sie sind auch auf der Internetseite des Rechnungshofes abrufbar. ${ }^{570}$

\section{Beratung}

Der Rechnungshof übt unselbständige (in unmittelbarem Zusammenhang mit einer Prüfung) und selbständige (prüfungsunabhängige) Beratung aus, in konkreten Gebarungsfällen findet ein vorherige Beratung jedoch nicht statt, da sie die spätere Prüfung beeinflussen könnte. ${ }^{571}$

Nach einer Resolution des Nationalrates aus dem Jahre 1981 werden dem Rechnungshof bestimmte Gesetzes- und Verordnungsentwürfe der Ministerien zur Stellungnahme hinsichtlich ihrer finanziellen Auswirkungen übermittelt. ${ }^{572}$ So sollen die Anliegen der Sparsamkeit, Wirtschaftlichkeit und Zweckmäßigkeit in die legislative Tätigkeit einfließen. Dies geschieht durch seine Berichte. Daneben berät der Rechnungshof gezielt und zeitnah bei der gesetzlich vorgesehenen Vorabbewertung von Gesetzesvorhaben; insbesondere werden ihre finanziellen Auswirkungen darauf überprüft, ob den in $\int 14$ Bundeshaushaltsgesetz normierten Verpflichtungen der Ministerien zur Berechnung der Folgekosten neuer Gesetze entsprochen wurde. 573

Die Erfahrungen des Hofes fließen in die Entscheidungsfindung der Exekutive dadurch ein, dass er gem. \6 Abs. 1 BRHG gemeinsam mit dem Finanzministerium für ein zweckmäßiges und möglichst einfaches Verrechnungsverfahren sorgt und dass gem. \6 Abs. 2 BRHG grundsätzliche Vorschriften und Anord-

\footnotetext{
${ }^{568}$ Kritisch hierzu: Ermacora, Der österreichische Rechnungshof im System der Staatsgewalten, in: FS Österreichischer Rechnungshof, 1961, S. 72 (78).

569 H. Schäffer, Kontrolle der Verwaltung durch Rechnungshöfe (Länderbericht Österreich), VVDStRL 55 (1996), S. 278, 291 f.

570 http://www.rechnungshof.gv.at/berichte.html.

571 Österreichischer Rechnungshof, Strategie, 2005, S. 27, abrufbar unter http://www.rechnungshof.gv.at/uploads/media/Strategie.pdf; eine Auflistung wichtiger Beratungsgegenstände aus der jüngeren Vergangenheit findet sich auf der Homepage des Rechnungshofes http://www.rechnungshof.gv.at/ueber-den-rh/beratung.html.

572 Österreichischer Rechnungshof, Leistungsbericht 2005/06, S. 22 f.; abrufbar unter: http://www.rechnungshof.gv.at/berichte/leistungsberichte/leistungsberichte/detail/leistungsber icht-200506.html.

573 Zum Ganzen: Österreichischer Rechnungshof, Leistungsbericht 2005/06, S. 22 f.; abrufbar unter: http://www.rechnungshof.gv.at/berichte/leistungsberichte/leistungsberichte/detail/leistungsber icht-200506.html.
} 
nungen im Rechnungs- und Kassenwesen von Bundesministerien nur im Einvernehmen mit Rechnungshof und Finanzministerium getroffen werden dürfen. ${ }^{574}$ Ferner sieht $\int 24$ BRHG eine Beratung der Bundesregierung durch den Rechnungshofpräsidenten hinsichtlich Gegenständen, die in den Aufgabenbereich des Rechnungshofes fallen, vor, beispielsweise Fragen der Gebarungskontrolle oder der Rechnungslegung.

\section{Stellung im System der Gewaltenteilung}

\section{Gewaltenteilung im österreichischen Verfassungsrecht}

Das Bundesverfassungsgesetz trennt in zwei unterschiedlichen Hauptstücken zwischen Organen der Gesetzgebung (Zweites Hauptstück: Gesetzgebung des Bundes) ${ }^{575}$ und solchen der Verwaltung (Drittes Hauptstück: Vollziehung des Bundes, Teil A. Verwaltung ${ }^{576}$ ). Mangels persönlicher Inkompatibilitätsregeln und durch die in der Staatsform als parlamentarischer Demokratie begründete Abhängigkeit der Bundesregierung vom Vertrauen des Nationalrates ${ }^{577}$ ist es, wie auch in Deutschland gesehen, 578 fraglich, ob man von einer echten Gewaltenteilung zwischen Legislative und Exekutive sprechen kann. ${ }^{579}$ Größere Bedeutung als den persönlichen Inkompatibilitätsregelungen muss aus rechtsstaatlicher Sicht jedoch dem Bestehen unabhängiger Gerichte beigemessen werden. ${ }^{580}$ Diese wird mit den typischen Garantien vom Bundesverfassungsgesetz gewährleistet. Das Dritte Hauptstück der Verfassung regelt die „Vollziehung“, worunter in der österreichischen Terminologie die Verwaltung ebenso wie die Gerichtsbarkeit gesehen wird, als staatliche Organe, die Normen im Einzelfall anwenden ${ }^{581}$. Dieses Hauptstück ist dementsprechend unterteilt in Teil A. Verwaltung und Teil B. Gerichtsbarkeit. Als Ausgangspunkt trennt Art. 94 B-VG, als letzte der die Judikative regelnden Normen, die Gerichtsbarkeit klar von den Organen der Verwaltung („Die Justiz ist von der Verwaltung in allen Instanzen getrennt"). Art. 92 Abs. 2 B-VG sieht

\footnotetext{
574 Bedenken an der verfassungsrechtlichen Zulässigkeit dieser Regelungen äußert Hengstscbläger, Der Rechnungshof, 1982, S. 332.

575 Vgl. Art. 24 B-VG „Die Gesetzgebung des Bundes übt der Nationalrat gemeinsam mit dem Bundesrat [in dem die Länder vertreten sind] aus.“.

576 hierunter fallen insbesondere Bundespräsident, Bundesregierung, Bundesministerien und untergeordnete Verwaltungsstellen.

577 Art. 74 B-VG, ausführlich: Prakke/Kortmann, Constitutional Law of 15 EU Member States, 2004, S. $45 \mathrm{f}$.

578 Oben: 1. Teil VI. 2. c), d).

579 Kritisch: Merli, Rechtsstaatlichkeit in Österreich, in: H/M/M/W, Rechtsstaatlichkeit in Europa, 1996, S. 83 (94).

${ }^{580}$ Hofmann, Die Bindung staatlicher Macht, in H/M/M/W, Rechtsstaatlichkeit in Europa, 1996, S. 3 (11).

581 Öblinger, Verfassungsrecht, 1999, Rn. 600, 625.
} 
die Inkompatibilität des Richteramtes mit einem Regierungsamt oder der Tätigkeit als Abgeordneter vor. Die Richter sind unabhängig (87 Abs. 1 B-VG) und besonders gegen Versetzung und Entlassung (Art. 88 Abs. 2, 3 B-VG) geschützt.

\section{Einordnung des österreichischen Rechnungshofes}

Der österreichische Rechnungshof hat eine Doppelnatur dadurch, dass er als Finanzkontrollorgan sowohl auf Bundes- wie auch auf Länderebene tätig wird. Dabei wird aus Art. 122 Abs. 2 B-VG klar, dass er kein Organ der Exekutive ist, sondern „von den Bundes- und Landesregierungen unabhängig und nur den Bestimmungen des Gesetzes unterworfen“. Das Bundesverfassungsgesetz geht hingegen nicht soweit, den Mitgliedern richterliche Unabhängigkeit zuzugestehen.

Auch in Österreich wurde über die Frage der Einordnung des Rechnungshofes in das System der Staatsgewalten diskutiert, wenn auch nicht annähernd in dem Umfang, den diese Diskussion in Deutschland einnimmt. ${ }^{582}$ Der Grund hierfür dürfte in den eindeutigeren Regelungen im österreichischen Bundesverfassungsgesetz, verglichen mit denen nach dem deutschen Grundgesetz, liegen.

Zunächst ist festzuhalten, dass die Kontrolltätigkeit des Rechnungshofes materiell keinen legislativen Charakter hat, ebenso wenig wie sie der Verwaltung oder Rechtsprechung zuzuordnen ist, sondern eine Tätigkeit eigener Art darstellt. 583 Insbesondere kann nicht daraus, dass Rechnungshöfe in erster Linie die Verwaltung kontrollieren, gewissermaßen also einen Gegenpol zu dieser darstellen, der Schluss gezogen werden, dass sie auch Bestandteil der Exekutive seien. ${ }^{584}$ Im Allgemeinen kann die Funktion der Rechnungshofkontrolle, mag sie inhaltlich auch eine Sonderrolle einnehmen und nicht als „,typisch“ einer der drei Gewalten zuzuordnen sein, vom Verfassungsgesetzgeber staatsorganisatorisch entweder einer Staatsgewalt zugeordnet werden oder aber außerhalb der drei verortet werden. Was die Wirkungsweise seiner Kontrolltätigkeit angeht, verfügt der Rechnungshof nicht über rechtliche Sanktionsmöglichkeiten, aber seine Tätigkeit entfaltet faktische Wirkung. So waren Berichte des Rechnungshofes „vielfach Grundlage für die Aufdeckung von Skandalen und ihrer Behandlung in parlamentarischen Untersuchungsausschüssen". 585

Für die Einordnung müssen jedoch neben der materiellen Bewertung der Finanzkontrollfunktion auch die organisatorischen Regelungen der Verfassung be-

\footnotetext{
582 Bedauernd dazu: Ermacora, Der österreichische Rechnungshof im System der Staatsgewalten, in: FS Österreichischer Rechnungshof, 1961, S. 72, der eine ähnliche Diskussion für wünschenswert erachtet.

583 Dies wurde bereits im Rahmen der Bewertung der Tätigkeit des deutschen Bundesrechnungshofes ausführlich dargelegt, vgl. 1. Teil IV. 2, VI. 3.

584 H. Schäffer, Kontrolle der Verwaltung durch Rechnungshöfe (Länderbericht Österreich), VVDStRL 55 (1996), S. 278 (280 f.)

585 H. Schäffer, Kontrolle der Verwaltung durch Rechnungshöfe (Länderbericht Österreich), VVDStRL 55 (1996), S. 278 (296 f.).
} 
achtet werden. Ausgangspunkt ist dabei Art. 122 B-VG, nach dessen Abs. 1 „untersteht der Rechnungshof unmittelbar dem Nationalrat". Bei Ausübung der Finanzkontrolle im Zuständigkeitsbereich des Bundes wird er dabei „als Organ des Nationalrates“, im Zuständigkeitsbereich der Länder ,als Organ des betreffenden Landtages“ tätig. Abs. 2 bestimmt weiter, dass der Rechnungshof „von Bundesund Landesregierungen unabhängig und nur dem Gesetz unterworfen ist".

Organisatorisch ordnet das Bundesverfassungsgesetz den Rechnungshof damit eindeutig dem Nationalrat, also der Legislative zu, wobei er als „Organ“586 des Nationalrates oder eines Landtages tätig werden kann, je nachdem in wessen $\mathrm{Zu}$ ständigkeit die geprüfte Gebarung fällt. Dafür spricht auch die geschichtliche Entwicklung: War der Rechnungshof ursprünglich ein Organ des Monarchen wechselte diese Zuordnung mit dem Übergang zur Republik auf das Volk als neuem Souverän beziehungsweise auf das Parlament als dessen Vertretung.

Im Ergebnis ist der österreichische Rechnungshof damit der Legislative als „selbständiges Hilfsorgan“ zuzuordnen. ${ }^{587}$ Diese Ansicht wird in der österreichischen Lehre fast einhellig vertreten. ${ }^{588}$ Funktional dient er in erster Linie der Unterstützung der Volksvertretungen, in ihrer Funktion als Repräsentanten des Souveräns, bei ihrer Kontrolle der Verwendung der Staatsfinanzen durch die Exekutive. ${ }^{589}$

Grundsätzlich ist die österreichische Ausgestaltung der Stellung des Rechnungshofes immer wieder massiver Kritik ausgesetzt gewesen, wie teilweise schon im Rahmen der eng hiermit verbundenen Verwirklichung der Unabhängigkeit dargestellt wurde. So sei der Rechnungshof durch seine Unterordnung unter das

586 Zur Terminologie als Organ im B-VG vgl. Kopp, Der Rechnungshof als gemeinsames "föderatives" Bund-Länder-Organ, 1978, S. 24 ff..

587 Hengstschläger, Der Rechnungshof, 1982, S. 54 ff., 57; bzw. als „Hilfseinrichtung zur Finanzkontrolle gegenüber der Exekutive" H. Scbäffer, Kontrolle der Verwaltung durch Rechnungshöfe (Länderbericht Österreich), VVDStRL 55 (1996), S. 278 (280 f., 283); Kandutsch, Öffentliche Finanzkontrolle in Österreich unter besonderer Berücksichtigung von Organisations- und Wirtschaftlichkeitsprüfungen, in: FS Schäfer, 1975, S. 189 (198 ff.).

588 H. Schäffer, Kontrolle der Verwaltung durch Rechnungshöfe (Länderbericht Österreich), VVDStRL 55 (1996), S. 278 (280 f.); Hengstschläger, Der Rechnungshof, 1982, S. 54 ff. mit zahlreichen Nachweisen; ebenso Kopp, Der Rechnungshof als föderatives Bund-Länder-Organ, 1978, S. 32 ff. m.w.N.; Kandutsch, Öffentliche Finanzkontrolle in Österreich unter besonderer Berücksichtigung von Organisations- und Wirtschaftlichkeitsprüfungen, in: FS Schäfer, 1975, S. 189 (198 ff.); Ermacora, Der österreichische Rechnungshof im System der Staatsgewalten, in: FS Österreichischer Rechnungshof, 1961, S. 72 ff., 76 m.w.N.; Öhlinger, Verfassungsrecht, 1999, Rn. 331; ebenso B. Tiemann / S. Tiemann, Zum staatsrechtlichen Standort der Finanzkontrolle in rechtsvergleichender Sicht, Der Staat, Bd. 13 (1974), 497 (508, 513 f.); a.A. Kobl, Die heutige Stellung des Rechnungshofes, seine Organisation und seine Aufgaben, in: FS Österreichischer Rechnungshof, 1961, S.35 (38 ff.), der mit Hilfe der Subtraktionsmethode den Rechnungshof der Exekutive zuordnen will.

589 Kopp, Der Rechnungshof als gemeinsames “föderatives” Bund-Länder-Organ, 1978, S. 30 f.; auf die besondere Bedeutung der Finanzkontrolle für das Parlament und seinen Kontrollauftrag gegenüber der Exekutive wurde bereits im 1. Teil hingewiesen. 
Parlament, mithin unter die Regierungsmehrheit, „kaum in der Lage, im System der österreichischen Staatsgewalten ohne Initiative des Parlaments oder der Regierung eine wirksame Kontrolltätigkeit zu entfalten“.590 In der Literatur ist daher eine stärkere Verselbständigung des Rechnungshofes gegenüber den Staatsgewalten gefordert worden, um seine Unabhängigkeit und Neutralität zu gewährleisten und die Akzeptanz seiner Kritik zu verbessern. ${ }^{591}$ Angeregt wurde, ihm eine gerichtsähnliche Form zu geben, ${ }^{592}$ zumindest was die Ausstattung seiner Mitglieder mit richterlichen Privilegien angeht, um größtmögliche Unabhängigkeit und Neutralität zu gewährleisten.

\section{Rechtsschutzmöglichkeiten}

Bei grundsätzlichen Meinungsverschiedenheiten zwischen dem Rechnungshof und einem der zu überprüfenden Rechtsträger (Art. 121 Abs. 1 B-VG) über das Bestehen oder die gesetzliche Ausgestaltung von Prüfungszuständigkeiten, regelt Art. 126 a B-VG, dass der Rechnungshof (ebenso wie Bundesregierung oder eine Landesregierung) Antrag auf Entscheidung des in Frage stehenden Falles beim Verfassungsgerichtshof stellen kann (vgl. im Einzelnen \$S 36a bis 36g Verfassungsgerichtshofgesetz) ${ }^{593} \cdot{ }^{594}$

In Deutschland wurde vereinzelt die Einführung der Aktivlegitimation des Bundesrechnungshofes im abstrakten Normenkontrollverfahren gefordert. ${ }^{595}$ Auch in Österreich besteht eine solche nach der gegenwärtigen Regelung nicht, es wurde aber auch dort in der Vergangenheit eine ähnlichen Diskussion angeregt. ${ }^{596}$

${ }^{590}$ Ermacora, Der österreichische Rechnungshof im System der Staatsgewalten, in: FS Österreichischer Rechnungshof, 1961, S. 72 (77) m.w.N.

591 H. Schäffer, Kontrolle der Verwaltung durch Rechnungshöfe (Länderbericht Österreich), VVDStRL 55 (1996), S. 278 (281) m.w.N.; Dies wurde im Übrigen in jüngerer Zeit selbst von Rechnungshofpräsident Fiedler gefordert, vgl. die Nachweise bei H. Schäffer, a.a.O.

592 So schon Kobl, Die heutige Stellung des Rechnungshofes, seine Organisation und seine Aufgaben, in: FS Österreichischer Rechnungshof, 1961, S. 35 (49); weitere Nachweise bei H. Schäffer, Kontrolle der Verwaltung durch Rechnungshöfe (Länderbericht Österreich), VVDStRL 55 (1996), S. 278 (281, Fn. 11); vgl. Fn. 551.

593 Verfassungsgerichtshofgesetz, BGBl. Nr. 85/1953 in der Fassung BGBl. Nr. 469/1995.

594 Ausführlich zum Verfahren: Hengstschläger, Der Rechnungshof, 1982, S. 344 ff.; H. Schäffer, Kontrolle der Verwaltung durch Rechnungshöfe (Länderbericht Österreich), VVDStRL 55 (1996), S. 278, 290 f. m.w.N.

595 Oben: 1. Teil VI. 4. c).

596 Schwab, Wege zu einer Neuordnung der öffentlichen Finanzkontrolle in Österreich, in: Das öffentliche Haushaltswesen in Österreich 1982, 64 (83 f.). 


\section{Spanien: Das Tribunal de Cuentas}

\section{Historische Entwicklung}

Erster Vorläufer der Einrichtung der Finanzkontrolle in Spanien war die Contaduría Mayor de Cuentas, die kastilische Rechenkammer, die Juan II. durch Verordnung (Ordenanza) im Jahre 1437 gründete, ihre Rolle war die eines Hilfsorgans, das die Cortes bei ihren Kontrollaufgaben unterstützte. ${ }^{597}$ Die Cortes der damaligen Zeit waren die periodisch einberufenen mittelalterlichen Ständevertretungen, denen im 13. bis 15. Jahrhundert sehr weitgehende Rechte einschließlich der Bewilligung von Steuern zukamen. ${ }^{598}$ In dieser Zuordnung spiegelt sich wider, dass es die Forderung der Volksvertreter nach Rechenschaft über den Verbleib der Steuergelder war, die letztlich zur Einrichtung der Rechenkammer führte. ${ }^{599}$ Bemerkenswert ist, dass die Rechenkammer bereits rechtsprechende Funktion hatte und Bußgelder und Strafen aussprechen konnte. ${ }^{600}$ Die Verordnung vom 30. September 1442 präzisierte den Auftrag weiter und hob die Aufgabe der Rech-

\footnotetext{
597 Cazorla Prieto, in: Garrido Falla y otros, Comentarios a la Constitución, Art. 136, S. 2359.

598 Brockhaus, Suchwort "Cortes”, 2006.

599 Vgl. das Kapitel „Evolución Histórica“ auf der Internetseite des Tribunal de Cuentas http://www.tcu.es/default.htm. ->LA INSTITUCIÓN Y SUS ANTECEDENTES->Historia$>$ Evolución Histórica.

600 Vgl. das Kapitel „Evolución Histórica“ auf der Internetseite des Tribunal de Cuentas http://www.tcu.es.
} 
nungsprüfer (Contadores Mayores de Cuentas) hervor, die Auszahlung von Geldern an die Angestellten der Krone vorzunehmen und darüber Buch zu führen. ${ }^{601}$ Mit wachsender Zentralmacht des Königs wurden die Cortes aber ab dem 16. Jahrhundert bis endgültig zum 18. Jahrhundert nahezu bedeutungslos. ${ }^{602}$

Durch die 1812 verabschiedete Verfassung von Cádiz ${ }^{603}$ wurde in Spanien die Macht der Krone eingeschränkt und eine konstitutionelle Monarchie begründet. Seit dieser Zeit ist „Cortes“ auch die Bezeichnung für das moderne spanische Parlament. ${ }^{604}$ Die Rechenkammer wurde funktionell den Cortes zugeordnet, was besonders dadurch deutlich wurde, dass die Rechnungslegung gegenüber diesen und nicht mehr gegenüber dem König erfolgte. ${ }^{605}$ Sie hatte auch gerichtliche Funktion und war der Exekutive gegenüber unabhängig.

Die weitere innenpolitische Entwicklung des 19. Jahrhunderts war von häufigen Wechseln zwischen Abschaffung und Wiederherstellung der konstitutionellen Monarchie geprägt, die Auswirkungen auf die Stellung der Rechnungskontrollinstitution zeigten sich entsprechend in ihrer Zuordnung zum König oder zum Parlament.

Die Verfassung vom 6. Juni $1869^{606}$ führte schließlich die konstitutionelle Monarchie wieder ein. Der Rechnungshof wurde erneut in der Nähe des Parlaments angesiedelt, was das Recht zur Ernennung und Absetzung des Präsidenten und der Mitglieder durch die Cortes gem. Art. 58 Nr. 5 verdeutlicht. ${ }^{607}$ Am 25. Juni 1869 wurde ein Rechnungshofgesetz erlassen (Ley Orgánica de 25 de junio de 1869 del Tribunal de Cuentas), das dem Hof eine dem Parlament nahe, unabhängige Stellung einräumte.

Am 13. September 1923 kam infolge eines Militärputsches Primo de Rivera y Orbaneja an die Macht und errichtete eine Diktatur. 1925 erfolgte die Gründung des Tribunal Supremo de la Hacienda Pública, dem die interne und externe Kontrolle der Bewirtschaftung öffentlicher Mittel oblag, da in ihm Organe der internen Kontrolle und das Tribunal de Cuentas zusammengelegt wurden; 608 das bis dahin geltende Rechnungshofgesetz von 1869 war damit außer Kraft gesetzt.

Nach dem Scheitern der Diktatur und der Ausrufung der zweiten Republik am 14. April 1931 verabschiedeten die Cortes am 9. Dezember 1931 eine neue Verfas-

601 Vgl. das Kapitel „Evolución Histórica“ auf der Internetseite des Tribunal de Cuentas http://www.tcu.es.

${ }^{602}$ Brockhaus, Suchwort "Cortes", 2006.

603 http://www.constitucion.es/otras_constituciones/espana/1812.html.

${ }^{604}$ Brockhaus, Suchwort “Cortes”, 2006.

605 Vgl. das Kapitel „Evolución Histórica“ auf der Internetseite des Tribunal de Cuentas http://www.tcu.es.

$606 \mathrm{http}: / /$ www.constitucion.es/otras_constituciones/espana/1869.html.

607 Vgl. Kapitel „Evolución Histórica“ auf der Internetseite des Tribunal de Cuentas http://www.tcu.es.

608 Reglamento del 3 de Marzo de 1925 del Tribunal Supremo de la Hacienda Pública; National Audit Office, State Audit in the European Union, 2005, S. 242; vgl. auch das Kapitel „Evolución Histórica“ auf der Internetseite des Tribunal de Cuentas http://www.tcu.es. 
sung $^{609}$, die erneut eine enge Bindung des Tribunal de Cuentas an das Parlament vorsah (vgl. Art. 120 Abs. 1 der Verfassung von 1931). ${ }^{610}$

Nach dem Ende des spanischen Bürgerkriegs legte General Franco am 6. Dezember 1940 durch das Syndikatsgesetz die Grundlage seiner Diktatur. ${ }^{611}$ Der neuen Staatsform entsprechend unterstellte das Gesetz über das Tribunal de Cuentas del Reino von 1953 den Rechnungshof dem Staatschef und den Cortes Orgánicas. ${ }^{612}$

Nach dem Tod Francos erfolgte der Umbau Spaniens in eine parlamentarische Monarchie: Am 15. Juni 1977 fanden erstmals Parlamentswahlen statt, am 29. Dezember 1978 trat die Verfassung des Königreiches Spanien ${ }^{613}$ (im Folgenden CE) in Kraft. Die Verfassung regelt in Art. 136 bereits sehr detailliert die Aufgaben und Privilegien des Tribunal de Cuentas. Hervorzuheben sind insbesondere die Funktionen der Finanzkontrolle, Rechtsprechung und Berichterstattung und die Unabhängigkeit seiner Mitglieder. Art. 153 d) CE unterstellt die Tätigkeit der Organe der Autonomen Gemeinschaften der Kontrolle durch den Rechnungshof.

Art. 136 Abs. 4 CE ermächtigt hinsichtlich der weiteren Ausgestaltung zum Erlass eines Organgesetzes. Dieses findet sich im 1982 erlassenen Ley Orgánica 2/1982, de 12 de mayo del Tribunal de Cuentas ${ }^{614}$. Es regelt als verfassungsausführendes Gesetz insbesondere Kompetenzen und Funktionen des Tribunals (Titel I.) sowie seine Zusammensetzung und Organisation (Titel II. und III.) und die Voraussetzungen, unter denen Personen für den gesetzwidrigen Verlust öffentlicher Mittel haftbar gemacht und zur Verantwortung gezogen werden können (Titel IV.). Das Gesetz über die Funktionsweise des Rechnungshofes (im Folgenden LFTCu ${ }^{615}$ konkretisiert weitere Einzelheiten.

\section{Verfassungsrechtliche Hilfsgarantien}

\section{Bestandsgarantie}

Die spanische Verfassung von 1978 garantiert in Art. 136 Abs. 1 CE den Bestand des Rechnungshofes als „oberstes Organ der Rechnungskontrolle und der Kon-

\footnotetext{
609 http://www.constitucion.es/otras_constituciones/espana/1931.html.

610 National Audit Office, State Audit in the European Union, 2005, S. 242.

611 Brockhaus, Suchwort "Spanien/Geschichte", 2006.

612 National Audit Office, State Audit in the European Union, 2005, S. 242.

613 Boletín Oficial del Estado (Staatsanzeiger) de 29 de diciembre de 1978; die Festlegung auf die parlamentarische Monarchie findet sich in Art. 1 Abs. 3 CE.

614 Boletín Oficial del Estado (Staatsanzeiger) de 21 de mayo de 1982, núm. 121.

${ }^{615}$ Ley 7/1988, de 5 de abril de Funcionamiento del Tribunal de Cuentas, Boletín Oficial del Estado (Staatsanzeiger) de 7 de Abril de 1988, núm. 84.
} 
trolle der Wirtschaftstätigkeit des Staates sowie des öffentlichen Sektors"616. Auch seine wesentlichen Funktionen (Prüfung, Rechtsprechung und Berichterstattung) sowie das Privileg der Unabhängigkeit seiner Mitglieder sind verfassungsrechtlich verbürgt (Art. 136 Abs. 2 und $3 \mathrm{CE}$ ).

\section{Unabhängigkeit}

Aus Art. 136 Abs. 3 CE ergibt sich, dass die Mitglieder des Rechnungshofes die gleichen Privilegien wie Richter genießen (vgl. Art. 117 Abs. 1 und 2 CE), sie sind mithin unabhängig und unabsetzbar und entsprechend auch denselben Inkompatibilitätsregelungen unterworfen. Gem. Art. 127 Abs. $1 \mathrm{CE}$ dürfen Richter während ihrer Amtszeit keine anderen öffentlichen Ämter bekleiden sowie weder politischen Parteien noch Gewerkschaften angehören. ${ }^{617}$ Das verfassungausführende Organgesetz über das Tribunal des Cuentas (im Folgenden LOTCu ${ }^{618}$ bestimmt in Art. 5, dass dieses seine Funktionen mit voller Unabhängigkeit ausübt und dabei nur dem Gesetz unterworfen ist.

Auch die Vorschriften über die Ernennung der Mitglieder tragen der Unabhängigkeit Rechnung. Nach Art. 30 Abs. 1 LOTCu ernennt jede der beiden Kammern des Parlaments (Abgeordnetenkongress und Senat) mit Drei-FünftelMehrheit je sechs der zwölf Rechnungsräte (Consejeros) für eine Amtszeit von neun Jahren. Es muss sich bei den Kandidaten um anerkanntermaßen geeignete Akademiker handeln (Art. 30 LOTCu führt den genauen Personenkreis zum Beispiel Professoren und höhere Beamte abschließend auf), die über mindestens fünfzehn Jahre Berufserfahrung verfügen müssen. Der zweite Absatz des Art. 30 LOTCu betont erneut, diesmal im Zusammenhang mit den Ernennungsregeln, die Unabhängigkeit und Unabsetzbarkeit der Mitglieder. Sachgerecht ist daher die Organisation des Rechnungshofes als Kollegium: Alle wichtigen Aufgaben werden durch das Plenum des Tribunals, bestehend aus den zwölf Mitgliedern, wahrgenommen (vgl. Art. 21 LOTCu hinsichtlich der Finanzkontrollfunktion und der Genehmigung der Berichte sowie Art. 24 LOTCu bezüglich der Rechtsprechungsfunktion). Systemgerecht erfolgt auch die Ernennung des Präsidenten auf Vor-

${ }^{616}$ El Tribunal de Cuentas es el supremo órgano fiscalizador de las cuentas y de la gestión económica del Estado, así como del sector público.

${ }^{617}$ Für das sonstige Personal des Rechnungshofes verweist Art. 1 der Ley Orgánica 1/1985, de 18 de enero (Boletín Oficial del Estado núm. 21, 24-Ene-1985), auf die Vorschriften der Ley de Incompatibilidades del Personal al servicio de las Administraciones Públicas, das genauso für das Personal des Verfassungsgerichtshofes gilt und zahlreiche Unvereinbarkeitsregelungen mit anderen Ämtern enthält.

${ }^{618}$ Ley Orgánica 2/1982, de 12 de mayo del Tribunal de Cuentas, Boletín Oficial del Estado (Staatsanzeiger) de 21 de mayo de 1982, núm. 121; Bei einem Organgesetz handelt es sich um ein verfassungausführendes Gesetz, das mit absoluter Mehrheit verabschiedet wird, vgl. Ibán, Introducción al Derecho Español, 1999, S. 24 f.; im Falle des LOTCu ergibt sich der verfassungsrechtliche Auftrag zum Erlass aus Art. 136 Abs. 4 CE. 
schlag des Plenums selbst, auf den hin das vorgeschlagene Mitglied gem. Art. 29 LOTCu vom König ernannt wird. Die Amtszeit beträgt drei Jahre.

Auch die sachliche Unabhängigkeit ist gewährleistet: Nach Art. 5 LOTCu „übt der Rechnungshof seine Tätigkeiten in voller Unabhängigkeit aus und ist dabei nur dem Gesetz unterworfen“. Dementsprechend legt das Plenum gemäß Art. 3 a) LFTCu jedes Jahr ein Arbeitsprogramm fest. ${ }^{619}$ Die Initiative, Prüfungen vorzunehmen, liegt beim Tribunal de Cuentas selbst, jedoch kann diese gem. Art. 45 LOTCu auch vom spanischen Parlament und in ihrem jeweiligen Zuständigkeitsbereich auch von den Regionalparlamenten der Comunidades Autónomas ausgehen.

Es stellt sich die Frage, wie im Zusammenhang mit der Unabhängigkeit Art. 136 Abs. 1 S. 2 CE zu beurteilen ist, wonach der Rechnungshof „unmittelbar von den Cortes Generales abhängig ist und er seine Prüfungs- und Kontrollfunktion hinsichtlich der Staatseinnahmen und -ausgaben in deren Vertretung ausübt" ${ }^{\text {"620, }}$ die Abhängigkeit wird auch in Art. 1 Abs. 2 S. 2 LOTCu aufgeführt. Die Regelung steht scheinbar im Widerspruch zu Art. 136 Abs. 3 CE sowie zu den zahlreichen Verbürgungen der Unabhängigkeit im Organgesetz über das Tribunal de Cuentas. Das Parlament hat jedoch angesichts der eindeutigen, weitreichenden Unabhängigkeitsgarantien keine direkten Einflussmöglichkeiten. Mithin handelt es sich mehr um ein Problem der staatsorganisationsrechtlichen Einordnung des Rechnungshofes als um eines der Unabhängigkeit, so dass es noch an entsprechender Stelle (IV. 1.) zu erörtern sein wird.

Abschließend bleibt darauf hinzuweisen, dass auch die finanzielle Unabhängigkeit des Tribunal de Cuentas dadurch gewährleistet ist, dass es gem. Art. 6 LOTCu seinen eigenen Haushalt ausarbeitet, ${ }^{621}$ der allerdings vom Parlament genehmigt werden muss.

\section{Informations- und Zugangsrechte}

Art. 7 Abs. 1 LOTCu garantiert dem Rechnungshof gegenüber allen seiner Kontrolle unterliegenden Stellen umfassende Informations- und Zugangsrechte. Für den Fall, dass dem Auskunftsersuchen des Rechnungshofes nicht nachgekommen wird, verweist Art. 7 Abs. 3 LOTCu auf das Gesetz über die Funktionsweise des Rechnungshofes. Dieses regelt im III. Kapitel die Zusammenarbeit mit dem Hof und bestimmt in Art. 30 Abs. 5, dass er bei Nichterfüllung des Ersuchens Geldstrafen gegen die Verantwortlichen verhängen kann.

${ }^{619}$ Das aktuelle Jahresprogramm sowie die Programme vergangener Jahre sind auf der Webseite des Tribunal de Cuentas http://www.tcu.es veröffentlicht.

620 [El Tribunal de Cuentas] «Dependerá directamente de las Cortes Generales y ejercerá sus funciones por delegación de ellas en el examen y comprobación de la Cuenta General del Estado ».

621 Hierzu ausführlich: Tribunal de Cuentas, Memoria de Actuaciones del Tribunal de Cuentas correspondiente al ejercicio 2006, del 27 de junio de 2007, III.3. El Presupuesto del Tribunal de Cuentas. 


\section{Aufgaben}

Das Tribunal de Cuentas nimmt eine besondere Stellung ein, weil ihm eine Doppelfunktion zugewiesen ist. Zum einen ist dies, wie aus Art. 136 Abs. 1 CE deutlich wird, die Ausübung der externen Finanzkontrolle der staatlichen Tätigkeit wirtschaftlicher und finanzieller Art im gesamten öffentlichen Bereich („Función de „fiscalización externa ... de la actividad económico-financiera del sector público“, vgl. Art. 2 Ziff. a. LOTCu). Zum anderen kommt dem Tribunal eine eigene Rechtsprechungsfunktion für den Bereich der öffentlichen Buchhaltung zu, in dem es über die Verantwortlichkeit derjenigen Amtswalter zu urteilen hat, die die Verantwortung für den Umgang mit öffentlichen Mitteln tragen („Enjuiciamiento de la responsibilidad contable...“ Art. 2 Ziff. b. LOTCu).

\section{Finanzkontrollfunktion}

Ausgangspunkt ist Art. 136 Abs. 1 CE, wonach der Rechnungshof als oberstes Organ der Finanzkontrolle Rechnungen und wirtschaftliche Tätigkeit des Staates und des gesamten öffentlichen Sektors (sector público) überwacht, sowie Abs. 2 S. 1, wonach die Rechnungen des Staates und des öffentlichen Sektors dem Rechnungshof zur Kontrolle übergeben werden.

Die Kontrollfunktion erstreckt sich auf den gesamten öffentlichen Sektor, der gem. Art. 4 Abs. 1 LOTCu insbesondere die Verwaltung des Staates, die Comunidades Autónomas (Autonome Regionen / räumliche Selbstverwaltungskörperschaften), die Verwaltungsstellen der Sozialversicherung sowie staatliche Unternehmen und Beteiligungen umfasst. Das Organgesetz über die Finanzierung politischer Parteien ${ }^{622}$ erstreckt seine Zuständigkeit weiter auf die Überprüfung der Rechtmäßigkeit der Parteifinanzen (Art. 16), über die sie ausführlich Rechenschaft abzulegen haben. Er gibt ihm gegebenenfalls auch das Recht, finanzielle Sanktionen gegen diese auszusprechen (Art. 17).

De facto erstreckt sich die Prüfungszuständigkeit des Rechnungshofes also auf die Einnahmen und Ausgaben der Gesamtheit der staatlichen Verwaltung sowie aller staatlichen Stellen und Unternehmen; ${ }^{623}$ die Finanzkontrolle ist somit grundsätzlich räumlich wie sachlich lückenlos gewährleistet.

Die Überprüfung erfolgt gem. Art. 9 Abs. 1 LOTCu anhand der Maßstäbe der Rechtmäßigkeit, Effizienz und Wirtschaftlichkeit des staatlichen Finanzsektors. Außerdem hat der Rechnungshof gem. Art. 316 Abs. 1 S. 2 CE die Prüfung und Kontrolle der Gesamtrechnung des Staates (Cuenta general del estado) mithin aller Einnahmen und Ausgaben in Vertretung der Cortes Generales vorzunehmen.

${ }^{622}$ Ley Orgánica 8/2007, de 4 de julio, sobre financiación de los partidos políticos, Boletín Oficial del Estado núm. 160, 5-Jul-2007.

${ }^{623}$ Espin, El Tribunal de Cuentas, in: López Guerra u.a., Derecho Constitucional, Volumen II, 1992, S. 217. 


\section{Gerichtliche Funktion}

Die eigenständige Rechtsprechung des Tribunal de Cuentas im Bereich des öffentlichen Finanzwesens ist verfassungsrechtlich in Art. 136 Abs. 2 S. 2 CE garantiert und wird in Art. 1 und 2 sowie Art. 15 bis 18 LOTCu inhaltlich präzisiert. Dem Tribunal de Cuentas obliegt es, über die buchhalterische Verantwortlichkeit von Amtsträgern zu urteilen und die Urteile auch selbst durchzusetzen. Es handelt sich um eine typische rechtsprechende Tätigkeit: Die Anwendung der Gesetzesnorm auf den buchhalterischen Sachverhalt, daran anschließend die Feststellung des Bestehens oder Nichtbestehens der Verantwortlichkeit des mit der öffentlichen Rechnung Betrauten und schließlich seine Verurteilung oder seine Entlastung durch Urteilsspruch. ${ }^{624}$

Ihrem Gegenstand nach erstreckt sich die buchhalterische Rechtsprechung (Jurisdicción contable) auf die mögliche Verurteilung derjenigen, deren Verantwortlichkeit für öffentliche Güter festgestellt wird. Das sind die öffentlichen Bediensteten, die gem. Art. 15 Abs. 1 LOTCu Rechnung legen müssen, weil sie Einnahmen zu erheben oder Rechnungen zu prüfen haben beziehungsweise öffentliche Güter, öffentliches Vermögen oder Wertpapiere verwalten, überwachen, damit umgehen oder sie benutzen. ${ }^{625}$ Derjenige, der durch Tun oder Unterlassen gesetzeswidrig öffentliches Vermögen vermindert, wird gem. Art. 38 Abs. 1 LOTCu zum Ersatz der Schäden und Nachteile herangezogen. Dabei wird eine Abstufung zwischen direkter (Art. $42 \mathrm{LOTCu}$ ) und subsidiärer (Art. 43 LOTCu) buchhalterischer Verantwortlichkeit vorgenommen (vgl. Art. 38 Abs. 2 LOTCu), nach der sich der Umfang der Ersatzansprüche bestimmt. Danach ist derjenige, dessen Handlung den Schaden unmittelbar und direkt ausgelöst hat, als direkt Verantwortlicher heranzuziehen. Ist dies nicht möglich, können gegebenenfalls subsidiär andere Verantwortliche herangezogen werden, die es fahrlässig oder durch schuldhaftes Zögern versäumt haben, den Schaden abzuwenden. ${ }^{626}$

Entsprechend seiner gerichtlichen Tätigkeit ist dem Tribunal de Cuentas auch eine eigene Staatsanwaltschaft zugeordnet (vgl. Art. 27 LOTCu „Fiscalía del Tribunal de Cuentas").

Es handelt sich bei dieser buchhalterischen Rechtsprechung um eine eigenständige in ihrer Funktion allein dem Tribunal de Cuentas zugewiesene Aufgabe. ${ }^{627}$ Bei der Wahrnehmung der Rechtsprechungsfunktion handelt der Rech-

\footnotetext{
${ }^{624}$ Tribunal de Cuentas, La Jurisdicción Propia del Tribunal de Cuentas: http://www.tcu.es/default.htm,

(ORGANIZACIÓN Y FUNCIONES -> La Jurisdicción Contable -> Descripción).

625 Art. 15 Abs. 1 LOTCu : „El enjuiciamiento contable, como jurisdicción propia del Tribunal de Cuentas se ejerce respecto de las cuentas que deban rendir quienes recauden, intervengan, administren, custodien, manejen o utilicen bienes, caudales o efectos públicos."

${ }^{626}$ National Audit Office, State Audit in the European Union, 2005, S. 244 f.

${ }^{627}$ Vgl. Art. 17 Abs. 1 LOTCu „La jurisdicción contable es necesaria e improrrogable, exclusiva y plena“.
} 
nungshof völlig unabhängig und auch nicht in Vertretung der Cortes. ${ }^{628}$ Wie schon aus dem Verfassungstext selbst deutlich wird, bezieht sich nämlich das Tätigwerden ,,in Vertretung der Cortes“ nach Art. 136 Abs. 1 S. 2 CE nur auf die Prüfung der Gesamtrechnung des Staates (Cuenta General del Estado).

Das Verhältnis der buchhalterischen Rechtsprechung zu anderen Gebieten der Rechtsprechung, insbesondere die Abgrenzung zur straf- und verwaltungsgerichtlichen, ergibt sich aus Art. 17, 18 LOTCu.

Berufung gegen Urteile des Tribunal de Cuentas kann gem. Art. 52 Abs. 2, 80 ff. LFTCu beim Tribunal Supremo eingelegt werden.

\section{Berichterstattung}

Unmittelbar aus der Verfassung ergibt sich die Pflicht des Rechnungshofes, jedes Jahr den Cortes Generales einen Jahresbericht (Informe Anual) vorzulegen (Art. 136 Abs. 2 S. 2 CE). In ihm hat er die festgestellten vorgefallenen GesetzesverstöBe und Verantwortlichkeiten mitzuteilen. ${ }^{629}$ Der Jahresbericht enthält nach Art. 13 LOTCu unter anderem eine Analyse der Gesamtrechnung des Staates und der sonstigen Rechnungen des öffentlichen Sektors sowie einen Bericht (Memoria) über die gerichtliche Tätigkeit des Tribunal de Cuentas (vgl. Art. 28 LFTCu). Neben diesen ordentlichen Berichten kann der Rechnungshof gem. Art. 28 Abs. 4 LFTCu, wenn er dies für notwendig hält, jederzeit außerordentliche Berichte erstellen und dem Parlament vorlegen.

Nach Art. 12 Abs. 1 LOTCu werden außerdem die Ergebnisse der Prüfungen (mithin die Ergebnisse der Finanzkontrolle) als Berichte ${ }^{630}$ dem Parlament zugeleitet und im Staatsanzeiger veröffentlicht. ${ }^{631}$

Der jährliche Prüfungsbericht wird dann über die gemeinsame Kommission für die Zusammenarbeit zwischen Rechnungshof und den beiden Kammern des Parlaments letzteren vorgelegt. Entsprechende Berichte über sie betreffende Angelegenheiten werden gem. Art. 13 Abs. 3 CE auch den (Regional-) Parlamenten der Comunidades Autónomas vorgelegt.

628 Cazorla Prieto, in: Garrido Falla y otros, Comentarios a la Constitución, Art. 136, S. 2373 m.w.N.; Espin, El Tribunal de Cuentas, in: López Guerra u.a., Derecho Constitucional, Volumen II, 1992, S. $216 \mathrm{f}$.

629 Ausführlich: Cazorla Prieto, in: Garrido Falla y otros, Comentarios a la Constitución, Art. 136, S. $2373 \mathrm{f}$.

${ }^{630}$ Unterschieden werden die Berichtsformen Informe, ordentliche und außerordentliche Memorias sowie Moción und Nota, vgl. Art. 12 Abs. 1 LOTCu.

$631 \mathrm{Zu}$ den verschiedenen Berichtsformen der Mitteilung der Prüfungsergebnisse, vgl. http://www.tcu.es (Organización y Funciones - > Informes y Memorias, Mociones y Notas); die Berichte des TCu sind ebendort auch abrufbar. 


\section{Beratung}

In den Gesetzen lassen sich Hinweise auf eine eigenständige, besondere Beratungsfunktion nur vereinzelt finden. Zu erwähnen ist Art. 14 Abs. 1 LOTCu, der festlegt, dass der Rechnungshof Maßnahmen zur Verbesserung der Haushaltsführung des öffentlichen Sektors vorschlägt.

Ganz allgemein findet Beratung durch die Berichterstattung des Hofes statt. Einzelne Verbesserungsvorschläge erfolgen durch Berichte, insbesondere in Form sog. „Mociones“, die der Rechnungshof gem. Art. 12 Abs. 1 LOTCu erlassen kann. Art. 3 c. LFTCu umschreibt diese als „Mittel, um Verbesserungen der Haushaltsführung im öffentlichen Sektor vorzuschlagen“, die den Cortes Generales beziehungsweise den Regionalparlamenten, soweit es diese betrifft, vorzulegen sind. ${ }^{632}$ Diese Verbesserungsvorschläge kann das Tribunal de Cuentas gem. Art. 28 Abs. 6 LFTCu, wann immer es dies für notwendig hält, vorlegen.

\section{Stellung im System der Gewaltenteilung}

\section{Gewaltenteilung im spanischen Verfassungsrecht}

Die Verfassung der parlamentarischen Monarchie ${ }^{633}$ Spanien verwirklicht die klassische Gewaltenteilung in Legislative, Exekutive und Judikative. ${ }^{634}$ Die Ausprägung des Systems der horizontalen Gewaltenteilung wird bereits aus der systematischen Einteilung der spanischen Verfassung deutlich: In jeweils eigenen Abschnitten sind die Krone (Titel II), die Cortes Generales (Titel III), die Exekutive bestehend aus Regierung und Verwaltung (Titel IV) und die rechtsprechende Gewalt (Titel VI) geregelt. Die Vorschriften über den Rechnungshof finden sich in dem separaten Abschnitt über Wirtschaft und Finanzwesen (Titel VII).

Die gesetzgebende Gewalt wird in Spanien gem. Art. 66 Abs. 2 CE von den beiden Parlamentskammern, den Cortes Generales, die gem. Art. 66 Abs. 1 CE aus dem Abgeordnetenkongress und dem Senat bestehen, ausgeübt. ${ }^{635}$ Ihnen ob-

${ }^{632}$ Das Tribunal de Cuentas definiert Moción unter http://www.tcu.es (Organización y Funciones -

$>$ Informes y Memorias, Mociones y Notas) als: "El documento elevado por el Tribunal de Cuentas a las Cortes Generales proponiendo modificaciones de la normativa aplicable u otras medidas para la mejora de la gestión analizada a la vista de los resultados recogidos en anteriores Informes de fiscalización" Übersetzung: An die Cortes gerichtetes Dokument, das Veränderungen des anwendbaren Rechts vorschlägt oder andere Maßnahmen zur Verbesserung der untersuchten Haushaltsführung in Ansehung von in früheren Prüfungsberichten gewonnenen Ergebnissen.

633 Vgl. Art. 1 Abs. 3 CE.

${ }^{634}$ González Encinar, Rechtsstaatlichkeit in Spanien, in: H/H/M/W, Rechtsstaatlichkeit in Europa, 1996, S. 167 (177).

${ }^{635}$ Hierzu Rubio Llorente, Die Gesetzgebungsverfahren in Spanien, in: López Pina, Spanisches Verfassungsrecht, 1993, S. 377. 
liegt gemäß Art. 66 Abs. 2 CE auch die Kontrolle der Regierung; entsprechend regelt die spanische Verfassung in Art. 99 und 108-115 typische parlamentarische Kontrollrechte, insbesondere kann im Abgeordnetenkongress gem. Art. 113 CE ein Misstrauensantrag gegen die Regierung gestellt werden.

Die in Titel VI der Verfassung geregelte rechtsprechende Gewalt geht nach Art. 117 Abs. 1 CE ,vom Volke aus und wird im Namen des Königs von Richtern ausgeübt, die die rechtsprechende Gewalt bilden; sie sind unabhängig, unabsetzbar, verantwortlich ${ }^{636}$ und allein dem Gesetz unterworfen“. Art. 127 CE enthält strenge Inkompatibilitätsregelungen, um die Unabhängigkeit der Judikative gegenüber den anderen Staatsgewalten zu gewährleisten. ${ }^{637}$

Spanien verfügt damit über ein klassisches System der Gewaltenteilung, das zwischen Legislative, Exekutive und Judikative trennt und besonders dem Bestehen unabhängiger Gerichte besondere Bedeutung beimisst.

\section{Einordnung des Tribunal de Cuentas}

Art. 136 Abs. 1 S. 1 CE bezeichnet den Rechnungshof als „oberstes Organ der Rechnungskontrolle und der Kontrolle der Wirtschaftstätigkeit des Staates sowie des öffentlichen Sektors“" ${ }^{338}$. Satz 2 der Vorschrift bestimmt seine Stellung dahingehend, dass er „unmittelbar von den Cortes Generales abhängig“ ist und seine Überwachungs- und Kontrollfunktion über die Staatseinnahmen und -ausgaben ,in ihrer Vertretung wahrnimmt" ${ }^{639}$ die Abhängigkeit wird auch in Art. 1 Abs. 2 S. 2 LOTCu aufgeführt.

Nach dem Verfassungswortlaut ist der spanische Rechnungshof damit formell hinsichtlich seiner Finanzkontrollfunktion im Bereich der Legislative mit direkter Abhängigkeit von den Cortes Generales, dem zweikammerigen Parlament bestehend aus Cámara de Diputados und Senado, einzuordnen. Hinsichtlich der Wahrnehmung seiner gerichtlichen Aufgaben bestimmt die Verfassung jedoch in Art. 136 Abs. 2 S. 2 CE, dass die jährliche Berichterstattung an die Cortes Generales „unbeschadet der eigenen Rechtsprechung“, die der Rechnungshof ausübt, erfolgt. Die Rechtsprechung erfolgt mithin völlig eigenständig und ohne Abhängigkeit von den Cortes. Die Regelung des Art. 136 Abs. 1 S. 2 CE steht scheinbar auch im Widerspruch zu Art. 136 Abs. 3 CE sowie zu den zahlreichen Verbürgungen der Unabhängigkeit im Organgesetz über das Tribunal de Cuentas (insbe-

\footnotetext{
636 Gemeint ist die strafrechtliche, zivilrechtliche und disziplinarrechtliche Verantwortlichkeit die auch die Richter trifft, vgl. Andrés Ibáñez, Die rechtsprechende Gewalt in der spanischen Verfassung von 1978, in: López Pina, Spanisches Verfassungsrecht, 1993, S. 435 (451 f.).

${ }^{637}$ Vgl. hierzu und zu den entsprechenden Regelungen für die Mitglieder des Rechnungshofes oben C. II. 2.

638 «El Tribunal de Cuentas es el supremo órgano fiscalizador de las cuentas y de la gestión económica del Estado, así como del sector público.».

639 [El Tribunal de Cuentas] «Dependerá directamente de las Cortes Generales y ejercerá sus funciones por delegación de ellas en el examen y comprobación de la Cuenta General del Estado.».
} 
sondere Art. 30 Abs. 2 und Art. 5 LOTCu). Die Cortes haben jedoch angesichts der eindeutigen, weitreichenden Garantien der Unabhängigkeit keine direkten Einflussmöglichkeiten. Das verdeutlicht auch ein Vergleich mit den entsprechenden Regelungen in Österreich, ${ }^{640}$ wo dem Parlament im Gegensatz zu Spanien erhebliche Einflussmöglichkeiten gegenüber dem Rechnungshof zukommen, die seine Unabhängigkeit beeinträchtigen und ihn eindeutig als Teil der Legislative dem Parlament unterordnen. Das Tribunal de Cuentas ist sicherlich im unmittelbaren Umkreis der Cortes einzuordnen. ${ }^{641}$ Das ist nicht ungewöhnlich, da es Hauptzweck der externen Finanzkontrolle ist, dem Organ, das die Budgethoheit ausübt, die hierfür notwendigen Informationen zu liefern. Die Finanzkontrollfunktion durch das Tribunal de Cuentas schafft damit die technischen Grundlagen für die Kontrolle der Regierung durch die Cortes Generales. ${ }^{642}$ Der Rechnungshof ist insofern nicht etwa ein eigenes Organ der Cortes, sondern vielmehr verdeutlicht die Abhängigkeit seine funktionelle Verortung im Bereich der Legislative. Die „Abhängigkeit" vom Parlament und die Ausübung der Tätigkeiten in dessen „Vertretung" sind zudem mehr historisch-politischer als rechtlicher Natur. ${ }^{643}$ Diese Auffassung lässt sich durch den Blick auf die wechselhafte Geschichte der Staatsorganisation Spaniens vom 19. Jahrhundert bis zum Ende der Franco-Ära stützen. Sie ist durch die ständigen Wechsel zwischen parlamentarischen (parlamentarische Monarchie, Republik) und autoritären (absolute Monarchie, Diktaturen Riveras und Francos) Staatsformen geprägt. Dementsprechend kommt der Stellung, die dem Parlament in Spanien eingeräumt wird, besondere symbolische und politische Bedeutung zu. Ebenso war und ist die Zuordnung des Tribunal de Cuentas zum Parlament oder zum Staatsoberhaupt von großer Symbolik.

Auch die Ausgestaltung der Rechtsstellung des Tribunals mit den zahlreichen Verbürgungen sachlicher und persönlicher Unabhängigkeit von allen anderen Staatsorganen lässt die „Abhängigkeit“ in diesem Licht erscheinen. Die Cortes haben keinerlei Handhabe, unmittelbaren Einfluss auf die Arbeit des Hofes zu nehmen. ${ }^{644}$

Im Ergebnis kann man die Rechtsnatur des spanischen Tribunal de Cuentas wohl am treffendsten als Doppelstellung charakterisieren ${ }^{645}$, indem es einerseits dem Bereich der Legislative zugeordnet ist, wenn auch vermittelt durch die Unabhängigkeitsregelungen als Institution eigener Art, und andererseits, was die Ausübung der Rechtsprechungsfunktion angeht, dem Bereich der Judikative.

640

641 Cazorla Prieto, in: Garrido Falla y otros, Comentarios a la Constitución, Art. 136, S. 2363 ff.

642 Tribunal de Cuentas, Memoria de Actuaciones del Tribunal de Cuentas correspondiente al ejercicio 2006, del 27 de junio de 2007, III.1.

${ }^{643}$ Cazorla Prieto, in: Garrido Falla y otros, Comentarios a la Constitución, Art. 136, S. 2363 ff. m.w.N.

${ }^{644}$ Cazorla Prieto, in: Garrido Falla y otros, Comentarios a la Constitución, Art. 136, S. 2363 ff.

${ }^{645}$ Espín, El Tribunal de Cuentas, in: López Guerra u.a., Derecho Constitucional, Volumen II, 1992, S. $216 \mathrm{f}$. 


\section{Rechtsschutzmöglichkeiten}

Bei Streitigkeiten über Kompetenzen oder Zuständigkeiten des Tribunal de Cuentas kann dieses gem. Art. 8 Abs. 1 LOTCu den Verfassungsgerichtshof zur Klärung anrufen. 


\section{Vereinigtes Königreich: Comptroller and Auditor General und National Audit Office}

\section{Historische Entwicklung}

Die älteste Erwähnung einer Finanzkontrolle gegenüber der Regierung geht auf das Jahr 1314 zurück und bezieht sich auf einen Buchprüfer eben des Schatzamtes. ${ }^{646}$ Somit fand in Großbritannien ursprünglich keine der Exekutive gegenüber unabhängige Rechnungsprüfung statt, die zuständige Behörde war vielmehr nichts anderes als ein Regierungsorgan; insbesondere unterlag die Festlegung von Prüfungsgegenstand und Methoden dem Schatzamt (Treasury). ${ }^{647}$

Erst der auf Initiative des Schatzkanzlers Gladstone ergangene Exchequer and Audit Departments Act von $1866^{648}$ führte ein, dass alle Ministerien eine Jahresrechnung zu erstellen hatten. ${ }^{649}$ Weiter schuf er das Amt des Comptroller General of the Receipt and Issue of HM Exchequer and Auditor General of Public Accounts (üblicherweise und im Folgenden als Comptroller and Auditor General bezeichnet) und das Exchequer and Audit Department. Der Comptroller and

\footnotetext{
646 National Audit Office, State Audit in the European Union, 2005, S. 265.

${ }^{647}$ Heinig, Das Budget, Bd. 1, 1949, S. 46 f.

648 Alle im Folgenden zitierten Gesetze sind in ihrer aktuellen Form abrufbar bei der UK Statute Law Database unter http://www.statutelaw.gov.uk/Home.aspx.

${ }^{649}$ National Audit Office, State Audit in the European Union, 2005, S. 265.
} 
Auditor General war dabei einerseits zuständig für die Freigabe staatlicher Gelder an die Regierung - er hatte also zu kontrollieren, ob diese innerhalb des vom Parlament festgelegten Rahmens ausgegeben wurden -, andererseits für die nachgängige Kontrolle der Rechnungen aller Ministerien und für die Berichterstattung darüber an das Parlament. ${ }^{650}$ Er erhielt bereits besondere Unabhängigkeit gegenüber Exekutive und Parlament, indem seine Abberufung an hohe Hürden geknüpft war (vgl. Section 3 Exchequer and Audit Departments Act 1866).

1870 betonte das Comittee of Public Accounts (der Rechnungsprüfungsausschuss des House of Commons) die Zweckmäßigkeit einer direkten Zuleitung der Berichte des Comptroller and Auditor General an das Unterhaus anstatt über den Umweg über das Schatzamt, was seitdem auch so gehandhabt wird. ${ }^{651}$

Die Novellierung des Exchequer and Audit Departments Act von 1921 bedeutete das Ende der bis dahin stattfindenden Gesamtkontrolle aller Finanzvorgänge und erlaubte es dem Comptroller and Auditor General und seinem Amt, teilweise auf interne Kontrollorgane der Ministerien zurückzugreifen; daneben hatte er von nun an darüber zu berichten, ob die öffentlichen Ausgaben nach den Vorgaben durch das Parlament getätigt wurden. ${ }^{652}$

Das National Audit Office ist durch den National Audit Act 1983 als Nachfolger des Exchequer and Audit Department, das bis dahin der Unterstützung des Comptroller and Auditor General gedient hatte, errichtet worden. ${ }^{653}$ Außerdem wurde dessen Stellung nun formell als die eines Beamten (Officer) des House of Commons festgelegt (vgl. Section 1 Subsection 2 National Audit Act 1983), was vor allem als Stärkung der Unabhängigkeit gegenüber der Exekutive verstanden wird. ${ }^{654}$ Die sachliche Unabhängigkeit angehend stellt Section 1 Subsection $3 \mathrm{Na}$ tional Audit Act 1983 die Erfüllung seiner Aufgaben allein in das Ermessen des Comptroller and Auditor General, der bei seinen Entscheidungen aber Vorschläge des Committee of Public Accounts berücksichtigen soll. Ferner kann er die Berichte über die Ergebnisse von Wirtschaftlichkeitsprüfungen nach Sections 7 und 8 jederzeit dem Parlament vorlegen.

Der Government Resources and Accounts Act 2000 erweiterte in seiner Section 8 die Prüfungs- und Zugangsrechte des Comptroller and Auditor General. 655

${ }^{650}$ National Audit Office, State Audit in the European Union, 2005, S. 265.

${ }^{651}$ Heinig, Das Budget, Bd. 1, 1949, S. 46; zum Committee of Public Accounts siehe Handbuch der internationalen Rechts- und Verwaltungssprache, Haushalts- und Rechnungsprüfung, 1988, S. 70.

652 National Audit Office, The History of the National Audit Office, abrufbar unter: http://www.nao.org.uk/about/history.htm

${ }^{653}$ Handbuch der internationalen Rechts- und Verwaltungssprache, Haushalts- und Rechnungsprüfung, 1988, S. 64.

${ }^{654}$ National Audit Office, State Audit in the European Union, 2005, S. 265.

655 National Audit Office, State Audit in the European Union, 2005, S. 265. 
In Wales (Wales Audit Office), Schottland (Audit Scotland) und Nordirland (Northern Ireland Audit Office) existieren Regionalprüfungsämter, deren Bedeutung besonders in jüngerer Zeit gewachsen ist.

\section{Hilfsgarantien}

\section{Bestandsgarantie}

Das Bestehen des Comptroller and Auditor General sowie des National Audit Office ist durch die aufgeführten Gesetze gewährleistet. Eine verfassungsrechtliche Bestandsgarantie im Sinne des deutschen Verfassungsrechts ist dem britischen System mit seinem Prinzip der Sovereignty (auch „Legislative Supremacy“) of Parliament jedoch fremd, da das britische Parlament an keinen Rechtsakt gebunden ist, auch nicht an solche, die es selbst zu einem früheren Zeitpunkt erlassen hat 656.657

\section{Unabhängigkeit}

Der Comptroller and Auditor General, als Chef des National Audit Office, ${ }^{658}$ genießt weitgehende sachliche und persönliche Unabhängigkeit von der zu kontrollierenden Exekutive; was die Durchführung seiner Aufgaben und fachliche Fragen angeht, ist er auch unabhängig vom Parlament. ${ }^{659}$

Die Nähe zum Parlament, aber auch die besondere mit bestimmten Unabhängigkeitsgarantien verbundene Stellung des Comptroller and Auditor General spiegelt sich in den Vorschriften zu seiner Ernennung und den hohen Hürden an seine Abberufung wider. Die Ernennung erfolgt durch die Krone auf Antrag des Unterhauses; die Initiative hierfür wird vorher vom Premierminister im Einverständnis mit dem Vorsitzenden des Committee of Public Accounts, der traditionell Angehöriger der Opposition ist, eingebracht. ${ }^{660}$ Es gibt keine zeitliche Beschränkung seiner Amtszeit; ${ }^{661}$ die Abberufung durch die Queen ist nur auf An-

656 Bradley/Ewing, Constitutional and Administrative Law, 2003, S. 60 ff.: "Rule that Parliament may not bind its successors".

657 Bradley/Ewing, Constitutional and Administrative Law, 2003, S. 59 ff.; Finer/Bogdanor/Rudden, Comparing Constitutions, 1998, S. 43 ff.; Einschränkungen bestehen jedoch hinsichtlich des Vorrangs des Gemeinschaftsrechts seit dem European Communities Act 1972, wie auch die Rechtsprechung des House of Lords in den Factortame-Fällen gezeigt hat, vgl. Nachweise bei Bradley/Ewing, Constitutional and Administrative Law, 2003, S. 68 f., 129 ff., 130 Fn. 102.

${ }^{658}$ Section 3, Subsection 1 (a) National Audit Act 1983.

${ }^{659} \mathrm{Handbuch}$ der internationalen Rechts- und Verwaltungssprache, Haushalts- und Rechnungsprüfung, 1988, S. 66; National Audit Office, Annual Report 2007, S. 8; Heinig, Das Budget, Bd. 1, 1949, S. 47 zur geschichtlichen Entwicklung und m.w.N.;

${ }^{660}$ National Audit Office, Annual Report 2007, S. 8; National Audit Office, State Audit in the European Union, 2005, S. 264.

${ }^{661}$ National Audit Office, State Audit in the European Union, 2005, S. 269. 
trag beider Häuser des Parlamentes hin möglich. ${ }^{662}$ Die Ausgestaltung als Hilfsorgan der Legislative bringt die monokratische Organisationsform mit dem Comptroller and Auditor General als Chef des ihm untergeordneten National Audit Office mit sich. Eine besondere Ausprägung der Unabhängigkeit ist die Tatsache, dass der Comptroller and Auditor General das Personal des National Audit Office (im Jahr 2007 ca. 850 Mitarbeiter) ${ }^{663}$ selbst ernennt und dass es sich bei diesen Angestellten ihrem Status nach nicht um Staatsbeamte (Civil Servants) handelt, ${ }^{664}$ und sie aus diesem Grund außerhalb der Ministerialbürokratie stehen und nur dem Comptroller and Auditor General verantwortlich sind, was die Unabhängigkeit von der Regierung bedeutet (vgl. Section 3 Subsection 2 - 4 National Audit Act 1983).

Was die sachliche Unabhängigkeit angeht, stellt Section 1 Subsection 3 National Audit Act 1983 die Erfüllung seiner Aufgaben allein in das Ermessen des Comptroller and Auditor General, insbesondere die Wahl sowie die Art und Weise der Behandlung des Prüfungsgegenstandes. Jedoch soll er bei seinen Entscheidungen Vorschläge des Committee of Public Accounts berücksichtigen.

Auch zur Gewährleistung finanzieller Unabhängigkeit gelten für Comptroller and Auditor General und National Audit Office besondere Regelungen. Die Bezahlung des Comptroller and Auditor General erfolgt aus dem Consolidated Fund, der nicht der jährlichen Budgetbewilligung durch Parlament oder Exekutive bedarf 665 (vgl. Section 1 Subsection 4 Exchequer And Audit Departments Act 1957). ${ }^{666}$ Seit dem National Audit Act von 1983 unterliegt das National Audit Office gem. Section 3 Subsect. 3 hinsichtlich seines Haushaltes einschließlich seiner Personalpolitik, insbesondere der Besoldung seiner Angestellten, nicht mehr der Kontrolle durch das Schatzamt. Die Finanzaufsicht übt vielmehr die vom Unterhaus gebildete Public Accounts Commission aus. ${ }^{667}$

\section{Informations- und Zugangsrechte}

Die Informations- und Zugangsrechte des Comptroller and Auditor General sind im Wesentlichen in Section 8 National Audit Act 1983 sowie Section 8 Government Resources and Accounts Act 2000 geregelt. Danach hat er jederzeit Zugang zu allen Dokumenten, die in Zusammenhang mit der Rechnungsführung von Ministerien stehen, soweit sie in einem Ministerium geführt werden oder dessen Kontrolle unterliegen. Ferner haben diejenigen Personen, die die entsprechenden Dokumente verwahren oder zu kontrollieren haben, ihm mit jeder Art

\footnotetext{
662 National Audit Office, State Audit in the European Union, 2005, S. 264.

${ }^{663}$ National Audit Office, Annual Report 2007, S. 8.

${ }^{664}$ National Audit Office, Annual Report 2007, S. 8.

665 Bradley/Ewing, Constitutional and Administrative Law, 2003, S. 351.

666 National Audit Office, State Audit in the European Union, 2005, S. 264.

${ }^{667}$ Handbuch der internationalen Rechts- und Verwaltungssprache, Haushalts- und Rechnungsprüfung, 1988, S. 66; National Audit Office, State Audit in the European Union, 2005, S. 264.
} 
von Informationen zur Verfügung zu stehen, die er benötigt. Der Comptroller and Auditor General hat weiter Zugriff auf Dokumente anderer öffentlicher Körperschaften (non-departmental public bodies) sowie von Körperschaften, die öffentliche Mittel erhalten; diese Zugriffsrechte sind entweder in dem Rechtsakt, durch den die Körperschaften errichtet wurden, enthalten oder basieren auf vertraglicher Vereinbarung bei der Mittelvergabe. ${ }^{668}$

\section{Aufgaben}

Das National Audit Office selbst betont, seine Hauptaufgabe sei die Unterstützung des Parlamentes bei der Regierungskontrolle zugunsten des Steuerzahlers. ${ }^{669}$ Diese erfüllt es durch die „klassischen“ Funktionen der unabhängigen Rechnungsprüfung gegenüber der Exekutive und der Berichterstattung an das Parlament.

\section{Prüfung}

Es erfolgt eine Prüfung von Rechnungsführung und Ordnungsmäßigkeit der Rechnungen der Exekutive sowie von Körperschaften, die öffentliche Gelder bekommen oder verwalten (vgl. Section 6-8 National Audit Act 1983), wie zum Beispiel National Health Service und Universitäten ${ }^{670}$.

Innerhalb der der externen Kontrolle durch den Comptroller and Auditor General unterworfenen Behörden bestehen auch interne Kontrollmechanismen. Typisch für das britische Finanzkontrollsystem ist, dass ein Schwerpunkt der Arbeit von Comptroller and Auditor General und National Audit Office auf einer engen Zusammenarbeit mit diesen behördeneigenen Kontrollinstanzen liegt und dass sie sich mithin von der Zuverlässigkeit und Aussagekraft der von ihnen angewandten Systeme überzeugen. ${ }^{671}$ Geprüft werden somit die Funktionsfähigkeit und Effizienz der von den geprüften Behörden angewandten Ansätze zur Mittelverwaltung und ihrer internen Kontrollmechanismen. Ergänzt wird dieser systemgestützte Prüfungsansatz durch Stichproben hinsichtlich der rechnerischen Richtigkeit. Im Anschluss an die Prüfung gibt das National Audit Office auch Empfehlungen an die Behörde ab, wie die geprüften Systeme verbessert werden können. 672

\footnotetext{
${ }^{668} \mathrm{Zu}$ den Prüfungsrechten im Einzelnen: National Audit Office, State Audit in the European Union, 2005, S. 265

669 National Audit Office, Corporate Plan 2006, S. 1.

${ }^{670}$ Bradley/Ewing, Constitutional and Administrative Law, 2003, S. 359.

${ }^{671}$ Handbuch der internationalen Rechts- und Verwaltungssprache, Haushalts- und Rechnungsprüfung, 1988, S. 66.

672 National Audit Office, State Audit in the European Union, 2005, S. 266.
} 
Neben der eigentlichen Prüfung von Ordnungsmäßigkeit und rechnerischer Richtigkeit überzeugt sich das National Audit Office auch davon, dass die vom Parlament zugebilligten Gelder auch in seinem Sinne, also im Rahmen des vom Parlament vorgegebenen Auftrages, verwendet wurden. ${ }^{673}$

Wie sich aus Section 6 National Audit Act 1983 ergibt, prüft der Comptroller and Auditor General neben der Ordnungsmäßigkeit und rechnerischen Richtigkeit (in Zusammenarbeit mit dem Public Accounts Committee) ${ }^{674}$ auch die Wirtschaftlichkeit im weiteren Sinne (,value for money audit"), das heißt die Sparsamkeit, Wirtschaftlichkeit und Zweckerreichung bei der Verwendung öffentlicher Mittel und erstattet dem Parlament hierüber Bericht. ${ }^{675}$ Dabei unterliegen seiner Prüfung dieselben Stellen wie bei der Prüfung der Ordnungsmäßigkeit (vgl. Sections 6, 7 National Audit Act 1983).

\section{Berichterstattung}

Der Comptroller and Auditor General erstattet dem Parlament einen Jahresbericht und kann gem. Section 9 National Audit Act 1983 jederzeit nach eigenem Ermessen dem Parlament weitere Berichte vorlegen. ${ }^{676}$

Eine enge Zusammenarbeit erfolgt auch bei der Berichterstattung mit dem Rechnungsprüfungsausschuss des House of Commons, mit dem insbesondere die Wirtschaftlichkeitsberichte abgestimmt werden und der auch selbst dem House of Commons Bericht erstatten kann. ${ }^{677}$ Die Berichte werden veröffentlicht und können beim National Audit Office angefordert werden, neuere und aktuelle Berichte sind zudem auf seiner Homepage abrufbar. ${ }^{678}$

\section{Beratung}

Eine Beratungsfunktion ist nicht ausdrücklich gesetzlich vorgesehen. Jedoch liegt bereits in dem Recht, dem Parlament jederzeit Berichte, insbesondere über die Wirtschaftlichkeit staatlichen Handelns, vorzulegen, in gewisser Weise ein Beratungsauftrag. Schließlich erscheint in diesem Bereich eine Prüfung und Berichterstattung ohne damit verbundene Beratungselemente kaum möglich. Ferner erfolgt eine Beratung der geprüften Stellen, indem der Comptroller and Auditor General wie gesehen auf seinen Prüfungsergebnissen basierende Verbesserungsvorschläge macht.

\footnotetext{
${ }^{673}$ Vgl. Section 6 (b) Government Resources and Accounts Act 2000; National Audit Office, State Audit in the European Union, 2005, S. 266.

${ }^{674}$ Handbuch der internationalen Rechts- und Verwaltungssprache, Haushalts- und Rechnungsprüfung, 1988, S. 68.

675 National Audit Office, Annual Report 2007, S. 8.

${ }^{676}$ Vgl. Im Einzelnen: National Audit Office, State Audit in the European Union, 2005, S. 267.

677 National Audit Office, Annual Report 2007, S. 10; National Audit Office, State Audit in the European Union, 2005, S. 267.

678 http://www.nao.org.uk/publications/index.htm.
} 


\section{Stellung im System der Gewaltenteilung des Vereinigten Königreiches}

\section{Die Ausprägung der Gewaltenteilung}

Die Gesetzgebung geht im Vereinigten Königreich grundsätzlich vom Souverän aus, also der Krone, die jedoch lediglich über formale Befugnisse verfügt, sowie von den beiden Parlamentskammern, dem House of Commons (Unterhaus) und dem House of Lords (Oberhaus). Oberstes Organ der Exekutive ist die Regierung. Jedoch gibt es (ebenso wie in Deutschland) keine strikte personelle Gewaltenteilung zwischen Legislative und Regierung; vielmehr sind die Minister in der Regel auch Mitglieder des Unterhauses, ${ }^{679}$ der Premierminister und die wichtigsten Minister müssen, so ist es in Conventions vorgesehen, sogar Parlamentsmitglieder sein. ${ }^{680}$ Die besondere Bedeutung, die dem Parlament im britischen Staatsverständnis zukommt, zeigt sich in der Doktrin der "Sovereignty of Parliament“ oder auch „Supremacy of Parliament“, wonach nichts über dem Parlament steht und es absolute Entscheidungsfreiheit und unbegrenzte Regelungsmacht besitzt. ${ }^{681}$

Entscheidender als eine strikte Trennung zwischen Legislative und Exekutive ist, wie schon mehrfach gesehen, das Bestehen einer unabhängigen Judikative. Was ihre Unabhängigkeit im Vereinigten Königreich angeht, sind die Richter durch Garantien geschützt, die sich aus Conventions und Statutes ergeben, hinsichtlich ihrer Ernennung, Bezahlung (die wie auch beim Comptroller and Auditor General aus dem Consolidated Fund erfolgt), Unabsetzbarkeit und richterlichen Immunität. ${ }^{62}$ Jedoch gibt es auch hier eine erhebliche personelle Überschneidung dadurch, dass der Lord Chancellor als Oberhaupt der Judikative zugleich Mitglied des Kabinetts und des House of Lords ist. 683

2. Die Verortung des Comptroller and Auditor General und des National Audit Office

Von grundlegender Bedeutung für das heute in Großbritannien bestehende System der externen Finanzkontrolle ist der Exchequer and Audit Act 1866, der diese in ihrer heutigen Form erst begründete. Bis dahin war die Rechnungsprüfung eine (abhängige) Einrichtung der Exekutive. Der Exchequer and Audit Act 1866 veränderte diesen Standort komplett und schuf eine von der Exekutive unabhängige,

\footnotetext{
${ }^{679}$ Barendt, An Introduction to Constitutional Law, 1998, S. 14.

${ }^{680}$ Lyall, An Introduction to British Law, 1994, S. 61.

681 Bradley/Ewing, Constitutional and Administrative Law, 2003, S. 58 f.; Finer/Bogdanor/Rudden, Comparing Constitutions, 1998, S. 43 ff.; mit Einschränkungen was die Bindungswirkung europäischen Rechts angeht.

682 Finer/Bogdanor/Rudden, Comparing Constitutions, 1998, S. 89.

683 Barendt, An Introduction to Constitutional Law, 1998, S. 14.
} 
dem Bereich der Legislative zuzuordnende Einrichtung, begründete mithin überhaupt erst eine externe Finanzkontrolle.

Typisch für die heutige Rolle des Comptroller and Auditor General ist Section 1, Subsection 2 National Audit Act 1983, wonach er ein Angestellter des Unterhauses („Officer of the House of Commons“) ist. Seine Aufgabe ist die Unterstützung des Parlaments bei seiner Kontrolle der Exekutive. Dementsprechend erfolgt wie gesehen auch die Zuleitung der Berichte seit 1870 direkt an das Parlament. Comptroller and Auditor General und National Audit Office sehen folglich als ihre Hauptaufgabe die Unterstützung des Parlamentes bei der Kontrolle des Umganges der Regierung mit den ihr zugewiesenen Geldern, und zwar zu Gunsten des Steuerzahlers. ${ }^{684}$ Eine gewisse Selbständigkeit auch von der Legislative zeigt sich darin, dass der Comptroller and Auditor General große sachliche Unabhängigkeit in Auswahl von Prüfungsgegenständen und Art der Prüfung genießt. Auch die finanzielle Ausstattung und die Tatsache, dass das Personal durch den Comptroller and Auditor General ernannt wird, tragen hierzu bei. Die Sonderstellung spiegelt sich ferner in den Regelungen zur Ernennung und Abberufung des Comptroller and Auditor General wider, die gewaltenübergreifend geregelt sind und auch die parlamentarische Opposition mit einbeziehen.

Der Comptroller and Auditor General und damit auch das National Audit Office ist der Legislative, gleichsam als Hilfsorgan des Parlaments, zuzuordnen, wenn auch als verselbständigter Teil, wie die Unabhängigkeit auf fachlichem Gebiet zeigt. Dieser Status ist durch die traditionelle Stellung, die das Parlament im britischen Staatsrecht einnimmt, zu erklären. Ihre Stellung als Hilfsorgane des Parlaments ebenso wie die starke Stellung des Committee of Public Accounts ist typisch für das britische Staatsverständnis, das mit dem obersten Grundsatz der Sovereignty of Parliament, als dem Vertreter des Volkes, dem demokratischen Element traditionell überragende Bedeutung und Einfluss in alle Bereichen des Staatswesens zuerkennt. ${ }^{685}$ Dementsprechend kommt auch der Kontrolle der Regierung durch das Parlament besondere Bedeutung zu, wie es der Auftrag des Comptroller and Auditor General, die Verwendung von Geldern nach Maßgabe der Vorgaben durch das Parlament zu überprüfen, zeigt. Besonders wichtig ist die Kontrolle der Finanzen, weil diese einen Machtfaktor ersten Ranges im Staate darstellen, was auch die Stellung des Committee of Public Accounts als bedeutendster aller Parlamentsausschüsse erklärt ${ }^{686}$. Diesem Parlamentsausschuss, der für die (in der Praxis sehr enge) ${ }^{67}$ Zusammenarbeit mit dem Comptroller and

${ }^{684}$ National Audit Office, Corporate Plan 2006, S. 1, 6.

685 B. Tiemann / S. Tiemann, Zum staatsrechtlichen Standort der Finanzkontrolle in rechtsvergleichender Sicht, Der Staat, Bd. 13 (1974, S. 497 (510).

686 Bradley/Ewing, Constitutional and Administrative Law, 2003, S. 359 m.w.N.: “...no other select committee having the same authority, clarity of remit and breadth and depth of advice available to it".

${ }^{687}$ National Audit Office, Corporate Plan 2006, S. 17. 
Auditor General zuständig ist, kommen ungewöhnlich weitgehende eigene Rechte zu. So erstattet er dem House of Commons eigenständig Bericht über Anhörungen des Comptroller and Auditor General und kann sogar, über die Arbeit des National Audit Office hinausgehend, Sachverhalte aufgreifen und selbständig prüfen. ${ }^{688}$

Die Zuordnung zum Parlament bedingt auch die stark monokratische Ausgestaltung der externen Finanzkontrolle im Vereinigten Königreich. ${ }^{689}$ Der Comptroller and Auditor General ist diesem gegenüber verantwortlich und nimmt die zentrale Stellung ein, ihm obliegt die Rechnungskontrolle, das National Audit Office dient wie schon sein Vorgänger, das Exchequer and Audit Department, seiner Unterstützung.

\section{Rechtsschutzmöglichkeiten}

Die Zuordnung zum Parlament zeigt sich auch in den Möglichkeiten, die der Comptroller and Auditor General zur Wahrung seiner Rechte hat, etwa wenn die Exekutive Informations- und Zugangsrechten nicht nachkommen sollte. Dann hat er lediglich die Möglichkeit, das Public Accounts Committee einzuschalten, was aber regelmäßig nicht nötig ist. ${ }^{690}$

Weitergehende eigene Klagemöglichkeiten hat er nicht. Dies lässt sich aus der Stellung des Comptroller and Auditor General als Hilfsorgan des Parlaments erklären: Es ist Sache des Parlamentes beziehungsweise seines Haushaltsausschusses Prüfungsrechte seines Hilfsorgans durchzusetzen, für den unwahrscheinlichen Fall, dass diese bestritten werden.

688 B. Tiemann / S. Tiemann, Zum staatsrechtlichen Standort der Finanzkontrolle in rechtsvergleichender Sicht, Der Staat, Bd. 13 (1974, S. 497 (510).

689 Zu den Parallelen in Österreich: B. II. 2. a).

${ }^{690}$ Handbuch der internationalen Rechts- und Verwaltungssprache, Haushalts- und Rechnungsprüfung, 1988, S. 68. 


\section{Dritter Teil: Der Europäische Rechnungshof (Curia Rationum)}

Die Notwendigkeit, durch die Einrichtung von Organen zur Finanzkontrolle ein effektives Wirtschaften mit staatlichen Geldern sicherzustellen, besteht nicht nur auf nationalstaatlicher Ebene, sondern bei jeder Wirtschaftseinheit. Die Europäische Union mit einem Haushalt von mehr als 100 Milliarden Euro und einer staatsähnlichen Einnahmen- und Ausgabenstruktur bedarf einer solchen Kontrolle ebenso wie die Mitgliedstaaten.

Kontrollbedarf besteht also einerseits auf Unionsebene, andererseits auf Ebene der Mitgliedstaaten, soweit ihre Behörden Gemeinschaftsmittel verwalten. Diesem wird teils durch den Europäischen Rechnungshof (im Folgenden auch als „EuRH“ abgekürzt) ${ }^{691}$ selbst, teils durch die nationalen obersten Rechnungskontrollorgane, mit denen er gem. Art. 248 Abs. 3 S. 2 EGV (287 Abs. 3 S. 2 AEUV) „unter Wahrung ihrer Unabhängigkeit vertrauensvoll zusammenarbeitet“, nachgekommen.

Mit In-Kraft-Treten des Vertrages von Lissabon ${ }^{692}$ am 1. Dezember 2009 ist der EUV modifiziert und der EGV durch den Verrag über die Arbeitsweise der EU (AEUV) ersetzt worden. Auswirkungen auf den Rechnungshof und seine

\footnotetext{
${ }^{691}$ In Anlehnung an die gebräuchliche Terminologie für den Europäischen Gerichtshof (EuGH).
} 692 ABl. 2007 Nr. C 306/1 
Rechtsstellung in der Union haben diese Änderungen jedoch nicht mit sich gebracht. Die Regelungen des AEUV über den EuRH entsprechen, wie noch im einzelnen zu sehen sein wird, denen des EGV, so dass es lediglich zu einer neuen Nummerierung in diesem Bereich gekommen ist sowie zu notwendigen Anpassungen. Diese beschränken sich jedoch auf Änderungen wie die Ersetzung des Wortes „Gemeinschaft“ durch „Union“, die erstere nach den neuen Verträgen ersetzt. Für die vorliegende (noch vor Inkrafttreten des Lissabonvertrages fertiggestellte) Arbeit hat dies zur Folge, dass im Bereich der Darstellung von Hilfsgarantien, Aufgaben und Rechtschutzmöglichkeiten des EuRH die jeweilige AEUVNorm in Klammern neben die ursprüngliche EGV-Norm gesetzt wird. Im Bereich der Darstellung der Funktionenteilung und des institutionellen Gleichgewichts ist es zu einer Reihe von Änderungen, insbesondere im Bereich der Gemeinschaftsrechtssetzung gekommen. Diese sind jedoch im Ergebnis für die Bewertung des Prinzips der Funktionenteilung und des institutionellen Gleichgewichts und die Einordnung des EuRH ohne Auswirkungen. Zwar hat sich das Gesetzgebungsverfahren dahingehend geändert, dass beim Erlass von Gesetzgebungsakten zwischen dem ordentlichen Gesetzgebungsverfahren nach Art. 294 AEUV und dem besonderen nach Art. 289 Abs. 2 AEUV unterschieden wird. Dabei entspricht das ordentliche Gesetzgebungsverfahren jedoch weitestgehend dem bisherigen Mitentscheidungsverfahren nach Art. 251 EGV, das Anhörungsbzw. Zustimmungsverfahren im Rahmen des besonderen Gesetzgebungsverfahrens entsprechen im wesentlichen ebenfalls den bisherigen Regelungen. ${ }^{693}$ Weder die Funktionsverteilung noch das Prinzip des institutionellen Gleichgewichts hat sich jedoch vom Grundsatz her verändert. Durch das Verhältnis des ordentlichen zum besonderen Gesetzgebungsverfahren hat sich die Stellung des Europäischen Parlaments dahingehend gestärkt, dass es im Gesetzgebungsverfahren ebenso wie im Haushaltsverfahren zu einem nahezu gleichberechtigten Gesetzgeber neben dem Rat geworden ist; ${ }^{694}$ an dem Grundprinzip, so wie es unter IV. dargestellt werden wird, und der Bewertung der Stellung des EuRH ändert dies aber nichts. Daher bleibt es bei der Darstellung der Mechanismen nach dem EGV unter IV, zumal sich sämtliche der Arbeit zugrunde gelegte Literatur hierauf bezieht. Die Rechtslage nach dem AEUV wird jeweils am Ende eines Abschnittes kurz dargestellt.

${ }^{693}$ Streinz/Obler/Herrmann, Der Vertrag von Lissabon, S. 91 f.

${ }^{6} 94$ Streinz/Obler/Herrmann, Der Vertrag von Lissabon, S. 52. 


\section{Entwicklung der externen Finanzkontrolle von den Anfän- gen der Europäischen Gemeinschaften bis heute}

Die Errichtung des Europäischen Rechnungshofes geht auf den Vertrag von Brüssel vom 22. Juli 1975 zurück, ${ }^{695}$ am 25. Oktober 1977 hielt er in Luxemburg seine konstituierende Sitzung ab ${ }^{696}$.

Er trat an die Stelle des bis dahin die Rechnungsprüfung innerhalb der Europäischen Gemeinschaften ausübenden Kontrollausschusses nach Art. 206 EWGVertrag und Art. 180 EAG-Vertrag und des Rechnungsprüfers der EGKS nach Art. 78 e EGKS-Vertrag. ${ }^{697}$ Der Kontrollausschuss war aber insbesondere mit der Aufgabe der Kontrolle in den Mitgliedstaaten völlig überfordert und nur unzureichend mit diesbezüglichen Rechten ausgestattet. ${ }^{698}$ Zwar war in Art. 206 EWGVertrag ebenso wie im Statut des Kontrollausschusses ${ }^{699}$ bereits verankert, dass er „aus Rechnungsprüfern, die volle Gewähr für ihre Unabhängigkeit bieten müssen," zu bestehen habe, in der Praxis kam ihm aber eher untergeordnete Bedeutung zu, die Prüfer trafen sich selten, ${ }^{700}$ und ihre Tätigkeit war nur als „Nebenamt $^{\text {‘'701 }}$ ausgelegt. ${ }^{702}$

Der Kontrollausschuss war damit als Instrument ungeeignet, um den Umgang mit Einnahmen und Ausgaben auf Mitgliedstaatenebene effektiv zu überwachen und die massiven Betrügereien vor allem im Agrarbereich einzudämmen. ${ }^{703}$ Seine

${ }^{695}$ Vertrag vom 22.7.1975 zur Änderung bestimmter Finanzvorschriften der Verträge zur Gründung der Europäischen Gemeinschaften und des Vertrages zur Einsetzung eines gemeinsamen Rates und einer gemeinsamen Kommission der Europäischen Gemeinschaften; ABl. Nr. L 359/1 vom 31.12.1977.

${ }^{696}$ Emile Nö̈l, Die Organe der EG und EU, 1997, S. 43.

${ }^{697}$ Detailliert zu diesen beiden Einrichtungen: Eblermann, Europäischer Rechnungshof, 1976, S. 12 ff.; Friedmann, Aufgabenstellung und rechtliche Rahmenbedingungen der Finanzkontrolle des EuRH, in: Ders., Der EuRH und die Wirtschafts- und Finanzhilfen der EU für Mittel- und Osteuropa, 1994, S. $10 \mathrm{ff}$.

${ }^{998}$ Gräfe, Auf dem Weg zu einem Rechnungshof für die Europäischen Gemeinschaften, in: FS Schäfer, 1975, S. 351 ff. mit Beispielen aus Berichten des Kontrollausschusses; Aigner, Finanzkontrolle der Europäischen Gemeinschaften: Entwicklung und Perspektiven, ZParl 1978, 186 (189).

${ }^{699}$ Vgl. Art. 2 Abs. 1 S. 2 des Statuts des Kontrollausschusses, ABl. 861/59, vom 17.8.1959.

700 Art. 1 Abs. 2 Statut des KA: „Der Kontrollausschuss tritt in regelmäßigen Abständen, zumindest alle zwei Monate zusammen“; Ehlermann, Der Europäische Rechnungshof, 1976, S. 13.

701 Gräfe, Auf dem Weg zu einem Rechnungshof für die Europäischen Gemeinschaften, in: FS Schäfer, 1975, S. 352, 354.

702 Vgl. Art. 2 Abs. 1 S. 1 2. HS Statut des KA, nur mit der Einschränkung in Art. 5 Abs. 1 des Statutes, dass das Amt des Rechnungsprüfers zumindest mit jeder Tätigkeit im Dienste der Gemeinschaft unvereinbar war.

703 Aigner, Finanzkontrolle der Europäischen Gemeinschaften: Entwicklung und Perspektiven, ZParl. 1978, 186 (189 f.) mit Hinweisen auf diesbezügliche Berichte des KA; Chavaki, Betrugsbekämpfung in der EU, ZEuS 1999, 431 (452) nennt die Betrugsbekämpfung als einen der Hauptgründe für die Gründung des Europäischen Rechnungshofes; Reister, Haushalt und Finanzen der Europäischen Gemeinschaften, 1975, S. 112 f. 
Kontrollschwäche hatte mehrere Gründe: Ein Problem waren die unzureichenden Kontrollmöglichkeiten gegenüber den Organen der Europäischen Gemeinschaften, was vor allem an der mangelnden Unterstützung durch die Kommission lag; außerdem verfügte der Kontrollausschuss über keine eigenen Rechte, Nachprüfungen in Mitgliedstaaten vorzunehmen. ${ }^{704}$ Die Organe Rat und Kommission unterließen es, dem Kontrollausschuss die hinsichtlich der unzureichenden Regelungen so wichtige Unterstützung zukommen zu lassen, ${ }^{705}$ so dass die Kontrollmöglichkeiten in der Praxis vollkommen unzureichend waren und somit nicht geeignet, das Ziel, Transparenz in die Einnahmen- und Ausgabenstruktur der Gemeinschaften durch Kontrolle auf Gemeinschafts- und auf Mitgliedstaatenebene zu bringen, zu erreichen.

Hinzu kam die geringe Zahl der Mitarbeiter, insbesondere der Bediensteten neben den Mitgliedern sowie die schwache Stellung des Europäischen Parlaments hinsichtlich Entlastung und Kontrollbefugnissen gegenüber der Exekutive. ${ }^{706} \mathrm{Da}$ der Kontrollausschuss selbst nicht berechtigt war, Staatsgewalt in Form von Exekutivbefugnissen oder Sanktionsmöglichkeiten auszuüben, wären solche Befugnisse des Parlaments aber die einzige Möglichkeit gewesen, um mit den gewonnenen Erkenntnissen über Missstände diesen auch zu begegnen. ${ }^{707}$

Die Notwendigkeit einer Verbesserung der externen Finanzkontrolle war offensichtlich; angesichts der Erhöhung des Haushaltes und der sich abzeichnenden Vergrößerung der Zahl der Mitgliedstaaten musste dieser Zustand der Unsicherheit beseitigt werden. Vor allem Abgeordnete des Europäischen Parlaments setzten sich seit 1964 für die Einrichtung eines Europäischen Rechnungshofes ein. ${ }^{708}$ Auch der Bundesrechnungshof, unterstützt nur durch den italienischen Rechnungshof, plädierte für die Schaffung einer vollwertigen externen Finanzkontrollinstitution, die über Unabhängigkeit, umfassende Befugnisse und eine angemessene Ausstattung an Personal und Finanzen verfügt. ${ }^{709}$

Die Einrichtung eines Europäischen Rechnungshofes durch dementsprechende Vertragsänderungen war im Gegensatz zu der Option, lediglich die Stellung des Kontrollausschusses im Rahmen der bestehenden vertraglichen Regelungen zu verbessern, öffentlichkeitswirksam und zeigte den Willen der Mitgliedstaaten,

${ }^{704}$ Gräfe, Auf dem Weg zu einem Rechnungshof für die Europäischen Gemeinschaften, in: FS Schäfer, 1975, S. 352 unter Zitierung von Kontrollausschussberichten, die diese Misere verdeutlichen.

705 Reister, Haushalt und Finanzen der Europäischen Gemeinschaften, 1975, S. 112 f.; Gräfe, Auf dem Weg zu einem Rechnungshof für die Europäischen Gemeinschaften, in: FS Schäfer, 1975, S. 352.

${ }^{706}$ Gräfe, Auf dem Weg zu einem Rechnungshof für die Europäischen Gemeinschaften, in: FS Schäfer, 1975, S. 352 f.

${ }^{707}$ Gräfe, Auf dem Weg zu einem Rechnungshof für die Europäischen Gemeinschaften, in: FS Schäfer, 1975, S. 353.

708 Vgl. zur Entwicklung im Europäischen Parlament mit zahlreichen Beispielen: Aigner, Plädoyer für einen Europäischen Rechnungshof, 1973, S. 72 ff..

${ }^{709}$ Gräfe, Auf dem Weg zu einem Rechnungshof für die Europäischen Gemeinschaften, in: FS Schäfer, 1975, S. 350. 
Kontrolle und Transparenz der Gemeinschaften zu stärken. ${ }^{710}$ So war er geeignet, die Akzeptanz der Gemeinschaften in der Öffentlichkeit der Mitgliedstaaten zu verbessern.

Die Umstände der Einführung des Europäischen Rechnungshofes zeigen auch gewisse Parallelen zu der natürlich viel älteren Entwicklung in den Nationalstaaten: Ein Parlament ist zur effektiven Wahrnehmung seiner Kontrollrechte auf die Zuarbeit durch einen Rechnungshof angewiesen. ${ }^{711}$ So war es letztlich auch das Europäische Parlament, das seinen wachsenden parlamentarischen Kontrollauftrag erfüllen musste und deshalb für einen verstärkten institutionellen Ausbau der externen Finanzkontrolle kämpfte. ${ }^{712}$ Damit stand die Gründung des Europäischen Rechnungshofes in unmittelbarem Zusammenhang einerseits mit der Zunahme der parlamentarischen Haushalts- und Kontrollrechte, besonders durch die Änderungsverträge von 1970 und 1975,713 andererseits mit der größer werdenden Relevanz der Finanzaktivitäten ${ }^{714}$ der Europäischen Gemeinschaften und der Zunahme ihrer Finanzautonomie gegenüber den Mitgliedstaaten ${ }^{715}$. Die Erwägungsgründe zum Haushaltsvertrag von 1975716, mit dem auch die Errichtung des Europäischen Rechnungshofes beschlossen wurde, verweisen darauf, dass ab dem 1. Januar 1975 der Haushalt der Gemeinschaften in vollem Umfang aus eigenen Mitteln der Gemeinschaft statt aus mitgliedstaatlichen Beiträgen finanziert werden sollte, wodurch auch eine Verstärkung der Haushaltsbefugnisse der Versammlung erforderlich wurde. ${ }^{717}$

Zwar gab es bereits zum damaligen Zeitpunkt Stimmen im Rat, die sogar die Einräumung der Organqualität an den neu zu schaffenden Europäischen Rechnungshof befürworteten, ${ }^{718}$ sie konnten sich aber zunächst nicht durchsetzen. Im

\footnotetext{
${ }^{710}$ In diese Richtung Eblermann, Der Europäische Rechnungshof, 1976, S. 18.

${ }^{711}$ S.o. am Beispiel der preußischen ORK: 1. Teil, I. 2.; sowie VI. 3. a) aa).

712 Aigner, Finanzkontrolle der Europäischen Gemeinschaften: Entwicklung und Perspektiven, ZParl 1978, 186 (186 f.) m.w.N.

713 Aigner, Finanzkontrolle der Europäischen Gemeinschaften: Entwicklung und Perspektiven, ZParl 1978, 186 (186 f.) m.w.N.; Ausführlich zur Erweiterung der Haushaltsbefugnisse des Europäischen Parlaments: Reister, Haushalt und Finanzen der EG, 1975, S. 114, 118 ff.; ders., Parlamentarisches Budgetrecht und Rechnungshof der EG, Europarecht 1976, 69 (70 ff.).

714 Bieber, in: v.d.Groeben/Schwarze, EUV/EGV, Art. 246 EG, Rn. 1.

715 Bieber, in: v.d.Groeben/Schwarze, EUV/EGV, Art. 246 EG, Rn. 5; Zu den Vorschriften über Finanzierung und Kontrolle des Haushaltes der Gemeinschaften bis 1973 vgl. Aigner, Plädoyer für einen Europäischen Rechnungshof, 1973, S. 43 ff.

716 Siehe Fn. 695.

717 Gräfe, Auf dem Weg zu einem Rechnungshof für die Europäischen Gemeinschaften, in: FS Schäfer, 1975, S. 354 ff. m.w.N.; Friedrich/Inghelram, Die Klagemöglichkeiten des Europäischen Rechnungshofs vor dem Europäischen Gerichtshof, DÖV 1999, 669 f.; zur Zielsetzung der Eigenfinanzierung siehe schon Art. 4 des Beschlusses des Rates vom 21. April 1970 über die Ersetzung der Finanzbeiträge der Mitgliedstaaten durch eigene Mittel der Gemeinschaften, ABl. Nr. L 94/19 v. 28.04.1970.

718 Vgl. Eblermann, Der Europäische Rechnungshof, 1976, S. 23.
} 
Gegensatz zum Wirtschafts- und Sozialausschuss lässt sich dem Wortlaut ${ }^{719}$ des vom Haushaltsänderungsvertrag von 1975 eingeführten Art. 4 Abs. 3 EWGVertrag keine Hilfsorganstellung des Europäischen Rechnungshofes entnehmen. ${ }^{720}$ Die Stellung seiner Mitglieder entsprach vielmehr schon im Wesentlichen der von Richtern am Europäischen Gerichtshof (vgl. Art. 206 Abs. 5, 8, 10 EWGVertrag); ferner zielte eine ins Ratsprotokoll aufgenommene Erklärung darauf ab, den Rechnungshof einem Organ gleichzustellen durch entsprechende Anpassung der Regelungen der Haushaltsordnung sowie des Status seiner Mitglieder. ${ }^{721}$

Ehlermann befürwortete in seiner Arbeit über den Europäischen Rechnungshof aus dem Jahre 1976 die Entscheidung, dem Rechnungshof keine Organqualität zu verleihen, da im Gegensatz zu diesem jedes der Organe umfangreiche eigene Entscheidungsbefugnisse habe, und da er für den Fall der Verleihung der Organqualität „gefährliche Auswirkungen auf die bestehenden Organe“ befürchtete, weil deren Status dadurch vermindert werden könnte. ${ }^{722}$ Angesichts der Ausgestaltung seiner Unabhängigkeit und seiner Kompetenzen wäre dem EuRH aber bereits zu diesem Zeitpunkt die Bezeichnung als „Hilfsorgan“723 ebenfalls nicht gerecht geworden, treffender wäre die Einstufung als „Nebenorgan“ gewesen. ${ }^{724}$

Derartige Befürchtungen, die Einräumung der Organqualität könne die übrigen Organe in ihrer Bedeutung herabsetzen, haben sich indes seit Einführung der (Haupt-)Organqualität durch den Vertrag von Maastricht vom 7. Februar $1992^{725}$ nicht bewahrheitet. Im Gegenteil ist die sukzessive Stärkung des Rechnungshofes, die schließlich in seiner Organqualität mündete, ein Garant für eine unabhängige, starke externe Finanzkontrolle und unterstreicht den Willen der Mitgliedstaaten, Verschwendung und Missbrauch innerhalb der EG entschieden entgegenzuwirken. Diese Absicht zeigt sich auch in der zum Vertrag zur Europäischen Union abgegebenen Erklärung Nr. 21 („Erklärung zum Rechnungshof‘), worin die Mit-

719 „Die Rechnungsprüfung wird durch einen Rechnungshof wahrgenommen, der nach Maßgabe der ihm in diesem Vertrag zugewiesenen Befugnisse handelt".

${ }^{720}$ Ehlermann, Der Europäische Rechnungshof, 1976, S. 23; Aigner, ZParl 1978, 186 (189 f.) wonach der Rechnungshof „Zwar nicht die Kompetenz eines Organs“ erhalten habe, „seine Stellung jedoch die eines Organs" sei; a.A.: Friedrich/Inghelram, Die Klagemöglichkeiten des Europäischen Rechnungshofs vor dem Europäischen Gerichtshof, DÖV 1999, 669 (670) sind der Auffassung, der EuRH sei nach dem neu eingefügten Abs. 3 des Art. 4 EGV als „Hilfsorgan ähnlich dem Wirtschafts- und Sozialausschuss" anzusehen gewesen, weisen jedoch auf die bereits bestehenden Besonderheiten, die mehr einem Organ ähneln (1 Mitglied pro MS, richterliche Unabhängigkeit), hin.

721 Abgedruckt bei Eblermann, Der Europäische Rechnungshof, 1976, S. 23 f.

722 Eblermann, Der Europäische Rechnungshof, 1976, S. 23, differenzierter: Hilf, Die Organisationsstruktur der EG, 1982, S. 18.

${ }^{723}$ So Eblermann, Der Europäische Rechnungshof, 1976, S. 26.

${ }^{724}$ Hilf, Die Organisationsstruktur der EG, 1982, 20.

725 ABl. Nr. C 191 vom 29. Juli 1992. 
gliedstaaten die Unterstützung aller Organe zur wirksameren Aufgabenerfüllung des Rechnungshofes verlangen. ${ }^{726}$

Die Stärkung der externen Finanzkontrolle hilft weiter dem Europäischen Parlament bei der Ausübung seiner Kontrollrechte und stärkt damit das unmittelbar demokratische Element in der Europäischen Union.

Mit dem Vertrag von Amsterdam vom 2. Oktober 1997727 wurde der Europäische Rechnungshof in Art. 5 EUV erstmals auch als Organ der Europäischen Union genannt. Der Vertrag erweiterte zudem seine Prüfungskompetenz auf den zweiten und dritten Pfeiler der Union, die gemeinsame Außen- und Sicherheitspolitik (vgl. Art. 28 Abs. 2, 3, 4 EUV) sowie die Zusammenarbeit im Bereich der Justiz und des Inneren (vgl. Art. 41 Abs. 2, 3, 4 EUV). Daneben brachte er die Kodifizierung der schon vorher implizit anerkannten ${ }^{728}$ Aktivlegitimation bei Nichtigkeitsklagen in Art. 230 Abs. 3 EGV, die der Europäische Rechnungshof zur Wahrung seiner Rechte gegenüber anderen Organen vor dem Europäischen Gerichtshof anstrengen kann. 729

Der Vertrag von Nizza ${ }^{730}$ vom 26. Februar 2001 führte mit Art. 248 Abs. 4 UAbs. 5 EGV die ausdrückliche Ermächtigung des EuRH ein, sich eine Geschäftsordnung zu geben, ${ }^{731}$ ferner ist für die Ernennung der Mitglieder seitdem nicht mehr Einstimmigkeit im Rat erforderlich, sondern es reicht gem. Art. 247 Abs. 3 EGV eine qualifizierte Mehrheit. Zum Zwecke der Verbesserung der Arbeitsfähigkeit sieht Art. 248 Abs. 4 UAbs. 3 EGV von nun an die Möglichkeit der Bildung von Kammern für die Annahme bestimmter Arten von Berichten und Stellungnahmen im Rahmen der Geschäftsordnung vor. ${ }^{732}$

Der gescheiterte Vertrag über eine Verfassung für Europa ${ }^{733}$ sah vor, den Europäischen Rechnungshof nicht in Art. I-19 Abs. 1 VerfEU zusammen mit Europäischem Parlament, Europäischem Rat, Ministerrat, Europäischer Kommission und Europäischem Gerichtshof, also als eines der „Organe der Union“, die den

726 Erklärung zum EUV (Nr. 21) zum Rechnungshof, ABl. 1992 Nr. C 191/102: „Die Konferenz weist darauf hin, dass sie den Aufgaben, die dem Rechnungshof...übertragen werden, besondere Bedeutung beimisst. Sie ersucht die anderen Organe der Gemeinschaft, zusammen mit dem Rechnungshof alle Mittel zu prüfen, die geeignet sind, eine wirksamere Erfüllung seiner Aufgaben zu gewährleisten“.

727 ABl. Nr. C 340 vom 10. November 1997.

728 So zum Europäschen Parlament: EuGH, Rs. C-70/88, Slg. 1990, 2041, Rn. 25 (Parlament/Rat); vgl. Waldhoff, in: Calliess/Ruffert, EUV/EGV, Art. 246 EGV, Rn. 1 m.w.N.; ausführlich unten IV. 4. a) aa).

${ }^{729}$ Waldhoff, in: Calliess/Ruffert, EUV/EGV, Art. 246 EGV, Rn. 1; Cremer, ebda, Art. 230 EGV, Rn. 4, 20. Zu den Rechtsschutzmöglichkeiten des Europäischen Rechnungshofes siehe im Einzelnen unter IV.4.

730 ABl. Nr. C 80 vom 10. März 2001, S. 1.

$731 \mathrm{Vgl}$. zur Geschäftsordnung und zur Rechtslage vor Nizza unter: II.2.a).

732 Zu den Änderungen durch den Vertrag von Nizza: Magiera, Der Rechnungshof, in: Jahrbuch der Europäischen Integration 2000/2001, S. 93.

733 Vertrag vom 29. Oktober 2004, ABl. Nr. C 310 vom 16. Dezember 2004 (im Folgenden VerfEU). 
„Institutionellen Rahmen“ bilden, zu nennen. Jedoch führte Kapitel II des Vertragsentwurfes in Art. I-31 Abs. 1 VerfEU den Europäischen Rechnungshof ebenso wie die Europäische Zentralbank (vgl. Art. I-30 Abs. 3 S. 1 VerfEU) als Organe auf, allerdings ausweislich der Kapitelüberschrift lediglich als ,sonstige Organe“. Formell hätte es sich sicherlich um eine Herabstufung gegenüber dem aktuellen Rechtszustand nach Art. 7 Abs. 1 EGV, Art. 5 EUV gehandelt. Da der Rechnungshof jedoch auch nach dem Verfassungsvertrag den Status eines Organs gehabt hätte und seine Rechte ungeschmälert geblieben wären, inhaltlich wurden die Regelungen im Wesentlichen beibehalten, wird dies wohl überwiegend als unerhebliche Änderung betrachtet. ${ }^{734}$

Auch ist zu bedenken, dass er keineswegs auf den Status eines Hilfsorgans reduziert worden wäre. Der Vertrag differenzierte lediglich zwischen den in Art. I19 Abs. 1 VerfEU genannten Organen, die den institutionellen Rahmen bilden, und in Art. I-31 VerfEU den Organen, die zwar keine derart exponierte Stellung haben, aber deren besondere Bedeutung durch den Organstatus (im Falle des Rechnungshofes einschließlich aller Rechte und Befugnisse nach der jetzigen Regelung) dennoch deutlich wird. So wäre die Nennung in Art. I-19 Abs. 1 VerfEU zwar wünschenswert, sie ist aber keine conditio sine qua non einer wirksamen externen Finanzkontrolle. Wie auch der Vergleich mit Obersten Rechnungskontrollbehörden auf Mitgliedstaatenebene zeigt, sind hierfür in erster Linie die Ausgestaltung der Unabhängigkeit und die dem Rechnungshof verliehenen Befugnisse erheblich.

Auch nach den durch den Vertrag von Lissabon geänderten EUV und dem den EGV ersetzenden AEUV ändert sich für den Rechnungshof nichts. Er wird weiter in Art. 13 Abs. 1 EUV n.F. ein Organ sein, dass zusammen mit den anderen Organen den institutionellen Rahmen der Union, die insoweit auch Rechtsnachfolger der EG ist, bildet. An seinen Hilfsgarantien und Befugnissen hat sich nichts geändert, ebensowenig an den Klagemöglichkeiten vor dem Europäischen Gerichtshof. Allein die Verfahrensvorschriften des Art. 279 EGV nun Art. 322 AEUV sehen anstelle einer „Stellungnahme“ des EuRH vor dem Erlass bestimmter für die Unionsfinanzen erheblicher Vorschriften nunmehr seine „Anhörung“ vor, ${ }^{735}$ was jedoch inhaltlich keinen Unterschied macht. ${ }^{736}$ Weiter fällt auf, dass die Unabhängigkeitsgarantie aus Art. 247 Abs. 4 UAbs. 1 EGV von nun an in Art.

\footnotetext{
734 Strein₹/Obler/Herrmann, Die neue Verfassung für Europa, 2005, S. 40: „Der Rechnungshof sinkt durch die Umstellung bestenfalls protokollarisch ab. Auf seine verfassungsrechtliche Stellung im Übrigen hat dies aber keinen Einfluss, wie sich aus Art. I-31 VerfEU ergibt.“; so wohl auch: Waldhoff, in: Calliess/Ruffert, Verfassung der EU, Art. I-31 VerfEU, Rn. 2; Oppermann, Europarecht, 2005, S. 136, Rn. 198; a.A.: Meyer/Hölscheidt, Die Europäische Verfassung des Europäischen Konvents, EuZW 2003, 613 (616); Bieber/Epiney/Haag, Die EU, 2005, \4, Rn. 113: „Verfassungsvertrag nimmt EuRH seine herausgehobene Organstellung“.

${ }^{735}$ Hierzu im Einzelnen: III. 2. a).

736 Kluth, in: Streinz, EUV/EGV, Art. 279 EGV, Rn. 4.
} 
285 AEUV geregelt ist, mithin symbolhaft an den Anfang der Vorschriften über den Rechnungshof gestellt wurde.

Zwischenergebnis: Die Entwicklung ist geprägt von der sukzessiven Stärkung der Stellung der externen Rechnungskontrolle auf europäischer Ebene. Vom zwar bereits aus unabhängigen Mitgliedern bestehenden, aber personell unterbesetzten und nur mit unzureichenden Befugnissen ausgestatteten Kontrollausschuss, zum Rechnungshof mit „Vollzeit-Mitgliedern“ und mehr Mitarbeitern sowie weitreichenden Befugnissen in Form von Informations- und Zugangsrechten.

Der Vertrag von Maastricht begründete seinen Status als Organ der EG. Der Vertrag von Amsterdam erweiterte auch den Kreis der Organe der EU um den Europäischen Rechnungshof und räumte ihm nun ausdrücklich die Aktivlegitimation bei Nichtigkeitsklagen ein, damit er seine Rechte gegenüber den anderen Organen verteidigen kann. Auch nach dem Vertrag von Lissabon ist der EuRH ein Organ der Union.

\section{Vertragliche Hilfsgarantien}

Für die Bewertung des Status des Europäischen Rechnungshofes sind die Stellung seiner Mitglieder sowie seine Rechte und Befugnisse von besonderer Bedeutung. Im Mittelpunkt steht hierbei unzweifelhaft die Gewährleistung der Unabhängigkeit.

\section{Unabhängigkeit}

Der EG-Vertrag wie auch der neue Vertrag über die Arbeitweise der Union gewährt den Mitgliedern des EuRH in Art. 247 Abs. 4 UAbs. 1 und Abs. 7, 9 (Art. 285 Abs. 2, Abs. 7 AEUV) persönliche und sachliche Unabhängigkeit. Eine weitere Konkretisierung der Unabhängigkeit als Weisungsfreiheit gegenüber allen staatlichen und nichtstaatlichen Stellen findet sich in Art. 247 Abs. 4 UAbs. 2 EGV (Art 286 Abs. 3 AEUV).

Bereits bei der Auswahl für die Nominierung als Mitglied des EuRH ist es gem. Art. 247 Abs. 2 UAbs. 2 EGV (Art. 286 Abs. 1 UAbs. 2 AEUV) Voraussetzung, dass die ausgewählte Persönlichkeit jede Gewähr für Unabhängigkeit bietet. Die Regelung entspricht dem Auswahlkriterium, das auch für Richter des Europäischen Gerichtshofs ${ }^{737}$ gilt.

Eine klare Veränderung gegenüber dem Vorgänger Kontrollausschuss stellt die in Art. 247 Abs. 5 EGV (Art. 286 Abs. 4 AEUV) verordnete Hauptberuflichkeit der Tätigkeit mit dem Verbot der Ausübung anderer Berufstätigkeiten während

${ }^{737}$ Art. 223 UAbs. 1 EGV (Art. 253 Abs. 1 AEUV). 
der Mitgliedschaft und dem Gebot der Zurückhaltung bei der Annahme solcher nach der Mitgliedschaft beim Europäischen Rechnungshof dar.

Art. 247 Abs. 7 EGV (Art. 286 Abs. 6 AEUV) setzt, wie im Folgenden zu sehen sein wird, der Unabhängigkeit geschuldet, hohe Hürden an die Amtsenthebung. Damit entspricht die Stellung der Mitglieder des Rechnungshofes im Wesentlichen der von Richtern am Europäischen Gerichtshof.

Dieser Status der Unabhängigkeit seiner Mitglieder prägt letztlich auch den Status des Rechnungshofes selbst ${ }^{738}$ und verleiht ihm, denn dies kann nicht anders als auf mitgliedstaatlicher Ebene zu bewerten sein, ${ }^{739}$ als Institution Unabhängigkeit. 740

Für die Bewertung der Unabhängigkeit der Mitglieder wesentlich ist nicht nur die vertragliche Garantie dieser selbst, sondern auch die Ausgestaltung in Hinblick auf Ernennungsverfahren, Amtszeit, Wiederwahlmöglichkeit und Amtsenthebung sowie Disziplinarmaßnahmen.

\section{a) Ernennung}

Typisch für ein Organ ist zunächst die Zahl der Mitglieder; der Rechnungshof ist gem. Art. 247 Abs. 1 EGV (Art. 285 Abs. 2 UAbs. 1 AEUV) mit je einem Staatsangehörigen pro Mitgliedstaat besetzt, obwohl Einigkeit besteht, dass sehr viel weniger ausreichend wären. ${ }^{741}$ Dieser Tatsache entsprach auch eine Stellungnahme der Europäischen Kommission aus dem Jahre 2000, die eine Reihe institutioneller Reformen bei Wahrung des bestehenden institutionellen Gleichgewichts zum Gegenstand hatte, um deren Effizienz auch in Hinblick auf die schnelle Vergrößerung der Zahl der Mitgliedstaaten zu gewährleisten. ${ }^{72}$ Dabei sprach sich die Kommission für eine Festsetzung der Zahl der Mitglieder des Rechnungshofes auf 12 aus bei gleichzeitiger Etablierung eines Rotationssystems unter den Mitgliedstaaten und Ausschluss ihrer Wiederwahl. ${ }^{743}$ Die heutige Zahl von 27 Mitgliedern erscheint vor diesem Hintergrund und mit Blick auf die Anzahl in den mitgliedstaatlichen obersten Rechnungskontrollbehörden geradezu grotesk und ist wohl leider beispielhaft für den stockenden Reformprozess insgesamt. Eine Ver-

\footnotetext{
738 Vgl. schon Brück/Kühne, Die Neuregelung der Finanzkontrolle der Europäischen Gemeinschaften, DÖV 1977, 23 (24).

739 Vgl. zum Bundesrechnungshof oben: 1. Teil, III. 1. a) mit zahlreichen Nachweisen.

${ }^{740}$ So auch: Bieber, in: v.d.Groeben/Schwarze, EUV/EGV, Art. 247 EG, Rn. 14.

741 Vgl. schon Eblermann, Der Europäische Rechnungshof, 1976, S. 24, wonach ein deutlich kleineres Kollegium aus 7, 5 oder gar 3 Mitgliedern zum damaligen Zeitpunkt im Rat nicht durchzusetzen war; Oppermann, Europarecht, 2005, S. 115, Rn. 119: „nach sachverständigem Urteil wären ca. 10 Mitglieder anstelle der heutigen 25 zur Aufgabenerfüllung ausreichend“.

742 Europäische Kommission, Institutionelle Reform für eine erfolgreiche Erweiterung, Bulletin der EU, Beilage 2/2000, S. 7, 15.

${ }^{743}$ Europäische Kommission, Institutionelle Reform für eine erfolgreiche Erweiterung, Bulletin der EU, Beilage 2/2000, S. 15, 39.
} 
minderung der Mitgliederzahl sah weder der gescheiterte Verfassungsvertrag vor, noch ist sie durch den Vertrag von Lissabon erfolgt.

Art. 247 Abs. 3 EGV (Art. 286 Abs. 2 AEUV) regelt die Ernennung der Mitglieder, danach nimmt der Rat mit qualifizierter Mehrheit die von den Mitgliedstaaten erstellte Liste nach Anhörung des Europäischen Parlaments an. Dass es sich um eine bloße Anhörung und nicht um einen Zustimmungsvorbehalt des Parlaments handelt, wie dies der ursprüngliche Entwurf der Kommission für die Neuregelung vorsah und wie es das Parlament verlangt hatte, ${ }^{744}$ beruht letztlich auf einem Kompromiss in diesem Punkt, in dem der Ratspräsident dem Parlament zusicherte, dass der in der Anhörung abgegebenen Stellungnahme Rechnung getragen werde. ${ }^{745}$

Die Auswahlkriterien, die bei der Ernennung zu beachten sind, sind denkbar schwammig; danach sind „Persönlichkeiten auszuwählen, die in ihren Ländern Rechnungsprüfungsorganen angehören oder angehört haben oder die für dieses Amt besonders geeignet sind. Sie müssen jede Gewähr für ihre Unabhängigkeit bieten“. Problematisch ist dabei das Kriterium der „,besonderen Eignung für das Amt". Gerade in diesem Zusammenhang ist es höchst bedauerlich, dass das Europäische Parlament nach wie vor lediglich angehört wird und die Ernennung nicht unter seinem Zustimmungsvorbehalt steht. Hinzukommt, dass ebenso wie bei der Ernennung der Kommission über eine Liste und nicht über einzelne Mitglieder abzustimmen ist. Das macht ein negatives Votum für den Fall, dass etwa nur einem der Vorgeschlagenen die Eignung für das Amt nach Ansicht des Parlaments fehlt, unwahrscheinlich.

Das Europäische Parlament hat zwar einen Katalog mit sachlichen Kriterien erstellt, die auf den Vorgeschlagenen zutreffen müssen, um diese Voraussetzung $\mathrm{zu}$ erfüllen, ${ }^{746}$ dieser Katalog wird jedoch vom Rat nicht als verbindlich angesehen, wie die Ernennung von Mitgliedern des Rechnungshofes trotz negativer Voten seitens des Parlaments in der Vergangenheit zeigte. ${ }^{747}$ Das Europäische Parlament betonte, dass die Zusammenarbeit zwischen Rechnungshof und Parlament das „Kernstück des Systems der Haushaltskontrolle der Europäischen Union“ darstelle und dass diese gestört sei, sobald es eine ablehnende Stellungnahme zu

${ }^{744}$ Eblermann, Der Europäische Rechnungshof, 1976, S. 21, 25.

745 Ziffer 4 des Schreibens des Ratspräsidenten vom 12.02.1975 an den Präsidenten des Europäischen Parlaments.

746 Entschließung A3-0345/92 zum Verfahren der Konsultation des Parlaments bei der Ernennung der Mitglieder des EuRH vom 17. November 1992, ABl. 1992 Nr. C 337/51, darin wird vor allem eine ,auf hohem Niveau erworbene Berufserfahrung auf dem Gebiet der öffentlichen Finanzen“, gegebenenfalls ein „makelloser Ruf als Verwalter“, ein Höchstalter und eine Beschränkung auf zwei Mandate gefordert, ferner sollten Mitglieder ab der Ernennung „kein durch Wahl übertragenes Mandat ausüben oder Verantwortung in einer Partei tragen"; vgl. ferner die EntschlieBung vom 19. Januar 1995, ABl. 1995 Nr. C 43/75.

747 Zu den genannten Fällen im Einzelnen: Bieber, in: v.d.Groeben/Schwarze, EUV/EGV, Art. 247 EG, Rn. 3. 
Mitgliedern des Rechnungshofes abgebe, diese aber dennoch vom Rat ernannt würden. ${ }^{78}$ Es wäre daher sinnvoll, wie vom Europäischen Parlament seit langem gefordert, ${ }^{749}$ diesem anstelle der bisher stattfindenden Anhörung ein Zustimmungsrecht zuzugestehen und über die Kandidaten einzeln und nicht nur als Gesamtheit abzustimmen. Dies wäre auch unter dem Gesichtspunkt der direkten demokratischen Legitimation der Mitglieder des Rechnungshofes sehr zu begrüBen.

Ferner sollte das Vorschlagsrecht der Regierungen der Mitgliedstaaten durch ein Vorschlagsrecht ihrer Rechnungshöfe ersetzt werden. ${ }^{750}$ Die obersten Finanzkontrollorgane der Mitgliedstaaten verfügen sowohl über besondere Unabhängigkeitsgarantien als auch über die notwendige Sachkunde, um eine größere Gewähr für eine geeignete Wahl zu geben.

\section{b) Amtszeit und Wiederwablmöglichkeit}

Art. 247 Abs. 3 S. 1 EGV (Art. 286 Abs. 2 UAbs. 1 AEUV) legt sechs Jahre als Dauer der Amtszeit fest, dabei ist gem. Art. 247 Abs. 3 S. 3 EGV (Art. 286 Abs. 2 UAbs. 2 AEUV) eine Wiederwahl möglich.

Einem Rechnungshofmitglied wird häufig, besonders da die Amtszeit relativ kurz ist, viel daran gelegen sein, erneut in das Amt gewählt zu werden. Im Falle der Europäischen Union wäre es dann aber darauf angewiesen, dass sein Mitgliedstaat mit seiner Arbeit zufrieden ist und es erneut nominiert. Deshalb kann seine Unbefangenheit diesem gegenüber angesichts der erwünschten Wiederwahl durchaus berührt werden. ${ }^{751}$ Wenn man sich nun vor Augen führt, dass ein erheblicher Teil der Unregelmäßigkeiten auf Ebene der Verwaltung und Vergabe von EU-Mitteln durch die Mitgliedstaaten erfolgt, scheint die kurze Amtszeit verbunden mit der Möglichkeit der Wiederwahl in Hinblick auf die Unabhängigkeit nicht klug gewählt.

Demgegenüber beträgt die Amtszeit eines Mitgliedes des Bundesrechnungshofes 12 Jahre, wobei eine Wiederwahl nicht möglich ist. Die Amtsdauer ist in Deutschland in Hinblick auf die notwendige Unabhängigkeit der Mitglieder bei gleichzeitigem Ausschluss der Wiederwahlmöglichkeit bewusst so lang gewählt.

\footnotetext{
748 Entschließung vom 19. Januar 1995, ABl. 1995 Nr. C 43, S. 75.

${ }^{749} \mathrm{Vgl}$. die bereits im Vorfeld der Errichtung des Rechnungshofes gemachten diesbezüglichen Vorschläge der Kommission und des Parlaments bei Ehlermann, Der Europäische Rechnungshof, 1976, S. 21, 25; sowie die Entschließung vom 19. Januar 1995, ABl. 1995 Nr. C 43, S. 75, die auf die Einführung des Zustimmungsverfahrens mit der nächsten Vertragsänderung abzielte.

750 So auch: Moussis, For a drastic reform of European institutions, European Law Review 2003, 250 (254 f.).

751 In diesem Sinne auch schon Gräfe, Auf dem Weg zu einem Rechnungshof für die Europäischen Gemeinschaften, in: FS Schäfer, 1975, S. 361.
} 


\section{c) Amtsenthebung und Aberkennung von Rubegehaltsansprüchen oder vergleichbarer Vorteile}

Die Ausgestaltung des Verfahrens zur Amtsenthebung beziehungsweise zur Aberkennung bestimmter Ansprüche oder Vergünstigungen gegen Mitglieder eines Rechnungshofes ist ebenso wie das Ernennungsverfahren erheblich für die Bewertung ihrer persönlichen und sachlichen Unabhängigkeit.

Nach Art. 247 Abs. 7 EGV (Art. 286 Abs. 6 AEUV) liegt es in der Hand des Europäischen Rechnungshofes, selbst einen Antrag beim Gerichtshof auf Feststellung zu stellen, dass ein Mitglied nicht mehr die für die Mitgliedschaft erforderlichen Voraussetzungen erfüllt oder seinen sich daraus ergebenden Verpflichtungen nicht nachkommt.

Die detaillierte Ausgestaltung des Verfahrens innerhalb des Rechnungshofes, die zu einem solchen Antrag führen kann, findet sich in Art. 4 GeschOEuRH. Danach beschließt der Rechnungshof bei Vorliegen von Informationen mit der Mehrheit seiner Mitglieder, ob diese für das Bestehen eines der in Art. 247 Abs. 7 EGV (Art. 286 Abs. 6 AEUV) genannten Ausschlussgründe sprechen. Daraufhin hat der Präsident oder, falls er selbst der Betroffene ist, das rangnächste Mitglied einen vorläufigen Bericht auszuarbeiten, der allen Mitgliedern zugestellt wird. Das betroffene Mitglied hat sich hierzu schriftlich und mündlich zu äußern. Der endgültige Beschluss, den Gerichtshof anzurufen, bedarf schließlich der Vierfünftelmehrheit der Stimmen der Mitglieder und ergeht in geheimer Wahl.

Bedeutsam ist, dass nach dem EGV / AEUV nur der Rechnungshof selbst den erforderlichen Antrag stellen kann und keines der kontrollierten Organe. Zudem ist der Beschluss mit der Erfordernis einer Vierfünftelmehrheit auch hofintern an eine hohe Hürde geknüpft. Die Vorschriften zur Amtsenthebung sind damit vorbehaltlos geeignet, in diesem Punkt die Unabhängigkeit zu gewährleisten.

\section{Geschäftsordnungsautonomie und interne Organisation}

Wie bereits anhand der Ausgestaltung bei nationalstaatlichen obersten Rechnungskontrollbehörden festgestellt, ist es für die Gewährleistung der Unabhängigkeit der Mitglieder erheblich, wie es um die Selbstorganisationsrechte des jeweiligen Rechnungshofes bestellt ist. Der Gewährleistung von Geschäftsordnungsautonomie und daraus folgend der internen Organisation (insbesondere des Kollegiumscharakters) des Rechnungshofes kommt neben der Ausgestaltung des Ernennungsverfahrens für seine Mitglieder dabei große Bedeutung zu. 


\section{a) Geschäftsordnungsautonomie}

Der Europäische Rechnungshof gibt sich gemäß Art. 248 Abs. 4 UAbs. 5 EGV (Art. 287 Abs. 4 UAbs. 5 AEUV) eine Geschäftsordnung ${ }^{752}$, die der mit qualifizierter Mehrheit zu treffenden Genehmigung des Rates bedarf. Diese ausdrückliche Geschäftsordnungsautonomie wurde erst 2001 durch den Vertrag von Nizza eingeführt. Jedoch stellt die Neueinführung der Regelung für den Rechnungshof nur auf den ersten Blick eine Verbesserung dar, wurde das Recht, sich eine Geschäftsordnung zu geben, bis dahin doch aus seinem Selbstorganisationsrecht hergeleitet ${ }^{753}$ und stand damit nicht unter dem Genehmigungsvorbehalt des Rates. ${ }^{754}$

\section{b) Interne Organisation}

Die Ausgestaltung des Rechnungshofes als Kollegialorgan zeigt sich schon in Art. 248 Abs. 4 UAbs. 3 EGV (Art. 287 Abs. 4 UAbs. 3 AEUV), wonach er „Berichte, Sonderberichte oder Stellungnahmen mit der Mehrheit seiner Mitglieder annimmt". Auch die Geschäftsordnung bestimmt in ihrem ersten Artikel, dass der Rechnungshof ein Kollegialorgan ist. Das verwundert nicht, da wohl allgemein anerkannt ist, dass diese Organisationsform am besten geeignet ist, die Unabhängigkeit zu gewährleisten. ${ }^{755}$ Bei einem hierarchischen Aufbau mit unweigerlich damit verbundenen Weisungsrechten wäre es hingegen nicht der Fall.

Eine gewisse der Arbeitseffizienz geschuldete Einschränkung erfuhr der Kollegialcharakter durch den Vertrag von Nizza, danach bleibt es zwar grundsätzlich bei der Entscheidung als Kollegium mit der Mehrheit der Mitglieder, jedoch wurde dem Rechnungshof die Möglichkeit gegeben, für die Annahme bestimmter Arten von Berichten Kammern zu bilden. ${ }^{756}$

Die Organisationsform als Kollegialorgan ist jedoch durchaus vielfältiger Interpretation und Ausgestaltung zugänglich. Beim Europäischen Rechnungshof wählen die Mitglieder gem. Art. 247 Abs. 3 UAbs. 2 EGV (Art. 286 Abs. 2 UAbs. 2 AEUV) aus ihrer Mitte den Präsidenten (vgl. zum Ablauf Art. 7 GeschOEuRH). Wurde im ersten Teil die starke Stellung des Präsidenten des Bundesrechnungshofes bemängelt, ${ }^{757}$ handelt es sich im Gegensatz dazu bei der des Präsidenten des Europäischen Rechnungshofes tatsächlich um die eines primus inter pares ${ }^{758}$. Die

752 Geschäftsordnung vom 1. Januar 2005, ABl. L 18/1vom 20.1.2005 (im Folgenden GeschOEuRH), die die vom Hof am 31. Januar 2002 verabschiedete Geschäftsordnung ersetzt.

753 Niedobitek, in: Streinz, EUV/EGV, Art. 248 EGV, Rn. 24; Bieber, in: v.d.Groeben/Schwarze, EUV/EGV, Art. 248 EG, Rn. 37 m.w.N.

${ }^{754}$ Eblermann, Der Europäische Rechnungshof, 1976, S. 42 f.

755 Vgl. zum Bundesrechnungshof 1. Teil, III. 1. a) m.w.N.

756 Magiera, Der Rechnungshof, in: Jahrbuch der Europäischen Integration 2000/2001, S. 93; ausführlich: Niedobitek, in: Streinz, EUV/EGV, Art. 248 EGV, Rn. 27 ff.

757 Oben: 1. Teil, III. 1. a).

${ }^{758}$ So auch Waldhoff, in: Calliess/Ruffert, EUV/EGV, Art. 247 EGV, Rn. 4. 
Aufgaben des Präsidenten ergeben sich aus Art. 9 GeschOEuRH, danach ist er für Organisation der Arbeit des Hofes, Gewährleistung ihres geordneten Ablaufes sowie für die Außenvertretung zuständig. Der Präsident schlägt gem. Art. 10 Abs. 3 GeschOEuRH die Zuweisung der Mitglieder zu einer Prüfungsgruppe vor, ebenso wie er gem. Art. 17 Abs. 1 GeschOEuRH für jede Sitzung den Entwurf einer Tagesordnung vorlegt, den die Mitglieder zu Beginn der Sitzung erst noch verabschieden müssen. Diese Regelungen zeigen, dass soweit wie möglich dem Rechnungshof selbst die Entscheidung überlassen wird, also besonderes Gewicht auf das Kollegialprinzip gelegt wird, was sich in der Stellung des Präsidenten widerspiegelt. Dem widerspricht auch nicht Art. 23 Abs. 4 GeschOEuRH, wonach bei Beschlussfassung mit einfacher Mehrheit bei Stimmengleichheit die Stimme des Präsidenten entscheidet, was vielmehr der Entscheidungseffizienz dient.

\section{Informations- und Zugangsrechte}

Ausgangspunkt für die Prüfungsrechte des Europäischen Rechnungshofes ist Art. 248 Abs. 3 EGV (Art. 287 Abs. 3 AEUV). Grundsätzlich finden die Prüfungen gem. UAbs. 1, S. 1 in Form der Überprüfung der Rechnungsunterlagen oder soweit erforderlich als Vor-Ort-Prüfungen statt. Der EuRH kann danach Prüfungen durchführen , anhand der Rechnungsunterlagen und erforderlichenfalls an Ort und Stelle bei anderen Gemeinschaftsorganen, in den Räumlichkeiten der Einrichtungen, die Einnahmen oder Ausgaben für Rechnung der Gemeinschaft verwalten, sowie der natürlichen und juristischen Personen, die Zahlungen aus dem Haushalt erhalten, und in den Mitgliedstaaten“. Konkretisiert werden diese Rechte durch Art. 140 bis 142 der Haushaltsordnung 759 (HO).

\section{a) Gegenüber anderen Gemeinschaftsorganen}

Nach Art. 248 Abs. 3 UAbs. 2 EGV (Art. 287 Abs. 3 UAbs. 2 AEUV) sind die Organe und Einrichtungen der Gemeinschaft verpflichtet, dem Rechnungshof auf seinen Antrag hin alle für die Erfüllung seiner Aufgaben erforderlichen Unterlagen und Informationen zu übermitteln. Ebenso kann er vor Ort Prüfungen in deren Räumlichkeiten vornehmen (Vgl. UAbs. 2 S. 1). Diese Informations- und Zugangsrechte konkretisieren Art. 140 Abs. 2 und Art. 142 HO, wonach alle Dokumente und Informationen zur Rechnungsführung zur Verfügung zu stellen sind, die für Einnahmen und Ausgaben verantwortlichen Bediensteten jederzeit gehört werden können und der Rechnungshof von allen der entsprechenden Stelle oder Einrichtung zustehenden Prüfungsrechten Gebrauch machen kann.

Die Prüfungsbefugnisse hat der Europäische Rechnungshof zwar im Wesentlichen seit seiner Gründung, ${ }^{760}$ aber erst durch den Vertrag von Amsterdam wurde

\footnotetext{
759 Verordnung (EG, Euratom) Nr. 1605/2002 des Rates vom 25. Juni 2002 über die Haushaltsordnung für den Gesamthaushaltsplan der Europäischen Gemeinschaften, ABl. 2002 Nr. L 248.

760 Inghelram, The European Court of Auditors: Current legal issues, CMLR 2000, 129 (136).
} 
die Möglichkeit, diese auch vor dem EuGH einzuklagen, in Art. 230 Abs. 3 EGV (Art. 263 Abs. 3 AEUV) ausdrücklich festgeschrieben. ${ }^{761}$

\section{b) Gegenüber Mitgliedstaaten}

Der Verwaltungsaufbau der Europäischen Union ist größtenteils ein dezentraler oder mittelbarer, der auf den Verwaltungsstellen der einzelnen Mitgliedstaaten basiert, dies gilt insbesondere im Bereich der Haushaltsführung. ${ }^{762}$ Dementsprechend wird der größte Teil der Einnahmen und Ausgaben des Gesamthaushalts durch die Verwaltungen der Mitgliedstaaten im Auftrage und unter Verantwortung der Kommission verwaltet. ${ }^{763}$ Diese Struktur mit ihren dezentralen Verwaltungsmechanismen führt zu einer besonderen Anfälligkeit für finanzielle Unregelmäßigkeiten, die zu Schädigungen der Finanzinteressen der Europäischen Union führen können. ${ }^{764}$ Sie macht daher eine entsprechende Ausgestaltung der externen Finanzkontrolle notwendig: zum einen durch Prüfungsrechte des EuRH auf Ebene der Mitgliedstaaten und zum anderen durch die Zusammenarbeit zwischen diesem und den entsprechenden mitgliedstaatlichen Kontrollinstitutionen.

Aus Art. 248 Abs. 3 UAbs. 1 S. 1 EGV (Art. 287 Abs. 3 UAbs. 1 S. 1 AEUV) ergibt sich, dass der Europäische Rechnungshof Prüfungen in den Mitgliedstaaten durchführen kann, diese erfolgen in Verbindung mit den einzelstaatlichen Rechnungsprüfungsorganen. Die Form der Prüfungszusammenarbeit zwischen Europäischem Rechnungshof und den entsprechenden nationalen Stellen ergibt sich aus Art. 248 Abs. 3 UAbs. 1 S. 2-4 EGV (Art. 287 Abs. 3, UAbs. 1 S. 2-4 AEUV) sowie Art. 140 Abs. 2 S. 3,4 HO. Sie trägt der in aller Regel mit ihrer Unabhängigkeit einhergehendenden besonderen Stellung der mitgliedstaatlichen Rechnungshöfe im Staatsaufbau Rechnung. Europäischer Rechnungshof und mitgliedstaatliche Rechnungskontrollorgane arbeiten nach Art. 248 Abs. 3 UAbs. 1 S. 3 EGV (Art. 287 Abs. 3 UAbs. 1 S. 3 AEUV) ,unter Wahrung ihrer Unabhängigkeit vertrauensvoll zusammen" (Vgl. auch Art. 140 Abs. Abs. 2 S. 3, 4 HO).

Grundsätzlich müssen die mitgliedstaatlichen Rechnungsprüfungsorgane über eine anstehende Prüfung informiert werden, und ihnen muss die Möglichkeit der Zusammenarbeit gegeben werden. ${ }^{765}$ Hierbei wird den nationalen Rechnungshö-

${ }^{761} \mathrm{Zu}$ den Klagemöglichkeiten vor dem EuGH und zur Lage vor 1995 siehe unten: IV. 3.

762 Theato/Graf, Das EP und der Haushalt der EG, 1994, S. 111.

763 Inghelram, in: Lenz/Borchardt, EUV/EGV, 3. Aufl. 2003, Art. 248 EGV, Rn. 8; ausführlich Magiera, Finanzkontrolle in der EG, in: v.Arnim, Finanzkontrolle im Wandel, 1989, S. 227 ff.; Eblermann, Der Europäische Rechnungshof, 1976, S. 33.

${ }^{764}$ Laffan, The Evolution of the European Court of Auditors, Journal of Common Market Studies 1999, 251 (262); Magiera, Der Schutz der finanziellen Interessen der EU, in: FS Friauf, 1996, S. 13 (20).

765 Bieber, in: v.d.Groeben/Schwarze, EUV/EGV, Art. 248 EG, Rn. 20; Niedobitek, in: Streinz, EUV/EGV, Art. 248 EGV, Rn. 15. 
fen eine Vorlaufzeit von sechs Wochen eingeräumt. ${ }^{766}$ Der Unabhängigkeit der nationalen obersten Rechnungsprüfungsorgane geschuldet erfolgt die Zusammenarbeit jedoch auf freiwilliger Basis: ${ }^{767}$ So haben sie dem Europäischen Rechnungshof nach Art. 248 Abs. 3, UAbs. 1, S. 4 EGV (Art. 287 Abs. 3 UAbs. 1 S. 4 AEUV) lediglich mitzuteilen, ob sie an der Prüfung teilzunehmen beabsichtigen. Lehnen sie dies ab, kann der Europäische Rechnungshof folglich alleine die Prüfungen durchführen. ${ }^{768}$

Aus Art. 248 Abs. 3, UAbs. 2 EGV (Art. 287 Abs. 3 UAbs. 2 AEUV) wird deutlich, dass neben den Gemeinschaftsorganen auch die einzelstaatlichen Rechnungsprüfungsorgane verpflichtet sind, dem Europäischen Rechnungshof auf seinen Antrag hin „die für die Erfüllung seiner Aufgaben erforderlichen Unterlagen oder Informationen“ zu übermitteln. Diese Vorschrift konkretisiert letztlich den Grundsatz der Gemeinschaftstreue nach Art. 10 EGV (findet sich sinngemäß nun in Art. 4 Abs. 3 EUV n.F.). ${ }^{769}$

Hierbei stellt sich die Frage, ob eine Pflicht der nationalen Rechnungsprüfungsorgane angenommen werden kann, im Rahmen der Übermittlung von Unterlagen und Informationen selbst auch Prüfungen im Auftrag des EuRH vorzunehmen. ${ }^{770}$

Diese Annahme ist vor dem Hintergrund der „,vertrauensvollen Zusammenarbeit unter Wahrung der gegenseitigen Unabhängigkeit" problematisch. Die Achtung der Unabhängigkeit schließt eine hierarchische Stufung verbunden mit Weisungsrechten des EuRH gegenüber mitgliedstaatlichen Rechnungshöfen gerade aus. ${ }^{771}$ Eine solche läge nach eigenem Bekunden auch nicht im Interesse des Europäischen Rechnungshofes. ${ }^{772}$ Vielmehr muss es sich um ein Nebeneinander auf

766 Friedmann, Finanzkontrolle von Mitteln der Europäischen Gemeinschaft, in: Rechnungshof Rheinland-Pfalz, Kooperation der Finanzkontrolle in Europa, 1999, S. 243.

${ }^{767}$ Isensee, Außenvertretung der deutschen Rechnungshöfe in der Europäischen Union, 2001, S. 1 f.

768 Bieber, in: v.d.Groeben/Schwarze, EUV/EGV, Art. 248 EG, Rn. 20 m.w.N.

769 Waldhoff, in: Calliess/Ruffert, EUV/EGV, Art. 248 EGV, Rn. 10 m.w.N.

770 Dafür Niedobitek, in: Streinz, EUV/EGV, Art. 248 EGV, Rn. 14; Bieber, in: v.d.Groeben/Schwarze, EUV/EGV, Art. 248 EG, Rn. 22; Ehlermann, Der Europäische Rechnungshof, 1976, S. 36; a.A.: Schmitr, in: Heuer, Haushaltsrecht, (Stand: 42. EL. September 2006), VII/2, Rn. 75.; Rechenberg, Der Europäische Rechnungshof in seinem Verhältnis zum Bundesrechnungshof - Kooperation oder Konfrontation?, in: FS Hahn, 1997, S. 701 f.; so wohl auch Magiera, Finanzkontrolle in der EG, in: v.Arnim, Finanzkontrolle im Wandel, 1989, S. 232 f.

771 Schmitz, in: Heuer, Haushaltsrecht, (Stand: 42. EL. September 2006), VII/2, Rn. 75; vgl. Hierzu auch die Aussagen von BRH-Präsident Engels, der einen Ausbau der (freiwilligen) Zusammenarbeit auf europäischer Ebene befürwortet, sich aber entschieden gegen eine die Unabhängigkeit bedrohende „Auftragsarbeit“ für die EU ausspricht, Deutsche Rechnungshöfe wehren sich, in: Frankfurter Allgemeine Zeitung, vom 30.08.2005, S. 19.

772 So der ehemalige Präsident des EuRH, Friedmann, Finanzkontrolle von Mitteln der Europäischen Gemeinschaft, in: Rechnungshof Rheinland-Pfalz, Kooperation der Finanzkontrolle in Europa, 1999, S. 254: „Der EuRH beansprucht nicht, ein Rechnungshof anderer oder höherer Kategorie im Vergleich zu den nationalen Rechnungshöfen zu sein; Vgl. auch die unten in V. 1. b) aufgeführten jüngeren Leitsätze und Sitzungsentschließungen des Kontaktausschusses. 
gleicher Stufe handeln, wobei sich zwar gewisse Kooperationspflichten durchaus ergeben können, wie sich in der Übermittlungspflicht zeigt; jedoch kann in diesem Zusammenhang allenfalls angenommen werden, dass mitgliedstaatliche Rechnungshöfe angeforderte Unterlagen oder Informationen selbst zu beschaffen haben. Auch die Verpflichtung zur ,vertrauensvollen Zusammenarbeit unter Wahrung der gegenseitigen Unabhängigkeit" ist Ausdruck der sich aus Art. 10 EGV (Art. 4 Abs. 3 EUV n.F.) ergebenden Pflicht zur loyalen Zusammenarbeit zwischen Gemeinschaftsorganen und Mitgliedstaaten. ${ }^{773}$ Eine Pflicht, selbst auf Anweisung des EuRH in die Prüfung einzusteigen, kann hingegen nicht angenommen werden. Dagegen spricht zunächst der Wortlaut des Art. 248 Abs. 3 UAbs. 1 S. 3,4 EGV (Art. 287 Abs. 3 UAbs. 1 S. 3, 4 AEUV), der eine Zusammenarbeit „unter Wahrung der Unabhängigkeit“ gebietet und den Rechnungsprüfungsorganen der Mitgliedstaaten eine Teilnahme an Prüfungen des EuRH freistellt. Auch widerspräche es dem Wesen der Unabhängigkeit der Rechnungshöfe an sich, deren besondere Bedeutung für die Effektivität der externen Finanzkontrolle bereits erörtert wurde. Dies unterstreicht die Auffassung, die die deutschen Rechnungshöfe von der Zusammenarbeit haben, dass ,für die nationalen Rechnungshöfe bei der Zusammenarbeit mit dem EuRH keine Verpflichtungen entstehen können, die nicht im Einklang mit den nationalen Regeln über Stellung und Aufgaben der Rechnungshöfe stehen“ und dass die Zusammenarbeit ,...immer auf freiwilliger Basis" erfolge. 774

Nicht zuletzt muss die Problematik von der praktischen Seite aus betrachtet werden: Der EuRH ist in vielen Bereichen auf die Zusammenarbeit mit den mitgliedstaatlichen Rechnungshöfen angewiesen, eine Erzwingung zur Vornahme von Prüfungshandlungen gegen den Willen des Beteiligten würde das notwendige Verhältnis der „vertrauensvollen Zusammenarbeit“ beschädigen und dürfte sich eher kontraproduktiv auswirken.

Gegen die Annahme einer solchen Prüfungspflicht kann weiter angeführt werden, dass die Gefahr einer Blockade des EuRH durch die Ablehnung der Prüfung durch einen mitgliedstaatlichen Rechnungshof schon deshalb nicht besteht, weil der EuRH wie eben gesehen für diesen Fall über ein eigenes autonomes Prüfungsrecht in dem Mitgliedstaat verfügt.

Die Zusammenarbeit erfolgt, soweit die obersten nationalen Rechnungskontrollbehörden nicht über die für die Prüfung notwendigen Kompetenzen verfügen, gem. Art. 248 Abs. 3 UAbs. 1 S. 2 EGV (Art. 287 Abs. 3 UAbs. 1 S. 2 AEUV) mit den jeweils zuständigen Dienststellen des Mitgliedstaates. Im Falle Deutschlands, als eines als Bundesstaat angelegten Mitgliedstaates, kann die Zusammenar-

\footnotetext{
773 Inghelram, in: Lenz/Borchardt, EUV/EGV, 3. Aufl. 2003, Art. 248 EGV, Rn. 9; Waldhoff, in: Calliess/Ruffert, EUV/EGV, Art. 248 EGV, Rn. 10 m.w.N..

774 Beschluss der Konferenz der Präsidentinnen und Präsidenten der Rechnungshöfe des Bundes und der Länder vom 22. bis 24. September 1997 in Potsdam zur Zusammenarbeit mit dem EuRH (abgedruckt bei: Engels, in: Heuer, Haushaltsrecht, (EL 39 Dezember 2004), VIII/2.1.
} 
beit demnach mit dem Bundesrechnungshof oder einem der Landesrechnungshöfe erfolgen. ${ }^{775}$ Der Zusammenarbeit mit anderen „Dienststellen“, denen die interne Kontrolle für ihren jeweiligen Bereich obliegt, kommt hingegen nur Bedeutung $\mathrm{zu}$, wenn der entsprechende Mitgliedstaat nicht über ein allumfassendes Rechnungsprüfungssystem durch externe oberste Rechnungskontrollbehörden verfügt. In Deutschland mit seinem umfassenden System lückenloser 776 externer Finanzkontrolle, das grundsätzlich keine prüfungsfreien Räume zulässt, ${ }^{777}$ kommt daher eine Zusammenarbeit des Europäischen Rechnungshofes nur mit einem der Rechnungshöfe in Betracht. ${ }^{778}$

Dem EuRH mitzuteilen, mit welcher Stelle eine Zusammenarbeit im jeweiligen Einzelfall erfolgt, bleibt den Mitgliedstaaten überlassen. ${ }^{779}$ Dies ist letztlich Folge der Tatsache, dass aus europarechtlicher Sicht keine Unterscheidung zwischen Bundesstaaten und Zentralstaaten getroffen wird und somit entsprechende Pflichten den Mitgliedstaat an sich treffen. ${ }^{780}$ Die Außenvertretungskompetenz in Deutschland obliegt dem Bundesrechnungshof, an den sich der Europäische Rechnungshof bei Prüfungsanfragen zunächst wendet, und der dann unter Umständen an einen Landesrechnungshof, dem nach deutschem Recht die Prüfungskompetenz zukommt, weiterverweist. ${ }^{781}$ Hinzuzufügen ist, dass in der Praxis häufig gerade die Landesrechnungshöfe zuständig sind und deshalb die Zusammenarbeit mit diesen zu erfolgen hat. Beispielsweise werden Zahlungen aus Strukturfonds der EG über den Bund an die Länder geleistet, damit sind sie Teil der Län-

${ }^{775}$ Isensee, Außenvertretung der deutschen Rechnungshöfe in der Europäischen Union, 2001, S. 2 f.; allgemein: Eblermann, Der Europäische Rechnungshof, 1976, S. 34.

776 Vgl. zum Gegenstand und Umfang der Finanzkontrolle in Deutschland: oben 1. Teil IV. 1. a).

777 St. Rspr. BVerwGE 116, 92 (94); 98, 163 (170); 82, 56 (60 f.); vgl. \ 88 Abs. 1 BHO: „Die gesamte Haushalts- und Wirtschaftsführung des Bundes... wird vom Bundesrechnungshof... geprüft“; vgl. auch \42 Abs. $1 \mathrm{HGrG}$.

778 Ausführlich zur Kompetenzabgrenzung zwischen Bundesrechnungshof und Landesrechnungshöfen in diesem Kontext: Isensee, Außenvertretung der deutschen Rechnungshöfe in der Europäischen Union, 2001, S. 2, 32 ff.; der Problematik der Abgrenzung der Prüfungsrechte von Bundesrechnungshof und Landesrechnungshöfen bei der Bewirtschaftung von EU-Mitteln durch die Bundesländer widmet sich ausführlich: Mäbring, Externe Finanzkontrolle im europäischen Mehrebenensystem, DÖV 2006, 195.

779 3. Erklärung zum EWG-Änderungsvertrag vom 22. Juli 1975, abgedruckt: BGBl. 1976 II, 1338.

${ }^{780}$ Isensee, Außenvertretung der deutschen Rechnungshöfe in der Europäischen Union, 2001, S. 13 m.w.N.

${ }^{781}$ Isensee, Außenvertretung der deutschen Rechnungshöfe in der Europäischen Union, 2001, S. 3. m.w.N.; Vgl. Beschluss der Konferenz der Präsidentinnen und Präsidenten der Rechnungshöfe des Bundes und der Länder vom 4. bis 6. Mai 1998 in Chorin zur Zusammenarbeit mit dem EuRH, Ziffer 1.7. (abgedruckt bei: Engels, in: Heuer, Haushaltsrecht, (EL 39 Dezember 2004), VIII/2.2): „,...der BRH ist grundsätzlich auch weiterhin für die Koordinierung des Informationsaustausches zwischen den deutschen Rechnungshöfen und dem EuRH zuständig“. 
derhaushalte und unterliegen dementsprechend im Rahmen der innerstaatlichen Kontrolle der Prüfung des zuständigen Landesrechnungshofes. ${ }^{782}$

Besondere Bedeutung im Rahmen der Zusammenarbeit kommt dem „Kontaktausschuss" der Präsidenten der Obersten Rechnungskontrollbehörden der Mitgliedstaaten und des Europäischen Rechnungshofes zu, der für Koordinierung und Verbesserung der Zusammenarbeit zuständig ist. 783

\section{Aufgaben und Kompetenzen des Europäischen Rech- nungshofes}

Die geschichtliche Entwicklung der Rechnungsprüfung in der Europäischen Union macht deutlich, dass im Vergleich mit der Finanzkontrolle auf Mitgliedstaatenebene der Betrugsbekämpfung eine besondere Bedeutung zukommt. ${ }^{784}$ Der Rechnungshof als Institution ersetzte den völlig überforderten Kontrollausschuss auch aus dem Grunde, dass auf diesem Gebiet erheblicher Verbesserungsbedarf bestand. In diesem Zusammenhang steht auch die Errichtung des Europäischen Amtes für Betrugsbekämpfung (OLAF) im Jahr 1999, mit dem der Europäische Rechnungshof zusammenarbeitet, indem er bei seinen Prüfungen entdeckte oder von Dritten erhaltene Informationen über mögliche Fälle von Betrug, Korruption oder sonstigen rechtswidrigen Handlungen zum Nachteile der finanziellen Interessen der Gemeinschaften an OLAF weiterleitet. ${ }^{785}$

Die aktuelle Entwicklung zeigt, dass ein Schwerpunkt immer noch auf den nach wie vor bestehenden Problemen im Bereich des Betrugs (insbesondere im Agrarsektor) liegt. Die Ursache dieser Betrugsprobleme liegt natürlich in der Natur der Europäischen Union als einer Wirtschaftsgemeinschaft. Diese Probleme erklären auch die unterschiedlichen Prüfungsschwerpunkte des Europäischen Rechnungshofes und des Bundesrechnungshofes. Während die Finanzkontrolle in Deutschland inzwischen (insbesondere seit der Haushaltsrechtsreform von 1969) schwerpunktmäßig die Wirtschaftlichkeit staatlichen Handelns zum Gegenstand

782 Piebl/Trautner, Zur Bedeutung der Kontroll-Strukturen und zu den Vorbeugungsstrategien gegen Missbrauch öffentlicher Fördergelder, in: Piehl, Europa in Ostdeutschland, S. 259 (262); Cqasche (von Wedel), Zur Bedeutung der Kontroll-Struktur und zu den Vorbeugungsstrategien gegen Missbrauch öffentlicher Förderungsmittel, ebendort, S. 268; vgl. hierzu aus volkswirtschaftlicher Sicht: Fehr, Mögliche Wechselwirkungen zwischen dem Europäischen Rechnungshof und nationalen Rechnungshöfen, in: FS Lüder, 2000, S. 675 (685 ff.).

${ }^{783}$ Zum Kontaktausschuss vgl. unten V. 1. b).

${ }^{784}$ Chavaki, Betrugsbekämpfung in der Europäischen Union, ZEuS, 1999, 431 (452 f.); siehe auch: Europäischer Rechnungshof, Der Europäische Rechnungshof - Optimierung des Finanzmanagements in der EU, 2004, S. 15; Zur Rolle des EuRH in der Betrugsbekämpfung vgl. auch: Inghelram, The European Court of Auditors: Current Legal Issues, CMLR 2000, 129 (134 ff.).

785 Art. 1, 2 und 6 Beschluss Nr. 97-2004 des Rechnungshofes über die Modalitäten der Zusammenarbeit mit dem Europäischen Amt für Betrugsbekämpfung in Bezug auf dessen Zugang zu prüfungsrelevanten Informationen, abrufbar unter http://www.eca.eu.int. 
hat, stehen auf europäischer Ebene die Recht- und Ordnungsmäßigkeit der Ausgaben im Mittelpunkt. ${ }^{786}$ Die EU steht letztlich vor dem Problem, dass vor allem die neuen Mitgliedstaaten in Mittel- und Osteuropa mit ihrer vergleichsweise jungen Geschichte als Demokratien und Rechtsstaaten häufig noch über keine Verwaltungsstrukturen und Kontrollinstitutionen verfügen, die dem Standard der alten Mitgliedstaaten entsprechen. Der Beitritt Rumäniens und Bulgariens dürfte dieses Problem noch verstärken, denn letztlich verfügen diese Länder kaum über die notwendigen Strukturen, um eine ordnungsgemäße Verteilung von EU-Mitteln gewährleisten zu können. Angesichts der Notwendigkeit, überhaupt die recht- und ordnungsmäßige Verwendung von Beihilfen etc. sicherzustellen, muss der Maßstab der Wirtschaftlichkeitsbewertung zwangsläufig in den Hintergrund rücken.

\section{Rechnungsprüfung}

Art. 246 EGV (Art. 285 Abs. 1 AEUV) bestimmt die Aufgabe des Europäischen Rechnungshofes zunächst relativ vage damit, dass er „die Rechnungsprüfung wahrnehme“. Die Ausgestaltung hinsichtlich Prüfungsgegenstand, -maßstäben, umfang und -ansatz des Europäischen Rechnungshofes soll im Folgenden erörtert werden.

\section{a) Prüfungsgegenstand}

Aus Art. 248 Abs. 1 UAbs. 1 S. 1 EGV (Art. 287 Abs. 1 UAbs. 1 S. 1 AEUV) ergibt sich, dass die Prüfung die Rechnung über alle Einnahmen und Ausgaben der Gemeinschaft (nun der Union) sowie der von der Gemeinschaft geschaffenen Einrichtungen (S. 2) umfasst, hier sind insbesondere die Agenturen zu nennen, soweit der Gründungsakt dies nicht ausschließt. Die Prüfungsbefugnis ist damit nicht auf die im Haushaltsplan ausgewiesenen Einnahmen und Ausgaben beschränkt, obwohl der ursprünglich von der Kommission vorgelegte Entwurf eine Prüfungskompetenz lediglich für im Haushaltsplan vorgesehenen Ausgaben vorsah. ${ }^{787}$

Auch für die zweite und dritte Säule der Europäischen Union, namentlich die Verwaltungsausgaben und operativen Ausgaben bei der gemeinsamen Außen- und Sicherheitspolitik (vgl. Art. 28 Abs. 2, 3, 4 EUV a.F.) und der polizeilichen und justiziellen Zusammenarbeit in Strafsachen (vgl. Art. 41 Abs. 2, 3, 4 EUV a.F.), findet, jedenfalls soweit sie zu Lasten des Haushaltes der Europäischen Gemeinschaften gehen, das im EGV vorgesehene Haushaltsverfahren Anwendung. Das bedeutet, dass die Ausgaben im Rahmen dieses Verfahrens Prüfungsgegenstand des Europäischen Rechnungshofes sind. Nach allgemeiner Meinung ist nicht

786 So Bundesrechnungshofpräsident Engels in der Frankfurter Allgemeinen Zeitung, Deutsche Rechnungshöfe wehren sich, vom 30. August 2005, S. 19.

787 Mart, Die Finanzkontrolle der Europäischen Gemeinschaften, in: FS zur 275. Wiederkehr der Errichtung des Preußischen General-Rechen-Kammer, 1989, S. 469 (477). 
maßgeblich, dass der Europäische Rechnungshof in Art. 28 Abs. 1 und Art. 41 Abs. 1 EUV a.F. nicht ausdrücklich erwähnt wird, ${ }^{788}$ denn erstens wird der Rechnungshof in Art. 5 EUV a.F. als Unionsorgan genannt und zweitens erklären Art. 28 Abs. 4 und 41 Abs. 4 EUV a.F. das Haushaltverfahren nach dem EG-Vertrag in pleno für anwendbar. Der Vertrag von Lissabon hat die Drei-Säulenstruktur zwar aufgehoben, dies hat im Ergebnis jedoch keine Auswirkung auf die Überprüfung von Ausgaben in diesen Bereichen durch den EuRH. Soweit Kosten hierfür zu Lasten des Haushaltes der Union gehen, unterliegen sie der Prüfung durch den EuRH. ${ }^{789}$

Ferner legen Art. 142 Abs. 5 und 120 Abs. 2 HO für den Bereich der Finanzhilfen fest, dass die ihnen zugrundeliegenden Finanzierungsvereinbarungen eine Prüfung durch den Rechnungshof vorsehen müssen. In diesem Zusammenhang sei darauf verwiesen, dass auch „Maßnahmen im Außenbereich“ nach Titel IV der Haushaltsordnung, also die Gewährung von Außenhilfen oder die Auftragsvergabe an Drittländer, gem. Art. $170 \mathrm{HO}$ durch die Finanzierungsvereinbarung der Kontrolle des EuRH zu unterstellen sind.

\section{b) Prüfungsmaßstäbe}

Als Maßstäbe der Prüfung ergeben sich aus Art. 248 Abs. 2 UAbs. 1 S. 1 EGV (Art. 287 Abs. 2 UAbs. 1 S. 1 AEUV) neben der Rechtmäßigkeit und Ordnungsmäßigkeit der Einnahmen und Ausgaben auch die Wirtschaftlichkeit der Haushaltsführung. Diese entsprechen also im Wesentlichen den vom Grundgesetz der Tätigkeit des Bundesrechnungshofes zugrundegelegten Maßstäben.

Was die Auslegung und Präzisierung dieser Maßstäbe angeht, so stellte Ehlermann ${ }^{790}$ richtig fest, dass es Sache des Europäischen Rechnungshofes selbst sein müsse, diese zu bestimmen, was ausdrücklich durch die Europäischen Leitlinien für die Anwendung der INTOSAI-Richtlinien unter Zusammenarbeit mit Obersten Rechnungskontrollbehörden einiger Mitgliedstaaten auch geschehen ist. ${ }^{791}$

aa) Rechtmäßigkeit

Hinsichtlich des Maßstabes der Rechtmäßigkeit besteht Uneinigkeit, wie weit diese Prüfung geht, insbesondere in Abgrenzung zur Rechtmäßigkeitsprüfung durch

\footnotetext{
788 Magiera, in: Grabitz/Hilf, Recht der EU, Bd. II (Stand: 18. EL Mai 2001), Art. 248 EGV, Rn. 7; m.w.N.; Waldhoff, in: Calliess/Ruffert, EUV/EGV, Art. 248 EGV, Rn. 4 m.w.N.; Niedobitek, in: Streinz, EUV/EGV, Art. 248 EGV, Rn. 5 m.w.N.

789 Vgl. Art. 41 AEUV ausdrücklich hinsichtlich der GASP, hinsichtlich der Zusammenarbeit in Strafsachen im RSFR gilt weitgehend das ordentliche Gesetzgebungsverfahren (Art. 289 i.V.m. Art. 294 AEUV).

790 Eblermann, Der Europäische Rechnungshof, 1976, S. 30.

${ }^{791}$ Vgl. Leitlinie Nr. 41 der Europäischen Leitlinien für die Anwendung der INTOSAI-Richtlinien, erstellt durch den Kontaktausschuss der Präsidenten der ORKB der Europäischen Union, abrufbar unter http://www.eca.eu.int.
} 
den EuGH. Dieser hat in seiner Rechtsprechung eine einschränkende Auslegung zugrundegelegt. Danach hat „der Rechnungshof lediglich die Rechtmäßigkeit einer Ausgabe im Hinblick auf den Haushaltsplan und den dieser Ausgabe zugrundeliegenden Akt des abgeleiteten Rechts (gemeinhin als grundlegender Rechtsakt bezeichnet) zu prüfen. Seine Kontrollbefugnis unterscheidet sich daher in jedem Fall von der des EuGH, die sich auf die Rechtmäßigkeit dieses grundlegenden Akts erstreckt.“" 792

Die Gegenansicht ${ }^{793}$ legt den Rechtmäßigkeitsmaßstab hingegen weit aus: Dieser umfasst danach die Prüfung der Einnahmen und Ausgaben auf ihre Vereinbarkeit mit dem gesamten dafür relevanten primären und sekundären Gemeinschaftsrecht.

Für diese Ansicht spricht, dass der Vertragstext keinen Anhaltspunkt für die einschränkende Ansicht des EuGH bietet. Auch der eindeutige Wortlaut der Haushaltsordnung (vgl. Art. 140 Abs. 1 HO: „Prüfung erfolgt ... im Hinblick auf die Verträge, den Haushaltsplan, diese Haushaltsordnung, die Durchführungsbestimmungen und alle in Umsetzung der Verträge erlassenen Rechtsakte") steht einer solchen restriktiven Auslegung entgegen.

Zudem wären mögliche Überschneidungen mit der Rechtmäßigkeitskontrolle durch den EuGH unschädlich, da die Prüfung durch den Rechnungshof nicht rechtsverbindlich ist und als Ganzes gesehen die gerichtliche Kontrolle durch den EuGH und die Finanzkontrolle andere Maßstäbe (Wirtschaftlichkeit etc.) haben und eine unterschiedliche Zielrichtung verfolgen. Auf die unterschiedliche Wirkung der Rechtmäßigkeitskontrolle durch den EuGH und den EuRH stellt auch Generalanwalt Mancini ab, um seine ausdrücklich im Widerspruch zum Urteil des EuGH in der Rs. 294/83794 stehende Ansicht zu begründen, dass der Rechnungshof die Beachtung jeder Bestimmung des Gemeinschaftsrechts, die ausgabenrelevant sein kann, prüfen kann. ${ }^{795}$ Danach zeichne sich die Funktion der Rechtsprechung im Gegensatz zur Kontrolle des Rechnungshofes „durch die zwingende Wirkung und die Rechtskraft aus"; außerdem setze das Tätigwerden der Judikative das Vorliegen einer Klage voraus und münde in einer „spezifischen und punktuellen Prüfung streitiger Akte oder Beziehungen“, während dem Rechnungshof eine „systematische und allgemeine Überprüfung der Verwaltungstätigkeit" obliege. ${ }^{796}$ Der EuGH hat es in dem darauf folgenden Urteil leider unterlassen, Stellung zu diesem Punkt zu beziehen.

\footnotetext{
${ }^{792}$ EuGH, Rs. 294/83, Slg. 1986, 1339, Rn. 28 (Les Verts/Parlament).

793 SA des GA Mancini, EuGH Rs. 204/86, Slg. 1988, 5323 (5342 f.) (Griechenland/Rat) m.w.N. ; Magiera, in: Grabitz/Hilf, Recht der EU, Bd. II (Stand: 18. EL Mai 2001), Art. 248 EGV, Rn. 10; Bieber, in: v.d.Groeben/Schwarze, EUV/EGV, Art. 248 EG, Rn. 15; Niedobitek, in: Streinz, EUV/EGV, Art. 248 EGV, Rn. 10; Ekelmans, in: Commentaire Megret, Bd. 9, S. 351f., 355; Inghelram, The European Court of Auditors: Current legal issues, CMLR 2000, 129 (133f.).

${ }^{794}$ EuGH, Rs. 294/83, Slg. 1986, 1339, Rn. 28 (Les Verts/Parlament).

795 SA des GA Mancini, EuGH Rs. 204/86, Slg. 1988, 5323 (5342 f.) (Griechenland/Rat).

796 SA des GA Mancini, EuGH Rs. 204/86, Slg. 1988, 5323 (5342 f.) (Griechenland/Rat).
} 
Hier erscheint es sinnvoll, einen vergleichenden Blick auf die Lage nach deutschem Recht zu werfen, denn das Bundesverfassungsgericht kommt, im Wesentlichen aufgrund der gerade ins Feld geführten Argumente, zu einem völlig anderen Ergebnis als der EuGH. Es versteht den Maßstab der Rechtmäßigkeit weiter, insbesondere falle darunter auch die Prüfung der Vereinbarkeit des Haushaltsgesetzes mit höherrangigen haushaltsrelevanten Normen, auch wenn diese keine unmittelbaren Rechtsfolgen nach sich zieht. ${ }^{797}$ Dabei ist der Ausgangspunkt derselbe: Sowohl der Vertrag über die Europäische Gemeinschaft ${ }^{798}$ als auch das deutsche Grundgesetz ${ }^{799}$ weisen dem Europäischen Rechnungshof beziehungsweise dem Bundesrechnungshof ohne weitere Einschränkungen die Prüfung der Rechtmäßigkeit zu.

Der EuGH sprach dem EuRH jedoch eine über die Prüfung anhand des Haushaltsplans und des grundlegenden Rechtsaktes hinausgehende Prüfungskompetenz ab, während das Bundesverfassungsgericht den Maßstab der Rechtmäßigkeit, der der Prüfung durch den BRH zugrunde liegt, weiter auslegt und damit einen größeren Bereich seiner Kontrolle unterstellt. Dem BRH wird im Ergebnis die Prüfung der Rechtmäßigkeit bis hin zu Feststellung der Verfassungswidrigkeit des fraglichen Gegenstandes zugestanden, auch wenn diese Feststellung keine direkten Konsequenzen hat in Ermangelung ihrer Rechtsverbindlichkeit nach deutschem Recht.

Der restriktiven Auslegung durch den EuGH mag die Auffassung zugrunde gelegen haben, dass eine über den grundlegenden Rechtsakt hinausgehende Kontrolle in den originären Kernbereich seiner gerichtlichen Zuständigkeit fällt und damit in Hinblick auf das institutionelle Gleichgewicht nicht auch dem EuRH zukommen könne. Angesichts des Wortlautes des EGV, der eine solche Einschränkung nicht vornimmt, kann diese Ansicht jedoch nicht überzeugen. Sie verkennt vor allem, dass aufgrund der rechtlichen Unverbindlichkeit der Rechnungshofprüfung wie auch aufgrund der unterschiedlichen Zielrichtungen der gerichtlichen Rechtmäßigkeitsprüfung und der Rechtmäßigkeitsprüfung durch den Rechnungshof Überschneidungen unschädlich und somit hinnehmbar sind.

bb) Ordnungsmäßigkeit

Die Prüfung der Ordnungsmäßigkeit betrifft die rechnungstechnische Prüfung der förmlichen und rechnerischen Richtigkeit der Rechnung. ${ }^{800}$ Daneben umfasst sie

797 BVerfGE 20, 56 (96); vergleiche die im 1. Teil unter IV. 1. c) aa) und VI. 2. gemachten Ausführungen.

798 Art. 248 Abs. 2 UAbs. 1 EGV: „Der Rechnungshof prüft die Rechtmäßigkeit und OrdnungsmäBigkeit der Einnahmen und Ausgaben...".

799 Art. 114 Abs. 2 S. 1 GG: „der BRH...prüft die Rechnung sowie die Wirtschaftlichkeit und Ordnungsmäßigkeit der Haushalts- und Wirtschaftsführung“", wobei der Maßstab der OrdnungsmäBigkeit notwendig den der Rechtmäßigkeit mitumfasst, vgl. 1. Teil IV. 1. c) aa).

800 Brück/Kühne, Die Neuregelung der Finanzkontrolle der Europäischen Gemeinschaften, DÖV 1977, 23 (26); Niedobitek, in: Streinz, EUV/EGV, Art. 248 EGV, Rn. 10. 
auch die Aufdeckung von Unregelmäßigkeiten wie aus Art. 248 Abs. 2, UAbs. 1, S. 2 EGV (Art. 287 Abs. 2, UAbs. 1, S. 2 AEUV) deutlich wird. ${ }^{801}$

cc) Wirtschaftlichkeit (im weiteren Sinne)

In der als Wirtschaftsgemeinschaft angelegten EG (seit Lissabon ihres Rechtsnachfolgers der EU) mit ihren komplexen Verteilungssystemen und vor allem der dezentral ausgelegten Verwaltung, die auf die Mitwirkung durch die Mitgliedstaaten angewiesen ist, kommt dem Prüfungsmaßstab der Wirtschaftlichkeit der Haushaltsführung im weiteren Sinne wichtige Bedeutung zu. ${ }^{802}$ Sie umfasst die Prüfung der Sparsamkeit, der Wirtschaftlichkeit im engeren Sinne und der Wirksamkeit der geprüften Tätigkeit, des geprüften Programms beziehungsweise der geprüften Stelle. ${ }^{803}$ Die Überprüfung der Wirtschaftlichkeit zielt damit auf die optimale Mittelverwendung ab. ${ }^{804}$

Sparsamkeit bedeutet in diesem Zusammenhang die Erreichung des gesetzten Ziels bei Minimierung der hierfür einzusetzenden Kosten und bei Wahrung entsprechender Qualitätsmaßstäbe. ${ }^{805}$

Wirtschaftlich (im weiteren Sinne) wurde dann verfahren, wenn das bestmögliche Input-Output-Verhältnis erreicht wurde, also zwischen Erfolg im Sinne produzierter Güter, Dienstleistungen oder ähnlichem und den dafür eingesetzten Mitteln. 806

Wirksamkeit betrifft den Grad der Zielverwirklichung hinsichtlich der Zielvorgaben der Unionspolitik und das Verhältnis zwischen der beabsichtigten und der tatsächlichen Wirkung einer Tätigkeit. ${ }^{807}$

\section{c) Prüfungsumfang und Prüfungsansatr.}

Zwar sind Prüfungsgegenstand und -maßstäbe der Finanzkontrolle durch den EuRH sehr weit gefasst (,alle Einnahmen und Ausgaben der Gemeinschaft"), in der Praxis kann allerdings keine Kontrolle sämtlicher Haushaltsbewegungen statt-

\footnotetext{
801 Schmitr, in: Heuer, Kommentar zum Haushaltsrecht, (Stand: 42. EL, September 2006) VII/2, Rn. 40 m.w.N.

802 Ausführlich Mart, Die Finanzkontrolle der Europäischen Gemeinschaften, in: FS zur 275. Wiederkehr der Errichtung des Preußischen General-Rechen-Kammer, 1989, S. 469 (478 ff.).

803 Vgl. Europäische Leitlinien für die Anwendung der INTOSAI-Richtlinien, Nr. 41, 3.1; Anhang 2 zu Nr. 13, 6.1., abrufbar unter http://www.eca.eu.int; Europäischer Rechnungshof, Der Europäische Rechnungshof - Optimierung des Finanzmanagements in der EU, 2004, S. 19, 21.

${ }^{804}$ Europäischer Rechnungshof, Der Europäische Rechnungshof - Optimierung des Finanzmanagements in der EU, 2004, S. 19 f.

${ }^{805}$ Europäische Leitlinien für die Anwendung der INTOSAI-Richtlinien, Nr. 41, 3.2.

806 Europäische Leitlinien für die Anwendung der INTOSAI-Richtlinien, Nr. 41, 3.2.; Waldhoff, in: Calliess/Ruffert, EUV/EGV, Art. 248 EGV, Rn. 6

807 Europäische Leitlinien für die Anwendung der INTOSAI-Richtlinien, Nr. 41, 3.1; Europäischer Rechnungshof, Der Europäische Rechnungshof - Optimierung des Finanzmanagements in der EU, 2004, S. 19, 21.
} 
finden, vielmehr muss der Hof sich auf die jährlich wechselnde Auswahl besonders haushaltsrelevanter Themen beschränken. ${ }^{808}$ Eine Prüfung aller Haushaltsbereiche würde die Ausstattung mit Personal- und Sachmitteln des Europäischen Rechnungshofes angesichts des Umfangs der Rechnungsvorgänge und auch der geographischen Größe, was Vor-Ort-Kontrollen betrifft, nicht erlauben, und eine solche Vollprüfung ist wie gesehen auch auf Mitgliedstaatenebene nicht üblich. ${ }^{809}$ Vielmehr sind anhand einer sorgfältig ausgewählten Anzahl von Prüfungsbereichen durchaus aussagekräftige Ergebnisse abzuleiten.

Der Europäische Rechnungshof verfolgt einen „systemgestützten Prüfungsansatz" ${ }^{\text {810. }}$. Dieser basiert darauf, dass jede geprüfte Einrichtung über ein eigenes internes Kontrollsystem verfügt, das vom EuRH zunächst abstrakt hinsichtlich seines Konzepts und Funktionierens untersucht wird, und sodann mit Hilfe von Stichproben überprüft wird. ${ }^{811}$ Der Vorteil dieses Verfahrens ist, dass bei Feststellung, dass das interne Kontrollsystem gut konzipiert ist und zuverlässig funktioniert, die Zahl der Stichproben in Form direkter Kontrollen erheblich reduziert werden kann. ${ }^{812}$ Der systemgestützte Ansatz kann dabei für die Prüfung der Rechnungsführung ebenso wie für die der Wirtschaftlichkeit herangezogen werden. ${ }^{813}$ Angesichts der geteilten Verwaltung von Kommission und Mitgliedstaaten mit den zahlreichen beteiligten Verwaltungsstellen und der großen Anzahl von Programmen, die wegen ihrer Komplexität ein Hauptrisiko für die Rechts- und Ordnungsmäßigkeit der Ausgaben darstellen, ${ }^{814}$ ist dieser Ansatz wohl die praktikabelste Möglichkeit der Kontrolle.

Hervorzuheben ist, dass es sich bei dem Prüfungsverfahren gegenüber den Gemeinschaftsorganen um ein kontradiktorisches Verfahren handelt. Der EuRH tauscht sich mit ihnen über die Ergebnisse aus und veröffentlicht ihre Antworten

808 Europäischer Rechnungshof, Der Europäische Rechnungshof - Optimierung des Finanzmanagements in der EU, 2004, S. 14.

${ }^{809} \mathrm{Vgl}$. nur oben 1. Teil IV. 1. a).

810 Europäischer Rechnungshof, Der Europäische Rechnungshof - Optimierung des Finanzmanagements in der EU, 2004, S. 25; ausführlich: Friedmann, Organisation und Koordination von Prüfungsmethoden des Europäischen Rechnungshofes, in: Ders., Der Europäische Rechnungshof und die Wirtschafts- und Finanzhilfen für Mittel- und Osteuropa, 1994, S. 59 ff.; Ekelmans, in: Commentaire Megret, Bd. 9, S. 353; Vgl. schon die allgemeinen Ausführungen des EuRH über seine Prüfungstätigkeit: EuRH, Jahresbericht für das Haushaltsjahr 1980, Einleitung Ziff. 22 f., ABl. Nr. C 344 vom 31.12.1981.

811 Ausführlich zum Ganzen: Europäischer Rechnungshof, Der Europäische Rechnungshof - Optimierung des Finanzmanagements in der EU, 2004, S. 25; Kok, The Court of Auditors of the European Community, CMLR, 1989, 345 (354 f.); Schmits, in: Heuer, Kommentar zum Haushaltsrecht, (Stand: 42. EL, September 2006) VII/2, Rn. 53.

812 Schmitr, in: Heuer, Kommentar zum Haushaltsrecht, (Stand: 42. EL, September 2006) VII/2, Rn. 53.

${ }^{813}$ Europäischer Rechnungshof, Der Europäische Rechnungshof - Optimierung des Finanzmanagements in der EU, 2004, S. 25.

814 So hinsichtlich Ausgaben für Strukturmaßnahmen: EuRH, Jahresbericht für das Haushaltsjahr 2003, Ziff. 5.8., ABl. Nr. C 293 vom 30.11.2004, S. 157. 
in seinen Berichten (vgl. Art. 248 Abs. 4 EGV (Art. 287 Abs. 4 AEUV)). Seit dem Jahresbericht zum Haushaltsjahr 2000 werden der Übersichtlichkeit halber die Antworten der Kommission oder anderer Organe direkt neben der jeweiligen Prüfungsziffer abgedruckt. ${ }^{815}$ Diese Praxis ist zweckmäßig und vermittelt sofort ein vollständiges Bild der Beanstandungen. Gegenüber Stellen der Mitgliedstaaten und anderen Zuwendungsempfängern ist dies aus der Notwendigkeit, effiziente Arbeitsabläufe zu gewährleisten und die Fristen einzuhalten, so nicht möglich; jedoch ist der EuRH gewillt und interessiert, auch die Argumente der Mitgliedstaaten zu hören und diese gegebenenfalls auch in seinem Jahresbericht zu berücksichtigen. ${ }^{816}$

\section{d) Prüfungszeitpunkt}

Dem Grundsatz nach nimmt der Europäische Rechnungshof eine ex-postKontrolle vor, wie sich aus Art. 248 Abs. 2 UAbs. 2, 3 EGV (Art. 287 Abs. 2, UAbs. 2, 3 AEUV) ergibt. ${ }^{817}$ Ganz entscheidend ist aber Art. 248 Abs. 2 UAbs. 4 EGV (Art. 287 Abs. 2, UAbs. 4 AEUV), wonach der EuRH seine Prüfungen bereits vor Abschluss der Rechnung des betreffenden Haushaltsjahres durchführen kann. Wie sich aus Art. 248 Abs. 2 UAbs. 2 und 3 EGV (Art. 287 Abs. 2, UAbs. 2, 3 AEUV) ergibt, setzt die Prüfung lediglich bei Gemeinschaftseinnahmen deren Feststellung und bei Gemeinschaftsausgaben deren Mittelbindung voraus, ohne dass die Zahlung selbst der jeweiligen Einnahme oder Ausgabe abgewartet werden müsste. ${ }^{818}$ Folge ist eine zeitnahe Prüfung in Form einer begleitenden Kontrolle, ${ }^{819}$ die zu einer größeren Aktualität der Prüfungsergebnisse führt. Zusammen mit dem Recht, gem. Art. 248 Abs. 4 UAbs. 2 EGV (Art. 287 Abs. 4, UAbs. 2 AEUV) jederzeit Bemerkungen zu besonderen Fragen und Stellungnahmen vorzulegen, hat er so ein Instrument, eventuell bestehende Missstände zeitnah aufzuzeigen und insofern seinen Einfluss auf das Verhalten der verantwortlichen Stellen zu stärken und damit den Druck auf sie, entsprechend zu handeln, zu erhöhen. ${ }^{820}$ Unter Umständen schafft diese Kompetenz der zeitnahen Prüfung des EuRH überhaupt erst die Möglichkeit zum Gegensteuern bei be-

\footnotetext{
815 EuRH, Jahresbericht für das Haushaltsjahr 2000, Ziff. 0.3.; ABl. Nr. C 359 vom 15.12.2001, S. 5.

816 Friedmann, Finanzkontrolle von Mitteln der Europäischen Gemeinschaft, in: Rechnungshof Rheinland-Pfalz, Kooperation der Finanzkontrolle in Europa, 1999, S. 243 f., auch zu anderen Beteiligungsmöglichkeiten in der Praxis; Ders., in: Weidenfeld/Wessels, Jahrbuch der Europäischen Integration 1997/98, S. 98.

817 Lienbacher, in: Schwarze, EU-Kommentar, Art. 248 EGV, Rn. 20.

818 Magiera, Finanzkontrolle in der EG, in: v.Arnim, Finanzkontrolle im Wandel, 1989, S. 221 (232); Niedobitek, in: Streinz, EUV/EGV, Art. 248 EGV, Rn. 2.

${ }^{819}$ Magiera, in: Grabitz/Hilf, Recht der EU, Bd. II (Stand: 18. EL, Mai 2001), Art. 248 EGV, Rn. 12 m.w.N.

820 Eblermann, Der Europäische Rechnungshof, 1976, S. 33; Bieber, in: v.d.Groeben/Schwarze, EUV/EGV, Art. 248 EG, Rn. 17.
} 
stimmten Missständen, die Jahre später nach einem regulären Bericht oft nicht mehr behebbar wären.

2. Beratung und Anhörungserfordernisse vor Erlass finanzrechtlicher Vorschriften

Dem Europäischen Rechnungshof kommt beratende Funktion zu: 821 So sehen einige Vorschriften des EG-Vertrages eine obligatorische Anhörung des EuRH vor (vgl. Art. 276 EGV (Art. 319 AEUV), 279 Abs. 1 a) und b) EGV (322 Abs. 1 a), b) AEUV)), 279 Abs. 2 EGV (322 Abs. 2 AEUV), 280 Abs. 4 EGV (325 Abs. 4 AEUV)), andere zielen darauf ab, dass Gemeinschaftsorgane sich von ihm in Form von Stellungnahmen beraten lassen können (Art. 248 Abs. 4 UAbs. 2 EGV (Art. 287 Abs. 4 UAbs. 2 AEUV)). Außerdem kann der Europäische Rechnungshof aus eigener Initiative beratend tätig werden und Sonderberichte zu besonderen Fragen vorlegen (vgl. Art. 248 Abs. 4 UAbs. 2 EGV (Art. 287 Abs. 4 UAbs. 2 AEUV)).

\section{a) Obligatorische Anbörung bei Entlastung und gemeinschaftlicher Normsetzung}

Neben der Unentbehrlichkeit von Jahresbericht, Zuverlässigkeitserklärung und Sonderberichten als Entscheidungsgrundlagen für das jedes Haushaltsjahr abschließende Entlastungsverfahren nach Art. 276 EGV (Art. 319 AEUV) ${ }^{822}$ bedarf auch die Normsetzung in bestimmten finanzrelevanten Bereichen der Beteiligung des Europäischen Rechnungshofes. Der Vertrag weist ihm eine Beratungsfunktion in Form obligatorischer Stellungnahme- und Anhörungserfordernisse zu. So enthält Art. 279 EGV (Art. 322 AEUV) zwingende Verfahrensvorschriften ${ }^{823}$ für bestimmte haushaltsrechtlich relevante Normsetzungsmaterien. Bei Erlass der Haushaltsordnung ist gem. Art. 279 Abs. 1 a) EGV (Art. 322 Abs. 1 a) AEUV) zuvor eine Stellungnahme des Europäischen Rechnungshofes einzuholen, ebenso wie gem. Abs. 1 b) vor Erlass der „Vorschriften über die Verantwortung der Finanzkontrolleure, der anweisungsbefugten Personen und der Rechnungsführer sowie der entsprechenden Kontrollmaßnahmen", die sich ebenfalls in der Haushaltsordnung in Art. 61 ff. finden.

821 Friedmann, Aufgabenstellung und rechtliche Rahmenbedingungen der Finanzkontrolle des EuRH, in: Ders., Der EuRH und die Wirtschafts- und Finanzhilfen der EU für Mittel- und Osteuropa, 1994, S. 20 f.

822 Europäischer Rechnungshof, Der Europäische Rechnungshof - Optimierung des Finanzmanagements in der EU, 2004, S. 30; Waldhoff, in: Calliess/Ruffert, EUV/EGV, Art. 276 EGV, Rn. 1.

${ }^{823}$ Ekelmans, in: Commentaire Megret, Bd. 9, S. 360 oben; so schon zum EWG-Vertrag: Mart, Die Finanzkontrolle der Europäischen Gemeinschaften, in: FS zur 275. Wiederkehr der Errichtung des Preußischen General-Rechen-Kammer, 1989, S. 469 (487 f.); Inghelram, The European Court of Auditors: Current legal issues, CMLR 2000, 129 (143 f.); vgl. zur entsprechenden Einstufung von Anhörungserfordernissen des Parlaments als zwingende Verfahrensvorschriften: EuGH, Rs. 138/79, Slg. 1980, 3333, Rn. 33 (Roquette Frères/Rat); Rs. 139/79, Slg. 1980, 3393, Rn. 33 ff. (Maizena/Rat); Rs. C-417/93; Slg. 1995, I-1185, Rn. 9 (Parlament/Rat); Rs. C- 21/94, Slg. 1995, I-1827, Rn. 17 (Parlament/Rat) m.w.N. 
Genauso verhält es sich gem. Art. 279 Abs. 2 EGV (Art. 322 Abs. 2 AEUV) beim Erlass von Verfahrensvorschriften hinsichtlich der Ausstattung der Kommission mit den in der Eigenmittelverordnung vorgesehenen Haushaltseinnahmen.

Regelungen auf dem Gebiet der europäischen Finanzgesetzgebung setzen somit eine vorherige förmliche Stellungnahme des Europäischen Rechnungshofes voraus. Außerdem bedürfen Beschlüsse des Rates über Maßnahmen zur Verhütung und Bekämpfung von Betrügereien nach Art. 280 Abs. 4 EGV (Art. 325 Abs. 4 AEUV) der vorherigen Anhörung des Rechnungshofes.

\section{b) Beratung auf Ersuchen anderer Gemeinschaftsorgane}

Aus Art. 248 Abs. 4 UAbs. 2 EGV (Art. 287 Abs. 4 UAbs. 2 AEUV) ergibt sich, dass „der Rechnungshof ... ferner auf Antrag eines der anderen Organe der Gemeinschaft Stellungnahmen abgeben kann“. Die Organe können also den Sachverstand des EuRH für Normsetzungsvorhaben oder sonstige Pläne nutzen, indem sie ihn um Rat bitten.

Jedoch wird aus dem Vertragswortlaut („kann“) deutlich, dass der Rechnungshof, seiner sachlichen Unabhängigkeit bei der Auswahl der Prüfungsgegenstände geschuldet, diesen Ersuchen nicht nachkommen muss, dies in aller Regel aber tun wird. In Art. 248 Abs. 4 UAbs. 4 EGV (Art. 287 Abs. 4 UAbs. 4 AEUV) wird jedoch festgelegt, dass der Rechnungshof Parlament und Rat bei Kontrolle der Ausführung des Haushaltsplans unterstützt; daraus folgt, dass Anträge dieser beiden Organe auf Abgabe seiner Stellungnahme ausnahmsweise doch verbindlich sein können, soweit sie im Rahmen ebendieser Unterstützungspflicht erfolgen. ${ }^{824}$

Die Gemeinschaftsorgane müssen Berichte und Stellungnahmen des EuRH zur Kenntnis nehmen, wie ihre Pflicht, auf die Bemerkungen zu antworten, zeigt. ${ }^{825}$ Teilweise wird sogar angenommen, dass die Organe diese auch bei ihrer Entscheidungsfindung berücksichtigen müssen. ${ }^{826}$ Gegen diese Sichtweise spricht jedoch, dass sie dem Vertrag so nicht zu entnehmen ist. Bei genauerer Betrachtung stellt sich vor allem heraus, dass es sich, bei der „Pflicht" zu antworten, von seinem Sinn her vielmehr um ein Recht handelt, ist es doch im Interesse der Organe selbst, in diesem kontradiktorischen Verfahren ihren Standpunkt darzustellen und Argumente vorbringen zu können, bevor der EuRH eine endgültige Bewertung ihres Umganges mit Finanzen vornimmt und diese veröffentlicht. Weiter dürfte es problematisch sein, im Einzelfall die Grenze zwischen einer „Zurkenntnisnahme“ und einer „Berücksichtigung“ zu ziehen. Dann stellte sich auch die Frage, welche qualitativen Anforderungen an letztere zu stellen wären. Vor allem aber bedeutete diese Annahme einen Eingriff in die politische Mei-

\footnotetext{
824 Magiera, Finanzkontrolle in der EG, in: v.Arnim, Finanzkontrolle im Wandel, 1989, 221 (234); Bieber, in: v.d.Groeben/Schwarze, EUV/EGV, Art. 248 EG, Rn. 32.

825 Vgl. Art. 248 Abs. 4 UAbs. 1 S. 2 EGV; Art. 143 Abs. 2 S. 2 Haushaltsordnung.

826 Niedobitek, in: Streinz, EUV/EGV, Art. 248 EGV, Rn. 23.
} 
nungsbildung, der dem EuRH von seiner Funktion her nicht zukommen soll. Auch müsste eine solche Pflicht zwangsläufig mit der Möglichkeit der Einklagbarkeit vor dem EuGH wegen fehlender Berücksichtigung einhergehen, denn bestünde diese Pflicht tatsächlich, bedeutete ihre Nichtbeachtung eine Verletzung des institutionellen Gleichgewichts.

Ein derart starker Eingriff in den politischen Entscheidungsfindungsprozess der EU dürfte wohl nicht die Intention der Verträge sein. Die Einflussmöglichkeiten des EuRH liegen vielmehr - rechnungshoftypisch - in der Professionalität und Unparteilichkeit, die seinen Äußerungen Bedeutung zukommen lassen und seinem neutralen Urteil Überzeugungskraft geben.

Daneben kann der Europäische Rechnungshof gem. Art. 248 Abs. 4 UAbs. 2 EGV (Art. 287 Abs. 4 UAbs. 2 AEUV) jederzeit Bemerkungen zu besonderen Fragen vorlegen, also von sich aus beratend tätig werden.

\section{Veröffentlichungen}

\section{a) Berichterstattung}

Die Berichterstattung durch den Europäischen Rechnungshof umfasst gem. Art. 248 Abs. 4 UAbs. 1 EGV (Art. 287 Abs. 4 UAbs. 1 AEUV) den Jahresbericht nach Abschluss eines jeden Haushaltsjahres, der zusammen mit den Antworten der Organe auf die Bemerkungen im Amtsblatt der Europäischen Union veröffentlicht wird. ${ }^{827}$ Er enthält an erster Stelle die seit 1994 in Art. 248 Abs. 1 UAbs. 2 EGV (Art. 287 Abs. 1 UAbs. 2 AEUV) geregelte „Erklärung über die Zuverlässigkeit der Rechnungsführung sowie die Rechtmäßigkeit und Ordnungsmäßigkeit der zugrunde liegenden Vorgänge" 828 , wobei es sich der Sache nach um die dem Bericht vorangestellten, formalisierten Ergebnisse desselben handelt. ${ }^{829}$ Die erste eigene Zielsetzung des Rechnungshofes war, das Zertifikat nur positiv auszustellen, wenn die Unregelmäßigkeiten nicht mehr als $1 \%$ des Haushaltsvolumens ausmachen, jedoch lagen im ersten Haushaltsjahr, zu dem die ZVE abzugeben war, auf der Ausgabenseite formelle Fehler und materielle Unregelmäßigkeiten in Höhe von insgesamt $9 \%$ vor, so dass eine positive Ausstellung nicht möglich war. 830

\footnotetext{
827 Vgl. auch Art. 143 Abs. 5 HO: Danach hat die Übermittlung des Jahresberichtes an die Entlastungsbehörde und die anderen Organe spätestens am 31. Oktober zu erfolgen und der Rechnungshof für die Veröffentlichung im Amtsblatt zu sorgen.

828 Üblicherweise als ZVE oder DAS (déclaration d`assurance) abgekürzt.

829 Ausführlich zur Zuverlässigkeitserklärung: Europäischer Rechnungshof, Der Europäische Rechnungshof - Optimierung des Finanzmanagements in der EU, 2004, S. 18; Bieber, in: v.d.Groeben/Schwarze, EUV/EGV, Art. 248, Rn. 24 f.

${ }^{830}$ Friedmann, Zur Bedeutung der Kontroll-Struktur und zu den Vorbeugungsstrategien gegen Missbrauch öffentlicher Gelder, in: Piehl, Europa in Ostdeutschland, 1996, S. 265 (266).
} 
Inzwischen verzichtet der EuRH auf eine Veröffentlichung der genauen Fehlerquote, inoffiziell gibt er diese jedoch als seit den neunziger Jahren bei 3-8\% liegend an. ${ }^{831}$

Die besondere Bedeutung des Jahresberichtes des Europäischen Rechnungshofes ergibt sich aus der Tatsache, dass er eine zentrale Grundlage für die Entlastung der Kommission durch das Europäische Parlament gem. Art. 276 Abs. 1 S. 2 EGV (Art. 319 Abs. 1 S. 2 AEUV) ist. 832

Daneben ist, wie bereits oben in Hinblick auf die Möglichkeit der zeitnahen Prüfung erörtert, das Recht bedeutsam, jederzeit Bemerkungen zu besonderen Fragen vorzulegen, insbesondere in Form von Sonderberichten (bis zum EUVertrag als Bemerkungen bezeichnet) ${ }^{833}$ und Stellungnahmen auf Antrag anderer Gemeinschaftsorgane (vgl. Art. 248 Abs. 4 S. 2 EGV (Art. 287 Abs. 4 S. 2 AEUV)). Wie unter 2. b) gesehen besteht grundsätzlich keine Pflicht, einem solchen Antrag eines anderen Organs nachzukommen, ausnahmsweise kann sie sich jedoch wegen der in Art. 248 Abs. 4 UAbs. 4 EGV (Art. 287 Abs. 4 UAbs. 4 AEUV) normierten Pflicht, Parlament und Rat bei Ausführung der Kontrolle des Haushaltplanes zu unterstützen, ergeben (vgl. etwa \39 GOEP).

Die Veröffentlichungen der Berichte erfolgen im Amtsblatt der Europäischen Union und auf der Homepage des Europäischen Rechnungshofes. Dies macht deutlich, dass die externe Finanzkontrolle durch den Europäischen Rechnungshof darauf angelegt ist, nicht nur gemeinschaftsintern, sondern auch in der europäischen Öffentlichkeit zu wirken. ${ }^{834}$

Die vertragliche Befugnis zur Berichterstattung verfolgt als Ziel die Gewährleistung der Kontrolle der Finanzgebarung der EU und, soweit es den Umgang mit Gemeinschaftsmitteln betrifft, der Mitgliedstaaten. Diese ist verbunden mit der Offenlegung ihrer Finanztätigkeit und dient dazu, rechtswidrige, nicht ordnungsgemäße sowie unwirtschaftliche Vorgänge aufzudecken und ihre Verhinderung beziehungsweise Beseitigung zu erwirken.

\section{b) Weiterverfolgung früherer Bemerkungen}

Wie auch auf nationaler Ebene üblich ${ }^{835}$ soll die Effizienz der Finanzkontrolle verbessert werden, indem einige Jahre nach Veröffentlichung der Prüfungsergebnisse eine Überprüfung hinsichtlich der Verbesserungsmaßnahmen, die die beanstandeten Organe (dies ist in aller Regel die Kommission) getroffen haben, erfolgt.

\footnotetext{
${ }^{831}$ Frankfurter Allgemeine Zeitung vom 31.10.2006, Rechnungsprüfer wehren sich gegen Kritik, S. 25.

832 Waldhoff, in: Calliess/Ruffert, EUV/EGV, Art 276 EGV, Rn. 1.

$833 \mathrm{Zu}$ den Begrifflichkeiten Bieber, in: v.d.Groeben/Schwarze, Art. EUV/EGV, Art. 248 EG, Rn. 29.

834 Hilf, Die Organisationsstruktur der EG, 1982, S. 338.

835 Vgl. zum Bundesrechnungshof: 1. Teil, IV. 5. am Ende.
} 
Die Ergebnisse dieser erneuten Überprüfung werden dann im jeweiligen Jahresbericht veröffentlicht. ${ }^{836}$

\section{c) Rechtsschutz, gegen Berichte des Europäischen Rechnungshofes}

Im Ergebnis entfalten die Berichte des Rechnungshofes keine unmittelbare Rechtswirkung, auch nicht gegenüber eventuell darin genannten Personen. ${ }^{837}$ Jedoch kann die faktische Auswirkung im Falle namentlicher Nennung Dritter aus allgemeinen rechtsstaatlichen Erwägungen die Notwendigkeit einer Anhörung begründen. 838

Grundsätzlich dürfen Personen, die der Kontrolle des EuRH unterliegen, namentlich in Berichten genannt werden. ${ }^{839}$ Dies ist hingegen bei dritten Personen, die nicht seiner Kontrolle unterliegen, nur ausnahmsweise aufgrund „besonderer Umstände“ (in einem schweren Fall oder bei Verwechslungsgefahr) erlaubt, und es müssen die vom EuGH festgestellten Anhörungserfordernisse beachtet werden. ${ }^{840}$ Folglich kann die namentliche Nennung Dritter in einem Bericht des EuRH, soweit sie rechtswidrig erfolgte, eine Schadenspflicht nach sich ziehen. ${ }^{841}$

Das Bedeutsame dieser beiden Entscheidungen ist allgemein die Feststellung der Anhörungsrechte. Die praktische Relevanz bezogen auf den EuRH dürfte hingegen gering bleiben, da dieser (ebenso wie der Bundesrechnungshof vgl. \ 9 Abs. 2 PO-BRH) in seinen Berichten die Daten aus seinen Erhebungen anonymisiert und eine Rechtsgutverletzung damit überhaupt nur in Ausnahmefällen in Betracht kommt.

836 Europäischer Rechnungshof, Der Europäische Rechnungshof - Optimierung des Finanzmanagements in der EU, 2004, S. 31.

${ }^{837}$ EuGH Rs. C-315/99 P, Slg. 2001, I-5281, Rn. 27 ff., 29 (ISMERI/EuRH): „Die Verabschiedung und die Veröffentlichung der Berichte des Rechnungshofes sind zwar keine Entscheidungen, durch die die Rechte der darin genannten Personen unmittelbar beeinträchtigt werden, können für diese aber so folgenschwer sein, dass den Betroffenen vor der endgültigen Verabschiedung der Berichte Gelegenheit gegeben werden muss, zu den darin enthaltenen Punkten, in denen sie namentlich genannt sind, Stellung zu nehmen“.

${ }^{838}$ EuGH Rs. C-315/99 P, Slg. 2001, I-5281, Rn. 27 ff., 40 f. (ISMERI/EuRH); zur Anhörung als allgemeinem Rechtsgrundsatz bereits EuGH Rs. 17/74, Slg. 1974, 1083, Rn. 15 (Transocean Marine Paint/Kommission).

839 Inghelram, LÁrrêt Ismeri: Quelles Conséquences pour la Cour des Comptes Européenne ?, Cahiers de droit européenne 2001, 707 (722 ff.); Ders., in: Lenz/Borchardt, EUV/EGV, 3. Aufl. 2003, Art. 248 EGV, Rn. 14.

${ }^{840}$ EuGH Rs. C-315/99 P, Slg. 2001, I-5281, Rn. 40 (ISMERI/EuRH): „Entsprechend der Auffassung des Gerichts ist der EuRH aufgrund besonderer Umstände, etwa wenn ein schwerwiegender Fall vorliegt oder eine Verwechslungsgefahr besteht, durch die Drittinteressen beeinträchtigt werden könnten, berechtigt, Personen, die grundsätzlich nicht seiner Überwachung unterliegen, in seinen Berichten namentlich zu nennen, sofern diesen Personen, wie oben in Rn. 28 und 29 hervorgehoben, ein Recht auf Anhörung zugestanden wird.“; EuG Rs. T-277/97, Slg. 1999, II1825, Rn. 109 (ISMERI/EuRH).

${ }^{841}$ Mader, Zu den Verteidigungsrechten im Verfahren - Der EuRH und die Rechte Dritter in der Rechnungsprüfung, European Law Reporter 2006, S. 283 (286). 


\section{Rechtsnatur der Handlungsformen}

Die Handlungsformen des Europäischen Rechnungshofes sind wie gesehen die auch nach den meisten nationalstaatlichen Regelungen „rechnungshoftypischen“: Sie umfassen die Prüfung einschließlich der zugehörigen Informations- und Zugangsrechte, die Beratung der politischen Entscheidungsträger und die Veröffentlichung der Ergebnisse.

Der Rechnungshof handelt damit durch keine der ihm vertraglich zugewiesenen Handlungsformen rechtsverbindlich im Sinne der in Art. 249 EGV (Art. 288 AEUV) normierten Rechtsakte. Er hat also nach der Konzeption des EGVertrages keine Entscheidungsbefugnisse, so dass seine Handlungen weder bestimmt noch geeignet sind, unmittelbare Rechtswirkung zu entfalten. ${ }^{842}$

Insbesondere kommen ihm auch keine richterlichen Befugnisse zu wie zum Beispiel die Kompetenz, „Finanzkontrolleure“ oder „öffentliche Rechnungsführer" persönlich und finanziell zur Verantwortung zu ziehen, ${ }^{843}$ wie dies etwa für die französische Cour des comptes und das spanische Tribunal de Cuentas typisch ist. ${ }^{844}$ Besonders in der französischsprachigen Literatur wird angemerkt, dass die Bezeichnung als „Hof“" beziehungsweise „Cour" eigentlich auf eine rechtsprechende Funktion schließen ließe, ${ }^{845}$ was hingegen beim EuRH eindeutig nicht der Fall ist. 846

Der Tätigkeit des Rechnungshofes ist rein innergemeinschaftlicher Natur, sie richtet sich an die Organe und verstärkt das System der gegenseitigen checks and balances, ohne dass ihr rechtliche Verbindlichkeit zukäme oder sie allein von sich aus zu unmittelbaren Konsequenzen führte.

Die rechtliche Unverbindlichkeit seiner Tätigkeit verdeutlicht auch die Tatsache, dass der Rechnungshof nicht in Art. 230 UAbs. 1 EGV (Art. 263 UAbs.1 AEUV) als eines der Organe genannt ist, die der Überwachung durch den EuGH unterliegen. Eine ausdrückliche passive Klagebefugnis enthält der EGV nicht. So kommt auch Verabschiedung und Veröffentlichung von Berichten und Stellungnahmen des Rechnungshofes gegenüber Bürgern, etwa wenn sie darin genannt

842 Niedobitek, in: Streinz, EUV/EGV, Art. 248 EGV, Rn. 21 m.w.N.; Europäischer Rechnungshof, Der Europäische Rechnungshof - Optimierung des Finanzmanagements in der EU, 2004, S. 7: „Der Hof ist kein rechtsprechendes Organ, folglich sind weder seine Berichte noch seine Stellungnahmen rechtlich bindend“; Friedrich/Inghelram, Die Klagemöglichkeiten des Europäischen Rechnungshofs vor dem Europäischen Gerichtshof, DÖV 1999, 669 (670).

843 Mart, Die Finanzkontrolle der Europäischen Gemeinschaften, in: FS zur 275. Wiederkehr der Errichtung des Preußischen General-Rechen-Kammer, 1989, S. 469 (476).

844 Oben: 2. Teil A. III. 2. und C. III. 2.

845 Ekelmans, in: Commentaire Megret, Bd. 9, S. 342; Mart, Die Finanzkontrolle der Europäischen Gemeinschaften, in: FS zur 275. Wiederkehr der Errichtung des Preußischen General-RechenKammer, 1989, S. 469 (476).

846 Schmidt-Gerritzen, in: Lenz, EGV, 2. Aufl. 1999, Art. 248 EGV, Rn. 12. 
sind, keine unmittelbare rechtliche Bedeutung zu. ${ }^{847}$ Dennoch haben EuGH und EuG Klagen von Dritten gegen den Rechnungshof wegen der faktischen Auswirkungen ihrer Nennung in Berichten zugelassen. ${ }^{848}$

Die Handlungsformen des Rechnungshofes können jedoch durchaus mittelbare rechtliche Wirkung entfalten. Seine Berichte bilden die Grundlage von Entscheidungen der Organe, insbesondere auf dem Gebiet der Finanzen. Hier ist vor allem die Bedeutung für das Entlastungsverfahren nach Art. 276 Abs. 1 EGV (Art. 319 Abs. 1 AEUV) zu nennen: ${ }^{49}$ Die Meinungsbildung des Rates und besonders des Europäischen Parlaments hängt entscheidend von den Berichten des EuRH ab. Diese Rolle spiegelt sich auch in Art. 248 Abs. 4 UAbs. 4 EGV (Art. 287 Abs. 4 UAbs. 4 AEUV) wider. Danach dienen seine Berichte Rat und Parlament zur Kontrolle der Ausführung des Haushaltsplans, sie bilden zudem die Grundlage für das Entlastungsverfahren. ${ }^{850}$ Das wie auch auf nationaler Ebene bestehende Informationsdefizit ${ }^{851}$ des Parlaments erklärt die große Bedeutung der Berichte des Rechnungshofes für seine Entscheidungen, verfügt es doch kaum über andere Möglichkeiten, entsprechende objektive Informationen über die ordnungsgemäße Mittelverwendung zu erhalten. Das Europäische Parlament selbst bezeichnete in einer Entschließung die Zusammenarbeit zwischen Rechnungshof und Parlament als „Kernstück des Systems der Haushaltskontrolle der EU“.852 Spürbare Folgen der Berichterstattung des Rechnungshofes können sich mithin auch dadurch ergeben, dass infolge seiner Berichte (insbesondere einer negativen Zuverlässigkeitserklärung) das Europäische Parlament die Entlastung der Kommission, wie bereits geschehen, aufschiebt oder sogar gänzlich verweigert. ${ }^{853}$

Auch die Beteiligung an der Willensbildung der Gemeinschaftsorgane durch die obligatorische, aber auch durch die fakultative Beratung ist zu betonen und führt zu faktischen Einflussnahmemöglichkeiten. Die Informationen fließen in den Entscheidungsprozess ein, so dass der Auswahl der Prüfungs- und Beratungsmaterien, der Schwerpunktsetzung und nicht zuletzt der für seine Glaubwürdigkeit maßgeblichen Qualität der Arbeit des Rechnungshofes entscheidende Bedeutung zukommt.

847 Oben: III. 3. c); EuGH, Rs. C-315/99, Slg. 2001, I - 5281, Rn. 29 (ISMERI/EuRH): ,...keine Entscheidungen, durch die die Rechte der darin genannten Personen unmittelbar beeinträchtigt werden".

848 Oben: III. 3. c); EuG Rs. T-277/97, Slg. 1999, II-1825 (ISMERI/EuRH); EuGH, Rs. C-315/99, Slg. 2001, I - 5281, Rn. 29 (ISMERI/EuRH) ; zur passiven Klagebefugnis des EuRH siehe unten IV.3.

849 Niedobitek, in: Streinz, EUV/EGV, Art. 248 EGV, Rn. 22.

850 Vgl. Hilf, Die Organisationsstruktur der EG, 1982, S. 339.

851 Oben: 1. Teil VI. 3. a) aa).

852 Entschließung vom 19. Januar 1995, ABl. 1995 Nr. C 43, S. 75.

853 Zum Entlastungsrecht des EP vgl. Theato/Graf, Das EP und der Haushalt der EG, 1994, S. 130 ff. 
Der ehemalige Präsident des Europäischen Rechnungshofes, Marcel Mart, umschrieb die Befugnisse des Hofes als „moralisch zwingende Einwirkungskraft“, die zu der präventiven Aufgabe der Beratung tritt. ${ }^{854}$ Prüfung und Beratung sind dabei untrennbar miteinander verbunden, die Grenzen fließend. 855

Faktische Bedeutung kann den Stellungnahmen nicht nur durch die Information und Überzeugung der Gemeinschaftsorgane zukommen, sondern auch durch die Erzeugung von Druck der Öffentlichkeit beziehungsweise der Mitgliedstaaten auf diese. ${ }^{856}$ Jedoch empfiehlt es sich, hiervon nur mit größter Vorsicht Gebrauch zu machen, denn es besteht die Gefahr, dass derartige Kritik zur Schürung antieuropäischer Ressentiments vor allem durch mitgliedstaatliche Parteien missbraucht wird, was dem gesamten europäischen Projekt Schaden zufügen kann. Insofern stellt der Umgang mit der Veröffentlichung von Informationen für den Europäischen Rechnungshof stärker noch als für die Rechnungshöfe der Mitgliedstaaten oft eine Gratwanderung dar.

Diese Zurückhaltung zeigt sich etwa darin, dass die Fehlerquote bei der Verteilung des EU-Budgets im Gegensatz zu früher nicht mehr in exakten Zahlen angegeben wird. ${ }^{857}$ Auch zieht der Rechnungshof soweit möglich keine Schlüsse aus aufgedeckten Fehlern, um eine Einmischung in die politische Bewertung derselben $\mathrm{zu}$ vermeiden und diese den politischen Entscheidungsträgern zu überlassen. 858

Ein gutes Beispiel für die faktische Bedeutung der Handlungen des Rechnungshofes und ihre Wirksamkeit ist in diesem Zusammenhang die Rolle, die der Rechnungshof bei der Prüfung von Korruptionsvorwürfen gegen die SanterKommission spielte. Der EuRH nahm die ihm in Art. 248 Abs. 2 UAbs. 1 S. 2 EGV (Art. 287 Abs. 2 UAbs. 1 S. 2 AEUV) zugewiesene Aufgabe, ,insbesondere über Fälle von Unregelmäßigkeiten“ zu berichten, entschieden und ohne falsche Scheu vor einem Konflikt mit der Kommission wahr. ${ }^{859}$ Die zahlreichen Sonderberichte wurden im Europäischen Parlament und über die Medien in der Öffentlichkeit so wahrgenommen, dass sie einen wesentlichen Anteil am geschlossenen Rücktritt der Kommission am 16. März 1999 hatten. ${ }^{860}$

854 Mart, Die Finanzkontrolle der Europäischen Gemeinschaften, in: FS zur 275. Wiederkehr der Errichtung des Preußischen General-Rechen-Kammer, 1989, S. 469 (476).

855 Oben: 1. Teil IV. 3. a).

856 Oppermann, Europarecht, 2005, S. 116, Rn. 122: „Wichtigste Waffe des RH bleibt die Öffentlichkeitswirkung seiner Berichte, besonders, wenn sich das Parlament ihrer annimmt“; Zur Sensibilität dieser Beziehung: Theato/Graf, Das EP und der Haushalt der EG, 1994, S. 116 f.

${ }^{857}$ Rechnungsprüfer wehren sich gegen Kritik, Frankfurter Allgemeine Zeitung vom 31.10.2006, S. 25.

858 So Rechnungshofpräsident Weber, Rechnungsprüfer wehren sich gegen Kritik, Frankfurter Allgemeine Zeitung vom 31.10.2006, S. 25.

859 Ausführlich: Nathe, Der Rechnungshof, in: Weidenfeld/Wessels, Jahrbuch der Europäischen Integration 1998/99, S. 93 (94ff.).

860 Nathe, Der Rechnungshof, in: Weidenfeld/Wessels, Jahrbuch der Europäischen Integration 1998/99, S. 93. Oppermann, Europarecht, 2005, S. 116, Rn. 122. 
Die Tätigkeit des Europäischen Rechnungshofes zielt vor allem auf die Mitteilung der Ergebnisse der Rechnungsprüfung und damit auf die Information über die Ordnungsmäßigkeit des Umganges mit den Gemeinschaftsfinanzen ab. ${ }^{861}$ Rechtlich sind seine Handlungsformen für die anderen Organe nicht verbindlich, insofern besteht in Bezug auf die Möglichkeiten der Einflussnahme auf den politischen Prozess in der Europäischen Union durchaus Ähnlichkeit mit der Stellung des Bundesrechnungshofes im deutschen Staatsaufbau. Jedoch stellt es eine europäische Besonderheit dar, dass er als Organ gleichberechtigt und auf einer Ebene neben den Organen steht, die für die Union die Hoheitsgewalt ausüben.

Der Europäische Rechnungshof übt im Ergebnis keine Gewalt in Form unmittelbarer rechtsverbindlicher Handlungen aus, weder gegenüber anderen Organen noch gegenüber dem Unionsbürger.

\section{Stellung des Europäischen Rechnungshofes im Organge- füge der Europäischen Gemeinschaft}

Der Europäische Rechnungshof ist Organ sowohl der Europäischen Union als auch der Europäischen Gemeinschaft. Unterschiedlich stark ausgeprägte Kompetenzen kommen ihm wie gesehen im Bereich aller drei „Säulen“ der Union zu. Für die Bewertung seiner Stellung als Organ liegt der Schwerpunkt dabei jedoch auf dem die erste Säule der Union bildenden Vertrag über die Europäische Gemeinschaft.

Mittelpunkt der Betrachtung ist somit die Rechtslage nach dem EGV. Im Anschluss an die jeweilige Darstellung unter 1. a) aa)-gg) wird auf die neue Rechtslage nach Lissabon eingegangen. Um Entwicklungstendenzen im institutionellen Gefüge zu verdeutlichen, wird jedoch das Augenmerk auch auf Vorgängernormen sowie auf den gescheiterten Entwurf einer Verfassung für Europa gerichtet.

\section{Gewaltenteilung in der Europäischen Gemeinschaft}

Eine Art. 20 Abs. 2 S. 2 GG entsprechende ausdrückliche Festlegung des Gewaltenteilungsgrundsatzes fehlt in den Gründungsverträgen. An dieser Stelle sollen Bestehen und Ausgestaltung eines Gewaltenteilungssystems auf europäischer Ebene untersucht werden und ins Verhältnis zum europäischen System der Funktionenteilung gesetzt werden. Dabei sollen Gemeinsamkeiten und Unterschiede hinsichtlich der mit der klassischen Gewaltenteilung grundsätzlich verfolgten Ziele und ihrer Erreichung auf europäischer Ebene beleuchtet werden.

861 Waldhoff, in: Calliess/Ruffert, EUV/EGV, Art. 248 EGV, Rn. 7; Niedobitek, in: Streinz, EUV/EGV, Art. 248 EGV, Rn. 18. 
a) Ausgestaltung der horizontalen Kompetenzverteilung nach dem EG-Vertrag und dem Vertrag über die Arbeitsweise der Union

aa) Funktionsverteilung im Normsetzungsverfahren

Das Verfahren zur Setzung von Gemeinschaftsrecht ist besonders stark von Funktionsverschränkungen durch die Beteiligung aller Organe mit Ausnahme des EuGH geprägt.

Zunächst besteht ein Vorschlagserfordernis (vgl. Art. 251 Abs. 2 UAbs. 1; Art. 252 a) EGV), wobei das Initiativmonopol ${ }^{862}$ bei der Kommission liegt. Gem. Art. 192 Abs. 2 EGV kann das Parlament diese jedoch zu Vorschlägen auffordern, ebenso wie der Rat nach Art. 208 EGV.

Weiter müssen bei einigen Normsetzungsmaterien Organe, namentlich das Europäische Parlament und der Rechnungshof, angehört werden oder Stellungnahmen abgeben, ${ }^{863}$ die als zwingende Verfahrensvorschriften unverzichtbar sind 864 .

Ursprünglich hatte das Europäische Parlament lediglich beratende Funktion, die Mitwirkung an der Setzung sekundären Gemeinschaftsrechts beschränkte sich auf eine für Rat und Kommission nicht verbindliche Anhörung, die heute die Ausnahme bildet. ${ }^{865}$ Heute nimmt es neben dem Rat aktiv am Normsetzungsprozess teil, so sind im Rahmen des Mitentscheidungsverfahrens nach Art. 251 EGV die Entscheidungen an seine Zustimmung gebunden, im Verfahren der Zusammenarbeit nach Art. 252 EGV stehen ihm Einspruchsmöglichkeiten zu. Auch beim Erlass des Haushaltplans kommt dem Parlament eine besondere Rolle zu, es kann gem. Art. 272 Abs. 8 EGV den Entwurf aus wichtigen Gründen ablehnen. Ein partielles Budgetrecht steht ihm gem. Art. 272 Abs. 6 EGV über die nicht obligatorischen Ausgaben zu. 866

Die Entscheidung durch den Rat schließlich wird je nach Rechtsgebiet mit einfacher oder qualifizierter Mehrheit oder einstimmig getroffen.

${ }^{862}$ Lenaerts, Some Reflections on the Separation of Powers in the European Community, CMLR 1991, 11 (16).

863 Vgl. für das Europäische Parlament Art. 93, 94, 308 EGV, für den EuRH Art. 279, 280 Abs. 4 EGV.

864 Oben: III. 2. a); Zur Einstufung der ordnungsgemäßen Anhörung des Parlaments als zwingende Verfahrensvorschriften: EuGH, Rs. 138/79, Slg. 1980, 3333, Rn. 33 (Roquette Frères/Rat); Rs. 139/79, Slg. 1980, 3393, Rn. 33 ff. (Maizena/Rat); Rs. C-417/93; Slg. 1995, I-0000, Rn. 9 (Parlament/Rat); Rs. C- 21/94, Slg. 1995, I-1827, Rn. 17 (Parlament/Rat).

865 Streinz, in: Streinz, EUV/EGV, Art. 7 EGV, Rn. 19; Dann, The Political Institutions, in: v.Bogdandy/Bast, Principles of European Constitutional Law, 2006, S. 229 (252); siehe auch Fn. 863.

866 Vgl. zur Entwicklung: Huber, Das institutionelle Gleichgewicht zwischen Rat und Europäischem Parlament in der künftigen Verfassung für Europa, EuR 2003, 581 ff. 
In sehr beschränktem Umfang hat auch die Kommission Rechtssetzungskompetenzen (vgl. etwa Art. 86 Abs. 3 EGV), ${ }^{867}$ wobei ihr diese weniger durch Primärrecht, sondern in erster Linie durch sekundärrechtliche Ermächtigung zugewiesen werden. ${ }^{868}$

Die Regelung nach dem Vertrag von Lissabon macht schon in Art. 289 AEUV das gemeinsame Tätigwerden von Rat und Parlament deutlich: Nach Abs. 1 soll der Regelfall im ordentlichen Gesetzgebungsverfahren nach Art. 294 AEUV die gemeinsame Annahme von Rechtsakten durch Parlament und Rat auf Vorschlag der Kommission sein, wie es auch schon der gescheiterte Verfassungsvertrag in Art. I-34 i.V.m. III-396 vorsah ${ }^{869}$. Als zweiten Fall sieht Art. 289 AEUV das besondere Gesetzgebungsverfahren in den bestimmten, in den Verträgen vorgesehenen Fällen vor. Danach erfolgt die Annahme des Rechtsaktes durch das Parlament mit Beteiligung des Rates oder umgekehrt durch den Rat mit Beteiligung des Europäischen Parlaments.

\section{bb) Parlamentarische Kontrollfunktion}

Neben den Beteiligungsformen bei der Rechtssetzung kommen dem Europäischen Parlament Kontrollrechte gegenüber der Kommission zu. Diese spiegeln sich insbesondere im in Art. 276 EGV (Art. 319 AEUV) geregelten Verfahren zur Entlastung der Kommission wider, die auf Grundlage der Berichte des Europäischen Rechnungshofes erfolgt. Das Parlament kann ferner gem. Art. 193 EGV (Art. 226 AEUV) Untersuchungsausschüsse einsetzen, um Verstöße gegen das Gemeinschaftsrecht oder Missstände bei seiner Anwendung durch andere Organe oder Institutionen zu prüfen. An dieser Stelle sind die Rechte des Parlaments durch den Vertrag von Lissabon gestärkt worden, als dieses gem. Art. 226 UAbs. 3 AEUV die Einzelheiten des Untersuchungsrechts nunmehr aus eigener Initiative durch Verordnung festlegt, wobei Rat und Kommission lediglich zuzustimmen haben. Als ultima ratio kann es gem. Art. 201 EGV (Art. 234 AEUV) einen Misstrauensantrag gegen die Kommission anstrengen, der zu deren Amtsniederlegung führt. Diese Rechte zeigen deutlich Parallelen zu herkömmlichen nationalstaatlichen Ausprägungen parlamentarischer Kontrollrechte gegenüber den Regierungen als Hauptorganen der Exekutive. ${ }^{870}$

${ }^{867}$ De Witte, The institutional balance in the EU: Is there a need for a new horizontal division of powers?, in: Herzog/Hobe, Die Europäische Union auf dem Weg zum verfassten Staatenverbund, 2004, S. 59; Ausführlich: Strein₹, Europarecht, 2005, Rn. 521 ff.; hierzu schon Petrold, Die Gewaltenteilung in den EG, 1966, S. 149 ff.

868 Vgl. die Ermächtigung zur Einräumung von Durchführungsbefugnissen durch den Rat nach Art. 202 Spgstr. 3 EGV; Vgl. auch die Regelungen des Verfassungsvertrages Art. I-35 Abs. 2, 1. Hs.; Art. I-36, I-37 VerfEU.

869 Ausführlich: Schoo, Das institutionelle System aus der Sicht des EP, in: Schwarze, Der Verfassungsentwurf des Europäischen Konvents, 2004, S. 65 ff.

$870 \mathrm{Ott}$, Kontrollfunktionen des Europäischen Parlaments gegenüber der Europäischen Kommission, ZeuS 1999, 232 (237). 
cc) Exekutive Funktion durch Kommission und Rat

Die Europäische Gemeinschaft ist in ihrem Verwaltungsaufbau größtenteils dezentral angelegt, so dass der Vollzug von Gemeinschaftsrecht meist den Verwaltungsstellen der einzelnen Mitgliedstaaten obliegt. ${ }^{871}$

In den Bereichen, in denen Gemeinschaftsnormen von der Europäischen Gemeinschaft selbst unmittelbar ausgeführt werden, ist es in erster Linie die Kommission aber auch der Rat und die von diesen geschaffenen Stellen, die diese Aufgabe übernehmen (vgl. etwa Art. 211, Art. 88 Abs. 2 EGV). ${ }^{872}$

dd) Gerichtliche Kontrollfunktion

Eine den üblichen nationalstaatlichen Ausprägungen vergleichbare gerichtliche Kontrollfunktion nehmen der Europäische Gerichtshof und das Gericht erster Instanz wahr. Ausgangspunkt ist Art. 220 Abs. 1 EGV (Art. 19 EUV n.F.), wonach sie ,im Rahmen ihrer Zuständigkeiten die Wahrung des Rechts bei Auslegung und Anwendung dieses Vertrages sichern“". Art. 230 Abs. 1 EGV (Art. 263 AEUV) bestimmt, dass dem EuGH die Überwachung der Rechtmäßigkeit der Handlungen der Organe Europäisches Parlament, Rat und Kommission obliegt.

Damit lassen sich EuGH und EuG als unabhängige Rechtsprechungsorgane der Judikative im Sinne des herkömmlichen Gewaltenteilungsmodells einordnen. 873

\section{ee) Finanzkontrollfunktion}

Eine besondere Rolle verglichen mit dem herkömmlichen nationalstaatlichen Modell nimmt der Europäische Rechnungshof dadurch ein, dass er nicht nur unabhängig ist, sondern auch den Status eines Organs hat. Er steht auf selber Höhe neben den anderen Organen, die im Gegensatz zu ihm ausnahmslos mit Entscheidungsbefugnissen ausgestattet sind. Ihm kommen vertraglich verbürgte und justitiable, sehr weitgehende Prüfungsrechte gegenüber den anderen Organen und Einrichtungen zu, die mit Informations- und Zugangsrechten einhergehen. Hervorzuheben ist weiter, dass der Rechnungshof eigeninitiativ tätig wird. Die Kontrollfunktion, die er wahrnimmt, lässt sich unter keine der aufgeführten Funktionsgruppen ordnen, sondern steht als originär rechnungshoftypische neben diesen.

871 Oben: II. 3. b).

872 Horn, Über den Grundsatz der Gewaltenteilung in Deutschland und Europa, JöR 2001, 287 (297); Lenaerts, Some Reflections on the Separation of Powers in the European Community, CMLR 1991, 11 (17 f., 30 ff.); zum Ganzen Möllers, Gewaltengliederung, 2005, S. 270 ff., 286 f.

873 Hailbronner, Das institutionelle System der EG, JuS 1990, 263; Arndt, Europarecht, 2006, S. 42 f.; Oppermann, Europarecht, 2005, S. 81, Rn. 10; Läufer, Die Organe der EG, 1990, S. 216: „Einzig die Stellung des Gerichtshofes weist deutlichere staatstypische Anlehnungen auf"; Möllers, Gewaltengliederung, 2005, S. 260 ff., 285; Hofmann, Rechtsstaatsprinzip und Europäisches Gemeinschaftsrecht, in: H/M/M/W, Rechtsstaatlichkeit in Europa, 1996, S. 326. 
ff) Geteilte Kompetenzen bei der Organbesetzung

Für die Besetzung von Kommission, Europäischem Gerichtshof und Europäischem Rechnungshof sieht der Vertrag unterschiedliche Formen des Zusammenwirkens von Mitgliedstaaten, Rat und Parlament vor. Das Übergewicht liegt dabei beim Rat, wobei sich durch den Vertrag von Lissabon eine Tendenz zur weiteren Verschiebung zugunsten des Europäischen Parlaments zeigt, indem er ihm die Wahl des Kommissionspräsidenten gem. Art. 17 Abs. 7 UAbs. 1 EUV n.F. nach Vorschlag durch den Europäischen Rat zuweist. Entsprechendes sah auch der Verfassungsvertrag in Art. I-27 Abs. 1 vor.

gg) Zwischenergebnis

Eine Unterteilung nach dem „klassischen Gewaltenteilungsmodell“ in Legislative, Exekutive und Judikative ist auf Gemeinschaftsebene so nicht vorhanden. Eine solche ist jedoch in Reinform auch auf staatlicher Ebene kaum zu finden, vielmehr ist das Prinzip der Gewaltenteilung vielfältiger Ausgestaltung zugänglich. Der Hauptunterschied zwischen der Ausprägung in der Europäischen Gemeinschaft und der in einem demokratischen Rechtsstaat liegt darin, dass bei letzterem das Parlament das prinzipielle Legislativorgan ist, 874 auf Gemeinschaftsebene ist es hingegen nach wie vor der Rat. Jedoch ist auch dort das Normsetzungsverfahren, besonders stark im Rahmen des Mitentscheidungsverfahrens nach Art. 251 EGV, von einem System des Zusammenwirkens mehrerer Organe geprägt, die Stellung des Parlaments hat hier eine sukzessive Stärkung erfahren. Seine gewachsene Bedeutung spiegelt sich auch in den weitreichenden Kompetenzen im Haushaltsverfahren wider, vom Ablehnungsrecht des Haushaltsplanentwurfs bis hin zum „letzten Wort" bei der Entlastung der Kommission. Vor diesem Hintergrund scheint es nicht übertrieben, bereits jetzt von einer beinahe „flächendeckenden negativen demokratischen Kompetenz" 875 des Europäischen Parlaments zu sprechen.Exekutive Funktionen nehmen Kommission und Rat wahr. Einzig die Rechtsprechungsfunktion, die EuGH und $\mathrm{EuG}$ ausüben, ist vergleichbar mit der auf nationalstaatlicher Ebene. Dabei ist festzuhalten, dass gerade das Bestehen einer unabhängigen Judikative das zentrale Element des Prinzips der Gewaltenteilung darstellt, ${ }^{876}$ macht sie doch die Handlungen der Funktionsträger erst justitiabel und bildet damit die Grundvoraussetzung seiner Effektivität.

Der EGV sieht also die Ausübung der auf die Gemeinschaft übertragenen Staatsgewalt durch unterschiedliche Funktionsträger vor, die in der Regel nach verschiedenen Verfahren der Zusammenarbeit rechtsverbindliche Entscheidungen treffen. Die typisch gemeinschaftsrechtliche Ausprägung ist vor dem Hintergrund

\footnotetext{
${ }^{874}$ Hofmann, Rechtsstaatsprinzip und Europäische Gemeinschaftsrecht, in: H/M/M/W, Rechtsstaatlichkeit in Europa, 1996, S. 326.

875 Huber, Das institutionelle Gleichgewicht zwischen Rat und Europäischem Parlament in der künftigen Verfassung für Europa, EuR 2003574 (581).

876 Saladin, Wozu noch Staaten?, 1995, S. 176.
} 
zu sehen, dass die Funktionenteilung nicht nur der rechtsstaatlichen Notwendigkeit Sorge tragen muss, die Staatsgewalt durch ein System der checks and balances zu mäßigen, sondern auch zu einem Ausgleich zwischen Gemeinschaftsinteressen und mitgliedstaatlichen Interessen führen muss. ${ }^{877}$ Entscheidend für die Organisationsstruktur der EG ist somit die Tatsache, dass sich einzelne Funktionen nicht unter der Zuständigkeit eines einzelnen Gemeinschaftsorgans konzentrieren, sondern in einem System der Funktionenteilung von verschiedenen Organen ausgeübt werden, ${ }^{878}$ die auf Zusammenwirken angewiesen sind und so ein System der checks and balances bilden.

Eine gemeinschaftsrechtliche Besonderheit ist die Tatsache, dass der Rechnungshof denselben Status besitzt wie die an der gemeinschaftlichen Gewaltausübung beteiligten Organe.

Der Vertrag von Lissabon hat dieses System nicht grundlegend geändert, er führte jedoch wie dargestellt zu einer Gewichtsverschiebung zugunsten des Europäischen Parlaments.

Das gemeinschaftliche System der Funktionenteilung ist vom EuGH als institutionelles Gleichgewicht umschrieben worden, den Terminus Gewaltenteilung benutzt er nicht.

\section{b) Das Prinzip des institutionellen Gleichgewichts}

aa) Die Rechtsprechung des Europäischen Gerichtshofs

In den Meroni-Entscheidungen ${ }^{879}$ aus dem Jahr 1958 hat der EuGH den Grundstein für seinen seitdem in ständiger Rechtsprechung ${ }^{880}$ bestätigten Begriff des „,institutionellen Gleichgewichts“ gelegt. Diesen hat er aus dem System der vertraglichen Zuständigkeitsverteilung zwischen den Organen ${ }^{881}$ (Art. 7 Abs. 1 EGV (Art. 13 Abs. 2 EUV n.F.) in Verbindung mit den an verschiedenen Stellen des Vertrages geregelten speziellen Kompetenzzuweisungen an die einzelnen Organe) als „,normatives, justitiables Gestaltungsprinzip“ 882 entwickelt. Inhaltlich besagt die Rechtsfigur des institutionellen Gleichgewichts, dass es ein vertraglich austariertes institutionelles Zuständigkeitssystem gibt, innerhalb dessen jedem Organ ein besonderer Auftrag zukommt, verbunden mit den zu dessen Erfüllung notwendigen Kompetenzen. ${ }^{883}$ Folge ist vor allem, dass ,jedes Organ seine Befugnisse unter

\footnotetext{
877 Calliess, in: Calliess/Ruffert, EUV/EGV, Art. 7 EGV, Rn. 7; Streinz, in: Streinz, EUV/EGV, Art 7 EGV, Rn. 19.

878 Constantinesco, Das Recht der Europäischen Gemeinschaften, Bd. I, 1977, S. 359 f.

${ }^{879}$ EuGH, Rs. 9/56, Slg. 1958, 9 (36 ff., 44) (Meroni I); Rs. 10/56, Slg. 1958, 51 (75 ff., 82) (Meroni II).

${ }^{880}$ EuGH, Rs. 138/79, Slg. 1980, 3333, Rn. 33 (Roquette Fréres/Rat); Rs. C-70/88, Slg. 1990, I2041, Rn. 20 ff. (Parlament/Rat); Rs. C-21/94, Slg. 1995, I-1827, Rn. 17 (Parlament/Rat).

${ }^{881}$ EuGH, Rs. C-70/88, Slg. 1990, I-2041, Rn. 21 ff. (Parlament/Rat).

882 Calliess, in: Calliess/Ruffert, EUV/EGV, Art. 7 EGV, Rn. 8.

883 Vgl. nur EuGH, Rs. C-70/88, Slg. 1990, I-2041, Leitsatz 1, Rn. 21 ff. (Parlament/Rat).
} 
Beachtung der Befugnisse der anderen Organe ausübt“", wobei besonders die Justitiabilität eventueller Verstöße gegen diesen Grundsatz bedeutsam ist, was im Rahmen der „Wahrung des Rechts bei der Auslegung und Anwendung des EGV“ gem. Art. 220 Abs. 1 EGV (Art. 19 Abs. 1 EUV n.F.) dem EuGH zukommt. ${ }^{884}$

Praktischer Anwendungsbereich des institutionellen Gleichgewichts ist die Beurteilung der Übertragung von Befugnissen auf andere als in den Verträgen vorgesehene Einrichtungen ${ }^{885}$ sowie die Achtung der vertraglichen Befugnisse eines Organs durch die anderen, etwa die wirksame Beteiligung des Europäischen Parlaments am gemeinschaftlichen Normsetzungsverfahren ${ }^{886}$ oder Anhörungs- und Stellungnahmeerfordernisse des Europäischen Rechnungshofes als zwingende Verfahrensvorschriften.

\section{bb) Der Meinungsstand im Schrifttum}

Ein Teil der Literatur lehnt die vom EuGH entwickelte Figur des institutionellen Gleichgewichts ab. ${ }^{887}$

So hält Hummer sie für nicht aussagekräftig und bestreitet ihre Normativität, weil sie ein bloßer „faktischer Reflex der jeweils geltenden Kompetenzverteilung“ sei. 888

Hieran anknüpfend zweifelt Läufer den normativen Charakter und die Justitiabilität des institutionellen Gleichgewichts aufgrund seines ,geringen objektiven Aussagewertes wegen sich ständig neu stabilisierender Interorganverhältnisse“ an, auch fehle es an einer schlüssigen Herleitung. ${ }^{889}$ Ferner kaschiere der Begriff die tatsächlich bestehenden Ungleichgewichte zwischen den Organen, insbesondere die ,mangelnde Parlamentarisierung der Entscheidungsverfahren und die unzureichende demokratische Legitimation von Gemeinschaftsbeschlüssen. "890

\footnotetext{
${ }^{884}$ EuGH, Rs. C-70/88, Slg. 1990, I-2041, Leitsatz 1, Rn. 21 ff. (Parlament/Rat).

885 Vgl. schon EuGH, Rs. 9/56, Slg. 1958, 9 (36 ff., 44) (Meroni I): „Die Übertragung von Befugnissen mit Ermessensspielraum auf andere Einrichtungen als solche, die im Vertrag zur Ausübung und Kontrolle dieser Befugnisse im Rahmen ihrer jeweiligen Zuständigkeiten vorgesehen sind, würde diese Garantie verletzen.“

${ }^{886}$ EuGH, Rs. C-417/93; Slg. 1995, I-0000, Rn. 9 (Parlament/Rat); Rs. C- 21/94, Slg. 1995, I-1827, Rn. 17 (Parlament/Rat).

887 Hummer, Das „Institutionelle Gleichgewicht“ als Strukturdeterminante der Europäischen Gemeinschaften, in: FS Verdross, 1980, S. 459 (483 ff.); Läufer, Die Organe der EG, 1990, S. 221 f. m.w.N.; Bieber, The Settlement of Institutional Conflicts on the Basis of Art. 4 of the EEC Treaty, CMLR 1984, S. 505 (509); vgl. die zahlreichen Nachweise bei Calliess, in: Calliess/Ruffert, EUV/EGV, Art. 7 EGV, Rn. 11.

888 Hummer, Das „Institutionelle Gleichgewicht“ als Strukturdeterminante der Europäischen Gemeinschaften, in: FS Verdross, 1980, S. 459 (483 ff.).

889 Läufer, Die Organe der EG, 1990, S. 220 f.; ebenso: Bieber, The Settlement of Institutional Conflicts on the Basis of Art. 4 of the EEC Treaty, CMLR 1984, S. 505 (509).

${ }^{890}$ Läufer, Die Organe der EG, 1990, S. 221 f.; so auch Kutscher, Über den Gerichtshof der EG, EuR 1981, 392 (410): „Angesichts der Machtfülle des Rats...kann nicht von einem institutionellen Gleichgewicht gesprochen werden“.
} 
Die Gegenansicht ${ }^{891}$ folgt dem EuGH und wendet das institutionelle Gleichgewicht als normatives und justitiables Prinzip ${ }^{892}$ für die Beurteilung der RechtmäBigkeit des Handelns der Organe sowie von Kompetenzverschiebungen zwischen ihnen an. Hiernach ist diese Rechtsfigur eine dem Gemeinschaftsrechtssystem angemessene Entsprechung des nationalstaatlich geprägten Gewaltenteilungsgrundsatzes. 893

cc) Stellungnahme

Die Hauptkritikpunkte am institutionellen Gleichgewicht sind seine unklare Herleitung und die einseitige Machtverteilung zugunsten des Rates einhergehend mit dem Defizit an demokratischer Legitimation als Folge der mangelnden Parlamentarisierung. Dazu kommt die Auffassung, es handele sich um eine bloße „Momentaufnahme“ in Form eines „faktischen Reflexes“ der jeweils gerade geltenden und sich ständig verändernden Interorganverhältnisse, weshalb seine Normativität und Justitiabilität teilweise bestritten werden.

Auf den Einwand der unklaren Herleitung ist zu erwidern, dass als vertragliche Grundlage Art. 7 Abs. 1 EGV (Art. 13 Abs. 2 EUV n.F.) beziehungsweise seine Vorgängernormen (vgl. Art. 4 Abs. 1 EWG-Vertrag) in Zusammenschau mit den speziellen Handlungsermächtigungen an die einzelnen Organe, die an verschiedenen Stellen des EGV zu finden sind, herhalten können. ${ }^{894}$ Ein Hinweis auf diese Erwägung findet sich schon in der ersten Meroni-Entscheidung. ${ }^{895}$ Die Art. 4 Abs. 1 EWG-Vertrag entsprechende Regelung findet sich heute in Art. 7 Abs. 1 EGV, wonach ,jedes Organ nach Maßgabe der ihm im Vertrag zugewiesenen Befugnisse handelt", die sich wiederum aus den an verschiedenen Stellen im Vertrag enthaltenen speziellen Kompetenzzuweisungen an die einzelnen Organe ergeben.

891 Borchardt, Die rechtlichen Grundlagen der EU, 2002, S. 57; Oppermann, Europarecht, 2005, S. 81; De Witte, The institutional balance in the EU: Is there a need for a new horizontal division of powers?, in: Herzog/Hobe, Die Europäische Union auf dem Weg zum verfassten Staatenverbund, 2004, S. 57 ff.; Hilf, Die Organisationsstruktur der EG, 1982, S. 312; Horn, Über den Grundsatz der Gewaltenteilung in Deutschland und Europa, JöR 2001, 287 (297 f.); Huber, Das institutionelle Gleichgewicht zwischen Rat und EP in der künftigen Verfassung für Europa, Europarecht 2003, 574 (576); Streinz, in: Streinz, EUV/EGV, Art. 7 EGV, Rn. 3, 14, 20 ff.; Calliess, in: Calliess/Ruffert, EUV/EGV, Art. 7 EGV, Rn. 12 m.w.N.

892 Calliess, in: Calliess/Ruffert, EUV/EGV, Art. 7 EGV, Rn.8;

893 Vgl. nur: Calliess, in: Calliess/Ruffert, EUV/EGV, Art. 7 EGV, Rn.15; Hofmann, Rechtsstaatsprinzip und Europäisches Gemeinschaftsrecht, in: H/M/M/W, Rechtsstaatlichkeit in Europa, 1996, S. 3265 ff.; Streinz, in: Streinz, EUV/EGV, Art. 7 EGV, Rn. 3.

${ }^{894}$ Calliess, in: Calliess/Ruffert, EUV/EGV, Art. 7 EGV, Rn.14.

${ }^{895} \mathrm{EuGH}$, Rs. 9/56, Slg. 1958, 9 (44) (Meroni I): „Die in Art. 3 des Vertrages aufgezählten Ziele gelten ... allgemein für die Organe der Gemeinschaft...im Rahmen der jedem von ihnen zugewiesenen Befugnisse (vgl. Art. 4 Abs. 1 EWG-Vertrag) und im gemeinsamen Interesse. Aus dieser Bestimmung ist zu schließen, dass das für den organisatorischen Aufbau der Gemeinschaft kennzeichnende Gleichgewicht der Gewalten eine grundlegende Garantie darstellt...". 
Als zweiter Ansatzpunkt der Kritik dient die „einseitige Machtverteilung“ zugunsten des Rates, die zu einer allenfalls beschränkten Aussagekraft des Begriffes des institutionellen Gleichgewichts führe, der als solcher die Realitäten nicht widerspiegele.

In Anbetracht der jetzigen Ausgestaltung des institutionellen Systems ist vor allem zu bemerken, dass das Prinzip der Gewaltenteilung in seiner jeweiligen Form kein eherner Grundsatz ist, sondern sehr unterschiedlichen Interpretationen zugänglich ist. Was das vom EuGH als institutionelles Gleichgewicht umschriebene System der checks and balances angeht, ist tatsächlich der deutlichste Unterschied zu den üblichen nationalstaatlichen Ausprägungen, dass nicht das gewählte Parlament das Hauptorgan der Legislative ist, sondern der Rat. Der Kritik kann jedoch entgegengehalten werden, dass erstens die Europäische Union kein Staat ist, insbesondere über keine Kompetenz-Kompetenz verfügt, was die Gefahr des Machtmissbrauchs verringert und dass zweitens auch der Rat als ihr prinzipielles Legislativorgan durch die Volksvertretungen der Mitgliedstaaten demokratisch legitimiert ist ${ }^{896}$. Es gibt also zwei demokratische Legitimationsstränge, einerseits den direkten über das unmittelbar gewählte Europäische Parlament, andererseits den durch die Volksvertretungen der Mitgliedstaaten an den Rat vermittelten. ${ }^{897}$ Im Rat werden Entscheidungen durch Vertreter der Mitgliedstaaten getroffen, die bei ihrer Entscheidungsfindung dem rechtsstaatlichen Verfahren des jeweiligen Mitgliedstaates unterliegen.

Die Europäische Union ist zum gegenwärtigen Zeitpunkt kein Bundesstaat, sondern ein Staaten- und Verfassungsverbund ${ }^{898}$. Auf gemeinschaftlicher Ebene wird zwar von den Mitgliedstaaten übertragene Staatsgewalt ausgeübt, 899 aber es besteht keine Kompetenz-Kompetenz ${ }^{900}$. Die Notwendigkeit der machtbegrenzenden Funktion der Gewaltenteilung ist auch hier durch die Ausübung von Staatsgewalt gegeben, jedoch nur in eingeschränktem Maße; ebenso wie die Ausübung von Staatsgewalt auf europäischer Ebene eingeschränkt ist, ist es spiegelbildlich auch die Notwendigkeit ihrer Begrenzung durch Gewaltenteilung. Mit anderen Worten steht das Ausmaß der erforderlichen Funktionentrennung in direkter Beziehung zum Ausmaß an übertragener hoheitlicher Gewalt.901 Außer-

896 BVerfGE 89, 155 (182 ff., 185 f.); Huber, Das institutionelle Gleichgewicht zwischen Rat und Europäischem Parlament in der zukünftigen Verfassung für Europa, EuR 2003, 574 (577, 594 f.); Streinz, in: Streinz, EUV/EGV, Art. 7 EGV, Rn. 19 m.w.N.

${ }^{897}$ Huber, Das institutionelle Gleichgewicht zwischen Rat und Europäischem Parlament in der künftigen Verfassung für Europa, EuR 2003, 574 (595); vgl. auch Schoo, Das institutionelle System aus der Sicht des EP, in: Schwarze, Der Verfassungsentwurf des Europäischen Konvents, 2004, S. 64.

898 Unten: V. 1. a).

${ }^{899}$ BVerfGE 22, 293 (295 f.).

900 Hilf, Die Organisationsstruktur der EG, 1982, S. 310 f. m.w.N.

901 Acbterberg, Rezension: Petzold, Herbert, Die Gewaltenteilung in den Europäischen Gemeinschaften, EuR 1968, 240 (241). 
dem muss ein Ausgleich zwischen den Interessen der Mitgliedstaaten und dem Gemeinschaftsinteresse gefunden werden, was durch das starke Gewicht des Rates, dem insofern eine Mittlerstellung zukommt, deutlich wird. ${ }^{902}$ Die Spiegelbildlichkeit einerseits der beschränkten Kompetenz und andererseits der dadurch bedingt nur beschränkt notwendigen Gewaltenteilung wird besonders bei der zunehmenden Übertragung mitgliedstaatlicher Kompetenzen auf die Gemeinschaft deutlich: Jede Vertragsänderung, die einen Kompetenzzuwachs mit sich brachte, verstärkte auch die „europäische Funktionenteilung“, namentlich durch die Erweiterung der Mitwirkungsrechte des Europäischen Parlaments am Normsetzungsverfahren. ${ }^{903}$ Diese Fortschritte waren der direkten demokratischen Legitimierung geschuldet und brachten gleichzeitig eine Verbesserung der Mechanismen zur gegenseitigen Kontrolle der europäischen Institutionen mit sich. Zugleich darf aber nicht aus den Augen verloren werden, dass der vielfach propagierten Stärkung des Europäischen Parlaments durch die mitgliedstaatlichen Verfassungen Grenzen gesetzt sind, bedeutet sie doch im Gegenschluss eine Schwächung der nationalen Parlamente hinsichtlich ihrer Mitwirkung an der gemeinschaftlichen Gewaltausübung. 904

Als entscheidend für die Bewertung muss vielmehr betrachtet werden, ob auf europäischer Ebene eine den Besonderheiten des Staaten- und Verfassungsverbundes in seiner jeweiligen Integrationsphase angemessene Verwirklichung der Ziele der Gewaltenteilung, namentlich der Machtbegrenzung und der Rationalisierung staatlichen beziehungsweise gemeinschaftlichen Handelns, erreicht wird. ${ }^{905}$ Das Prinzip der Gewaltenteilung muss von seiner Zielrichtung her betrachtet werden: der Begrenzung staatlicher Macht und damit der Wahrung der Freiheit des Bürgers durch das Gleichgewicht verschiedener Funktionsträger einerseits und der Steigerung staatlicher Entscheidungen zu möglichst großer Richtigkeit andererseits. ${ }^{906}$ Hiervon ausgehend ist es ,„jeder Zeit aufgegeben, die ihrer Situation und ihren Problemen angemessene Verteilungsform zu finden" ${ }^{9}{ }^{907}$ Es lassen sich

902 Huber, Das institutionelle Gleichgewicht zwischen Rat und Europäischem Parlament in der künftigen Verfassung für Europa, EuR 2003, 574 (595).

903 Dann, The Political Institutions, in: v.Bogdandy/Bast, Principles of European Constitutional Law, 2006, S. 229 (245) m.w.N.: „In an almost revolutionary development, the EP has developed from a mere consultant assembly into an equal counterpart to council and commission."; Zu diesem Prozess bejahend auch Läufer, Die Organe der EG, 1990, S. 225 m.w.N.

904 Huber, Europäisches und nationales Verfassungsrecht, VVDStRL 60 (2001), S. 194 (236 f.); in der Maastricht-Entscheidung betonte auch das Bundesverfassungsgericht, dass es „zuvörderst die Staatsvölker der Mitgliedstaaten sind, die die Ausübung von Hoheitsgewalt durch den Staatenverbund über die nationalen Parlamente demokratisch zu legitimieren haben“, vgl. BVerfGE 89, 155 (184, 187); zum Nebeneinander der verschiedenen Legitimationsstränge auch Möllers, Gewaltengliederung, 2005, S. 255 f., 286.

905 In diese Richtung schon Constantinesco, Das Recht der Europäischen Gemeinschaften, Bd. I, 1977, S. $3361 \mathrm{f}$.

906 Sommermann, in: v.Mangoldt/Klein/Starck, GG, Art. 20, Rn. 198, 203 f.

907 v.Arnim, Staatslehre, 1984, S. 500 m.w.N. 
sehr unterschiedliche Strukturen und Organisationsformen mit dem Prinzip der Gewaltenteilung begründen, ihr Ziel, staatliche Macht zu begrenzen, kann mithin auf sehr unterschiedlichen Wegen verfolgt werden. ${ }^{908}$

Wie festgestellt findet durch die Verträge eine Verteilung von Funktionen an verschiedene Funktionsträger statt. Parlament, Rat und Kommission üben nach von Verschränkungen und Zusammenarbeit geprägten Verfahren Funktionen aus, die nach herkömmlichen Kriterien der rechtssetzenden und vollziehenden Gewalt zuzuordnen sind. Auch der Rechnungshof ist, wenn auch nur beschränkt, insbesondere durch Anhörungs- und Stellungnahmeerfordernisse, in einen Teil dieser Verfahren eingebunden. Sie sind einer effektiven Rechtmäßigkeitskontrolle durch den Gerichtshof unterstellt, die Machtkonzentration und willkürliche Ausübung der Funktionen zu verhindern vermag. ${ }^{909}$ Richtig ist, dass der Rat ein Übergewicht bei der gemeinschaftlichen Gewaltausübung hat und insofern das zentrale Organ $^{910}$ in der institutionellen Struktur ist. Jedoch ist allein deswegen der Begriff des „Gleichgewichts“ oder der „Balance“ nicht zu beanstanden; schließlich sind auch auf nationaler Ebene je nach Ausgestaltung gewisse Asymmetrien vorhanden, in der Form, dass die Parlamente als Legislativorgane ein besonders starkes Gewicht haben und den Rahmen festlegen, in dem die anderen Gewaltträger handeln dürfen. Vor diesem Hintergrund liegt nie ein vollkommenes Gleichgewicht im wörtlichen Sinne vor.

Als Bewertungskriterium entscheidend ist vielmehr der Schutz bestimmter Kernbereiche eines Funktionsträgers vor dem Eingriff eines anderen, der auch justitiabel sein muss. ${ }^{911}$ Genau das ist eine Grundaussage der klassischen Gewaltenteilung wie auch des institutionellen Gleichgewichts: Die den Organen zugewiesenen Kernbereiche sind durch die anderen Organe unantastbar, die Beachtung dieses Grundsatzes unterliegt der Kontrolle durch den Europäischen Gerichtshof.

Teilweise wird angesichts der Ausprägung des institutionellen Gleichgewichts als Funktionsverteilung auf die verschiedenen Organe sogar die Ansicht vertreten, dass die Europäische Union das Ziel der Gewaltenteilung durch das institutionelle Gleichgewicht besser erreiche als viele Mitgliedstaaten, bei denen faktisch ein zu starkes Übergewicht der Regierung bestehe. ${ }^{912}$ Dies dürfte wohl vor dem Hintergrund der Bedeutung der Parteien in vielen mitgliedstaatlichen Rechtsordnungen

\footnotetext{
908 Saladin, Wozu noch Staaten?, 1995, S. 177.

909 Constantinesco, Das Recht der europäischen Gemeinschaften, Bd. I, 1977, S. 360 f.

910 Huber, Das institutionelle Gleichgewicht zwischen Rat und Europäischem Parlament in der künftigen Verfassung für Europa, EuR 2003, 574 (577).

911 Hofmann, Die Bindung staatlicher Macht, in: H/M/M/W, Rechtsstaatlichkeit in Europa, 1996, S. 3 (11); für das institutionelle Gleichgewicht: EuGH Rs. C-70/88, Slg. 1990, I-2041, Rn. 22 f. (Parlament/Rat).

912 De Witte, The institutional balance in the EU: Is there a need for a new horizontal division of powers?, in: Herzog/Hobe, Die Europäische Union auf dem Weg zum verfassten Staatenverbund, 2004, S. 57 (63 f.).
} 
zu sehen sein, die zu einem eklatanten Pluralismusverlust geführt hat. Gesetze werden letztlich von der Regierung, die sich auf die Parlamentsmehrheit stützt, gemacht; eine Kontrolle im Sinne des Ablehnens oder auch nur der kritischen Distanz zur Regierung tritt neben dem Ziel des Machterhalts in den Hintergrund. Begünstigt wird dies durch das systemwidrige Fehlen von Regelungen zur persönlichen Unvereinbarkeit der Stellung als Abgeordneter und gleichzeitig als Regierungsmitglied.

Vor diesem Hintergrund scheint das System der checks and balances auf europäischer Ebene durchaus wirkungsvoll und angemessen. Ein Pluralismusdefizit ist hier keinesfalls zu beklagen, dafür sorgen bereits die unterschiedlichen Interessen zwischen Mitgliedstaaten und Gemeinschaft, die sich jeweils intraorganisch, hauptsächlich innerhalb des Rates, auswirken, ebenso wie die zu interorganischem Pluralismus führenden Funktionenverteilungen auf die Organe. Hinzu kommt das Fehlen einer europäischen Parteienlandschaft, die in ihrer Homogenität der nationalstaatlichen vergleichbar wäre.

Schließlich bleibt zu erörtern, ob das institutionelle Gleichgewicht tatsächlich nur eine „Momentaufnahme“ in Form eines „faktischen Reflexes“ der jeweils gerade geltenden und sich ständig verändernden Interorganverhältnisse ist. Zunächst ist es richtig, dass Rechte und Pflichten der Organe und damit das institutionelle Gleichgewicht in verschiedenen Integrationsphasen unterschiedlich ausgeprägt waren. ${ }^{913}$ Jedoch ist die Ausgestaltung nicht beliebig und ohne weiteres grundlegend zu verändern: Zum einen bedürfte es einer von allen Mitgliedstaaten zu ratifizierenden (vgl. Art 48 EUV a.F.) Vertragsänderung, zum anderen setzt die Festlegung der Europäischen Union auf die Basis der Grundsätze der Rechtsstaatlichkeit und Demokratie in Art. 6 Abs. 1 EUV a.F. dem enge Grenzen, so dass ein Schritt weg von der zumindest ansatzweise verwirklichten Gewalteneilung in Form der Funktionenteilung als eines zentralen Prinzips formeller Rechtsstaatlichkeit ${ }^{914}$ kaum denkbar erscheint. Allenfalls eine Bewegung in die andere Richtung, namentlich der Parlamentarisierung, im Rahmen fortschreitender Demokratisierung und gleichzeitiger Entwicklung hin zu einer „echten“ Gewaltenteilung scheint vor diesem Hintergrund möglich.

Als nichts anderes als „faktische Reflexe“ wären dann aber auch die Gewaltenteilungsmodelle in ihren jeweiligen nationalstaatlichen Ausprägungen zu sehen, die ebenfalls die gerade geltende Kompetenzverteilung widerspiegeln.

Im Ergebnis kann mit guten Gründen davon gesprochen werden, dass die Europäische Gemeinschaft grundsätzlich gewaltenteilig-demokratisch angelegt ist. ${ }^{915}$ Durch das als institutionelles Gleichgewicht umschriebene System der Zuständig-

\footnotetext{
913 Möllers, Gewaltentgliederung, 2005, S. 254.

914 Zum Prinzip des institutionellen Gleichgewichts als Einzelgehalt der Rechtsstaatlichkeit auf europäischer Ebene: Calliess, in: Calliess/Ruffert, EUV/EGV, Art. 6 EUV, Rn. 19 ff., 23.

915 Calliess, in: Calliess/Ruffert, EUV/EGV, Art. 7 EGV, Rn. 15; Huber, Europäisches und nationales Verfassungsrecht, VVDStRL 60 (2001), S. 194 (197).
} 
keitsverteilung wird der Zweck der Gewaltenteilung, die Mäßigung staatlicher Gewaltausübung und damit verbunden die Freiheitswahrung ebenso wie die Rationalisierung staatlichen Handelns durch gegenseitige checks and balances, für die Europäische Gemeinschaft in angemessener und sachdienlicher Weise erreicht. ${ }^{916}$ Eine besondere Rolle kommt dem Europäischen Rechnungshof dabei zu, dass er als Organ eine herausgehobene Stellung hat und gleichberechtigt auf einer Ebene neben den Organen steht, die Recht setzen und exekutive oder iudikative Funktionen ausüben.

Die Kritikpunkte des Übergewichts des Rates und der mangelnden Parlamentarisierung mögen $\mathrm{zu}$ früheren Zeitpunkten (insbesondere vor Maastricht) durchaus berechtigt gewesen sein; bis heute hat es aber so erhebliche Änderungen in der institutionellen Struktur im Hinblick auf die gemeinschaftlichen Entscheidungsmechanismen gegeben, bei denen dem Parlament eine immer stärkere Rolle eingeräumt wurde, dass sie überdacht werden müssen. Die Europäische Gemeinschaft muss vor diesem Hintergrund als Prozess begriffen werden, wobei ihre geschichtliche Entwicklung zeigt, dass eine mit der zunehmenden Integration verbundene Erweiterung der Kompetenzen immer auch eine Verstärkung eigener rechtsstaatlicher und demokratischer Elemente mit sich brachte. Hervorzuheben ist besonders, dass sich das Europäische Parlament vom bloßen Berater im Normsetzungsverfahren zum Mitgesetzgeber neben dem Rat entwickelt hat. Das Mitentscheidungsverfahren stellt heute bereits den Regelfall dar. ${ }^{917}$ Diese Entwicklung verdeutlicht auch die Regelung durch den Vertrag von Lissabon, der ausdrücklich die gemeinsame gesetzgeberische Verantwortung von Rat und Parlament als Regelfall vorsieht. ${ }^{918}$ Auch im Bereich des Haushaltsverfahrens haben Parlament und Rat nach der Neuregelung in Art. 314 AEUV eine grundsätzlich gleichberechtigte Stellung. Auch hier gilt ein dem ordentlichen Gesetzgebungsverfahren ähnliches Verfahren, das im Ergebnis dazu führt, dass der Erlass eines Haushaltsgesetzes die Übereinstimmung von Parlament und Rat bzw. eine Einigung im Vermittlungsausschuss voraussetzt. ${ }^{919}$

Das in den Verträgen angelegte System des institutionellen Gleichgewichts bringt eine Verteilung von Funktionen auf verschiedene Organe mit sich, die in ihren Kernbereichen wie auch in der herkömmlichen Gewaltenteilung einen justitiablen Schutz genießen. Die Notwendigkeit eines solchen gewaltenteilig angelegten Systems ergibt sich aus dem Bekenntnis zur Rechtsstaatlichkeit in Art. 6 Abs. 1 und auch Abs. 2 EUV a.F., der die „Achtung der Grundrechte..., wie sie sich aus den gemeinsamen Verfassungsüberlieferungen der Mitgliedstaaten als allgemeine

\footnotetext{
916 Oppermann, Europarecht, 2005, S. 81.

917 Dann, The Political Institutions, in: v.Bogdandy/Bast, Principles of European Constitutional Law, 2006, S. 229 (252): "The codecision procedure can be regarded as the standard law-making procedure".

918 Oben: IV. 1. a) aa) am Ende.

${ }^{919}$ Im einzelnen: Streinz/Obler/Herrmann, Der Vertrag von Lissabon zur Reform der EU, S. 43 f.
} 
Grundsätze des Gemeinschaftsrechts ergeben“ festschreibt. Die Gewaltenteilung ist zentrales Element formeller Rechtsstaatlichkeit, ihr kommt gewaltbegrenzender und damit freiheitswahrender Charakter gegenüber den Bürgern zu; dieser Zweck macht sie auch durch das Bekenntnis zu den „Gemeinschaftsgrundrechten“, die als materielle Rechtsstaatskriterien den gleichen Zweck verfolgen, unverzichtbar. Dieser rechtliche Hintergrund, der sich praktisch in der beschriebenen Entwicklung der Stärkung des Parlaments und allgemein der Stärkung rechtsstaatlicher und demokratischer Elemente bei zunehmender Integration widerspiegelt, verhindert eine Entwicklung in die entgegengesetzte Richtung. Der Kritikpunkt der „Momentaufnahme" hat sich hiervor als unberechtigt erwiesen.

\section{c) Einordnung des Europäischen Rechnungshofes}

Der Europäische Rechnungshof mit seiner Kontrollfunktion wurde durch die Einräumung der Organstellung in der EG und später auch in der EU auf die gleiche Ebene gehoben wie die anderen Organe Parlament, Rat, Kommission und Gerichtshof, 920 die jedoch Hoheitsgewalt ausüben. Im Rahmen des institutionellen Gleichgewichts kommt ihm damit eine gleichberechtigte privilegierte Stellung zu. 921 Der Blick auf den Europäischen Rechnungshof hinsichtlich seiner vertraglichen Hilfsgarantien sowie seiner Aufgaben, die Prüfung, Beratung und Information umfassen, zeigt viele Parallelen zu den untersuchten Rechnungshöfen der Mitgliedstaaten. Dies ist vor allem vor dem Hintergrund zu sehen, dass die Finanzverfassung der Europäischen Union der eines Staates sehr stark ähnelt: So verfügt sie über eigene Einnahmen und auch der Haushalts- und Budgetkreislauf weist in seinen Grundzügen Parallelen zu einem nationalstaatlichen auf. ${ }^{922}$

Jedoch ist trotz aller bestehender Gemeinsamkeiten zwischen den verschiedenen mitgliedstaatlichen Rechnungshöfen die verfassungsrechtliche Einordnung im Verhältnis zu den Organen von Legislative, Exekutive und Judikative völlig unterschiedlichen Ausgestaltungen zugänglich. Im Folgenden soll die Einordnung des Europäischen Rechnungshofes in das europäische Organgefüge untersucht werden.

Ausgangspunkt muss dabei die europarechtliche Besonderheit sein, dass der Europäische Rechnungshof ein den anderen Organen vollkommen gleichgestelltes (Haupt-) Organ ist, die von ihm ausgeübte externe Finanzkontrolle somit eine eigenständige, gleichberechtigte Gemeinschaftsfunktion darstellt.

\footnotetext{
${ }^{920}$ Inghelram, The European Court of Auditors: Current legal issues, CMLR 2000, 129 (130): “...it is of interest to see how, within the Union, the audit task has been brought to the level of the legislative, executive and judiciary task, the three powers in the Montesquieu model"; s. auch Ternes, Finanzkontrolle in der Europäischen Union, 1996, S. 29, der jedoch nur im übertragenen Sinne von einer vierten Gewalt spricht.

921 Ekelmans, in: Commentaire Megret, Bd. 9, 2000, S. 365 f.

922 Magiera, Finanzkontrolle in der EG, in: v.Arnim, Finanzkontrolle im Wandel, 1989, S. 221 f.
} 
Als Folge dessen wird die Auffassung vertreten, dass anders als im traditionellen nationalstaatlichen Modell der Gewaltenteilung die Rechnungsprüfung damit an der unmittelbaren verfassungsrechtlichen Gewaltausübung teilnehme. ${ }^{223}$

So formuliert dürfte diese Aussage allerdings zu weit gehen, denn inhaltlich unterscheiden sich Aufgaben und Hilfsgarantien nicht wesentlich beispielsweise von denen des Bundesrechnungshofes, der als Institution sui generis neben den Staatsgewalten einzuordnen ist. Insbesondere hoheitliche Gewalt übt der Europäische Rechnungshof wie dargelegt nicht aus, seine Handlungsformen sind weder rechtsverbindlich im Sinne des Art. 249 EGV, noch haben sie wie die des Europäischen Gerichtshofs Urteilscharakter. Es erscheint insofern sehr fraglich, ob der Europäische Rechnungshof vergleichbar einer Staatsgewalt im herkömmlichen Sinne eingestuft werden kann, verfügt er doch über keinerlei Entscheidungsbefugnisse. Auch in den Fällen der obligatorischen Anhörung kommt ihm lediglich ein Beratungsrecht zu; ob seine Stellungnahme berücksichtigt wird, hängt allein von den gesetzgebenden Organen ab. Seine Rolle unterscheidet sich damit vom Inhalt seiner Aufgaben her nicht sehr von solchen nationalen Modellen, bei denen eine Einstufung als „Staatsgewalt“ abzulehnen ist.

So unterscheidet sich die Funktion der externen Finanzkontrolle von ihrem Wesen her auch grundlegend von denen der anderen Organe. Sie ist ebensowenig mit den drei „handelnden Organen der Union“924 - Parlament, Rat und Kommission - vergleichbar wie mit der Rechtsprechungsfunktion, jedoch steht sie, und das ist das Besondere, vollkommen gleichberechtigt als eigenständige Finanzkontrollfunktion neben diesen. Der EuRH arbeitet und wirkt gewissermaßen ,innerstaatlich" und nimmt damit nicht unmittelbar an der Gewaltausübung teil und kann auch nicht als einer „Staatsgewalt" entsprechend eingestuft werden.

Die Besonderheit der Einräumung der Organstellung ist vielmehr von der Zielrichtung seiner Arbeit her zu betrachten:

Zunächst ist die Einräumung einer Sonderrolle für die externe, unabhängige Rechnungsprüfung von großer symbolischer Bedeutung, sie bildet zudem ein mäßigendes Gegengewicht zu den über die Mittelverwendung entscheidenden Organen und dient der Rationalisierung ihrer Entscheidungen. Durch die Einräumung der Organstellung steht der Rechnungshof gleichberechtigt neben den anderen Organen, die er prüft und berät; die Stellung vermag damit seine Autorität zu unterstreichen. ${ }^{925} \mathrm{Am} \mathrm{Maßstab} \mathrm{mitgliedstaatlicher} \mathrm{Ausprägungen} \mathrm{gemessen}$ ist die Ausgestaltung der Gewaltenteilung auf Unionsebene bisher unvollkommen, wenn auch wie dargelegt den Besonderheiten angemessen, verwirklicht. Dies ist

923 Friedrich/Inghelram, Die Klagemöglichkeiten des Europäischen Rechnungshofs vor dem Europäischen Gerichtshof, DÖV 1999, 669 f. (670 f.).

924 Läufer, Der Europäische Gerichtshof - moderate Neuerungen des Verfassungsentwurfs, INTEGRATION 2003, 510.

925 Laffan, The Evolution of the European Court of Auditors, Journal of Common Market Studies 1999, 251 (262). 
ein weiterer Grund, der die starke Stellung des EuRH zu erklären vermag. Seine Kontrolle dient den klassischen Zielen der Gewaltenteilung, indem er im Rahmen des Systems der checks and balances, das seine europarechtliche Entsprechung im institutionellen Gleichgewicht findet, zur gegenseitigen Mäßigung beiträgt und durch Kontrolle und Beratung die Rationalisierung des Organhandelns fördert.

Hinzu kommt, dass die Europäische Union stärker als die Mitgliedstaaten mit der Sicherstellung der Transparenz und der Bekämpfung der Verschwendung von Mitteln zu kämpfen hat. Ein starker Rechnungshof ist geeignet, im bedeutenden Finanzbereich dem Transparenzdefizit entgegenzuwirken, indem er Institutionen und Öffentlichkeit über seine Kontrollergebnisse informiert. So waren und sind es vor allem Fälle von Verschwendung und finanziellen Unregelmäßigkeiten bis hin zu Korruption, die von der Öffentlichkeit wahrgenommen werden und so dem Ansehen der Union Schaden zufügen können. Die Einrichtung eines starken, glaubwürdigen Rechnungshofes (ebenso wie die Gründung von OLAF) war daher ein geeignetes Mittel, um dem entgegenzuwirken, für Transparenz zu sorgen und zu helfen, die Akzeptanz seitens der Bevölkerung zu verbessern. Denn hierfür sind gut funktionierende Kontrollmechanismen unabdingbar. Unter diesen Gesichtspunkten muss auch die Stellung des Europäischen Rechnungshofes als Hauptorgan betrachtet werden: Er steht ganz im Dienste der Kontrolle der auf die EU übertragenen Staatsgewalt im finanziellen Bereich und sorgt für Transparenz. In der Einräumung der Organqualität manifestiert sich der Wille, Unregelmäßigkeiten entschiedener entgegenzutreten und den wirtschaftlichen Umgang mit Gemeinschaftsmitteln zu verbessern.

Weiter geht die Einrichtung und Stärkung der Rechnungskontrolle, wie die geschichtliche Einführung deutlich macht, einher mit der Stärkung der Rechte des Europäischen Parlaments und dient damit mittelbar der Verringerung des Demokratiedefizits auf europäischer Ebene. Das Haushaltsrecht nimmt bei der Machtausübung eine besondere Stellung ein; 926 bei der Kontrolle kommt dem Europäischen Parlament durch das Entlastungsrecht inzwischen eine Schlüsselrolle zu, bei deren Wahrnehmung es auf die Arbeit des EuRH angewiesen ist. Die besondere Stellung des EuRH ist damit auch vor dem Hintergrund der sukzessiven Stärkung des Europäischen Parlaments zu sehen. Nicht zuletzt war es schließlich das Parlament, das die Ersetzung des überforderten Kontrollausschusses durch einen Rechnungshof verlangte, um bei seinen Rechten im Haushaltsverfahren (besonders der Entlastung der Kommission) Unterstützung zu erfahren. Der Rechnungshof genießt zwar auch dem Parlament gegenüber Unabhängigkeit, seine Tätigkeit ist jedoch für dieses von ungleich größerer Bedeutung als für die anderen Organe. Der Rechnungshof versetzt durch seine Tätigkeit das Europäische Parla-

926 Oben: 1. Teil VI. 1.; Friedmann, Aufgabenstellung und rechtliche Rahmenbedingungen der Finanzkontrolle des EuRH, in Ders., Der EuRH und die Wirtschafts- und Finanzhilfen der EU für Mittel- und Osteuropa, 1994, S. 29. 
ment vielfach überhaupt erst in die Lage, seine eigene Kontrollfunktion gegenüber der Kommission wirkungsvoll wahrzunehmen.

Nicht zuletzt ist die Europäische Union aus einer Wirtschaftsgemeinschaft entstanden, der heutigen Europäischen Gemeinschaft, innerhalb derer der Schwerpunkt der Prüfungsaufgaben des EuRH liegt. Diese war und ist in erster Linie ein wirtschaftlicher Zusammenschluss. Da Wirtschaft und Finanzierung und damit die Gefahr der Verschwendung stärker als bei einem Nationalstaat im Mittelpunkt stehen, muss der Finanzkontrolle eine besondere Stellung zukommen.

Die Prüfung durch den Rechnungshof dient nämlich sowohl der Kontrolle auf Unionsebene selbst als auch der Kontrolle auf Ebene der Mitgliedstaaten, soweit diese EU-Gelder verwalten.

Das System der Europäischen Union, das auf der mittelbaren Verwaltung durch die entsprechenden Stellen der Mitgliedstaaten basiert, führt zu einer höchst komplexen und unübersichtlichen Einnahmen- und Ausgabenstruktur. Auch diese Komplexität erklärt die Bedeutung der Finanzkontrolle durch die Gemeinschaft, die sich in der im Vergleich zu den entsprechenden Regelungen der Mitgliedstaaten herausgehobenen Stellung des Europäischen Rechnungshofes als Hauptorgan zeigt, das auf gleicher Ebene steht wie die Funktionsträger, die Hoheitsgewalt in legislativer, exekutiver und judikativer Form ausüben.

Der geschichtliche Vergleich mit dem Kontrollausschuss zeigt, dass es vor allem auch die Bekämpfung von Korruption und Betrügereien auf Ebene der Mitgliedstaaten war, die dieser nicht unter Kontrolle bringen konnte, die letztlich die Errichtung eines starken Rechnungshofes notwendig machte.

Die Sonderstellung des EuRH im Vergleich zu nationalen Rechnungshöfen fußt damit im Wesentlichen auf drei Gründen: dem Schwerpunkt der Union auf finanziellem und wirtschaftlichem Gebiet, was einhergehend mit ihrer besonderen Verwaltungsstruktur eine besonders effektive Finanzkontrolle notwendig macht, der notwendigen Unterstützung des Europäischen Parlaments bei der Wahrnehmung seiner Kontrollrechte und der Sicherstellung von Transparenz.

Die Rechnungsprüfung steht im Dienste des mit der Gewaltenteilung verfolgten Systems der checks and balances und weiter im Dienste der Öffentlichkeit ${ }^{227}$, die an den Informationen teilhat. Wie schon vor dem Hintergrund der Stellung des deutschen Bundesrechnungshofes geklärt wurde, ist Transparenz eine grundlegende Forderung des Demokratieprinzips. Die Europäische Union hat, wie sich aus Art. 6 Abs. 1 EUV a.F. ergibt, den Anspruch, auf Demokratie und Rechtsstaatlichkeit zu beruhen. Vor diesem Hintergrund sind Demokratiedefizit und Notwendigkeit der Transparenz der Union zu sehen, ebenso wie vor dem, dass nur, wenn diesen Prinzipien ausreichend Rechnung getragen wird, die Akzeptanz durch die Bürger gewährleistet werden kann. Diese Tatsache vermag die vergli-

927 Theato/Graf, Das EP und der Haushalt der EG, 1994, S. 116 f. zum Verhältnis Haushaltskontrolle und Öffentlichkeit. 
chen mit den nationalen Rechnungshöfen besondere Stellung des Europäischen Rechnungshofes als Hauptorgan zu erklären, das damit auf gleicher Ebene mit den die Aufgaben der Legislative, Exekutive und Judikative ausübenden Organen steht.

Es ist durchaus möglich, dass sich die Organstellung des Europäischen Rechnungshofes durch die mit dem Integrationsprozess einhergehende Veränderung der Europäischen Union von einer Wirtschaftsgemeinschaft hin zu einer Wertegemeinschaft und durch die zunehmende Parlamentarisierung dahingehend verändern wird, dass sie mehr und mehr nationalstaatlichen Modellen gleichen wird. Sie könnte sich der Stellung der Rechnungshöfe in den Mitgliedstaaten in der Form angleichen, dass es sich um ein unabhängiges Kontrollorgan handelt, dem eine Sonderstellung im organisatorischen Aufbau zukäme, ohne dass sie aber so exponiert wie aktuell wäre. Die Hauptorganqualität des EuRH ist mithin möglicherweise nur vorübergehender Natur. So wurde sie erst formell durch den Vertrag von Maastricht 1992 eingeführt. Der Rechnungshof wird seitdem in Art. 5 EUV a.F. und Art. 7 Abs. 1 EGV (jetzt nur noch Art. 13 Abs. 1 EUV n.F. für die Union) gleichrangig als eines der Hauptorgane genannt, was auch der Änderungsvertrag unberührt lassen wird.

Beispielsweise war der Europäische Rechnungshof im gescheiterten Vertrag über eine Verfassung für Europa in Art. I-19 VerfEU, der das institutionelle Gefüge der zukünftigen Union zum Inhalt hatte, also Art. 7 I EGV ersetzten sollte, nicht mehr unter den Hauptorganen aufgeführt. Art I-31 VerfEU (Kapitel II "Sonstige Organe und Einrichtungen") bezeichnete ihn aber als Organ, so dass er durch die Umstellung höchstens protokollarisch abgesunken wäre ${ }^{928}$; auf den verfassungsrechtlichen Status hätte dies jedoch keinen Einfluss gehabt, da Rechte und Aufgaben gleich bleiben sollten. ${ }^{929}$

Eine Bewertung der Stellung der EuRH im Gewaltengefüge der Europäischen Union darf im Ergebnis daher nicht nur anhand der Organqualität, sondern muss auch anhand inhaltlicher materiellrechtlicher Gesichtspunkte erfolgen. Wie gesehen hat die Organstellung an sich eher Symbolcharakter, entscheidend sind vielmehr vertraglich verbürgte Hilfsgarantien, wie Unabhängigkeit und Informationsrechte, die nicht zwangsläufig von der Organqualität abhängen. Staatsgewalt übt der EuRH trotz der formellen Gleichstellung mit den rechtsverbindlich handelnden Organen nicht aus, seine Tätigkeit wirkt vielmehr ,innerstaatlich“ innerhalb des europäischen Staaten- und Verfassungsverbundes.

Andererseits ist es auch vorstellbar, dass die Mitgliedstaaten aufgrund der bleibenden Besonderheiten und des hohen Bedürfnisses nach effektiver Kontrolle und Transparenz an der besonderen Stellung des Rechnungshofes als Hauptorgan längerfristig festhalten werden.

928 Streinz/Obler/Herrmann, Die neue Verfassung für Europa, 2005, S. 40.

${ }_{929}$ Bieber/Epiney/Haag, Die Europäische Union: Europarecht und Politik, S. 151 f. 
Von daher betrachtet hat der EuRH durch seinen Hauptorganstatus eine der Europäischen Union in ihrer gegenwärtigen Integrationsphase angemessene Stellung - dass es bei dieser bleibt, ist aber weder sicher noch zwingend.

2. Betrachtung der Wahrnehmung seiner Stellung anhand ausgewählter Rechnungshofberichte

Die Aufgaben des Europäischen Rechnungshofes lassen sich klassischerweise in Prüfung, Beratung und Veröffentlichung unterteilen. Bedeutsam für den Einfluss, den er auszuüben vermag, ist nicht zuletzt die Art der Wahrnehmung dieser Kompetenzen.

Das Verhältnis zwischen Kommission als Kontrollunterworfene und EuRH als Kontrolleur bietet von jeher Konfliktpotential. ${ }^{930}$ Schon Ende der siebziger Jahre wird aus den im Jahresbericht für das Haushaltsjahr 1979 abgedruckten Antworten der Kommission auf die Bemerkungen des Rechnungshofes deutlich, dass diese ihre Bemühungen zur Verbesserung der Ausführung des Haushaltsplanes als vom Rechnungshof nur unzureichend gewürdigt sieht, sie beklagt die Berichte des Rechnungshofes als unausgewogen und sieht ihre Tätigkeit „eher negativ als positiv dargestellt ${ }^{\text {“. }} .931 \mathrm{Im}$ darauffolgenden Jahresbericht für das Haushaltsjahr 1980 nahm der EuRH anscheinend diese Aussagen der Kommission zum Anlass, in den allgemeinen einleitenden Erwägungen klarzustellen, dass es ihm nicht darum geht, „Kritik um der Kritik willen zu üben“, sondern durch die Aufdeckung von Mängeln eine Verbesserung von Verfahren und Systemen zu erreichen, was im allgemeinen Interesse der Gemeinschaft liege. ${ }^{932}$

Auch die Arbeit des Rechnungshofes im Vorfeld des Rücktritts der SanterKommission hat gezeigt, dass dieser, wenn erforderlich, seine Rechte selbstbewusst wahrzunehmen vermag und seine Kontrollfunktion insbesondere gegenüber der Kommission wirksam ausübt. ${ }^{933}$ Jedoch zeigt sich auch, dass die Rolle, die er in dieser Hinsicht zu spielen vermag, nicht unerheblich von der Person des Rechnungshofpräsidenten abhängt, nämlich ob dieser Konfrontationen aus dem Weg geht oder sie nicht scheut, wenn es darauf ankommt. 934

Anlässlich der Überprüfung der Entwicklung der Mehrwertsteuereinnahmen durch die Mitgliedstaaten prüfte der Hof im Jahr 1998 auch die Übereinstimmung nationaler Vorschriften mit dem Europarecht auf ebendiesem Gebiet. Er kam dabei allgemein zu dem Schluss, dass eine systematische Überwachung der fristgerechten und ordnungsgemäßen Umsetzung von Gemeinschaftsrichtlinien in nati-

\footnotetext{
930 Theato/Graf, Das Europäische Parlament und der Haushalt der EG, 1994, S. 111 f.

931 EuRH, Jahresbericht für das Haushaltsjahr 1979, Anhang IV, S. 249, Ziff. 2. und 3., ABl. Nr. C 342 vom 31.12. 1980.

932 EuRH, Jahresbericht für das Haushaltsjahr 1980, Einleitung, S. 8, Ziff. 24; ABL. Nr. C 344 vom 31.12.1981.

933 Oben: III. 5.

934 Nathe, in: Weidenfeld/Wessels, Jahrbuch der Europäischen Integration 1997/98, S. 93 f. (94).
} 
onales Recht durch die Kommission nicht stattfindet. Mit deutlichen Worten kritisierte der EuRH dabei die Arbeit der Kommission, die ihre diesbezüglichen Aufgaben, systematische Prüfungen vorzunehmen und gegebenenfalls Vertragsverletzungsverfahren einzuleiten, nicht ausreichend erfülle. ${ }^{935}$ Betont wird die „wesentliche Bedeutung der vollständigen und getreuen Umsetzung“ von Gemeinschaftsrechtsakten in nationales Recht „für die innere Geschlossenheit und Einheit des europäischen Aufbauwerks". ${ }^{936}$

Die klare Kritik, die aus Anlass der Mehrwertsteuerüberprüfung stattfand, aber auch über dieses eingeschränkte Thema hinaus allgemein Versäumnisse bei der Überwachung benennt, verdeutlicht die Auffassung des EuRH von seiner eigenen Rolle als eines gleichberechtigten Organs, das seine Kontrollaufgaben im Rahmen des institutionellen Gleichgewichts selbstbewusst wahrnimmt.

Der EuRH trägt entscheidend dazu bei, die Kontrollfunktion durch die Kommission zu verbessern, so würdigt er in seinen Berichten regelmäßig auf seine frühere Kritik hin umgesetzte Verbesserungen und weist darauf hin, in welchen Bereichen weiterhin Optimierungsbedarf besteht. Jedoch fällt auf, dass sich die Kritikpunkte im Laufe der Jahre oft auch wiederholen beziehungsweise stark ähneln, wenngleich auch die Kommission ständig Verbesserungsvorschläge annimmt und auch formelle Zusagen zur Mängelbeseitigung gibt. ${ }^{937} \mathrm{Im}$ Ergebnis besteht also immer noch Verbesserungsbedarf bei der Umsetzung der Empfehlungen des EuRH an die Kommission etwa hinsichtlich der Optimierung von Kontrollsystemen oder Verfahrensabläufen.

Regelmäßig betont der EuRH seine Stellung als ,vollkommen unabhängiges Prüfungsorgan" und weist darauf hin, dass er ständig daran arbeite, sich den wechselnden Bedingungen seines Aufgabenumfeldes, etwa durch die Erweiterung der Europäischen Union um neue Staaten und die damit verbundenen Veränderungen im Haushaltsbereich, durch Verbesserung seiner Arbeitsweise anzupassen. ${ }^{938}$

Auch in der aktuellen Situation spiegelt sich wider, dass das Verhältnis zwischen Kontrolleur und Kontrollierten nicht immer harmonisch ist, so kritisierte der Kommissar Siim Kallas den Rechnungshof im Anschluss der Vorstellung der Bemerkungen für das Haushaltsjahr 2005, in denen der Hof erneut auf wesentliche Fehler hinwies, dahingehend, dass der EuRH ,in kleinen Stichproben einzelne Fehler aufdecke und daraus missverständliche Schlüsse ziehe“, auch treibe die

\footnotetext{
935 EuRH, Jahresbericht für das Haushaltsjahr 1998, Ziff. 1.27. ff (1.43. f.), ABl. Nr. C 349/1 vom 3.12.1999.

936 EuRH, Jahresbericht für das Haushaltsjahr 1998, Ziff. 1.42., ABl. Nr. C 349/1 vom 3.12.1999.

${ }^{937}$ EuRH, Jahresbericht für das Haushaltsjahr 2001, Ziff. 0.22., ABl. Nr. C 295/1 vom 28.11.2002, S. 7.

938 EuRH, Jahresbericht für das Haushaltsjahr 2002, Ziff. 0.18., ABl. Nr. C 286/1 vom 28.11.2003, S. 7; EuRH, Jahresbericht für das Haushaltsjahr 2003, Ziff. 0.8., ABl. Nr. C 293/1 vom 30.11.2004, S. 6.
} 
Kommission falsch verausgabte Subventionen wieder ein. ${ }^{939}$ Der Rechnungshof hatte in seinem Bericht Fehler der einzelnen Generaldirektionen bei den Haushaltsabschlussarbeiten festgestellt, ${ }^{940}$ daneben erkannte er zwar Verbesserungen des internen Kontrollsystems der Kommission an, stellte aber immer noch „erhebliche Unzulänglichkeiten in den Überwachungs- und Kontrollsystemen“ fest. ${ }^{941}$ Der EuRH verwehrte sich entschieden gegen diese Kritik des Kommissars. Präsident Weber betonte, dass der Rechnungshof „fundamentale und weitreichende Fehler" aufdecke, auch sei das Argument, die Kommission fordere widerrechtlich ausgezahlte Subventionen zurück, wenig schlagkräftig, da dies meist erst Jahre später geschehe, wenn der Endempfänger oftmals gar nicht mehr existiere, was nicht sehr abschreckend für die Mitgliedstaaten sei, ${ }^{942}$ ferner decke die zurückgeforderte Summe bei weitem nicht die Fehler bei der Verausgabung ab. ${ }^{943}$

Rechnungshofpräsident Weber betonte angesichts der Kritik die Zurückhaltung des EuRH, er decke lediglich Fehler auf, enthalte sich aber regelmäßig einer Beurteilung, denn Schlüsse aus den Feststellungen zu ziehen sei in erster Linie Aufgabe der Kommission. ${ }^{944}$

Die Reaktionen der Kommission auf die Berichte des EuRH machen deutlich, dass er bei der Wahrnehmung seines Kontrollauftrages erfolgreich ist und seine Kritik ernst genommen wird.

Eine relativ starke Präsenz kommt den Rechnungshöfen auch in den führenden Medien zu; kritische Berichte von Rechnungshöfen werden hier häufig und ausführlich dargestellt.

Der EuRH muss sich angesichts der Probleme der Gemeinschaft in diesem Bereich auf die Kontrolle der Ordnungs- und Rechtmäßigkeit der Gemeinschaftsmittel konzentrieren. Damit ist auch seine Rolle in der EG eine andere als etwa die des Bundesrechnungshofes in Deutschland, bei dem die Wirtschaftlichkeitsprüfung im Mittelpunkt steht und der damit stärker durch Prüfung und vor allem Beratung die Entscheidungsfindung von Legislative und Exekutive bei der Verbesserung der Wirtschaftlichkeit staatlichen Handelns in unterschiedlichsten Bereichen mit beeinflusst.

${ }^{939}$ Heftiger Streit um EU-Haushaltskontrolle, in: Frankfurter Allgemeine Zeitung vom 25.10.2006, S. 15.

940 EuRH, Jahresbericht für das Haushaltsjahr 2005, Ziff. 1.14., ABl. Nr. C 263/1 vom 31.10.2006, S. 19.

941 EuRH, Jahresbericht für das Haushaltsjahr 2005, Ziff. 2.24. f., ABl. Nr. C 263/1 vom 31.10.2006, S. 49.

942 Heftiger Streit um EU-Haushaltskontrolle, in: Frankfurter Allgemeine Zeitung vom 5.10.2006, S. 15.

943 Rechnungsprüfer wehren sich gegen Kritik, in: Frankfurter Allgemeine Zeitung vom 31.10.2006, S. 25.

944 Rechnungsprüfer wehren sich gegen Kritik, in: Frankfurter Allgemeine Zeitung vom 31.10.2006, S. 25 . 
Im Ergebnis wird aus den Berichten deutlich, dass der EuRH seine Befugnisse mutig und ohne falsche Scheu anderen Organen gegenüber wahrnimmt. ${ }^{945}$ Wie besonders sein Verhalten hinsichtlich der Unregelmäßigkeiten in der SanterKommission gezeigt hat, scheute er auch vor einer möglichen Konfrontation nicht zurück, wenn es darum geht, seine Aufgabe gem. Art. 248 Abs. 2 UAbs. 1 EGV zu erfüllen, die Recht- und Ordnungsmäßigkeit zu prüfen und UnregelmäBigkeiten aufzudecken. Dies wird an den Reaktionen der Kommission deutlich, die auch zeigen, dass die Arbeit des EuRH durch seine Veröffentlichungen starke Außenwirkung hat und von den Geprüften und der Öffentlichkeit ernst genommen wird. So vermag sie Druck zu erzeugen, Fehler abzustellen und Verbesserungen vorzunehmen. Bedeutung kommt dabei auch der in den Jahresberichten aufgeführten Weiterverfolgung früherer Bemerkungen zu; der Rechnungshof stellt darin fest, inwieweit seinen früher gemachten Beanstandungen nachgekommen wurde, indem er darstellt, wie Rat und Parlament seine Empfehlungen bewertet haben und welche Maßnahmen die Kommission als Folge eingeleitet hat.

\section{Rechtsschutzmöglichkeiten vor dem EuGH}

Der EGV räumt dem Rechnungshof bestimmte Garantien und Befugnisse gegenüber den anderen Organen und gegenüber den Mitgliedstaaten ein. Besondere Bedeutung kommt daher der Möglichkeit zu, diese vor dem EuGH auch verteidigen zu können. An dieser Stelle soll daher die aktive Klagebefugnis des Europäischen Rechnungshofes behandelt werden. Am Rande erwähnt sei, dass der EGV zwar nicht ausdrücklich eine passive Klagebefugnis des EuRH regelt, EuGH und EuG aber dennoch Klagen gegen den Rechnungshof zugelassen haben. ${ }^{946}$ Dabei handelte es sich um Klagen von Mitgliedern des Rechnungshofes, aber wie im Fall „ISMERI“ gesehen, auch um Klagen Dritter gegen die Erwähnung in Berichten. Allein die Herleitung der passiven Klagebefugnis blieb unklar.947

Im Folgenden ist zu prüfen, inwieweit die Garantien und Rechte, die der EGV dem Europäischen Rechnungshof gegenüber Gemeinschaftsorganen und Mitgliedstaaten einräumt, vor dem Gerichtshof einklagbar sind. Denn ein Recht, das nicht justitiabel ist, ist nicht viel wert.

Die Rechtsschutzmöglichkeiten des EuRH nach dem AEUV entsprechen denen nach dem EGV, die entsprechende Norm nach dem AEUV wird daher nach der betreffenden Regelung des EGV zitiert.

\footnotetext{
945 Theato/Graf, Das Europäische Parlament und der Haushalt der EG, 1994, S. 111 f.

946 Vgl. nur: EuGH, Rs. C-315/99, Slg. 2001, I - 5281 (ISMERI/EuRH); verb. Rs. 193 u. 194/87,

Slg. 1989, 1045 (Maurissen/EuRH); Rs. C-416/92, Slg. 1994, I-1741 (H./EuRH); Rs. C-258/94

P, Slg. 1995, I-1609 (Branco/EuRH); EuG, Rs. T-121/97, Slg. 1998, II-3885 (Ryan/EuRH).

947 Hailbronner/Jocbum, Europarecht I, 2005, Rn. 453.
} 
1. Rechtsschutz gegenüber anderen Gemeinschaftsorganen

Ausgangspunkt für die Rechtsschutzmöglichkeiten des Rechnungshofes gegen andere Organe ist die Rechtsprechung des EuGH zum institutionellen Gleichgewicht. Der Gerichtshof sieht es dabei als wesentlich an, dass bei Verstößen gegen den Grundsatz, dass jedes Organ seine Befugnisse unter Beachtung der Befugnisse der anderen Organe auszuüben hat, das betroffene Organ die Möglichkeit haben muss, Klage zu erheben. ${ }^{948}$ Als Klagegründe kommen die behandelten Rechte des Rechnungshofes in Betracht.

a) Nichtigkeitsklage Art. 230 EGV (Art. 263 AEUV)

Der Amsterdamer Vertrag von 1997 räumte mit Art. 230 Abs. 3 EGV dem Europäischen Rechnungshof die (teilprivilegierte) aktive Parteifähigkeit im Rahmen der Nichtigkeitsklage ein. Dies war angesichts seiner Stellung im institutionellen Gleichgewicht nur konsequent. Der EuRH ist jedoch nicht als einer der privilegiert Klageberechtigten in Abs. 2 genannt, sondern kann den Gerichtshof nur zur Wahrung eigener Rechte anrufen (Art. 263 UAbs. 3 AEUV).

Die Frage, ob der EuRH vor der Einführung der Klagebefugnis bereits gerichtlich tätig werden konnte, ist damit nur noch von theoretischer Bedeutung. Die entsprechende Problematik ergab sich parallel für das Europäische Parlament, für das die Verträge vor Maastricht ebenfalls keine ausdrückliche Klagebefugnis vorsahen. ${ }^{949}$ Im Rahmen eines Verfahrens, in dem das Parlament sich gegen die Wahl der Rechtsgrundlage durch den Rat richtete, die seines Erachtens falsch war und im Gegensatz zum Verfahren der Zusammenarbeit nach der richtigen Rechtsgrundlage lediglich die Anhörung des Parlaments vorsah, hatte der Gerichtshof hierüber zu entscheiden. Der EuGH räumte dem Europäischen Parlament die Befugnis zur Erhebung einer Nichtigkeitsklage zur Verteidigung seiner Befugnisse ein, indem er feststellte, dass auch dann, wenn eine Bestimmung in den Verträgen fehle, die das Recht des Parlaments zur Erhebung einer Nichtigkeitsklage vorsehe, dennoch die Wahrung des institutionellen Gleichgewichts es gebiete, „dass jedes Organ seine Befugnisse unter Beachtung der Befugnisse der anderen Organe ausübe“ und dass Verstöße gegen diesen Grundsatz auch einklagbar sein müssen. 950

\footnotetext{
948 EuGH vom 22.5.1990, Rs. C-70/88, Slg. 1990, I-2041, Rn. 21 ff. (Parlament/Rat). ${ }^{449}$ Vgl. hierzu Koenig/Pechstein/Sander, EU-/EG-Prozessrecht, 2002, Rn. 328 ff.

${ }^{950}$ EuGH Rs. C-70/88, Slg. 1990, I-2041, Rn. 21 ff., 26 f. (Parlament/Rat); seitdem ständige Rechtsprechung vgl. nur EuGH Rs. C-316/91, Slg. 1994, I-625, Rn. 12 (Lomé); Rs. C-187/93, Slg. 1994, I- 2857, Rn. 14 f. (Abfallverbringung).
} 
Hieraus kann für den EuRH nur der Schluss gezogen werden, dass zumindest seit der Verleihung des Status als Gemeinschaftsorgan durch den Vertrag von Maastricht für ihn nichts anderes gegolten haben kann. ${ }^{951}$

Aus Art. 230 Abs. 3 EGV (Art. 263 UAbs. 3 AEUV) ergibt sich, dass der EuRH ausschließlich die Wahrung seiner sich aus dem Vertrag ergebenden Rechte einklagen kann.

Als Klagegründe kommen nur die in Abs. 2 (UAbs. 2) genannten in Betracht. ${ }^{952}$ Für den Europäischen Rechnungshof relevant ist die Verletzung wesentlicher Formvorschriften, hier ist besonders das Versäumnis einer vertraglich vorgeschriebenen Anhörung beziehungsweise Stellungnahme im Rahmen des Normsetzungsverfahrens zu nennen. Daneben besteht die Möglichkeit einer Vertragsverletzung durch die Beeinträchtigung seiner Kontrollbefugnisse aufgrund der Verweigerung eines Organs, seinen Informations- und Zugangsrechten nach Art. 248 Abs. 3 EGV (Art. 287 Abs. 3 AEUV) nachzukommen. In Betracht kommt ferner der Erlass von Sekundärrecht, das im Widerspruch zur vertraglichen Regelung der Rechtsstellung des Rechnungshofes steht, ${ }^{953}$ indem es seine vertraglichen Rechte beschneidet oder ihm nicht vorgesehene Verpflichtungen auferlegt und damit ebenfalls gegen das institutionelle Gleichgewicht verstieße.

Damit beinhaltet die Nichtigkeitsklage nach Art. 230 Abs. 3 EGV (Art. 263 UAbs. 3 AEUV) sowohl Elemente, die mit dem deutschen Organstreitverfahren vergleichbar sind, als auch solche, die einer Normenkontrolle entsprechen. ${ }^{954}$ Sie stellt so die für das institutionelle Gleichgewicht maßgebliche Unverletzlichkeit und Einklagbarkeit der Befugnisse des EuRH als Organ sicher.

b) Untätigkeitsklage Art. 232 EGV (Art. 265 AEUV)

Der Europäische Rechnungshof ist (privilegiert) aktiv parteifähig im Rahmen einer Untätigkeitsklage nach Art. 232 Abs. 1 EGV (Art. 265 UAbs. 1 AEUV). Passiv parteifähig ist er hingegen nicht, was durch seine Unabhängigkeit (und die fehlende Rechtsverbindlichkeit seiner Akte) zu erklären ist.

Klagegegenstand ist das „Unterlassen unter Verletzung dieses Vertrages, einen Beschluss zu fassen“. Dieser ist damit nach dem Wortlaut der Vorschrift nicht auf die in Art. 249 EGV (Art. 288 AEUV) aufgeführten Handlungsformen beschränkt

\footnotetext{
951 Inghelram, The European Court of Auditors: Current legal issues, CMLR 2000, 129 (137 f.); Friedrich/Inghelram, Die Klagemöglichkeiten des Europäischen Rechnungshofs vor dem Europäischen Gerichtshof, DÖV 1999, 669 (673) m.w.N.; siehe auch Lenaerts/Arts/Maselis, Procedural Law of the European Union, 2006, S. 241 f., die ausdrücklich auf den Zusammenhang zwischen der früheren Rechtsprechung des EuGH zur Aktivlegitimation des EP und ihrer vertraglichen Einräumung für den EuRH hinweisen; Waldhoff, in: Calliess/Ruffert, EUV/EGV, Art. 246 EGV, Rn. 1 m.w.N.

952 Koenig/Pechstein/Sander, EU-/EG-Prozessrecht, 2002, Rn. 381.

953 Friedrich/Inghelram, Die Klagemöglichkeiten des Europäischen Rechnungshofs vor dem Europäischen Gerichtshof, DÖV 1999, 669 (672).

954 Koenig/Pechstein/Sander, EU-/EG-Prozessrecht, 2002, Rn. 380.
} 
und nach überwiegender Ansicht weit auszulegen. ${ }^{955}$ Die Erhebung einer Untätigkeitsklage vor dem Gerichtshof kommt daher insbesondere in Frage, wenn Parlament, Rat oder Kommission ihrer Informationspflicht gegenüber dem Rechnungshof nicht nachkommen.

Letztlich ist die Untätigkeitsklage aber aufgrund der Möglichkeit des untätigen Organs, durch eine Stellungnahme i.S.d. Art. 232 Abs. 2 S. 2 EGV (Art. 265 UAbs. 2 S. 2 AEUV) ihre Erhebung zu verhindern, für den EuRH nur von geringer Bedeutung. ${ }^{956}$ Als weiterer Schritt käme dann die Erhebung einer Nichtigkeitsklage in Betracht. ${ }^{9572}$. Rechtsschutz gegenüber Mitgliedstaaten

Wie gesehen findet der Großteil der Verwaltung der Einnahmen und Ausgaben auf mitgliedstaatlicher Ebene statt. Als Folge dessen findet gemäß Art. 248 Abs. 3 EGV (Art. 287 Abs. 3 AEUV) die Prüfung nicht nur bei anderen Organen, sondern auch bei den Mitgliedstaaten statt. In diesem Rahmen sind besonders die Informations- und Zugangsrechte gegenüber diesen und ihren Behörden zu nennen. ${ }^{958}$

Der Europäische Rechnungshof kann seine Rechte nach derzeitigem Stand der Verträge jedoch nur mittelbar durch die Kommission im Rahmen eines Vertragsverletzungsverfahrens gem. Art. 226 EGV (Art. 258 AEUV) geltend machen. Die Möglichkeit, dass dies durch einen anderen Mitgliedstaat nach Art. 227 EGV (Art. 259 AEUV) erfolgt, dürfte hingegen allenfalls von theoretischer Bedeutung sein. Problematisch erscheint, dass auch die Kommission ein Organ ist, das der Prüfung durch den Rechnungshof unterliegt.

Zum Teil wird daher erwogen, der Rechnungshof könne auch ohne ausdrückliche Erwähnung im Vertragstext selbst Vertragsverletzungsklage gegen einen Mitgliedstaat erheben. ${ }^{959}$ Ausgangspunkt dieses Gedankens ist die erwähnte Rechtsprechung des Gerichtshofes zur Zulässigkeit einer Nichtigkeitsklage des Europäischen Parlaments, ${ }^{960}$ obwohl zum damaligen Zeitpunkt nicht vertraglich klageberechtigt, mit der Begründung der Wahrung des institutionellen Gleichgewichts.

955 Burgi, in: Rengeling/Middeke/Gellermann, Handbuch des Rechtsschutzes in der EU, 2003, \8 Rn. 20 f. m.w.N.; Koenig/Pechstein/Sander, EU-/EG-Prozessrecht, 2002, Rn. 593 f.; Cremer, in: Calliess/Ruffert, EUV/EGV, Art. 232 EGV, Rn. 5 m.w.N.; Ehricke, in: Streinz, EUV/EGV, Art. 232, Rn. 14.

956 Friedrich/Inghelram, Die Klagemöglichkeiten des Europäischen Rechnungshofs vor dem Europäischen Gerichtshof, DÖV 1999, 669 (674 f.).

957 Zum Verhältnis von Untätigkeits- und Nichtigkeitsklage und den an die „Stellungnahme“ zu stellenden Voraussetzungen Burgi, in: Rengeling/Middeke/Gellermann, Handbuch des Rechtsschutzes in der EU, 2003, § 8 Rn. 3, 39.

958 Oben: II. 3. b).

${ }^{959}$ Inghelram, The European Court of Auditors: Current legal issues, CMLR 2000, 129 (140 f.); Friedrich/Inghelram, Die Klagemöglichkeiten des Europäischen Rechnungshofs vor dem Europäischen Gerichtshof, DÖV 1999, 669 (675 f.).

${ }^{960}$ EuGH Rs. C-70/88, Slg. 1990, I-2041, Rn. 22 (Parlament/Rat). 
Jedoch ist in der Konstellation der möglichen Klagebefugnis im Rahmen eines Vertragsverletzungsverfahrens der Ausgangspunkt ein anderer als in der zitierten Entscheidung des Gerichtshofes: Es geht nicht um die Verteidigung vertraglich garantierter Befugnisse gegenüber einem anderen Gemeinschaftsorgan, sondern gegenüber einem Mitgliedstaat. $\mathrm{Ob}$ also eine eigene Klagebefugnis des Europäischen Rechnungshofes gegenüber einem Mitgliedstaat aus dem institutionellen Gleichgewicht hergeleitet werden kann, erscheint daher höchst fraglich; zudem war es in der Ausgangsentscheidung das Europäische Parlament, das klagte.

Als Klagegegenstand bei einem Vertragsverletzungsverfahren kommen die vertraglich garantierten Informations- und Zugangsrechte des EuRH gegenüber den Mitgliedstaaten in Betracht, nicht jedoch die Zusammenarbeit mit den nationalen Rechnungshöfen; diese erfolgt wie ausführlich dargelegt freiwillig und kann insoweit nicht einklagbar sein. Die Vertragsverletzung durch die Verweigerung der Übermittlung der Informationen wird dabei, wie im Europarecht üblich, dem Mitgliedstaat als solchem zugerechnet, unabhängig davon, durch welche innerstaatliche Stelle sie erfolgte, so dass die Klage sich allein gegen diesen richten kann (vgl. Art. 226 EGV / 258 AEUV). 961

\section{Die Zusammenarbeit des Europäischen Rechnungshofes und der obersten Rechnungskontrollbehörden der Mitglied- staaten}

\section{Die Rechnungshöfe im europäischen Staaten- und Verfassungsverbund}

\section{a) Der europäische Staaten- und Verfassungsverbund}

Hinsichtlich der Zusammenarbeit des EuRH mit den mitgliedstaatlichen obersten Rechnungskontrollbehörden im europäischen Rechnungshofsystem stellt sich auch die Frage nach der Rechtsnatur der EU und ihrem Verhältnis zu den Mitgliedstaaten.

Ausgangspunkt ist zunächst die vom Bundesverfassungsgericht in seinem Maastricht-Urteil gewählte Umschreibung der EG beziehungsweise EU als Staatenverbund. ${ }^{962}$ Hierin ist ein Mehr im Vergleich zu einem bloßen Staatenbund zu sehen, wenn auch (noch) kein Bundesstaat ${ }^{963} .{ }^{964}$ Jedoch wurde vielfach kritisiert, dass dieser Begriff die Natur der EU nicht in ihrer Gänze zu beschreiben ver-

\footnotetext{
961 Burgi, in: Rengeling/Middeke/Gellermann, Handbuch des Rechtsschutzes in der EU, 2003, \6 Rn. 39 m.w.N. zur Rspr. des EuGH.

962 BVerfGE 89, 155 (184).

963 BVerfGE 89, 155 (188).

964 P. Kirchhof, Die rechtliche Struktur der EU als Staatenverbund, in: v.Bogdandy, Europäisches Verfassungsrecht, 2003, S. 893 (900).
} 
mag. ${ }^{965}$ Daher musste ein Begriff beziehungsweise eine Ergänzung gefunden werden, der die Europäische Union treffender umschreibt.

Der Begriff des Staatenverbundes ist für sich betrachtet nur eine formelle Hülle, die erst durch die Verfassung inhaltlich ausgefüllt wird. 966 Dabei stellt sich zuallererst die Frage, ob die Verträge, auf denen die Europäische Union basiert, schon heute eine Verfassung darstellen.

Der Europäische Gerichtshof hat den Verfassungscharakter der Verträge angenommen: "Der EWG-Vertrag stellt, obwohl in Form einer völkerrechtlichen Übereinkunft geschlossen, die grundlegende Verfassungsurkunde einer Rechtsgemeinschaft dar". ${ }^{967}$

Diese Auffassung war zunächst auch in der Rechtsprechung des BVerfG erkennbar: „Der EWG-Vertrag stellt gewissermaßen die Verfassung dieser Gemeinschaft dar...", 968 jedoch scheint es später in seinem Maastricht-Urteil hiervon wieder Abstand genommen zu haben ${ }^{969}$.

Ausgangspunkt für die Bewertung muss zunächst sein, dass die wesentlichen Funktionen und Inhalte einer Verfassung auch den Verträgen zukommen, mit dem entscheidenden Aspekt, dass ihre Rechtssubjekte nicht nur die Mitgliedstaaten, sondern auch die Unionsbürger sind ${ }^{970} .{ }^{971}$ Den Verträgen kommt somit formell wie materiell Verfassungscharakter zu. ${ }^{972}$ Dies lässt es sinnvoll erscheinen, einen der verfassungsrechtlichen Wirklichkeit in Europa angemessenen ,postnationalen Verfassungsbegriff“ zu etablieren, der nicht den Staat als conditio sine qua non voraussetzt. ${ }^{973}$ Die Ausgestaltung auf europäischer Ebene lässt sich treffend mit dem Begriff „,Verfassungsverbund“ umschreiben. ${ }^{974}$

965 Pernice, Die Dritte Gewalt im europäischen Verfassungsverbund, EuR 1996, 27 (29 f.) m.w.N.; Calliess, Das Demokratieprinzip im Europäischen Staaten- und Verfassungsverbund, in: FS Ress, 2005, S. 402.

966 Calliess, Das Demokratieprinzip im Europäischen Staaten- und Verfassungsverbund, in: FS Ress, 2005, S. 402.

967 EuGH Gutachten 1/91, Slg. 1991, I-6079 (I-6080).

968 BVerfGE 22, 293 (296).

969 BVerfGE 89, 155; vgl. Calliess, in: Calliess/Ruffert, EUV/EGV, Art. 1 EUV, Rn. 26 m.w.N.

970 EuGH Gutachten 1/91, Slg. 1991, I-6079 (I-6080).

971 Ausführlich: Pernice, Europäisches und nationales Verfassungsrecht, VVDStRL 60 (2001), S. 148 (163 f.) m.w.N.; Calliess, in: Calliess/Ruffert, EUV/EGV, Art. 1 EUV, Rn. 33; zur Erfüllung der Verfassungsfunktionen im Einzelnen: Huber, Europäisches und nationales Verfassungsrecht, VVDStRL 60 (2001), S. 194 (199 ff.); dagegen: P. Kirchbof, Die rechtliche Struktur der EU als Staatenverbund, in: v.Bogdandy, Europäisches Verfassungsrecht, 2003, S. 893 (904).

972 Huber, Europäisches und nationales Verfassungsrecht, VVDStRL 60 (2001), S. 194 (199) m.w.N.

973 Calliess, in: Calliess/Ruffert, EUV/EGV, Art. 1 EUV, Rn. 35 m.w.N.; Pernice, in: Dreier, GGKommentar, Art. 23, Rn. 20.

974 Calliess, Das Demokratieprinzip im Europäischen Staaten- und Verfassungsverbund, in: FS Ress, 2005, S. 402 f.; Pernice, Europäisches und nationales Verfassungsrecht, VVDStRL 60 (2001), S. 148 (163 ff.); Huber, Das institutionelle Gleichgewicht zwischen Rat und Europäischem Parlament in der künftigen Verfassung für Europa, EuR 2003, 574 (594 f.) 
Die Besonderheit der europäischen Verfassungsstaatlichkeit ist ihre Offenheit: Das europäische System aus Union und Mitgliedstaaten ist geprägt von der wechselseitigen „Durchdringung und Verflechtung“ der mitgliedstaatlichen und der europäischen Ordnung; 975 diese Formen der gegenseitigen Beeinflussung hat auch das Bundesverfassungsgericht in seiner Rechtsprechung betont. ${ }^{976}$ Impulse gehen dabei von der Unions-Ebene an die mitgliedstaatliche Ebene und umgekehrt, wie besonders aus Art. 6 Abs. 2 und auch Abs. 1 EUV a.F. (Art. 6 Abs. 3, Art. 2 EUV n.F.) deutlich wird, wodurch ein System der gegenseitigen „Verfassungsbefruchtung und -stabilisierung“ entsteht. ${ }^{977}$ Dementsprechend existieren über das Europäische Parlament einerseits und über den Rat mit den nationalen Parlamenten andererseits zwei sich wechselseitig ergänzende demokratische Legitimationsstränge. ${ }^{978}$ Als entscheidend ist vor dem Hintergrund der europäischen Verfassungsebene die teilweise direkte demokratische Legitimation hervorzuheben, die die gemeinschaftliche Gewaltausübung über das von den europäischen Bürgern direkt gewählte Europäische Parlament als Mitgesetzgeber neben dem Europäischen Rat erfährt. 979

Grundlegende Bedeutung für den Verfassungsverbund kommt den Öffnungsklauseln der nationalen Verfassungen (etwa Art. 23 Abs. 1 GG) zu, welche die Durchlassstelle zwischen den beiden Verfassungsebenen und damit die Voraussetzung für ihre Verklammerung und Verschränkung bilden. ${ }^{980}$

Nach alledem vermag der Begriff des europäischen Staatenverbundes inhaltlich ausgefüllt durch den des Verfassungsverbundes die derzeitige Ausgestaltung der Europäischen Union am treffendsten zu umschreiben.

Entscheidend ist dabei, dass zur Verzahnung der Verfassungsebenen im Rahmen des Verfassungsverbundes ein „loyales Kooperationsverhältnis zwischen nationalen und europäischen Verfassungsorganen “981 erforderlich ist, wie auch Art. 10 EGV (Art. 4 Abs. 3 EUV n.F.) sowie speziellere diesen konkretisierende

975 Calliess, Demokratie im Europäischen Staaten- und Verfassungsverbund, in: Göttinger OnlineBeiträge zum Europarecht, Nr. 14 vom 23.11.2004, S. 6.

976 BVerfGE 52, 187 (200): „,...aufeinander bezogen, miteinander verschränkt und wechselseitigen Einwirkungen...geöffnet"; entsprechendes ist auch der Solange II-Entscheidung des BVerfG vom 22.10.1986 zu entnehmen: In BVerfGE 73, 339 (367): ,...funktionale Verschränkung der Gerichtsbarkeit der EG mit der Gerichtsbarkeit der MS“ und (384) „,normative Verklammerung der in den Verfassungen der MS ... enthaltenen Grundrechtsverbürgungen mit den allg. Rechtsgrundsätzen des Gemeinschaftsrechts...".

${ }^{977}$ Calliess, Das Demokratieprinzip im Europäischen Staaten- und Verfassungsverbund, in: FS Ress, 2005, S. 402 f.; Huber, Das institutionelle Gleichgewicht zwischen Rat und Europäischem Parlament in der künftigen Verfassung für Europa, EuR 2003, 574 (594 f.), spricht vom Staaten- und Verfassungsverbund als einer ,wechselseitigen Auffang- und Kooperationsordnung“.

978 Huber, Das institutionelle Gleichgewicht zwischen Rat und Europäischem Parlament in der künftigen Verfassung für Europa, EuR 2003, 574 (594 f.).

979 Calliess, Demokratie im Europäischen Staaten- und Verfassungsverbund, in: Göttinger OnlineBeiträge zum Europarecht, Nr. 14 vom 23.11.2004, S. 4 ff.

980 Calliess, in: Calliess/Ruffert, EUV/EGV, Art. 1 EUV, Rn. 38.

981 Calliess, in: Calliess/Ruffert, EUV/EGV, Art. 1 EUV, Rn. 38. 
Normen (z.B. Art. 248 Abs. 3 S. 3 EGV (Art. 287 Abs. 3 S. 3 AEUV) hinsichtlich der vertrauensvollen Zusammenarbeit der Rechnungshöfe) deutlich machen. Im Folgenden wird zu erörtern sein, inwieweit hinsichtlich der Zusammenarbeit von Europäischem Rechnungshof und mitgliedstaatlichen Rechnungshöfen von einem solchen Kooperationsverhältnis gesprochen werden kann.

\section{b) Bedeutung für das europäische Rechnungshofsystem}

Der Europäische Rechnungshof wurde natürlich bereits hinsichtlich seiner Gründung und Ausgestaltung durch die Erfahrungen der Mitgliedstaaten im Bereich der externen Finanzkontrolle und deren Rechnungshofmodelle maßgeblich beeinflusst. Die Gewährung von Hilfsgarantien, allen voran der Unabhängigkeit, ist hier besonders bedeutsam, aber auch bei der Ausgestaltung von Prüfungsmaßstäben und -methoden haben die mitgliedstaatlichen Rechnungshöfe Pate gestanden. Der Unabhängigkeit geschuldet nehmen der Europäische Rechnungshof und die mitgliedstaatlichen Rechnungshöfe jedoch auch eine Sonderrolle im Staaten- und Verfassungsverbund ein. Sie setzt zumindest der (rechtsverbindlichen) gegenseitigen Beeinflussung von mitgliedstaatlichen Rechnungshöfen und EuRH Grenzen, was sich in Art. 248 Abs. 3 UAbs. 1 S. 2, 3 EGV (Art. 287 Abs. 3 UAbs. 1 S. 2, 3 AEUV) widerspiegelt, der die Achtung der jeweils garantierten Unabhängigkeit festschreibt. Nach dem Verständnis der Konferenz der deutschen Rechnungshöfe erfolgt die Zusammenarbeit immer auf freiwilliger Basis, was bedeutet, dass für die mitgliedstaatliche Seite keine Verpflichtungen entstehen können, die „nicht im Einklang mit den im jeweiligen nationalen Recht bestehenden Regeln über Stellung und Aufgaben der Rechnungshöfe stehen." "982 Die Pflicht zur Übermittlung von Informationen und Unterlagen an den EuRH steht hierzu in keinem Widerspruch, sie beeinträchtigt in keiner Weise inhaltlich die Tätigkeit der mitgliedstaatlichen Rechnungshöfe, so dass von ihr keine Gefahr für die Unabhängigkeit ausgeht. In Anbetracht der Unabhängigkeit könnte sie lediglich dann an ihre Grenzen stoßen, wenn der EuRH seine Informationsrechte derart ausübte, dass sie die eigene Prüfungstätigkeit der Informationsverpflichteten beeinträchtigte. Das ist aber nicht zu befürchten; außerdem zöge dieser hypothetische Fall aufgrund der Pflicht zu gemeinschaftstreuem Verhalten nach Art. 10 EGV (Art. 4 Abs. 3 EUV n.F.) eine Verpflichtung des betreffenden Mitgliedstaates nach sich, sein Personal so aufzustocken, dass den Informationspflichten nachgekommen werden kann.

Die nationalen Rechnungsprüfungsorgane haben die Pflicht, Unterlagen und Informationen an den Europäischen Rechnungshof zu übermitteln, die Annahme

\footnotetext{
982 Konferenz der Präsidentinnen und Präsidenten der Rechnungshöfe des Bundes und der Länder vom 22. bis 24. September 1997 in Potsdam zur Zusammenarbeit mit dem EuRH (abgedruckt bei Engels, in: Heuer, Kommentar zum Haushaltsrecht, (Stand 38. EL 2004), VIII/2.1); Isensee, Außenvertretung der deutschen Rechnungshöfe in der Europäischen Union, 2001, S. 1 f.
} 
jedoch, dass sie gegebenenfalls verpflichtet seien, Prüfungen im Auftrage des europäischen Rechnungshofes durchzuführen, ${ }^{983}$ geht zu weit und steht im Widerspruch zum Wortlaut des Vertrages. Vielmehr steht es im Ermessen des mitgliedstaatlichen Rechnungsprüfungsorgans zu entscheiden, ob es auf eine Anfrage des Europäischen Rechnungshofes hin lediglich den Kontakt zu der zu prüfenden Stelle herstellt, diesen bei der Prüfung begleitet oder ob es selbst parallele Prüfungen vornimmt oder sich sogar für eine gemeinsame Prüfung entscheidet.984

Der Zusammenschluss der Mitgliedsländer zur Europäischen Union bringt zwangsläufig eine immer enger werdende „Verzahnung ihrer Haushalts- und Finanzpolitik" mit sich, was ein abgestimmtes Handeln notwendig macht. ${ }^{985}$ Dementsprechend kommt es auch zu Berührungspunkten im Bereich der externen Finanzkontrolle im europäischen Rechnungshofsystem ${ }^{986}$, da bestimmte Bereiche sowohl der Prüfung durch den nationalen Rechnungshof als auch durch den EuRH unterliegen und gleichgerichtete Prüfungsinteressen bestehen. ${ }^{987}$

Eine Zusammenarbeit der Rechnungshöfe der Mitgliedstaaten und des Europäischen Rechnungshofes erfolgt vor allem im Rahmen des jährlich tagenden „Kontaktausschusses“, der sich aus deren Präsidenten zusammensetzt. ${ }^{988}$ Die Einrichtung geht bereits auf eine erste Sitzung der Präsidenten der Obersten Rechnungskontrollbehörden der Mitgliedstaaten der EWG aus dem Jahre 1960 zurück, 1978 trat dieser der EuRH als zehntes Mitglied bei. ${ }^{989}$ Die Ermächtigung des Präsidenten des EuRH zur Schaffung eines „Ausschusses für Kontakte mit den Präsidenten der einzelstaatlichen Rechnungsprüfungsorgane“, die sich aus der Erklärung Nr. 18 der Schlussakte zum Vertrag von Nizza ergibt, bezog sich somit auf eine bereits existente Einrichtung. Diese Erklärung definiert als Auftrag des Kontaktausschusses, „den Rahmen und die Bedingungen für ihre [der mitgliedstaatlichen Rechnungshöfe] Zusammenarbeit unter Beibehaltung ihrer jeweiligen Autonomie zu verbessern.“

Im Zentrum der Zusammenarbeit stehen Fragen der Prüfung von Einnahmen und Ausgaben der EG in den Mitgliedstaaten, wobei besonders die Schaffung

983 So Bieber, in: v.d.Groeben/Schwarze, Art 248 EG, Rn. 22 m.w.N.; Niedobitek, in: Streinz, EUV/EGV, Art. 248 EGV, Rn. 14.

984 So auch der Präsident des Europäischen Rechnungshofes, Weber, Vertrauensvolle Zusammenarbeit zwischen Europäischem Rechnungshof und den Rechnungshöfen der Mitgliedstaaten, in: Österreichischer Rechnungshof, Positionen - Öffentliche Finanzkontrolle in Österreich, 2007, S. 37 (39).

985 Zavelberg, Die Arbeit der Rechnungshöfe im internationalen Bereich, DÖV 1993, 1000 (1002).

986 Mähring, Externe Finanzkontrolle im europäischen Mehrebenensystem, DÖV 2006, 195, geht davon aus, dass „die externe Finanzkontrolle ein kohärentes und funktionierendes „Europäisches Netzwerk Externer Finanzkontrolle" implementieren muss, um die ordnungsgemäße und wirtschaftliche Verwendung der EU-Mittel sicherzustellen“.

987 Von Wedel, Finanzkontrolle von Mitteln der Europäischen Gemeinschaft, in: Rechnungshof Rheinland-Pfalz, Kooperation der Finanzkontrolle in Europa, 1999, S.260 ff., 262.

988 Zavelberg, Die Arbeit der Rechnungshöfe im internationalen Bereich, DÖV 1993, 1000 (1002).

${ }^{989}$ Vgl. http://www.contactcommittee.eu. 
gemeinsamer Standards durch die Harmonisierung von Prüfungsbefugnissen und die Angleichung von Prüfungsverfahren und -methoden bedeutsam ist. ${ }^{990}$

Neben dem Kontaktausschuss tagen halbjährlich Verbindungsbeamte des EuRH und der mitgliedstaatlichen Rechnungshöfe.

Jedoch ist auch im Kontaktausschuss die Zusammenarbeit freiwillig, wie aus den „Leitsätzen zur Zusammenarbeit“, die dieser sich im Jahr 2003 gegeben hat, deutlich wird. ${ }^{991}$ So heißt es im zweiten Leitsatz: „Der Vertrag von Amsterdam ruft den Europäischen Rechnungshof und die nationalen obersten Rechnungskontrollbehörden zur vertrauensvollen Zusammenarbeit „unter Wahrung ihrer Unabhängigkeit"“ auf. Das Verhältnis ist dahingehend einmalig, dass gleichberechtigte und unabhängige Prüfungsbehörden zur Zusammenarbeit gehalten sind, um den Rahmen und die Bedingungen für die Prüfung von EU-Mitteln zu verbessern." Der dritte Leitsatz legt fest, dass die Zusammenarbeit funktionieren muss, „ohne die Beteiligten an der Erfüllung ihres jeweiligen Auftrages zu behindern“. Leitsatz 5 stellt klar, dass ,alle Institutionen vollkommen unabhängig darüber entscheiden, an welchen Zusammenarbeitsaktivitäten sie sich beteiligen“"

Dies wurde ferner auf der Sitzung des Kontaktausschusses im Jahr 2005 erneut ausdrücklich festgestellt, danach bedeutet die ,,vertrauensvolle Zusammenarbeit unter Wahrung ihrer Unabhängigkeit“ gem. Art. 248 Abs. 3 EGV (Art. 287 Abs. 3 AEUV) in der Praxis, „dass der EuRH sich auf die Arbeit der nationalen Rechnungshöfe stützen kann, Inhalt und Umfang dieser Zusammenarbeit jedoch jeweils der unabhängigen Entscheidung der beteiligten Rechnungshöfe unterliegt".992

Das Europäische Rechnungshofsystem bildet letztlich einen den Besonderheiten der externen Finanzkontrolle angemessenen Rahmen hinsichtlich der Freiwilligkeit der Zusammenarbeit. Zum einen kann der Europäische Rechnungshof im Gegensatz zu allen anderen Organen grundsätzlich keine rechtsverbindlichen Akte erlassen und schon aus diesem Grund keine zwingenden Anweisungen an andere Rechnungshöfe geben. Zum anderen ist es die gemeineuropäische Tradition der Unabhängigkeit und Weisungsfreiheit der Rechnungshöfe, die dies notwendig macht. Hier sei darauf hingewiesen, dass es sich in Deutschland mit seinen dem föderalen System entsprechenden Rechnungshöfen auf Bundes- und auf Landesebene genauso verhält; es besteht ein enges Kooperationsverhältnis, das von ei-

990 Bundesrechnungshof, Bemerkungen 1993, BT-Drs.12/5650, S. 13, Tz. 1.7.3.; Weber, Vertrauensvolle Zusammenarbeit zwischen Europäischem Rechnungshof und den Rechnungshöfen der Mitgliedstaaten, in: Österreichischer Rechnungshof, Positionen - Öffentliche Finanzkontrolle in Ö́sterreich, 2007, S. 37 (40).

991 Die Leitsätze nebst Erläuterungen sind abrufbar unter: http:/ /www.contactcommittee.eu.

992 Sitzung des Kontaktausschusses vom 5. - 6. Dezember 2005 in Stockholm, Stellungnahme zur Rolle der externen Finanzkontrolle innerhalb des rechtlichen Rahmens der Rechnungslegung für Gemeinschaftsmittel, S. 2, abrufbar unter http://www.contactcommittee.eu. 
nem Nebeneinander und nicht von einem Hierarchieverhältnis mit Weisungsrechten des Bundesrechnungshofes an die Landesrechnungshöfe geprägt ist. ${ }^{993}$

Jedoch ist der Vertrag im Lichte des Art. 10 EGV (Art. 4 Abs. 3 EUV n.F.) systematisch dahingehend auszulegen, dass zumindest ein gewisses Mindestmaß an Kooperation gewährleistet sein muss. Die nationalen obersten Rechnungskontrollorgane können sich nicht völlig der Zusammenarbeit verschließen. Darauf deutet Art. 248 Abs. 3 UAbs. 1 S. 3 EGV (Art. 287 Abs. 3 UAbs. 1 S. 3 AEUV) („Der Europäische Rechnungshof und die nationalen Rechnungsprüfungsorgane arbeiten unter Wahrung ihrer Unabhängigkeit vertrauensvoll zusammen.") hin. Dies klingt auch im zweiten Leitsatz zur Zusammenarbeit an, wonach die Rechnungshöfe „zur Zusammenarbeit gehalten“ sind. Die Grenze stellt die Sicherstellung der Unabhängigkeit und der Erfüllung der eigenen Prüfungstätigkeiten dar. Zwar entscheiden die Rechnungshöfe selbst, an welchen Zusammenarbeitsaktivitäten sie teilnehmen, eine völlige Verweigerung der Zusammenarbeit verstieße jedoch gegen Art. 248 EGV (Art. 287 AEUV). Dieses Problem stellt sich derzeit in der Praxis aber ohnehin nicht, da die Zusammenarbeit von allen Seiten erwünscht ist. Damit erfüllt auch das europäische Rechnungshofsystem mit den aufgeführten Besonderheiten das dem Staaten- und Verfassungsverbund geschuldete „loyale Kooperationsverhältnis“ zwischen europäischen und mitgliedstaatlichen Stellen.

Im Kontext des gemeinsamen Rechnungshofsystems ist auch die Forderung des Kontaktausschusses in der auf seiner Konferenz in Den Haag 1989 erlassenen Resolution zu sehen, dass ,in Fällen, in denen die Prüfungsrechte von nationalen Rechnungshöfen hinter denen des Rechnungshofes der EG zurückbleiben, die Prüfungsrechte der nationalen Rechnungshöfe denen des EuRH angeglichen werden sollen“. 994 Ohne rechtlich hierzu verpflichtet zu sein, leiteten daraufhin Italien und Luxemburg erste Schritte dazu ein. ${ }^{995}$

Dieses Beispiel zeigt, dass neben der Zusammenarbeit an sich auch Impulse zur Weiterentwicklung und Angleichung der Kontrollstandards ergehen. In für den Staaten- und Verfassungsverbund typischer Weise erfolgen diese Auswirkungen in beide Richtungen, von der europäischen Ebene auf die mitgliedstaatliche und umgekehrt. Ausgestaltung und Weiterentwicklung des EuRH basieren auf den mitgliedstaatlichen Rechnungshofmodellen und Erfahrungen und umgekehrt bewirkt dieser Weiterentwicklungen und Anpassungen auf nationaler Ebene, insbesondere durch die Vereinheitlichung von Prüfungsstandards und der Verbesserung der Zusammenarbeit. Gerade die Entwicklung im Rahmen der Osterweiterung der Europäischen Union wird zeigen, ob diese Form des Zusammenwirkens

\footnotetext{
993 Bundesrechnungshof, Bundesrechnungshof und Prüfungsämter des Bundes, 2005, S. 21; vgl. auch $\$ $93 \mathrm{BHO}$.

994 Bundesrechnungshof, Bemerkungen 1993, BT-Drs.12/5650, S. 13, Tz. 1.7.3.; Zavelberg, Die Arbeit der Rechnungshöfe im internationalen Bereich, DÖV 1993, 1000 (1003).

995 Zavelberg, Die Arbeit der Rechnungshöfe im internationalen Bereich, DÖV 1993, 1000 (1003).
} 
ausreicht, um europaweit ein homogenes und effizientes System der Finanzkontrolle zu gewährleisten.

Nicht aus den Augen verloren werden darf vor allem, dass es durchaus zu Prüfungszielkonflikten zwischen EuRH und nationalen Rechnungshöfen kommen kann. Schließlich sind falsch verausgabte EU-Mittel an den Unionshaushalt zurückzuerstatten, so dass die Aufdeckung unter Umständen, etwa bei Zahlungsunfähigkeit des Endbegünstigten, zu Nachteilen für die nationalen Haushalte führen kann. ${ }^{996}$

Zahlreiche Beispiele bi- und multilateraler Zusammenarbeit auf europäischer Ebene verdeutlichen ferner, dass gemeinsame Prüfungen nicht nur mit dem EuRH, sondern auch mit anderen mitgliedstaatlichen Rechnungshöfen stattfinden. So erfolgten zusammen mit der französischen Cour des comptes und dem britischem National Audit Office gemeinsame Erhebungen im Programmbüro für die multilaterale Entwicklung des Panzerabwehr-Lenkwaffensystems PARS 3. ${ }^{997} \mathrm{Da}$ neben nahm der Bundesrechnungshof eine begleitende Prüfung der Entwicklung des Eurofighters zusammen mit den Rechnungshöfen der beteiligten Staaten vor. ${ }^{998}$ Ein weiteres Beispiel ist die 1994 erfolgte Initiative des Bundesrechnungshofes zur Prüfung des Übergangssystems bei der Mehrwertsteuer, dem sich die niederländische Algemene Rekenkammer anschloss. ${ }^{999}$

In den Jahren 2005/2006 erfolgte eine gemeinsame Prüfung des Bundesrechnungshofes mit dem Rechnungshof der Tschechischen Republik hinsichtlich der Ausgaben für den Autobahnbau Dresden-Prag. ${ }^{1000}$

Zwischenergebnis: Das europäische Rechnungshofsystem ist geprägt von $\mathrm{Zu}$ sammenarbeit und regem Austausch untereinander. Die Rechnungshöfe stimmen sich in ihrer Arbeitsweise aufeinander ab. Um der Besonderheit gesetzlich verbürgter Unabhängigkeit in unterschiedlichen Ausprägungen gerecht zu werden, erfolgt die Zusammenarbeit auf freiwilliger Basis. Jedoch hat der EuRH bestimmte Informations- und Zugangsrechte hinsichtlich in den Mitgliedstaaten verwendeter EU-Mittel, die gegenüber der mitgliedstaatlichen Seite verbindlich und verpflichtend sind. Verbesserungsbedarf besteht dabei aufgrund der Tatsache, dass die Verträge dem Europäischen Rechnungshof kein geeignetes Instrumentarium zur Hand geben, um seine Rechte selbst durchzusetzen. Insbesondere hat er wie gesehen keine eigenen Klagemöglichkeiten gegenüber den Mitgliedstaaten und

\footnotetext{
996 Ausführlich: Fehr, Mögliche Wechselwirkungen zwischen dem Europäischen Rechnungshof und nationalen Rechnungshöfen, in: FS Lüder, 2000, S. 675 (687).

997 Bundesrechnungshof, Bemerkungen 1993, BT-Drs. 12/5650, Tz. 1.7.2.

998 Bundesrechnungshof, Bemerkungen 1993, BT-Drs. 12/5650, Tz. 1.7.2. mit weiteren Beispielen.

999 Rechenberg, Der Europäische Rechnungshof in seinem Verhältnis zum Bundesrechnungshof, in: FS Hahn, 1997, S. 697 (701).

1000 Noch nicht veröffentlicht, aber abrufbar unter: http://www.bundesrechnungshof.de/aktuelles.
} 
kann nur mittelbar durch die Kommission ein Vertragsverletzungsverfahrens einleiten.

2. Zusammenarbeit einzelstaatlicher Rechnungshöfe im Rahmen von EUROSAI und INTOSAI

Eine Zusammenarbeit verschiedener Rechnungskontrollorgane findet neben der Zusammenarbeit der „EU-Rechnungshöfe“ auch im Rahmen spezifischer internationaler Organisationen statt. Auf internationaler Ebene sind vor allem die Internationale Organisation der Obersten Rechnungskontrollbehörden (INTOSAI) und auf europäischer (über den Kreis der EU-Mitgliedstaaten hinausgehend) die Europäische Organisation der Obersten Rechnungskontrollbehörden (EUROSAI) zu nennen, die aber im Rahmen dieses Themas keiner vertiefenden Betrachtung bedürfen. ${ }^{1001}$

\section{Zusammenfassung der Ergebnisse des 3. Teils}

Der Europäische Rechnungshof ersetzte nach dem Vertrag von Brüssel 1975 den bis dahin die Rechnungsprüfung der Europäischen Gemeinschaften ausübenden Kontrollausschuss. Bereits in der Errichtung des Hofes, die maßgeblich auf die Initiative von Abgeordneten des Europäischen Parlaments zurückging, manifestierte sich der Wille, eine unabhängige, effiziente Finanzkontrolle auf Gemeinschaftsebene zu schaffen, um Unregelmäßigkeiten und Betrügereien zu bekämpfen und für Transparenz auf dem Gebiet der Gemeinschaftsfinanzen zu sorgen. Der Kontrollausschuss war hierzu nicht mehr geeignet, weil ihm entsprechende Kontrollrechte sowohl gegenüber Organen als auch gegenüber Mitgliedstaaten fehlten. Seinem Aufgabenbereich war bis dahin auch nur untergeordnete Bedeutung zugemessen worden, was die als „Nebenamt“ ausgelegte Tätigkeit seiner Mitglieder verdeutlichte.

Die Errichtung des Europäischen Rechnungshofes stand damit deutlich im Einklang mit der Erweiterung der Finanzaktivitäten der Europäischen Gemeinschaften aufgrund der Vergrößerung ihrer Mitgliederzahl und der Zunahme ihrer Finanzautonomie durch die Änderungsverträge von 1970 und 1975. Zugleich ging sie einher mit dem erheblichen Bedeutungszuwachs für das Parlament, dem immer größere Haushalts- und Kontrollrechte zugestanden wurden. Für das Parlament ist nämlich zur sinnvollen Ausübung dieser Rechte eine effektive Finanzkontrolle unabdingbar, was erklärt, dass es wohl der größte Befürworter der Errichtung war. Zugleich zeigte sie den Willen der Mitgliedstaaten, Kontrolle und Transparenz auf Gemeinschaftsebene öffentlichkeitswirksam zu stärken, um so

1001 Ausführlich: Nawrath, Die internationale Zusammenarbeit der Rechnungshöfe, DÖV 2000, 861; Isensee, Außenvertretung der deutschen Rechnungshöfe in der EU, 2001, S.27 ff. 
die Akzeptanz für das gemeinsame Projekt in der Bevölkerung zu verbessern. Die Stellung der Mitglieder des Rechnungshofes entsprach schon von der Gründung an der von Richtern am Europäischen Gerichtshof.

Die sukzessive Stärkung der externen Finanzkontrolle der Europäischen Gemeinschaft mündete schließlich in der Organqualität des Europäischen Rechnungshofes durch den Vertrag von Maastricht 1992 für die Europäische Gemeinschaft und durch den Vertrag von Amsterdam 1997 für die Europäische Union. Durch Letzteren wurde ihm auch die für die Gewährleistung seiner Unabhängigkeit bedeutsame Aktivlegitimation bei Nichtigkeitsklagen vor dem Europäischen Gerichtshof eingeräumt.

Die Verträge sorgen für eine gute Absicherung der persönlichen wie sachlichen Unabhängigkeit der Rechnungshofmitglieder. Was die Ernennung der Mitglieder angeht, so führt das Vorschlagsrecht der Mitgliedstaaten für je ein Mitglied zu einer unnötig hohen Zahl an Rechnungshofmitgliedern. Dass es auch nach dem Änderungsvertrag noch bei dieser bleiben wird, steht beispielhaft für den stockenden Reformprozess und die fehlende Bereitschaft der Mitgliedstaaten Kompromisse einzugehen, soweit sie einen Bedeutungsverlust befürchten. Jedoch haben die hohe Zahl der Mitglieder des Rechnungshofes und das Verfahren des Vorschlagsrechts der Mitgliedstaaten auch ihr Gutes: Es droht keine einseitige Ernennung aus parteipolitischen Gründen, was der Unabhängigkeit der Institution als ganzer zugutekommt.

Der Rechnungshof nimmt die klassischen Aufgaben oberster Finanzkontrollorgane wahr, indem er die Recht- und Ordnungsmäßigkeit sowie die Wirtschaftlichkeit des Finanzgebarens der Europäischen Union und der Mitgliedstaaten, soweit diese Gemeinschaftsmittel verwalten, kontrolliert und hierüber berichtet. Daneben kommt ihm ein Beratungsauftrag zu, der insbesondere seine obligatorische Anhörung beim Erlass gemeinschaftlicher Normen in finanzrelevanten Bereichen umfasst. Staatsgewalt im Sinne eines verbindlichen, hoheitlichen Tätigwerdens übt er nicht aus, vielmehr ist seine Tätigkeit innerstaatlicher beziehungsweise innergemeinschaftlicher Natur.

Der Europäische Rechnungshof hat gegenüber den anderen Gemeinschaftsorganen und den ihnen untergeordneten Stellen weitreichende Informations- und Zugangsrechte, die er notfalls auch im Wege einer Untätigkeits- oder einer Nichtigkeitsklage vor dem Europäischen Gerichtshof durchsetzen kann. Hinsichtlich der entsprechenden Rechte gegenüber den Mitgliedstaaten ergeben sich für das Rechnungshofsystem im europäischen Staaten- und Verfassungsverbund gewisse Besonderheiten. Der Europäische Rechnungshof führt Prüfungen in den Mitgliedstaaten in Zusammenarbeit mit den mitgliedstaatlichen obersten Rechnungskontrollorgane durch. Sie arbeiten dabei unter Wahrung ihrer Unabhängigkeit vertrauensvoll zusammen. Hieraus wird deutlich, dass das Verhältnis zwischen den Rechnungshöfen kein hierarchisches, sondern vielmehr ein kooperatives ist, aus dem sich jedoch auch gewisse Pflichten zur Zusammenarbeit ergeben. Für den 
Fall, dass ein nationales Rechnungskontrollorgan nicht an einer Prüfung teilzunehmen beabsichtigt, kommt dem Europäischen Rechnungshof jedoch auch ein eigenständiges Prüfungsrecht gegenüber mitgliedstaatlichen Stellen zu. Problematisch ist hierbei, dass er weder über eigene Mittel zur Durchsetzung seiner Rechte verfügt, insbesondere keine Aktivlegitimation in einem Vertragsverletzungsverfahren besitzt. Der Europäische Rechnungshof könnte mithin allenfalls mittelbar über die Kommission eine solche Klage anstrengen.

Die Stellung des EuRH im Organgefüge von Europäischer Union und Europäischer Gemeinschaft weist im Gegensatz zu den untersuchten nationalstaatlichen Modellen die Besonderheit auf, dass er gleichberechtigt und selbst mit Organstatus versehen auf einer Ebene mit den auf Gemeinschaftsebene die Legislative, Exekutive und Judikative ausübenden anderen Hauptorganen steht. Jedoch handelt der Rechnungshof weder im Sinne einer der Handlungsformen des Art. 249 EGV rechtsverbindlich, noch spricht er Recht wie EuGH und EuG. Der Europäische Rechnungshof übt damit im Ergebnis keine Staatsgewalt aus, sondern ist ein innergemeinschaftlich tätiges Kontrollorgan. Er nimmt damit eine Sonderstellung im Rahmen des institutionellen Gleichgewichts ein. Die Organstellung lässt sich durch den Schwerpunkt der Europäischen Gemeinschaft auf wirtschaftlichem und finanziellen Gebiet erklären und dem damit einhergehenden Bedürfnis an wirksamer Kontrolle. Auch ermöglicht der Rechnungshof durch seine Arbeit dem Europäischen Parlaments in vielerlei Hinsicht überhaupt erst die Wahrnehmung seiner Kontrollaufgaben. Besonders wichtig ist auch seine Rolle als Informant der Öffentlichkeit. In seiner starken Stellung manifestiert sich der Kontrollwille der Mitgliedstaaten auf europäischer Ebene, er dient so dazu, die Transparenz für die Bürger zu erhöhen und damit mittelbar die Akzeptanz für die europäische Integration zu verbessern.

Wie aus den Rechnungshofberichten deutlich wird, übt der Rechnungshof seine Aufgaben selbstbewusst gegenüber Mitgliedstaaten wie auch gegenüber den anderen Organen aus. Beispielhaft sei hier die Rolle des Europäischen Rechnungshof genannt, die seinerzeit für den Rücktritt der Santer-Kommission mitverantwortlich war.

Im Ergebnis ist die Einräumung einer derart exponierten Stellung, wie sie der Europäische Rechnungshof in der Union hat, vorbildlich für ein oberstes Finanzkontrollorgan. Jedoch gibt es durchaus noch Verbesserungsmöglichkeiten: So wäre es sinnvoll, dem Hof eigene Möglichkeiten zu geben, seine Informationsund Zugangsrechte in den Mitgliedstaaten durchzusetzen, insbesondere könnte ihm ein eigenes Klagerecht eingeräumt werden, falls nationale Stellen seine Rechte verweigern. Die Zusammenarbeit mit den nationalen obersten Rechnungskontrollorganen würde dies jedoch nicht betreffen, hier gelten die der Unabhängigkeit geschuldeten Besonderheiten des europäischen Rechnungshofsystems. 



\section{Vierter Teil: \\ Rechtsvergleichende Stellungnahme und Resümee}

Im Rahmen des Vergleichs sollen Unterschiede und Gemeinsamkeiten der Rechnungshöfe Deutschlands, Frankreichs, Österreichs, Spaniens, des Vereinigten Königreichs und des Europäischen Rechnungshofes aufgezeigt und bewertet werden. Im Anschluss an die separate Darstellung der ausgewählten mitgliedstaatlichen obersten Rechnungskontrollinstitutionen im ersten und zweiten Teil und des Europäischen Rechnungshofes im dritten Teil dieser Arbeit sollen nun die verschiedenen Systeme mit ihren Besonderheiten hinsichtlich der ihnen gewährten Hilfsgarantien, ihrer Aufgaben und Handlungsformen, ihrer Einordnung im System der Staatsgewalten und ihrer Klagemöglichkeiten verglichen werden.

\section{A. Vergleich}

Die geschichtliche Entwicklung zeigt, dass die Stellung aller untersuchten mitgliedstaatlichen Rechnungshöfe, mithin ihre Zuordnung zu einer Gewalt im Staate und die Ausgestaltung ihrer Unabhängigkeit, sehr wechselvoll war. Diese Zuordnung drückte die tatsächlichen Machtverhältnisse im Staate und seine jeweilige Staatsform aus. Sie zeigt, dass Rechnungshöfe von jeher als Machtmittel ver- 
standen wurden, weil sie dem Staatsorgan, das auf sie zurückgreifen kann, die Kontrolle der Finanzen des Staates ermöglichen. Besonders deutlich ist diese wechselvolle Geschichte in Spanien im 19. und bis zur Mitte des 20. Jahrhunderts: Oft wechselnde Staatsformen, Revolutionen und Gegenrevolutionen bedingten eine sehr häufige Veränderung des Standortes des spanischen Rechnungshofes und seiner Vorgänger. Einzig im Vereinigten Königreich ist die Geschichte des Comptroller and Auditor General relativ konstant, was aber daran liegt, dass dieses Amt und damit eine echte externe Finanzkontrolle erst 1866 eingeführt wurde und es seitdem auch zu keinen wesentlichen staatsrechtlichen Veränderungen im Sinne von grundlegenden Machtverschiebungen gekommen ist.

Die geschichtliche Entwicklung der Rechnungsprüfung ist geprägt von wechselnden Abhängigkeiten und Erweiterungen beziehungsweise Verkleinerungen der Aufgabenkreise. So standen etwa am Beginn der Entwicklung in Preußen und Österreich sehr weitgehende Zugeständnisse, was die Unabhängigkeit und vor allem die Prüfungsrechte gegenüber der Exekutive anging. In Österreich zeigte sich dies in der Präventivkontrolle durch aufschiebend wirkende Gutachten in allen wichtigen Finanzangelegenheiten; in Preußen war es die „Zwangsberatung“ der Exekutive durch den Rechnungshof. Zwischenzeitlich wurden diese Rechte eingeschränkt, weil es zu Konflikten mit der derart überwachten Verwaltung kam, oder wieder ausgedehnt, um bestmögliche Finanzkontrolle zu gewährleisten.

\section{Verfassungsrechtliche Hilfsgarantien}

Alle untersuchten mitgliedstaatlichen Rechnungshöfe mit Ausnahme des britischen - aufgrund der Besonderheiten des britischen Rechtssystems - sind in den jeweiligen Verfassungen garantiert, ${ }^{1002}$ der Europäische Rechnungshof dementsprechend in den Verträgen. ${ }^{1003}$ Darin zeigen sich Stellenwert und Unabdingbarkeit externer Finanzkontrolleinrichtungen für den modernen Rechtsstaat.

Eine der wichtigsten, typbestimmenden Eigenschaften von Rechnungshöfen ist ihre Unabhängigkeit. Diese wird gemeinhin als entscheidende Voraussetzung für die Fähigkeit, die Kontrollaufgaben wirksam und objektiv auszuüben, mithin als conditio sine qua non der Finanzkontrolle, betrachtet. ${ }^{1004}$ So ist allen hier untersuchten Rechnungskontrollorganen gemeinsam, dass ihnen besondere Unabhängigkeitsgarantien zugestanden werden, wenn auch in ganz unterschiedlicher Weite und Ausprägung.

\footnotetext{
1002 Deutschland: Art. 114 Abs. 2 GG; Frankreich: Art. 47 Abs. 6 CF; Österreich: Art. 121- 128 BVG; Spanien: Art. 136 Abs. 1 CE.

1003 Art. 5 EUV, Art. 7 und $246-248$ EGV.

1004 v.Pfublstein, Der Weg von der Preußischen Generalrechenkammer zum Bundesrechnungshof, in: Bundesrechnungshof, 250 Jahre Rechnungsprüfung, 1964, S. 8; v.Arnim, Staatslehre, 1984, S. 407.
} 
Zunächst ist dies die persönliche Unabhängigkeit der Mitglieder, die auch die Unabhängigkeit der Rechnungshöfe als Institutionen begründet ${ }^{1005}$. Ihre prägenden Elemente sind die Regelungen zu Ernennung und Abberufung in engem Zusammenhang mit Amtszeit und Wiederwahlmöglichkeiten der Mitglieder. Weiter ist es die organisatorische Ausgestaltung des Organs und seiner Entscheidungsmechanismen entweder als kollegial verfasste oder als - notwendigerweise hierarchische - monokratische.

In Deutschland ist die Ernennung des Präsidenten des Bundesrechnungshofes gem. $\int 5$ Abs. 1 BRHG durch ein Zusammenwirken von Organen der Legislative und Exekutive ausgestaltet: Bundestag und Bundesrat wählen auf Vorschlag der Bundesregierung den Präsidenten und den Vizepräsidenten jeweils mit einfacher Mehrheit, die dann vom Bundespräsidenten ernannt werden. Die Amtszeit beträgt zwölf Jahre, wobei eine Wiederwahl ausgeschlossen ist.

Auch die interne Organisation des Hofes ist an der Sicherstellung der Unabhängigkeit orientiert. Der Rechnungshof ist daher als Kollegialorgan verfasst. Als kritikwürdig lassen sich, wie ausführlich im 1. Teil unter III. 1. a) dargestellt, die Wahl mit nur einfacher Mehrheit im Parlament und die starke Stellung des Präsidenten ausmachen, wobei die geringe Anforderung der Wahl mit der Regierungsmehrheit im Bundestag durch die Notwendigkeit ihrer Bestätigung im Bundesrat zu einem gewissen Grad ausgeglichen wird. Positiv zu bewerten sind die gewaltenübergreifende Ausgestaltung des Ernennungsverfahrens und die lange Amtszeit des Präsidenten verbunden mit dem Ausschluss der Wiederwahl sowie die richtergleiche Unabhängigkeit der Mitglieder.

In Frankreich erfolgt die Ernennung des Rechnungshofpräsidenten und der obersten Ränge im Rechnungshof gem. Art. L 121-1 CJF durch den Ministerrat. Die Mitglieder sind traditionell unabsetzbar, die Amtszeit wird lediglich durch die Altersgrenze von 68 Jahren beschränkt. Der Eigenschaft als Gericht entsprechend ist der französische Rechnungshof als Kollegialorgan ausgestaltet, seine Mitglieder Richter mit allen dementsprechenden Unabhängigkeitsgarantien. Staatsrechtlich ist der französische Rechnungshof zwischen Legislative und Exekutive zu verorten. Von daher überrascht auch die Ernennung allein durch den Ministerrat. Eine Einbeziehung des Parlaments erschiene zum einen als Folge aus der verfassungsrechtlichen Einordnung der Cour des comptes, und zum anderen angesichts ihrer Unabhängigkeit sachgemäßer, weil nach der aktuellen Regelung in gewisser Weise die Gefahr besteht, dass der Kontrollierte seinen Kontrolleur ernennt.

In Österreich erfolgt die Ernennung des Präsidenten für eine Amtszeit von zwölf Jahren gem. Art. 122 Abs. 1 B-VG durch den Nationalrat mit einfacher Mehrheit, ohne dass eine Wiederwahlmöglichkeit besteht; die Abberufung erfolgt nach demselben Verfahren. Den Mitgliedern des Rechnungshofes wird weder die Qualität von Richtern zugestanden noch vergleichbare Unabhängigkeitsverbür-

1005 Brück/Kühne, Die Neuregelung der Finanzkontrolle der EG, DÖV 1977, 23 (24). 
gungen; zumindest enthält die Verfassung jedoch zahlreiche Inkompatibilitätsregelungen (Art. 122 Abs. 5, Art. 126 B-VG). Auch die innere Ausgestaltung des österreichischen Rechnungshofes ist als Folge seiner Stellung als Hilfsorgan der Legislative nicht an der Kollegialverfassung der Gerichte orientiert, sondern monokratisch organisiert. Unter dem Aspekt der Gewährleistung persönlicher Unabhängigkeit zu begrüßen ist die lange Amtszeit des Präsidenten des österreichischen Rechnungshofes von zwölf Jahren ohne Wiederwahlmöglichkeit. Die Abhängigkeit von der einfachen Nationalratsmehrheit bei der Ernennung und insbesondere bei seiner ebenfalls jederzeit möglichen Abberufung vermag hingegen in keiner Weise zu überzeugen. Verglichen mit allen hier behandelten Institutionen ist die Unabhängigkeit beim österreichischen Rechnungshof deutlich am schwächsten ausgeprägt.

Vorbildlich sind hingegen die Regelungen zur Sicherstellung der Unabhängigkeit in Spanien.

Hier ernennt jede der beiden Kammern des Parlamentes je sechs der zwölf Mitglieder für eine Amtszeit von neun Jahren (Art. 30 Abs. 1 LOTCu) mit DreiFünftel Mehrheit, wobei eine Wiederwahl nicht ausgeschlossen ist. Sehr hohe Anforderungen, auch das ist eine spanische Besonderheit, werden an die Qualifikation der Mitglieder gestellt, die Voraussetzung für die Ernennung ist. Die Mitglieder genießen die gleichen Privilegien wie Richter, sie sind unabhängig und unabsetzbar und auch den gleichen strengen Inkompatibilitätsregelungen unterworfen. Gut gewählt sind auch die Regelungen zur Ernennung des Präsidenten: Diese erfolgt auf Vorschlag des Plenums der Mitglieder selbst, das unter sich einen geeigneten Kandidaten auswählt, um das Amt drei Jahre lang auszuüben. Somit hat niemand anders als der Rechnungshof selbst die Wahl zu treffen, den Fähigsten unter seinen Mitgliedern zu ernennen. Entsprechend seinem Charakter als Gericht ist auch das Tribunal de Cuentas als Kollegialorgan ausgestaltet.

Eine sachgerechte Ausgestaltung des Ernennungsverfahrens für seinen Comptroller and Auditor General gibt es auch im Vereinigten Königreich: Seine Ernennung erfolgt durch die Krone auf Vorschlag des Unterhauses hin; die Initiative hierfür wird vorher vom Premierminister im Einverständnis mit dem Vorsitzenden des Committee of Public Accounts, der traditionell Angehöriger der Opposition ist, eingebracht. Die Einbeziehung von Organen der Legislative und der Exekutive ist damit ebenso wie die der Opposition gewährleistet, letztere sichert eine breite parlamentarische Zustimmung. Hohe Hürden gelten auch für die Abberufung, die nur auf Antrag beider Häuser des Parlaments erfolgen kann. Die Stellung als Hilfsorgan der Legislative bringt die monokratische, auf den Comptroller and Auditor General zugeschnittene Ausgestaltung des National Audit Office mit sich.

Der Europäische Rechnungshof wird mit einem Mitglied pro Mitgliedstaat besetzt. Der Rat ernennt diese nach Vorschlag durch die Mitgliedstaaten, das Europäische Parlament wird lediglich angehört. Ihre Amtszeit beträgt sechs Jahre bei 
möglicher Wiederwahl. Die Mitglieder des als Kollegialorgan aufgebauten Rechungshofes wählen gem. Art. 247 Abs. 3 UAbs. 2 EGV (Art. 286 Abs. 2 UAbs. 2 AEUV) aus ihrer Mitte den Präsidenten für drei Jahre.

Die Ausgestaltung beim Europäischen Rechnungshof mit nur sechsjähriger Amtszeit seiner Mitglieder und der Möglichkeit, erneut von ihrem Mitgliedstaat vorgeschlagen zu werden, ist problematisch. Wer als Rechnungshofmitglied eine weitere Amtszeit anstrebt, ist in Bezug auf das Tätigwerden gegenüber seinem Herkunftsland eingeschränkt, wird von ihm doch gewissermaßen erwartet, auch die eigenen nationalen Interessen zu beachten. Tut er dies nicht, ist es wahrscheinlich, dass er nach sechs Jahren von jemandem ersetzt wird, der dies aus Sicht der mitgliedstaatlichen Regierung besser vermag. Es wäre daher sinnvoll, die Amtszeit der Mitglieder bei Ausschluss der Wiederwahl auf zwölf Jahre zu verdoppeln.

Ansonsten ist die Ausgestaltung der Unabhängigkeit beim Europäischen Rechnungshof jedoch mit der Kollegialverfassung, der Wahl des Präsidenten als einem primus inter pares durch die Mitglieder selbst und ihrer richterlichen Unabhängigkeit sachgerecht geregelt. Hier sind auch die Unvereinbarkeitsvorschriften des Art. 247 Abs. 5 EGV (Art. 286 Abs. 4 AEUV) für Tätigkeiten während und nach Beendigung Mitgliedschaft zu nennen.

Hinsichtlich der sachlichen Unabhängigkeit bestehen weniger Unterschiede als Gemeinsamkeiten zwischen den verschiedenen untersuchten Ausgestaltungsformen. Grundsätzlich genießen bezüglich der Auswahl der Prüfungsgegenstände und der folgenden selbständigen Prüfung alle untersuchten Finanzkontrollorgane weitgehende Unabhängigkeit. Einzig in Österreich sieht Art. 126b Abs. 4 S. 1 BVG vor, dass der Nationalrat den Rechnungshof verbindlich mit bestimmten Prüfungen beauftragen kann. Gleiches gilt für Landtage in ihrem Zuständigkeitsbereich und sogar auf „begründetes Ersuchen“ der Bundesregierung oder eines Bundesministers; entsprechendes gilt auf Landesebene für Landesregierungen und -minister. Alle anderen Länder kennen nur die Möglichkeit, bestimmte Prüfungsersuchen unverbindlich an den Rechnungshof heranzutragen.

Die österreichische Ausgestaltung nimmt bei der sachlichen Unabhängigkeit wie auch schon bei den Regelungen zu Ernennung und Abberufung des Präsidenten eine Sonderstellung ein. Obwohl Einigkeit darüber besteht, dass die Effektivität der Finanzkontrolle und die Aussagekraft der von ihr erarbeiteten Ergebnisse gerade durch ihre Unabhängigkeit gewährleistet wird, konnte sich der österreichische Gesetzgeber bis heute trotz der seit langem geübten Kritik im Schrifttum ${ }^{1006}$ nicht dazu durchringen, eine diesbezügliche Neuregelung zu schaffen. Das offensichtliche Problem des zu großen Einflusses der die Regierung tragenden einfachen Parlamentsmehrheit spiegelt sich in den Mängeln der persönlichen und sachlichen Unabhängigkeit wider.

1006 Oben: 2. Teil B. II. 2. a), b) und VI. 2. mit Reformvorschlägen. 
Im Ergebnis können folgende Kriterien als beste Regelungen für die Sicherstellung der persönlichen Unabhängigkeit festgehalten werden: Wahl und Ernennung des Präsidenten sollten gewaltübergreifend geregelt sein, wobei der Schwerpunkt auf einer mehr als einfachen Parlamentsmehrheit liegen muss. Es ist eine lange Amtszeit von etwa zehn Jahren festzulegen, wobei eine Wiederwahlmöglichkeit auszuschließen ist. Den Mitgliedern ist richterliche Unabhängigkeit zu gewähren, was bei konsequenter Weiterführung die Ausgestaltung des Rechnungshofes als Kollegialorgan und die Stellung seines Präsidenten als primus inter pares notwendig macht. Die richtergleiche Stellung muss insbesondere die Unversetzbarkeit und die Unabsetzbarkeit der Mitglieder gewährleisten - unbeschadet der Möglichkeit, Verfehlungen zu ahnden. Die Unabhängigkeit muss sich weiter in strengen Regelungen zur Inkompatibilität der Mitgliedschaft an einem Rechnungshof mit anderen Ämtern widerspiegeln. Auch ist wie in Spanien ein Katalog über bestimmte Qualifikationen nachahmenswert, die ein Kandidat erfüllen muss, um überhaupt Mitglied des Rechnungshofes werden zu können. Ansonsten besteht die Gefahr, dass es allein von den Parteien ernannte „Experten“ sind, die bei unter Umständen zweifelhafter Fachkompetenz für ihre Verdienste um die Partei in die entsprechenden Ämter gewählt werden. Auf europäischer Ebene hat das Europäische Parlament, wie im 3. Teil unter II. 1. a) gesehen, einen sinnvollen Katalog aufgestellt, der aber leider vom Rat nicht als verbindlich betrachtet wird. Stattdessen gilt weiter das inhaltlich unbrauchbare Kriterium der „besonderen Eignung“ aus Art. 247 Abs. 2 EGV (Art. 286 Abs. 1 AEUV). ${ }^{1007}$

Was die sachliche Unabhängigkeit angeht, so muss völlige Weisungsfreiheit hinsichtlich des $\mathrm{Ob}$ und Wie jeder Prüfung, Beratung und Berichterstattung bestehen. Unproblematisch und sogar sinnvoll ist jedoch das Recht anderer Organe, insbesondere des Parlaments sowie seiner Ausschüsse oder der Regierung beziehungsweise einzelner Ministerien, den Rechnungshof um Prüfung bestimmter Gegenstände zu ersuchen. Auf europäischer Ebene entspricht dem die Anfrage eines anderen Organs.

\section{Aufgaben}

Gemeinsam ist allen hier untersuchten Obersten Rechnungskontrollorganen die Prüfungstätigkeit als rechnungshofspezifische Aufgabe. Auch hinsichtlich der Maßstäbe besteht Übereinstimmung: Geprüft wird anhand des Maßstabes der Ordnungsmäßigkeit und der Wirtschaftlichkeit, wobei die Gewichtung zugunsten des einen oder anderen der beiden durchaus unterschiedlich ausfällt. Hinzu kommen die Aufgaben der Beratung und Berichterstattung. Eine Besonderheit ergibt sich in Frankreich und Spanien durch das Bestehen einer gerichtlichen Funktion der Rechnungshöfe.

1007 Ausführlich oben: 3. Teil II. 1. a). 


\section{Die Prüfungstätigkeit}

Durch die Entwicklung zum Leistungs- und Sozialstaat in den untersuchten Mitgliedstaaten in der zweiten Hälfte des zwanzigsten Jahrhunderts trat neben die Prüfung der Recht- und Ordnungsmäßigkeit staatlichen Handelns der Maßstab der Wirtschaftlichkeit. Dennoch zeigen sich bei einem vergleichenden Blick in die Berichte der verschiedenen Rechnungshöfe deutliche Unterschiede in der Schwerpunktsetzung, das heißt darin, welches Gewicht beziehungsweise welcher Umfang diesen Maßstäben im Verhältnis zueinander zukommt. Je nach praktischen Notwendigkeiten und Prüfungsphilosophie kommt es zu einer unterschiedlich starken Schwerpunktsetzung bei der Ordnungsmäßigkeits- oder Wirtschaftlichkeitsprüfung.

So zeigen die Berichte des deutschen Bundesrechnungshofes eine sehr deutliche Betonung: Auf der Prüfung und Bewertung der Wirtschaftlichkeit staatlich finanzierter Vorhaben liegt ein klarer Schwerpunkt. Der Europäische Rechnungshof hingegen legt aus naheliegenden Gründen seinen Schwerpunkt auf die Prüfung der Ordnungsmäßigkeit des Umgangs mit Gemeinschaftsmitteln auf europäischer und auf mitgliedstaatlicher Ebene. Das Problem der Unregelmäßigkeiten und der nicht ordnungsgemäßen Mittelverwendung bis hin zum gezielten Betrug zeigt sich bei der dezentral angelegten komplizierten Verwaltungsstruktur der Union stärker als auf Ebene der Mitgliedstaaten. Das Ausmaß dieses Grundproblems ist aber leider so erheblich, dass es zwangsläufig in den Mittelpunkt europäischer Finanzkontrolle treten muss. ${ }^{1008}$

\section{Die Beratungstätigkeit}

Alle behandelten Rechnungshöfe haben einen Beratungsauftrag. In Österreich und beim Europäischen Rechnungshof sind vor dem Erlass von Gesetzen im Bereich bestimmter finanzrelevanter Regelungsmaterien sogar vorherige Anhörungen vorgeschrieben.

\section{Die Berichterstattung}

Gemeinsam ist den Rechnungshöfen auch die Aufgabe der Berichterstattung. Die besondere Rolle, die die Rechnungsprüfung allgemein für die Volksvertretung zur Ausübung ihrer Kontrollrechte hat, wird daraus deutlich, dass in allen untersuchten Ausgestaltungen oberster Rechnungskontrollorgane die Parlamente Empfänger der Berichte sind. In Österreich, Spanien und im Vereinigten Königreich sind diese sogar ausschließliche Adressaten der Berichterstattung durch die Rechnungshöfe. In Deutschland sind es neben dem Bundestag die Bundesregierung und der Bundesrat, in Frankreich außerdem der Staatspräsident.

$1008 \mathrm{Zu}$ den Fehlerquoten vgl. oben: 3. Teil III. 3. a). 
Die besondere Rolle, die der Europäische Rechnungshof in der Europäischen Union einnimmt, zeigt sich auch in den Regelungen zur Berichterstattung. Als Ausgangspunkt veröffentlicht er selbst den Jahresbericht und legt ihn dann offiziell den Präsidenten der anderen Organe sowie dem Vorsitzenden des Haushaltskontrollausschusses des Europäischen Parlaments vor. Ferner erfolgt eine Übermittlung an den Haushaltsausschuss des Rates, alle mitgliedstaatlichen Parlamente sowie die Präsidenten der obersten Rechnungskontrollorgane der Mitgliedstaaten. Hierin zeigt sich die Eigenständigkeit, die der Hof als Organ genießt: Er befindet sich in keinerlei Abhängigkeitsverhältnis zu den Adressaten seiner Berichte, sondern auf Augenhöhe mit ihnen und sorgt selbst und allein für die Veröffentlichung.

\section{Handlungsformen}

Mit Ausnahme der Rechnungshöfe Frankreichs und Spaniens, denen durch die Zuweisung judikativer Funktionen neben ihrer rechnungshoftypischen Tätigkeit in Form von Prüfung und Beratung eine Doppelstellung zukommt, entfalten die Handlungsformen der Rechnungshöfe keine rechtliche Außenwirkung gegenüber dem Bürger oder der zu prüfenden Stelle. Ihre Tätigkeit ist staatsinterner beziehungsweise gemeinschaftsinterner Natur. Schon aus diesem Grund war eine Verortung als „vierte Staatsgewalt“ im wörtlichen Sinne in keinem der untersuchten Fälle möglich. Die Rechnungshöfe Frankreichs und Spaniens bilden hiervon nur bezüglich ihres gerichtlichen Zweigs eine Ausnahme, innerhalb dessen Aufgabenbereich sie als Organe der Judikative unzweifelhaft Staatsgewalt in Form vollstreckbarer Urteile ausüben. Daneben können sie bei Verweigerung eines Auskunftsverlangens Geldstrafen gegen die Verantwortlichen verhängen. ${ }^{1009}$

Es stellt sich die Frage, ob die Ausgestaltung als Gericht beziehungsweise die Ausstattung mit eigenen Zwangsmitteln eine größere Wirksamkeit der Finanzkontrolle durch Rechnungshöfe zu begründen vermag. Diese Frage lässt sich wohl verneinen, denn entscheidend ist letztlich, dass der Gesetzgeber entsprechende Straftatbestände schafft. Stößt ein Rechnungshof nun auf Unregelmäßigkeiten oder entsteht bei den Prüfern der Verdacht eines Betruges, so wird er den Sachverhalt an die zuständige Staatsanwaltschaft weiterleiten. Auf europäischer Ebene entspricht dem die Weiterleitung an das Europäische Amt für Betrugsbekämpfung, OLAF, beziehungsweise an die zuständige Staatsanwaltschaft eines Mitgliedstaates. ${ }^{1010}$ Es besteht auch eine Pflicht der Mitgliedstaaten nach Art. 280 Abs. 2 EGV (Art. 325 Abs. 2 AEUV) zur Bekämpfung von Betrügereien, welche sich gegen die finanziellen Interessen der Gemeinschaft richten, die gleichen Maßnahmen zu ergreifen wie gegen solche, die sich gegen die eigenen Interessen richten.

${ }^{1009}$ Frankreich: Art. L 140-1 CJF; Spanien: Art. 30 Abs. 5 LFTCu.

1010 Oben: 3. Teil III. 
Am Beispiel Deutschlands kann hier die Einführung des Straftatbestandes des Subventionsbetruges gem. \246 Abs. 6 StGB und die Regelungen zum Steuerstrafrecht gem. $\iint 369$ ff. AO genannt werden. ${ }^{1011}$ Anstatt den Rechnungshof selbst als Gericht auszugestalten, ist es somit genauso wirksam, wenn bei der Prüfung festgestellte Rechts- und Ordnungswidrigkeiten an die zuständigen Stellen, die Staatsanwaltschaft oder auf Unionsebene OLAF, weitergeleitet werden, die bei Erfüllung eines Straftatbestandes entsprechende Verfahren vor den ordentlichen Gerichten einzuleiten haben.

\section{Einordnung in das staatliche Gewaltenteilungsschema beziehungsweise das institutionelle Gleichgewicht auf euro- päischer Ebene}

Eine gewisse Sonderstellung der Finanzkontrolle wird meist schon durch die Systematik der Verfassungen deutlich, die die Regelungen über die externe Finanzkontrolle durch einen Rechnungshof in einem separaten, von den Vorschriften über die Organe von Legislative, Exekutive und Judikative getrennten, Abschnitt enthalten. ${ }^{1012}$

Erkennbar ist eine Nähe der Rechnungshöfe zur Macht im Staate, die je nach Staatsform und Verfassungstradition durchaus unterschiedlich ausfallen kann. Dies erklärt sich dadurch, dass das Organ, das faktisch die Macht in den Händen hält, die Kontrollrechte gegenüber allen anderen Funktionsträgern hat. Im wichtigen Bereich der Finanzkontrolle ist das nur mit Hilfe von Rechnungshöfen als Kontrollinstitutionen möglich. So waren diese zum Beispiel in Frankreich, Österreich, Preußen und später Deutschland ursprünglich der Krone zugeordnet. Im 19. Jahrhundert kam es zunehmend zu Machtkämpfen zwischen den erstarkenden Parlamenten und dem Monarchen um die Kontrolle über die Finanzen und das damit verbundene Recht, die Erkenntnisse der externen Finanzkontrollorgane hierfür zu nutzen.

Heute kommt dem Bundesrechnungshof eine Sonderstellung zwischen den Gewalten zu, jedoch mit einer strukturellen Nähe zum Parlament. Auch die französische Cour des comptes steht unabhängig zwischen Legislative und Exekutive, wobei wie gesehen auch hier tendenziell eine stärkere Nähe zur Legislative besteht.

\footnotetext{
1011 Magiera, Der Schutz der finanziellen Interessen der EU, in: FS Friauf, 1996, S. 13 (21).

1012 Abschnitt X. „Finanzwesen“ des deutschen GG; das österreichische Bundesverfassungsgesetz regelt dies im separaten fünften Hauptstück; In Spanien Titel VII „Wirtschaft und Finanzwesen“ der spanischen Verfassung; die französische Verfassung regelt dies in Titel V, der die Beziehungen zwischen Parlament und Regierung zum Gegenstand hat; Der EuRH ist im 5. Teil, Titel I., Kapitel 1. des EGV wie die anderen Organe in einem eigenen, dem 5. Abschnitt, geregelt.
} 
Das spanische Tribunal de Cuentas untersteht dem Parlament. Auf den zweiten Blick jedoch, vor allem auf den politisch-historischen Kontext der Entstehung dieser Regelung, ist zu bemerken, dass sich hierin vielmehr der Wille des Verfassungsgebers manifestierte, eindeutig dem Parlament die wichtigste Rolle im Staate zuzuweisen und ihm daher auch den Rechnungshof zumindest formal unterzuordnen. Diese Intention beruht auf den Erfahrungen des 19. und 20. Jahrhunderts mit ihren ständigen Machtwechseln zunächst zwischen Monarchen und Parlament und später zwischen Diktatoren und Parlament. Dabei veränderte sich auch die Stellung des Tribunal de Cuentas ständig, indem es immer der Person oder dem Organ zugeordnet war, das die Macht im Staate ausübte. Mit dem Ende des Franco-Regimes ist in der Zuordnung zum Parlament schließlich ein Bekenntnis zu Demokratie und Rechtsstaat zu sehen. Rechtlich und tatsächlich ist der Rechnungshof hingegen auch dem Parlament gegenüber stark verselbständigt, was auch durch die vorbildliche Ausgestaltung der Unabhängigkeit, insbesondere der Ernennungsregelungen, deutlich wird.

Die Zuordnung des Comptroller and Auditor General zum Unterhaus ist mit der besonderen Stellung des Parlaments nach der britischen Verfassungstradition zu erklären, die vom Grundsatz der Sovereignty of Parliament ausgeht. So wird zum Beispiel auch die Regierung lediglich als Exekutivausschuss des Unterhauses betrachtet. Die Gewaltenteilung im Vereinigten Königreich ist stärker asymmetrisch ausgeprägt mit einem größeren Übergewicht des Parlamentes als in den untersuchten kontinentaleuropäischen Staaten. Dennoch sind wie gesehen die Ernennungsregelungen für den Comptroller and Auditor General derart ausgestaltet, dass sie durch die Einbeziehung von Premierminister und Opposition der Gewährleistung größtmöglicher Unabhängigkeit Rechnung tragen. Die Zuordnung zur Legislative erklärt sich mithin aus den Besonderheiten des britischen Verfassungsverständnisses.

Anders ist die Situation in Österreich: Verfassungstradition und Rolle des Parlaments ähneln eher der deutschen als der britischen. Dennoch ist der Rechnungshof dem Nationalrat unterstellt, was in der österreichischen Lehre bis heute erheblicher Kritik ausgesetzt ist. Besonders die Ausgestaltung der Ernennungsund Abberufungsvoraussetzungen, die nicht gewaltenübergreifend geregelt sind und lediglich der einfachen (Regierungs-) Mehrheit des Nationalrates bedürfen, lässt daran zweifeln, ob hier die geeignetsten Regelungen getroffen wurden, um eine unabhängige externe Finanzkontrolle zu gewährleisten. Selbst im Vereinigten Königreich garantieren die Ernennungsregelungen trotz der Eigenschaft des Comptroller and Auditor General als Hilfsorgan des Parlaments dessen Unabhängigkeit besser.

Eine besondere Art der Ausgestaltung bestimmter Rechnungshöfe ist es, ihnen Gerichtseigenschaft zu geben. Die Gerichtseigenschaft, welche die Verfassungen Frankreichs und Spaniens den Rechnungshöfen zuweisen, fußt in beiden Ländern auf einer sehr spezifischen Verfassungsgeschichte: In Frankreich beruht sie in 
ihrer heutigen Ausgestaltung auf dem unmittelbar nach der Revolution eingeführten Grundsatz des Art. 15 der Erklärung der Menschen- und Bürgerrechte vom 26. August 1789, dass „die Gesellschaft das Recht hat, jeden Mitarbeiter der öffentlichen Verwaltung zur Rechenschaft zu ziehen“. Dementsprechend können im französischen Verwaltungssystem auch die für die Ordnungsmäßigkeit der von ihnen zu überwachenden Einnahmen und Ausgaben verantwortlichen Comptables publics vom Rechnungshof zur Verantwortung gezogen werden.

In Spanien geht das Bestehen von Finanzkontrollorganen, denen neben ihren Prüfungsaufgaben gerichtliche Funktion zukommt, sogar bis ins Mittelalter zurück, wo die Rechenkammern auch das Recht hatten, Strafen und Bußgelder zu verhängen.

Das Bestehen eines gerichtlichen Zweiges oberster Rechnungsorgane ist als Ergänzung der Kernaufgaben Prüfung, Berichterstattung und Beratung zu sehen. Die Entscheidung des Verfassungsgebers für oder gegen sie ist eine Systemfrage, die vor dem Hintergrund der jeweiligen Verfassungstradition entschieden wird. Die Vor- und Nachteile einer solchen Kompetenzerweiterung sind diskutabel, Voraussetzung für eine effektive und unabhängige externe Finanzkontrolle ist sie jedoch nicht. Vielmehr kann die Schaffung entsprechender Straftatbestände und die konsequente Weiterleitung bei den Prüfungen aufgedeckter Unregelmäßigkeiten an die zuständige Staatsanwaltschaft genauso wirksam sein. ${ }^{1013}$

Der Blick auf die verfassungsrechtliche Stellung der anderen Rechnungshöfe vermag auch die hier vertretene Ansicht von der Sonderstellung des Bundesrechnungshofes außerhalb der drei herkömmlichen Staatsgewalten bei gleichzeitiger struktureller Nähe zum Parlament zu untermauern. Zuerst zeigen die vollkommen unterschiedlichen Verortungen der Rechnungshöfe bei im Wesentlichen gleichen Aufgaben, dass von ihrer Tätigkeit allein nicht auf den Standort in der Gewaltenteilung geschlossen werden kann, diese ist vielmehr eine eigene, rechnungshofspezifische.

Eine Zuordnung zur Legislative, wie sie in Österreich, dem Vereinigten Königreich und in organisatorischer Hinsicht bei gleichzeitig sehr weitgehenden Unabhängigkeitsverbürgungen auch in Spanien verwirklicht ist, kann nicht angenommen werden. Das Grundgesetz regelt nämlich keine Zuordnung des Bundesrechnungshofes zum Parlament, wie dies die Verfassungen Österreichs und Spaniens sowie die Gesetze des Vereinigten Königreiches ausdrücklich tun. Auch ist im Gegensatz zu diesen nicht nur das Parlament Adressat seiner Berichte, sondern auch Bundesregierung und Bundesrat. Hinzukommt, dass die Ernennung in Deutschland gewaltenübergreifend geregelt ist und der Bundesrechnungshof vollkommen unabhängig und weisungsfrei handelt. Zur Bestimmung der Stellung des Bundesrechnungshofes im Verhältnis zur Legislative hilft insbesondere ein vergleichender Blick auf die entsprechende Regelung in der österreichischen Verfas- 
sung: ${ }^{1014}$ Auch dort genießt der Rechnungshof formell als Organ der externen Finanzkontrolle Unabhängigkeit. Gleichwohl ist er durch die Verfassung ausdrücklich dem Nationalrat unterstellt und damit eindeutig dem Bereich der Gesetzgebung zuzuordnen. Vorschlag und Ernennung des Präsidenten sind allein Sache der Legislative, außerdem ist jederzeit seine Abberufung durch das Parlament möglich. Die Regelungen in Deutschland sind von einer solchen Unterstellung und letztlich auch mittelbaren Abhängigkeit weit entfernt.

Gerichtseigenschaft wie die Rechnungshöfe Frankreichs und Spaniens besitzt der Bundesrechnungshof ganz zweifellos nicht, so dass auch eine Zuordnung zur Judikative von vornherein ausscheidet. Eine solche gerichtliche Funktion wird der französischen Cour des comptes und dem spanischen Tribunal de Cuentas zusätzlich oder besser ergänzend zu ihrer eigentlichen Finanzkontrollfunktion ausdrücklich von der jeweiligen Verfassung beziehungsweise durch Gesetz zugewiesen. ${ }^{1015}$ Sie basiert auf dem unterschiedlichen Rechtssystem der beiden Länder, nach dem Mittelverwalter und öffentliche Rechnungsführer persönlich haftbar gemacht werden können und dies durch den gerichtlichen Zweig der Rechnungshöfe geschieht. Im Gegensatz zum Bundesrechnungshof fällen sie rechtsverbindliche Urteile, die sie auch selbst durchsetzen können.

Gegen die Zuordnung des Bundesrechnungshofes zur Exekutive sprechen, wie im 1. Teil der Arbeit erörtert, zahlreiche Argumente. Eine solche Zuordnung anhand der Subtraktionsmethode ist als Folge des besonderen Charakters der Institution und ihrer Aufgaben auch gar nicht notwendig. Die Überflüssigkeit einer derartigen Notlösung zeigt der vergleichende Blick auf den französischen Rechnungshof. Dieser nimmt als Institution mit vergleichbaren rechnungshoftypischen Kernaufgaben, unbeschadet seiner gerichtlichen Funktionen, eine Sonderstellung zwischen Legislative und Exekutive ein. 1016 Zudem stützt der rechtsvergleichende Blick auf die gesetzlich garantierten Informations- und Zugangsrechte der Rechnungshöfe anderer Länder die hier vertretene Auffassung, dass diese nicht als exekutives Tätigwerden zu bewerten sind und damit keine Zuordnung zur vollziehenden Gewalt begründen können. Völlig unabhängig davon, welcher Staatsgewalt sie zugeordnet sind, verfügen alle im zweiten Teil dieser Arbeit untersuchten Institutionen über vergleichbare Rechte dieser Art. Dabei sind der österreichische Rechnungshof und der Comptroller and Auditor General im Vereinigten Königreich eindeutig der Legislative zuzuordnen. Der französische Rechnungshof hingegen nimmt eine unabhängige Stellung zwischen Legislative und Exekutive ein bei gleichzeitigem Bestehen seiner Eigenschaft als Gericht. Das spanische Tribunal de Cuentas nimmt eine Doppelstellung ein, indem es einerseits als unabhängiges Organ dem Bereich der Legislative zuzuordnen ist und andererseits hinsichtlich seines gerichtlichen Zweiges eine eigenständige Stellung als Or-

1014 Dazu ausführlich unten 2. Teil B. IV. 2.

1015 Unten: 2. Teil A. und C.

1016 Oben: 2. Teil A. IV. 2. 
gan der Rechtsprechung hat. Allen diesen Organen sind ähnliche weitgehende Prüfungsrechte gegenüber den ihrer Prüfung unterstehenden Stellen gemeinsam, wobei allein die Rechnungshöfe, die die Eigenschaft als Gericht haben, diese auch selbst durchzusetzen vermögen.

Zum Europäischen Rechnungshof bleibt zu sagen, dass die Einschätzung, seine Finanzkontrollfunktion sei ,auf die gleiche Ebene erhoben worden wie die Aufgaben der Legislative, Exekutive und Judikative“1017, grundsätzlich richtig ist, steht der Hof doch gleichberechtigt als Organ neben den anderen Organen, die die spezifischen Aufgaben der klassischen drei Teilbereiche der Staatsgewalt ausüben. Sie darf aber nicht dazu führen anzunehmen, dass der Rechnungshof durch seine Tätigkeit selbst Staatsgewalt ausüben würde; denn die Tatsache, dass es sich materiellrechtlich bei Prüfung, Berichterstattung und Beratung nicht um die Ausübung von Staatsgewalt handelt, wurde hinreichend klar dargestellt. Dem Europäischen Rechnungshof kommt eine besondere Rolle bei der Unterstützung des Europäischen Parlaments zur Wahrnehmung seiner Kontrollrechte sowie allgemein für die Gewährleistung von Transparenz auf europäischer Ebene zu. Daraus lässt sich auch seine besondere Stellung als Organ der Europäischen Union und der Europäischen Gemeinschaft erklären: Angesichts ihres Schwergewichts auf wirtschaftlichem Gebiet und den von Kritikern immer wieder angeführten Problemen der mangelnden Transparenz und des Demokratiedefizits ist eine starke externe Finanzkontrolle dringend nötig.

Die Einordnung als Organ neben anderen, Staatsgewalt ausübenden Organen der Union macht auch einen entscheidenden Unterschied zwischen dem Prinzip des institutionellen Gleichgewichts und dem klassischen Gewaltenteilungsgrundsatz mitgliedstaatlicher Ausprägung deutlich. Beim Gewaltenteilungsgrundsatz spielt neben der formal funktionalen Trennung bestimmter staatlicher Aufgabenträger auch die inhaltlich-materiellrechtliche Bewertbarkeit der fraglichen Staatsfunktion eine Rolle, auch wenn es vielfach zu Überschneidungen und Verschränkungen der Funktionsbereiche kommt. Die Differenzierung nach dem institutionellen Gleichgewicht basiert hingegen ausschließlich auf der formalen Trennung der Organe, völlig losgelöst von der Frage, wie ihre Tätigkeiten materiellrechtlich zu bewerten sind. Die Fragen, ob eine Organtätigkeit als Ausübung von Staatsgewalt zu qualifizieren ist und (falls ja) welchem der drei Teilbereiche der klassischen Gewaltenteilung sie zuzuordnen wäre, rücken hiervor in den Hintergrund.

Im Ergebnis zeigt sich, dass die untersuchten Rechnungshöfe völlig unterschiedlich in die Gewaltenteilungssysteme einzuordnen sind, obwohl sie sich hinsichtlich ihrer Kernaufgaben stark ähneln. Jedoch stehen sie alle in unterschiedli-

1017 Inghelram, The European Court of Auditors: Current legal issues, CMLR 2000, 129 (130): “...it is of interest to see how, within the Union, the audit task has been brought to the level of the legislative, executive and judiciary task, the three powers in the Montesquieu model" 
cher Ausprägung dem Parlament nahe. Dies zeigt sich darin, dass die untersuchten Rechnungshöfe ausnahmslos durch ihre Berichterstattungsrechte und -pflichten direkte Zugangsmöglichkeiten zum jeweiligen Parlament haben, was die grundsätzliche strukturelle Nähe der Funktion der Finanzkontrolle zu diesem als dem Hauptkontrollorgan im demokratischen Staat zeigt.

Die rechnungshoftypischen Aufgaben an sich sind in keinem der Fälle als Form der Ausübung von Staatsgewalt zu bewerten. Eine Ausnahme bilden hierbei die Rechnungshöfe Frankreichs und Spaniens, die über einen gerichtlichen Zweig verfügen. Sie üben zweifelsohne in ihrer rechtsprechenden Funktion Staatsgewalt als Teil der Judikative aus. Da dies aber nur ein Teilaspekt ihrer Arbeit ist, letztlich sogar nur ein die Grundaufgabe der Prüfung ergänzender und weiterführender, sind sie als Institution nur hinsichtlich ihres Gerichtszweiges dem Bereich der Judikative zuzuordnen; ansonsten nehmen sie eine unabhängige Sonderstellung zwischen Legislative und Exekutive (Cour des comptes) beziehungsweise als Teil der Legislative - wenn auch verbunden mit besonderen Unabhängigkeitsgarantien gegenüber dem Parlament - ein (Tribunal de Cuentas).

\section{Klagemöglichkeiten der obersten Rechnungskontrollor- gane}

\section{Gegenüber Prüfungsunterworfenen}

Zunächst stellt sich die Frage, wie Rechnungshöfe ihre Prüfungsrechte auch gegen den Widerstand prüfungsunterworfener Stellen durchsetzen können. Hierbei kann die grundsätzliche Unterscheidung gemacht werden zwischen Rechnungshöfen, die Gerichtfunktion haben, und solchen, die diese nicht haben.

Eine besondere Stellung nehmen die mit gerichtlichen Kompetenzen ausgestatteten Rechnungshöfe Frankreichs und Spaniens ein. Diese sind zumindest hinsichtlich der Durchsetzung von Prüfungsrechten gegenüber prüfungsunterworfenen Stellen nicht auf Rechtsschutz angewiesen, da sie diese selbst durch vollstreckbare Urteile und die Verhängung von Zwangsgeldern durchsetzen können.

Alle anderen behandelten obersten Rechnungskontrollorgane mit Ausnahme des Comptroller and Auditor General haben jedoch die Möglichkeit, ihre Prüfungsrechte durchzusetzen, indem sie diese vor Gericht einklagen. Das Fehlen dieser Möglichkeit im Vereinigten Königreich erklärt sich in der staatsrechtlichen Zuordnung des Comptrollers zum Parlament als dessen Hilfsorgan und dem traditionellen Verständnis hiervon. Für den praktisch unwahrscheinlichen Fall, dass ein Prüfungsunterworfener sich der Prüfung verweigert, wäre es danach der Haushaltsausschuss des britischen Unterhauses, der zuständig wäre, den Rechten Geltung zu verschaffen. 
2. Gegenüber anderen Staatsorganen zur Wahrung des verfassungsrechtlich garantierten Status

Mit Ausnahme Frankreichs und des Vereinigten Königreichs sehen alle untersuchten Verfassungen beziehungsweise der EG-Vertrag Klagemöglichkeiten der obersten Rechnungskontrollorgane zur Wahrung ihrer Rechte vor. ${ }^{1018}$ Das Fehlen derartiger Regelungen für den Comptroller and Auditor General erklärt sich dabei aus seinem - wenn auch in vielerlei Hinsicht unabhängigen - Status als Hilfsorgan des Parlaments. Angesichts des Fehlens bei der Cours des comptes ist anzunehmen, dass aufgrund ihres besonderen Status als eines der drei Grands Corps de L'État und ihrer starke Stellung als Gericht, das seine Rechte gegenüber anderen Staatsorganen selbst durchzusetzen vermag, besondere Klagemöglichkeiten nicht für notwendig erachtet wurden.

Über diese Rechtsschutzgarantien hinausgehend wird in Deutschland und Österreich diskutiert, Rechnungshöfen auch die Möglichkeit zu geben, im Wege eines abstrakten Normenkontrollverfahrens gegen verfassungswidrige Haushaltsgesetze vorzugehen. Ein solches Klagerecht gegen ein aus politischen Opportunitätserwägungen von Parlament und Regierung gebilligtes, die Kreditgrenzen überschreitendes Haushaltsgesetz wäre eine sinnvolle Ergänzung der Möglichkeit von Rechnungshöfen, die Verfassungswidrigkeit lediglich unverbindlich festzustellen. Ana$\log \mathrm{zu}$ dieser Diskussion sollte auch erwogen werden, den Europäischen Rechnungshof in den Kreis der nach Art. 230 Abs. 2 EGV (Art. 263 Abs. 2 AEUV) privilegiert Klageberechtigten aufzunehmen, so dass er nicht nur zur Verteidigung eigener Rechte, sondern auch bei sonstigen Zweifeln an der Rechtmäßigkeit von Gemeinschaftsrechtshandlungen den EuGH anrufen könnte. Diese Vorschläge, die keine der untersuchten Rechtsordnungen ihren Rechnungshöfen zugesteht, wären geeignet, ihre Wirksamkeit als Kontrollmechanismen im Zusammenspiel mit den Gerichten erheblich zu stärken, ohne dabei die hergebrachte Stellung der Rechnungshöfe zu verändern.

\section{B. Resümee}

Die externe Finanzkontrolle durch Rechnungshöfe und die Öffentlichkeit ihrer Arbeit schaffen Transparenz und ermöglichen parlamentarische Kontrolle des Umgangs der Exekutive mit staatlichen Mitteln. Sie sind daher unabdingbar für die Gewaltenteilung als Bestandteil formeller Rechtsstaatlichkeit und für das Demokratieprinzip.

Die Untersuchung der verschiedenen Rechnungshofmodelle in Deutschland, Frankreich, Österreich, Spanien, dem Vereinigten Königreich und der Europäi-

1018 Deutschland: 1. Teil VI. 4. b), c) ; Frankreich: 2. Teil A. V.; Österreich: 2. Teil B. V.; Spanien: 2. Teil C. V.; Vereinigtes Königreich: 2. Teil D. V.; Europäischer Rechnungshof 3. Teil IV. 3. 
schen Union hat ergeben, dass trotz der allen gemeinsamen und sich im Wesentlichen gleichenden Kernaufgaben der Prüfung, Beratung und Berichterstattung unterschiedliche Einordnungen im Verhältnis zu den Staatsgewalten gewählt wurden. Ausnahmslos ist jedoch eine mehr oder weniger stark ausgeprägte Nähe zum jeweiligen Parlament erkennbar. Besondere Bedeutung für eine effektive Finanzkontrolle ist der Unabhängigkeit der Rechnungshöfe zuzumessen. Sie ist in allen untersuchten Rechtsordnungen zu finden, wenn auch mit mehr oder weniger starken Einschränkungen im Vereinigten Königreich und insbesondere in Österreich.

Das Bestehen eines eigenen gerichtlichen Zweiges neben Prüfung, Beratung und Berichterstattung und die damit verbundene Ausübung von Staatsgewalt ist keine zwingende Voraussetzung effektiver Finanzkontrolle; die damit verfolgten Ziele sind ebenso gut durch die Schaffung geeigneter Straftatbestände beziehungsweise Haftungsnormen und die konsequente Weiterleitung bei Prüfungen erlangter Kenntnisse hierüber an die zuständigen Stellen (Staatsanwaltschaften, OLAF) zu erreichen. Die untersuchten Rechnungshöfe, die über keinen gerichtlichen Zweig verfügen, üben keine Staatsgewalt aus. Keiner von ihnen stellt eine vierte Staatsgewalt dar. Hingegen besteht bei allen eine besondere strukturelle Nähe zur Legislative, die auf das Fachwissen der Rechnungshöfe zur Wahrnehmung ihrer Kontrollrechte angewiesen ist. Auch der Europäische Rechnungshof hat trotz seines Organstatus keine einer vierten Staatsgewalt gleichkommende Rolle. Seine besondere Stellung erklärt sich vielmehr aus der Eigenschaft der Europäischen Gemeinschaft als Wirtschaftsgemeinschaft und dem Willen der Mitgliedstaaten, auf europäischer Ebene für Transparenz zu sorgen und dem Demokratiedefizit - der Rechnungshof unterstützt besonders das Parlament - entgegenzuwirken. Außerdem bestand die Notwendigkeit, seine Autorität gegenüber den anderen Organe, die er prüft, zu erhöhen, indem er ihnen auf gleicher Augenhöhe begegnen kann.

Die herausgehobene Stellung des Europäischen Rechnungshofes macht auch Unterschiede zwischen dem klassischen Gewaltenteilungsgrundsatz und dem Prinzip des institutionellen Gleichgewichts deutlich: Letzteres basiert allein auf einer rein formalen Trennung der Organe, gleichgültig ob und in welcher Form sie Staatsgewalt ausüben; bei der herkömmlichen Gewaltenteilung sind es hingegen trotz Überschneidungen und Verschränkungen auch materiellrechtliche Kriterien, nach denen sich die Einordnung richtet.

Rechnungshöfe stehen im Dienste der mit der Gewaltenteilung verfolgten Ziele der gegenseitigen Kontrolle und der Optimierung staatlichen Handelns: Sie ermöglichen erst effektive parlamentarische Kontrolle auf dem wichtigen Gebiet staatlicher Finanzen und tragen besonders auch durch die Beratung zur Rationalisierung staatlichen Handelns bei. Daneben spielen sie eine wichtige Rolle als Informant der Öffentlichkeit, indem sie für Transparenz sorgen. 
Zur Erreichung dieser Ziele sind die Rechnungshöfe geeignet, auch wenn es unter anderem die empfohlenen Verbesserungsmöglichkeiten gibt. Die Konsequenzen aus der Arbeit der Rechnungshöfe haben hingegen die kontrollierten beziehungsweise beratenen Organe selbst zu ziehen, besonders die Parlamente mit ihren Kontrollrechten gegenüber der Exekutive. Ob diese Kontrolle letztlich sinnvoll ausgeübt wird und die Erkenntnisse der Rechnungshöfe umgesetzt werden, ist kein Problem der Handlungsformen der Rechnungshöfe, sondern ist eine Verantwortung allein der Parlamente sowie der geprüften beziehungsweise beratenen Organe. Defizite bei der Umsetzung der Erkenntnisse der Rechnungshöfe und Kontrollmängel ergeben sich als Folge des Pluralismusdefizits im modernen Parteienstaat, das eine wirksame Kontrolle oft unmöglich macht, was sich auch ganz allgemein im teilweisen Versagen der durch die Gewaltenteilung bezweckten gegenseitigen Kontrolle der drei Gewalten zeigt.

Nicht zuletzt verschafft die Öffentlichkeit der Arbeit der Rechnungshöfe auch den Wählern Informationen, die in die Wahlentscheidung mit einfließen können. Somit ist die Öffentlichkeit ihrer Arbeit in Form der Berichterstattung auch notwendiger Ausfluss des Demokratieprinzips.

Eine sinnvolle Ergänzung des Kontrollauftrages von Rechnungshöfen wäre die Erweiterung ihrer Klagerechte dahingehend, ihnen die Möglichkeit zu geben, etwa Haushaltsgesetze bei offenkundiger Verfassungswidrigkeit wegen Überschreitung der Defizitgrenzen verfassungsgerichtlich prüfen zu lassen. Im deutschen Recht könnte das durch eine Antragsbefugnis im abstrakten Normenkontrollverfahren geschehen, auf Gemeinschaftsebene wäre eine privilegierte Klagebefugnis für Nichtigkeitsklagen denkbar, um Gemeinschaftsrechtsakte vom Europäischen Gerichtshof überprüfen zu lassen.

Aus den untersuchten Berichten von Bundesrechnungshof und Europäischem Rechnungshof wurde deutlich, dass beide ihre Rolle selbstbewusst wahrnehmen und häufig deutliche Kritik äußern. Die Aufgabe, für Transparenz zu sorgen, erfüllen sie dabei ausgezeichnet. Weiter wurde die unterschiedliche Schwerpunktsetzung bei den Prüfungsmaßstäben der Ordnungsmäßigkeit und der Wirtschaftlichkeit deutlich, die vor allem daher rührt, dass sich das Problem der nicht ordnungsgemäßen Verwendung von Geldern stärker auf Unionsebene zeigt.

Prägend für die Zusammenarbeit der Rechnungshöfe im europäischen Staaten- und Verfassungsverbund ist ihre loyale Zusammenarbeit. Eine gewisse Sonderrolle verglichen mit anderen Stellen, die im Europäischen Staaten- und Verfassungsverbund zusammenarbeiten, nehmen sie jedoch aufgrund ihrer Unabhängigkeit ein, die auch der EG-Vertrag grundsätzlich respektiert und unberührt lässt. Diese setzt zumindest der rechtserverbindlichen gegenseitigen Beeinflussung Grenzen. Jedoch ergeben sich aus der Pflicht zum gemeinschaftstreuen Verhalten und ihren vertraglichen Konkretisierungen für das europäische Rechnungshofsystem Mindestanforderungen an die Zusammenarbeit. Daneben sind Prüfungslücken auch deshalb nicht zu befürchten, da der Europäische Rechnungshof für den 
Fall, dass der Rechnungshof eines Mitgliedstaates bei einer Prüfung die Zusammenarbeit ablehnt, eigene Prüfungsrechte hat. Wünschenswert wäre jedoch ein eigenes Klagerecht des Europäischen Rechnungshofes im Vertragsverletzungsverfahren gegen Mitgliedstaaten für den Fall, dass nationale Stellen sich seiner Prüfung verweigern, so dass er nicht auf den Umweg über die Kommission angewiesen wäre. 


\section{Literaturverzeichnis}

Achterberg, Norbert, Rezension: Petzold, Herbert, Die Gewaltenteilung in den Europäischen Gemeinschaften, Europarecht 1968, S. 240-245.

Aigner, Heinrich, Plädoyer für einen Europäischen Rechnungshof, Dokumentensammlung des Europäischen Parlaments, Luxemburg, September 1973.

Aigner, Heinrich, Finanzkontrolle der Europäischen Gemeinschaften: Entwicklung und Perspektiven, ZParl 1978, S. 186-192.

Andrés Ibáñé, Perfecto, Die rechtsprechende Gewalt in der spanischen Verfassung von 1978, in: López Pina, Antonio (Hrsg.), Spanisches Verfassungsrecht, Heidelberg 1993, S. 435-457.

Amaud, Desire, La Cour des Comptes Française, in: Schiffer, Eckart / Karehnke, Helmut (Hrsg.), Verfassung, Verwaltung, Finanzkontrolle, Festschrift für Hans Schäfer zum 65. Geburtstag, Köln Berlin Bonn München 1975, S. 310-329.

Arndt, Hans-Wolfgang, Europarecht, 8. Auflage, Heidelberg 2006.

Amdt, Hans-Wolfgang, Staatshaushalt und Verfassungsrecht, JuS 1990, S. 343-347

v. Amim, Hans Herbert, Staatslehre der Bundesrepublik Deutschland, 1. Auflage 1984.

v. Amim, Hans Herbert, Finanzkontrolle in der Demokratie - Einordnung der Rechnungshofkontrolle in das politisch-administrative System der Bundesrepublik Deutschland, in: ders. (Hrsg.), Finanzkontrolle im Wandel, Berlin 1989, S. 39-63.

v. Amim, Hans Herbert, Grundprobleme der Finanzkontrolle, DVBl. 1983, S. $664-$ 675.

Barendt, Eric, An Introduction to Constitutional Law, Oxford 1998.

Beckensträter, Friedrich Wilhelm, Die Stellung der Rechnungshöfe im System der Dreiteilung der Staatsgewalt, Univ. Diss. Frankfurt a. M. 1961. 
Bebrendt, Dirk, Die Prüfungstätigkeit des Bundesrechnungshofs außerhalb der unmittelbaren Bundesverwaltung, Köln Berlin München 2004; zugleich Univ. Diss. Freie Universität Berlin 2002.

Belemann, Gerd Dieter, Rechtsschutzprobleme im Bereich der Finanzkontrolle, DÖV 1990, S. 58-63.

Belemann, Gerd Dieter, Anmerkung zum Urteil des OVG Münster vom. 9.5.1978 XII A 687/76, DÖV 1979, S. 684-685.

Beran, Peter / Konvicka, Zdenko (Hrsg.), Finanzkontrolle international gesehen Versuch einer rechtsvergleichenden Darstellung, Auswertung einer Umfrage zur Erhebung der rechtlichen und organisatorischen Grundlagen der obersten Rechnungskontrollbehörden, Wien 1967.

Bieber, Roland / Epiney, Astrid / Haag, Marcel, Die Europäische Union: Europarecht und Politik, 6. Aufl., Baden-Baden 2005.

Bieber, Roland, The Settlement of Institutional Conflicts on the Basis of Art. 4 of the EEC Treaty, Common Market Law Review 1984 (21), S. 505-523.

Blasius, Hans / Stadtmann, Burkhard, Justiz und Finanzkontrolle, DÖV 2002, S. 12 19.

Blasius, Hans, Der Rechnungshof: Kontrolleur und Informant, DÖV 1993, S. 642648.

Blasius, Hans, Finanzkontrolle und Gesetzgebung - Können die Rechnungshöfe einen Beitrag zur Gesetzgebung leisten?, DÖV 1989, S. 298-306.

Blasius, Hans, Recht und Finanzkontrolle in den Gestaltungsräumen von Politik und Verwaltung, DÖV 1988, S. 819-828.

Böning, Wolfgang, Finanzkontrolle im repräsentativ-demokratischen System, in: Böning, Wolfgang / v. Mutius, Albert (Hrsg.), Finanzkontrolle im repräsentativdemokratischen System, Heidelberg 1990, S. 39-65.

Bonner Kommentar zum Grundgesetz, Band 9 (Art. 104a - 115), Hamburg/Heidelberg seit 1950 (Loseblattsammlung).

Borchardt, Klaus-Dieter, Die rechtlichen Grundlagen der Europäischen Union, 2. Auflage, Heidelberg 2002. 
Bradley, A. W. / Ewing, K. D., Constitutional and Administrative Law, 13. Auflage, London u.a. 2003.

Brockhaus, Enzyklopädie in 30 Bänden, 21. völlig neubearbeitete Auflage, Leipzig - Mannheim 2006.

Brück, Werner / Kühne, Horst, Die Neuregelung der Finanzkontrolle der Europäischen Gemeinschaften, DÖV 1977, S. 23-27.

Brunner, Georg, Kontrolle in Deutschland, Köln 1972, zugleich Habilitationsschrift der Universität Köln 1969/70.

Brunner, Gotthard, Möglichkeiten und Grenzen der öffentlichen Finanzkontrolle, in: Schiffer, Eckart / Karehnke, Helmut (Hrsg.), Verfassung, Verwaltung, Finanzkontrolle, Festschrift für Hans Schäfer zum 65. Geburtstag, Köln Berlin Bonn München 1975, S. 169-187.

Bundesrechnungshof (Hrsg.), Der Bundesrechnungshof und die Prüfungsämter des Bundes, Bonn 2005.

Calliess, Christian, Das Demokratieprinzip im europäischen Staaten- und Verfassungsverbund, in: Brohmer/Bieber/Calliess/Langenfeld/Weber/Wolf, Internationale Gemeinschaft und Menschenrechte, Festschrift für Georg Ress zum 70. Geburtstag, Köln Berlin München 2005.

Calliess, Christian, Demokratie im europäischen Staaten- und Verfassungsverbund - Eine Analyse mit Blick auf den Konventsentwurf für den Europäischen Verfassungsvertrag, in: Institut für Völkerrecht und Europarecht der Universität Göttingen - Abteilung Europarecht, Göttinger Onlinebeiträge zum Europarecht, Nr. 14 vom 23.11.2004.

Calliess, Christian / Ruffert, Matthias (Hrsg.), Kommentar zu EU-Vertrag und EGVertrag, 3. Aufl., München 2006.

Calliess, Christian / Ruffert, Matthias (Hrsg.), Verfassung der Europäischen Union, Kommentar der Grundlagenbestimmungen, München/Wien 2006.

Chavaki, Paraskevi, Betrugsbekämpfung in der Europäischen Union, ZEuS 1999, S. 431-466.

Constantinesco, Léontin-Jean, Das Recht der Europäischen Gemeinschaften, Bd. I: Das institutionelle Recht, 1. Auflage, Baden-Baden 1977. 
Constantinesco, Léontin-Jean, Rechtsvergleichung, Band II: - Die rechtsvergleichende Methode, Köln 1972.

Czasche, Hedda (später: von Wedel); Zur Bedeutung der Kontroll-Struktur und zu den Vorbeugungsstrategien gegen Mißbrauch öffentlicher Förderungsmittel, in: Piehl, Ernst (Hrsg.), Europa in Ostdeutschland: Zur Zwischenbilanz und zu den Perspektiven der europäischen Strukturförderung in den neuen Bundesländern und in Berlin sowie in den Reformländern von Mittel- und Osteuropa, Bonn 1996, S. 268-272.

Dann, Philipp, The Political Institutions, in: von Bogdandy, Armin / Bast, Jürgen (Hrsg.), Principles of European Constitutional Law, Oxford, 2006, S. 229-279.

Degenhart, Christoph, Kontrolle der Verwaltung durch Rechnungshöfe - 1. Bericht, VVDStRL 55 (1996), S. 190-230.

Degenhart, Christoph, Staatsrecht I - Staatsorganisationsrecht, 22. Auflage, Heidelberg 2006.

Descheemaeker, Christian, La Cour des Comptes, 3 `eme édition, Paris 2005.

Detterbeck, Steffen, Allgemeines Verwaltungsrecht mit Verwaltungsprozeßrecht, 3. Auflage, München 2005.

De Witte, Bruno, The institutional balance in the European Union: Is there a need for a new horizontal division of powers? S. 57-65, in: Herzog, Roman / Hobe, Stephan (Hrsg.), Die Europäische Union auf dem Weg zum verfassten Staatenverbund: Perspektiven der europäischen Verfassungsordnung, München 2004.

von Ditfurth, Theodor, Zur Geschichte der Königlich Preußischen OberRechnungskammer, Berlin 1909.

Dommach, Herrmann A., Der Reichsrechnungshof während der Amtszeit seines Präsidenten Saemisch (1922 bis 1938), in: Zavelberg (Hrsg.), Die Kontrolle der Staatsfinanzen, Festschrift zur 275. Wiederkehr der Errichtung der Preußischen General-Rechen-Kammer, 1989, S. 65-113.

Dreier, Horst (Hrsg.), GG Kommentar, Bd. II (Art. 20-82), 2. Auflage, Tübingen 2006.

Eblermann, Claus-Dieter, Der Europäische Rechnungshof - Haushaltskontrolle in der Gemeinschaft, Baden-Baden 1976. 
Eickenboom, Peter / Heuer, Ernst, Das neue Bundesrechnungshofgesetz, DÖV 1985, S. 997-1002.

Ekelmans, Marc, La Cour des Comptes, in: Commentaire J. Megret, Le Droit de la CE et de 1’Union Europèenne, Bd. 9, Brüssel 2000.

Ermacora, Felix, Der Österreichische Rechnungshof im System der Staatsgewalten, in: Österreichischer Rechnungshof (Hrsg.), 200 Jahre Rechnungshof, Festschrift zum zweihundertjährigen Bestand der obersten staatlichen Kontrollbehörde Österreichs, Wien 1961, S. 72-81.

Europäische Kommission (Hrsg.), Institutionelle Reform und erfolgreiche Erweiterung - Stellungnahme der Kommission nach Art. 48 EUV zur Einberufung einer Konferenz der Vertreter der Regierungen der Mitgliedsstaaten im Hinblick auf die Änderungen der Verträge, in: Bulletin der Europäischen Union, Beilage 2/2000.

Europäischer Rechnungshof (Hrsg.), Der Europäische Rechnungshof - Optimierung des Finanzmanagements in der Europäischen Union, 2004.

Fehr, Hendrik, Mögliche Wechselwirkungen zwischen dem Europäischen Rechnungshof und nationalen Rechnungshöfen, in: Budäus, Dietrich / Küpper, Wille / Streitferd, Lothar (Hrsg.), Neues öffentliches Rechnungswesen - Stand und Perspektiven, Festschrift für Klaus Lüder, 1. Auflage, Wiesbaden 2000, S. 675-692.

Finer, S. E. / Bogdanor, Verno / Rudden, Bernard, Comparing Constitutions, Oxford, 1998 (Reprint der Ausgabe von 1995).

Fittschen, Dierk, Durchsetzung der Prüfungsrechte der Rechnungshöfe, Verwaltungsarchiv 1992, S. 165-200.

Friedmann, Bernhard, Aufgabenstellung und rechtliche Rahmenbedingungen der Finanzkontrolle des Europäischen Rechnungshofes, in: ders. (Hrsg.), Der Europäische Rechnungshof und die Wirtschafts- und Finanzhilfen der EU für Mittel- und Osteuropa, 1. Auflage, Bonn 1994, S. 7-31.

Friedmann, Bernhard, Organisation und Koordination von Prüfungsmethoden des Europäischen Rechnungshofes, in: ders. (Hrsg.), Der Europäische Rechnungshof und die Wirtschafts- und Finanzhilfen der EU für Mittel- und Osteuropa, 1. Auflage, Bonn 1994, S. 47-75. 
Friedmann, Bermhard, Zur Bedeutung der Kontroll-Struktur und zu den Vorbeugungsstrategien gegen Mißbrauch öffentlicher Förderungsmittel, in: Piehl, Ernst (Hrsg.), Europa in Ostdeutschland: Zur Zwischenbilanz und zu den Perspektiven der europäischen Strukturförderung in den neuen Bundesländern und in Berlin sowie in den Reformländern von Mittel- und Osteuropa, Bonn 1996, S. 265-267.

Friedmann, Bernhard, Finanzkontrolle von Mitteln der Europäischen Gemeinschaft, in: Rechnungshof Rheinland-Pfalz (Hrsg.), Kooperation der Finanzkontrolle in Europa, 1999, S. 239-258.

Friedrich, Christina / Inghelram, Jan, Die Klagemöglichkeiten des Europäischen Rechnungshofs vor dem Europäischen Gerichtshof, DÖV 1999, S. 669-676.

Garrido Falla, Fernado y otros, Comentarios a la Constitución, 3. Auflage, Madrid 2001.

Göke, Wolfgang, Der Niedersächsische Landesrechnungshof: Wandel und Struktur der Finanzkontrolle in Niedersachsen, NdsVBl. 2001, S. 62-68.

González Encinar, José Juan, Rechtsstaatlichkeit in Spanien, in: Hofmann/Marko/Merli/Wiederin (Hrsg.), Rechtsstaatlichkeit in Europa, Heidelberg 1996, S. 167-198.

Grabit, Eberbart / Hilf, Meinhard (Hrsg.), Das Recht der Europäischen Union, Kommentar, Band II, München (Loseblattsammlung).

Gräfe, Horst, Auf dem Weg zu einem Rechnungshof für die Europäischen Gemeinschaften, in: Schiffer, Eckart / Karehnke, Helmut (Hrsg.), Verfassung, Verwaltung, Finanzkontrolle, Festschrift für Hans Schäfer zum 65. Geburtstag, Köln Berlin Bonn München 1975, S. 349-371.

von der Groeben, Hans / Schwarze, Jürgen (Hrsg.), Kommentar zum EU-/EG-Vertrag, 6. Auflage, Baden-Baden 2004.

Groß, Thomas, Exekutive Befugnisse der Rechnungshöfe, Verwaltungsarchiv 2004, S. 194-222.

Grupp, Klaus, Die Stellung der Rechnungshöfe in der Bundesrepublik Deutschland: Unter besonderer Berücksichtigung der historischen Entwicklung der Rechnungsprüfung, Berlin 1972, zugl. Univ. Diss. Köln 1971.

Guimezanes, Nicole, Introduction au droit française, 1. Auflage, Baden-Baden 1995. 
Haase, Hans, Die Errichtung und die erste Instruktion der Preußischen OberRechnungskammer, Finanzarchiv 1922, S. 1-75.

Hager, Richard, Die Entwickelung der Rechnungskontrolle von der ersten Hofrechenkammer bis zum Rechnungshof (Verfassung 1934), Österreichisches Verwaltungsblatt, Jahrgang 7, 1936, Heft 3, S. 55-59.

Hailbronner, Kay, Europa 1992: Das institutionelle System der Europäischen Gemeinschaften, JuS 1990, S. 263-268.

Hailbronner, Kay / Jochum, Georg, Europarecht I - Grundlagen und Organe, Stuttgart 2005.

Häußer, Otto, Zur Antragsbefugnis der Rechnungshöfe im verfassungsrechtlichen Organstreit, DÖV 1998, S. 544-550.

Hauser, Norbert, Stellung des Bundesrechnungshofs im System der Gewaltenteilung und in der öffentlichen Verwaltung, DVB1. 2006, S. 539-543.

Hauser, Norbert, Rechtsqualität von Prüfungsankündigungen des Bundesrechnungshofs, DÖV 2004, S. 786-790.

Haverkate, Görg, Der Schutz subjektiv-öffentlicher Rechte in der Rechnungsprüfung, AöR 107 (1982), S. 539-561.

Heinig, Kurt, Das Budget, Erster Band: Die Budgetkontrolle, Tübingen 1949.

Hengstschläger, Johannes, Der Rechnungshof - Organisation und Funktion der Finanzkontrolle in Österreich, Schriften zum öff. Recht Bd. 426, Berlin 1982.

Hertel, Hans, Die Preußische Ober-Rechnungskammer (Rechnungshof des deutschen Reichs) ihre Geschichte, Einrichtung und Befugnisse, Berlin 1884.

Hesse, Joachim Jens / Ellwein, Thomas, Das Regierungssystem der Bundesrepublik Deutschland, Band 1, 9. Auflage, Berlin 2004.

Heuer, Ernst, Kommentar zum Haushaltsrecht, München, 42. Ergänzungslieferung September 2006.

Heun, Werner, Staatshaushalt und Staatsleitung, Baden-Baden 1989, zugl. Habilitationsschrift Friedrich-Wilhelm-Universität zu Bonn WS 1987/88. 
Heuss, Theodor, Ansprache anlässlich der Einweihung des neuen Dienstgebäudes des Bundesrechnungshofes am 19.02.1954, DÖH 1954, S. 6-8.

Hilf, Meinhard, Die Organisationsstruktur der Europäischen Gemeinschaften, Rechtliche Gestaltungsmöglichkeiten und Grenzen, Berlin Heidelberg New York 1982.

Hockenbrink, Ullrich, Zur Befugnis der Rechnungshöfe, im Prüfungsverfahren Verwaltungsakte zu erlassen, DÖV 1991, S. 241-243.

Hoffmann, Siegfried, Die Kontrolle der Regierung durch parlamentarische Rechnungsprüfung im Deutschen Bundestag, Göttingen 1970.

Hofmann, Rainer, Die Bindung staatlicher Macht, in: Hofmann/Marko/Merli/Wiederin (Hrsg.), Rechtsstaatlichkeit in Europa, Heidelberg 1996, S. 3-29.

Horm, Hans-Detlev, Über den Grundsatz der Gewaltenteilung in Deutschland und Europa, Jahrbuch des öffentlichen Rechts 2001 (Band 49), S. 287-298.

Huber, Ernst Rudolf, Die institutionelle Verfassungsgarantie der Rechnungsprüfung, in: Festschrift für Arthur Nikisch, Tübingen 1958, S. 331-361.

Huber, Peter, Das institutionelle Gleichgewicht zwischen Rat und Europäischem Parlament in der künftigen Verfassung für Europa, Europarecht 2003, S. 574-599.

Huber, Peter, Europäisches und nationales Verfassungsrecht, Veröffentlichungen der Vereinigung der Deutschen Staatsrechtslehrer, Heft 60 (2001), S. 194-245.

Hummer, Waldemar, Das „Institutionelle Gleichgewicht" als Strukturdeterminante der Europäischen Gemeinschaften, in: Ius Humantis, Festschrift für Alfred Verdross, Berlin 1980, S. 459-485.

Ibán, Iván C., Introducción al Derecho Español, Baden-Baden, 1999.

Inghelram, Jan, L`Arrêt ISMERI: Quelles Conséquences pour la Cour des Comptes Européenne?, Cahiers de droit européen 2001, S. 707-728.

Inghelram, Jan, The European Court of Auditors: Current legal issues, Common Market Law Review 2000 (37), S. 129-146 
Internationales Institut für Rechts- und Verwaltungssprache (Hrsg.), Handbuch der Internationalen Rechts- und Verwaltungssprache, Haushalt und Rechnungsprüfung, Deutsch/Englisch, Köln, Berlin, Bonn, München 1988.

Isensee, Josef / Kirchhof, Paul, Handbuch des Staatsrechts der Bundesrepublik Deutschland,

Band II, Verfassungsstaat, 3. Auflage, Heidelberg 2004

Band III, Demokratie - Bundesorgane, 3. Auflage, Heidelberg 2005.

Isensee, Josef, Finanzkontrolle im Bundesstaat - Zur Vollständigkeit und Einheitlichkeit der Rechnungsprüfung im deutschen und österreichischen Recht, Zeitschrift für öffentliches Recht 63 (2008), S. 29-48.

Isensee, Josef, Außenvertretung der deutschen Rechnungshöfe in der Europäischen Union - Bundesstaatliche Fragen der Mitwirkung in informellen Gremien der zwischen- und überstaatlichen Zusammenarbeit, Heidelberg, 2001.

Kandutsch, Jörg, Öffentliche Finanzkontrolle in Österreich unter besonderer Berücksichtigung von Organisations- und Wirtschaftlichkeitsprüfungen, in: Schiffer, Eckart / Karehnke, Helmut (Hrsg.), Verfassung, Verwaltung, Finanzkontrolle, Festschrift für Hans Schäfer zum 65. Geburtstag, Köln Berlin Bonn München 1975, S. 189-208.

Kirchhof, Ferdinand, Grundsätze der Finanzverfassung des vereinten Deutschland, VVDStRL 52 (1993), S. 71-110.

Kirchhof, Paul, Die rechtliche Struktur der EU als Staatenverbund, in: v. Bogdandy (Hrsg.), Europäisches Verfassungsrecht, Berlin Heidelberg 2003, S. 893-929.

Kirchhof, Paul, Die Steuerung des Verwaltungshandelns durch Haushaltsrecht und Haushaltskontrolle, NVwZ 1983, S. 505-515.

Klein, Friedrich, Die Finanzkontrolle im nationalsozialistischen Staat, in: Schiffer, Eckart / Karehnke, Helmut (Hrsg.), Verfassung, Verwaltung, Finanzkontrolle, Festschrift für Hans Schäfer zum 65. Geburtstag, Köln Berlin Bonn München 1975, S. 209-232

Koenig, Christian / Pechstein, Matthias / Sander, Claude, EU-/EG-Prozessrecht, 2. Auflage, Tübingen 2002. 
Kobl, Friedrich, Die heutige Stellung des Rechnungshofes, seine Organisation und seine Aufgaben, in: 200 Jahre Rechnungshof, Festschrift Österreichischer Rechnungshof, 1961, S. 35-51.

Kok, Chris, The Court of Auditors of the European Communities: „The other european court in Luxembourg", Common Market Law Review 1989 (26), S. 345367.

Kopp, Ferdinand, Der Rechnungshof als gemeinsames "föderatives" Bund-LänderOrgan, Wien-Köln-Graz 1978.

Korthals, Gernot, Perspektiven für eine wirksamere öffentliche Finanzkontrolle, DÖV 2002, 600-607.

Korthals, Gernot, Beiträge der Rechnungshöfe zur Verwaltungsreform, DÖV 2000, S. 855-861.

Kortmann, Constantijn, The French Republic, in: Prakke, Lucas/Kortmann, Constantijn (Hrsg.), Constitutional Law of 15 EU Member States, 6. Auflage, Deventer 2004, S. 237-308.

Krebs, Walter, Kontrolle in staatlichen Entscheidungsprozessen, Heidelberg 1984, zugleich Habilitationsschrift Universität Münster, 1983.

Krebs, Walter, Die rechtliche Stellung der Rechnungshöfe und der Vorbehalt des $\mathbb{S}$ 40 Abs. 1 VwGO zugunsten der verfassungsrechtlichen Streitigkeit, Verwaltungsarchiv, 1980, S. 77-85.

Krïger, Hartmut, Eigenart, Methode und Funktion der Rechtsvergleichung im öffentlichen Recht, in: Ziemske, Burkhardt / Langheid, Theo u. A. (Hrsg.), Staatsphilosophie und Rechtspolitik, Festschrift für Martin Kriele zum 65. Geburtstag, München 1997, S. 1393-1405.

Kutscher, Hans, Über den Gerichtshof der Europäischen Gemeinschaft, Europarecht 1981, S. 392-413.

Laffan, Brigid, Becoming a „Living Institution“: The Evolution of the European Court of Auditors, Journal of Common Market Studies 1999, S. 251-268.

Läufer, Thomas, Die Organe der EG - Rechtsetzung und Haushaltsverfahren zwischen Kooperation und Konflikt, Bonn 1990; zugleich Diss. Univ. Bonn 1989. 
Läufer, Thomas, Der Europäische Gerichtshof - moderate Neuerungen des Verfassungsentwurfs, in: Integration 2003, S. 510-519.

Lenaerts, Koen, Some Reflections on the separation of powers in the European Community, Common Market Law Review 1991 (28), S. 11-35.

Lenaerts, Koen / Arts, Dirk / Maselis, Ignace (Editor: Robert Bray), Procedural Law of the European Union, Second Edition, London 2006.

Lenz, Carl Otto (Hrsg.), EG-Vertrag Kommentar, 2. Auflage, Köln u.a. 1999.

Lenz, Carl Otto / Borchardt, Klaus-Dieter (Hrsg.), EU- und EG-Vertrag, 3. Auflage, Köln u.a. 2003.

Léonard, Roger, La Cour des Comptes de France et la Cour des Comptes fédérale d'Allemagne, in: Bundesrechnungshof (Hrsg.), 250 Jahre Rechnungsprüfung - Festschrift zur zweihundertfünfzigjährigen Wiederkehr der Errichtung der Preußischen Generalrechenkammer, Frankfurt a.M. 1964, S. 190-203.

López Guerra, Luis y otros, Derecho Constitucional, Volumen II, Los poderes del estado - La organización territorial del Estado, Valencia 1992 (zit. Bearbeiter, in: López Guerra u.a. (Hrsg.)).

Lyall, Francis, An Introduction to British Law, 1. Auflage, Baden-Baden 1994.

Mader, Oliver, Zu den Verteidigungsrechten im Verfahren - Der Europäische Rechnungshof und die Rechte Dritter in der Rechnungsprüfung, European Law Reporter 2006, S. 283-288.

Mähring, Matthias, Externe Finanzkontrolle im europäischen Mehrebenensystem Betrachtungen zu den föderativen Rahmenbedingungen im EU-Mitgliedsstaat Deutschland, DÖV 2006, S. 195-204.

Magiera, Siegfried, Der Rechnungshof, in: Jahrbuch der Europäischen Integration 2000/2001, S. 93-96.

Magiera, Siegfried, Der Schutz der finanziellen Interessen der Europäischen Union, in: Wendt, Rudolf/ Höfling, Wolfram/ Karpen, Ulrich/ Oldiges, Martin (Hrsg.), Staat, Wirtschaft, Steuern, Festschrift für Karl Heinrich Friauf zum 65. Geburtstag, Heidelberg 1996, S. 13-36. 
Magiera, Siegfried, Finanzkontrolle in der Europäischen Gemeinschaft, in: v. Arnim (Hrsg.) Finanzkontrolle im Wandel, Berlin 1989, S. 221-241.

Mahrenholr, Ernst-Gottfried, Festrede anläßlich des Festaktes zum 50-jährigen Bestehen des Niedersächsischen Landesrechnungshofs am 5. November 1998, S. 1122.

v. Mangoldt, Hermann / Klein, Friedrich / Starck, Christian (Hrsg.), Kommentar zum Grundgesetz (3 Bände), Band 2: Art. 20 bis 82, 5. Auflage München 2005, Band 3: Art. 83 bis 146, 5. Auflage München 2005.

Mann, Günter, Unabhängige Kontrolleure? Probleme der Besetzung von Kontrollämtern, dargestellt am Beispiel des Leitungspersonals von Rechnungshöfen, Zeitschrift für Parlamentsfragen 1981, 353-367.

Mart, Marcel, Die Finanzkontrolle der Europäischen Gemeinschaften, in: Zavelberg (Hrsg.), Die Kontrolle der Staatsfinanzen - Geschichte und Gegenwart 1714 1989, Festschrift zur 275. Wiederkehr der Errichtung der preußischen GeneralRechen-Kammer, Berlin 1989, S. 469-492.

Martinez Soria, José, Die Bedeutung der (Verfassungs-) Rechtsvergleichung für den europäischen Staaten- und Verfassungsverbund: Die Methode der Rechtsvergleichung im Öffentlichen Recht, in: Göttinger Online-Beiträge zum Europarecht, Nr. 48 vom 08.07.2006.

Maun₹, Theodor / Dürig, Günter, Grundgesetz, Kommentar, Band VI (Art. 100-146 GG), München (Loseblattsammlung).

Maurer, Hartmut, Staatsrecht I - Grundlagen • Verfassungsorgane $\bullet$ Staatsfunktionen, 5. Auflage, München 2007.

Maurer, Hartmut, Allgemeines Verwaltungsrecht, 15. Auflage, München 2004.

Mayer, Josef, Rechnungshöfe und Publizität, DÖH 1954, S. 4-6.

Menzel, Eberhard, Der staatsrechtliche Standort der Finanzkontrolle in der Bundesrepublik und im Ausland, DÖV 1968, S. 593-604.

Merli, Fran₹, Rechtsstaatlichkeit in Österreich, in: Hofmann/Marko/Merli/Wiederin (Hrsg.), Rechtsstaatlichkeit in Europa, Heidelberg 1996, S. 83-106. 
Meyer, Jürgen / Hölscheidt, Sven, Die Europäische Verfassung des Europäischen Konvents, EuZW 2003, S. 613-621.

Möllers, Christoph, Gewaltengliederung - Legitimation und Dogmatik im nationalen und internationalen Rechtsvergleich, Tübingen 2005.

Moussis, Nicholas, For a drastic reform of European institutions, European Law Review 2003, 250-258.

Müller, H., Die staatsrechtliche und staatspolitische Stellung des Rechnungshofs im Dritten Reich, Finanzarchiv 1940 (Neue Folge 7), S. 193-205.

v. Münch, Ingo / Kunig, Philip (Hrsg.), Grundgesetz-Kommentar (Drei Bände), Band 2: Art. 20 - 69 GG, 4./ 5. Aufl., München 2001, Band 3: Art. 70 - 146 GG, 4./ 5. Aufl., München 2003.

v. Mutius, Albert, Finanzkontrolle und Öffentlichkeit, in: Zavelberg (Hrsg.), Die Kontrolle der Staatsfinanzen - Geschichte und Gegenwart 1714 - 1989, Festschrift zur 275. Wiederkehr der Errichtung der preußischen General-RechenKammer, Berlin 1989, S. 305-323.

Nathe, Hartwig, Der Rechnungshof, in: Weidenfeld / Wessels (Hrsg.), Jahrbuch der Europäischen Integration 1998/99, Bonn 1999, S. 93-98.

National Audit Office (Hrsg.), State Audit in the European Union, London 2005.

National Audit Office (Hrsg.), Corporate Plan 2006, London 2006 (abrufbar unter www.nao.gov.uk).

Nawrath, Axel, Die internationale Zusammenarbeit der Rechnungshöfe, DÖV 2000, S. 861-866.

Nö̈l, Emile, Die Organe der Europäischen Gemeinschaft und der Europäischen Union, Amt für amtliche Veröffentlichungen der Europäischen Gemeinschaften, Luxemburg 1997.

Öhlinger, Theo, Verfassungsrecht, 4. Auflage, Wien 1999.

Oppermann, Thomas, Europarecht, 3. Auflage, München 2005.

Ott, Andrea, Die Kontrollfunktion des Europäischen Parlaments gegenüber der Europäischen Kommission, ZEuS 1999, S. 232-247. 
Österreichischer Rechnungshof, Strategie, Wien 2005.

Patzig, Werner, Haushaltsrecht des Bundes und der Länder, Kommentar zu Rechtsund Verwaltungsvorschriften, Loseblattsammlung, Baden-Baden 8. Lieferung 1991.

Pernice, Ingolf, Die Dritte Gewalt im europäischen Verfassungsverbund, Europarecht 1996, S. 27-43.

Pernice, Ingolf, Europäisches und nationales Verfassungsrecht, Veröffentlichungen der Vereinigung der Deutschen Staatsrechtslehrer, Heft 60 (2001), S. 148-193.

Petzold, Herbert, Die Gewaltenteilung in den Europäischen Gemeinschaften, Göttingen 1966.

Peucker, Herbert, Grundfragen neuzeitlicher Finanzkontrolle, Göttingen 1952.

v. Pfublstein, Friedrich, Der Weg von der preussischen Generalrechenkammer zum Bundesrechnungshof, in: Bundesrechnungshof (Hrsg.), 250 Jahre Rechnungsprüfung Festschrift zur zweihundertfünfzigjährigen Wiederkehr der Errichtung der Preußischen Generalrechenkammer, Frankfurt a.M. 1964, S. 7-127.

Piduch, Erwin Adolf, Kommentar zum Bundeshaushaltsrecht, Loseblattsammlung, 2. Auflage, Stuttgart 2004.

Piebl, Ernst / Trautner, Tobias, Zur Bedeutung der Kontroll-Struktur und zu den Vorbeugungsstrategien gegen Mißbrauch öffentlicher Förderungsmittel, in: Piehl, Ernst (Hrsg.), Europa in Ostdeutschland: Zur Zwischenbilanz und zu den Perspektiven der europäischen Strukturförderung in den neuen Bundesländern und in Berlin sowie in den Reformländern von Mittel- und Osteuropa, Bonn 1996, S. 259-264.

Rechenberg, Hermann H.-K., Der Europäische Rechnungshof in seinem Verhältnis zum Bundesrechnungshof - Kooperation oder Konfrontation?, in: Weber, Albrecht u.a. (Hrsg.), Währung und Wirtschaft: Das Geld im Recht, Festschrift für Hugo J. Hahn zum 70. Geburtstag, 1. Aufl. Baden-Baden 1997, S. 697-705.

Reister, Erwin, Haushalt und Finanzen der Europäischen Gemeinschaften, BadenBaden 1975. 
Reister, Erwin, Parlamentarisches Budgetrecht und Rechnungshof der Europäischen Gemeinschaften: Ornamentik oder Demokratisierung der gemeinschaftlichen Finanzverfassung?, Europarecht 1976, S. 69-78.

Rengeling, Hans-Werner / Middeke, Andreas / Gellermann, Martin, Handbuch des Rechtsschutzes in der Europäischen Union, 2. Auflage, München 2003.

Rubio Llorente, Francisco, Die Gesetzgebungsverfahren in Spanien. Die Ortsbestimmung des Gesetzes innerhalb der Rechtsquellen, in: López Pina, Antonio (Hrsg.), Spanisches Verfassungsrecht, Heidelberg 1993, S. 377-406.

Sachs, Michael (Hrsg.), Grundgesetz Kommentar, 5. Auflage, München 2009.

Saemisch, Friedrich Ernst Mority, Der Rechnungshof des Deutschen Reichs nach der Novelle zur Reichshaushaltsordnung, DJZ 1934, Spalte 172-179.

Saladin, Peter, Wozu noch Staaten? Zu den Funktionen eines modernen demokratischen Rechtsstaats in einer zunehmend überstaatlichen Welt, 1. Auflage, BernMünchen-Wien 1995.

Schäfer, Friedrich, Zur Stellung des Präsidenten des Bundesrechnungshofes, in: Schiffer, Eckart / Karehnke, Helmut (Hrsg.), Verfassung, Verwaltung, Finanzkontrolle, Festschrift für Hans Schäfer zum 65. Geburtstag, Köln Berlin Bonn München 1975, S. 147-167.

Schäfer, Hans, Wer kontrolliert unsere Steuergelder? Finanzprüfung durch den Bundesrechnungshof, Stuttgart 1977.

Schäfer, Hans, Verfassungsrechtliche Stellung Bundesrechnungshof - Parlament, Bulletin der Bundesregierung Nr. 118 vom 22. November 1977, S. 1083-1087.

Schäfer, Hans, Der Bundesrechnungshof im Verfassungsgefüge der Bundesrepublik, DÖV 1971, S. 542-544.

Schäffer, Fritz, Ansprache anlässlich der Einweihung des neuen Dienstgebäudes des Bundesrechnungshofs am 19.02.1954, DÖH, S. 9-11.

Schäffer, Heinz, Kontrolle der Verwaltung durch Rechungshöfe (Länderbericht Österreich), VVDStRL 55(1996), 279-297.

Schmidt-Bleibtreu, Bruno / Klein, Franz. (Hrsg.), Kommentar zum Grundgesetz, 10. Auflage, München 2004. 
Schneider, Paul Georg, Externe Finanzkontrolle in Deutschland, Vortrag anlässlich des III. EURORAI-Kongresses in Straßburg 1998, abrufbar beim Rechnungshof Rheinland-Pfalz: http://www.rechnungshof-rlp.de/Downloads/DownloadVortr age _und_Aufsatze/12.pdf.

Schulze, Harald, Aufgabenwandel der Finanzkontrolle: Bestandsaufnahmen aus der Prüfungspraxis, in: Engelhardt/Schulze/Thieme (Hrsg.), Stellung und Funktion der Rechnungshöfe im Wandel?, Baden-Baden 1993, S. 33-42.

Schwab, Walter, Wege zu einer Neuordnung der öffentlichen Finanzkontrolle in Österreich: Materialien zur Rechnungshofreform, in: Das öffentliche Haushaltswesen in Österreich 1982, 64-107.

Schwaræe, Jürgen (Hrsg.), Der Verfassungsentwurf des Europäischen Konvents Verfassungsrechtliche Grundstrukturen und wirtschaftsverfassungsrechtliches Konzept, 1. Auflage, Baden-Baden 2004.

Schwarze, Jürgen (Hrsg.), EU-Kommentar, 1. Auflage, Baden-Baden 2000.

Service communication de la Cour des Comptes, Cour des Comptes, Paris 2007.

Sigg, Wolfgang, Die Stellung der Rechnungshöfe im politischen System der Bundesrepublik Deutschland, Berlin 1983, zugleich Univ. Diss. Freiburg 1982. (FMAG ZA 15845: 441)

Sommermann, Karl-Peter, Die Bedeutung der Rechtsvergleichung für die Fortentwicklung des Staats- und Verwaltungsrechts in Europa, DÖV 1999, S. 1017-1029.

Starck, Christian, Rechtsvergleichung im öffentlichen Recht, JZ 1997, S. 1021-1030.

Stern, Klaus, Der verfassungsrechtliche Status der Rechnungshöfe des Bundes und der Länder, in: Böning, Wolfgang / v. Mutius, Albert (Hrsg.), Finanzkontrolle im repräsentativ-demokratischen System, Heidelberg 1990, S. 11-37.

Stern, Klaus, Bundesrechnungshof und Finanzkontrolle aus verfassungsrechtlicher Sicht, DÖV 1990, S. 261-264.

Stern, Klaus, Die staatsrechtliche Stellung des Bundesrechnungshofes und seine Bedeutung im System der Finanzkontrolle, in: Zavelberg (Hrsg.), Die Kontrolle der Staatsfinanzen - Geschichte und Gegenwart 1714 - 1989, Festschrift zur 275. Wiederkehr der Errichtung der preußischen General-Rechen-Kammer, Berlin 1989. 
Stern, Klaus, Das Staatsrecht der Bundesrepublik Deutschland, Band II: Staatsorgane, Staatsfunktionen, Finanz- und Haushaltsverfassung, Notstandsverfassung, 1. Auflage, München 1980.

Streinz, Rudolf (Hrsg.), EUV/EGV, Vertrag über die Europäische Union und Vertrag zur Gründung der Europäischen Gemeinschaft, München 2003.

Streinz, Rudolf, Europarecht, 7. Auflage, Heidelberg 2005

Streinz, Rudolf / Obler, Christoph / Herrman, Christoph, Die neue Verfassung für Europa, München 2005.

Ternes, Stefan Johannes, Die Finanzkontrolle in der Europäischen Union, Frankfurt a. M. 1996.

Tesar, Helmuth, Die oberste Rechnungskontrollbehörde Österreichs - ein Streifzug durch die Geschichte des Rechnungshofes, in: Österreichischer Rechnungshof (Hrsg.), 200 Jahre Rechnungshof, Festschrift zum zweihundertjährigen Bestand der obersten staatlichen Kontrollbehörde Österreichs, Wien 1961, S. 1-23.

Theato, Diemut R. / Graf, Rainer, Das Europäische Parlament und der Haushalt der Europäischen Gemeinschaft, 1. Auflage, Baden-Baden 1994.

Tiemann, Susanne, Die staatsrechtliche Stellung der Finanzkontrolle des Bundes, Berlin 1974, zugleich Univ. Diss. München 1973/74.

Tiemann, Burkhard / Tiemann, Susanne, Zum staatsrechtlichen Standort der Finanzkontrolle in rechtsvergleichender Sicht, Der Staat 1974 (Band 13), S. 497-526.

Tiemann, Burkhard, Zur staatsrechtlichen Stellung und Funktion des Bundesrechnungshofes nach der Haushaltsreform, DVB1. 1970, S. 954-960.

Tribunal de Cuentas, Memoria de Actuaciones del Tribunal de Cuentas correspondiente al ejercicio 2006, del 27 de junio de 2007; Abrufbar unter www.tcu.es.

Vialon, Friedrich Karl, Haushaltsrecht - Kommentar zur Haushaltsordnung (RHO) und zu den Finanzbestimmungen des Bonner Grundgesetzes, 2. Auflage, Berlin und Frankfurt a.M. 1959.

Vialon, Friedrich Karl, Streitfragen der öffentlichen Finanzkontrolle, Finanzarchiv Band 22 (1962/63), S. 1-34. 
Vogel, Klaus, Verfassungsrechtliche Grenzen der öffentlichen Finanzkontrolle, DVB1. 1970, S. 193-200.

Wagner, Norbert Berthold, 50 Jahre Bundesrechnungshof - Zugleich ein Beitrag zu den organisatorischen Entwicklungslinien im preußisch-deutschen Rechnungskontrollwesen, Archiv des öffentlichen Rechts, Band 126 (2001), S. 93-133.

Wank, Rolf, Gewaltenteilung - Theorie und Praxis in der Bundesrepublik Deutschland, Jura 1991, 622-628.

Wassermann, Rudolf (Hrsg.), Alternativkommentar zum Grundgesetz für die Bundesrepublik Deutschland in zwei Bänden, 2. Auflage, Neuwied 1989.

Weber, Hubert, Vertrauensvolle Zusammenarbeit zwischen Europäischem Rechnungshof und den Rechnungshöfen der Mitgliedsstaaten, in: Österreichischer Rechnungshof (Hrsg.), Positionen - Öffentliche Finanzkontrolle in Österreich, Reihe 2007/2, Wien September 2007, S. 37-43.

von Wedel, Hedda, Finanzkontrolle von Mitteln der Europäischen Gemeinschaft, in: Rechnungshof Rheinland-Pfalz (Hrsg.), Kooperation der Finanzkontrolle in Europa, 1999, S. 259-278.

Wernstedt, Rolf, Rede anläßlich des Festakts zum 50-jährigen Bestehen des Niedersächsischen Landesrechnungshofes am 5. November 1998, S. 1-4.

Wieland, Joachim, Rechnungshofkontrolle im demokratischen Rechtsstaat, DVB1. 1995, S. 894-904.

Wieser, Bernd, Vergleichendes Verfassungsrecht, Wien New York 2005.

Wittrock, Karl, Der Rechnungshof als Berater, DÖV 1989, S. 346-349.

Wittrock, Karl, Über die Kontrolle geheimer Ausgaben, Die Verwaltung 1988, S. 277-290.

Wittrock, Karl, Parlament, Regierung und Rechnungshof - Zur Geschichte einer schwierigen Dreierbeziehung, ZParl 1986, S. 414-422.

Wittrock, Karl, Warum muß Finanzkontrolle unabhängig sein? DVBl. 1984, S. 823 826. 
Wittrock, Karl, Auf dem Weg zu einem neuen Bundesrechnungshof-Gesetz, DÖV 1984, S. 649- 654.

Wittrock, Karl, Möglichkeiten und Grenzen der Finanzkontrolle. Das Verhältnis des Bundesrechnungshofes zum Bundestag, ZParl 1982, S. 209-219.

Wittrock, Karl, Möglichkeiten und Grenzen der Finanzkontrolle, Bulletin der Bundesregierung 1982, 524-527.

Wrege, Wolf Reinhard, Das System der Gewaltenteilung im Grundgesetz, Jura 1996, S. 436-440.

Zavelberg, Heinz Günter, Staatliche Finanzkontrolle in Deutschland - Über Arbeit und Effektivität des Bundesrechnungshofes, Die Verwaltung 1995, S. 513-542.

Zavelberg, Heinz Günter, Die Arbeit der Rechnungshöfe im internationalen Bereich, DÖV 1993, S. 1000-1003.

Alle verwendeten Abkürzungen entstammen folgendem Abkürzungsverzeichnis:

Kirchner, Hildebert/Butz, Cornelie, Abkürzungsverzeichnis der Rechtssprache, 5. Auflage, Berlin 2003.

\section{Informationen der Rechnungshöfe im Internet:}

Europäischer Rechnungshof

Kontaktausschuss

Bundesrechungshof

Cours des comptes

Österreichischer Rechnungshof

Tribunal de Cuentas

National Audit Office

EUROSAI

INTOSAI http://www.eca.europa.eu

http://www.contactcommittee.eu

http://www.bundesrechnungshof.de

http://www.ccomptes.fr

http://www.rechnungshof.gv.at

http://www.tcu.es

http://www.nao.gov.uk

http://www.eurosai.org

http://www.intosai.org 
Eine effiziente staatliche Finanzkontrolle braucht unabhängige Rechnungshöfe. Die gegenseitige Kontrolle der Staatsgewalten im Bereich des öffentlichen Finanzwesens wird teilweise überhaupt erst durch ihre Arbeit ermöglicht. Die faktischen Einwirkungsmöglichkeiten der Rechnungshöfe auf die Staatsgewalten durch die Veröffentlichung von Prüfungsberichten, Aussprechen von Warnungen und Beratung bei der Entscheidung über Gesetzesvorhaben macht ihre Einordnung in das Schema der Gewaltenteilung beziehungsweise das institutionelle Gleichgewicht notwendig. Hier soll eine vergleichende Betrachtung verschiedener Rechnungshofmodelle für größere Klarheit sorgen. Besondere Bedeutung kommt dabei der Betrachtung der Rationalisierung staatlichen Handelns als Grundzweck der Gewaltenteilung zu. 